- MASTER

\title{
SNAP 19 Generator \\ Heat Distribution Test at Mach 8
}

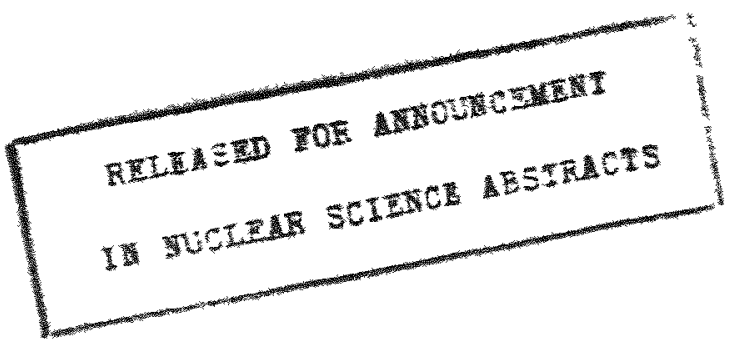




\section{DISCLAIMER}

This report was prepared as an account of work sponsored by an agency of the United States Government. Neither the United States Government nor any agency Thereof, nor any of their employees, makes any warranty, express or implied, or assumes any legal liability or responsibility for the accuracy, completeness, or usefulness of any information, apparatus, product, or process disclosed, or represents that its use would not infringe privately owned rights. Reference herein to any specific commercial product, process, or service by trade name, trademark, manufacturer, or otherwise does not necessarily constitute or imply its endorsement, recommendation, or favoring by the United States Government or any agency thereof. The views and opinions of authors expressed herein do not necessarily state or reflect those of the United States Government or any agency thereof. 


\section{DISCLAIMER}

Portions of this document may be illegible in electronic image products. Images are produced from the best available original document. 
Distribution: C92-A

M-3679 (46th Ed.)

LEAL NOTICE

Thus report This report was prepared as an acting on behalf of the Commission:

States, nor the Commission, nor any per implied, with respect to the accu-

A. Makes any warranty or representation, expressed or ined in this report, or that the use racy, completeness, or usefulness of the lnformation disclosed in this report may not infringe of any information, apparatus, method, or process drclosed in this report may not infringe

privately owned rights; or
B. Assumes any liabilities with respect to the use of, or for damages resulting from the use of any information, apparatus, method, or process disclosed in this report.

As used in the above, "person acting on behalf of the Com contractor, to the extent that ployee ox contractor on the Cor the Commission, or employee of such contractor prepares, such employee or condes access to, any information pursuant to his employment or contract with the Commission, or his employment with such contractor.

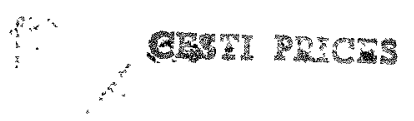

H.C. 300 ; nux 65

\title{
SNAP 19 Generator
}

\section{Heat Distribution Test at Mach 8}

\author{
MND -3607-92 \\ Volume 1 \\ March 1967
}

Prepared by: R. C. Adams and

C. A. Fluet

Approved by: $\frac{\text { Mathel }}{\text { H. S. Nickel, Jr. }}$

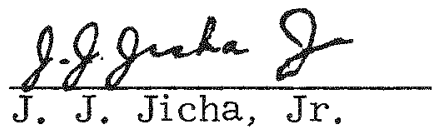

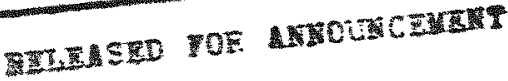

筷

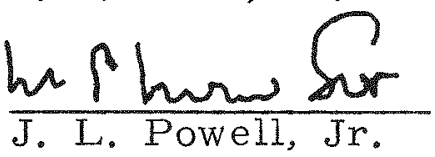




\section{LEGAL NOTICE}

This report was prepared as an account of Government sponsored work. Neither the United States, nor the Commission, nor any person acting on behalf of the Commission:

A. Makes any warranty or representation, expressed or implied, with respect to the accuracy, completeness, or usefulness of the information contained in this report, or that the use of any information, apparatus, method, or process disclosed in this report may not infringe privately owned rights; or

B. Assumes any liabilities with respect to the use of, or for damages resulting from the use of any information, apparatus, method, or process disclosed in this report.

As used in the above, "person acting on behalf of the Commission" includes any employee or contractor of the Commission, or employee of such contractor, to the extent that such employee or contractor of the Commission, or employee of such contractor prepares, disseminates, or provides access to, any information pursuant to his employment or contract with the Commission, or his employment with such contractor. 


\section{FOREWORD}

This report was prepared under United States Atomic Energy Commission Contract AT(30-1)-3607 and covers Item 3(c) of the proposed experimental program for SNAP 19, dated January 1966.

For convenience, Appendices $\mathrm{A}, \mathrm{B}$ and $\mathrm{C}$ have been put in a separate volume of this report. 
$\bullet$

Blank 


\section{CONTENTS}

Page

Legal Notice ............................ ii

Foreword.............................. iii

Contents............................. v v

Summary ..................................... vii

Symbols and Definitions ..................... ix

I. Introduction $\ldots \ldots \ldots \ldots \ldots \ldots \ldots \ldots \ldots \ldots \ldots \ldots \ldots \ldots$

II. Model Description and Instrumentation ............. 3

III. Test Facility Description..................... 5

IV. Test Procedure............................ 7

V. Data Presentation ........................... 9

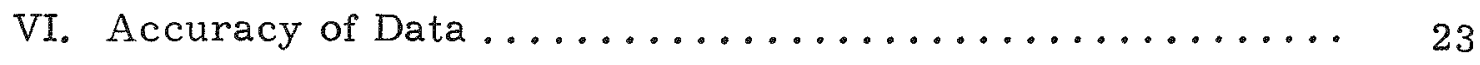

VII. Discussion of Results ..................... 27

VIII. Conclusions.............................. 29

IX. References ........................... 31 
Blank

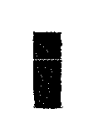

$\mathbf{P}$ 


\section{SUMMARY}

The purpose of this program was to obtain heating data for three $30 \%$ scale models of the SNAP 19 generator. The three models having different fin spans (full, two-third and one-third span) were tested at the Von Karman Facility, AEDC Tunnel $\mathrm{B}$ under the following conditions: $\mathrm{M}_{\infty}=7.86 ; \mathrm{P}_{0}=70 \mathrm{psia} ; \mathrm{T}_{0}=1170^{\circ} \mathrm{R} ; \mathrm{q}_{\infty}=0.35$ psia and $\operatorname{Re}_{\infty} \times 10^{-6}=$ $0.4 \mathrm{ft}^{-1}$. The one-third span model was also tested under the following conditions to determine the effects of increased Reynolds number:

$M_{\infty}=7.95 ; P_{0}=300$ psia; $T_{0}=1270^{\circ} R ; q_{\infty}=1.42$ psia and $\operatorname{Re}_{\infty} \times 10^{-6}=$ $1.5 \mathrm{ft}^{-1}$. The models were tested at roll angles of 0 and 30 degrees over the angle of attack range of 0 to 90 degrees.

Data obtained during the test were processed and presented in the form of $\dot{\mathrm{q}} / \dot{\mathrm{q}}_{\mathrm{FR}}$ versus $\alpha$ plots for all thermocouples of each configuration and average heating rates for each thermocouple over a 90-degree angle of attack range obtained by integration of the $\dot{\mathrm{q}} / \dot{q}_{\mathrm{FR}}$ versus $\alpha$ curves.

The data presented in this report are sufficiently comprehensive and accurate to be used in a burnup analysis of the SNAP 19 generator during re-entry. The precision of the data was demonstrated by repeat runs to be within the reported accuracy.

The results indicate that the average heating rates decreased on both the generator body and fins as the fin span decreased, i. e., during simulated fin disintegration. It was also observed that increasing the Reynolds number tends to increase the average heating rate on both the generator body and the fins. 
Blank 


\section{SYMBOLS AND DEFINITIONS}

$\underline{\text { Symbol }}$

$\alpha$

b model skin thickness

g gravitational constant

H air enthalpy

${ }^{h_{H}} \quad$ heat transfer coefficient

M Mach number

$\mathrm{n}$ number of points used to determine repeatability

$\mu \quad$ air viscosity

p pressure

$\phi \quad$ roll angle

q dynamic pressure

$\dot{q} \quad$ heat transfer rate per unit area

$\overline{\mathrm{q}} \quad$ integrated heat rate per unit area for $\alpha$ between 0 and $90^{\circ}$

$\rho \quad$ density

$\mathrm{R} \quad$ universal gas constant

$r$ arbitrary reference length based on a one-foot sphere

$\mathrm{Re} / \mathrm{ft} \quad$ Reynolds number per foot

St Stanton number

T temperature

t time

$\mathrm{V} \quad$ velocity

$\frac{d V e}{d x}$

velocity gradient along the edge
Units

degrees

feet

$\mathrm{ft} / \sec ^{2}$

Btu/1b $\frac{\mathrm{Btu} / \mathrm{ft}^{2}-\mathrm{sec}}{\mathrm{Btu} / \mathrm{Ib}}$

$1 b-\sec / f t^{2}$

psia

degrees

psia

$\mathrm{Btu} / \mathrm{ft}^{2}-\mathrm{sec}$

$\mathrm{Btu} / \mathrm{ft}^{2}-\mathrm{sec}$

slugs $/ \mathrm{ft}^{3}$

feet

$\mathrm{ft}^{-1}$

${ }^{\circ} \mathrm{R}$

seconds

$\mathrm{ft} / \mathrm{sec}$

$1 / \mathrm{sec}$ 
Subscripts

FR

0

w

$\infty$
Definitions

computed from Fay-Riddell theory

tunnel stagnation conditions

model wall conditions

tunnel free-stream conditions

Superscripts

' (prime) conditions aft of a normal shock 


\section{INTRODUCTION}

The SNAP 19 radioisotope fueled thermoelectric generator has been designed for use on the Nimbus B satellite. It is required to establish and confirm the safety of the system as it re-enters the atmosphere.

Calculations performed at the Martin Marietta and Sandia Corporations indicate the potential existence of aerodynamic and aerothermodynamic conditions under which the fuel particulate would not maintain integrity. This causes a downward shifting of the particle size distribution and leads to an unsatisfactory condition from the safety aspect. The potentiality of fuel size degeneration emphasizes the need for an accurate description of the aerodynamic and aerothermodynamic properties of systems and subsystems housing the fuel.

The aerodynamic burnup analysis of the SNAP 19 generator involves three configurations representing various degrees of ablation (full, twothirds and one-third fins) which are difficult to analyze insofar as the aeroheating distributions are concerned. The available theoretical methods are usually applied to more conventional type configurations, and attempting to apply such methods to other configurations could be misleading. Therefore, experimental data are required to substantiate any theoretical analysis of aeroheating distributions on the generator.

The objective of this test was to obtain the experimental data required to perform an aeroheating analysis of the generator during re-entry. The Mach 8 heat transfer test of three $30 \%$ scale models of the SNAP 19 generator (full span, two-thirds span, one-third span fin models) was conducted at the Arnold Engineering Development Center, VKF, Tunnel B. Testing was initiated on July 11, 1966 and completed on July 16, 1966. 
Blank

I

f 


\section{MODEL DESCRIPTION AND INSTRUMENTATION}

Three $30 \%$ scale models of the SNAP 19 generator were tested. To simulate fin ablation, each model had a different fin span as shown in Figs. 1, 2 and 3.

The models are constructed of thin-skin Inconel. The generator body wall thickness is 0.050 inch and the fins are 0.062 inch constant thickness. The chromel-alumel thermocouples, made of 28 gage wire, were welded to the skin at the locations shown in Figs. 4a through $4 \mathrm{e}$.

Thermocouples 1 through 13 are positioned on the front face of the model, and Thermocouples 14 through 58 are located on the body. The remaining thermocouples are on the fins. The full span and two-thirds span models have 98 thermocouples, while the one-third span model has 78 thermocouples.

The typical installation of a thermocouple is illustrated in Fig. 5. Thermocouple wires leading to the mounting hole are fastened down as shown in the figure. The wires are passed through an insulating disk before they are twisted to ensure that the final twist occurs at the point where the desired temperature measurement is to be made. The thermocouple is inserted in a hole bored for the wires and welded in place.

The model configurations are defined as follows:

Configuration

\begin{tabular}{|c|c|c|}
\hline No. & Description & $\underline{\mathrm{Re} / \mathrm{ft}}$ \\
\hline 100 & Full span model at $0^{\circ}$ roll & $0.4 \times 10^{6}$ \\
\hline 130 & Full span model at $30^{\circ}$ roll & $0.4 \times 10^{6}$ \\
\hline 200 & Two-thirds span model at $0^{\circ}$ roll & $0.4 \times 10^{6}$ \\
\hline 230 & Two-thirds span model at $30^{\circ}$ roll & $0.4 \times 10^{6}$ \\
\hline 300 & One-third span model at $0^{\circ}$ roll & $0.4 \times 10^{6}$ \\
\hline 330 & One-third span model at $30^{\circ}$ roll & $0.4 \times 10^{6}$ \\
\hline 400 & One-third span model at $0^{\circ}$ roll & $1.5 \times 10^{6}$ \\
\hline 430 & One-third span model at $30^{\circ}$ roll & $1.5 \times 10^{6}$ \\
\hline
\end{tabular}


Blank 


\section{TEST FACILITY DESCRIPTION}

This test was conducted at the VKF 50-Inch Hypersonic Tunnel B (Figs. 6 and 7) at Arnold Research Development Center, Tullahoma, Tennessee. The tunnel is a continuous, variable density wind tunnel equipped with axisymmetrical contoured Mach 6 and 8 nozzles. The tunnel is served by the main VKF compressor system and utilizes a propane-fired air heater to provide stagnation temperatures up to $900^{\circ} \mathrm{F}$, required to prevent liquefaction in the main airstream. The entire tunnel--throat, nozzle, test section, model support section and diffuser-is cooled by integral, external water jackets. The test section is equipped with fused quartz windows of optical quality with two viewing areas of 17.4 inches in diameter.

The facility is equipped with a Schlieren system for making photographs of the shock wave patterns around the model. Typical results can be seen in Figs. 8 through 21.

The model and support system can be retracted into the installation chamber below the test section. During heat transfer tests, the model is cooled between runs by an airstream blowing over it.

The tunnel is sealed from the installation chamber allowing the tunnel to maintain airflow while the model is being prepared for the next run.

In either the retracted or extended positions, the model support (sting) can be remotely pitched about the attachment point of the model through a range of +15 degrees with a straight sting, and \pm 12 degrees with any of the AEDC prebent stings. The system can also be rolled \pm 180 degrees about the sting support axis.

Once the model is cooled, the attitude set and the airflow established, the model is injected into the stream. The model takes approximately two seconds to reach the centerline of the tunnel. 


\section{Blank}




\section{TEST PROCEDURE}

The test in the AEDC Tunnel $B$ was conducted under the following conditions:

$\begin{array}{lcccc}\frac{\mathrm{M}_{\infty}}{7.86} & \frac{\mathrm{P}_{0} \text { (psia) }}{70} & \frac{\mathrm{T}_{0}\left({ }^{\circ} \mathrm{R}\right)}{1170} & \frac{\mathrm{q}_{\infty} \text { (psia) }}{0.35} & \frac{\mathrm{Re} / \mathrm{ft}}{0.4 \times 10^{6}} \\ 7.95 & 300 & 1270 & 1.42 & 1.5 \times 10^{6}\end{array}$

All fin configurations were tested at the first set of tunnel conditions. In addition, the one-third fin generator model with $\phi=0$ and 30 degrees was tested under the second set of conditions. The complete run program is presented in Table 1 (Appendix A* provides a complete list of tunnel conditions for each run).

The general procedure for performing this test, under both sets of tunnel conditions, is as follows:

(1) The model was placed in the installation chamber at initial $\alpha(15,45$ or 75 degrees with respect to the sting) and $\phi$ ( 0 or 30 degrees) settings.

(2) The chamber was sealed, and pressure in the chamber was reduced to the tunnel static pressure.

(3) The model was injected into the test section and remained in the flow for five seconds.

(4) The data recording process started approximately two seconds before the injected model reached the centerline of the tunnel.

(5) After each five-second test run, the model was retracted into the installation chamber and cooled by blowing cold air over the model.

(6) After cooling the model to the point where the time-temperature variations become negligible, necessary angle of attack and roll angle changes were made in preparation for the next run.

*See Volume 2 . 
TABLE 1

Heat Transfer Run Program

\begin{tabular}{|c|c|c|c|c|c|}
\hline \multirow{2}{*}{$\phi$} & \multirow[b]{2}{*}{$\begin{array}{c}\alpha \\
\left(d^{e g}\right)\end{array}$} & Full Fin & Two-thirds Fin & One-third Fin & One-third Fin \\
\hline & & $\begin{array}{c}\mathrm{Re} / \mathrm{ft}=0.4 \times 10^{6} \\
\text { Group No. }\end{array}$ & $\begin{array}{c}\mathrm{Re} / \mathrm{ft}=0.4 \times 10^{6} \\
\text { Group No. }\end{array}$ & $\begin{array}{c}\text { Re/ft }=0.4 \times 10^{6} \\
\text { Group No. }\end{array}$ & $\begin{array}{c}\mathrm{Re} / \mathrm{ft}=1.5 \times 10^{6} \\
\text { Group No. }\end{array}$ \\
\hline 0 & 0 & 27,28 & 82 & 130 & 156,163 \\
\hline 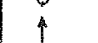 & 5 & 26 & 81 & 129 & 157 \\
\hline & 10 & 25,29 & 80 & 128 & 158 \\
\hline & 15 & 24 & 79,83 & 127,131 & 159,164 \\
\hline & 20 & 23,30 & 78 & 126 & 160 \\
\hline & 25 & 22 & 77 & 125 & 161 \\
\hline & 30 & 18,21 & 74,76 & 122,124 & 162,165 \\
\hline & 35 & 17 & 73 & 121 & 166 \\
\hline & 40 & 16,19 & 72 & 120 & 167 \\
\hline & 45 & 15 & 71,75 & 119,123 & 168,172 \\
\hline & 50 & 14,20 & 70 & 118 & 169 \\
\hline & 55 & 13 & 69 & 117 & 170 \\
\hline & 60 & 8,12 & 66,68 & 114,116 & 171,173 \\
\hline & 65 & 7 & 65 & 113 & 174 \\
\hline & 70 & 6,11 & 64 & 112 & 175 \\
\hline & 75 & 5 & 63,67 & 111,115 & 176,180 \\
\hline & 80 & 4,10 & 62 & 110 & 177 \\
\hline & 85 & 3 & 61 & 109 & 178 \\
\hline 0 & 90 & $1,2,9$ & 60 & 108 & 179 \\
\hline 30 & 0 & 31,40 & 84 & 132 & 181 \\
\hline 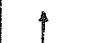 & 5 & 32 & 85 & 133 & 182 \\
\hline & 10 & 33,39 & 86 & 134 & 183 \\
\hline & 15 & 34 & 87,91 & 135,139 & 184,188 \\
\hline & 20 & 35,38 & 88 & 136 & 185 \\
\hline & 25 & 36 & 89 & 137 & 186 \\
\hline & 30 & $3 \overline{7}, 41$ & 90,92 & 138,140 & 187 \\
\hline & 35 & 42 & 93 & 141 & -- \\
\hline & 40 & 43,49 & 94 & 142 & -- \\
\hline & 45 & 44 & 95,99 & 143,147 & -- \\
\hline & 50 & 45,48 & 96 & 144 & -- \\
\hline & 55 & 46 & 97 & 145 & -- \\
\hline & 60 & 47,50 & 98,100 & 146,148 & 189 \\
\hline & 65 & 51 & 101 & 149 & 190 \\
\hline & 70 & 52,59 & 102 & 150 & 191 \\
\hline & 75 & 53 & 103,107 & 151,155 & 192 \\
\hline & 80 & 54,58 & 104 & 152 & 193 \\
\hline & 85 & 55 & 105 & 153 & 194 \\
\hline 30 & 90 & 56,57 & 106 & 154 & 195 \\
\hline
\end{tabular}




\section{DATA PRESENTATION}

Data were recorded at the AEDC Tunnel $B$ facility in the form of temperature-time histories for each model configuration tested. Temperature values measured with the model thermocouples were recorded on magnetic tape and processed at the facility. During the data processing at the facility, the temperature-time histories were converted by digital computer program to useful parameters. The following describes the methods and equations used in the AEDC data processing.

For each thermocouple, at each data reduction time, $\mathrm{T}_{\mathrm{W}}$ in ${ }^{\circ} \mathrm{R}$ and $\mathrm{dT}_{\mathrm{w}} / \mathrm{dt}$ in ${ }^{\circ} \mathrm{R} / \mathrm{sec}$, were computed from the center of a least-squares parabola through 21 consecutive wall temperature points. Using the $\mathrm{dT}_{\mathrm{w}} / \mathrm{dt}$ computed at each reduction time, the following equation yields q:

$$
\dot{q}=w b c \frac{d T_{w}}{d t}\left(B t u / f t^{2}-s e c\right)
$$

where:

$$
\begin{aligned}
& \text { w, density of model material }=526 \mathrm{lb} / \mathrm{ft}^{3} \text { (Ref. 5) } \\
& \mathrm{b} \text {, model skin thickness }=(\mathrm{ft}) \\
& \mathrm{c}, \text { constant specific heat of model material } \\
& (\text { Inconel } 600)=0.113 \mathrm{Btu} / 1 \mathrm{~b}-{ }^{\circ} \mathrm{R} \text { (Ref. 5) }
\end{aligned}
$$

Using $\dot{\mathrm{q}}$ from Eq (1), the enthalpy, heat transfer coefficient and Stanton number are determined by the standard heat transfer equation used at AEDC (Ref. 6) as follows:

$$
\begin{aligned}
& \mathrm{H}_{\mathrm{w}}=4.875+0.2235 \mathrm{~T}_{\mathrm{w}}+0.0000135 \mathrm{~T}_{\mathrm{w}}^{2} \text { Btu/1b } \\
& \mathrm{H}_{0}=4.875+0.2235 \mathrm{~T}_{0}+0.0000135 \mathrm{~T}_{0}^{2} \text { Btu/lb }
\end{aligned}
$$

Now:

$$
\mathrm{h}_{\mathrm{H}}=\frac{\dot{q}}{\mathrm{H}_{0}-\mathrm{H}_{\mathrm{W}}} \quad \frac{\mathrm{Btu} / \mathrm{ft}^{2}-\mathrm{sec}}{\mathrm{Btu} / \mathrm{Ib}}
$$




$$
\begin{aligned}
& \mathrm{T}_{\infty}=\frac{\mathrm{T}_{0}}{1+\frac{\gamma-1}{2} \mathrm{M}_{\infty}^{2}}=\frac{\mathrm{T}_{0}}{\left(1+0.2 \mathrm{M}_{\infty}^{2}\right)}{ }^{\circ} \mathrm{R} \\
& \mathrm{p}_{\infty}=\frac{\mathrm{p}_{0}}{\left(1+\frac{\gamma-1}{2} \mathrm{M}^{2}\right)^{3.5}}=\frac{\mathrm{p}_{0}}{\left(1+0.2 \mathrm{M}^{2}\right)^{3.5}} \quad \mathrm{psia}
\end{aligned}
$$

Using Eqs 5 and 6 , solve for $\rho_{\infty}$ and $V_{\infty}$ :

$$
\begin{aligned}
& V_{\infty}=49 \mathrm{M}_{\infty}\left(\mathrm{T}_{\infty}\right)^{1 / 2} \mathrm{fps} \\
& \rho_{\infty}=0.0839 \mathrm{p}_{\infty}\left(\mathrm{T}_{\infty}\right)^{-1} \text { slugs } / \mathrm{ft}^{3}
\end{aligned}
$$

The Stanton number can be evaluated:

$$
\mathrm{ST}=\frac{\mathrm{h}_{\mathrm{H}}}{\rho_{\infty} \mathrm{V}_{\infty}} \frac{1}{\mathrm{~g}}
$$

where:

$$
g=32.17 \mathrm{ft} / \mathrm{sec}^{2}
$$

The parameter, $\mathrm{St}_{\mathrm{SSt}} \mathrm{FR}$, is also computed. In order to perform this calculation, $\mathrm{St}_{\mathrm{FR}}$ must first be evaluated. To find $\mathrm{ST}_{\mathrm{FR}}$, the Stanton number based on the Fay-Riddell heat transfer equation, $\mu_{0}^{\prime}$ and $\mathrm{p}_{0}^{\prime}$ (where the prime indicates conditions aft of a normal shock) must be evaluated:

$$
\begin{gathered}
\mu_{0}^{\prime}=2.270 \mathrm{~T}_{0}^{\prime 1.5}\left(\mathrm{~T}_{0}^{\prime}+198.6\right)^{-1} \times 10^{-8} \mathrm{lb-sec} / \mathrm{ft}^{2} \\
\mathrm{p}_{0}^{\prime}=\mathrm{p}_{0}\left(\frac{6 \mathrm{M}_{\infty}^{2}}{\mathrm{M}_{\infty}^{2}+5}\right)^{3.5}\left(\frac{6}{7 \mathrm{M}_{\infty}^{2}-1}\right)^{2.5} \mathrm{psia}
\end{gathered}
$$

Equations (10) and (11) are easily solved since $\mathrm{p}_{0}, \mathrm{~T}_{0}$ and $\mathrm{M}_{\infty}$ are known from tunnel operating conditions and $\mathrm{T}_{0}=\mathrm{T}_{0}^{\prime}$. Now compute $\mathrm{ST}_{\mathrm{FR}}$ : 


$$
\mathrm{St}_{F R}=\frac{0.254}{\rho_{\infty} V_{\infty} r^{0.5}} \frac{\mu_{0}^{\prime} 0.4}{\mathrm{~T}_{0} 0.15}\left(\mathrm{p}_{0}^{\prime}\right)^{0.5}
$$

where:

$r$, arbitrary reference length based on a one-foot sphere equals one foot.

The data obtained from the AEDC facility computation is presented in Table 2 .

A digital computer program was developed at the Martin Marietta Corporation using the data from AEDC, Table 2 , to compute $\dot{q} / \dot{q}$ FR and to correct the data for conduction effects.

The data in this report are presented in tabulated and graphical form. The plotted data describes the variation of $\dot{q} / \dot{q}_{F R}$ with angle of attack for the different fin lengths and roll angles under consideration. The following description indicates the theory and mathematics involved in modifying the facility data to obtain the desired $\dot{q} / \dot{q}_{\mathrm{FR}}$ ratio.

The Fay-Riddell heat transfer equation yielding $\dot{\mathrm{q}}_{\mathrm{FR}}$ is obtained from the basic equation:

$$
\dot{q}_{\mathrm{FR}}=0.94\left(\rho_{\mathrm{w}} \mu_{\mathrm{w}}\right)^{0.1}\left(\rho_{0}^{\prime} \mu_{0}^{\prime}\right)^{0.4}\left(\mathrm{H}_{0}^{\prime}-\mathrm{H}_{\mathrm{w}}\right) \sqrt{\left(\frac{\mathrm{dVe}}{\mathrm{dx}}\right)_{0} \mathrm{~g}}
$$

where:

$$
\left(\frac{\mathrm{dVe}}{\mathrm{dx}}\right)_{0}=\frac{1}{r} \sqrt{\frac{2\left(\mathrm{p}_{0}^{\prime}-\mathrm{p}_{\infty}\right)}{\mathrm{p}_{0}^{1}}}
$$

(from Newtonian theory for a hemisphere)

since:

$$
\rho_{0}^{\prime}=\frac{\rho_{0}^{\prime}}{R T_{0}^{\prime}}
$$

Eq. (15) becomes:

$$
\left(\frac{\mathrm{dVe}}{\mathrm{dx}}\right)_{0}=\frac{1}{r} \sqrt{2 \mathrm{R} \mathrm{T}_{0}^{\prime}\left(1-\frac{\rho_{\infty}}{\rho_{0}^{\prime}}\right)}
$$


TABLE 2

Average Heating Rates

$\overline{\dot{q}} / q_{F R}=\int_{0}^{90} \dot{\mathrm{q}} / \dot{\mathrm{q}}_{\mathrm{FR}} \mathrm{d} \alpha / 90^{\circ}$

\begin{tabular}{|c|c|c|c|c|c|c|c|c|}
\hline \multirow{2}{*}{$\begin{array}{c}\text { Gage } \\
\text { No. }\end{array}$} & \multicolumn{2}{|c|}{ Configuration } & \multicolumn{2}{|c|}{ Configuration } & \multicolumn{2}{|c|}{ Configuration } & \multicolumn{2}{|c|}{ Configuration } \\
\hline & 100 & 130 & 200 & 230 & 300 & 330 & 400 & 430 \\
\hline 1 & 2.69 & 2.66 & 2.86 & 2. 88 & 3.38 & 3.15 & 2.89 & \\
\hline 2 & 1.27 & 1.42 & 1.22 & 1. 14 & 1. 16 & 1. 36 & 1. 42 & \\
\hline 3 & 0.96 & 0.98 & 0.97 & 1. 17 & 1. 20 & 1. 10 & 1. 34 & \\
\hline 4 & 0.97 & 1.13 & 0.98 & 1.07 & 1. 08 & 1.07 & 1.06 & \\
\hline 5 & 0.97 & 1. 11 & 1.03 & 1. 17 & 0.96 & 1.20 & 1. 26 & \\
\hline 6 & 2.01 & 3.01 & 2.11 & 3.16 & 2. 19 & 3.06 & 2.10 & \\
\hline 7 & 1.28 & 1. 58 & 0.81 & 1.00 & 1.26 & 1.38 & 1. 20 & \\
\hline 8 & 1.02 & 1.08 & 0.91 & 1.06 & 1.06 & 1.09 & 1. 10 & \\
\hline 9 & 1.08 & 1.02 & 1. 13 & 1. 10 & 1. 26 & 1.03 & 1.23 & \\
\hline 10 & 1.64 & 2.81 & 1.67 & 2.58 & 2.04 & 2.83 & 2. 19 & \\
\hline 11 & 1. 18 & 1. 40 & 1.06 & 1. 28 & 1. 19 & 1. 46 & 1. 38 & \\
\hline 12 & 1.09 & 1. 12 & 0.87 & 1.02 & 1.06 & 1. 13 & 1. 18 & \\
\hline 13 & 1. 66 & 0.94 & 1.60 & 1.01 & 1. 76 & 1. 12 & 1. 86 & \\
\hline 14 & 2.71 & 3.17 & 2.70 & 3.14 & 3.21 & 2.86 & 4.07 & \\
\hline 15 & 0.96 & 1.52 & 0.56 & 1.69 & 0.29 & 0.91 & 0.44 & \\
\hline 16 & 1. 64 & 1. 54 & 1. 58 & 2.18 & 0.86 & 1. 96 & 1. 41 & \\
\hline 17 & 1.84 & 1. 75 & 1.27 & 1.95 & 0.97 & 1.62 & 1. 28 & \\
\hline 18 & 1.88 & 2.38 & 1. 78 & 2.54 & 0.97 & 1.20 & 1. 41 & \\
\hline 19 & 1.77 & 2.08 & 1.63 & 1. 73 & 1. 11 & 1. 36 & 1. 56 & \\
\hline 20 & 0.43 & 0.80 & 0.42 & 0.52 & 0.26 & 0.32 & 0.47 & \\
\hline 21 & 1. 72 & 2.25 & 1. 24 & 1. 46 & 1.06 & 1. 27 & 1.33 & \\
\hline 22 & 1.20 & 1.60 & 0.92 & 1.27 & 0.76 & 1.04 & 1.07 & \\
\hline 23 & 1. 42 & 1.84 & 1.00 & 1. 72 & 0.90 & 1. 16 & 1.30 & \\
\hline 24 & 1.06 & 1. 30 & 0.92 & 1. 17 & 1.06 & 1.06 & 1. 46 & \\
\hline 25 & 2.73 & 2.49 & 2.87 & 2.81 & 3.19 & 3.17 & 2.98 & \\
\hline 26 & 0.58 & 1.20 & 0.47 & 1.04 & 0.38 & 0.83 & 0.67 & \\
\hline 27 & 1. 17 & 2. 03 & 1.01 & 1. 74 & 0.88 & 1. 71 & 1.32 & \\
\hline 28 & 1.34 & 2.23 & 1.07 & 1. 79 & 0.99 & 1. 77 & 1. 41 & \\
\hline 29 & 1.73 & 2. 28 & 1.55 & 2.46 & 1.06 & 1.61 & 1.66 & \\
\hline 30 & 1. 48 & 1.81 & 1. 31 & 1. 26 & 1. 48 & 1. 45 & 1.97 & \\
\hline 31 & 0.42 & 0.72 & 0.36 & 0.53 & 0.30 & 0.38 & 0.61 & \\
\hline 32 & 1. 54 & 1.65 & 1.01 & 1.24 & 0.87 & 1. 11 & 1.31 & \\
\hline 33 & 1.27 & 1.53 & 1.02 & 1.69 & 0.99 & 1. 26 & 1. 32 & \\
\hline 34 & 1.86 & 2.71 & 1.39 & 2.46 & 1.24 & 1. 79 & 1. 72 & \\
\hline 35 & 0.78 & 1. 49 & 0.81 & 1.02 & 1.30 & 1.40 & 1. 79 & \\
\hline 36 & 2.73 & 2.91 & 2.89 & 3.26 & 3.10 & 3.57 & 3.13 & \\
\hline 37 & 0.97 & 0.68 & 0.72 & 0.64 & 0 & 0 & 0.27 & \\
\hline
\end{tabular}


TABLE 2 (continued)

\begin{tabular}{|c|c|c|c|c|c|c|c|c|}
\hline \multirow{2}{*}{$\begin{array}{c}\text { Gage } \\
\text { No. }\end{array}$} & \multicolumn{2}{|c|}{ Configuration } & \multicolumn{2}{|c|}{ Configuration } & \multicolumn{2}{|c|}{ Configuration } & \multicolumn{2}{|c|}{ Configuration } \\
\hline & 100 & 130 & 200 & 230 & 300 & 330 & 400 & 430 \\
\hline 38 & 1.86 & 1.24 & 1. 57 & 1.07 & 0.83 & 1.01 & 1. 36 & \\
\hline 39 & 2.19 & 1. 29 & 1.29 & 0.94 & 0.90 & 0.01 & 1. 24 & \\
\hline 40 & 1.97 & 2.09 & 2.00 & 1. 43 & 1.01 & 1.19 & 1. 46 & \\
\hline 41 & 1. 90 & 1.07 & 1. 57 & 1. 03 & 1.27 & 1.20 & 1. 62 & \\
\hline 42 & 0.38 & 0.41 & 0.46 & 0.43 & 0.26 & 0.27 & 0.50 & \\
\hline 43 & 1.42 & 1.05 & 1.26 & 0.86 & 1.01 & 0.92 & 1.39 & \\
\hline 44 & 0.91 & 0.81 & 0.79 & 0.93 & 0.81 & 0.73 & 1. 07 & \\
\hline 45 & 1.56 & 1.71 & 1. 06 & 1.31 & 0.92 & 1.01 & 1.46 & \\
\hline 46 & 1.05 & 0.27 & 1. 14 & 0.61 & 0.92 & 0.95 & 1. 31 & \\
\hline 47 & 0.68 & 1.52 & 0.66 & 1.52 & 0.51 & 0.84 & 0.78 & \\
\hline 48 & 1.32 & 1.88 & 1. 08 & 1.89 & 0.83 & 1.50 & 1. 31 & \\
\hline 49 & 1.57 & 2. 16 & 1. 18 & 2.14 & 0.82 & 1.47 & 1. 24 & \\
\hline 50 & 0.18 & 0.69 & 0.22 & 0.54 & 0.26 & 0.42 & 0.57 & \\
\hline 51 & 0.79 & 0.78 & 0.81 & 1. 31 & 0.17 & 0.14 & 1.70 & \\
\hline 52 & 0.97 & 1.77 & 0.68 & 1.28 & 0.64 & 0.98 & 1. 16 & \\
\hline 53 & 0 & 0.09 & 0 & 0.07 & 0 & 0.10 & 0.03 & \\
\hline 54 & 0 & 0.19 & 0.07 & 0.27 & 0 & 0.36 & 0.128 & \\
\hline 55 & 0 & 0.31 & 0 & 0.37 & 0 & 0.18 & 0.12 & \\
\hline 56 & 0 & $0.05 *$ & 0 & 0 & 0 & 0.06 & 0.03 & \\
\hline 57 & 0 & 0.27 & 0.04 & 0.34 & 0.12 & 0.30 & 0.20 & \\
\hline 58 & 0 & 0.26 & 0.01 & 0.24 & 0.03 & 0.16 & 0.23 & \\
\hline 59 & $6.21 *$ & 2.62 & 0.55 & 12.39 & 3.41 & 5.67 & 3.59 & \\
\hline 60 & 1.84 & -- & 0.79 & 1.63 & 0.47 & 1. 36 & 0.76 & \\
\hline 61 & 1. $31 *$ & -- & 0.56 & 0.92 & 0 & -- & -- & \\
\hline 62 & 5.78 & 7.86 & 4. 46 & 5.89 & -- & -- & - & -- \\
\hline 63 & 0.48 & 0.81 & 0.72 & 1. 11 & -- & -- & -- & -- \\
\hline 64 & 0.38 & 0.77 & 0.20 & 0.48 & -- & -- & -- & -- \\
\hline 65 & 1.83 & 4.03 & 1.21 & 2.33 & 0.96 & 1.63 & 1. 42 & \\
\hline 66 & 0.60 & 0.92 & 0.66 & 1. 14 & 0.61 & 1.06 & 0.81 & \\
\hline 67 & 0.41 & 0.78 & 0.43 & 1.07 & 0.41 & 0.58 & 0.63 & \\
\hline 68 & 1.07 & 2.59 & 0.71 & 2. 16 & -- & -- & -- & -- \\
\hline 69 & 0.58 & 0.75 & 0.42 & 0.48 & -- & -- & -- & -- \\
\hline 70 & 0.49 & 0.46 & 0.32 & 0.43 & -- & -- & -- & -- \\
\hline 71 & 9.00 & 8.61 & 7.96 & -- & 9.40 & 8.33 & 8.77 & \\
\hline 72 & 4.21 & $2.22 *$ & 4.98 & 3.53 & 3.29 & 3.43 & 4.17 & \\
\hline 73 & $4.07 *$ & -- & 3.59 & 2.80 & 2.60 & 3.13 & 2.88 & \\
\hline 74 & 10.33 & 9.02 & 8.84 & 8.21 & -- & -- & -- & $\cdots$ \\
\hline 75 & 2.19 & 3.11 & 2.03 & 2.36 & -- & - & -- & -- \\
\hline 76 & 1. 47 & $2.17 *$ & 1. 37 & 2.87 & -- & -- & -- & -- \\
\hline 77 & 8.30 & $7.33 *$ & 4.61 & 4. 47 & 3.96 & 6.50 & 4. 53 & \\
\hline 78 & 2.45 & 2.50 & 2.74 & 2.44 & 2. 19 & 2.13 & 2. 43 & \\
\hline 79 & 2.29 & 3.28 & 2.19 & 2. 12 & 1.89 & 2.31 & 2.33 & \\
\hline 80 & 4.03 & 7.22 & 4.69 & 7.11 & -- & -- & -- & -- \\
\hline
\end{tabular}


TABLE 2 (concluded)

\begin{tabular}{|l|l|l|l|l|l|l|l|l|}
\hline \multirow{2}{*}{$\begin{array}{l}\text { Gage } \\
\text { No. }\end{array}$} & \multicolumn{2}{|c|}{ Configuration } & \multicolumn{2}{c|}{ Configuration } & \multicolumn{2}{c|}{ Configuration } & \multicolumn{2}{c|}{ Configuration } \\
\cline { 2 - 9 } & 100 & 130 & 200 & 230 & 300 & 330 & 400 & 430 \\
\hline 81 & 0.78 & 1.50 & 0.91 & 1.38 & -- & -- & -- & -- \\
82 & 0.71 & 1.61 & 1.01 & 1.93 & -- & -- & -- & - \\
83 & $9.30 *$ & -- & $6.87 *$ & 6.62 & 8.96 & 9.71 & 8.93 & \\
84 & $5.73 *$ & -- & 6.35 & -- & 3.73 & 5.74 & 5.07 & \\
85 & $4.93 *$ & -- & 4.33 & 6.29 & 3.42 & 6.78 & 5.07 & \\
86 & $5.28 *$ & -- & $4.39 *$ & 5.63 & 3.79 & 6.64 & 5.44 & \\
87 & 7.10 & 9.22 & 9.72 & 10.61 & -- & -- & -- & - \\
88 & 2.90 & 3.61 & 4.82 & 7.02 & -- & -- & -- & - \\
89 & 3.42 & 4.89 & 2.95 & 4.47 & -- & -- & -- & - \\
90 & 3.71 & 5.13 & 3.77 & 5.30 & -- & -- & -- & - \\
91 & $8.63 *$ & -- & -- & -- & 7.99 & 9.29 & 7.66 & \\
92 & 3.82 & 7.67 & 3.67 & 6.72 & 2.74 & 6.21 & 3.82 & \\
93 & 3.62 & $6.28 *$ & $3.34 *$ & 6.06 & 2.21 & 5.43 & 3.08 & \\
94 & $3.91 *$ & -- & $3.96 *$ & 3.44 & 3.18 & 5.24 & 4.28 & \\
95 & 7.09 & -- & 7.56 & 7.67 & -- & -- & -- & -- \\
96 & 2.56 & 4.74 & 2.81 & 6.00 & -- & -- & -- & -- \\
97 & 2.30 & 4.11 & 3.56 & 5.33 & -- & -- & -- & - \\
98 & 3.71 & 6.61 & 2.88 & 4.76 & -- & -- & -- & - \\
\hline
\end{tabular}

*Estimated values, test data incomplete 
Neglecting $\frac{\rho_{\infty}}{\rho_{0}^{\prime}}$ is a simplifying assumption which introduces a maximum error in $\dot{q}$ of $+0.3 \%$ for a Mach number of 8 . With this as sumption, Eq (15) is:

$$
\left(\frac{\mathrm{dVe}}{\mathrm{dx}}\right)_{0}=\frac{1}{\mathrm{r}} \sqrt{2 \mathrm{RT} \mathrm{T}_{0}^{\mathrm{r}}}
$$

Noting the following relations:

$$
\begin{gathered}
\rho_{\mathrm{w}}=\frac{\mathrm{p}_{0}^{\prime}}{\mathrm{R \textrm {T } _ { \mathrm { w } }}} \\
\rho_{0}^{\prime}=\frac{\mathrm{p}_{0}^{\prime}}{\mathrm{R} \mathrm{T}_{0}^{\prime}}
\end{gathered}
$$

Equations (16), (17) and (18) are used in Eq (14) to give:

$$
\begin{aligned}
& \dot{\mathrm{q}}_{\mathrm{FR}}= \\
& 0.94\left(\frac{\mathrm{p}_{0}^{\prime} \mu_{\mathrm{W}}}{\mathrm{R} \mathrm{T}_{\mathrm{W}}}\right)^{0.1}\left(\frac{\mathrm{p}_{0}^{\prime} \mu_{0}^{\prime}}{\mathrm{R} \mathrm{T}_{0}^{\prime}}\right)^{0.4} \mathrm{H}_{0}^{\prime}-\mathrm{H}_{\mathrm{W}}\left[\frac{1}{\mathrm{r}}\left(2 \mathrm{R} \mathrm{T}_{0}^{\prime}\right)^{0.5}\right]^{0.5} \mathrm{~g}
\end{aligned}
$$

Manipulation of Eq (19) yields:

$$
\begin{aligned}
& \dot{\mathrm{q}}_{F R}= \\
& \frac{0.94\left({ }^{\mathrm{p}}\right)^{0.5}\left({ }^{\prime} \mu_{0}^{\prime} 0.4\left(\mathrm{H}_{0}^{\prime}-\mathrm{H}_{\mathrm{w}}\right) \mathrm{g}(2)^{0.25}\right.}{\mathrm{r}^{0.5}\left(\mathrm{~T}_{0}^{\prime}\right)^{0.15}(\mathrm{R})^{0.25}}\left(\frac{\mu_{\mathrm{W}}}{\mathrm{T}_{\mathrm{W}}}\right)^{0.1}
\end{aligned}
$$

where:

$$
\left(\frac{\mu_{w}}{T_{w}}\right)^{0.1}=0.1214 \text { for } T_{w}=540^{\circ} \mathrm{R}
$$


Rearrange Eq (21) and use Eq (22):

$$
\begin{aligned}
& \dot{\mathrm{q}}_{F R}= \\
& \frac{0.94(0.1214)(2)^{0.25}(32.17)}{(1716)^{0.25}} \quad \frac{\left(\mathrm{p}_{0}^{\prime}\right)^{0.5}\left(\mu_{0}^{\prime}\right)^{0.4}\left({ }^{H_{0}^{\prime}}-\mathrm{H}_{w)}\right.}{(r)^{0.5}\left(\mathrm{~T}_{0}^{\prime}\right)^{0.15}}
\end{aligned}
$$

Assuming: $\quad \mathrm{T}_{0}^{\prime}=\mathrm{T}_{0}$

$$
\mathrm{H}_{0}^{\prime}=\mathrm{H}_{0}
$$

Equation (22) simplifies to:

$$
\dot{\mathrm{q}}_{\mathrm{FR}}=8.138\left[\frac{\left(\mathrm{p}_{0}^{\prime}\right)^{0.5}\left({ }^{\prime} 0\right)^{\prime} 0.4\left(\mathrm{H}_{0}-\mathrm{H}_{\mathrm{w}}\right)}{(\mathrm{r})^{0.5}\left(\mathrm{~T}_{0}^{\prime}\right)^{0.15}}\right]
$$

Using Eq (4) and (9), an expression for the Stanton number, ST, is found:

$$
\text { St }=\frac{\dot{q}}{\rho_{\infty} V_{\infty} g\left(\mathrm{H}_{0}-\mathrm{H}_{\mathrm{w}}\right)}
$$

Based on the Fay-Riddell heat transfer equation, the Fay-Riddell Stanton number is:

$$
\mathrm{St}_{\mathrm{FR}}=\frac{\dot{\mathrm{q}}_{\mathrm{FR}}}{\rho_{\infty} \mathrm{V}_{\infty} \mathrm{g}\left(\mathrm{H}_{0}-\mathrm{H}_{\mathrm{w}}\right)}
$$

Divide Eq (25) by Eq (26):

$$
\frac{\dot{q}}{\dot{\mathrm{q}}_{\mathrm{FR}}}=\frac{\mathrm{St}}{\mathrm{St}} \mathrm{FR}_{\mathrm{FR}} \frac{\left(\mathrm{H}_{0}-\mathrm{H}_{\mathrm{w}}\right)}{\left(\mathrm{H}_{0}-\mathrm{H}_{\mathrm{w}}\right)}
$$

In Eq (28) the last term containing the $\left(\mathrm{H}_{0}-\mathrm{H}_{\mathrm{w}}\right)$ expressions will not cancel because the wall enthalpy, $\mathrm{H}_{\mathrm{w}}$, in the denominator is an arbitrary reference constant based on a wall temperature of $540^{\circ} \mathrm{R}$; where $\mathrm{H}_{\mathrm{w}}$ of the numerator is a variable dependent upon the local wall temperature, $T_{W}$, at each thermocouple. Since $H_{w}=129.5$ at $540^{\circ} \mathrm{R}$ 
(see $\mathrm{Eq}(2)$ ), Eq (26) takes the form:

$$
\frac{\dot{q}}{{ }^{\mathrm{q}} \mathrm{FR}}=\frac{\mathrm{St}}{\mathrm{St}} \frac{\left(\mathrm{H}_{0}-\mathrm{H}_{\mathrm{w}}\right)}{\left(\mathrm{H}_{0}-129.5\right)}
$$

Equation (27) indicates how $\frac{\dot{q}}{{ }^{q} \text { FR }}$ was obtained from the AEDC data which were presented as $\frac{\mathrm{St}}{\mathrm{St} \mathrm{FR}_{\mathrm{FR}}}$.

Data were recorded over a span of approximately seven seconds, at a rate of 20 times per second for each run. The time breakdown is as follows: Two seconds recording time while the model is in the chamber, 0.25 second recording time while the model is in transit to the tunnel centerline, and five seconds recording time after the model reaches the centerline. The time chosen to evaluate the data is $t=0.25$ second after the model reaches the centerline of the tunnel. Choosing $t=0.25$ second eliminates undesirable transient effects in the data which occur before this time and keep conduction effects, which increase with time, to a minimum.

The parameter, $\dot{q} / \dot{q}_{F R}$, defines (for the reference time) the quantity of heat that is being retained at a given point on the model. However, a thermocouple located near a heat sink or local hot spot will incur a heat loss because heat will be conducted to a surrounding area at a lower temperature. The conduction loss will cause values of $\dot{q}$ to be lower than the actual values. Conversely, thermocouples near a local cool spot will yield q values higher than the actual values because heat is being conducted to the cool spot from the surrounding region at a higher temperature. Thermocouples located in a region where temperature variations are linear (see the sketch) in each direction (which is the most common case) require no conduction correction because heat flux to and from the thermocouple location remains balanced.

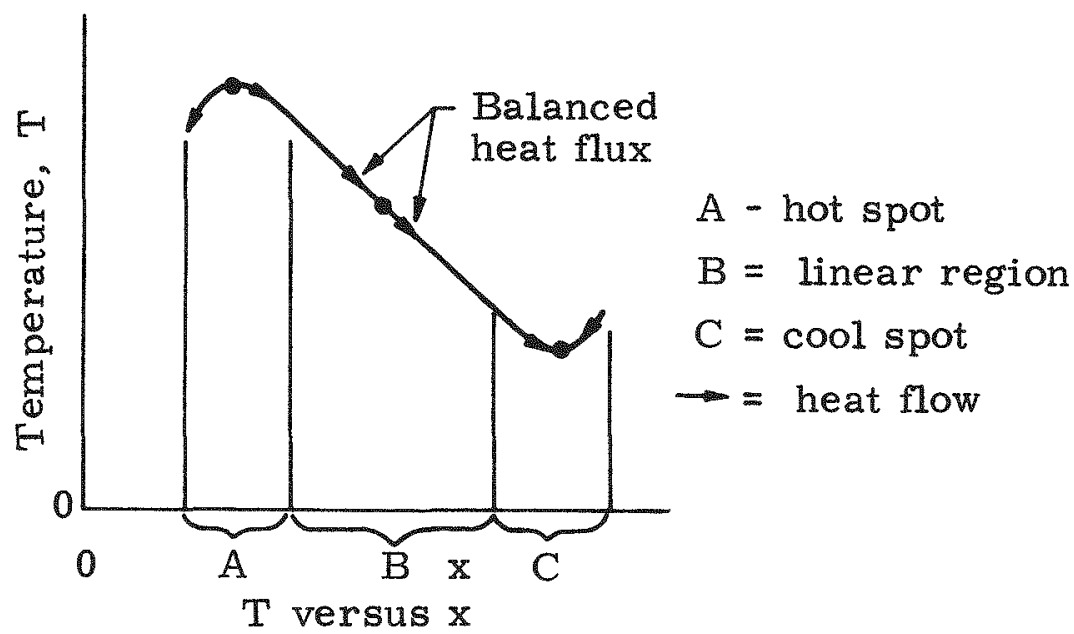


It should be noted that the thermocouple numbering used in AEDC does not agree with the Martin Marietta Corporation numbering system for Configurations $300,330,400$ and 430 . The differences are in the fin instrumentation only (TC numbers greater than 59). The relation of the Martin Marietta numbers to AEDC numbers are listed in Table 2. The data given in Appendices $B$ and $C$ use the $A E D C$ numbering system. All other references to $\mathrm{TC}$ number used in this report are with respect to the Martin Marietta system.

The uncorrected values of the heat inputs for each thermocouple at the reference time $(0.25$ second after the model reaches the tunnel centerline) and 0.50 second later $(0.75$ second after the model reaches the tunnel centerline) are recorded in Appendix B. *. Heat conduction to and from each thermocouple location is proportional to the difference between the uncorrected heat input values measured at the times mentioned. A $\dot{q}$, which decreases the time, indicates a conduction of heat away from the location being considered, and a $\dot{q}$ increasing

*The modified data were computed and are presented in Appendix B under the following headings:

$\begin{array}{llllll}\text { (a) (b) (c) } & \text { (d) } & \text { (e) } & \text { (f) }\end{array}$

TC ALPHA Q1/QFR Q2/QFR COR/QFR QC1/QFR QC.5/QFR

where:

(1) $\mathrm{TC}=$ thermocouple number

(2) ALPHA = angle of attack

(3) Q1/QFR uncorrected $q / \dot{q}_{F R}$ ratio, calculated with Eq (27) for a reduction time at 0.25 second after the model reaches the centerline of the tunnel.

(4) $Q 2 / Q F R$ is the uncorrected $\dot{q} / \dot{q}_{F R}$ ratio, calculated with $\mathrm{Eq}(27)$ for a reduction time at 0.75 second after the model reaches the centerline of the tunnel.

(5) COR/QFR represents the conduction correction increment which is evaluated as : $C O R / Q F R=(c)-(d)=\Delta \dot{q} / \dot{q}_{F R}$

(6) QC1/QFR is the corrected $\dot{\mathrm{q}} / \dot{\mathrm{q}}_{\mathrm{FR}}: \mathrm{QC} 1 / \mathrm{QFR}=(\mathrm{c})+(\mathrm{e})$.

(7) QC. 5/QFR represents $\dot{q} / \dot{q}_{F R}$ corrected by one-half the conduction correction, (e): $\mathrm{QC} .5 / \mathrm{QFR}=(\mathrm{c})+1 / 2(\mathrm{e})$. 
TABLE 3

Relationship of Test Thermocouple Numbers to Model Thermocouple Numbers

$\mathrm{TC}$ of

Appendices B \& C

1 to 58

59

60

61

62

63

64

65

66

67

68

69

70

71

72

73

74

75

76

77

78
Correct TC No.

(Configurations $300,330,400,430)$

1 to 58

59

60

61

65

66

67

71

72

73

77

78

79

83

84

85

86

91

92

93

94 
with time indicates that heat is being conducted to the considered location. A $\dot{q}$ value, which has negligible variation, shows that heat conduction to and from the location in question is approximately equal.

Most of the plotted data presented in this report required little or no correction for the effects of conduction. However, a conduction correction was determined and applied to all the uncorrected data. The determination of this correction is best explained with the aid of the following sketch.

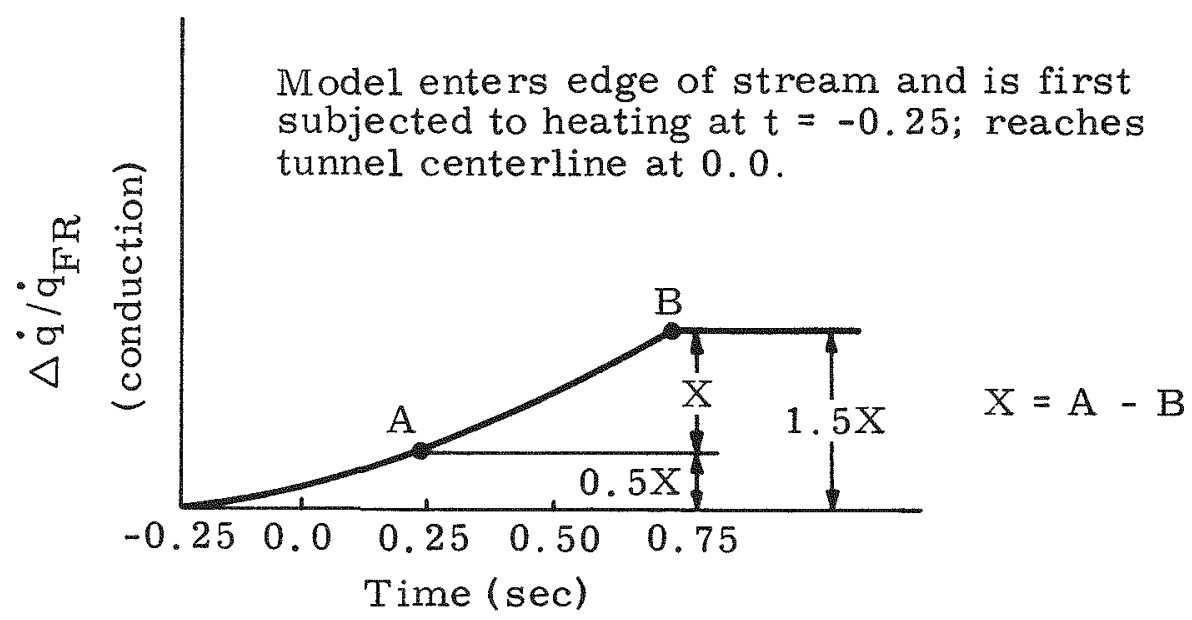

It is estimated that the conduction values at $t=0.25$ second is one-third the value at $t=0.75$ second. Therefore, the difference between the values for these two times would be double the conduction value at $t=0.25$ second. For this reason, the difference in the heating rate ratios (given as COR/Q $\mathrm{Q}_{\mathrm{FR}}$ in Appendix $\mathrm{B}$ ) is multiplied by 0.5 to determine the final correction increment which is then added to the uncorrected value for $t=0.25$ second. The result (given as QC. $5 / Q_{F R}$ in Appendix $B$ ) is considered to be the corrected value of $\dot{q} / \dot{q}_{F R}$ and this parameter was plotted versus $\alpha$ for all model configurations in Figs. 22 through 260. 
The actual procedure for reducing the test data to final form was as follows:

(1) Tunnel data were processed at the AEDC facility, recorded on magnetic tape and listed. Schlieren pictures (Figs. 8 to 21) were also obtained at the facility.

(2) The AEDC data were modified by a digital program, at the Martin Marietta Corporation, to yield the desired parameter, $\dot{\mathrm{q}} / \dot{q}_{\mathrm{FR}}$

(3) The $\dot{q} / \dot{q}_{F R}$ values were listed and put onto the tape for use on the plotter (see Appendix B).

(4) The magnetic plotting tape was used to make the plots of $\dot{q} / \dot{q}_{F R}$ versus $\alpha$ (see Figs. 22 through 260 ) on the BensonLehner STE electronic plotter.

(5) The $\dot{q} / \dot{q}_{F R}$ versus $\alpha$ plots were integrated with a planimeter to determine the average heat inputs to selected thermocouples over the angle of attack range 0 to 90 degrees. The integrated values are presented in Appendix $\mathrm{C}$ and in Figs. 261 through 288. 
Blank 


\section{ACCURACY OF DATA}

The plotted data given in Figs. 22 through 260 have three sources of errors that may be significant; the data recording system at the test site; the conduction correction; and the plotting accuracy. The estimates and effects of each of these sources are shown in the following table:

\begin{tabular}{|c|c|c|c|}
\hline Source & Error & Value in $\dot{\mathrm{q}} / \dot{\mathrm{q}}_{\mathrm{FR}}$ & Limits \\
\hline \multirow[t]{2}{*}{ Measurement } & $\pm 0.2^{\circ} \mathrm{R} / \mathrm{sec}$ & \pm 0.04 & $0<\dot{\mathrm{q}} / \dot{\mathrm{q}}_{\mathrm{FR}}<2.0$ \\
\hline & $\pm 0.02(\Delta T / \Delta t)$ & $\pm 0.02 \dot{q} / \dot{q}_{F R}$ & $\dot{\mathrm{q}} / \dot{\mathrm{q}}_{\mathrm{FR}}>2.0$ \\
\hline \multirow[t]{2}{*}{ Conduction } & $\pm 0.20\left(\Delta \dot{\mathrm{q}}_{\text {cond }} / \dot{\mathrm{q}}_{\mathrm{FR}}\right)$ & \pm 0.10 & $0<\dot{\mathrm{q}} / \dot{\mathrm{q}}_{\mathrm{FR}}<10$ \\
\hline & & $+0.01 \dot{\mathrm{q}} / \dot{\mathrm{q}}_{\mathrm{FR}}$ & $\dot{\mathrm{q}} / \dot{\mathrm{q}}_{\mathrm{FR}}>10$ \\
\hline \multirow[t]{2}{*}{ Plotting } & \pm 0.015 in. to center & \pm 0.02 & TC $1-58$ \\
\hline & of symbol & \pm 0.04 & TC $59-98$ \\
\hline \multirow[t]{2}{*}{ Total } & & \pm 0.30 & $0<\dot{\mathrm{q}} / \dot{\mathrm{q}}_{\mathrm{FR}}<10$ \\
\hline & & $\pm 0.03 \dot{\mathrm{q}} / \dot{\mathrm{q}}_{\mathrm{FR}}$ & $\dot{\mathrm{q}} / \dot{\mathrm{q}}_{\mathrm{FR}}>10$ \\
\hline
\end{tabular}

The average heating rate values, $\overline{\mathrm{q}} / \dot{\mathrm{q}}_{\mathrm{FR}}$, have another source of error in that they were obtained by integrating the plotted values of $\dot{\mathrm{q}} / \dot{\mathrm{q}}_{\mathrm{FR}}$ over the 90 -degree $\alpha$ range with a planimeter, which has a probable error of $\pm 3 \%$. The accuracy of the average heating data (found by taking the square root of the sum of the squares of the $\dot{q} / \dot{q}_{F R}$ error and the planimeter error) is approximately within $\pm 4 \%$ of the $\overline{\mathrm{q}} / \dot{\mathrm{q}}_{\mathrm{FR}}$ values.

During the tests, the data were obtained at every 5 degrees of $\alpha$ with repeat points at every 10 degrees. The repeatability of the data was estimated by taking the root mean square of the differences at the repeat points.

$$
\dot{\mathrm{q}} / \dot{\mathrm{q}}_{\mathrm{FR}}= \pm \sqrt{\Sigma \Delta \dot{\mathrm{q}} / \dot{\mathrm{q}}_{\mathrm{FR} / \mathrm{n}}}
$$

for each thermocouple on Configuration 100.

The body data (TC 1 through 58) gave $\Delta \dot{q} / \dot{q}_{F R}= \pm 0.125$.

The fin data (TC 59 through 98 ) gave $\Delta \dot{q} / \dot{q}_{F R}= \pm 0.246$. 
Certain thermocouples were found to be giving faulty readings that were caused by loose or broken wires. A list of the faulty thermocouples and the range over which they were malfunctioning is given in Table 4.

When the model was rolled 30 degrees (Configurations 130, 230, 330 and 430 ), the data on Thermocouples 83 through 98 may be inaccurate because the fins on which they were located are parallel to the stream and therefore were subject to heating on both sides. The thermocouple wires were also open to the free stream and may have disturbed the flow so that the heating on one surface of the fin may not be equal to one half the total indicated. 


\section{TABLE 4}

Damaged Thermocouples

\begin{tabular}{|c|c|c|c|}
\hline Configuration & Thermocouple & $\alpha$ Range (deg) & Comment \\
\hline \multirow[t]{10}{*}{100} & 59 & 0 to 25 & \\
\hline & 61 & 0 to 35 & \\
\hline & 73 & 0 to 25 & \\
\hline & 77 & & \\
\hline & 83 & 0 to 55 & \\
\hline & 84 & 0 to 35 & \\
\hline & 85 & 0 to 35 & \\
\hline & 86 & 0 to 40 & \\
\hline & 91 & 0 to 60 & \\
\hline & 94 & 0 to 60 & \\
\hline \multirow[t]{19}{*}{130} & 26 & 55 & \\
\hline & 34 & 30 & \\
\hline & 59 & & $\mathrm{TC}$ is out \\
\hline & 61 & & TC is out \\
\hline & 72 & 60 to 90 & \\
\hline & 73 & & $\mathrm{TC}$ is out \\
\hline & 74 & 0 to 10 & \\
\hline & 76 & 60 to 90 & \\
\hline & 77 & 55 to 90 & \\
\hline & 79 & 75 to 90 & \\
\hline & 83 & & $\mathrm{TC}$ is out \\
\hline & 84 & & $\mathrm{TC}$ is out \\
\hline & 85 & & $\mathrm{TC}$ is out \\
\hline & 86 & & TC is out \\
\hline & 87 & 0 & \\
\hline & 91 & & $\mathrm{TC}$ is out \\
\hline & 93 & 55 to 90 & \\
\hline & 94 & & $\mathrm{TC}$ is out \\
\hline & 95 & 60 to 90 & \\
\hline \multirow[t]{6}{*}{200} & 78 & 60 to 80 & \\
\hline & 86 & & Questionable data \\
\hline & 83 & 30 to 60 & \\
\hline & 91 & & $\mathrm{TC}$ is out \\
\hline & 93 & 30 to 65 & \\
\hline & 94 & & Questionable data \\
\hline \multirow[t]{4}{*}{230} & 61 & 65 to 90 & \\
\hline & 71 & 30 to 90 & \\
\hline & 84 & 30 to 90 & \\
\hline & 87 & & \\
\hline 300 & 61 & & $\mathrm{TC}$ is out \\
\hline 330 & 61 & & $\mathrm{TC}$ is out \\
\hline
\end{tabular}


Blank

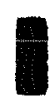




\section{DISCUSSION OF RESULTS}

The purpose of this test was to obtain heating data on the SNAP 19 generator configuration with three simulated degrees of fin ablation (full, $2 / 3,1 / 3$ span fins). These data are to be used in a burnup analysis of the generator.

Each of the three models tested in the program had uniform span fins positioned at 60-degree intervals around the generator. Three pairs of fins were instrumented such that for 0-degree roll, the instrumented fins were located at 30,90 and 150 degrees (see Figs. 4D and $4 \mathrm{E}$ ). For the model at 30 degrees roll, the fin locations were 0 , 60 and 120 degrees. Testing at 0 and 30 degrees roll yields fin data for a $\phi$ range of 0 to 150 degrees.

With the exception of the front face, all the instrumentation was symmetrical about the fore and aft midpoint of the model, thus allowing simulation of data through 180-degree alpha polars, while only testing through 90-degree alpha polars. Recording data on the front face of the model for angles of attack greater than 90 degrees are unnecessary since the front face will be in the shadow of the body beyond the 90-degree position.

The data for a row of thermocouples along the body such as Thermocouples 26 through 29 (see Fig. 261 and Figs. 94 through 101) point up the effects of shadowing and flow deflection due to the flanges. Thermocouple 26 is in the shadow of the flange of the front cover plate and therefore has a generally low heat input; TC 29, located near the center flange, incurs a high heating rate as the result of flow deflection near the flange.

The data presented in Figs. 22 through $260\left(\dot{q} / \dot{q}_{\mathrm{FR}}\right.$ versus $\left.\alpha\right)$ can be used to determine the heating distribution on the generator for any given angle of attack. These data also indicate that local areas of high heating rates exist that change in both location and intensity with a change in angle of attack.

The average heat inputs over the $\alpha$ range of 0 to 90 degrees (Figs. 261 through 288) are more useful in describing the general effects of ablation on the heat distribution on the generator.

Figure 261 may be used as a typical example of the effects of fin ablation on the body heating. The decreased fin spans had little effect on the front face heating (TC 2, 3, 4 and 5); the heating on the front flange (TC 1 and 25) increased as the fin span was decreased, but the heating on the rest of the body (TC 26 through 35 ) decreased as the fin span decreased.

As expected, the heating rates on the fins are much higher than on the body. In general, the heating rates on the fins decreased as the fin span was decreased. 
The Schlieren photograph shown here indicates the occurrence of turbulent flow during one of the test runs (Configuration 100 at $\alpha=30$ deg). The flow in this case appears to be in the process of breaking down. The tabulated data for this particular run yield extremely high heating rates, $\dot{q} / \dot{q}_{F R}$, which may be attributed to the turbulence.

Data acquired during this run were not used. However, a duplicate run was made (Group 21, Fig. 10) and the data from the duplicate run were used.

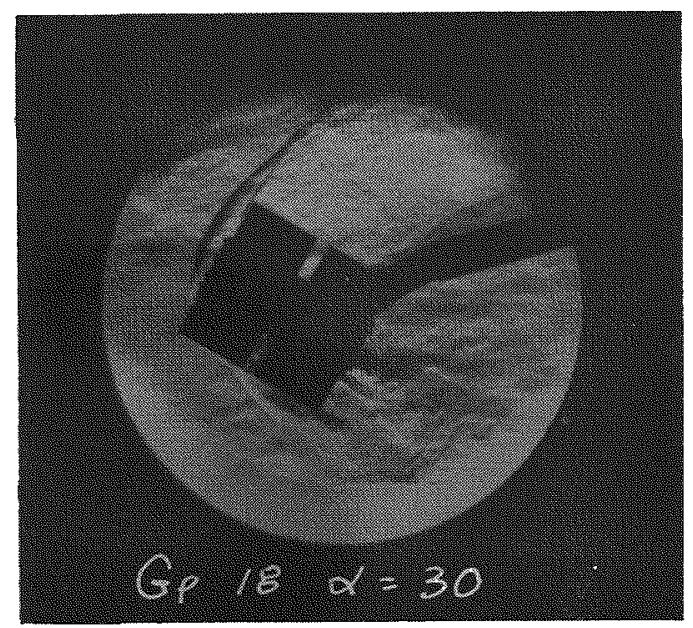

Configurations 400 and 430 were tested to determine the effects of changing the Reynolds number. Configuration 400 is a one-third span generator model tested at $\operatorname{Re} \times 10^{-6}=1.5 \mathrm{ft}^{-1}$ (other configurations had $\operatorname{Re} \times 10^{-6}=0.4 \mathrm{ft}^{-1}$; Appendix A contains all tunnel conditions). A comparison of average heating values, $\dot{q} / \dot{q}_{F R}$, for Configurations 300 and 400 shows that heating on the body and fins of the model is higher for the larger Reynolds number (Figs. 274 and 284). It is noted that the change in Reynolds number has little effect on the average heating rates of the front cover plate (see TC 2 through 5, Fig. 263). However, an increased Reynolds number appears to decrease the average heating values on the flange of the front cover (see TC 1 and 25, Fig. 263). The flange area is near a stagnation point which is subjected to high heating input. However, an increase of Reynolds number causes the bow shock standoff distance to increase (the increase is too small to be noticed in the Schlieren pictures), resulting in the lower heating values on the flange.

The burnup analysis will be based upon the heating data obtained at the lower Reynolds number ( $\operatorname{Re} \times 10^{-6}=0.4 \mathrm{ft}^{-1}$ ). This Reynolds number is within the flight regime of the generator, and it is the lowest Reynolds number obtainable in the AEDC Tunnel B. 


\section{CONCLUSIONS}

Based on the test results presented in this report, the following conclusions are drawn.

(1) Local areas of high heating rates exist on the fins and the body that vary in both position and intensity with changes in angle of attack.

(2) The average heating rates on the body decrease as the fin span is decreased.

(3) Generator fin disintegration is accompanied by a decrease in the average heating on the fins.

(4) Increasing the Reynolds number tends to increase values of the average heating rates $\left(\dot{\mathrm{q}} / \dot{\mathrm{q}}_{\mathrm{FR}}\right)$ on both the body and the fins. 
Blank 


\section{REFERENCES}

1. Test Facilities Handbook. Sixth Edition, Arnold Engineering Development Center, November 1966.

2. Burt, R. H., "Mach 8 Aerodynamic and Aerothermodynamic Characteristics of the Nimbus B Spacecraft and SNAP 19 Nuclear Generator." AEDC-TR-66-194, October 1966.

3. Ball, H., "General Heat Transfer Program, Tunnels A, B, and C, "Departmental Correspondence, October 1966.

4. Dagold, R. G., "Test Plan Report SNAP 19 Generator Force and Stability Test, Mach 8," Martin Company, MND-3607-59, Revised June 1966.

5. "The Heat Capacity and Thermal Conductivity of Inconel 600," Union Carbide Nuclear Division, 7933-1865-I, August 1966. 
Blank

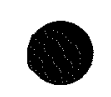




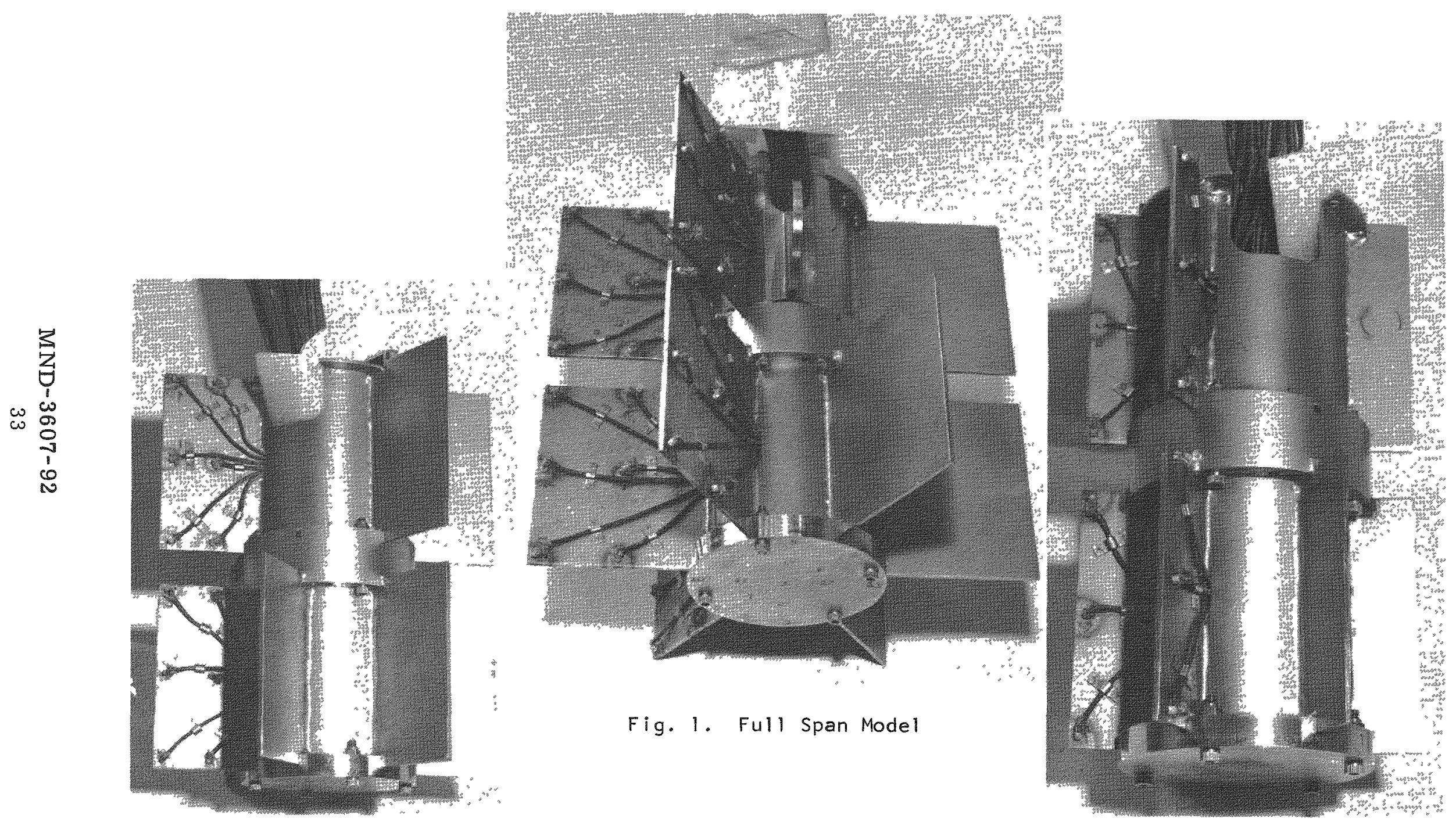

Fig. 2. Two-Thirds Span Model

Fig. 3. One-Third Span Model 

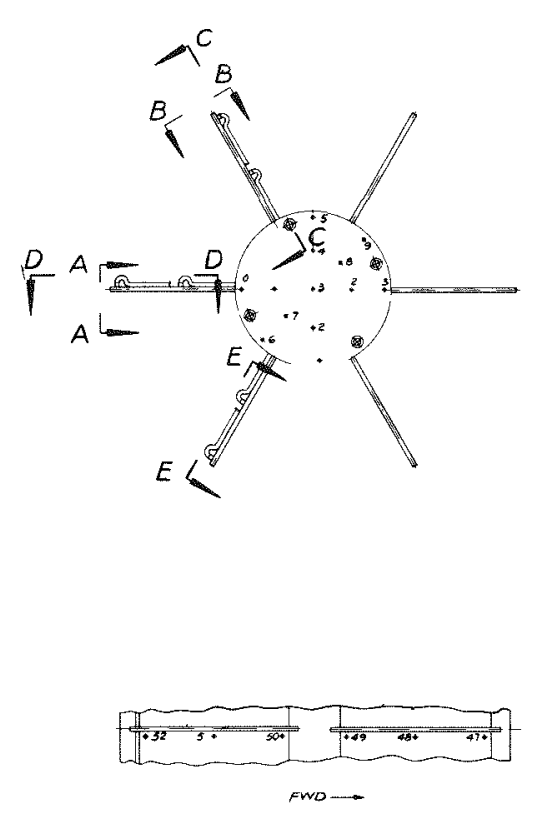

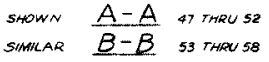

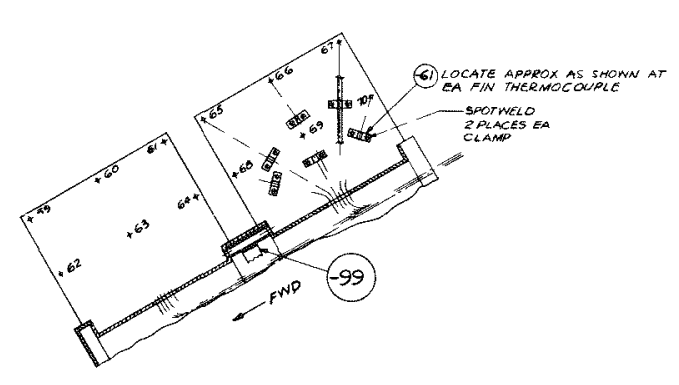

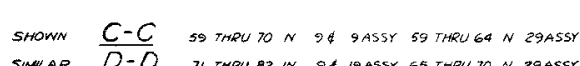

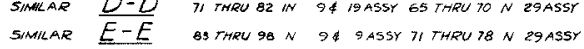

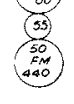

(遠)

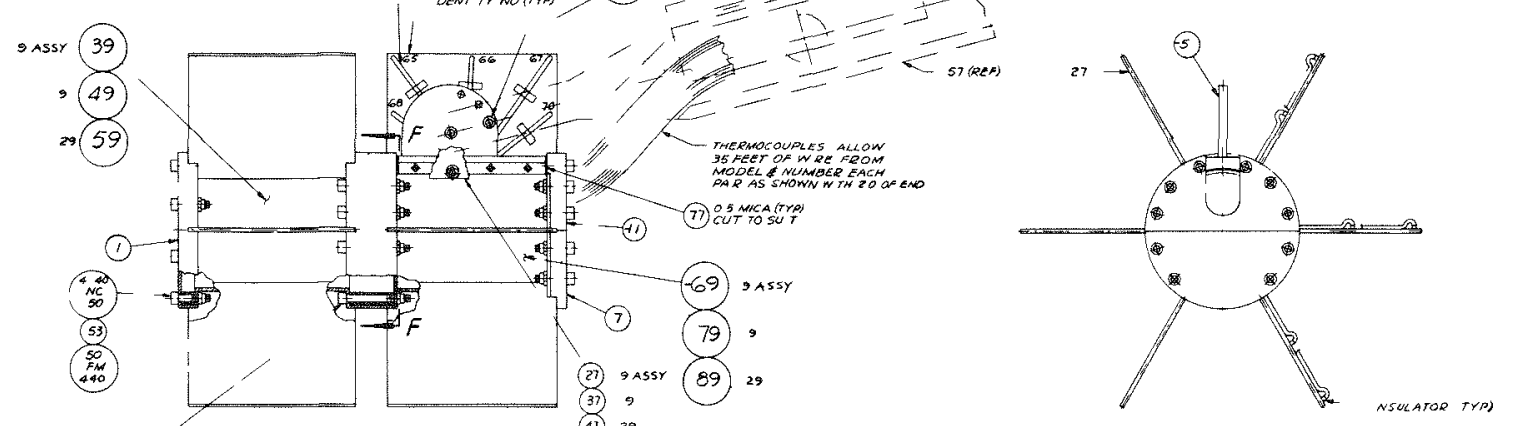

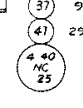

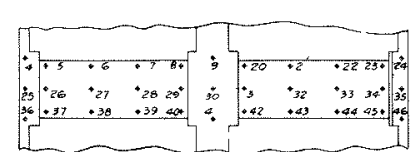

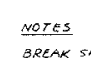

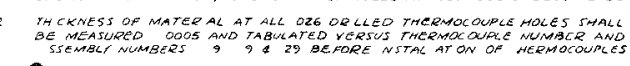

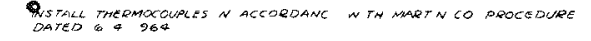

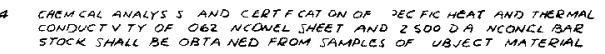

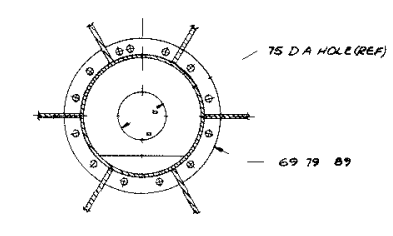

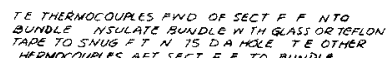

$F-F$

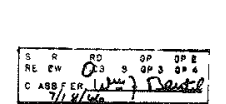

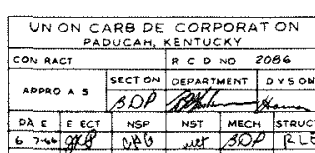

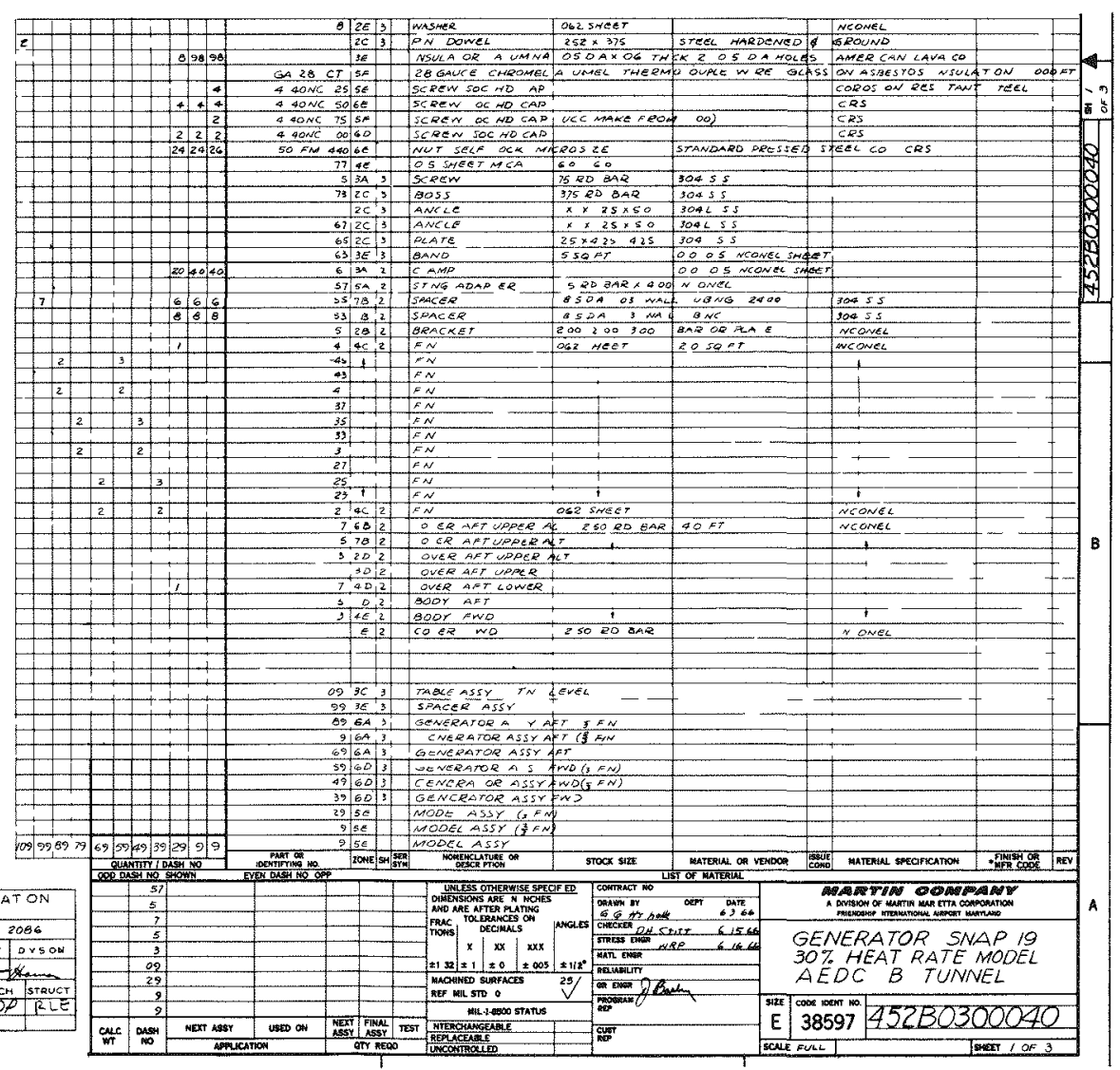

Fig. 4a. Thermocouple Locations

MND-3607-92 

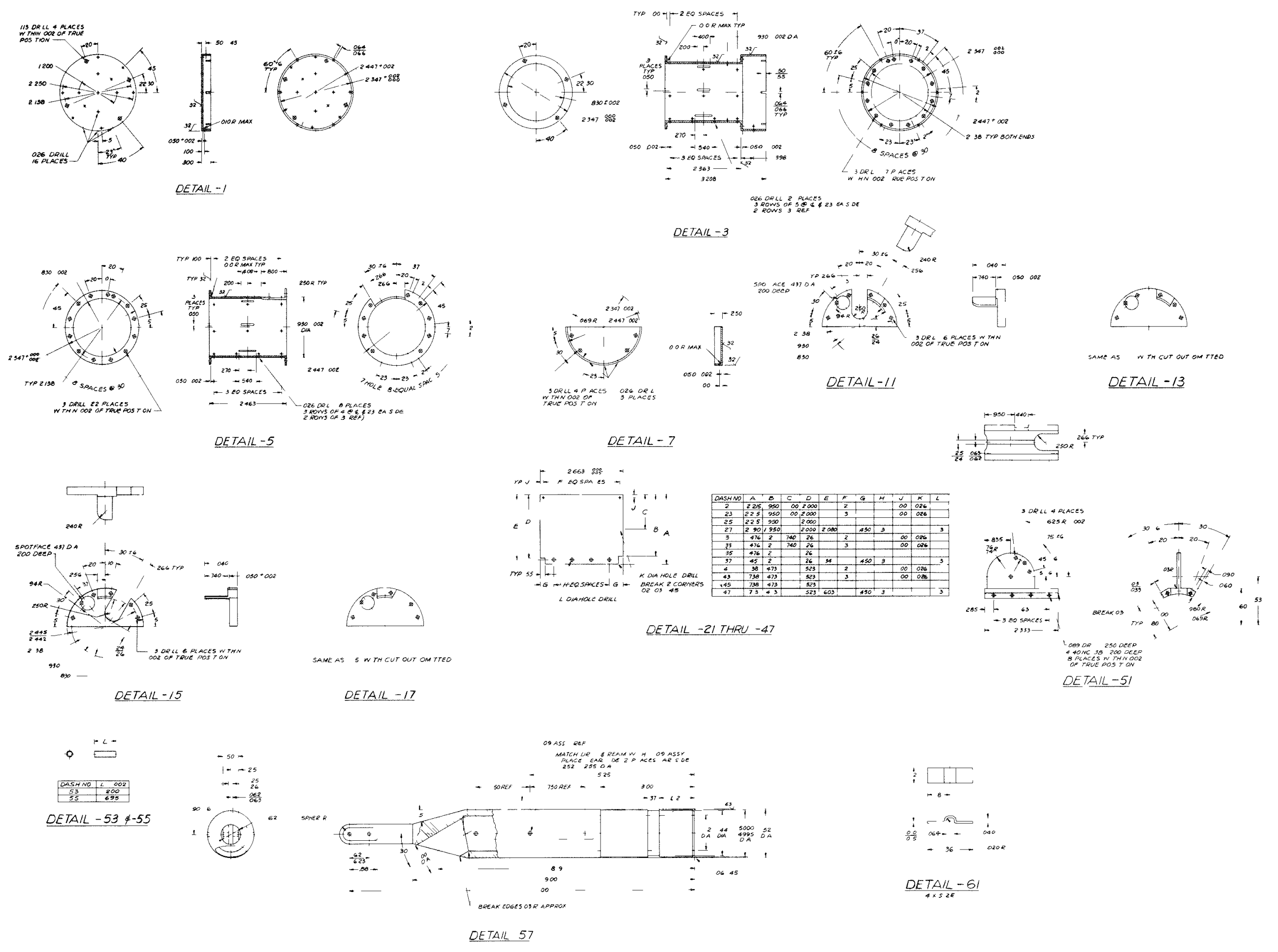

Fig. 4b. Thermocouple Locations 


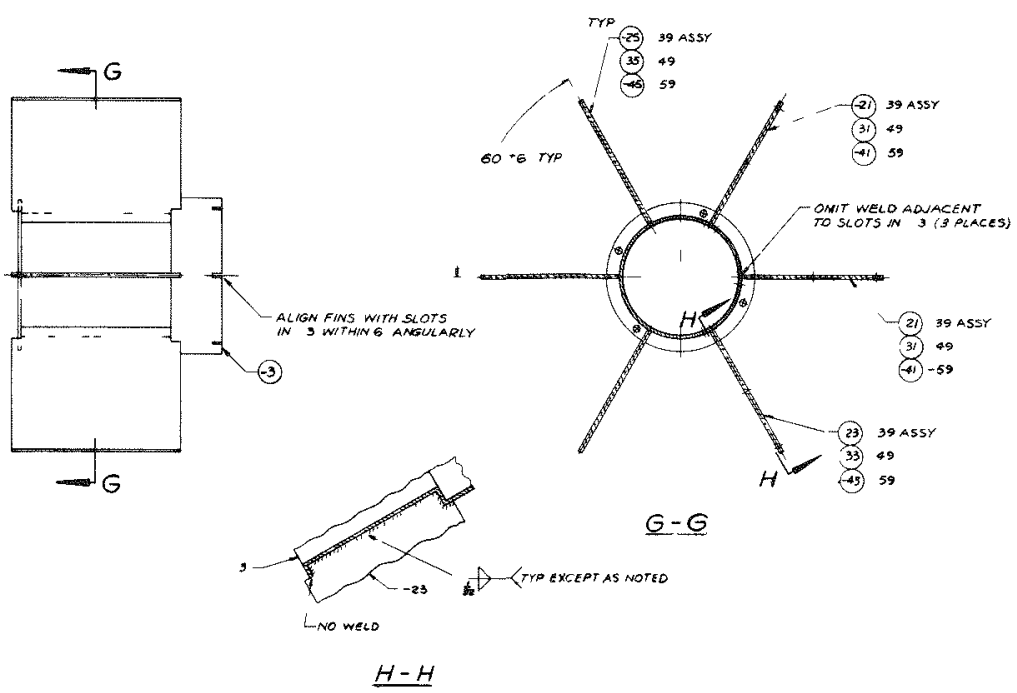

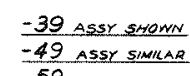
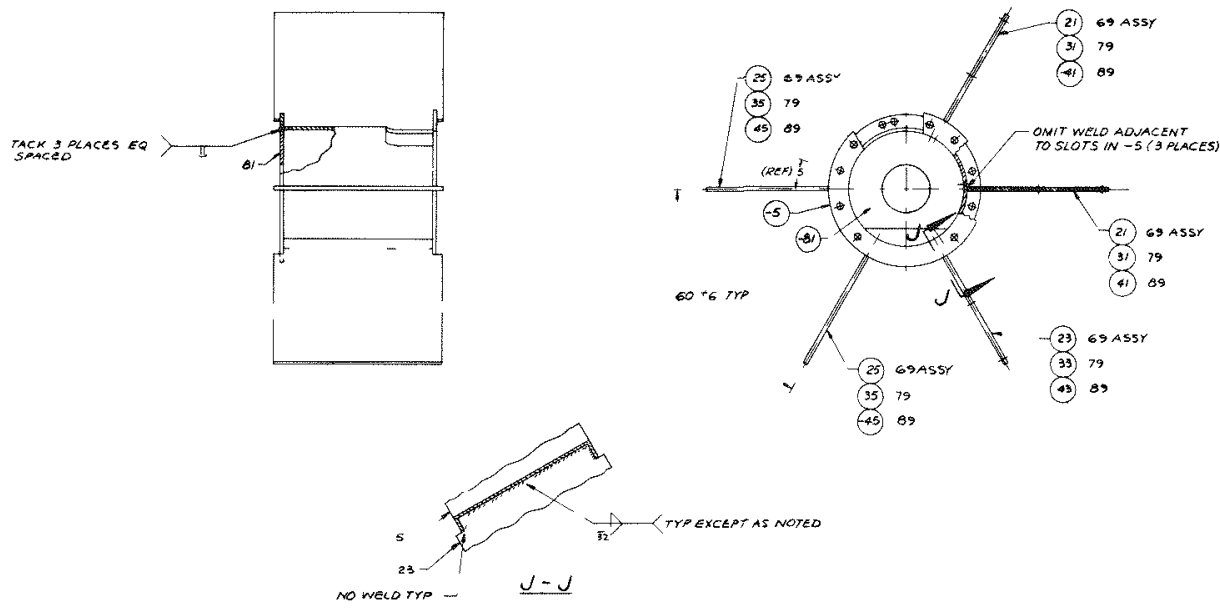

(주요 8

69 ASSY SHOWN

$\frac{-79 \text { ASSY SMMLAR }}{-89 \text { ASSY SMMLAAR }}$

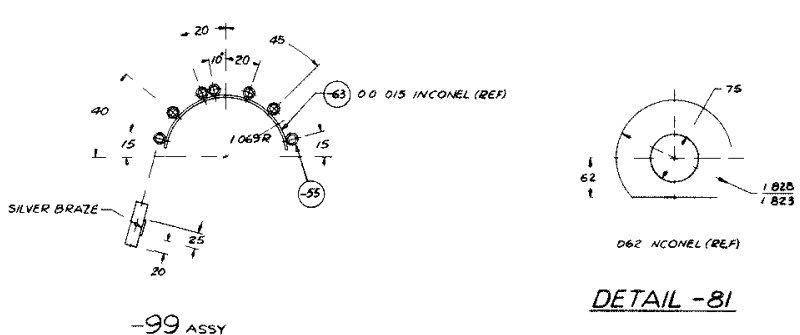

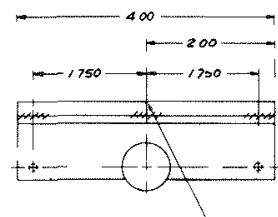

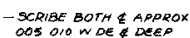

-109 A5s

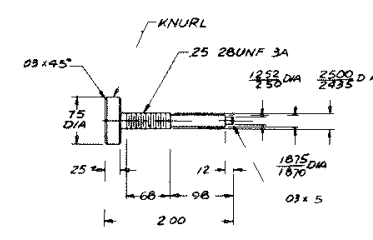

DETAR-75

ingr

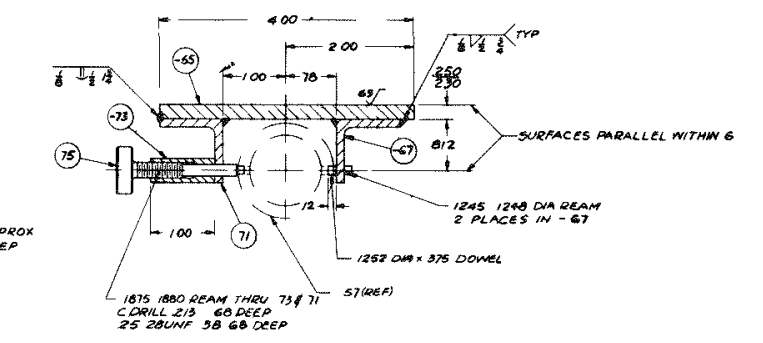

Fig. 4c. Thermocouple Locations 

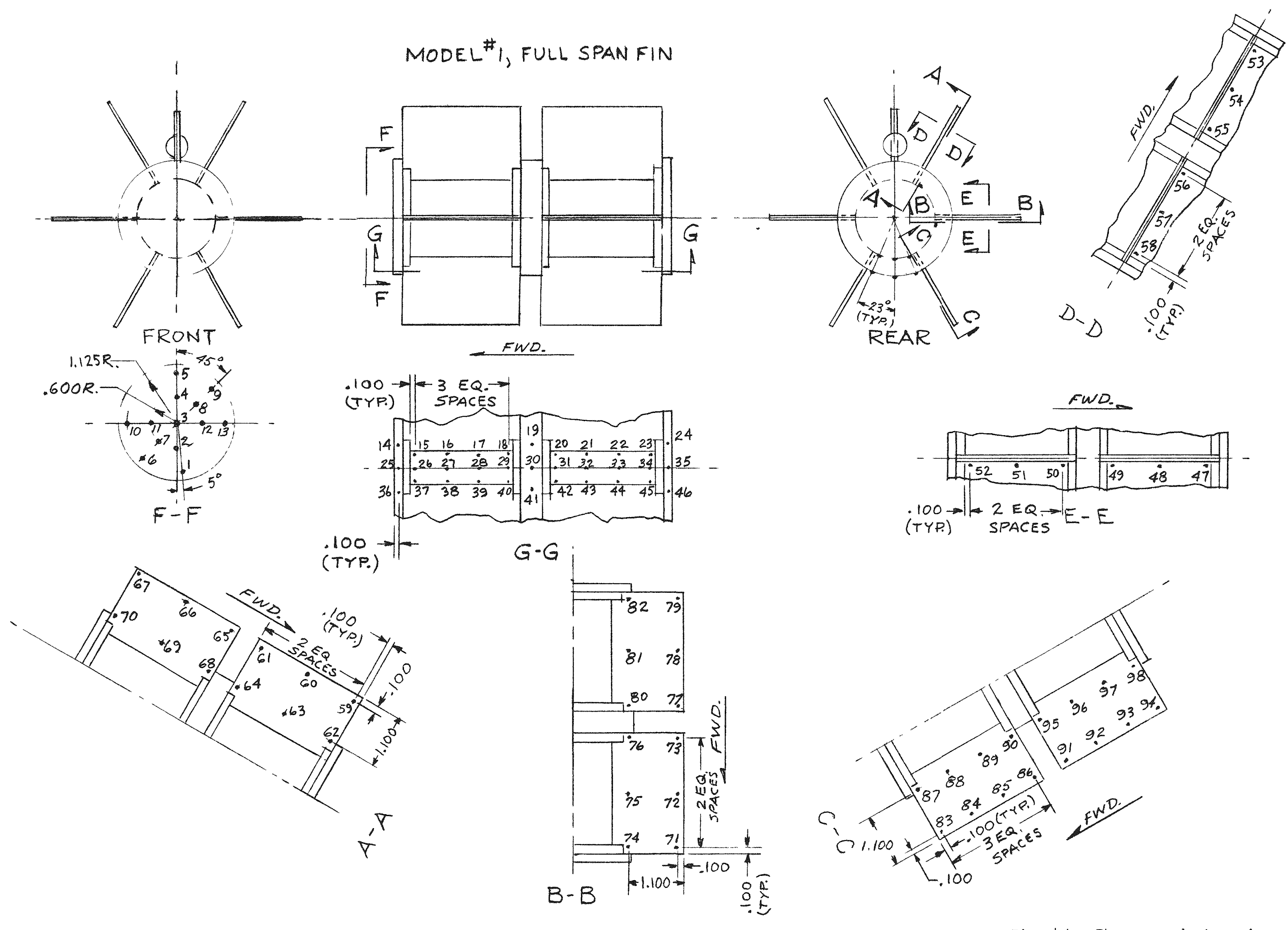

Fig. 4d. Thermocouple Locations 

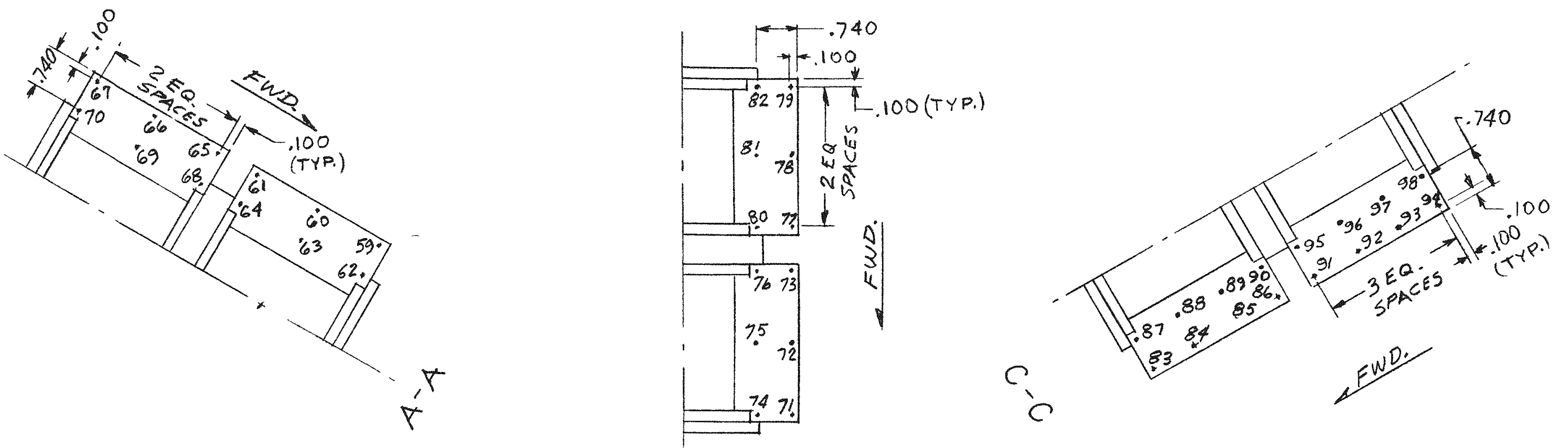

B- B

MODEL \#2, $\frac{2}{3}$ SPAN

SAME AS MODEL EXCEPT AS SHOWN
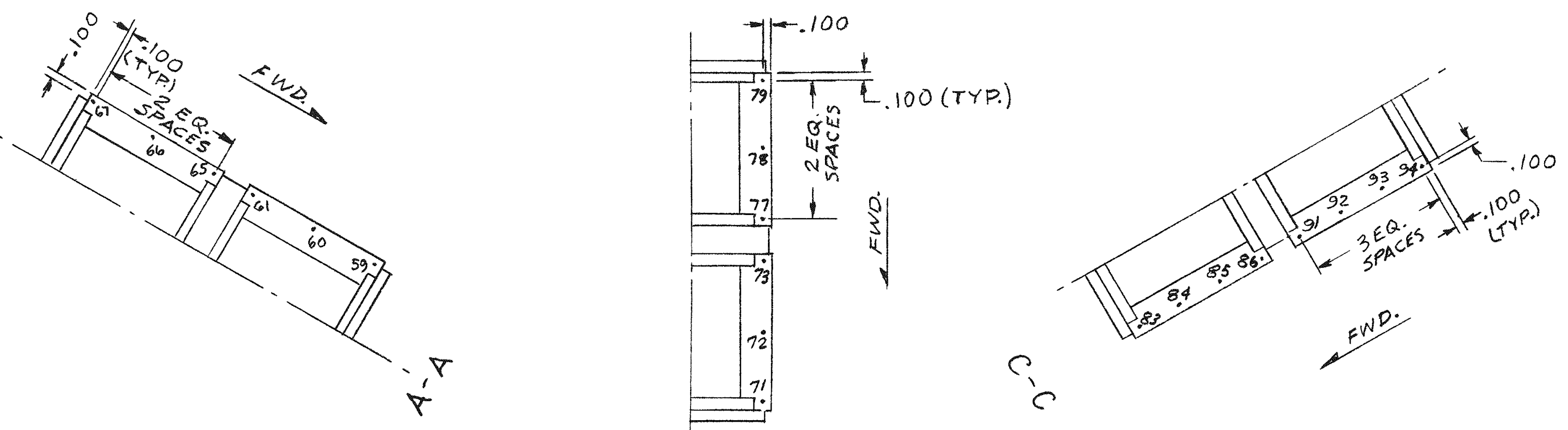

$B \cdot B$

MODEL \#3, $\frac{1}{3}$ SPAN

SAME AS MODEL A' EXCEPT AS SHOWN

Fig. 4e. Thermocouple Locations 


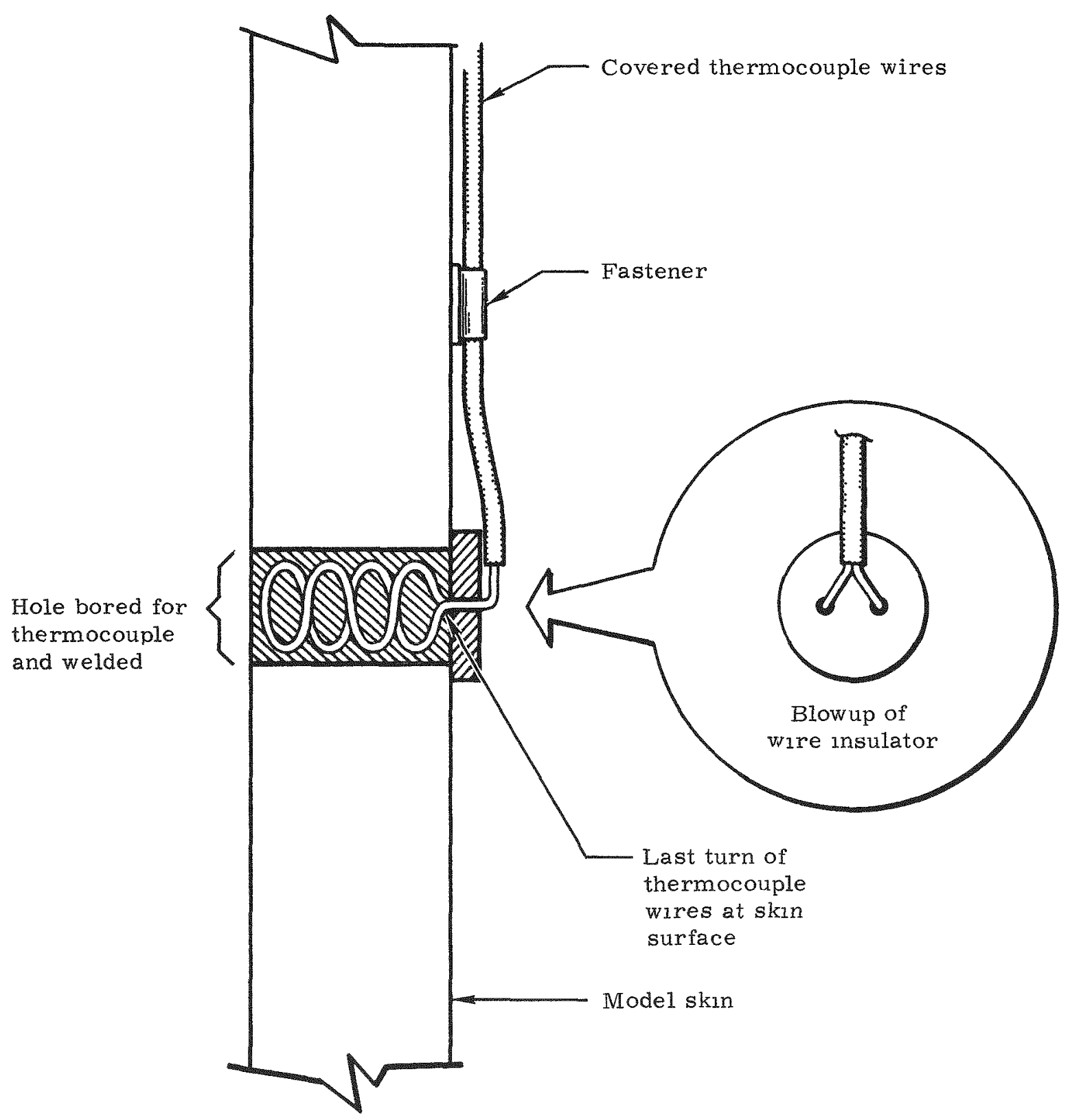

Fig. 5. Thermocouple Installation 


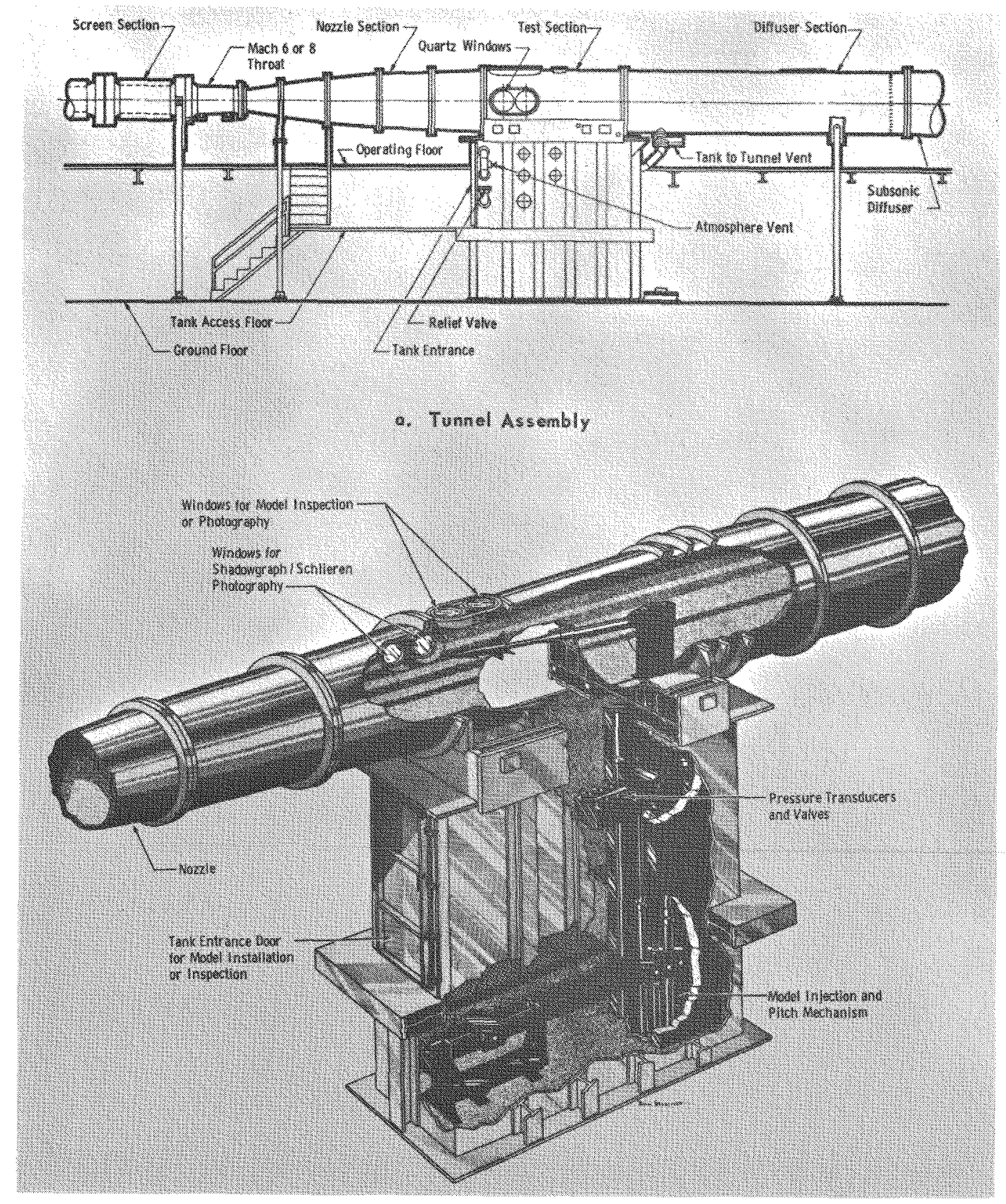

Fig. 6. Diagram of Tunnel $B$ and Test Section 
Full fin

$R e=0.4 \times 10^{6} / \mathrm{ft}$

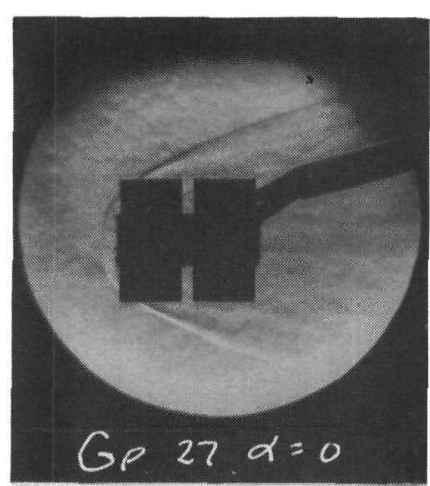

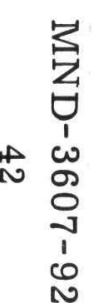
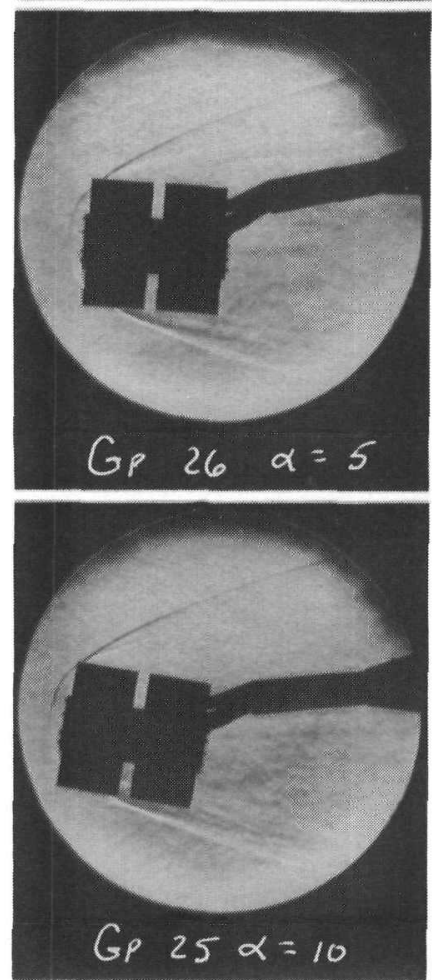

Two-thirds fin

$\mathrm{Re}=0.4 \times 10^{6} / \mathrm{ft}$
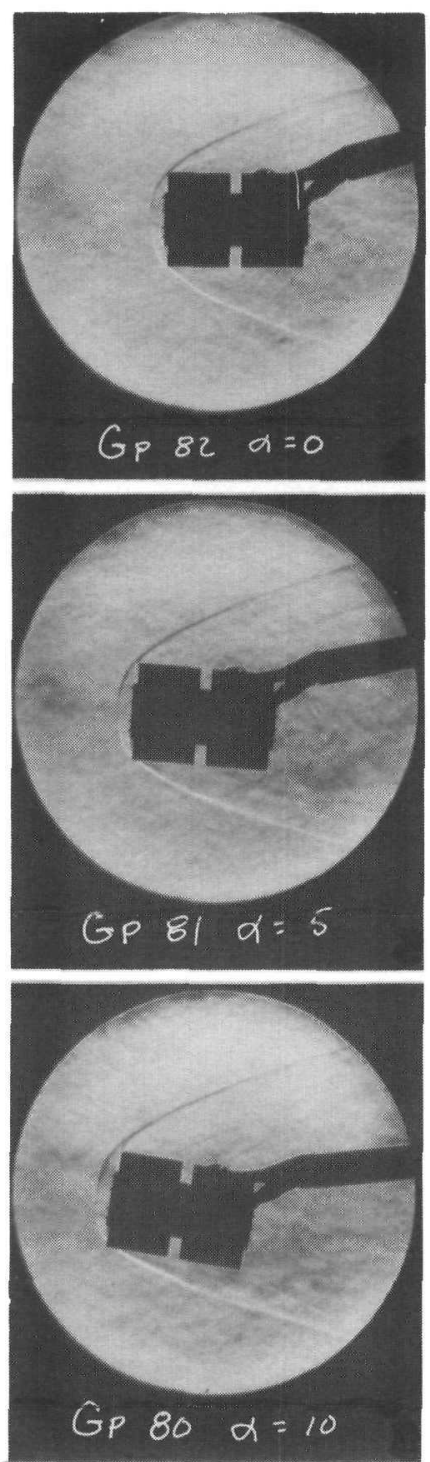

One-third fin

$\mathrm{Re}=0.4 \times 10^{6} / \mathrm{ft}$
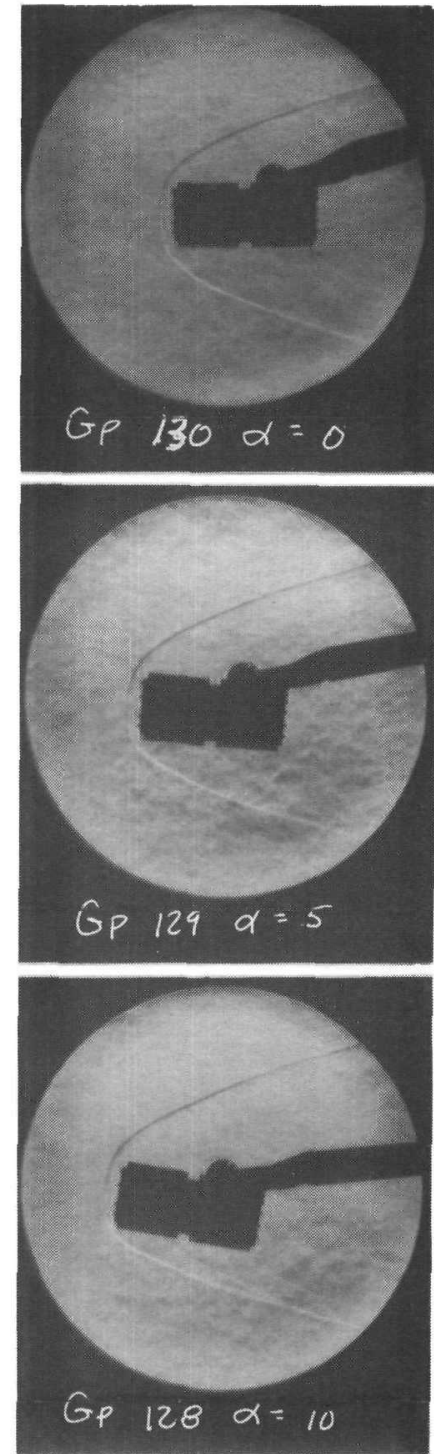

One-third fin

$\mathrm{Re}=1.5 \times 10^{6} / \mathrm{ft}$
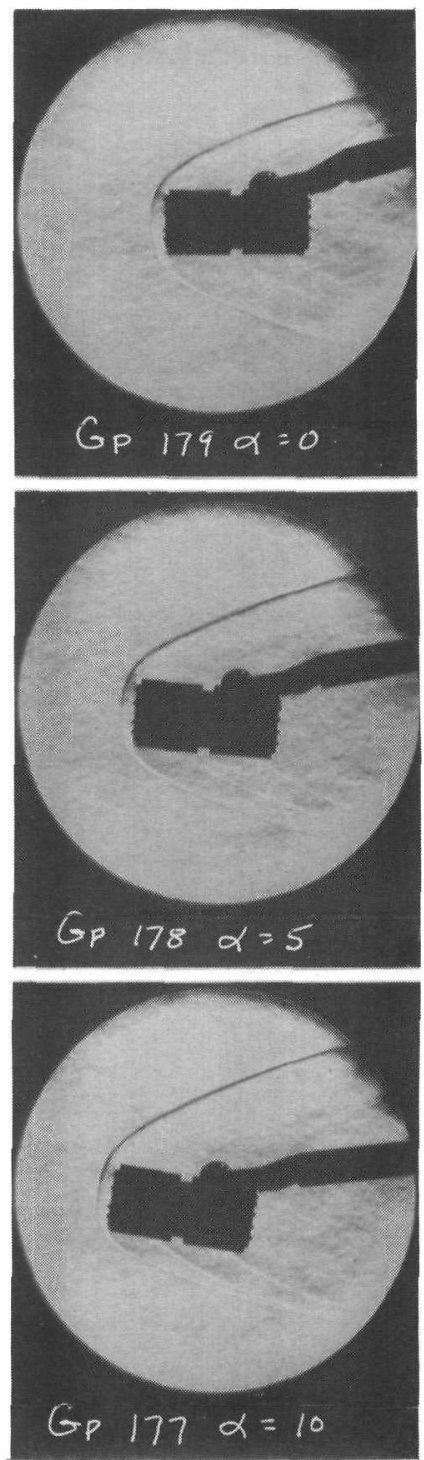

Fig. 8. Schlieren Photographs 


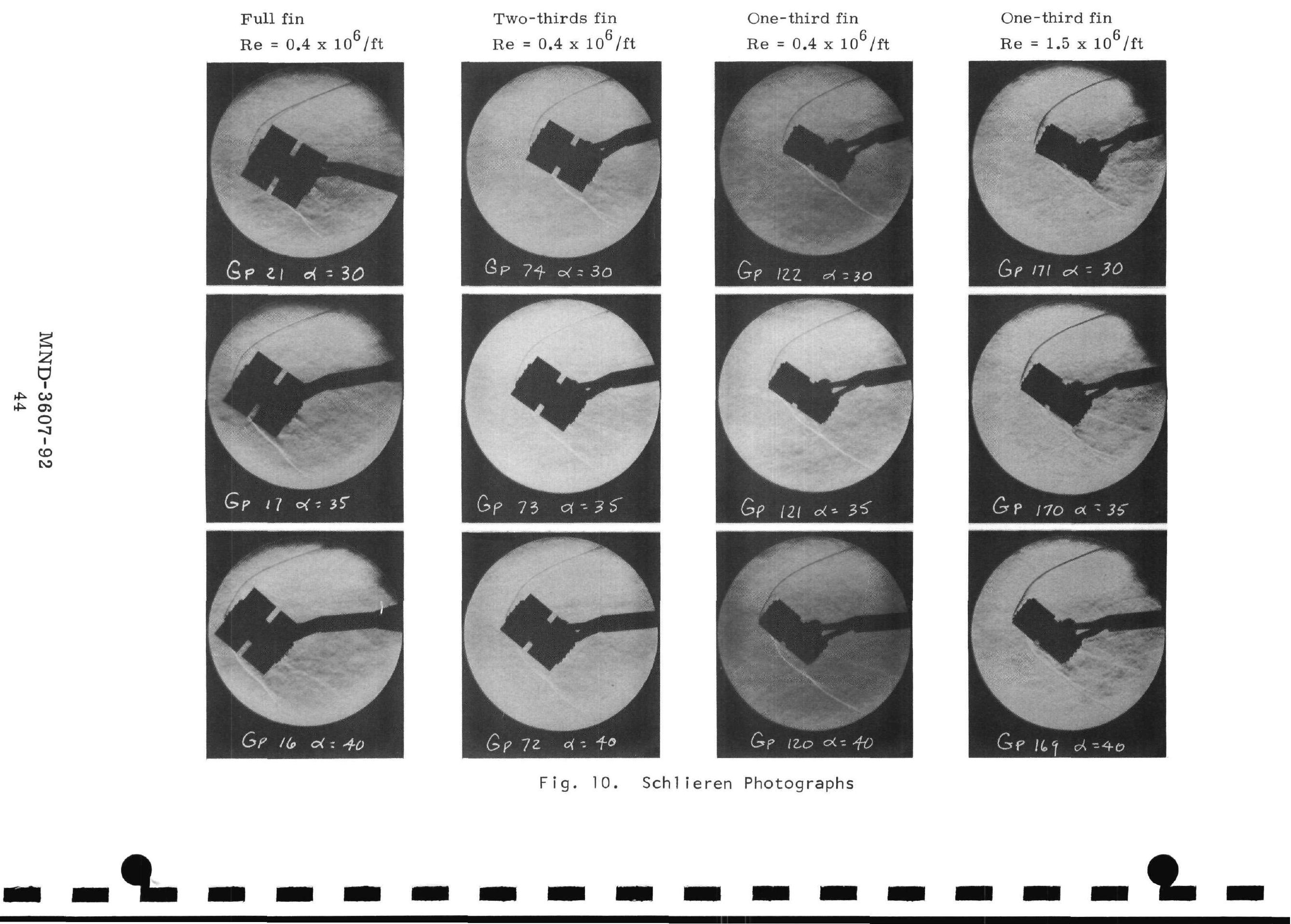


Full fin

$\mathrm{Re}=0.4 \times 10^{6} / \mathrm{ft}$

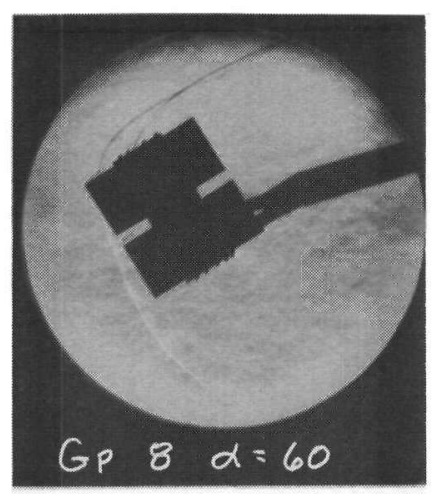

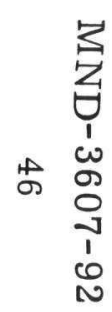
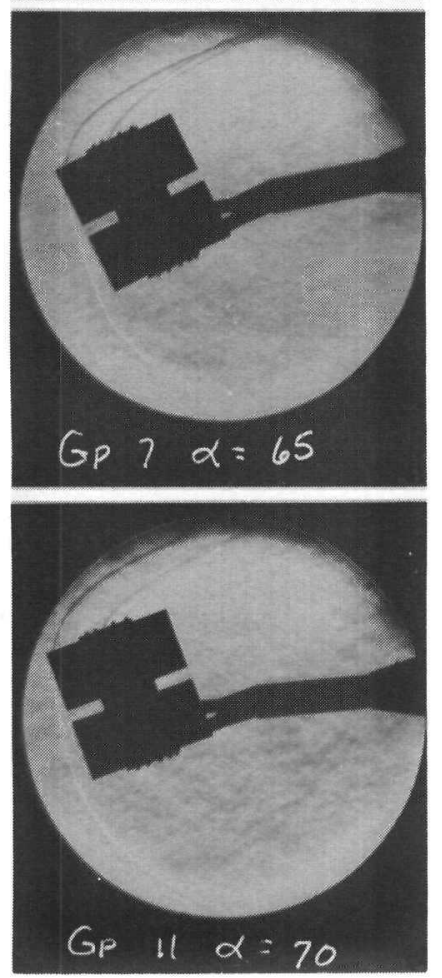

Two-thirds fin

$\operatorname{Re}=0.4 \times 10^{6} / \mathrm{ft}$
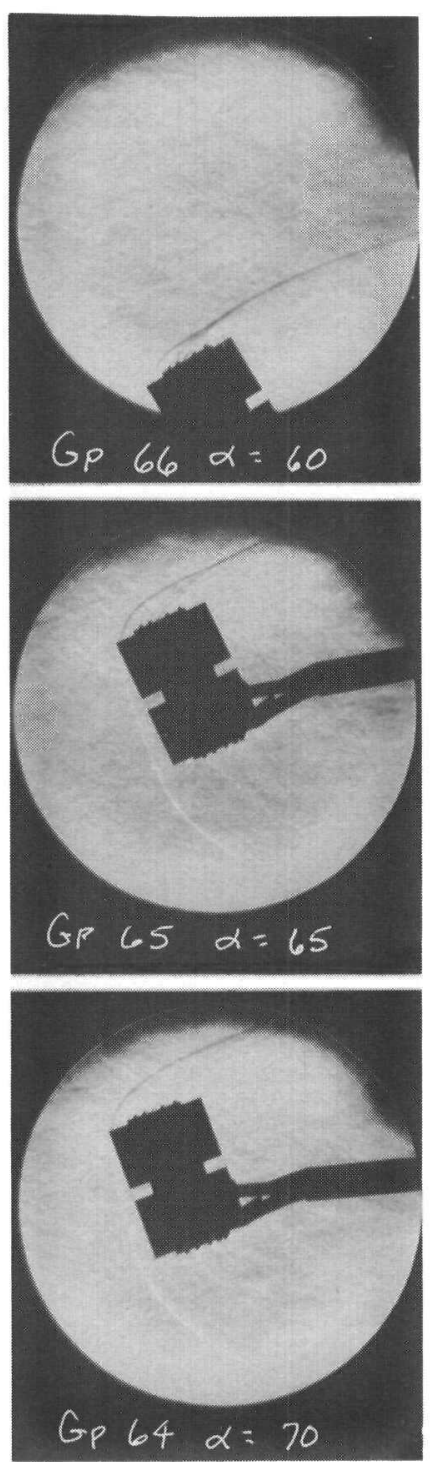

One-third fin

$\mathrm{Re}=0.4 \times 10^{6} / \mathrm{ft}$
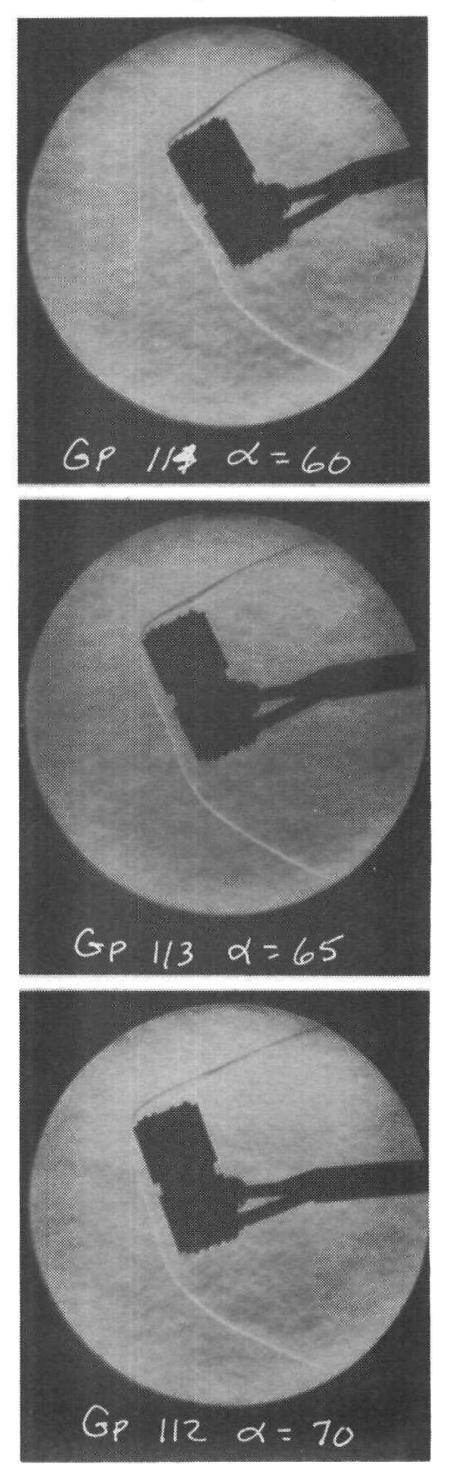

One-third fin

$\operatorname{Re}=1.5 \times 10^{6} / \mathrm{ft}$
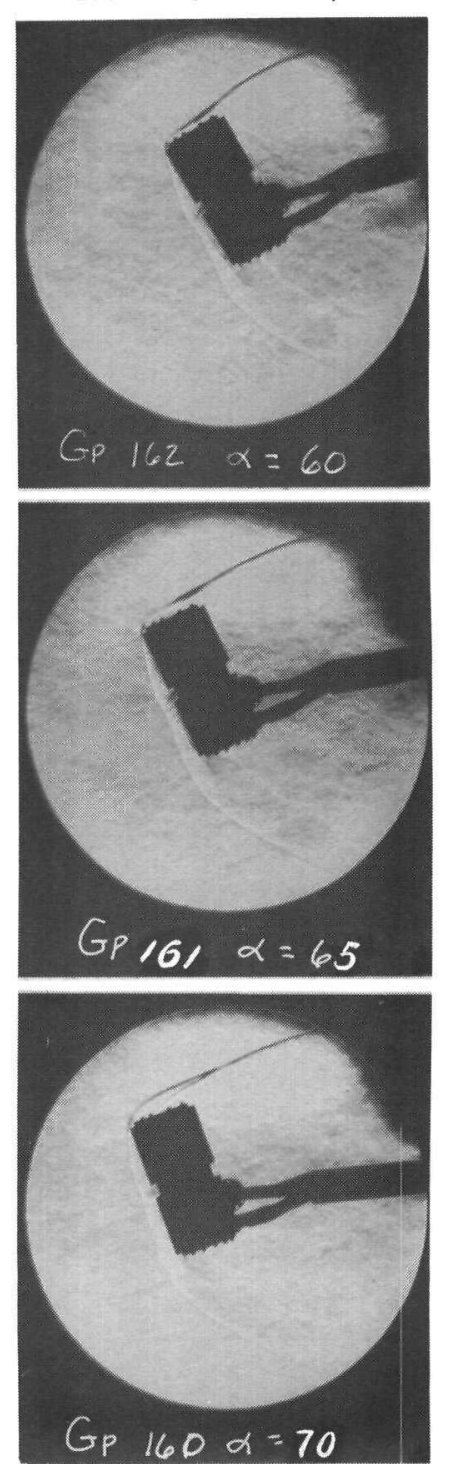

Fig. 12. Schlieren Photographs

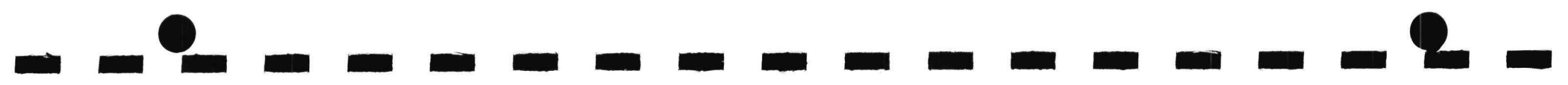




\section{$\square$

Full fin

$\mathrm{Re}=0.4 \times 10^{6} / \mathrm{ft}$

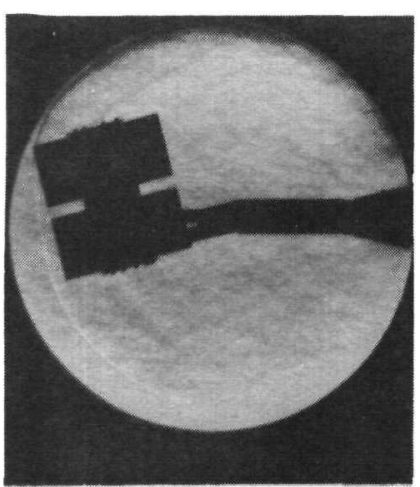

3
3
3
1
1
1
0
0
0
0
0
1
1
0
$N$
Two-thirds fin

$R e=0.4 \times 10^{6} / \mathrm{ft}$
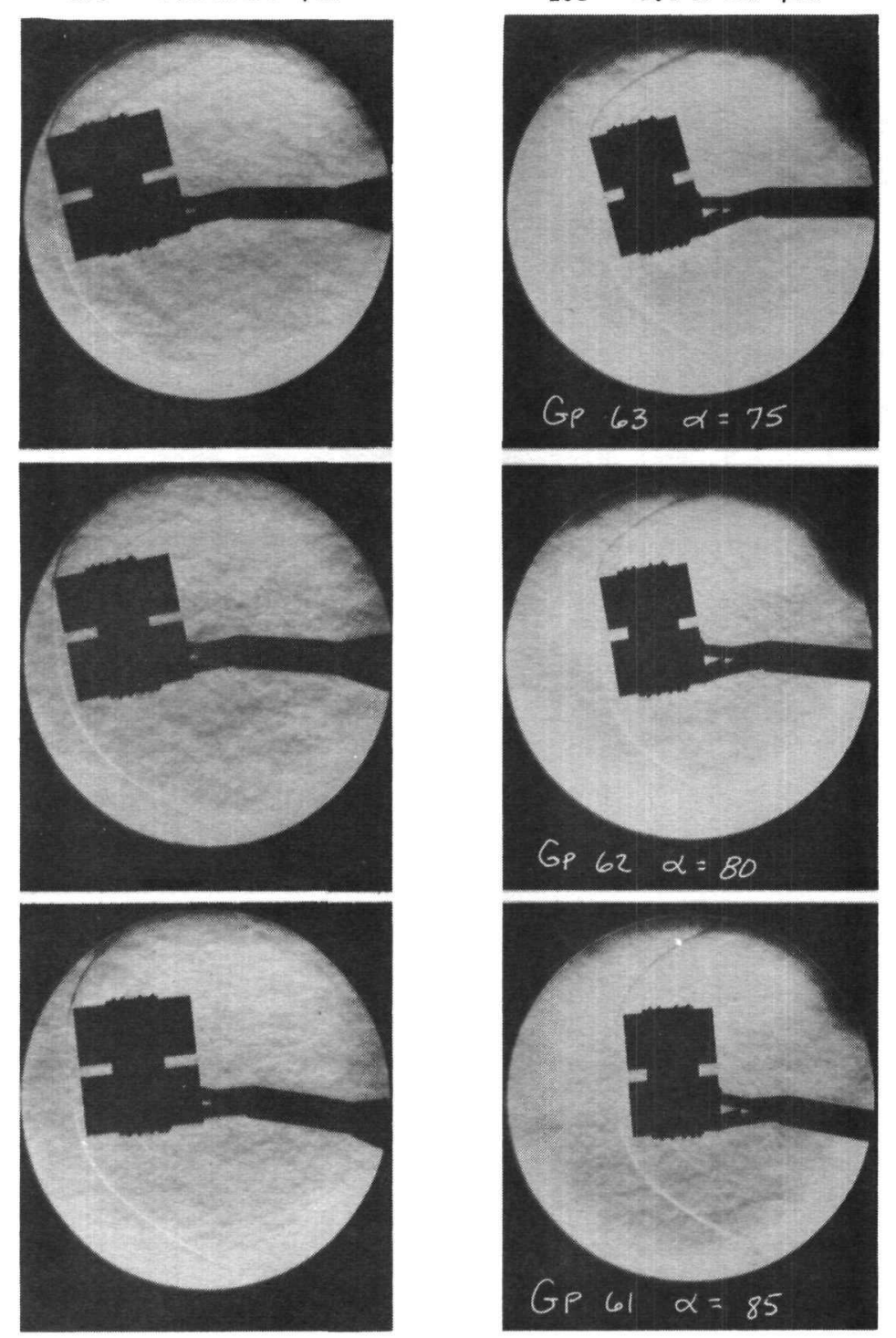
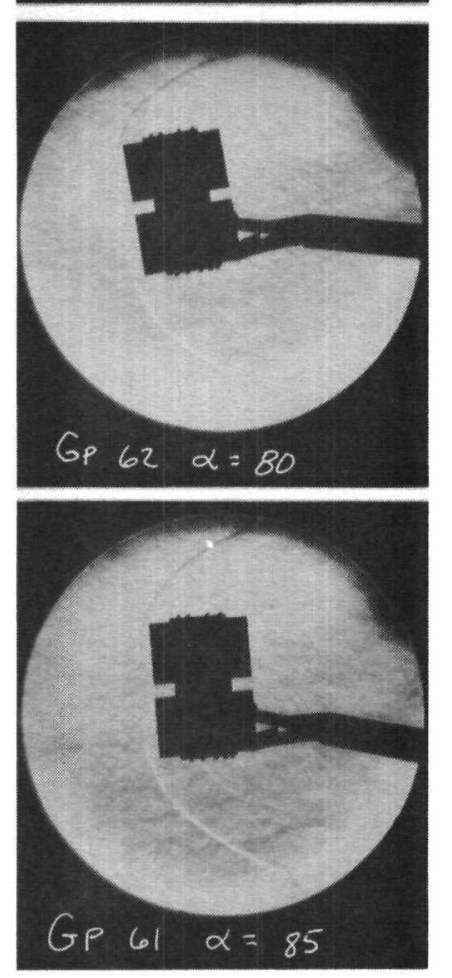

One-third fin

$\operatorname{Re}=0.4 \times 10^{6} / \mathrm{ft}$
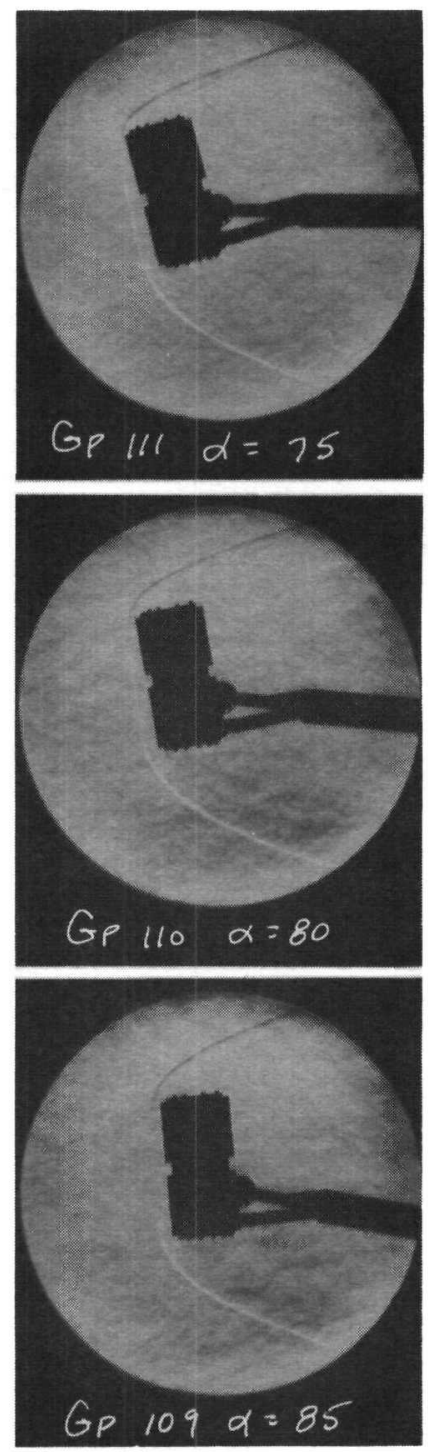

One-third fin

$\mathrm{Re}=1.5 \times 10^{6} / \mathrm{ft}$
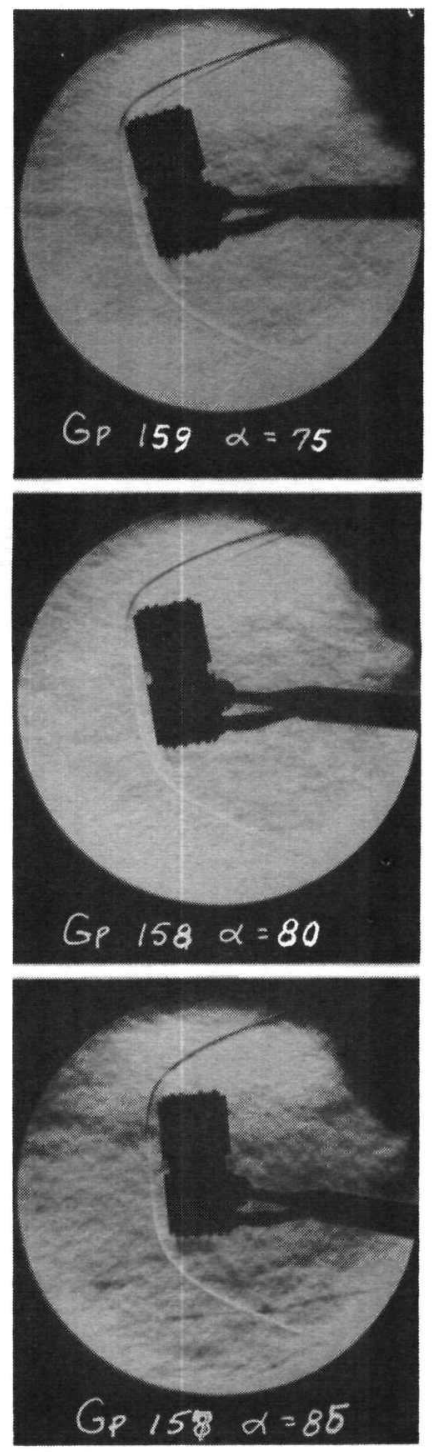

Fig. 13. Schlieren Photographs 

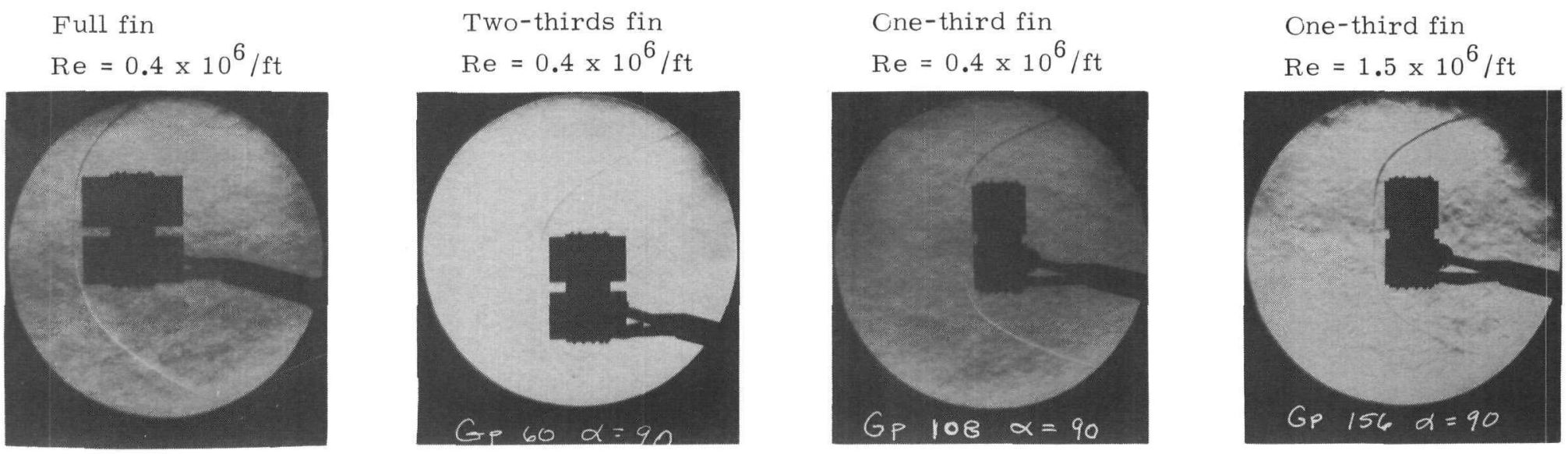

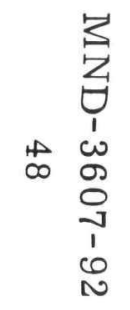

Fig. 14. Schlieren Photographs 


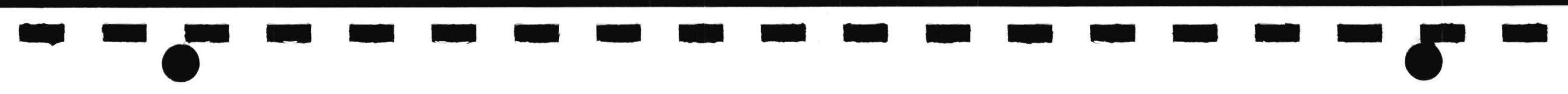

Full fin

$\operatorname{Re}=0.4 \times 10^{6} / \mathrm{ft}$

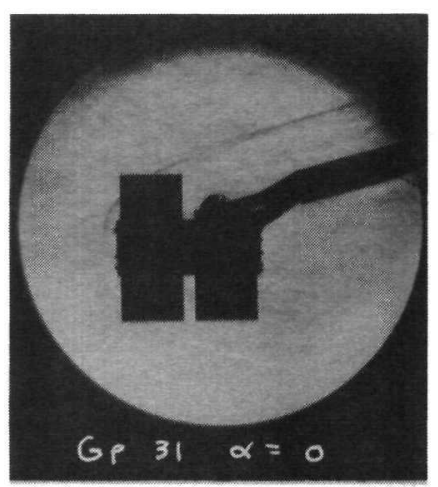

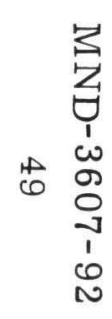

Two-thirds fin $\mathrm{Re}=0.4 \times 10^{6} / \mathrm{ft}$
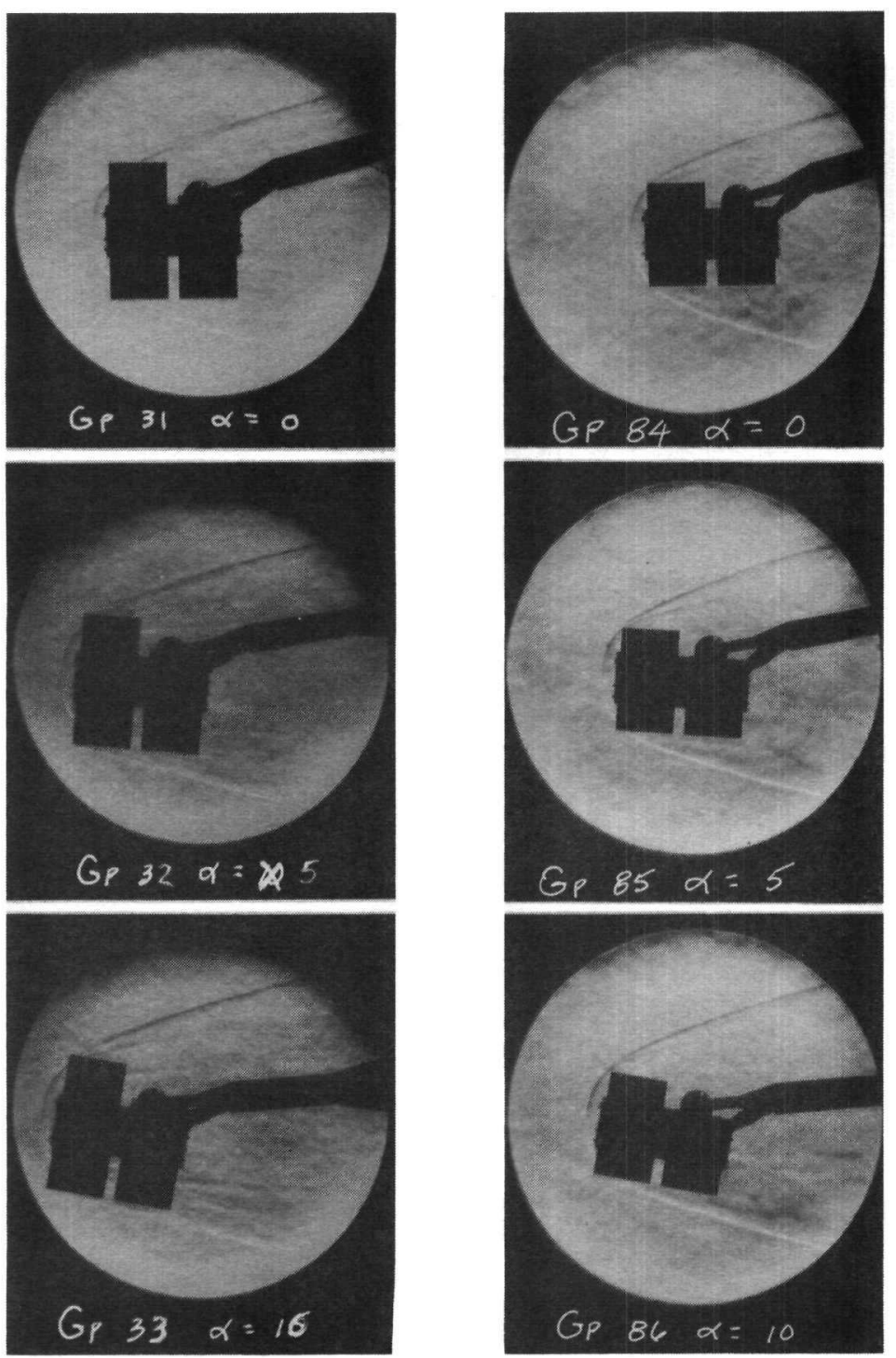
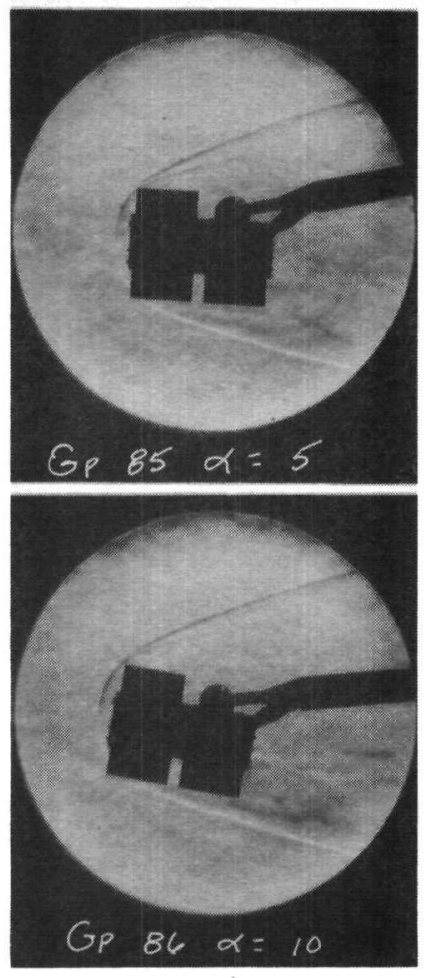

Fig. 15. Schlieren Photographs
One-third fin

$\operatorname{Re}=0.4 \times 10^{6} / \mathrm{ft}$
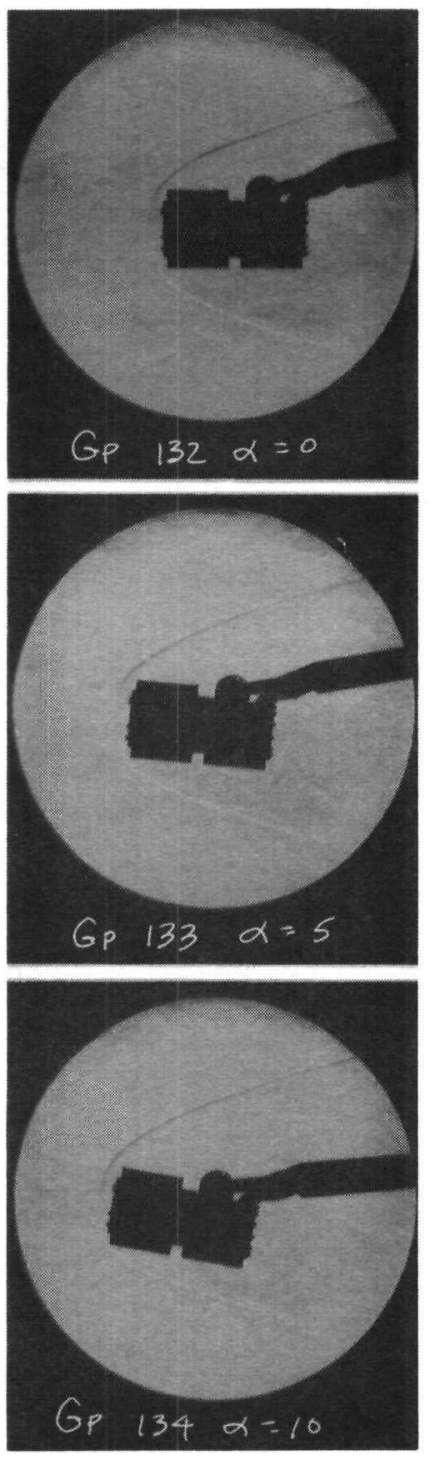

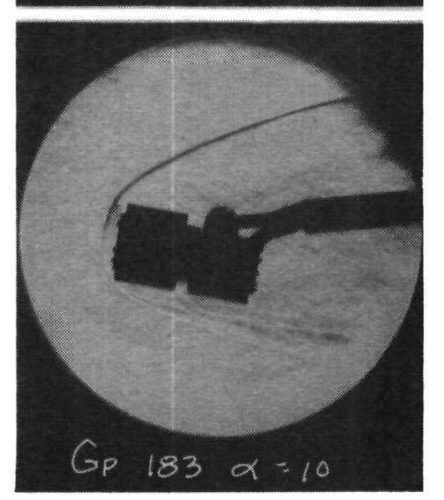

One-third fin

$\operatorname{Re}=1.5 \times 10^{6} / \mathrm{ft}$
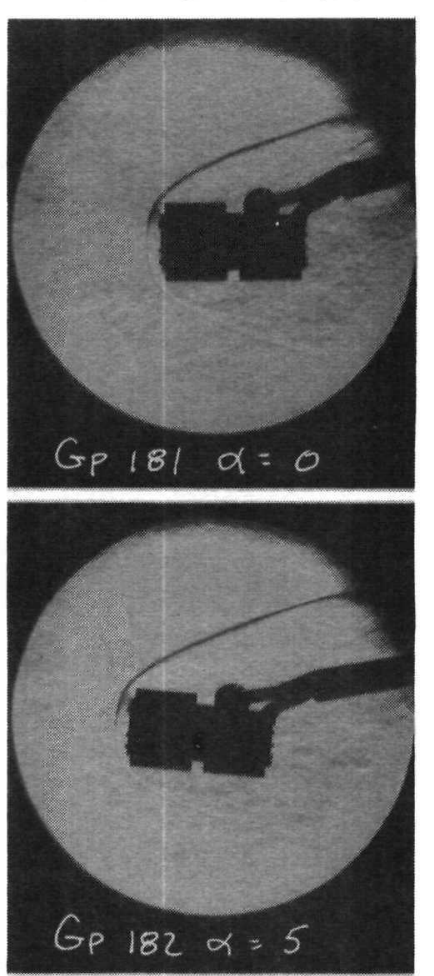


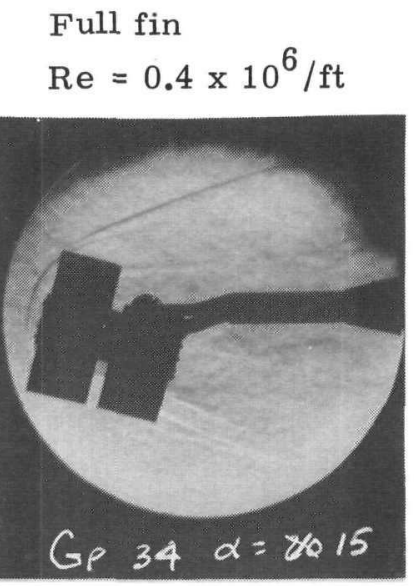

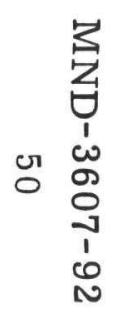
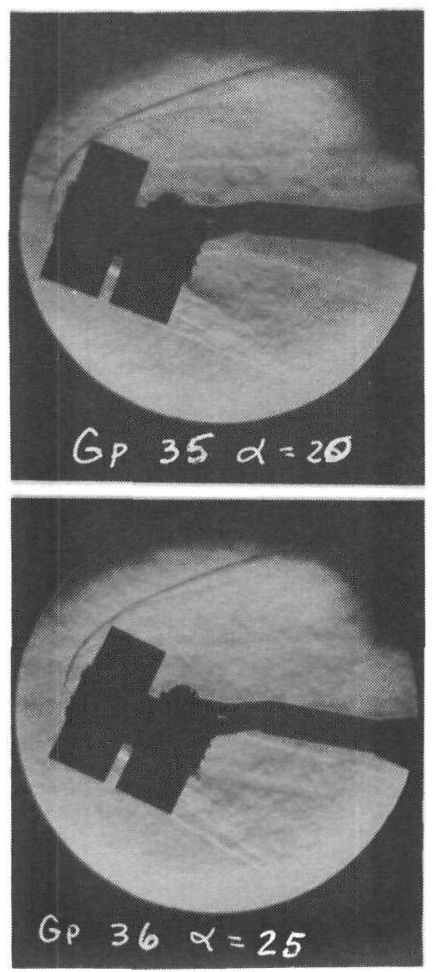

Two-thirds fin

$\mathrm{Re}=0.4 \times 10^{6} / \mathrm{ft}$

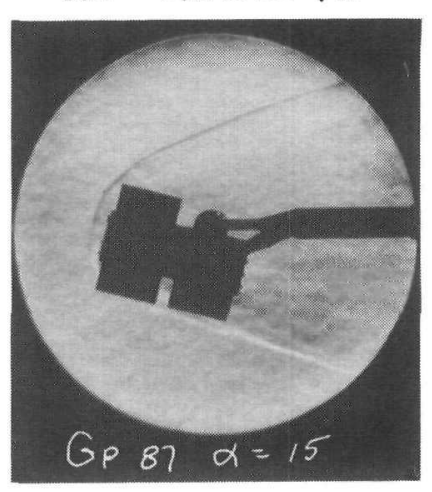

One-third fin

$\mathrm{Re}=0.4 \times 10^{6} / \mathrm{ft}$
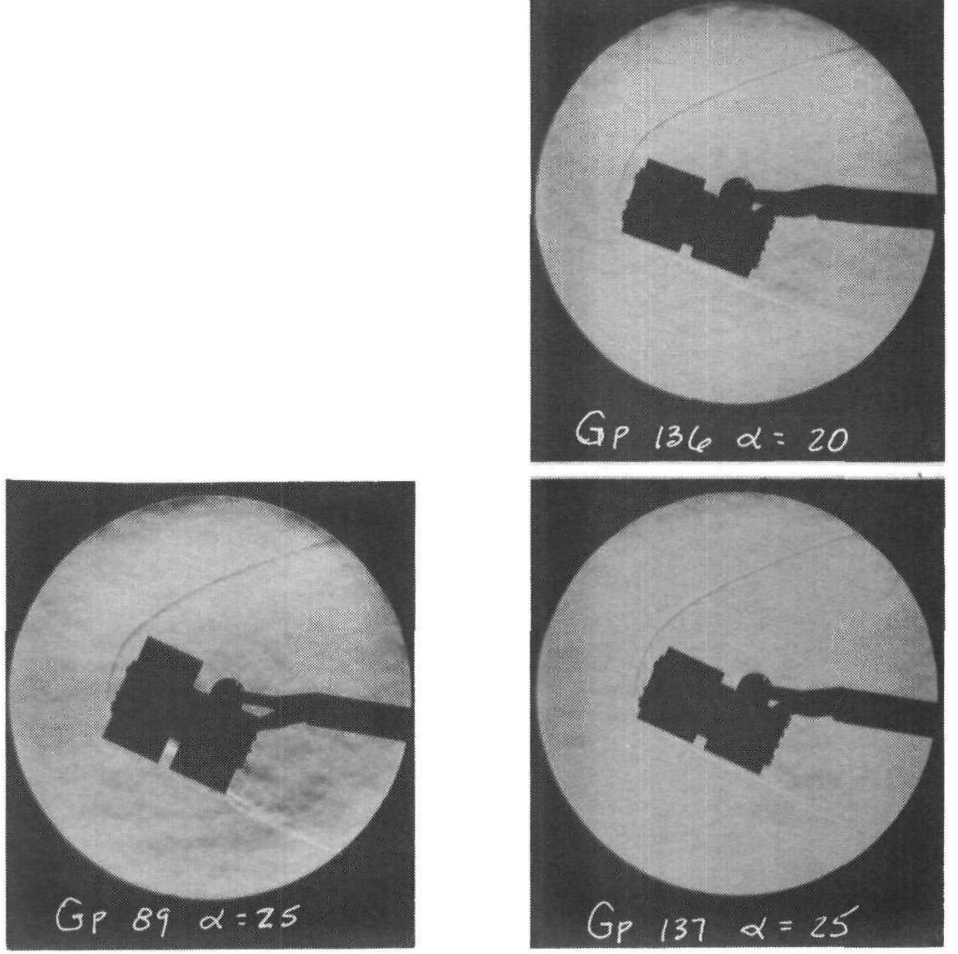

One-third fin

$\operatorname{Re}=1.5 \times 10^{6} / \mathrm{ft}$
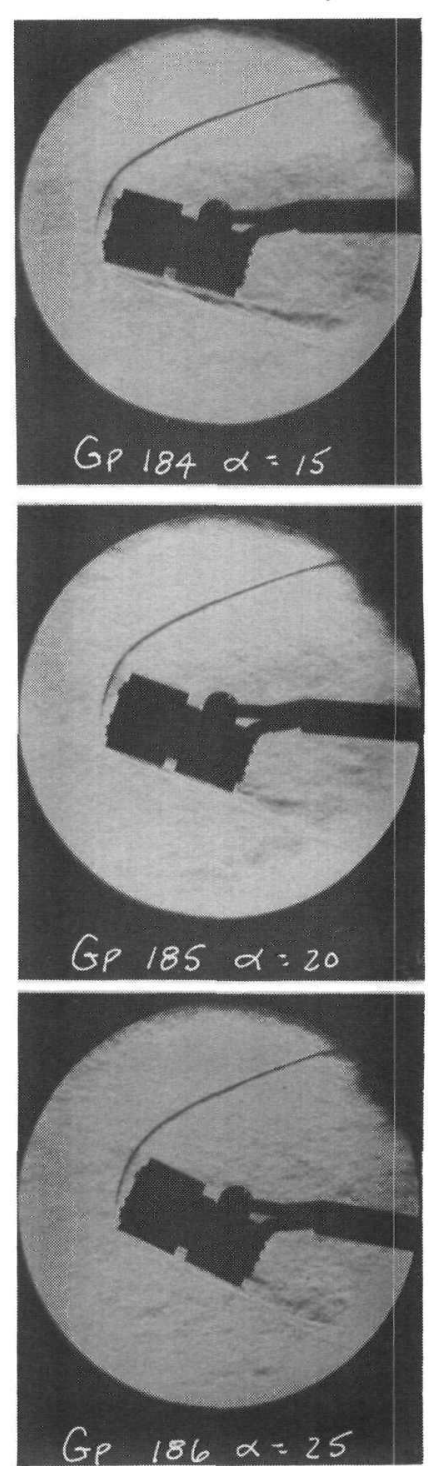

Fig. 16. Schlieren Photographs 


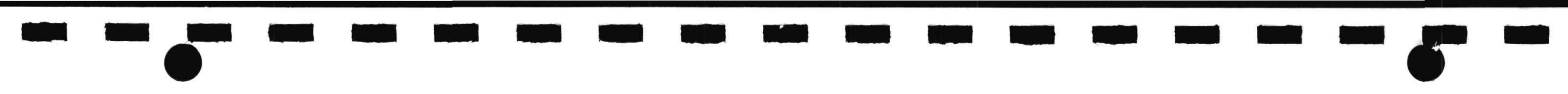
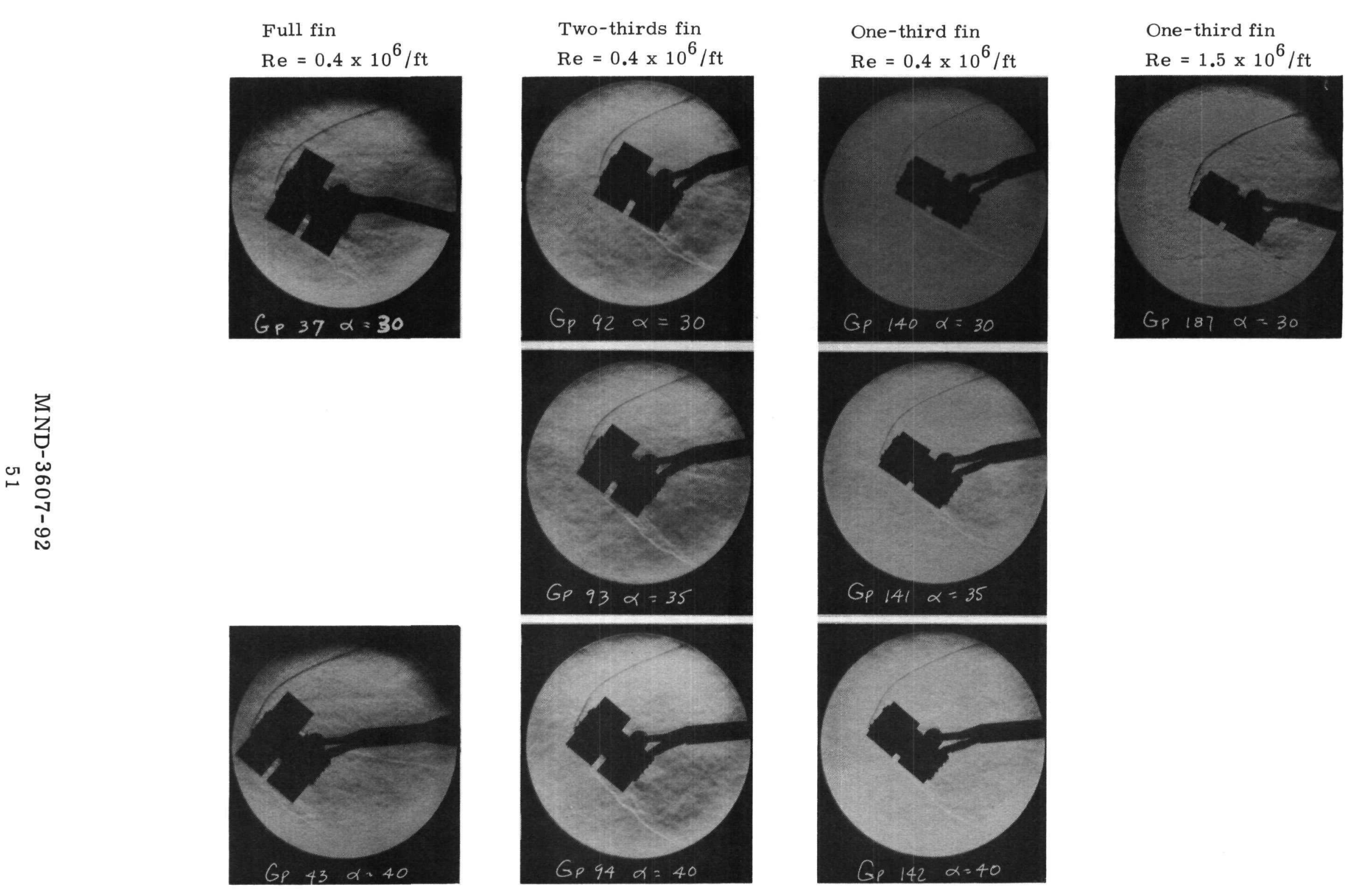

Fig. 17. Schlieren Photographs 

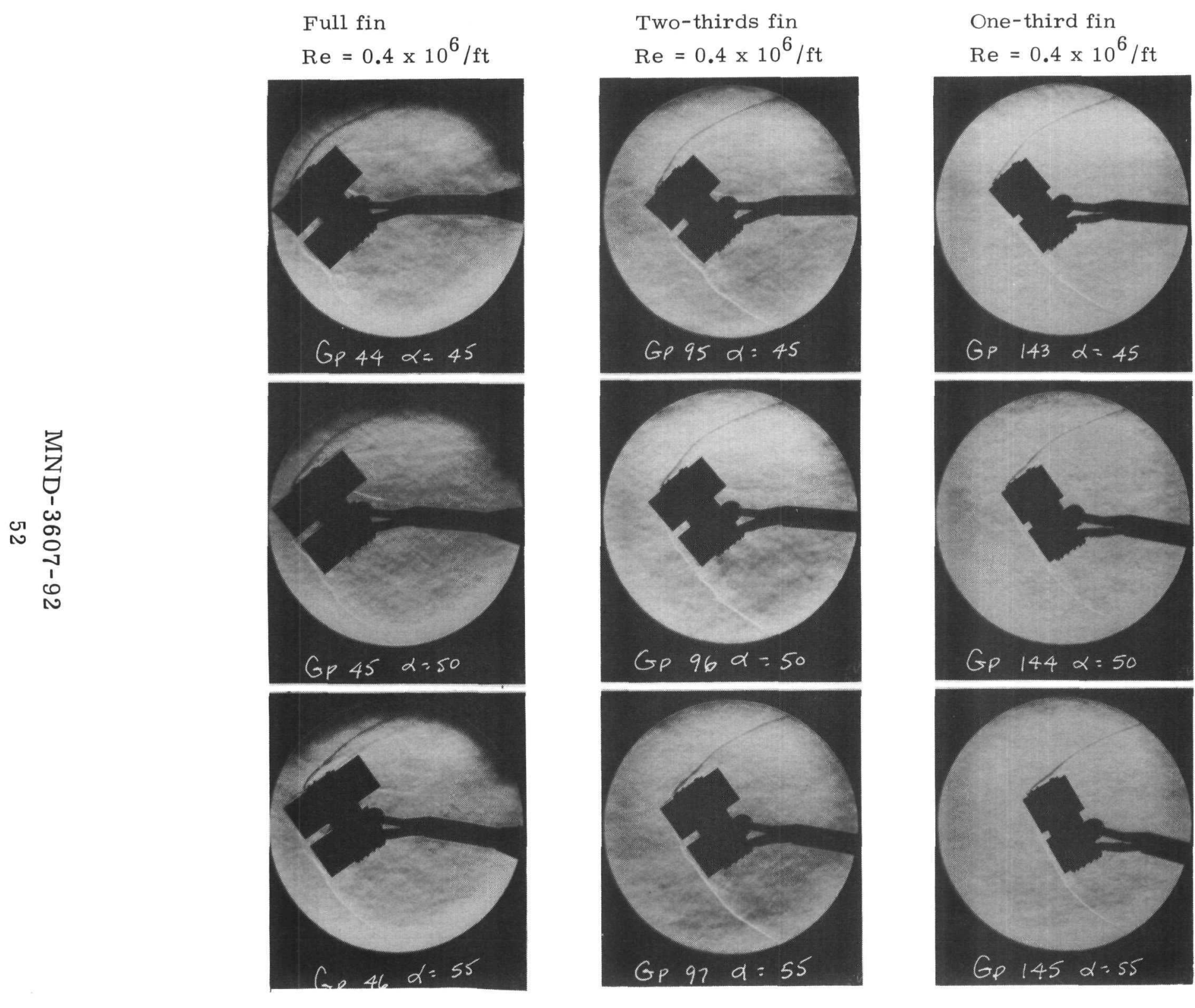

One-third fin

$\mathrm{Re}=1.5 \times 10^{6} / \mathrm{ft}$
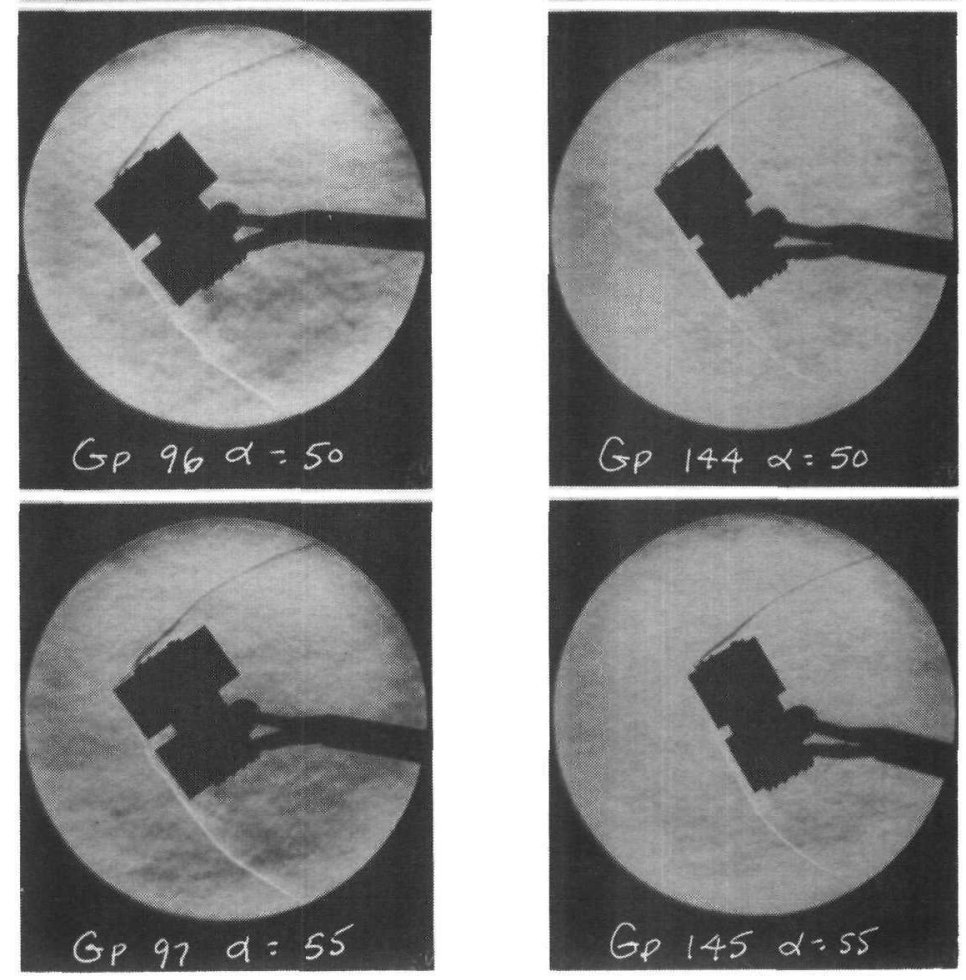

Fig. 18. Schlieren Photographs

-゚- - 
Full fin

$\operatorname{Re}=0.4 \times 10^{6} / \mathrm{ft}$

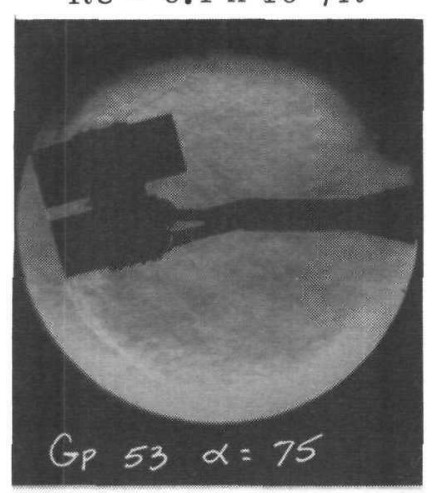

3
$z$
1
1
1
0
0
0
0
0
0
1
1
0
0
0
Two-thirds fin

$\mathrm{Re}=0.4 \times 10^{6} / \mathrm{ft}$
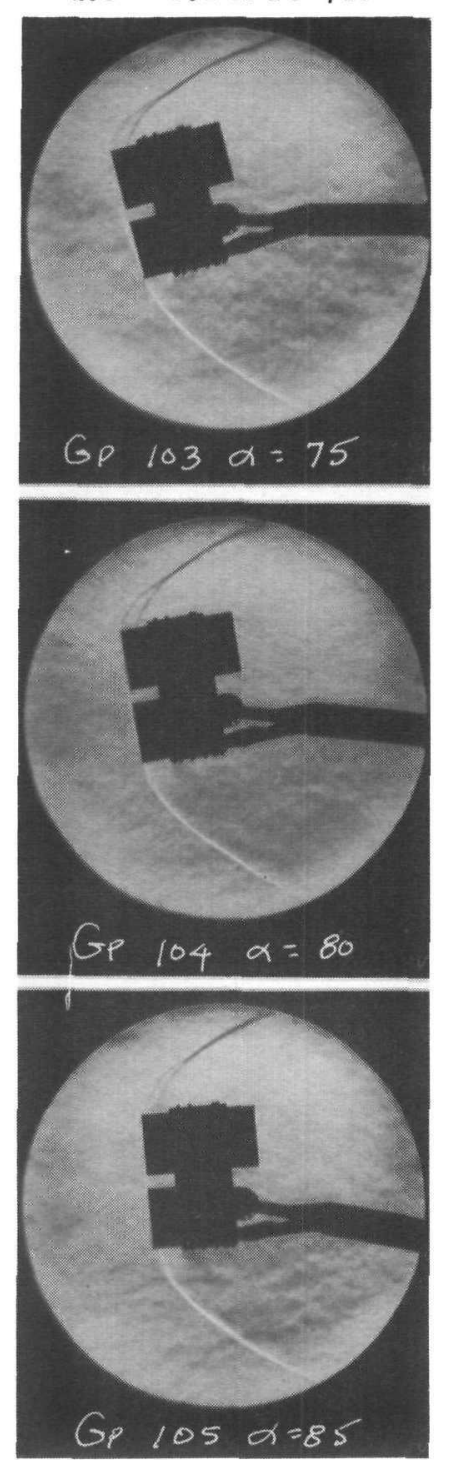

One-third fin

$\mathrm{Re}=0.4 \times 10^{6} / \mathrm{ft}$
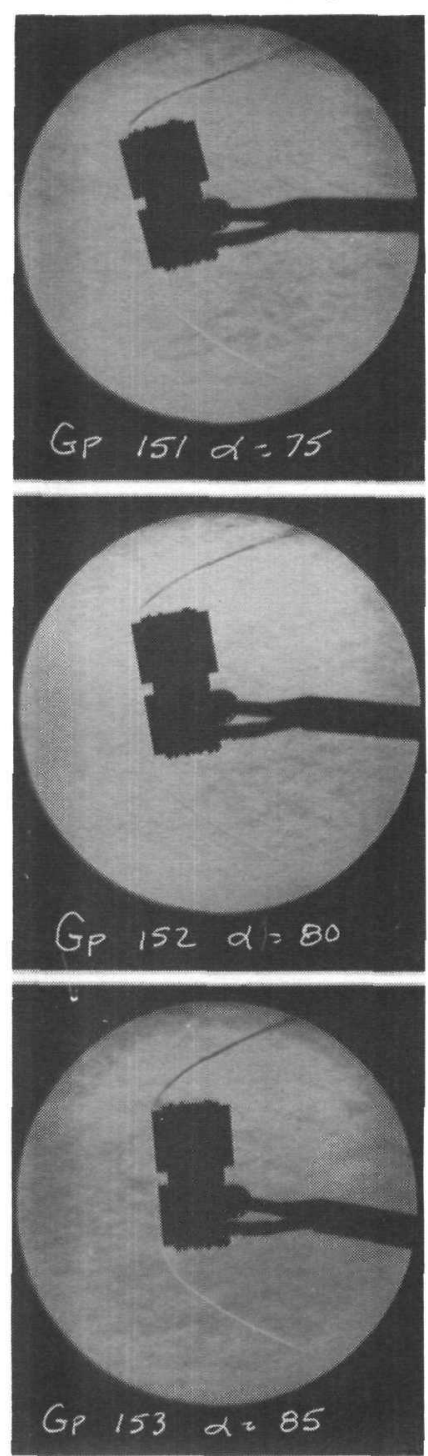

One-third fin

$\mathrm{Re}=1.5 \times 10^{6} / \mathrm{ft}$
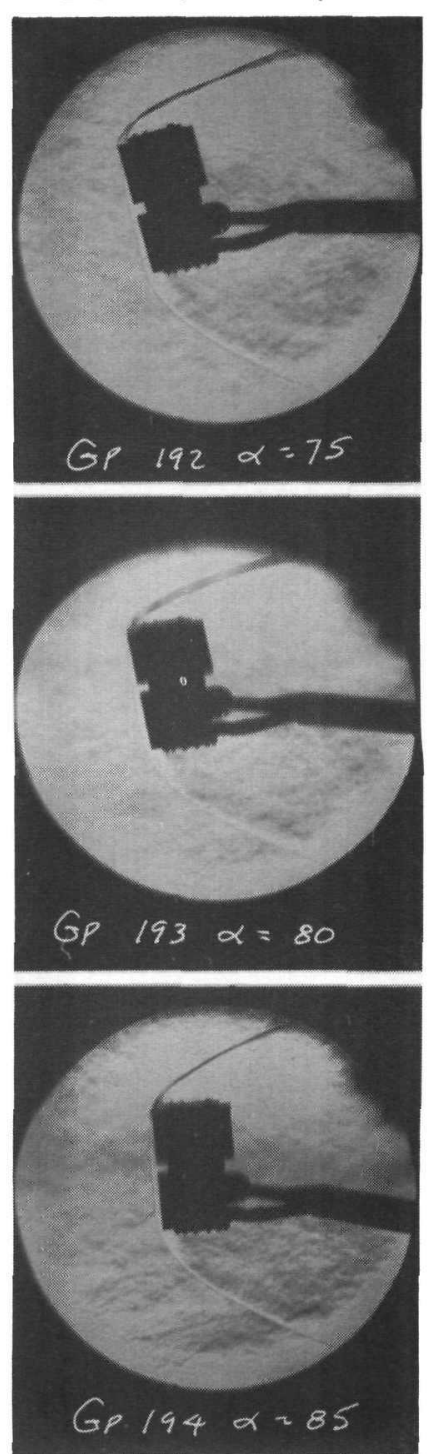

Fig. 20. Schlieren Photographs

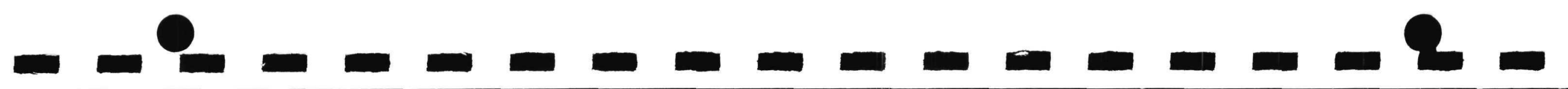




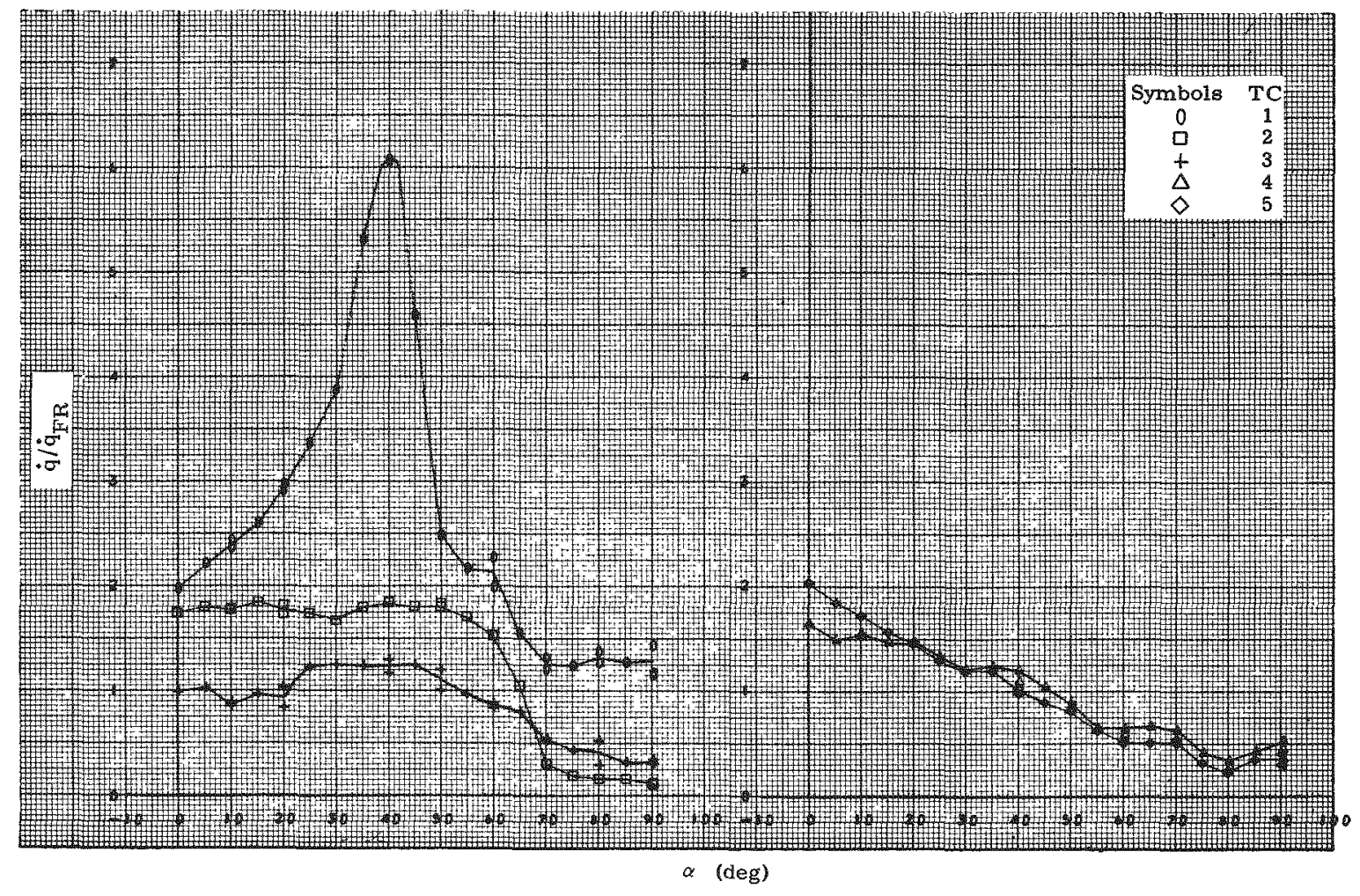

Fig. 22. Heat Transfer, TC 1 - 5, Configuration 100

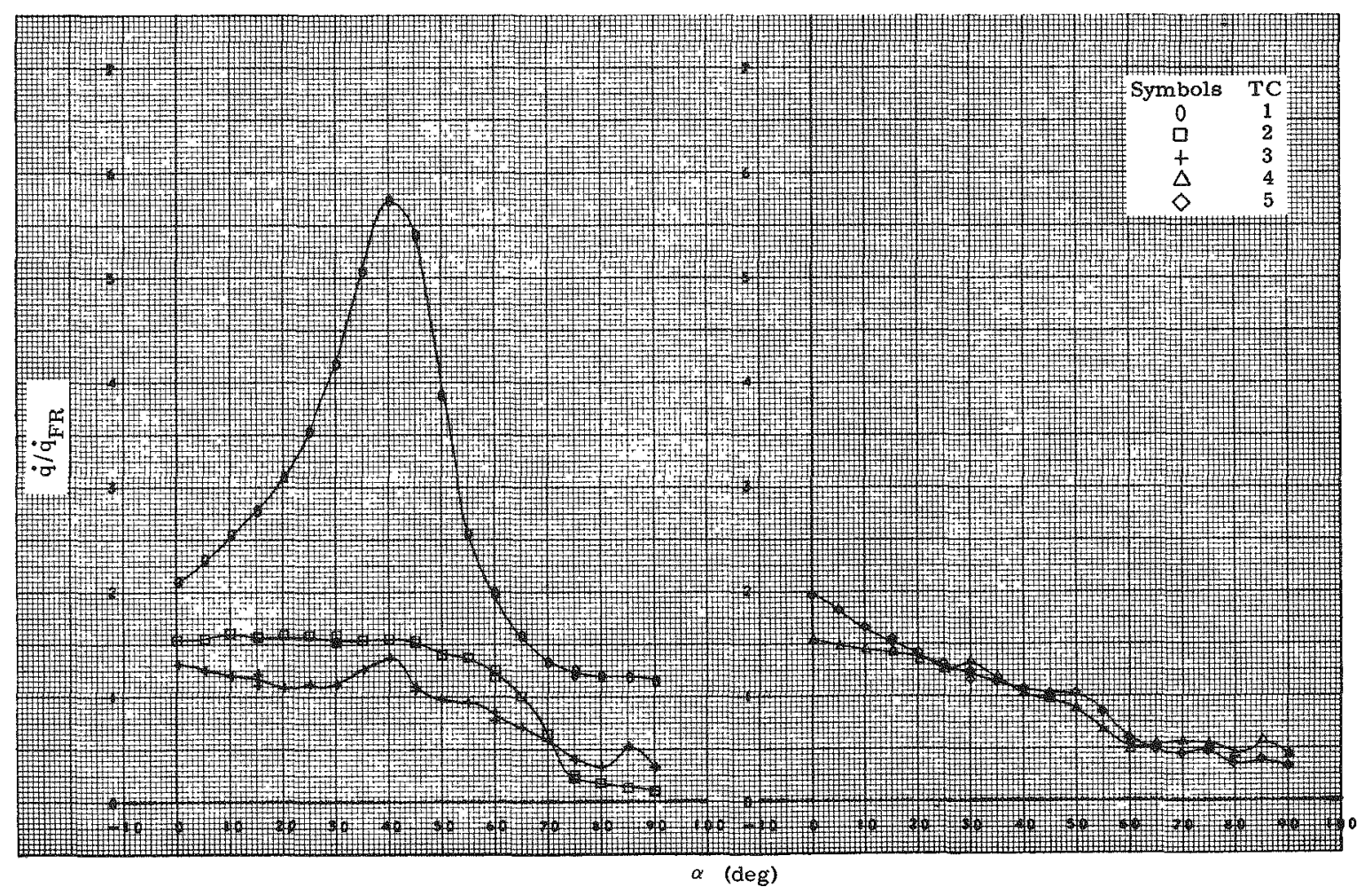

Fig. 23. Heat Transfer, TC $1-5$, Configuration 200 


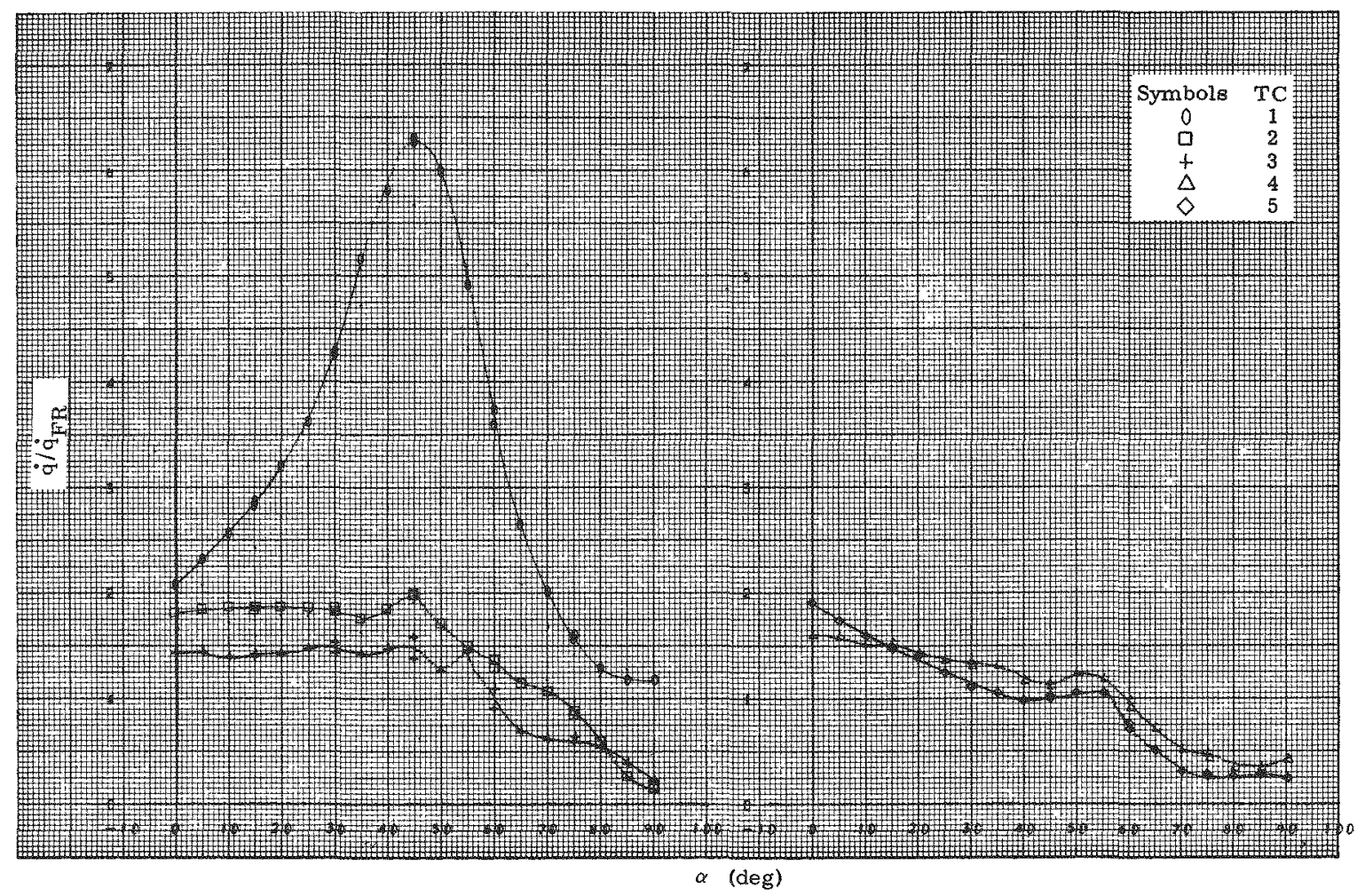

Fig. 24. Heat Transfer, TC 1-5, Configuration 300

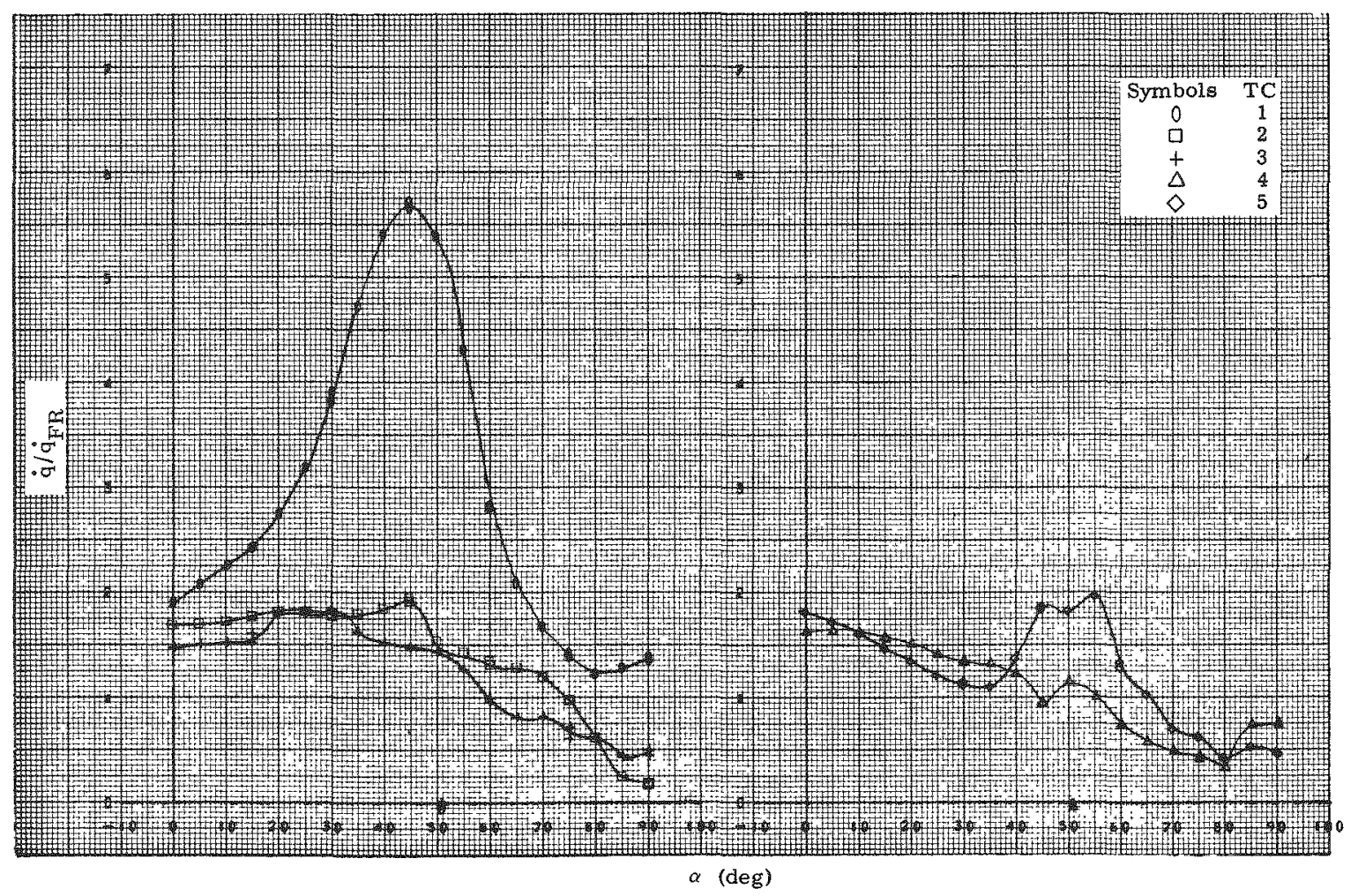

Fig. 25. Heat Transfer, TC 1- 5, Configuration 400 


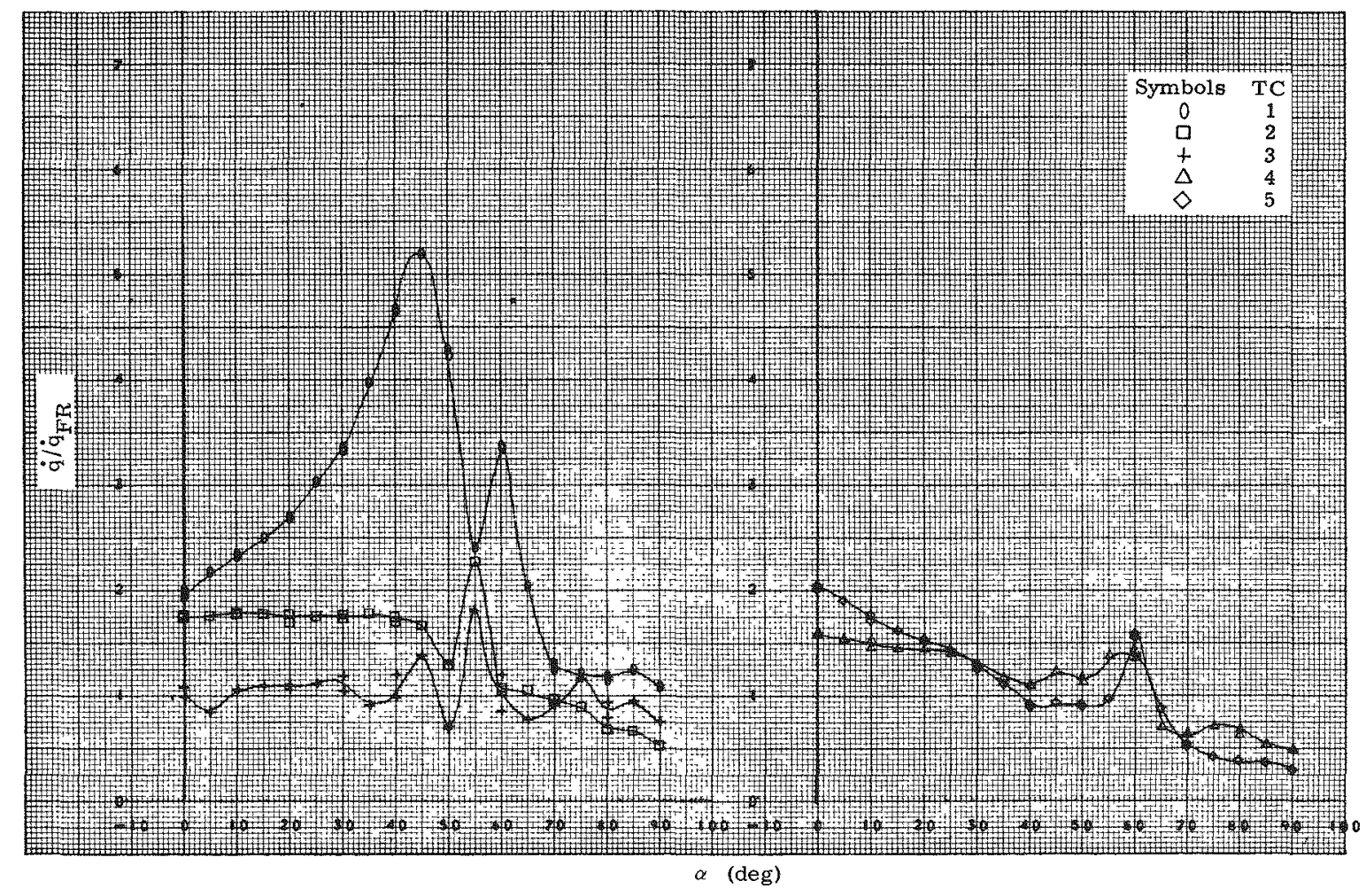

Fig. 26. Heat Transfer, TC $I$ - 5, Configuration 130

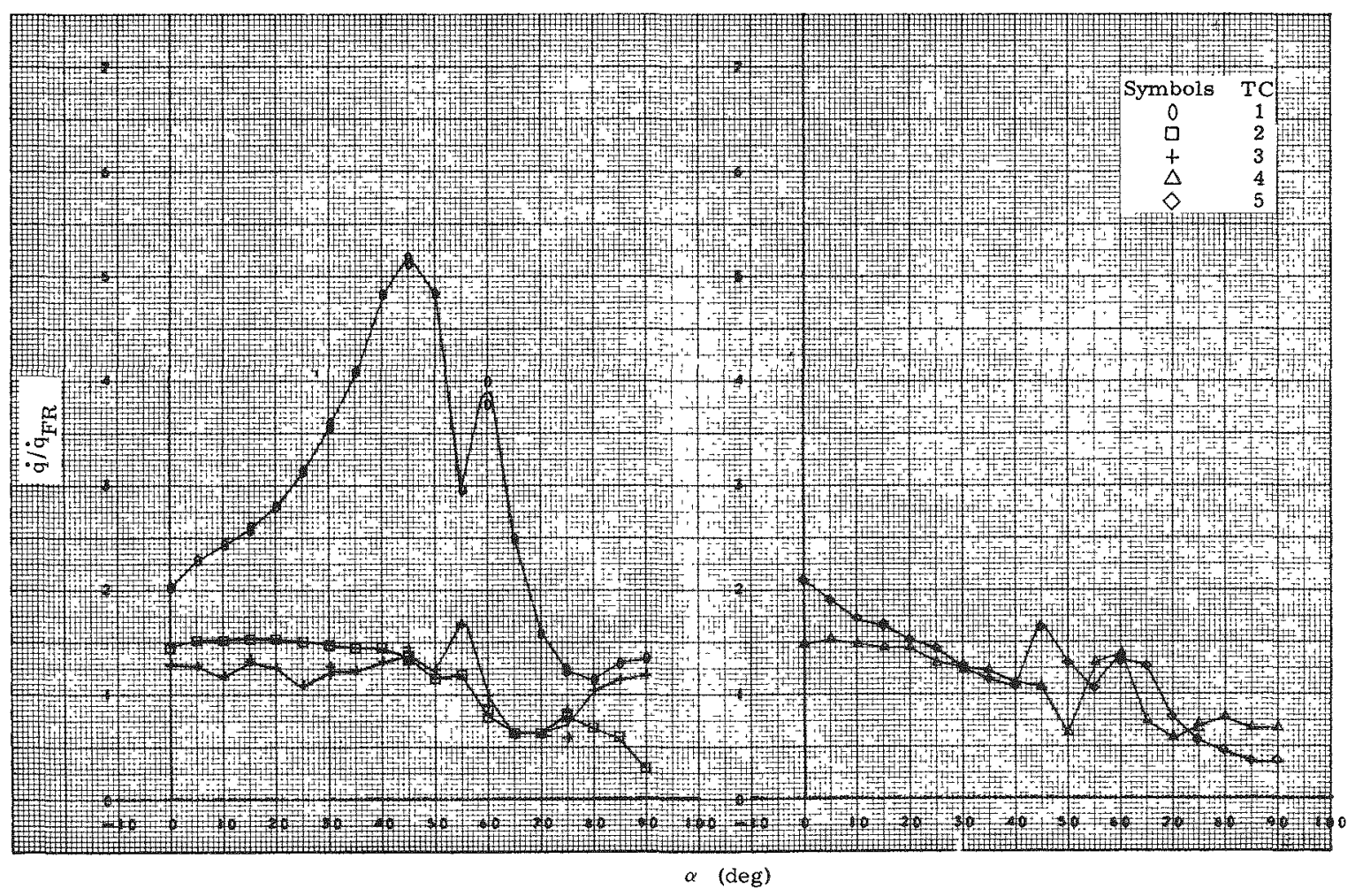

Fig. 27. Heat Transfer, TC $1-5$, Configuration 230 


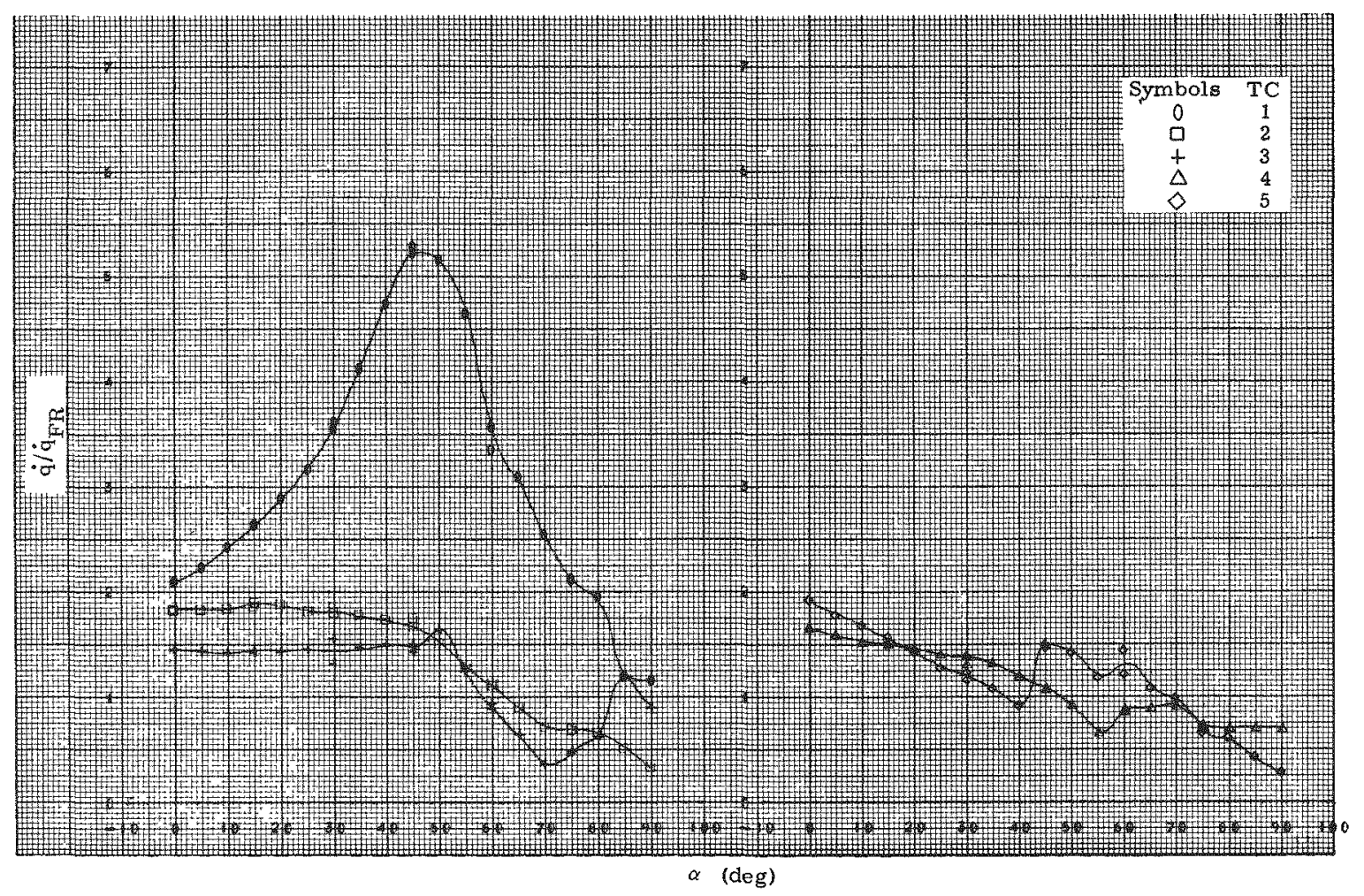

Fig. 28. Heat Transfer, TC $\mid-5$, Configuration 330

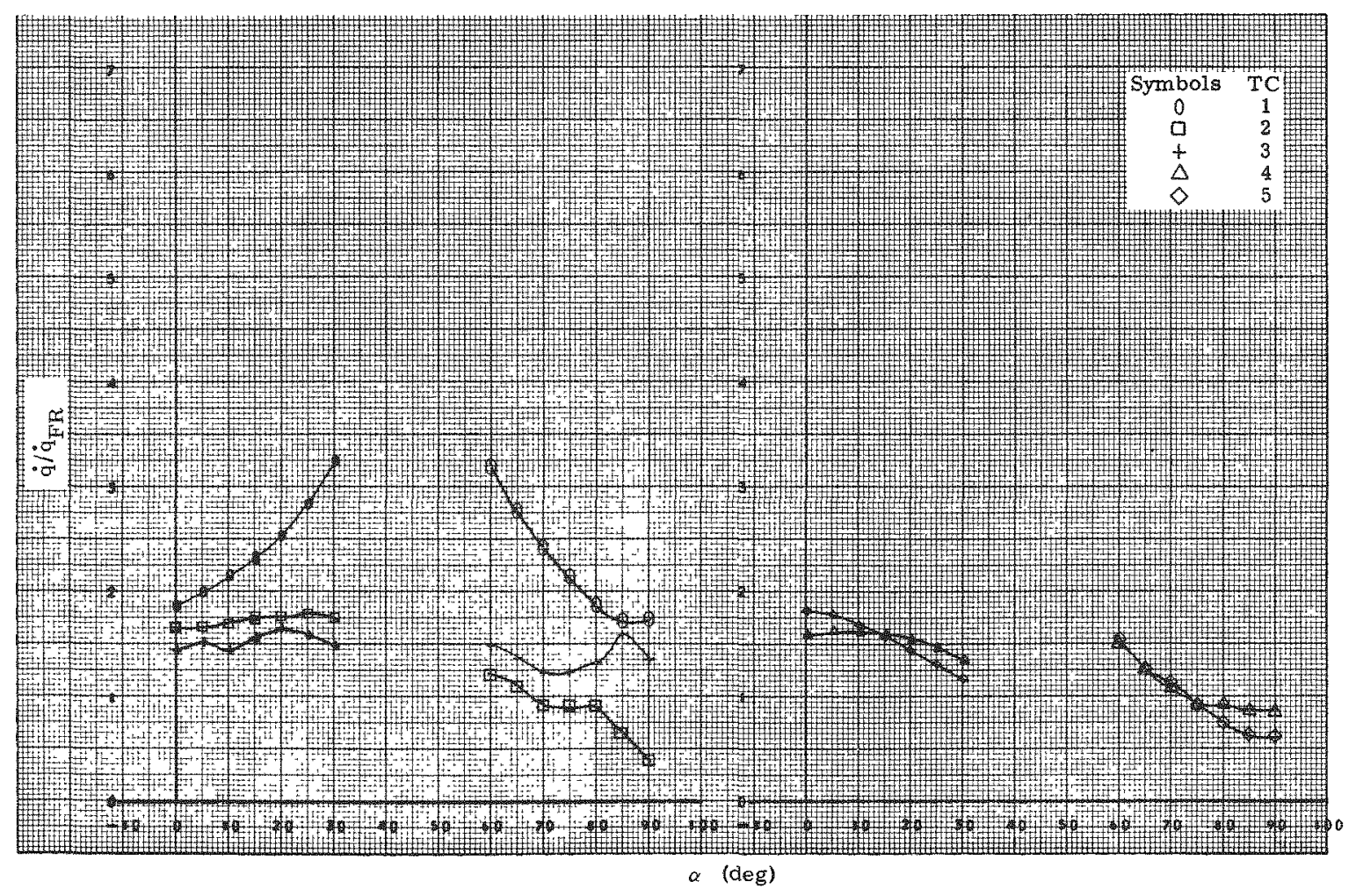

Fig. 29. Heat Transfer, TC 1 - 5, Configuration 430 


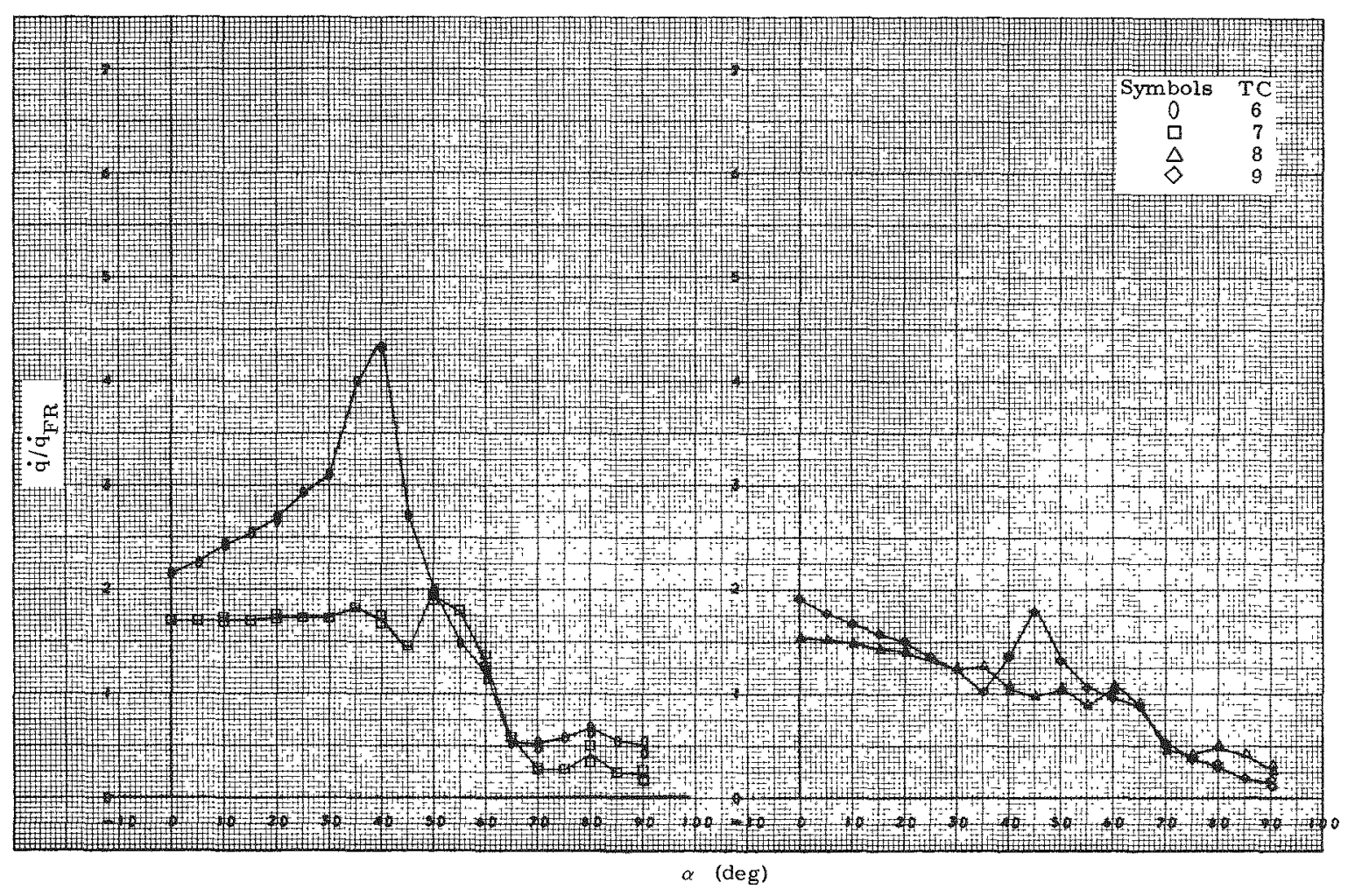

Fig. 30. Heat Transfer, TC $6-9$, Configuration 100

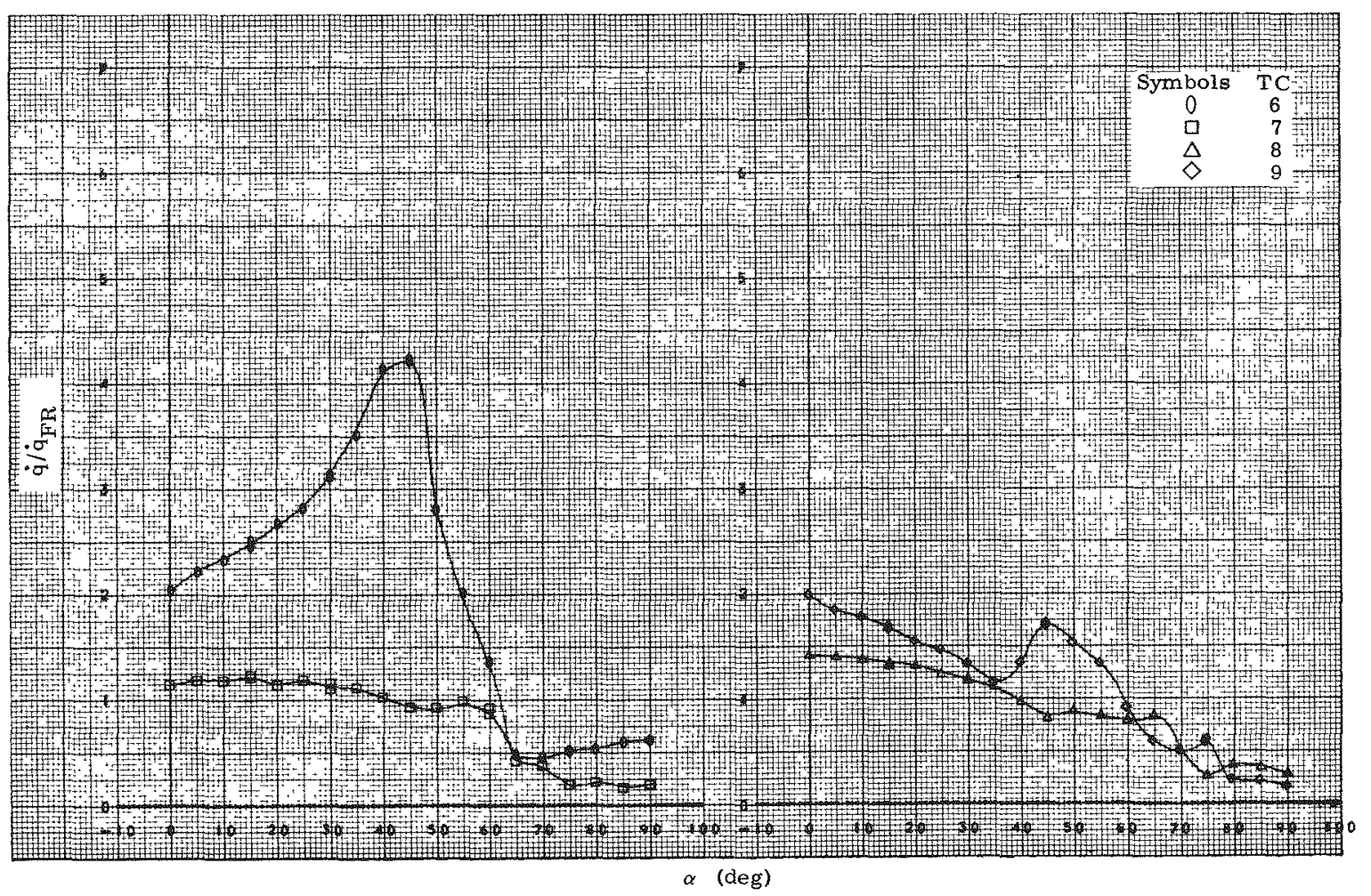

Fig. 31. Heat Transfer, TC $6-9$, Configuration 200 


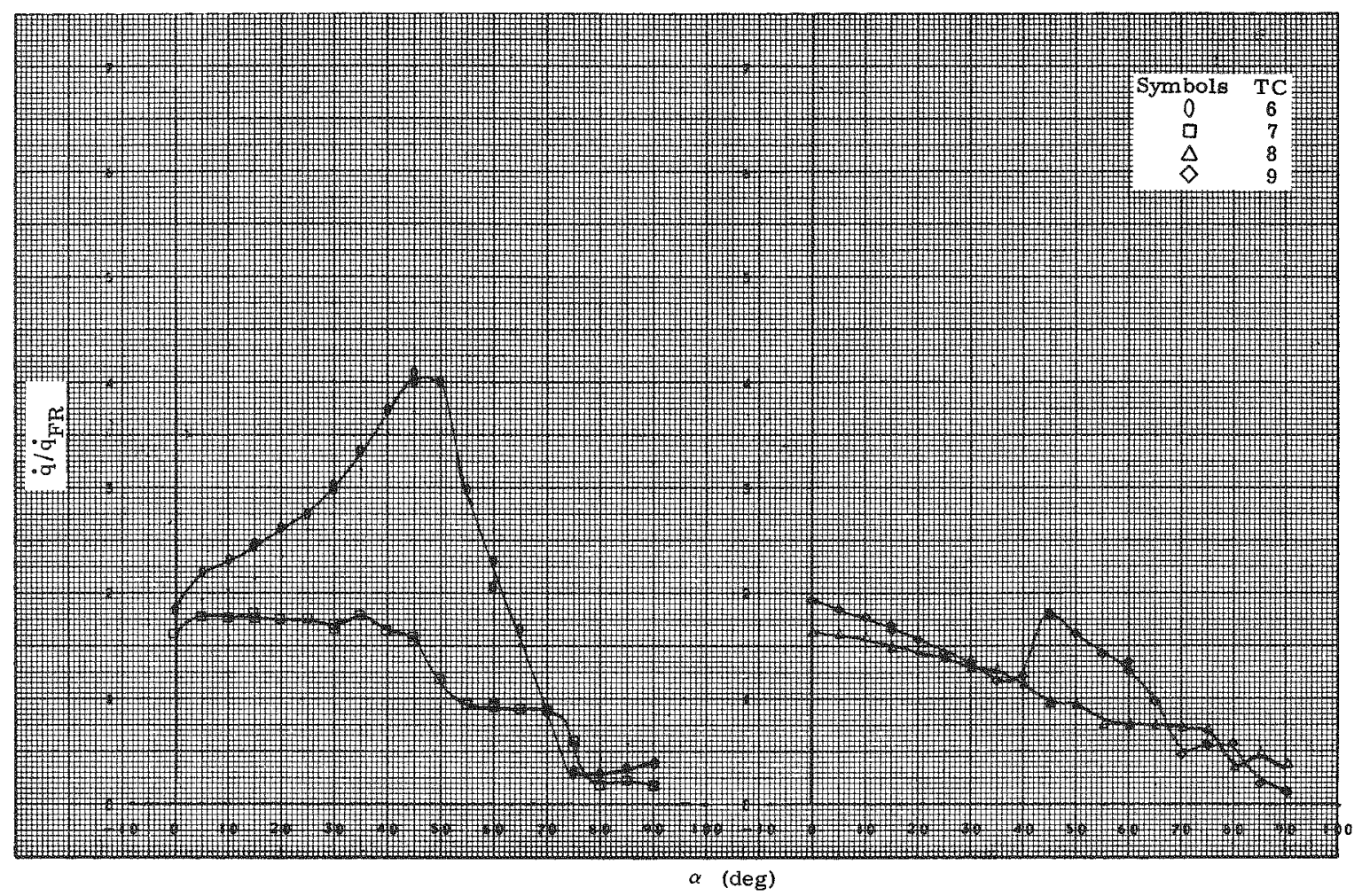

Fig. 32. Heat Transfer, TC $6-9$, Configuration 300

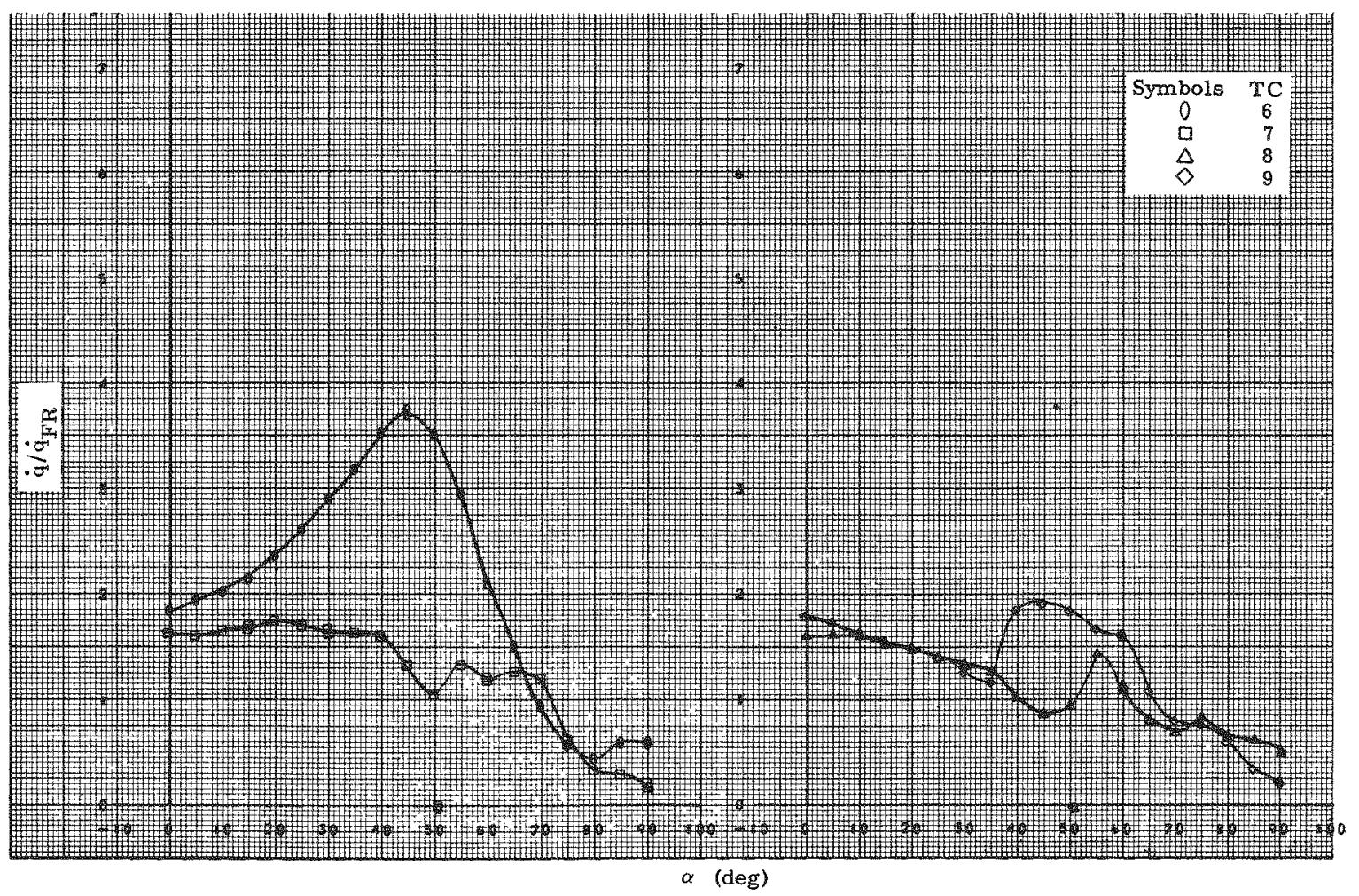

Fig. 33. Heat Transfer, TC 6 - 9, Configuration 400 


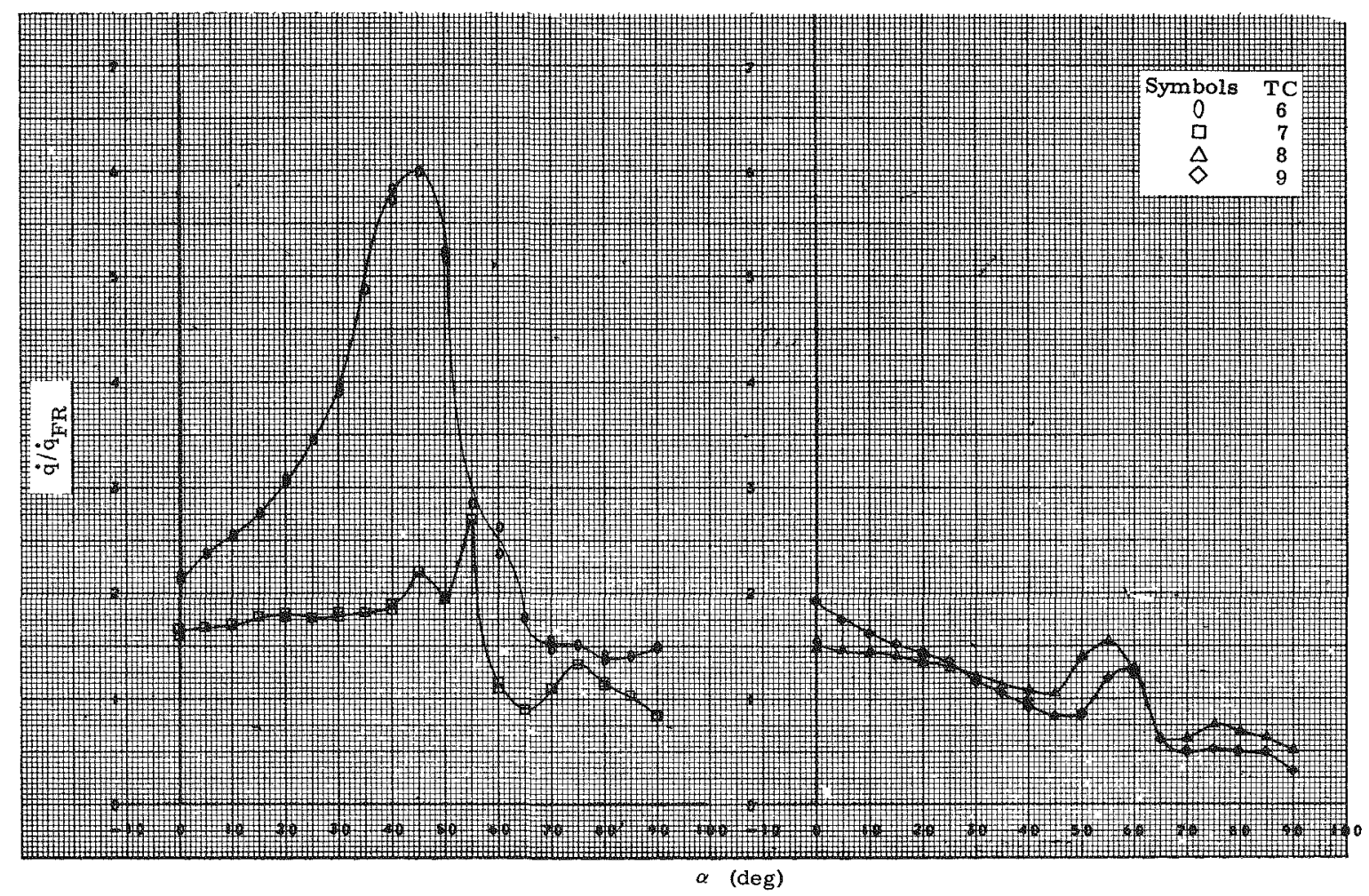

Fig. 34. Heat Transfer, TC $6-9$, Configuration 130

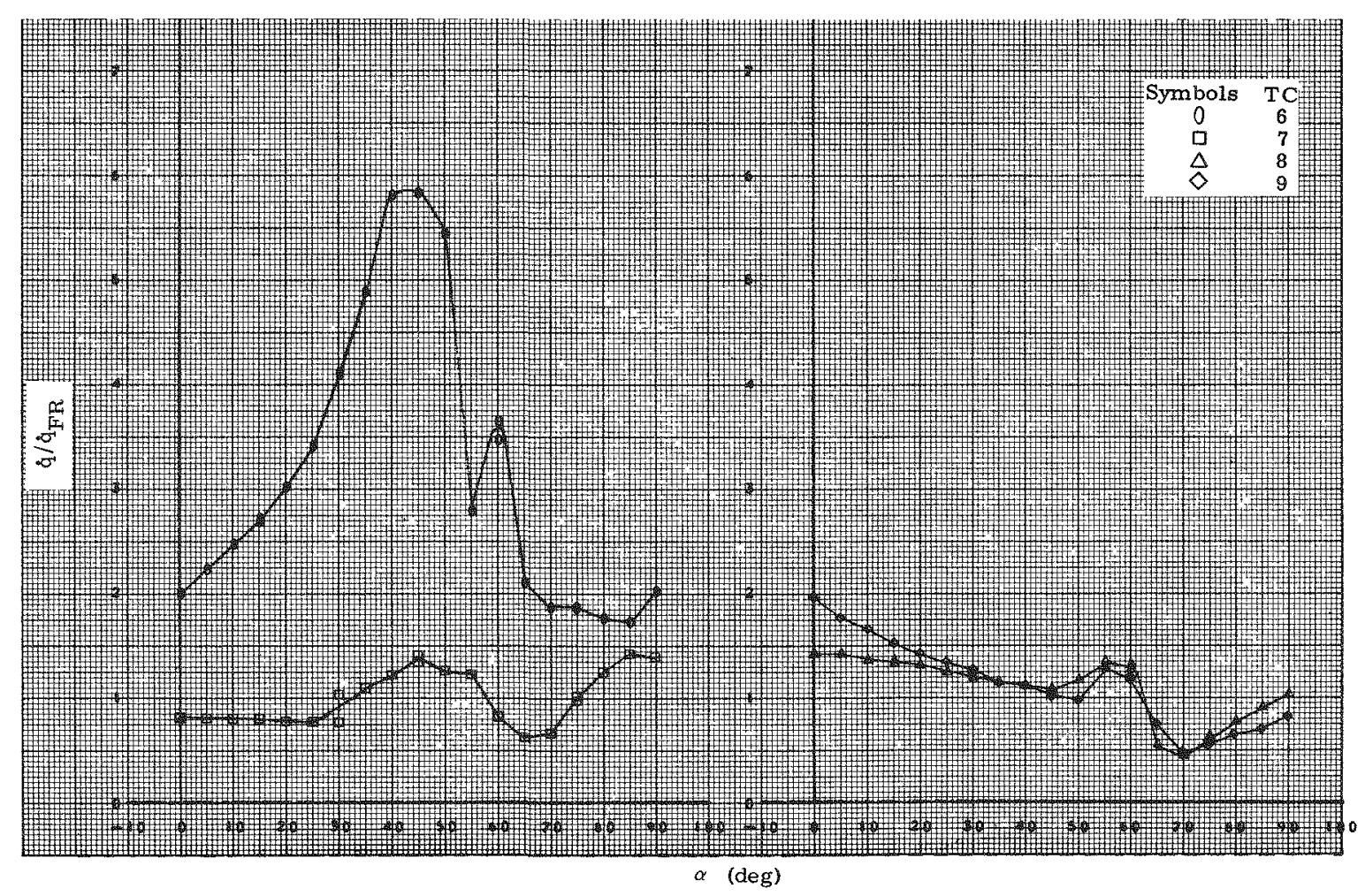

Fig. 35. Heat Transfer, TC $6-9$, Configuration 230 


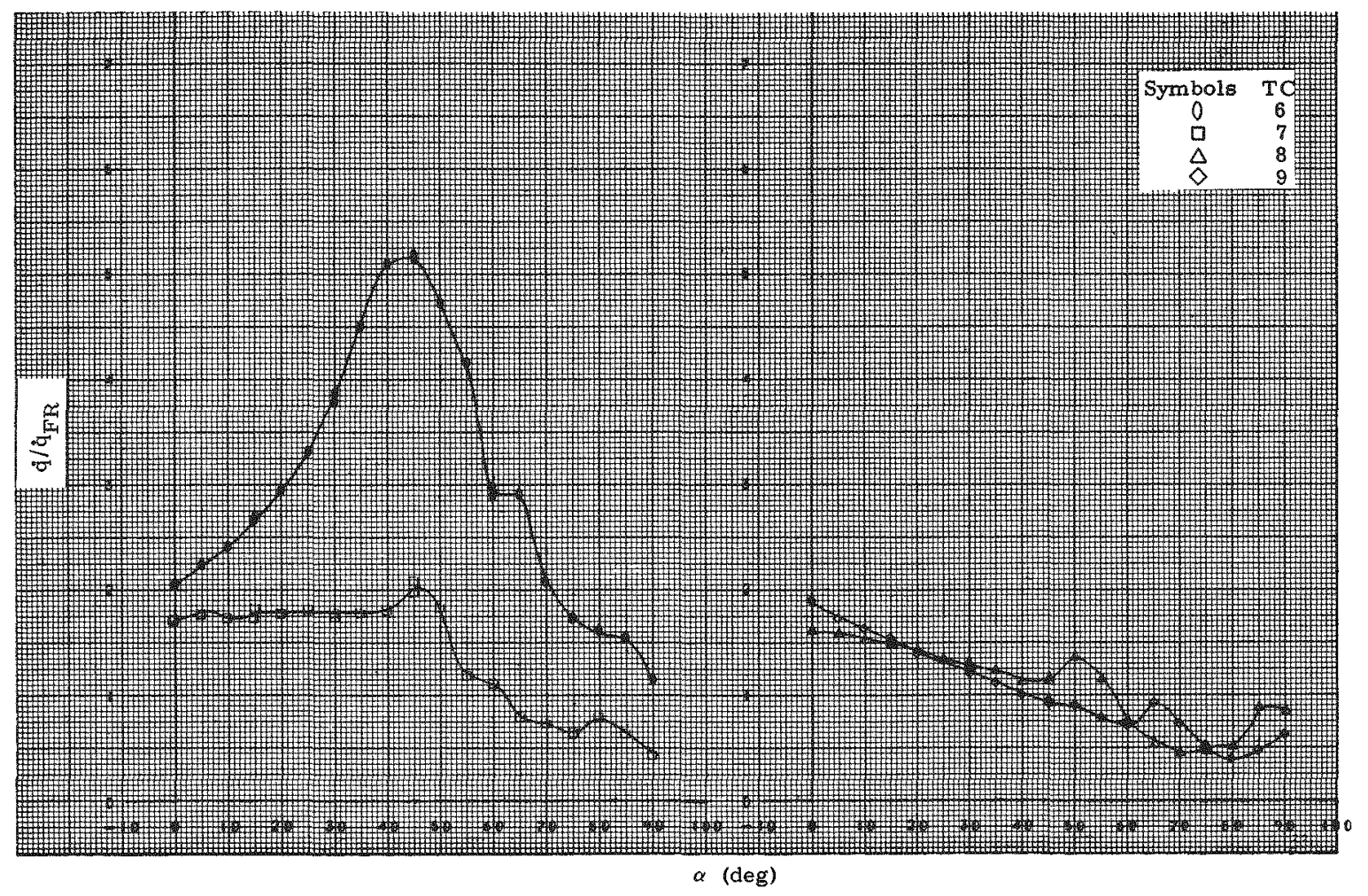

Fig. 36. Heat Transfer, TC 6-9, Configuration 330

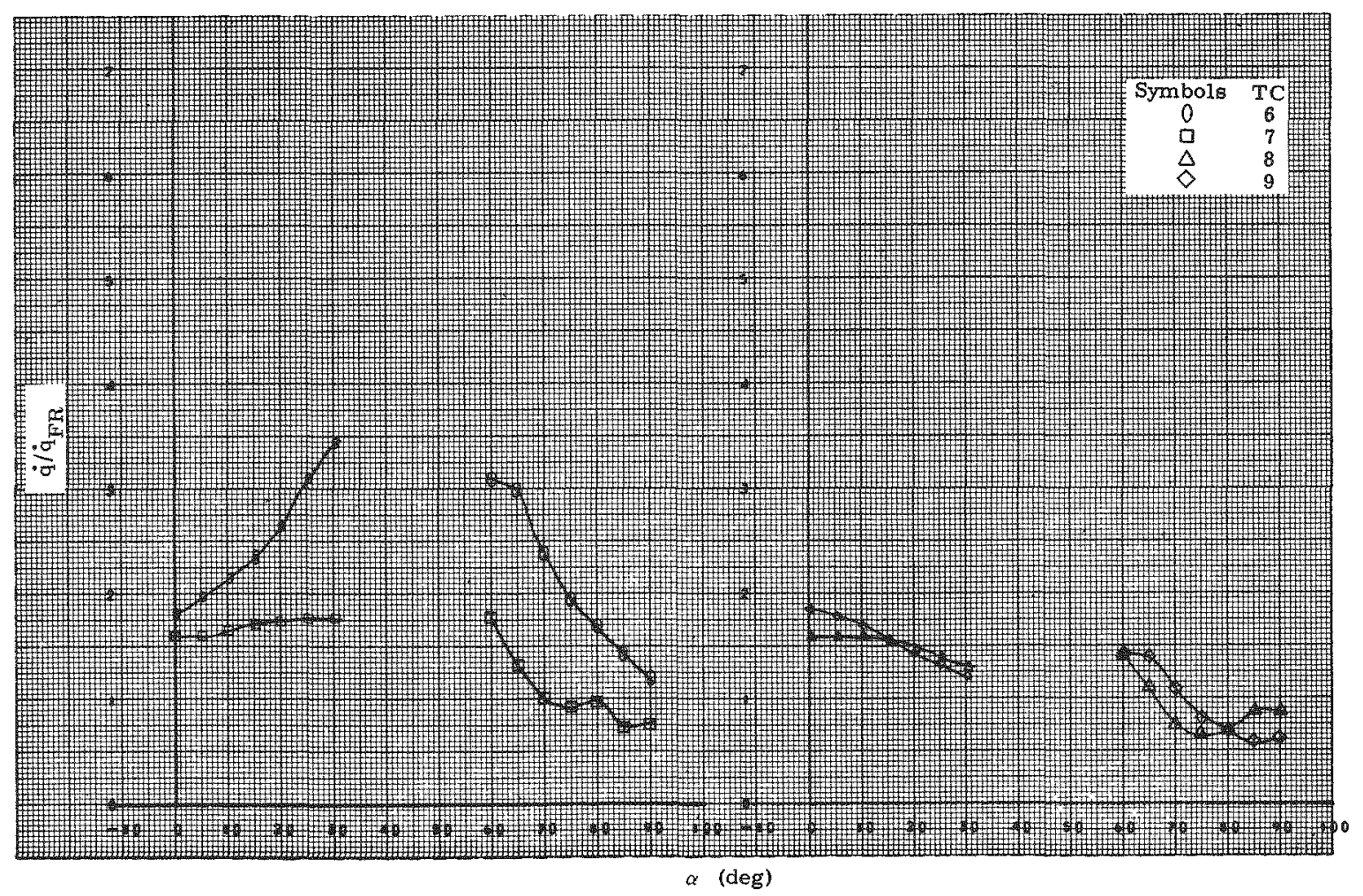

Fig. 37. Heat Transfer, TC $6-9$, Configuration 430 


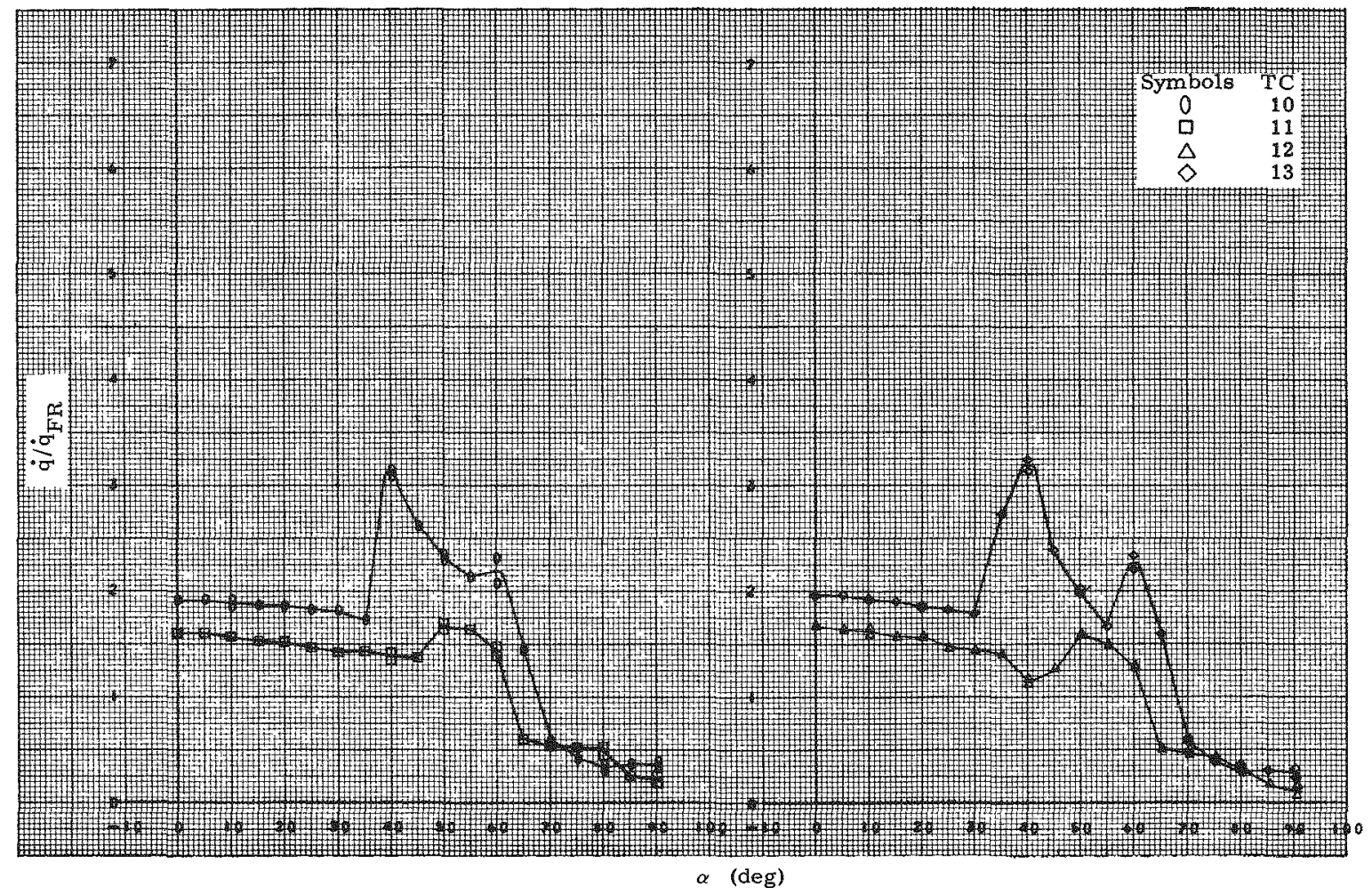

Fig. 38. Heat Transfer, TC 10-13, Configuration 100

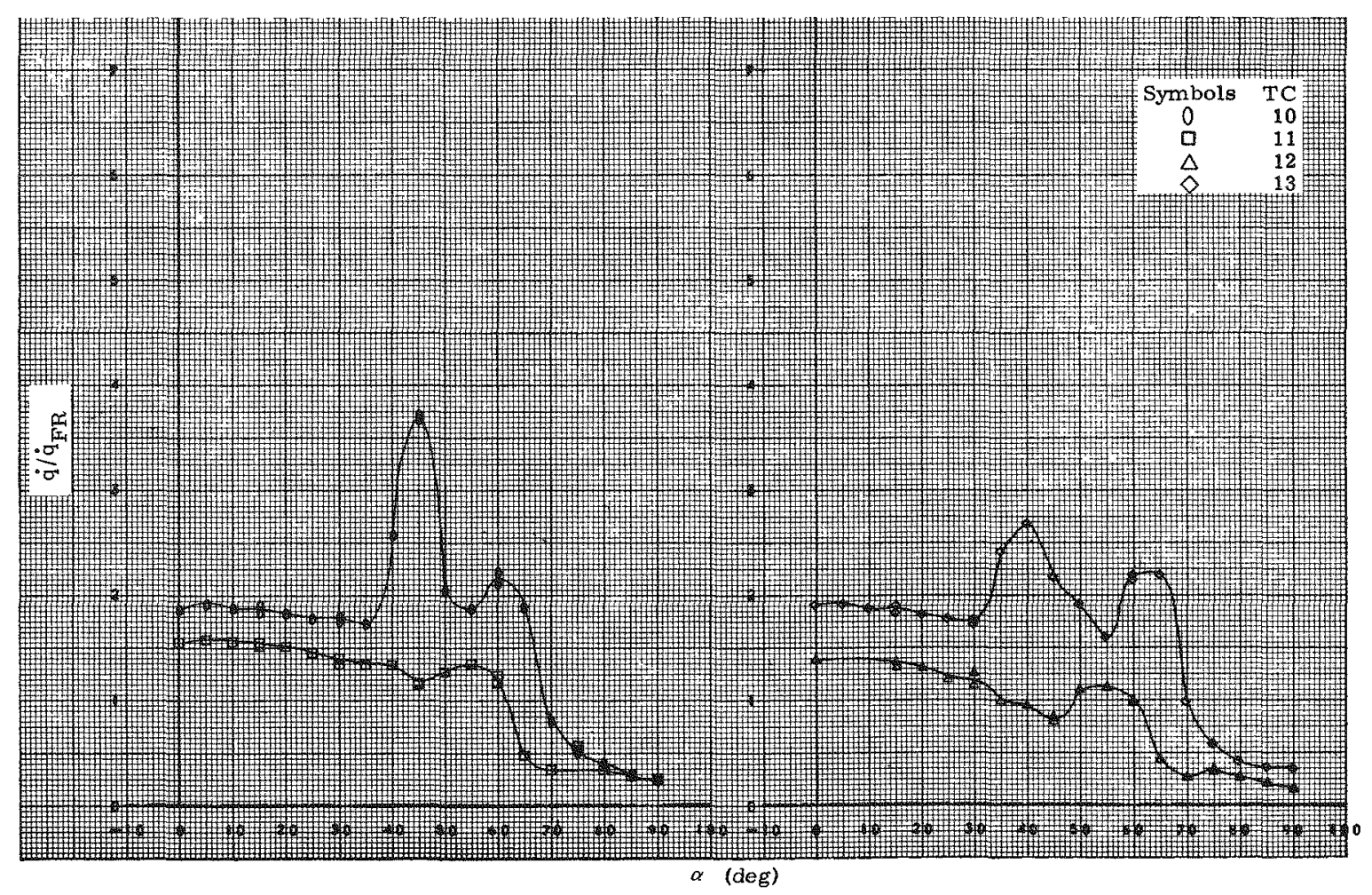

Fig. 39. Heat Transfer, TC $10-13$, Configuration 200 


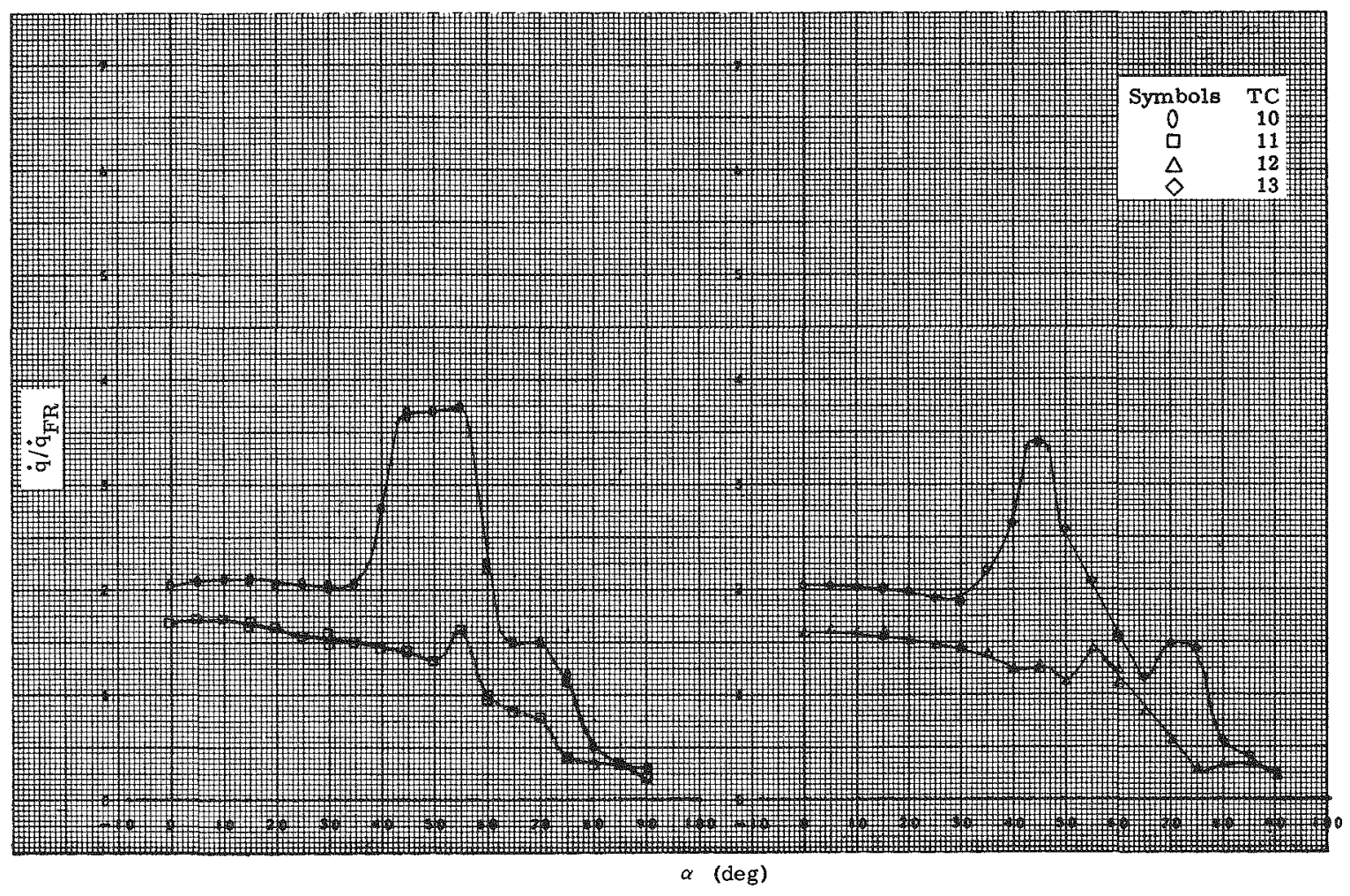

Fig. 40. Heat Transfer, TC $10-13$, Configuration 300

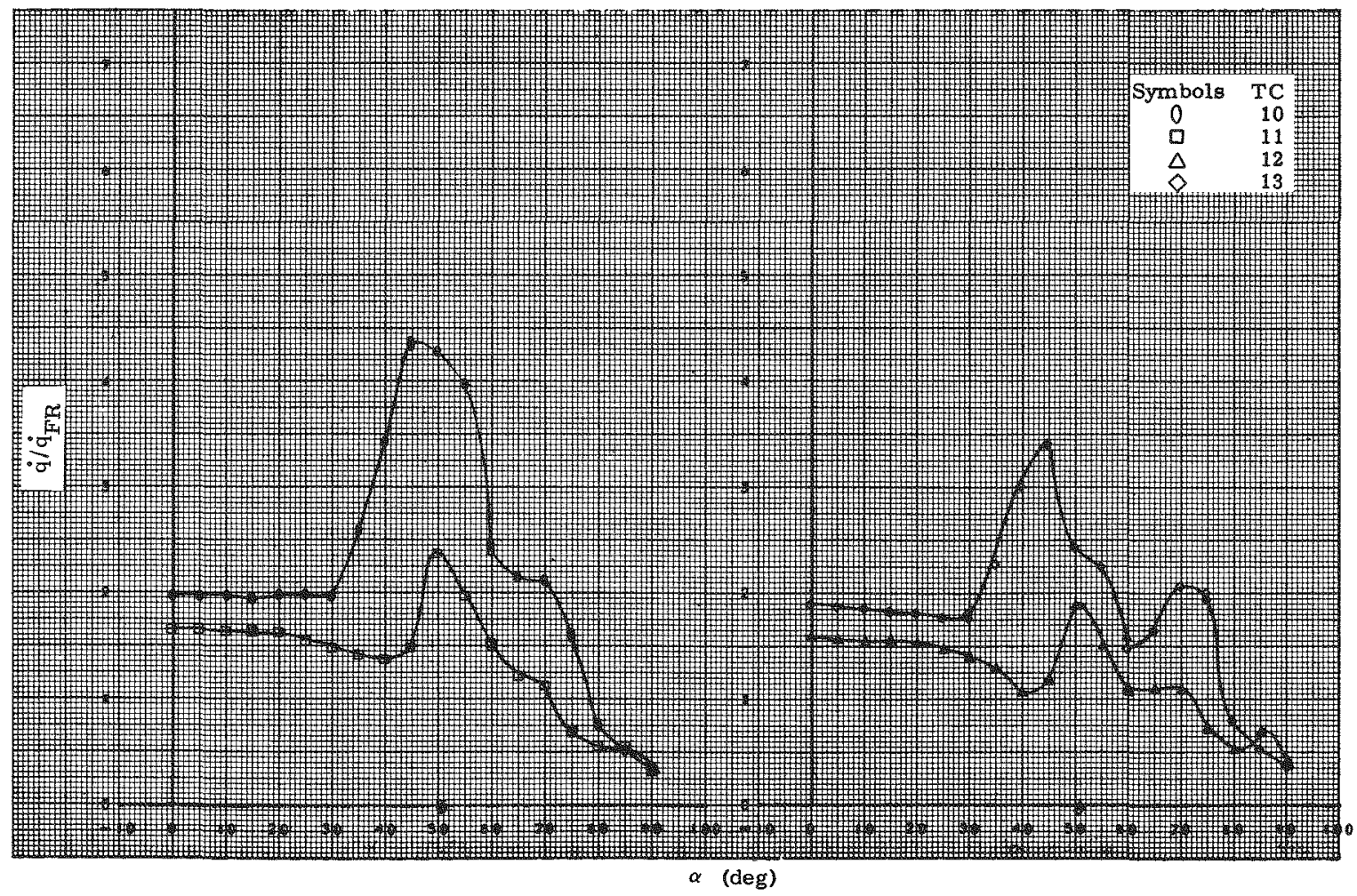

Fig. 41. Heat Transfer, TC $10-13$, Configuration 400 


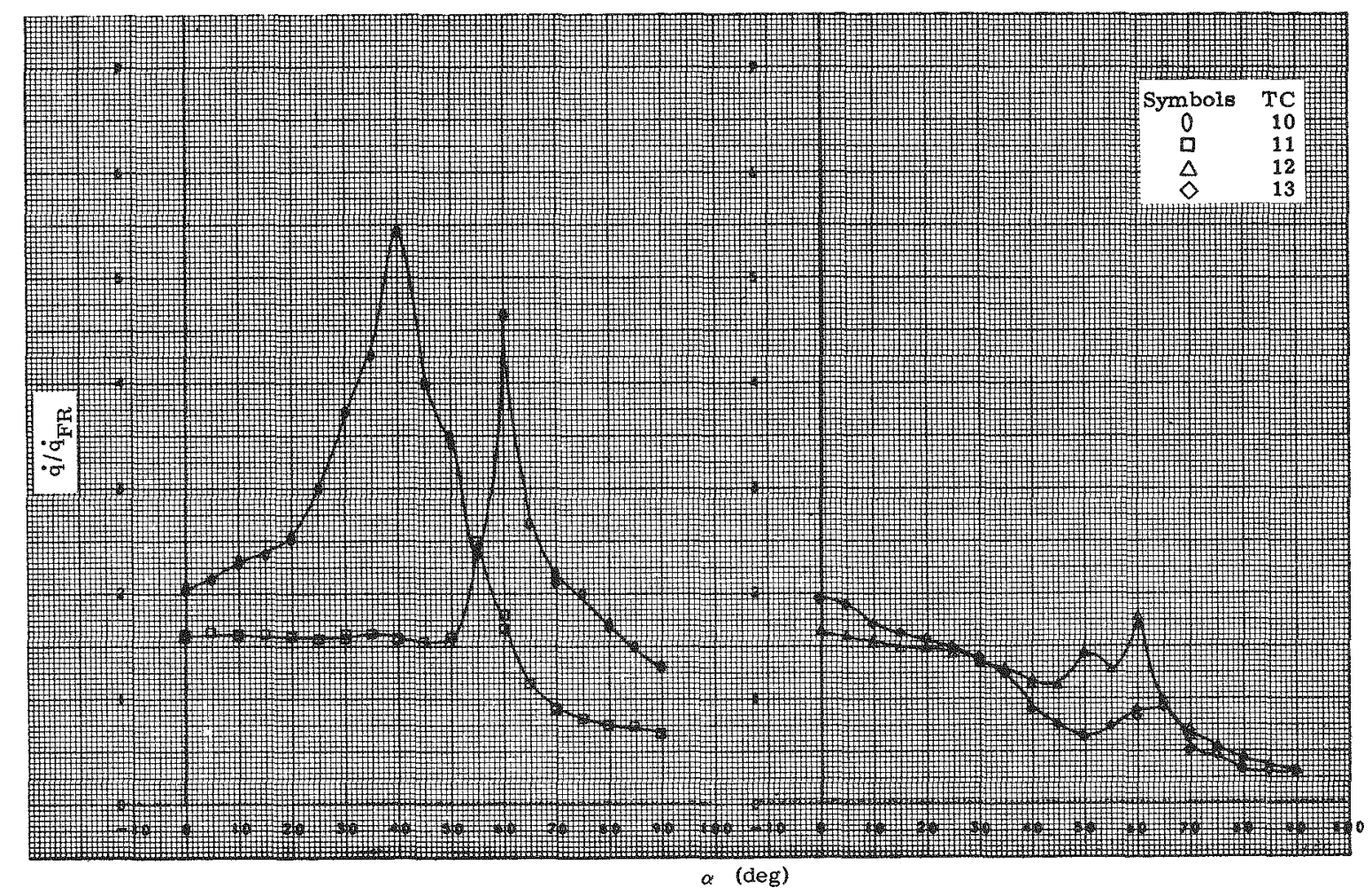

Fig. 42. Heat Transfer, TC 10-13, Configuration 130

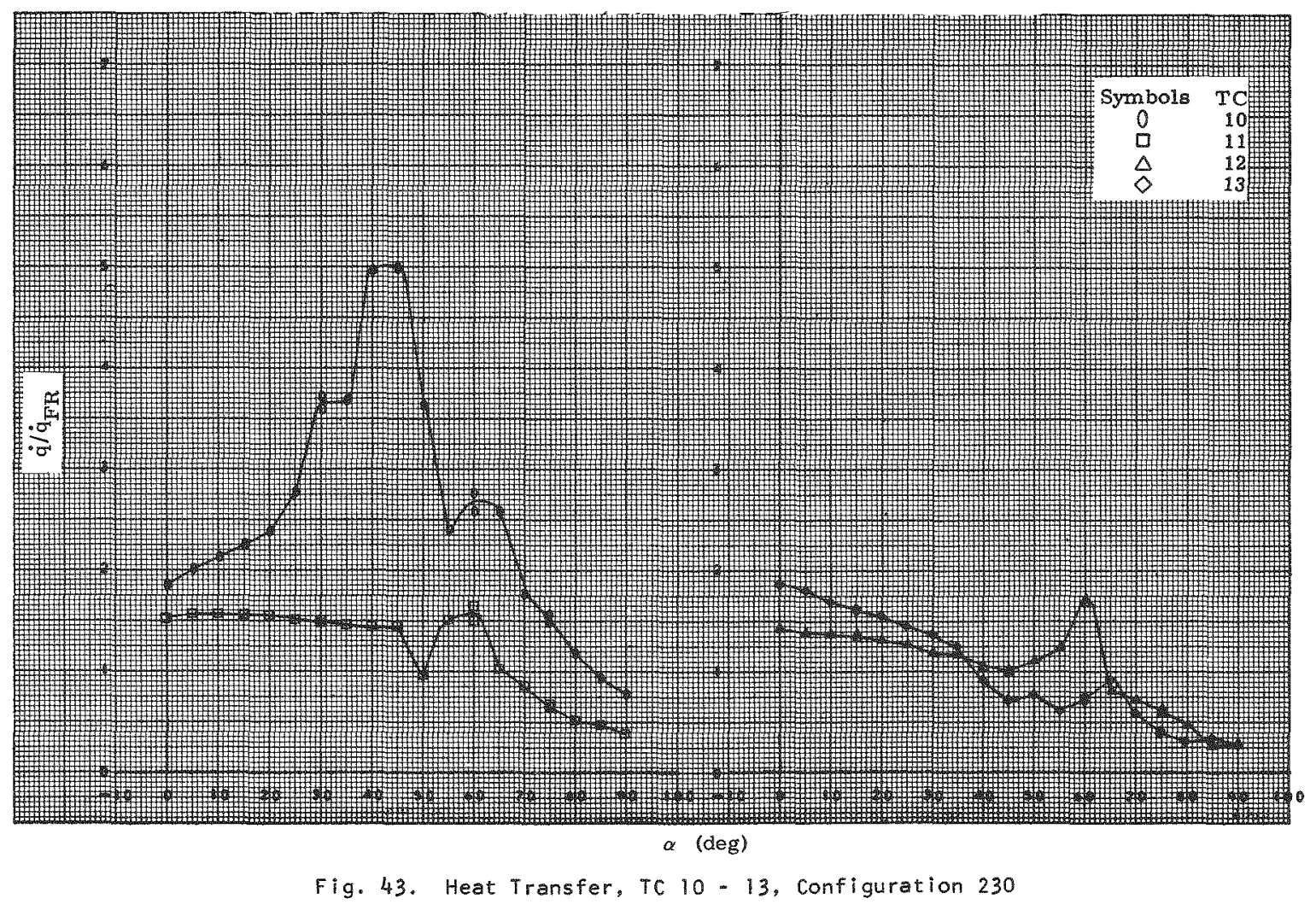

MND-3607-92

66 


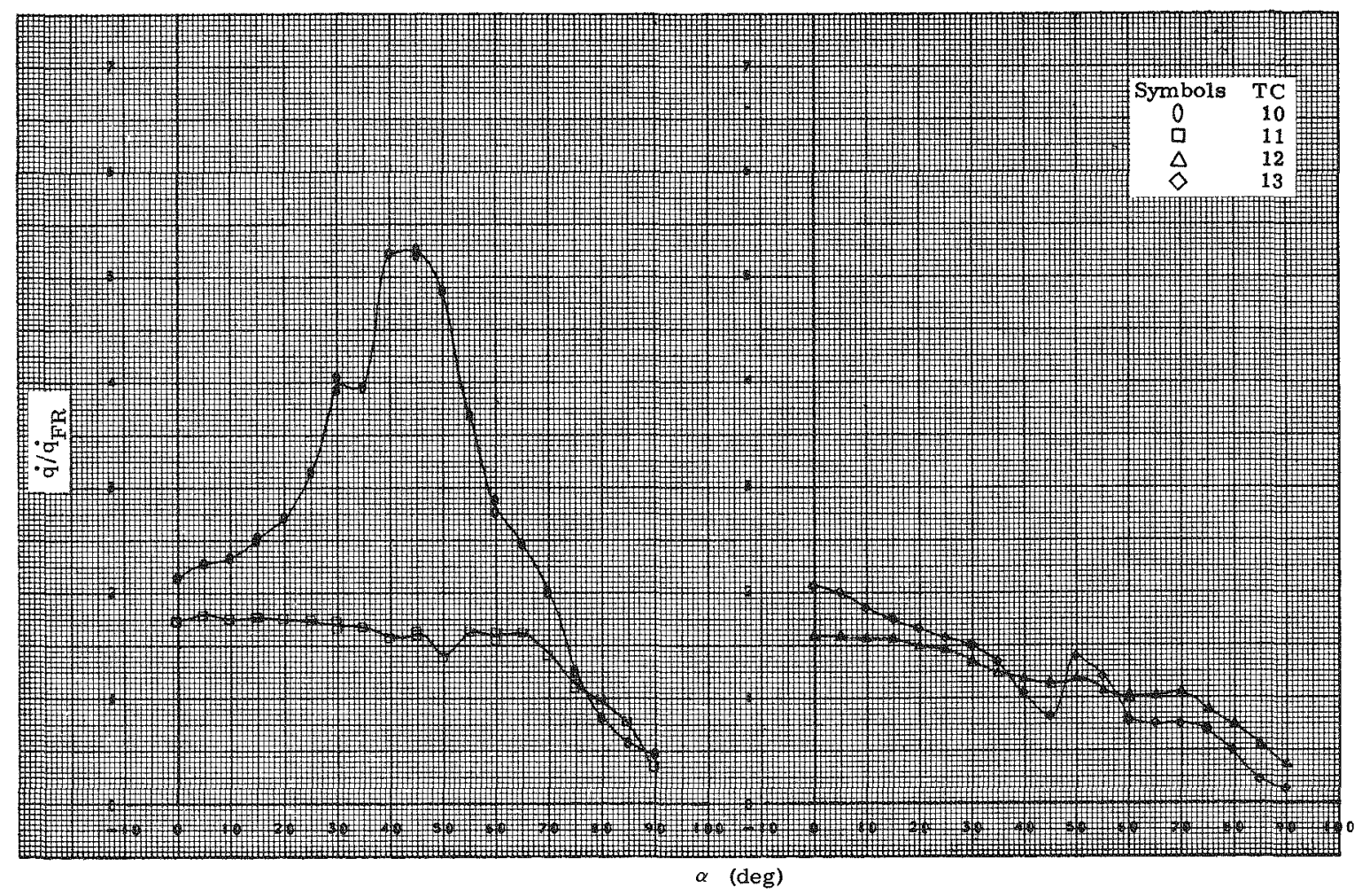

Fig. 44. Heat Transfer, TC $10-13$, Configuration 330

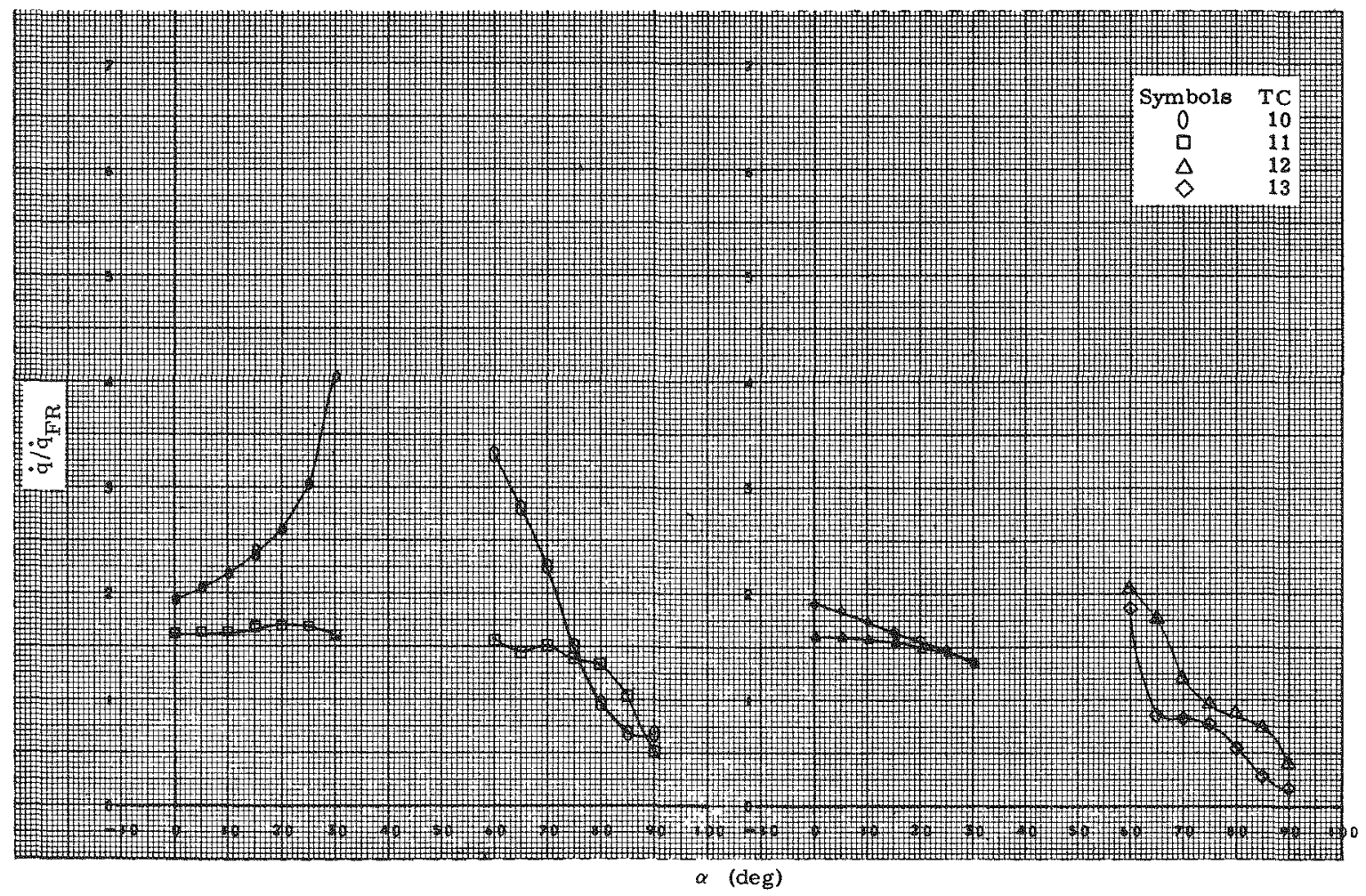

Fig. 45. Heat Transfer, TC $10-13$, Configuration 430 


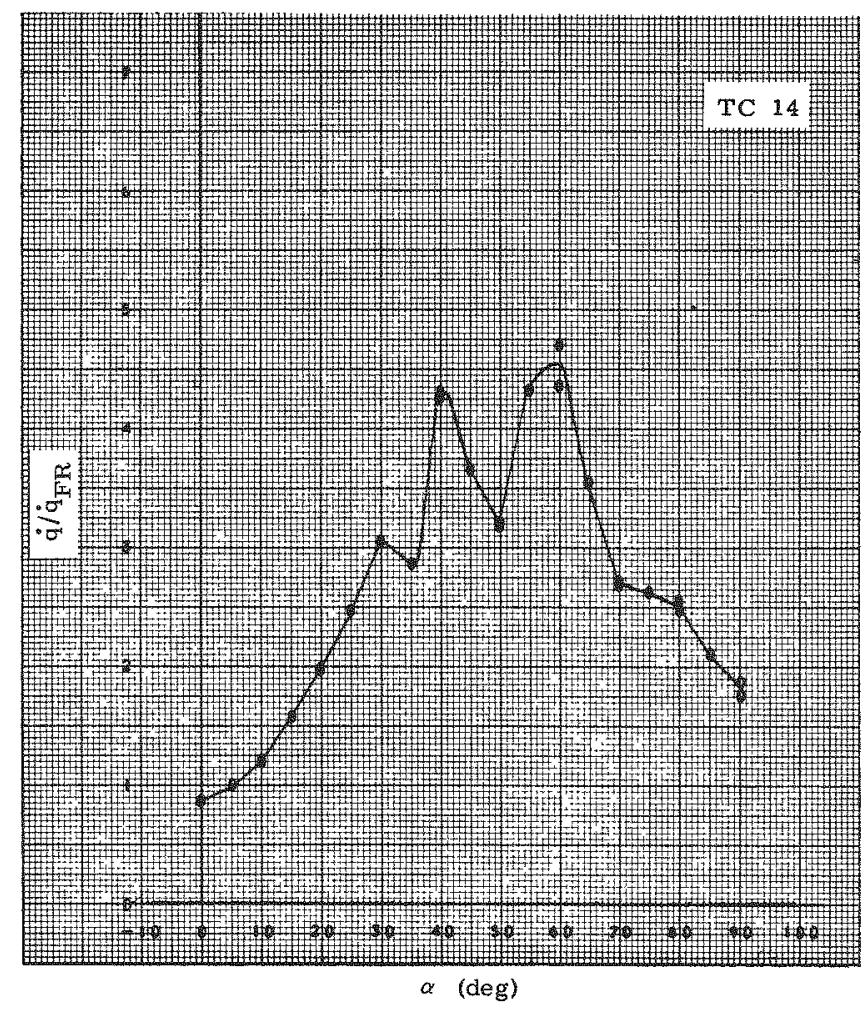

Fig. 46. Heat Transfer, TC 14, Configuration 100

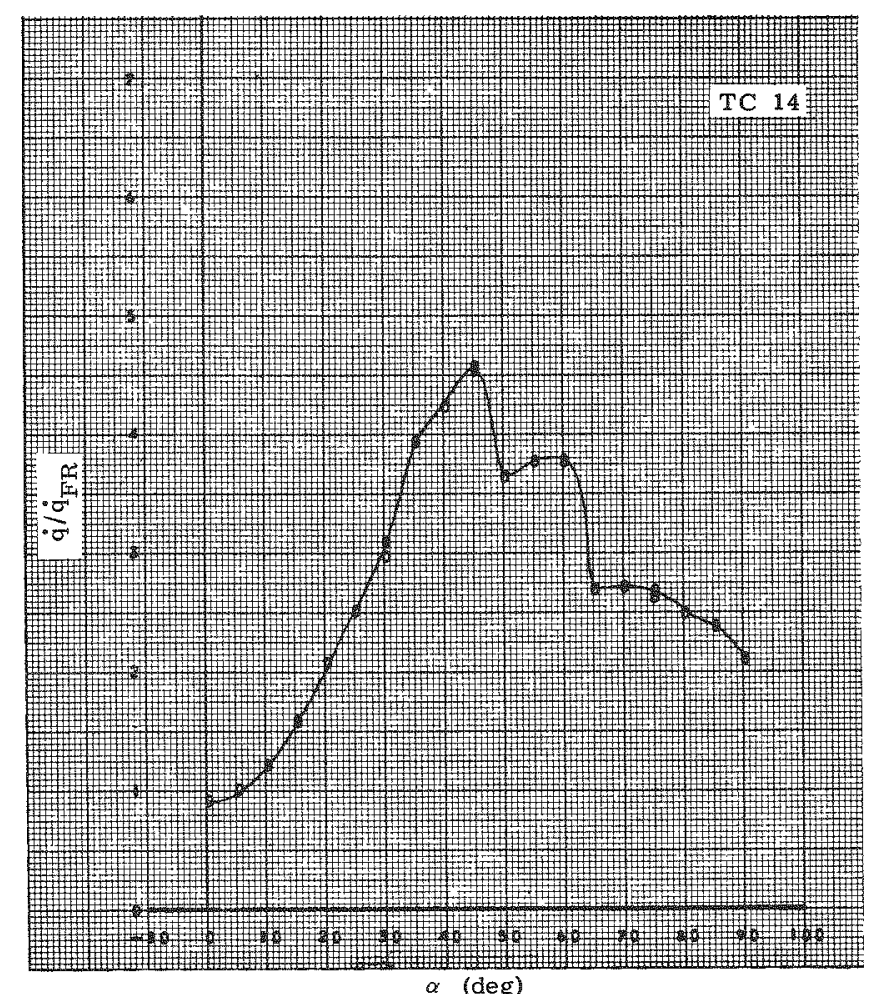

Fig. 47. Heat Transfer, TC 14, Configuration 200

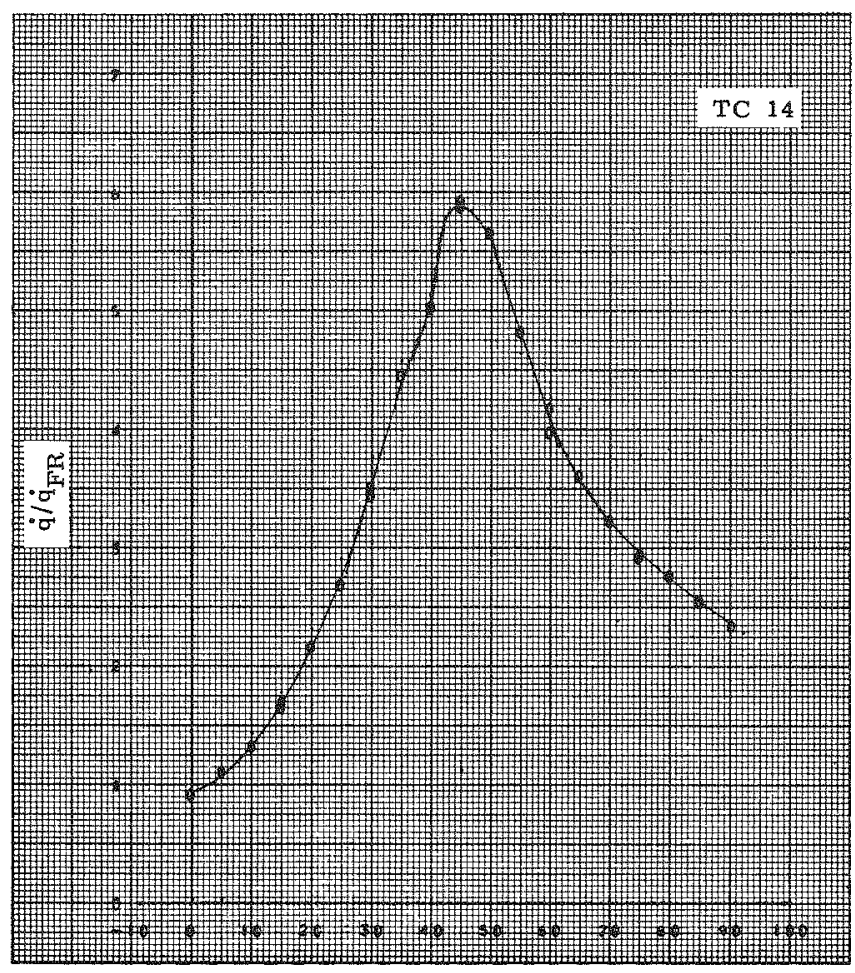

$\alpha$ (deg)

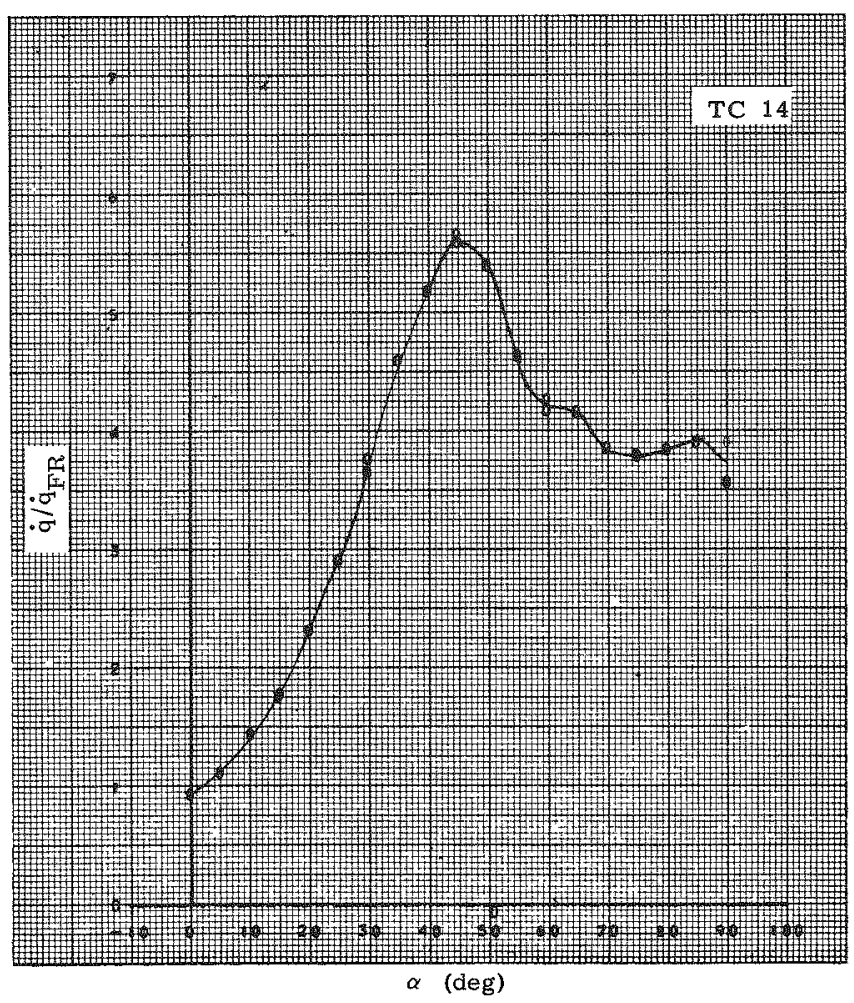

Fig. 48. Heat Transfer, TC 14, Configuration 300

Fig. 49. Heat Transfer, TC 14, Configuration 400 


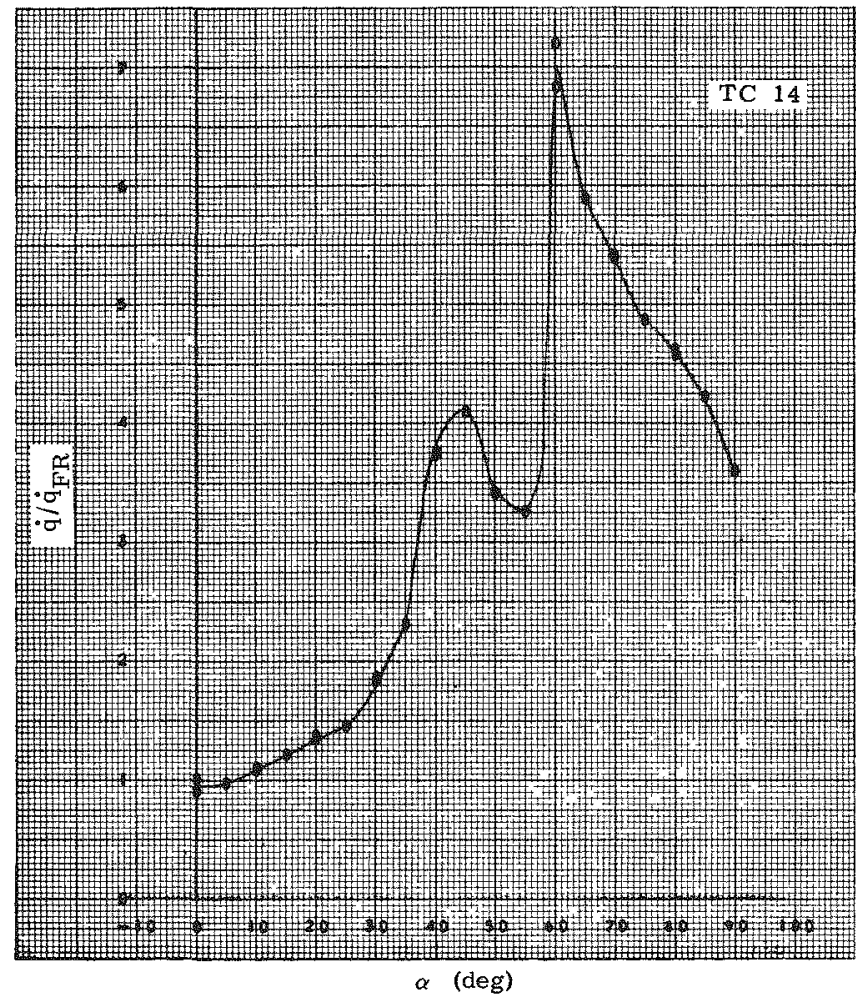

Fig. 50. Heat Transfer, TC 14, Configuration 130

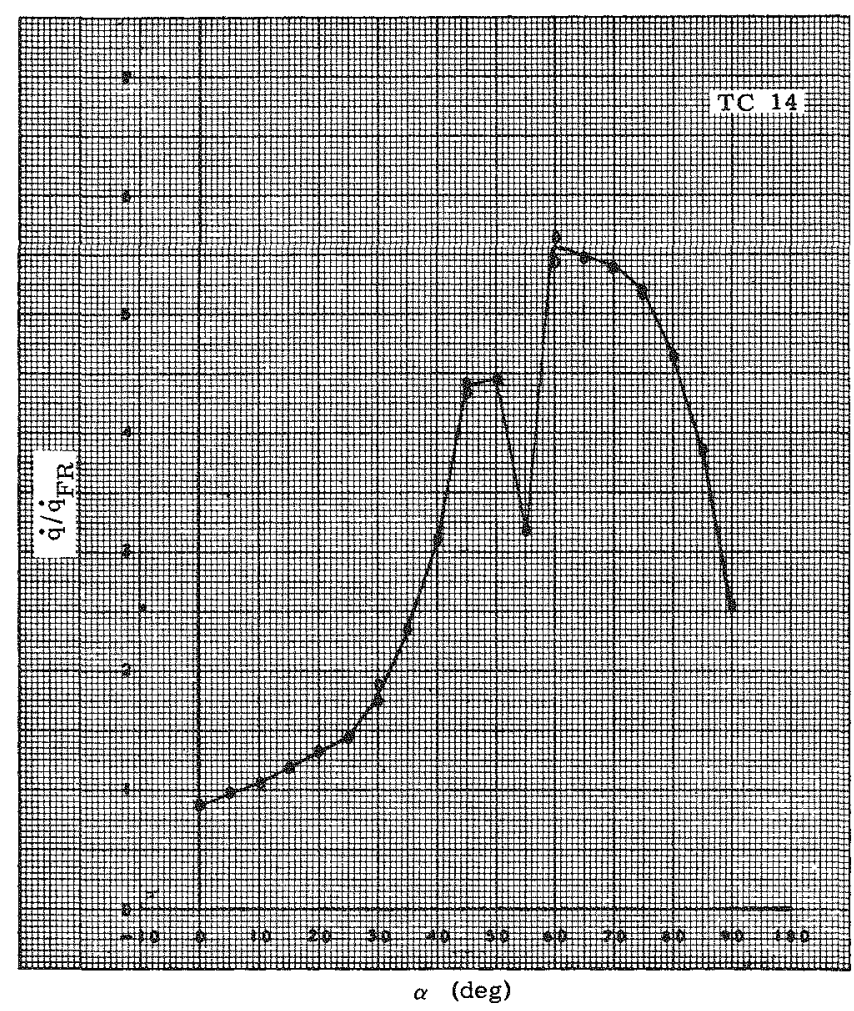

Fig. 51. Heat Transfer, TC 14, Configuration 230

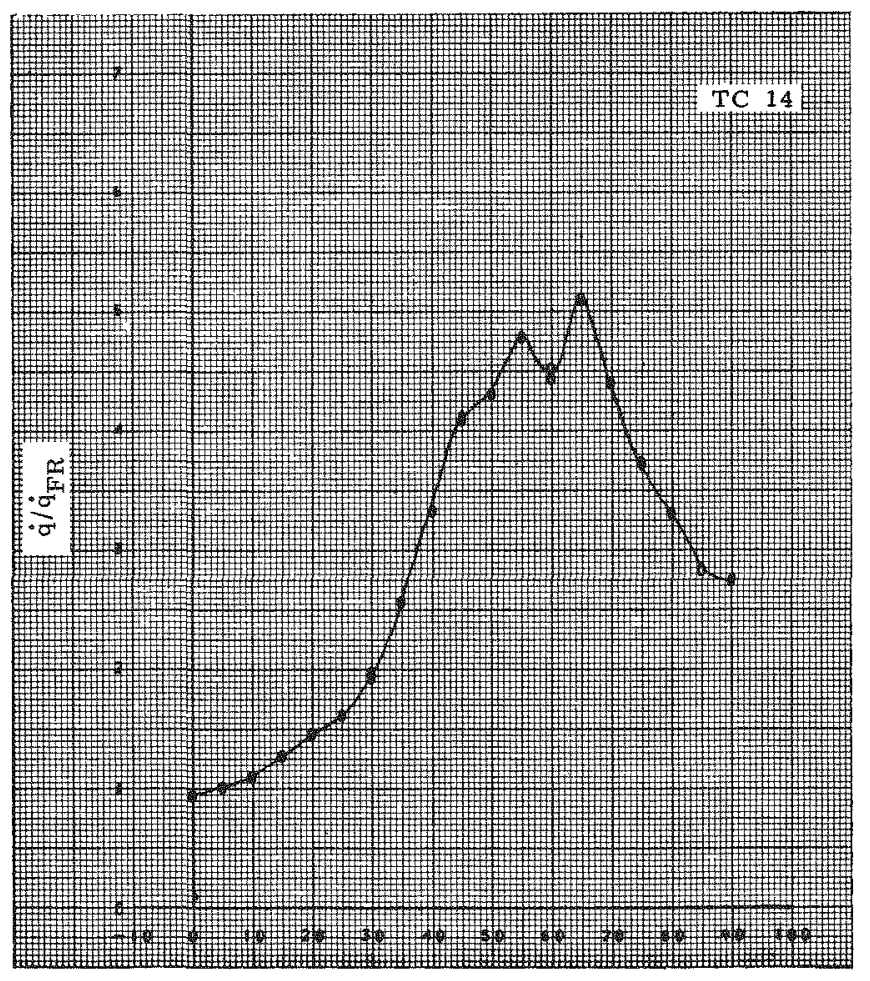

$\alpha$ (deg)

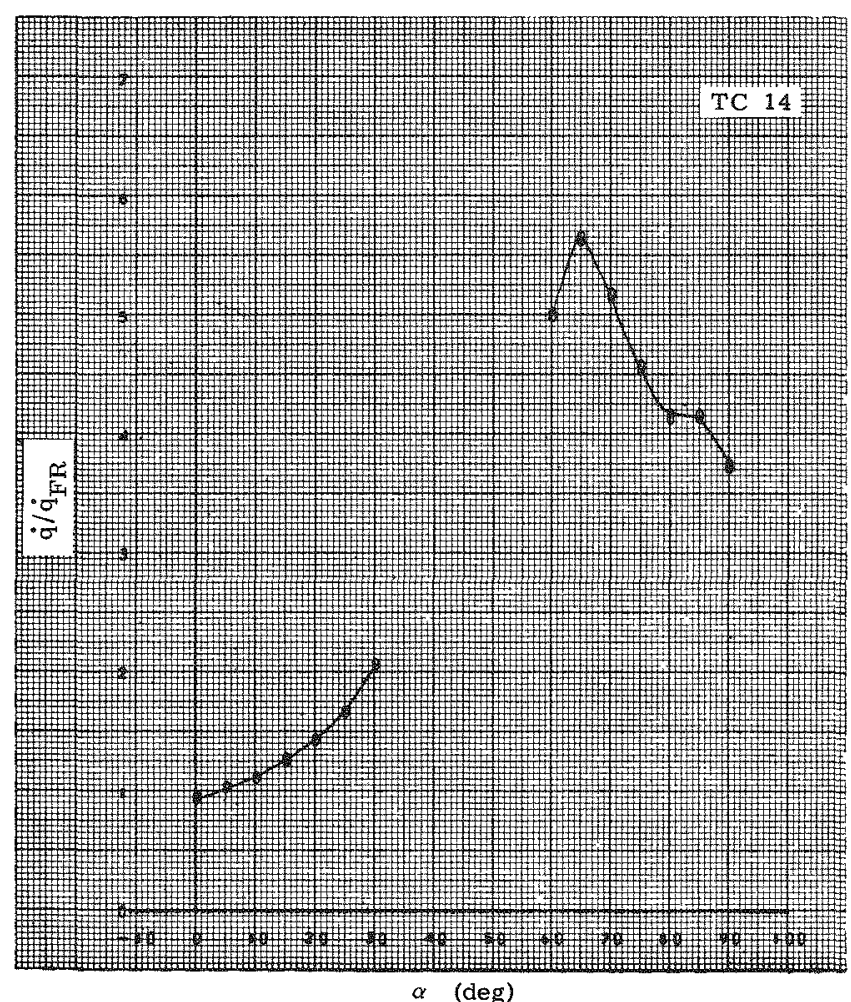

Fig. 53. Heat Transfer, TC 14, Configuration 430

Fig. 52. Heat Transfer, TC 14, Configuration 330 


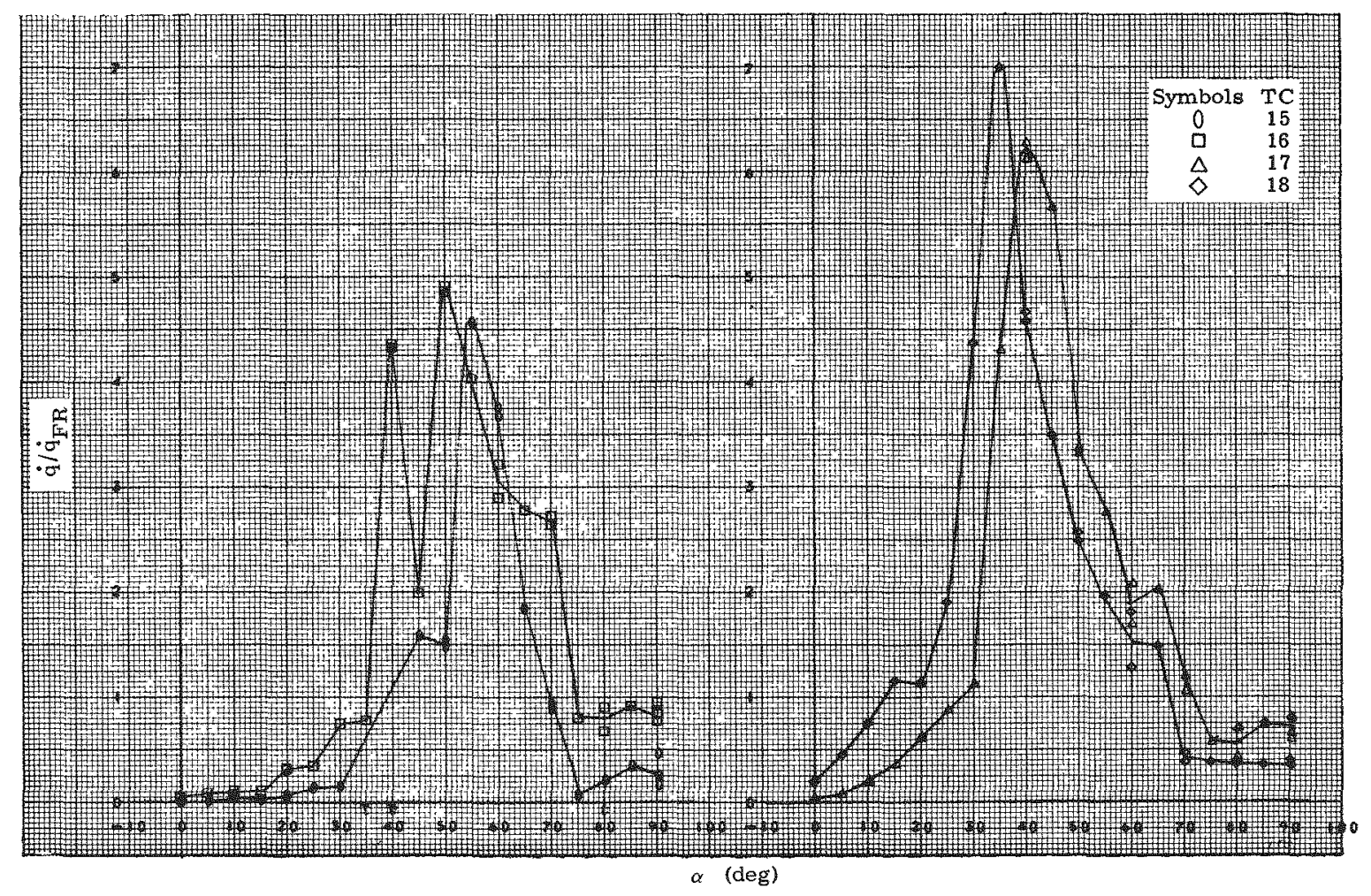

Fig. 54. Heat Transfer, TC 15-18, Configuration 100

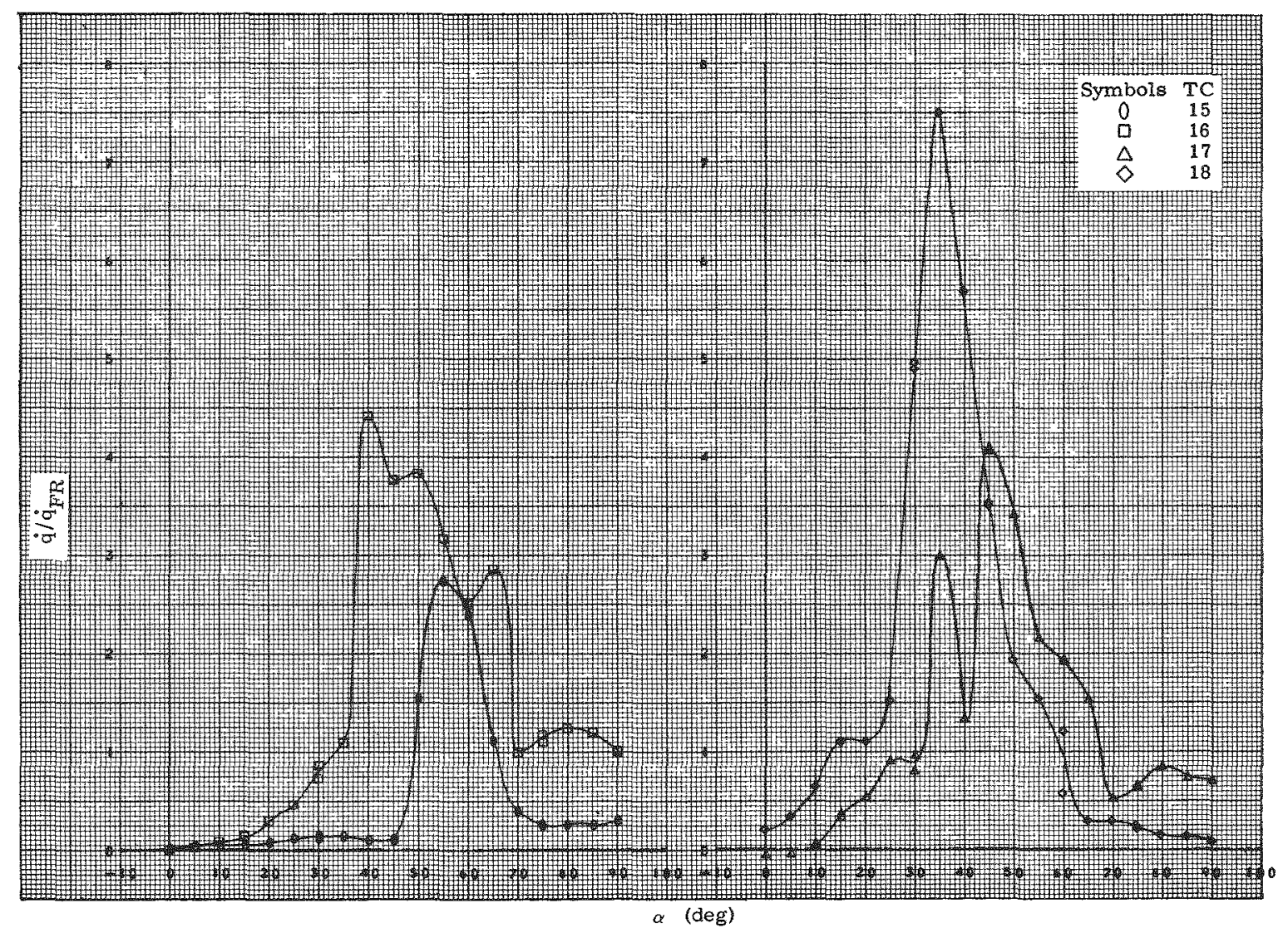

Fig. 55. Heat Transfer, TC 15- 18, Configuration 200 


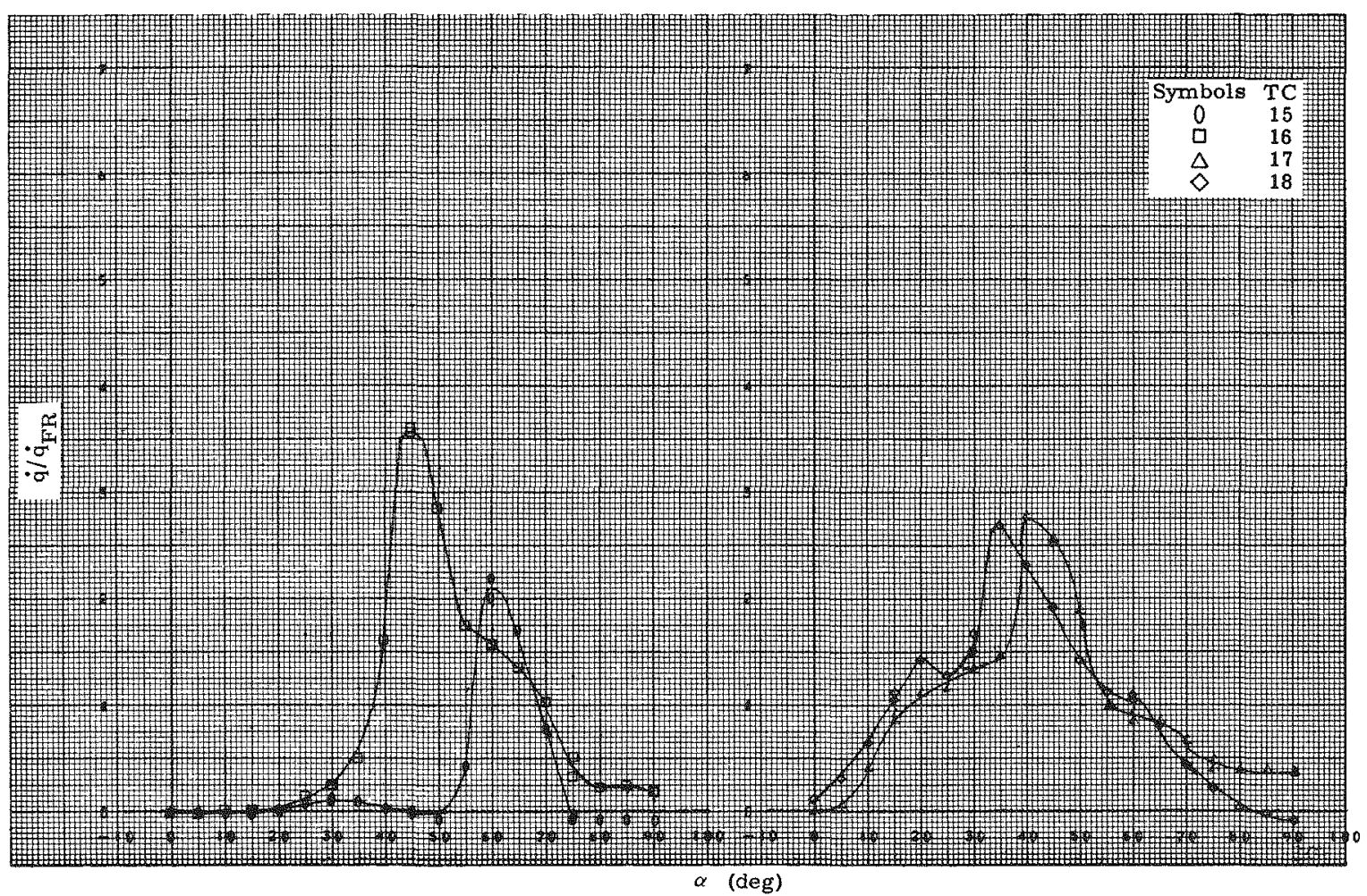

Fig. 56. Heat Transfer, TC 15-18, Configuration 300

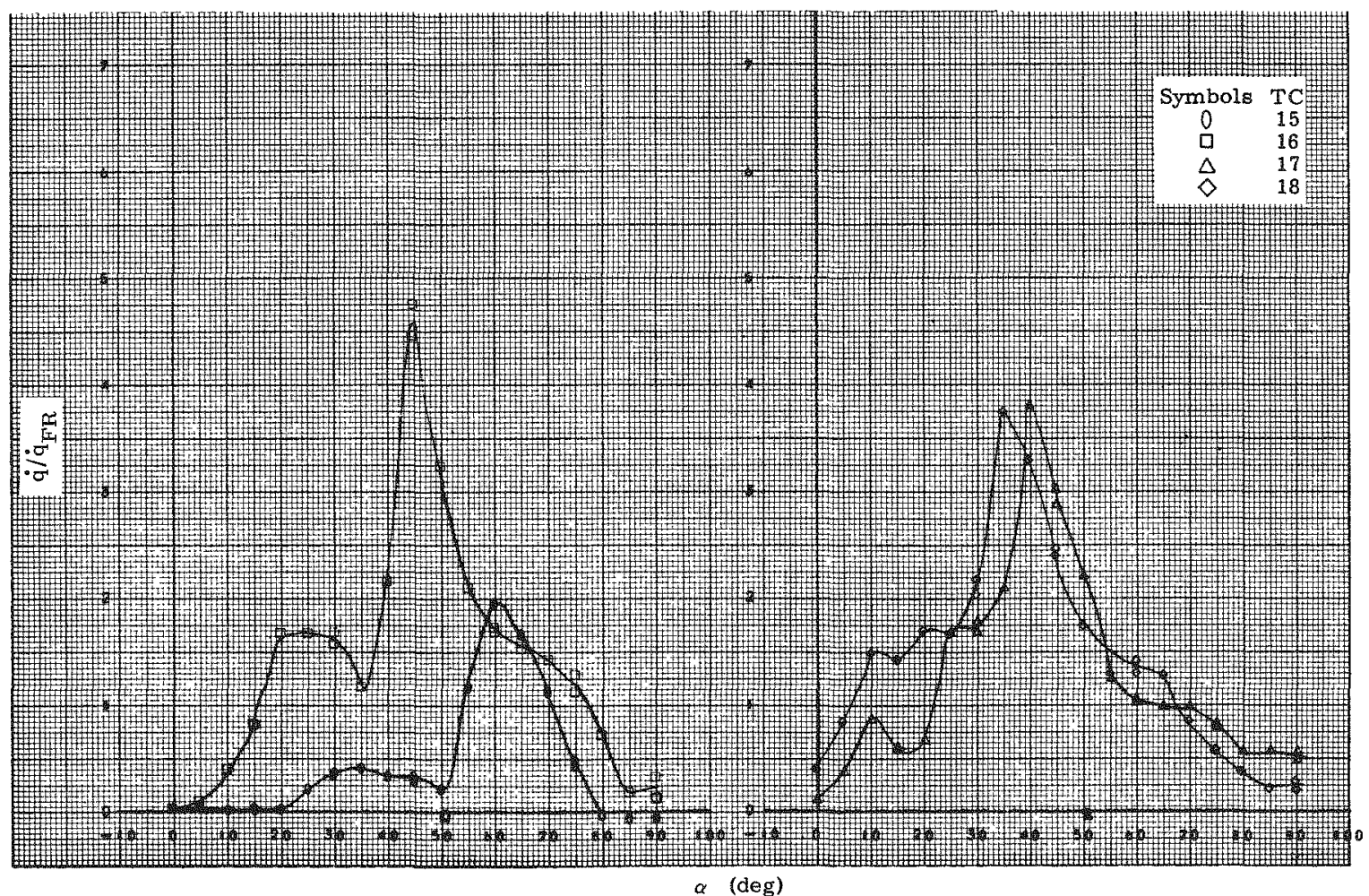

Fig. 57. Heat Transfer, TC $15-18$, Configuration 400 


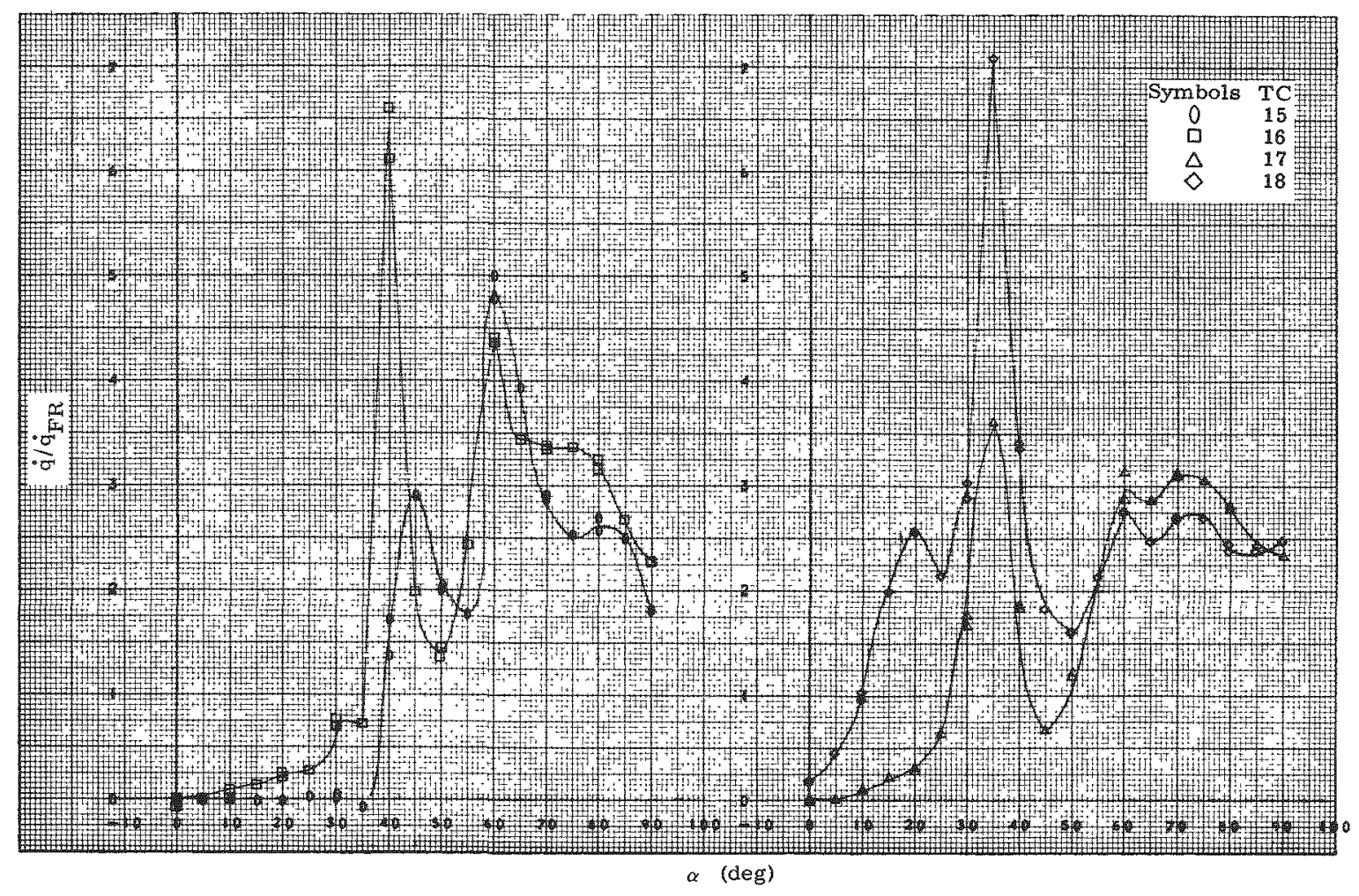

Fig. 58. Heat Transfer, TC $15-18$, Configuration 130

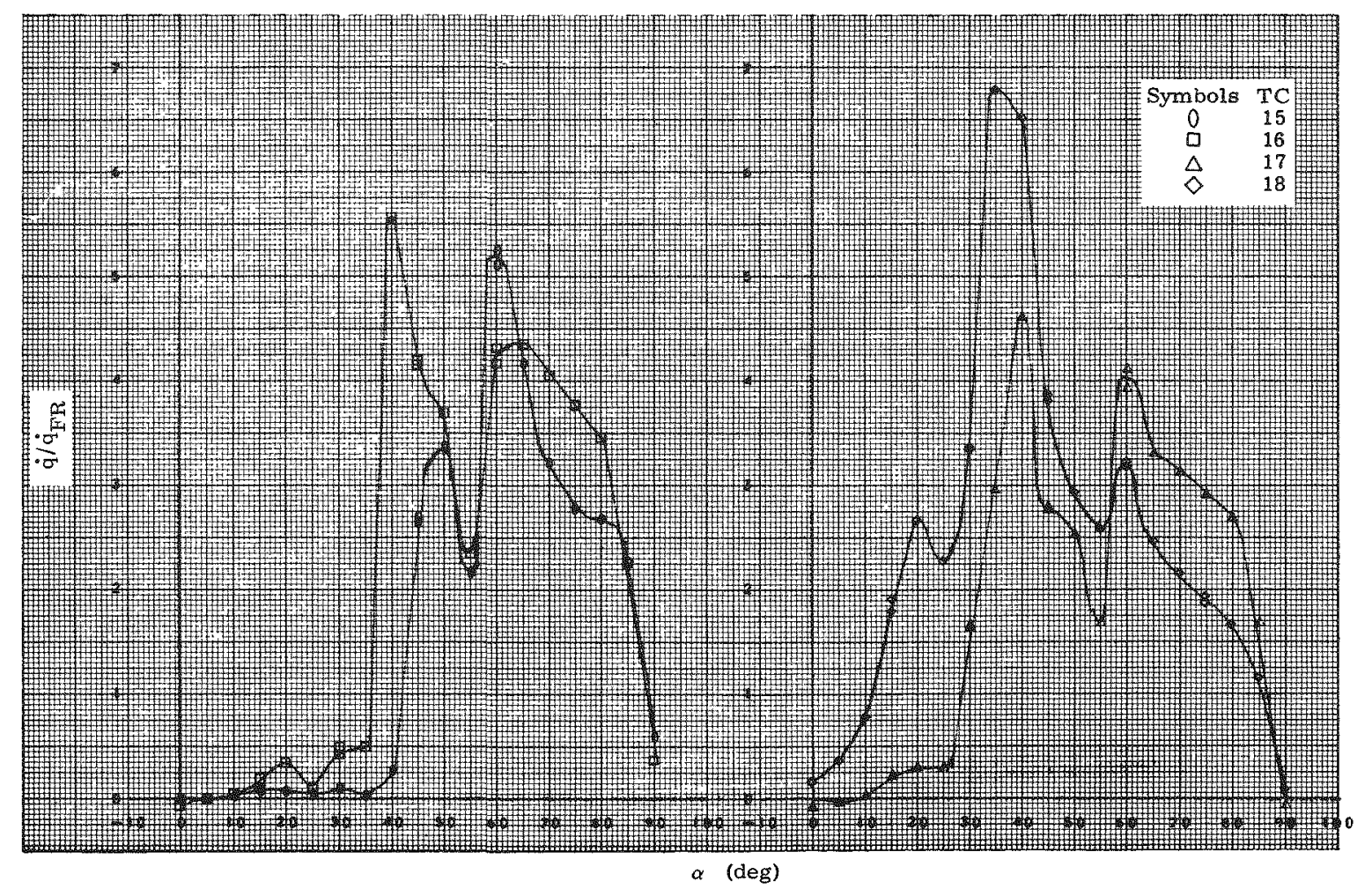

Fig. 59. Heat Transfer, TC $15-18$, Configuration 230 


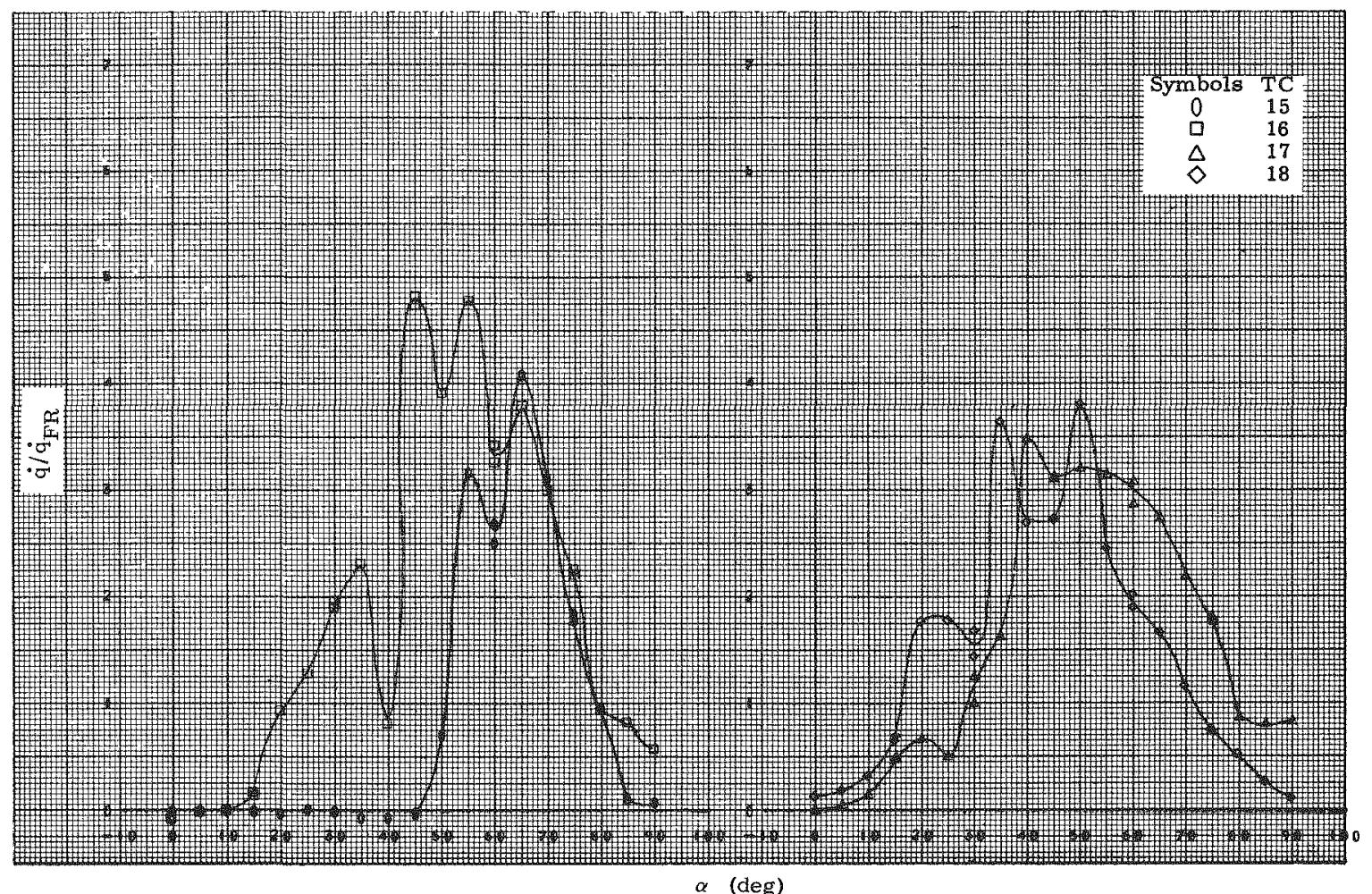

Fig. 60. Heat Transfer, TC 15-18, Configuration 330

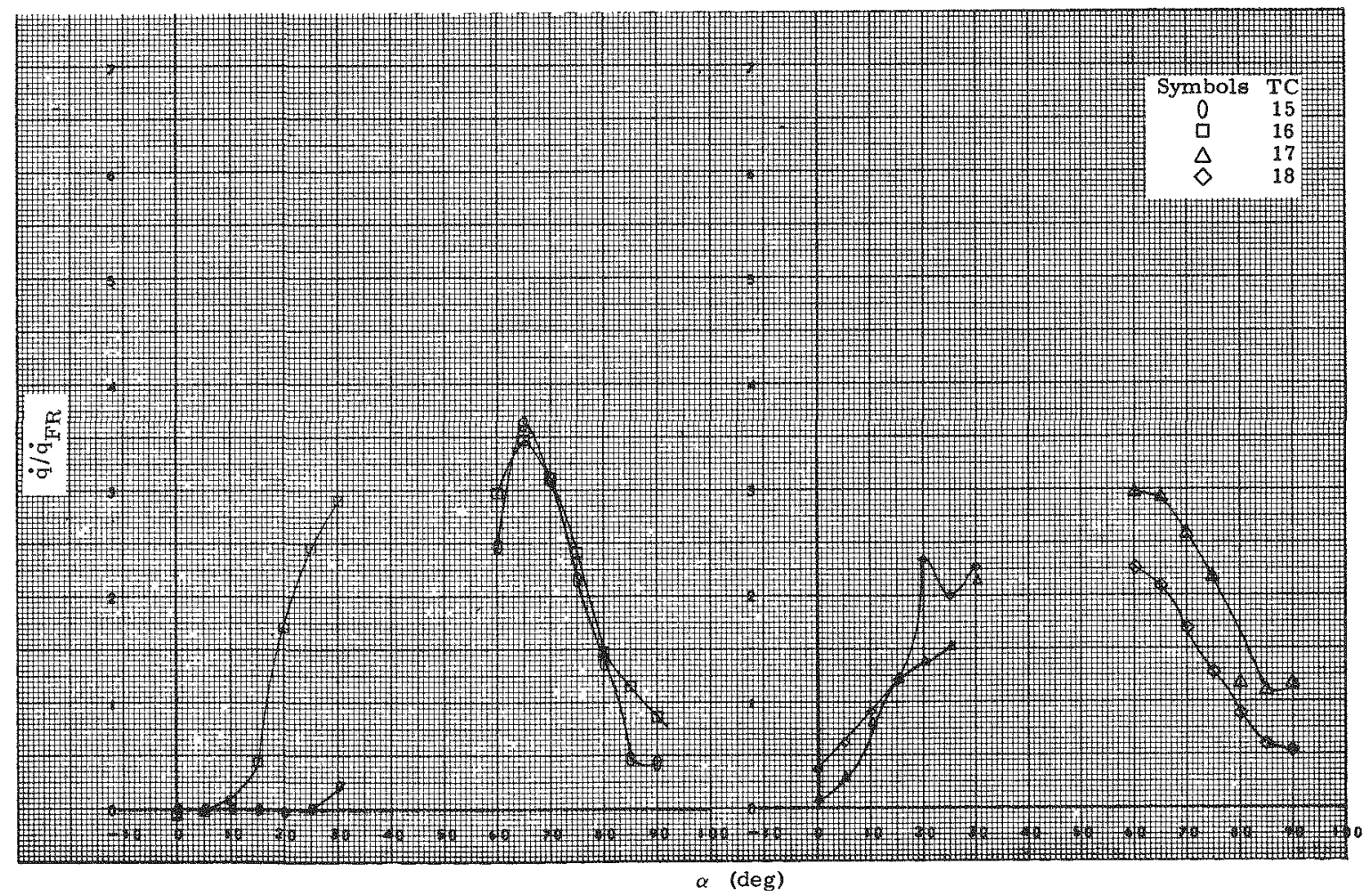

Fig. 61. Heat Transfer, TC 15-18, Configuration 430 


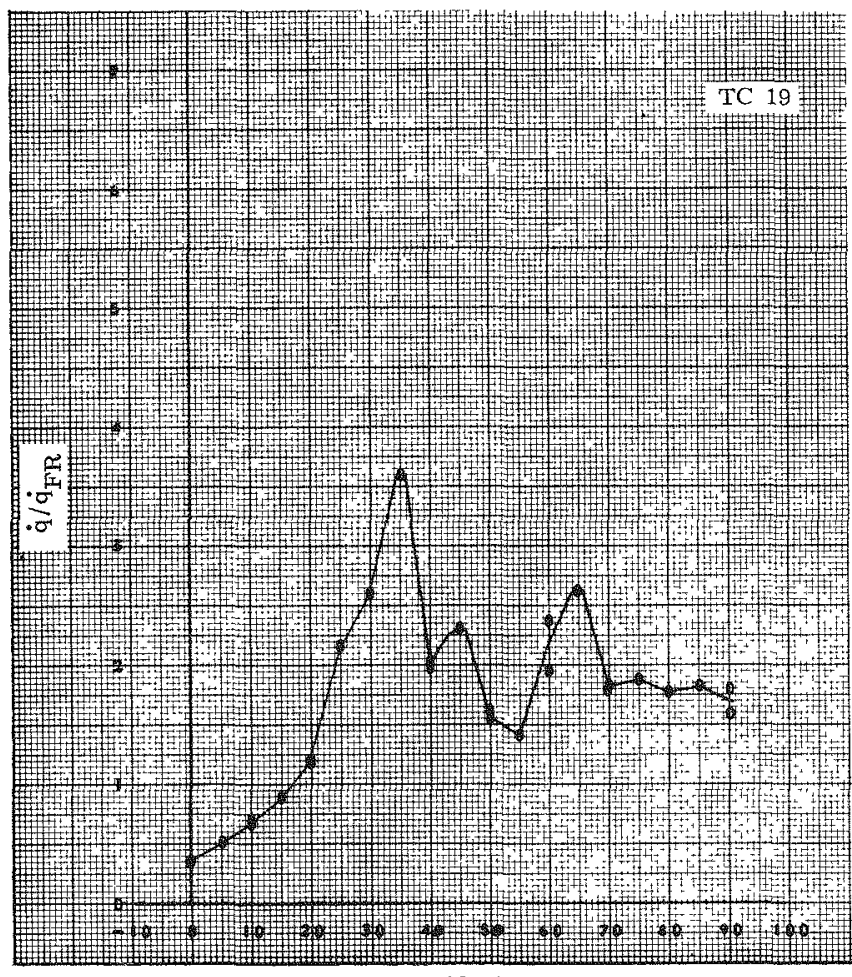

$\alpha$ (deg)

Fig. 62. Heat Transfer, TC 19, Configuration 100

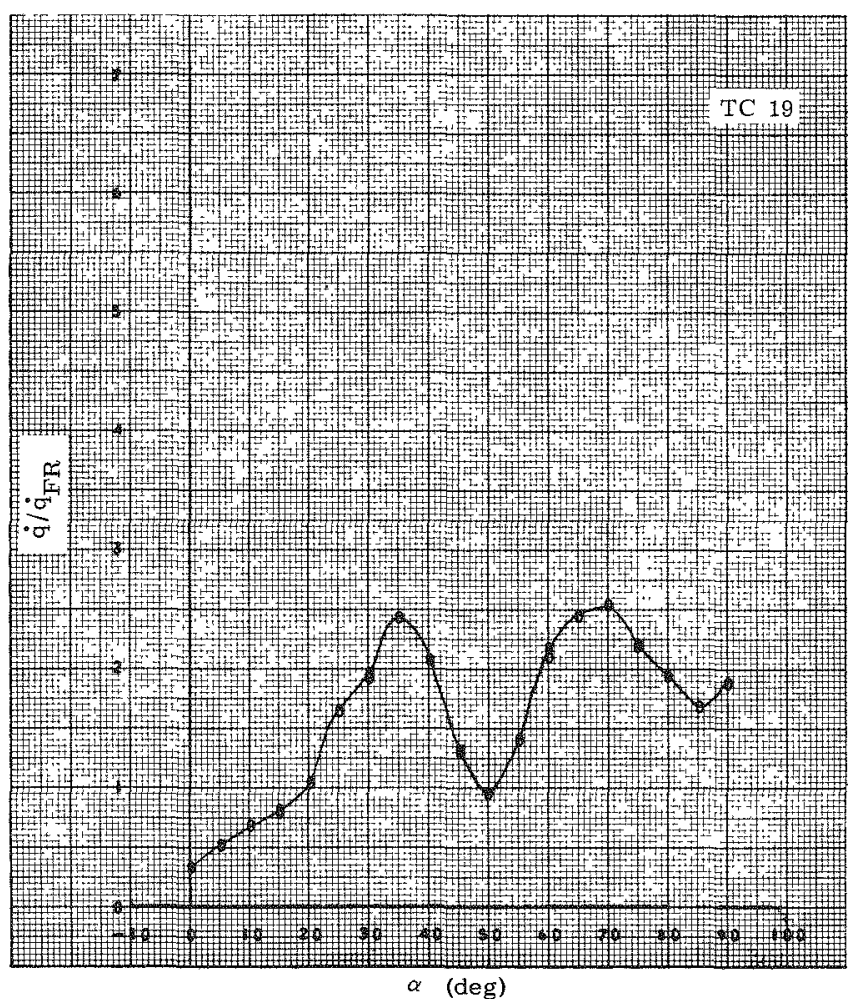

Fig. 63. Heat Transfer, TC 19, Configuration 200

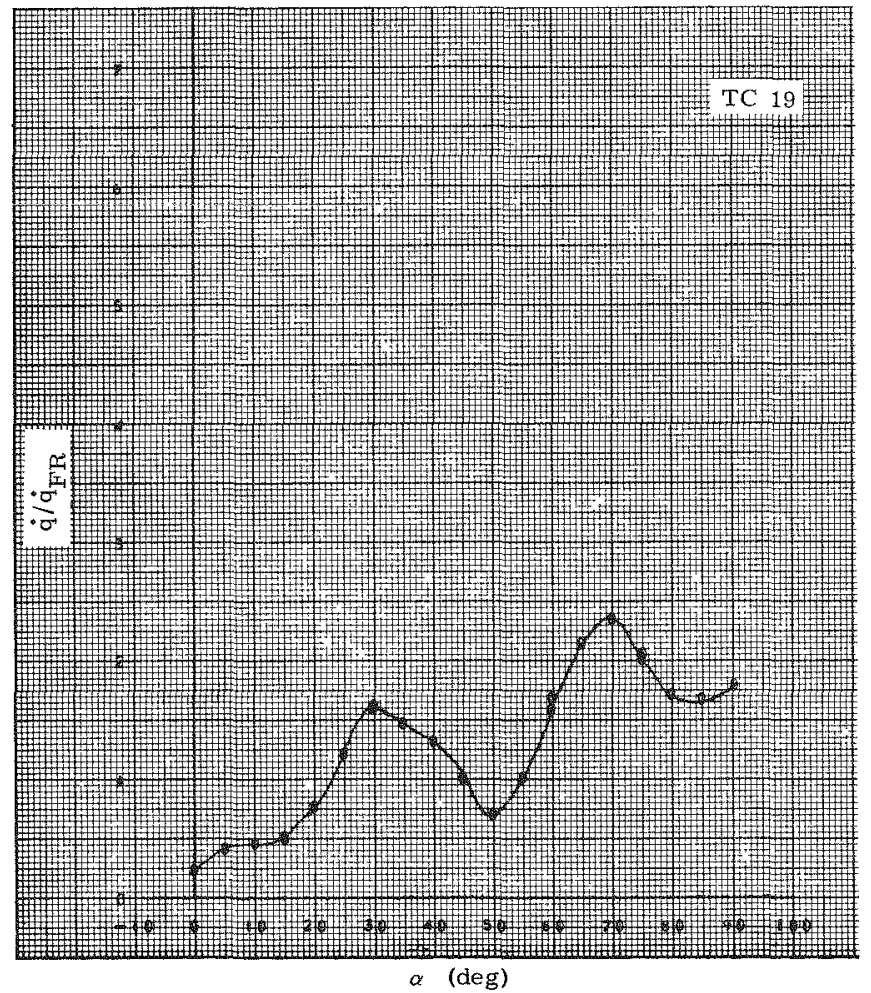

Fig. 64. Heat Transfer, TC 19, Configuration 300

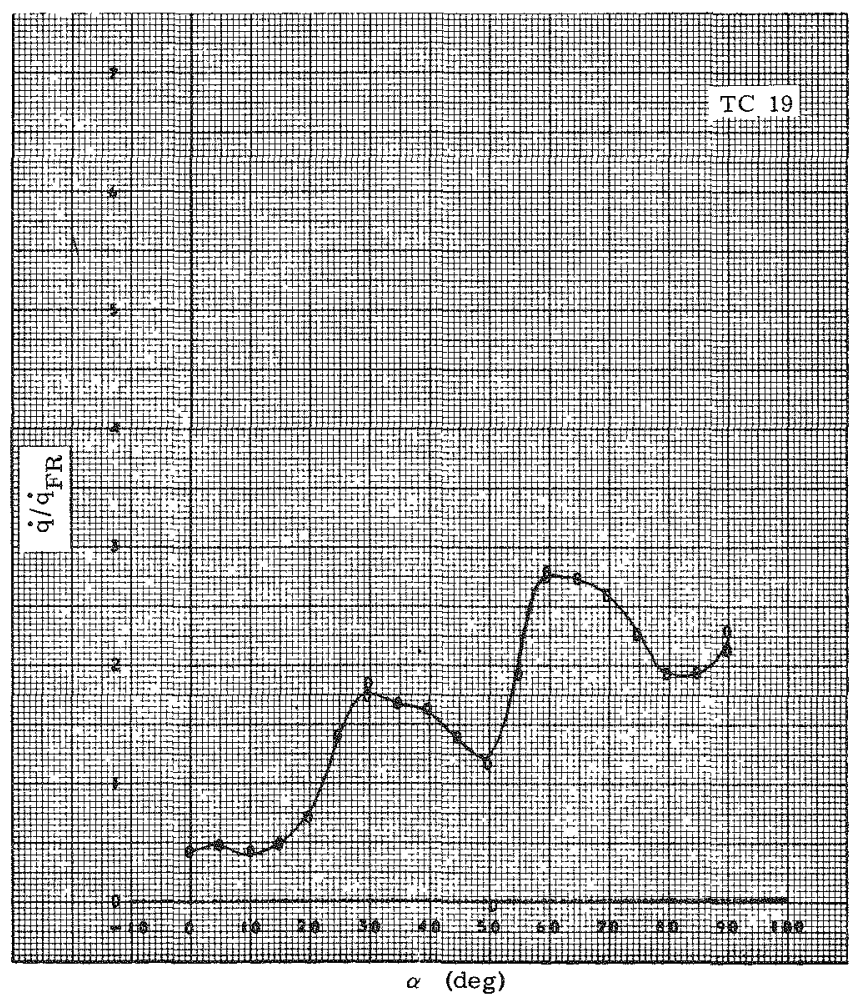

Fig. 65. Heat Transfer, TC 19, Configuration 400 


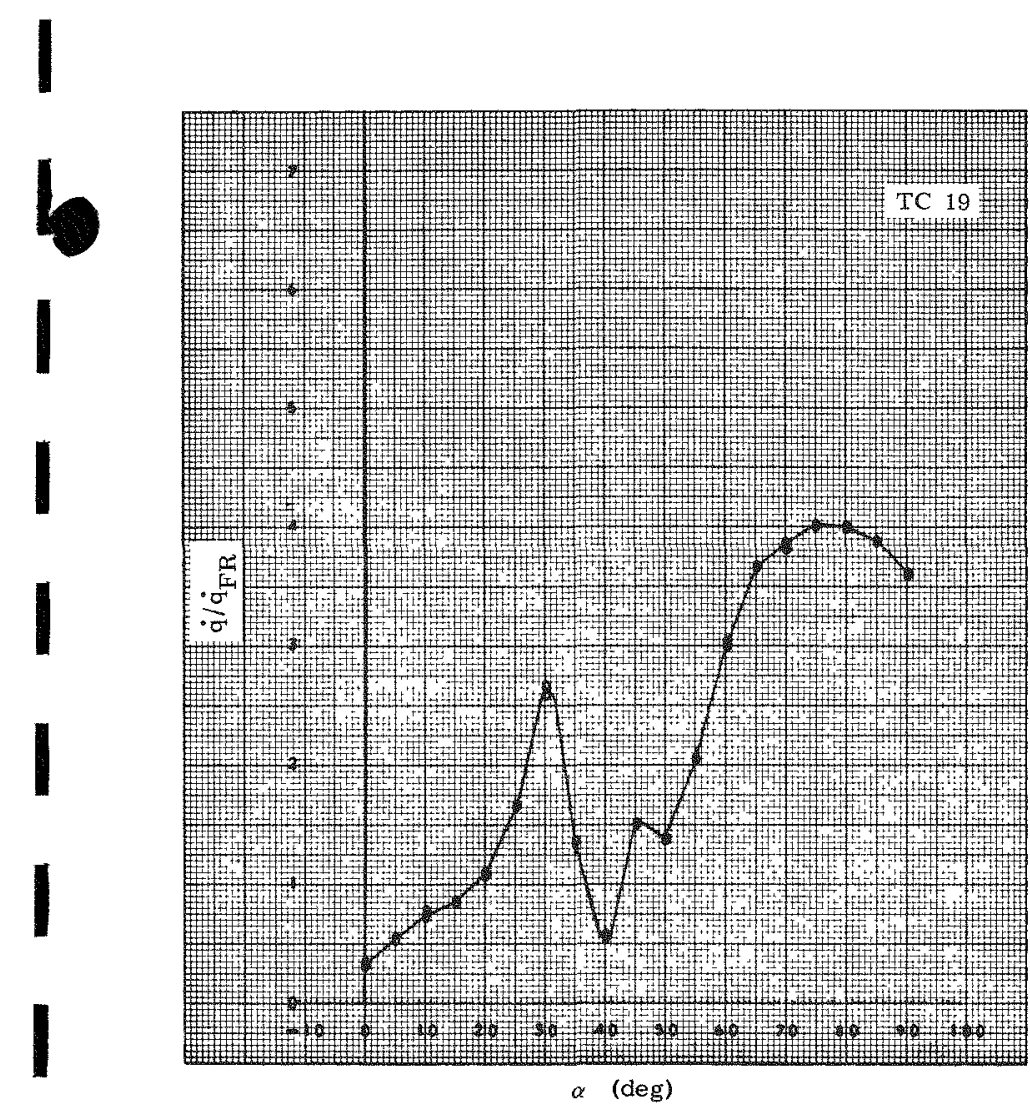

Fig. 66. Heat Transfer, TC 19, Configuration 130

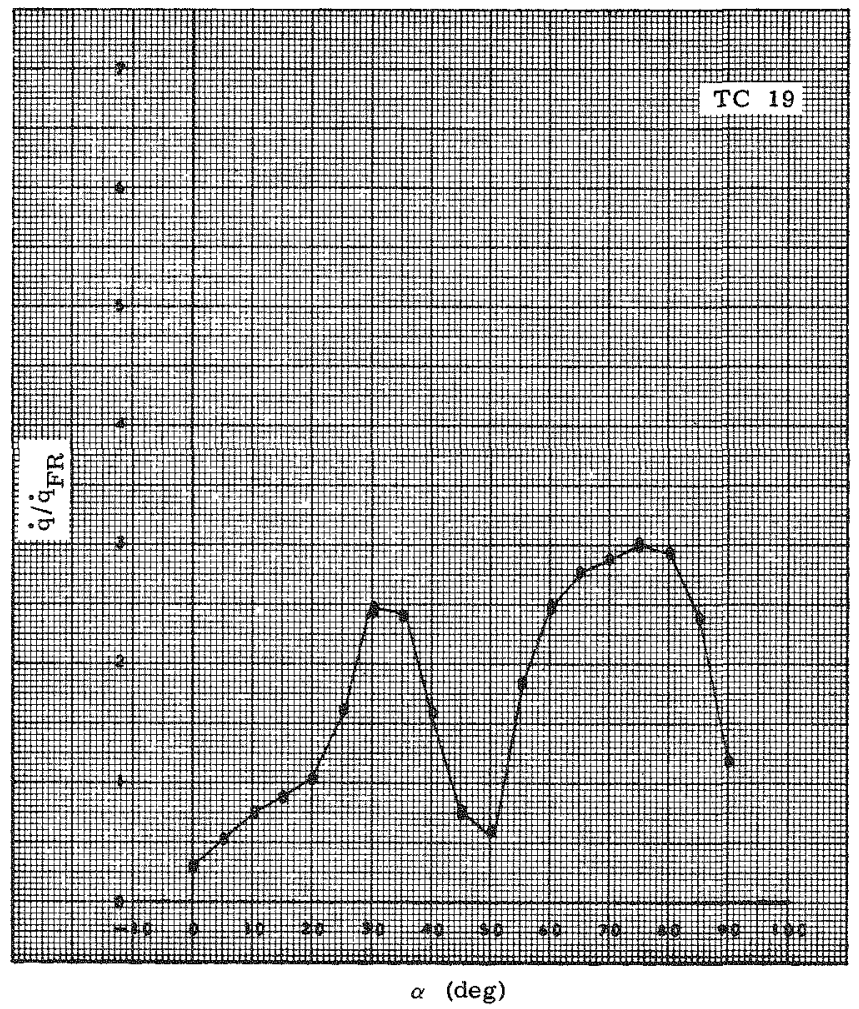

Fig. 67. Heat Transfer, TC 19, Configuration 230

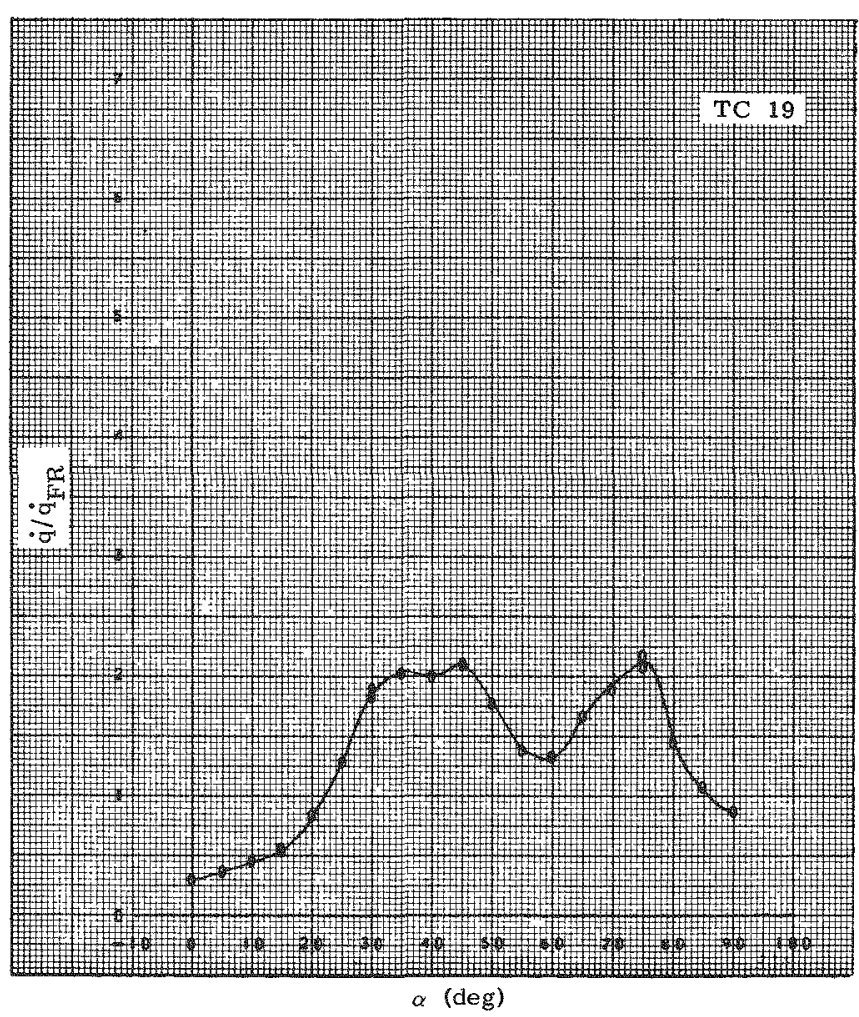

Fig. 68. Heat Transfer, TC 19, Configuration 330

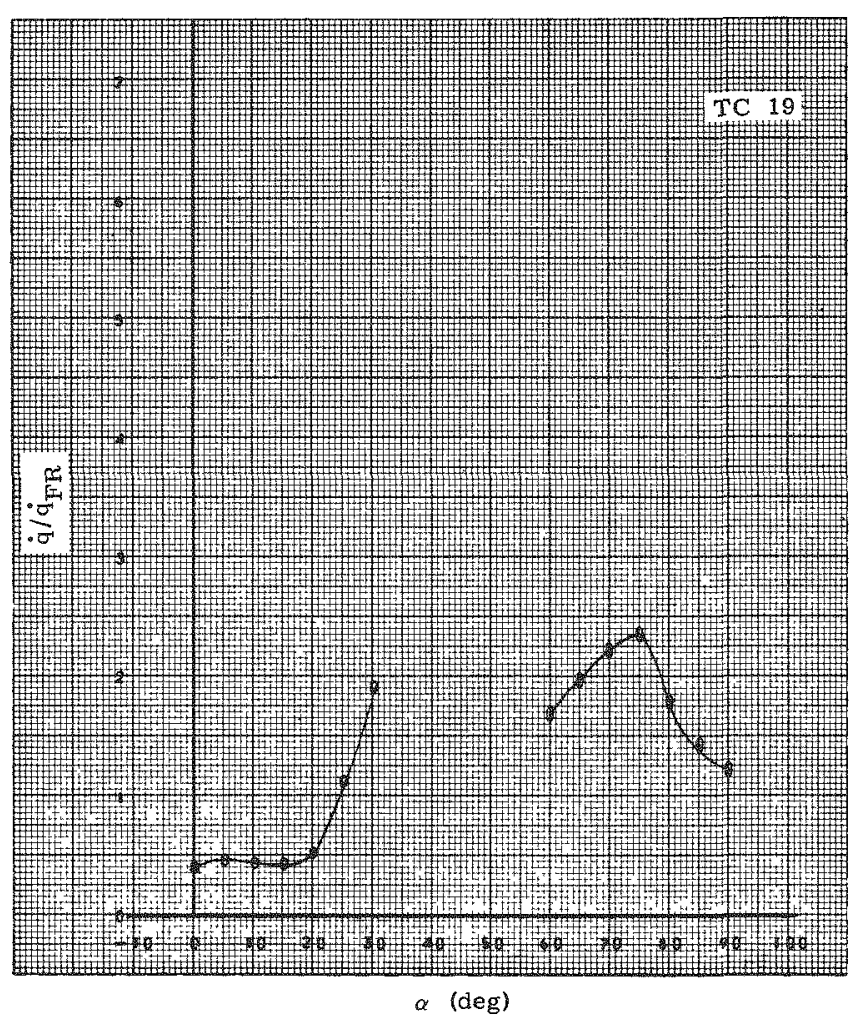

Fig. 69. Heat Transfer, TC 19, Configuration 430 

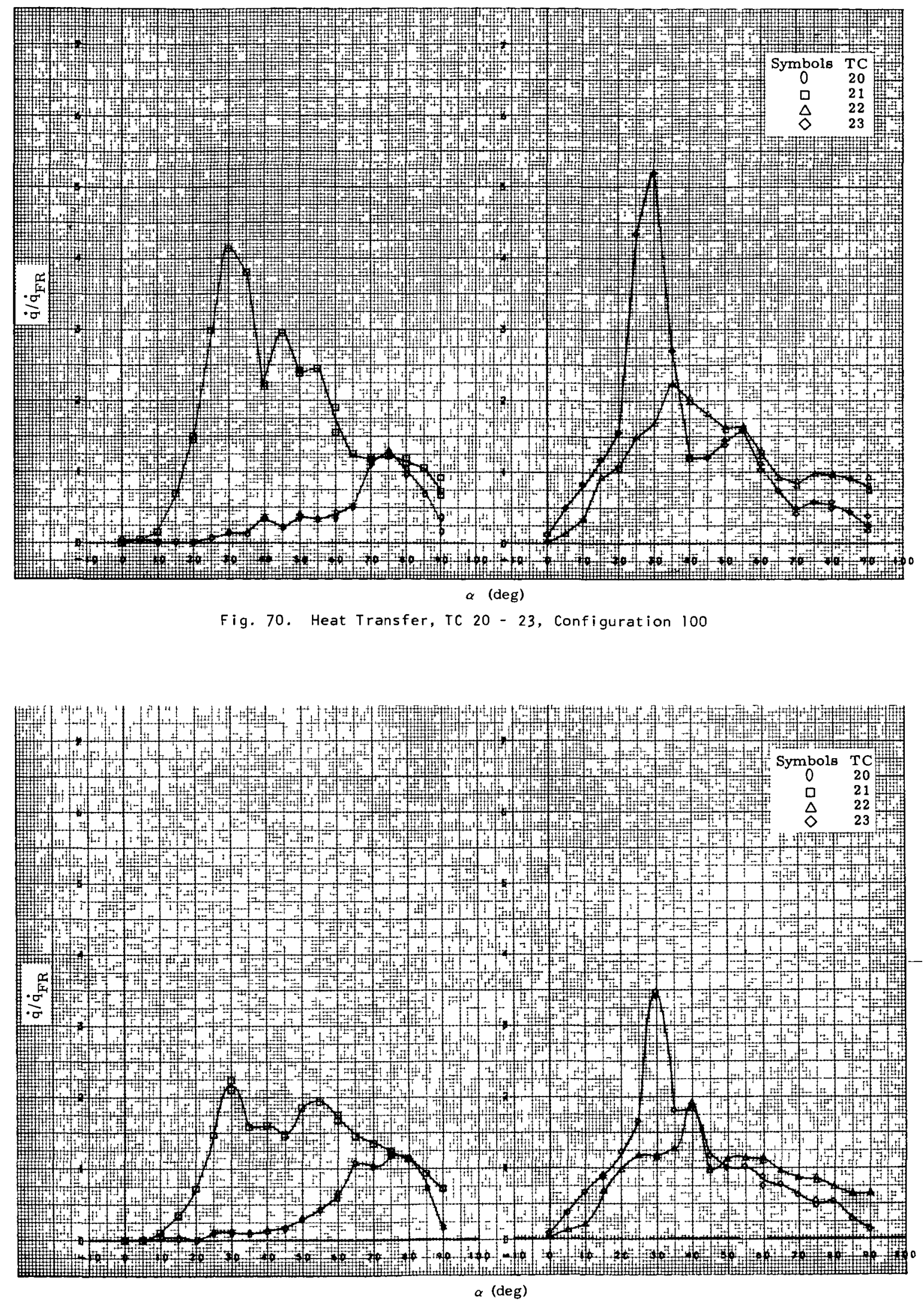

Fig. 71. Heat Transfer, TC $20-23$, Configuration 200 


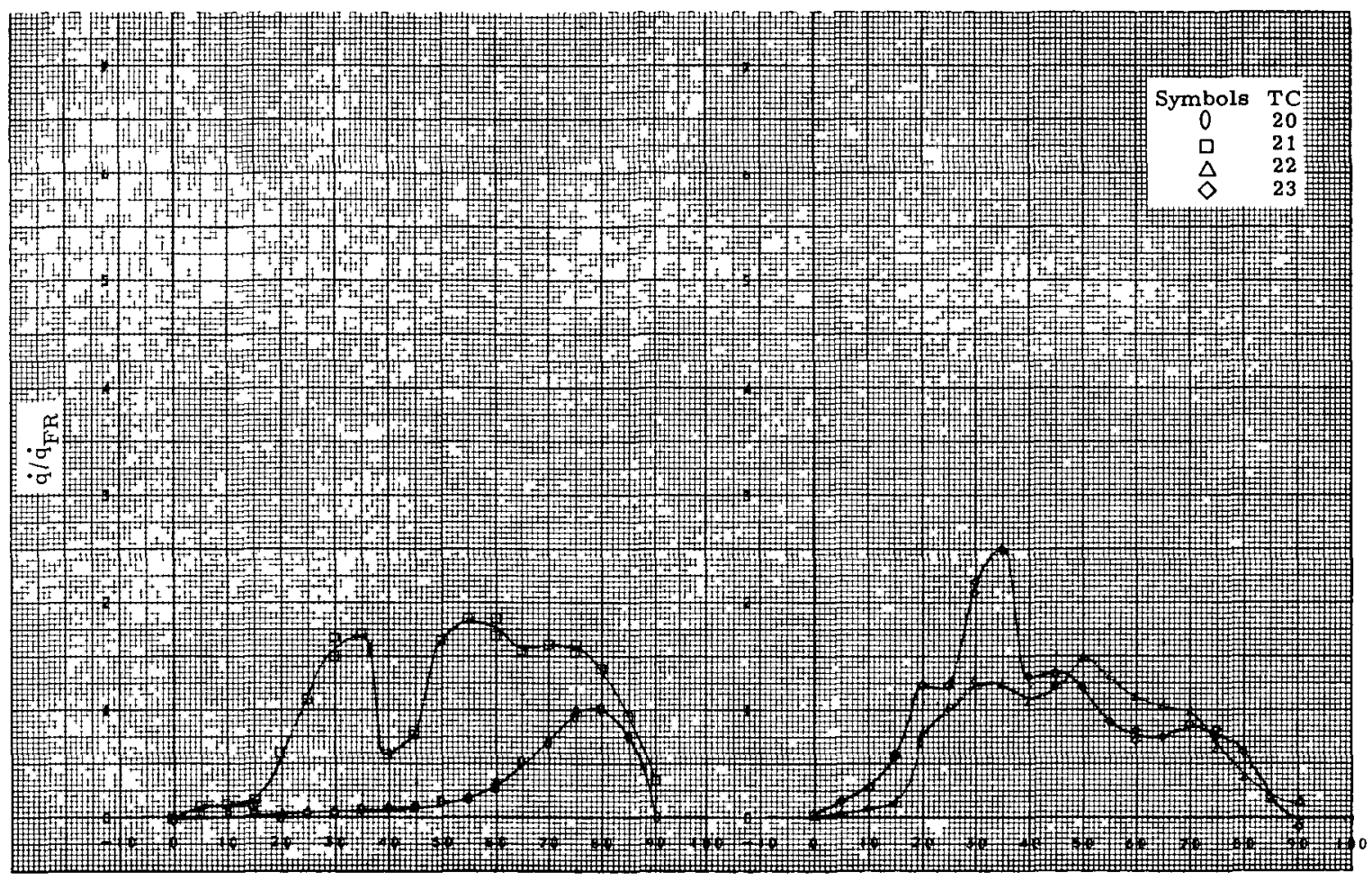

$\alpha$ (deg)

Fig. 72. Heat Transfer, IC 20-23, Configuration 300

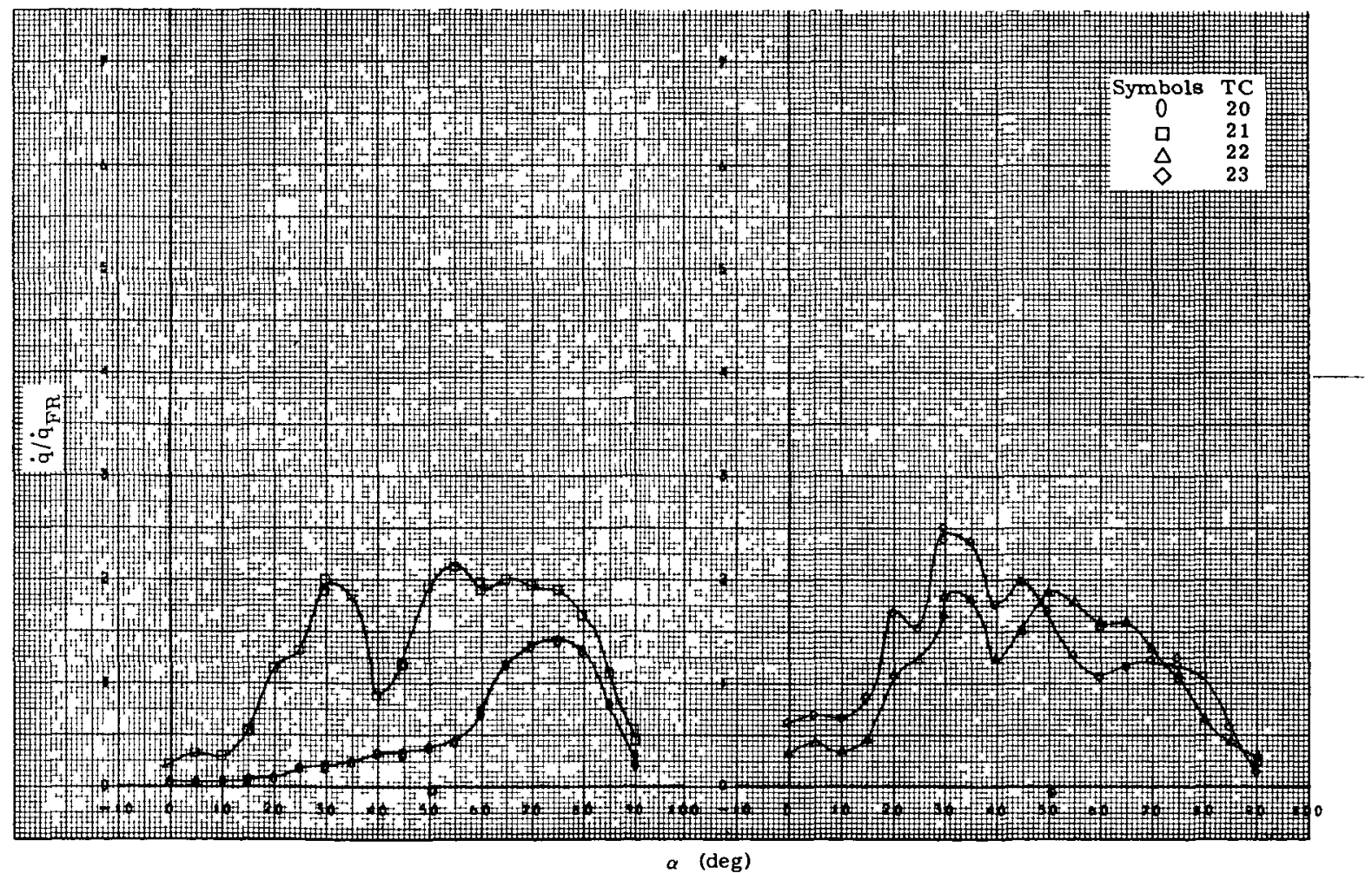

Fig. 73. Heat Transfer, IC 20-23, Configuration 400 


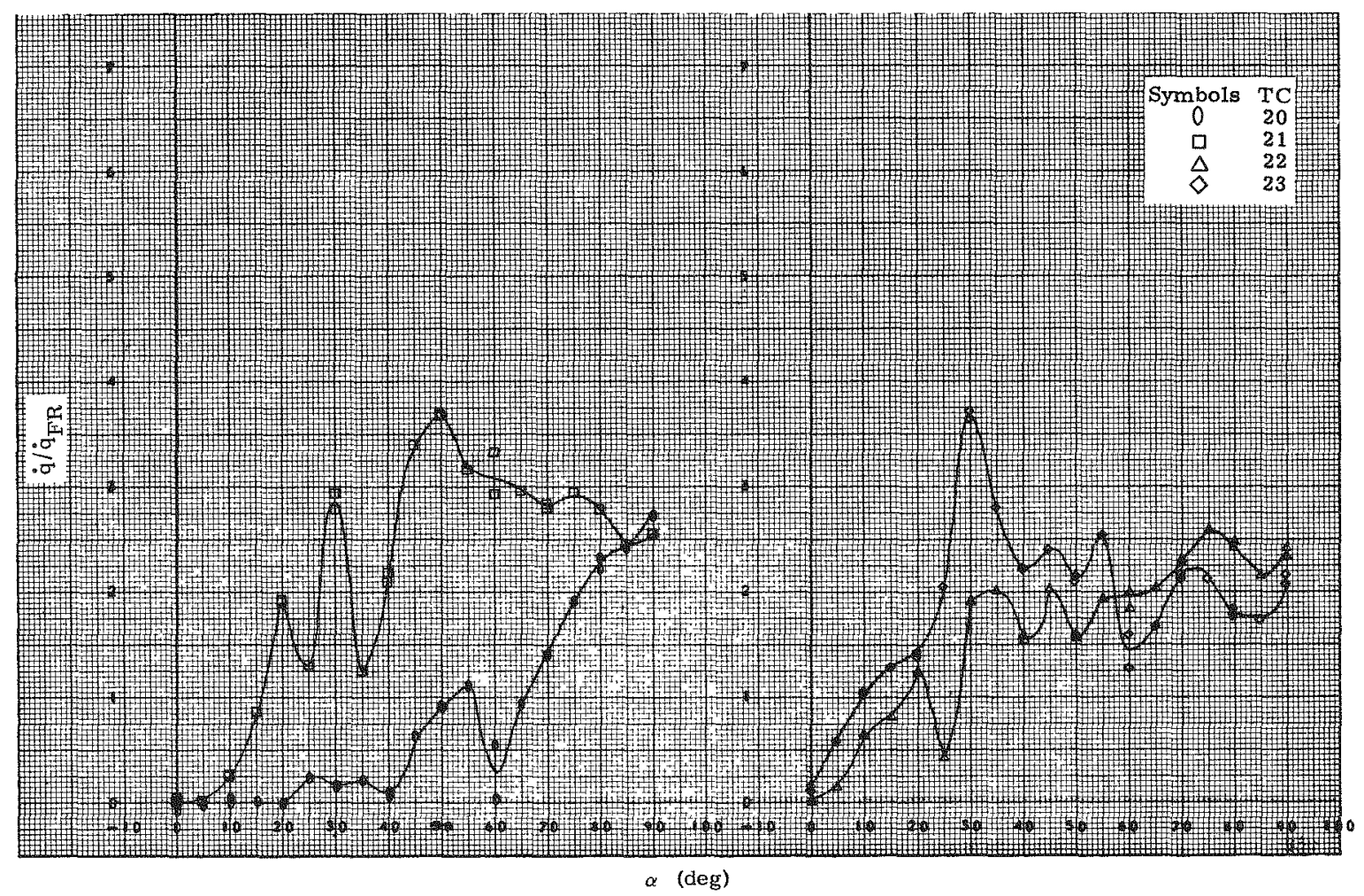

Fig. 74. Heat Transfer, TC $20-23$, Configuration 130

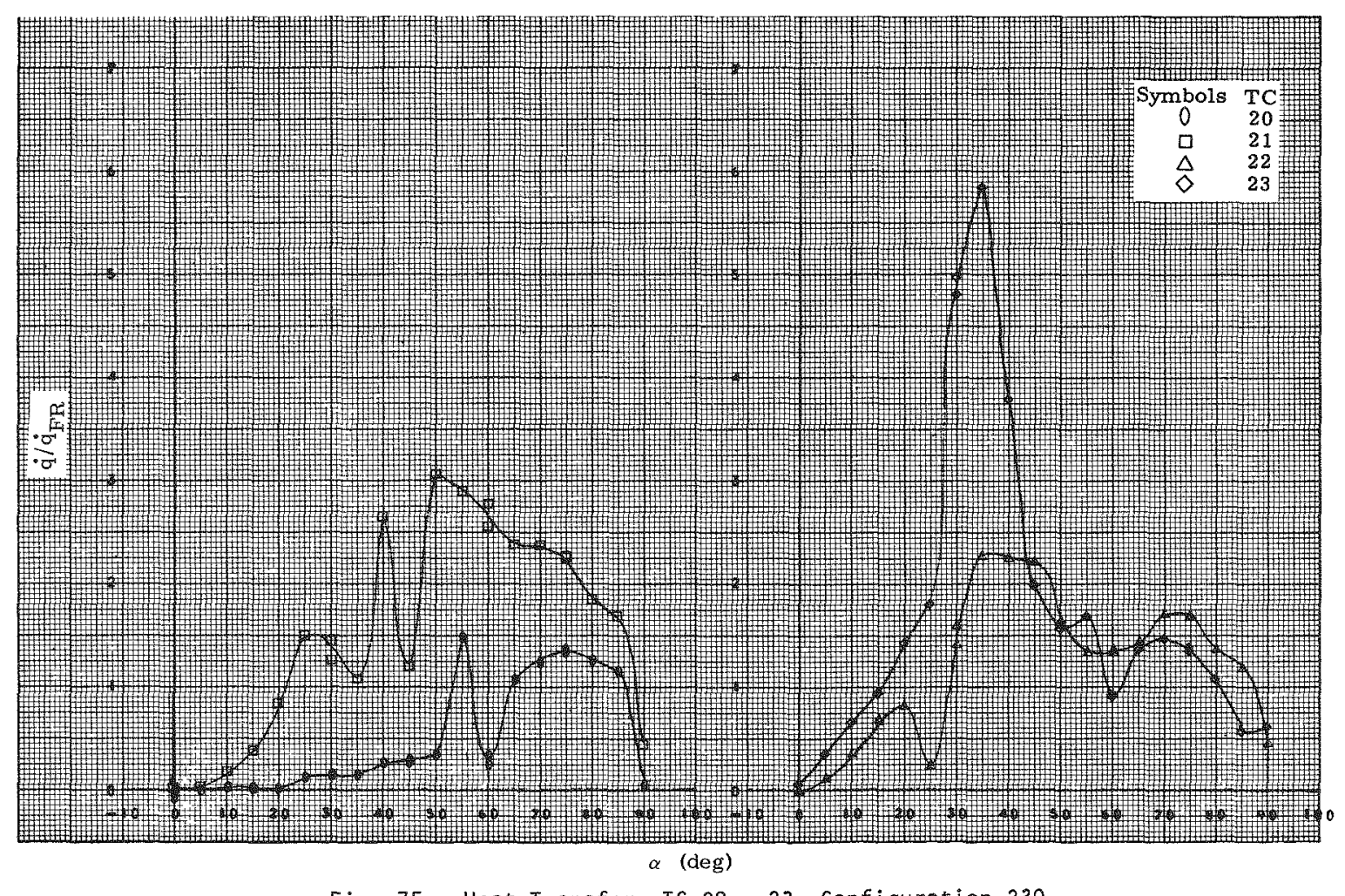

Fig. 75. Heat Transfer, TC $20-23$, Configuration 230 


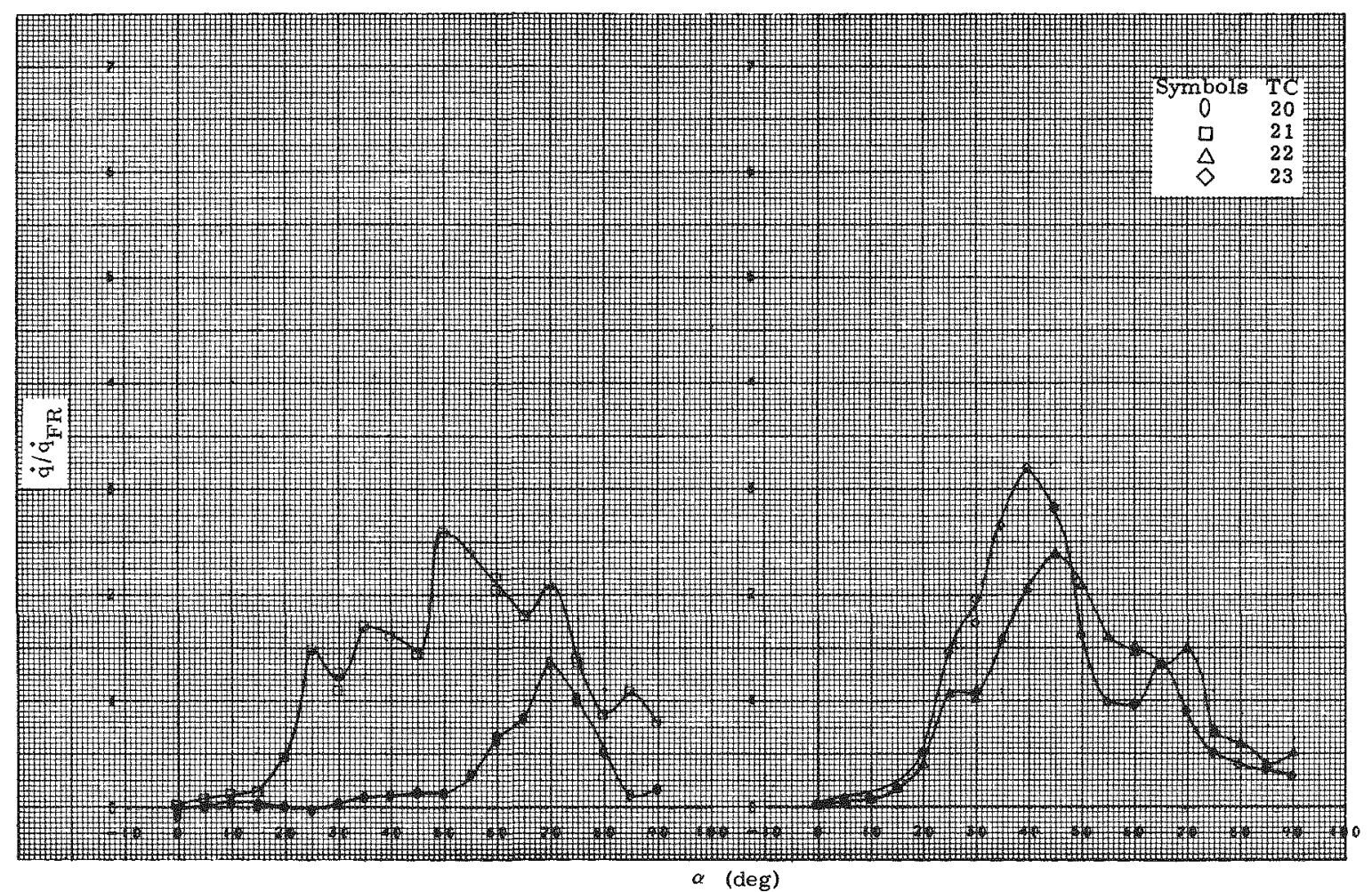

Fig. 76. Heat Transfer, TC $20-23$, Configuration 330

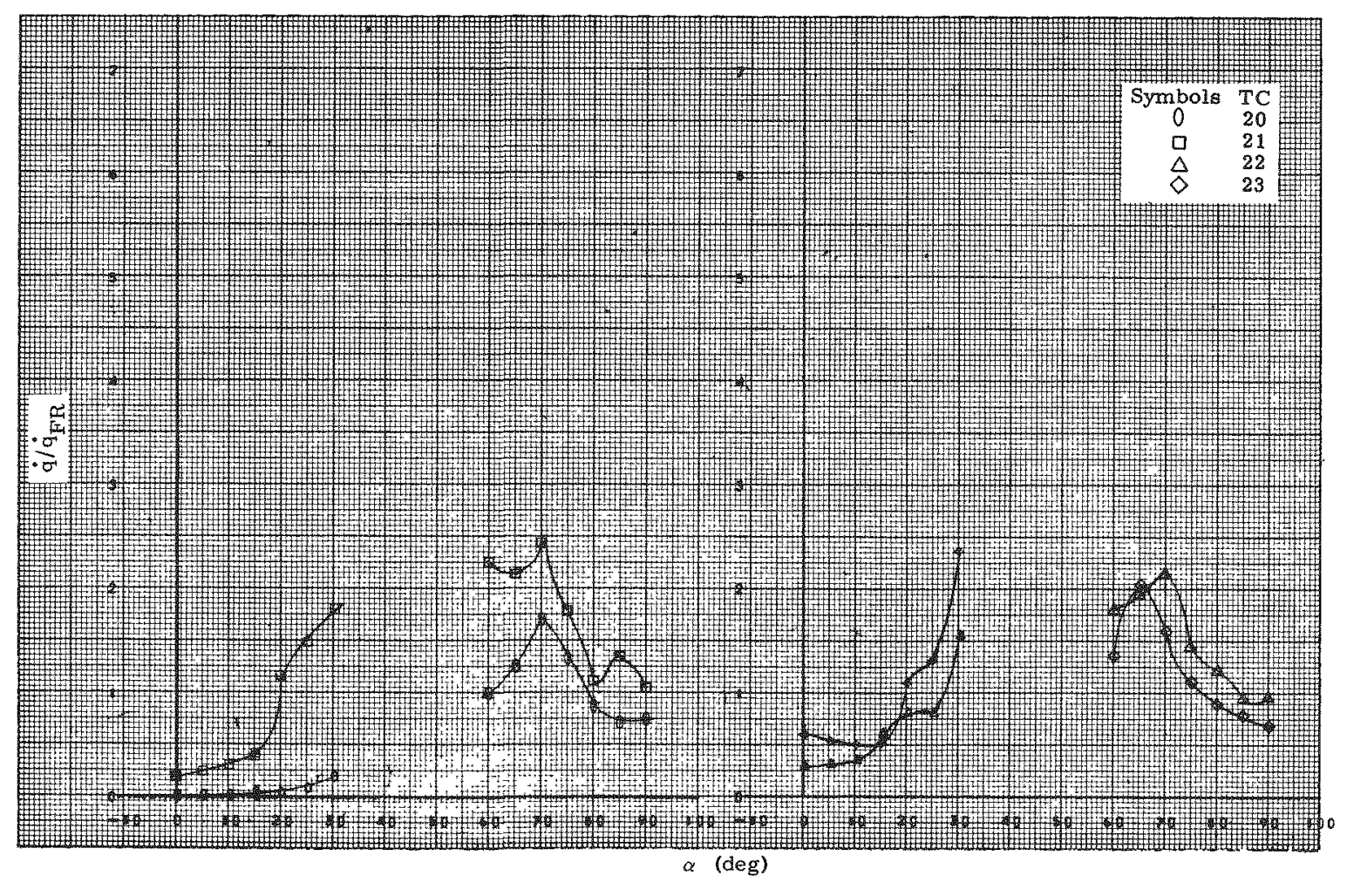

Fig. 77. Heat Transfer, TC $20-23$, Configuration 430 


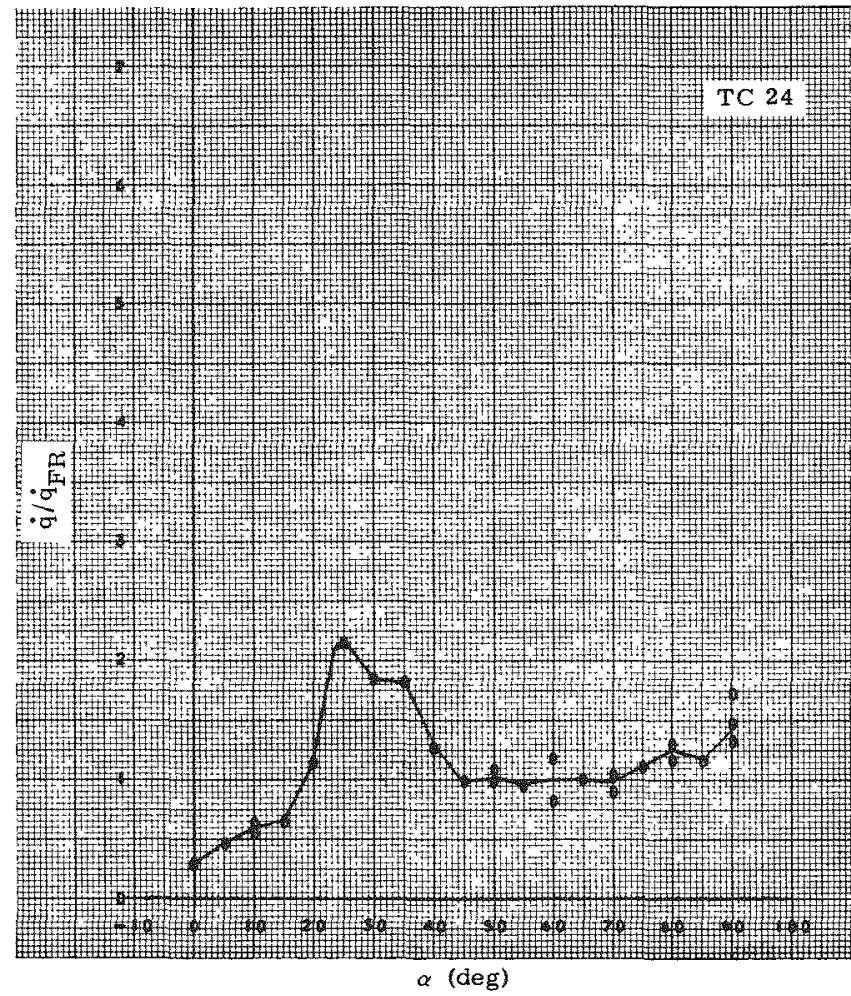

Fig. 78. Heat Transfer, TC 24, Configuration 100

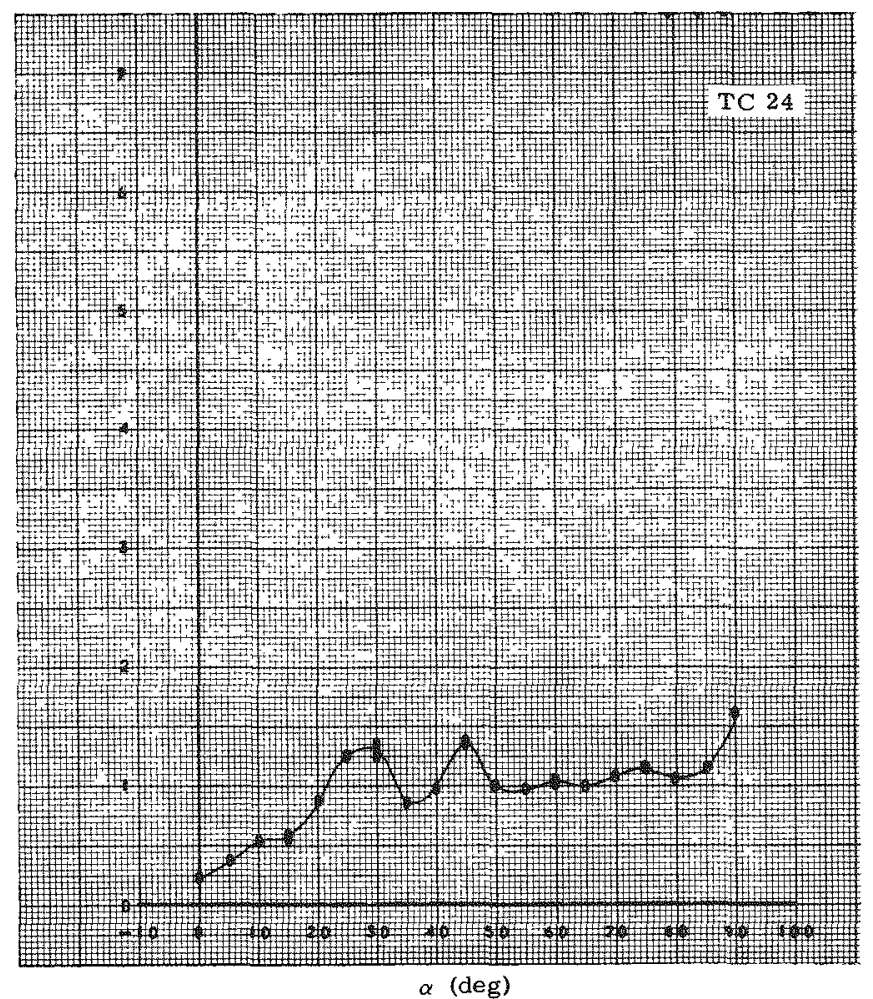

Fig. 79. Heat Transfer, TC 24, Configuration 200

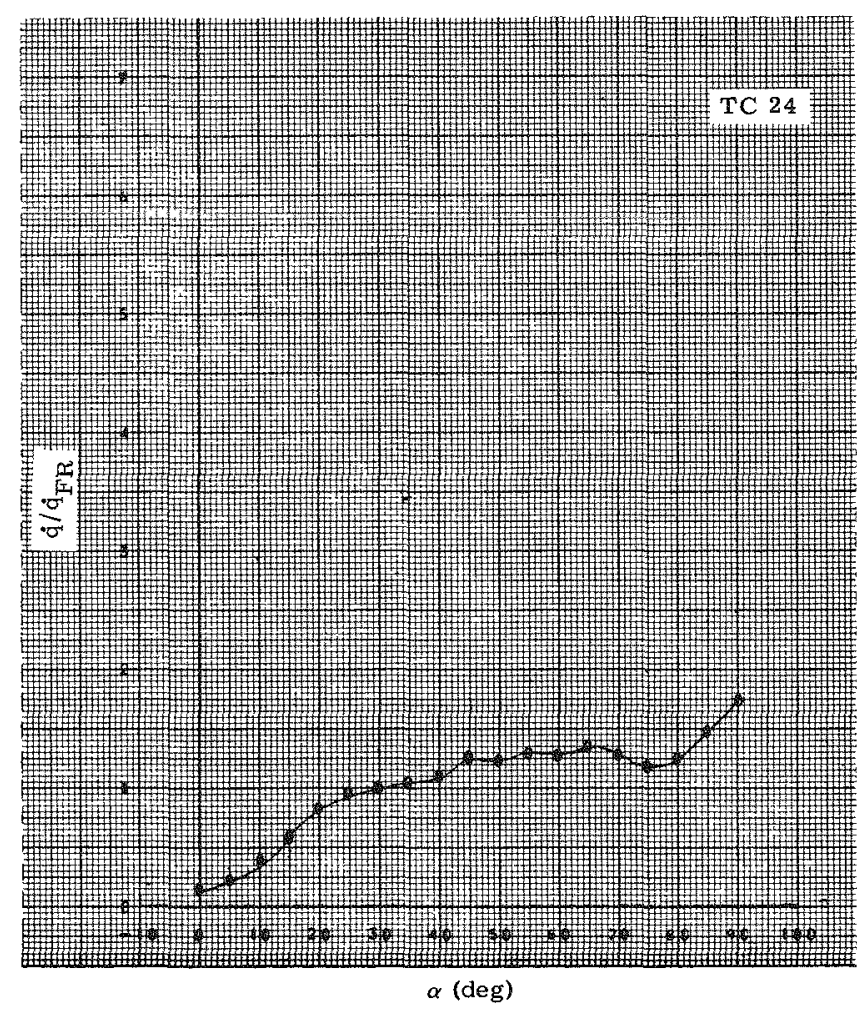

Fig. 80. Heat Transfer, TC 24, Configuration 300

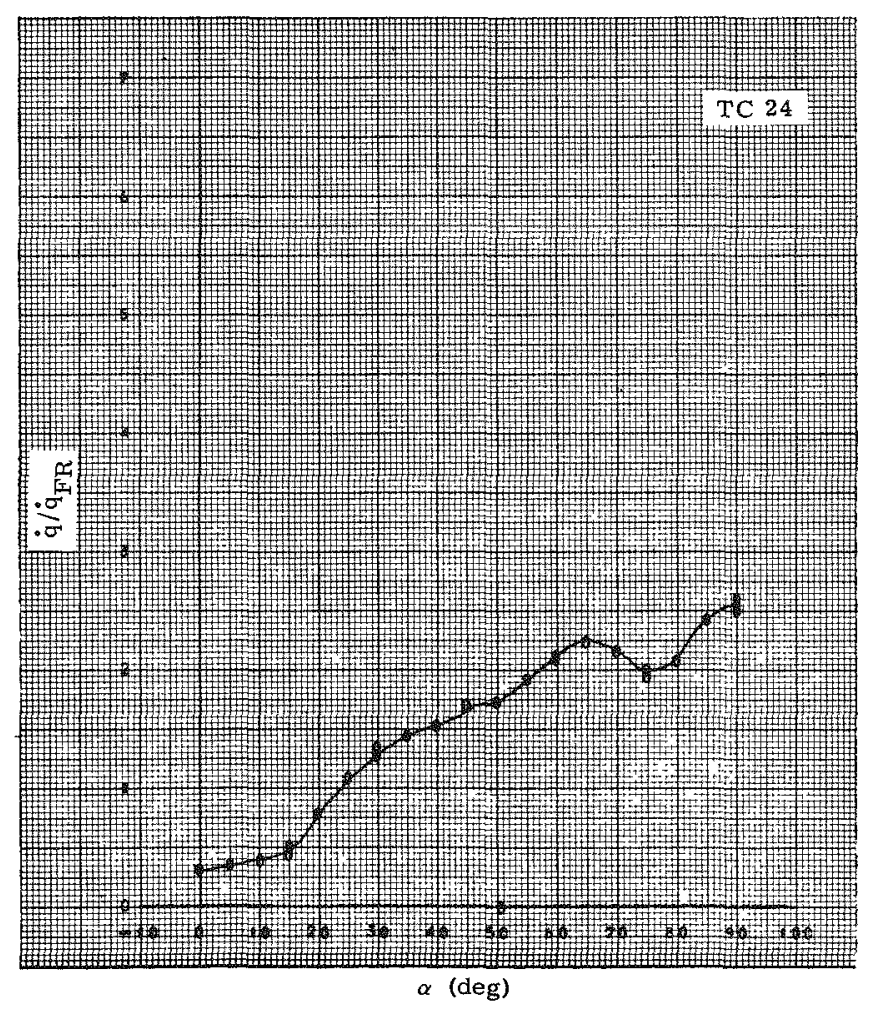

Fig. 81. Heat Transfer, TC 24, Configuration 400 


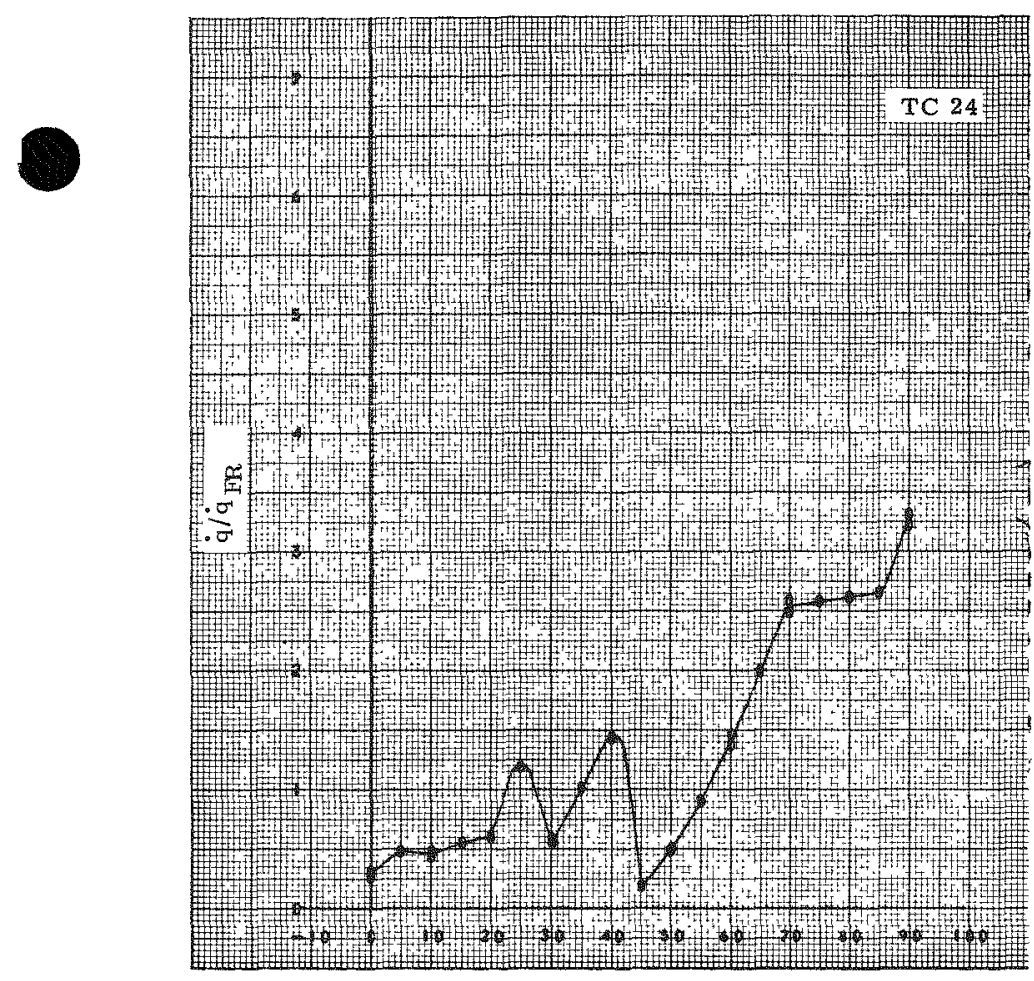

Fig. 82. Heat Transfer, TC 24, Configuration 130

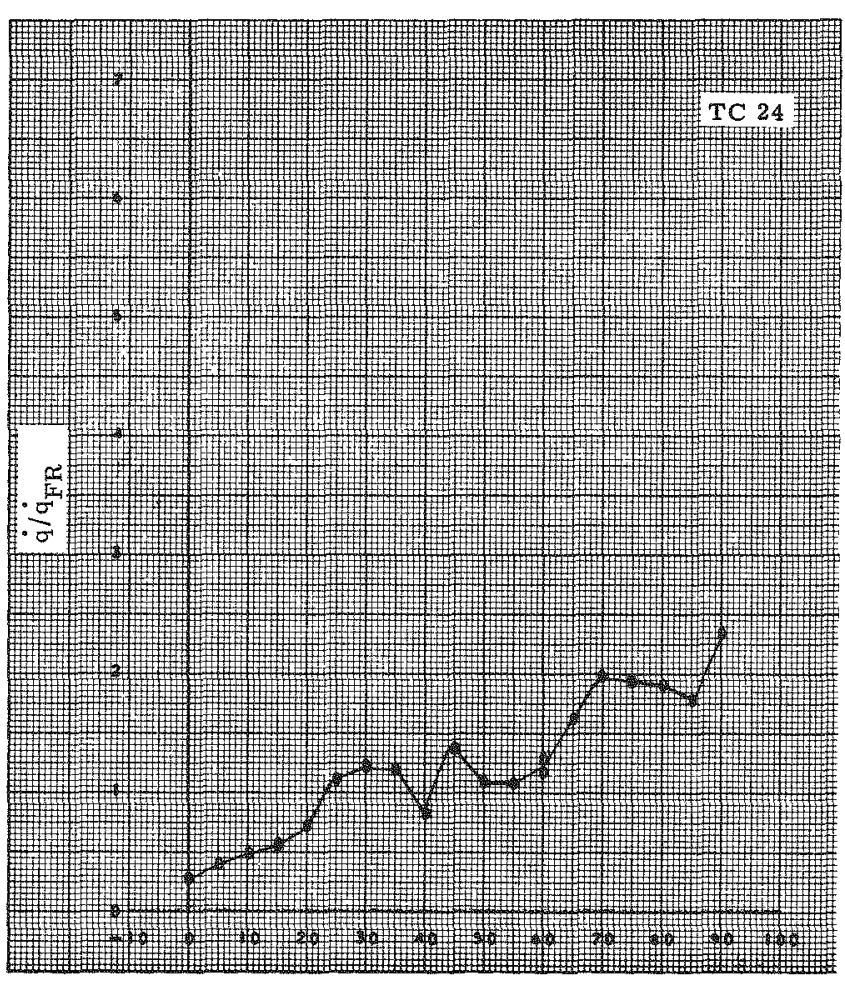

$\alpha$ (deg)

Fig. 83. Heat Transfer, TC 24 , Configuration 230

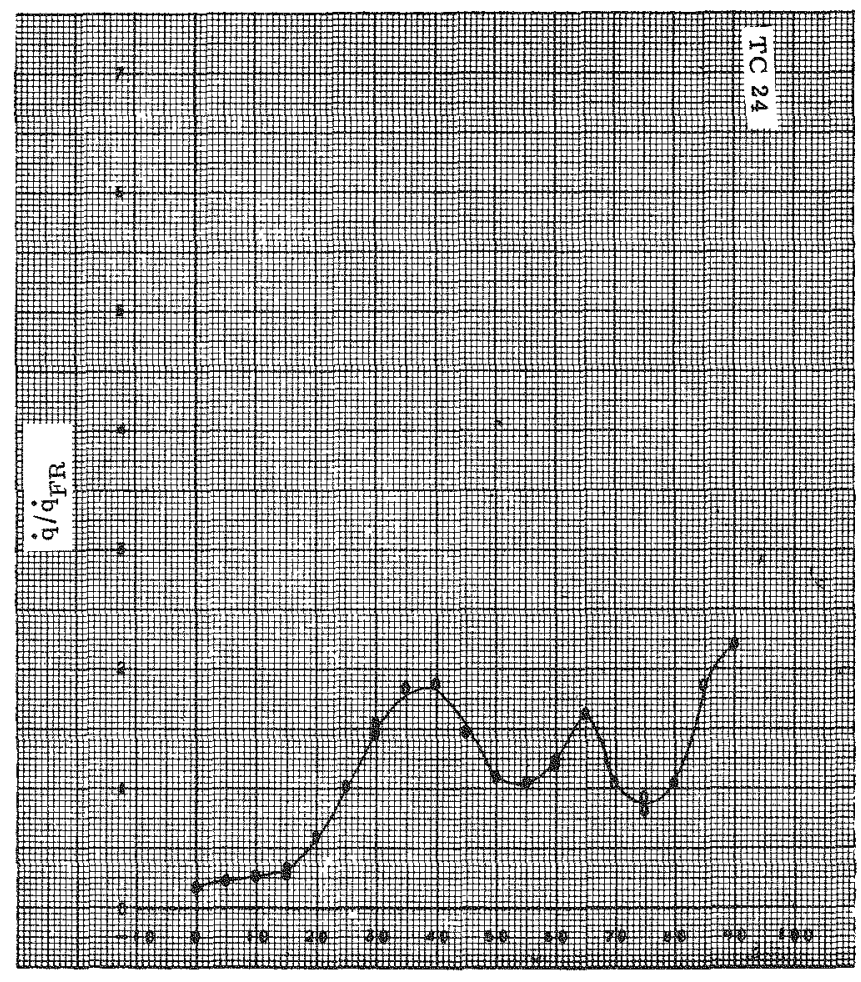

a (deg)

Fig. 84. Heat Transfer, TC 24, Configuration 330

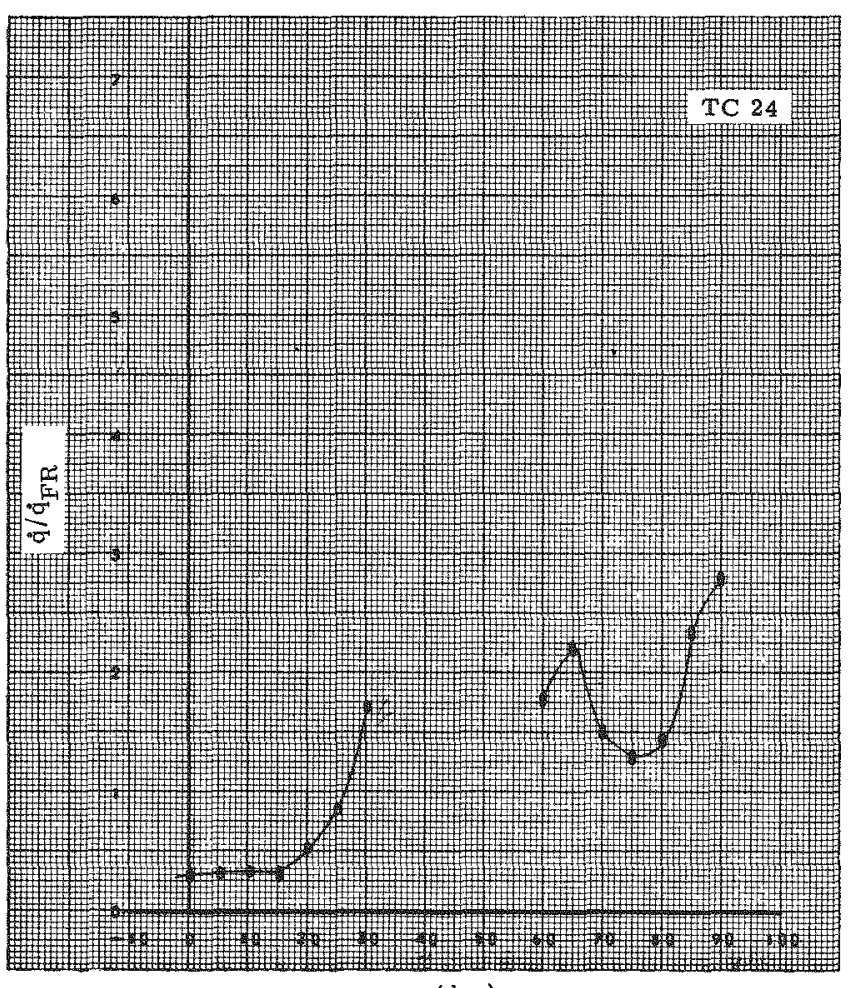

$\alpha$ (deg)

Fig. 85. Heat Transfer, TC 24, Configuration 430 


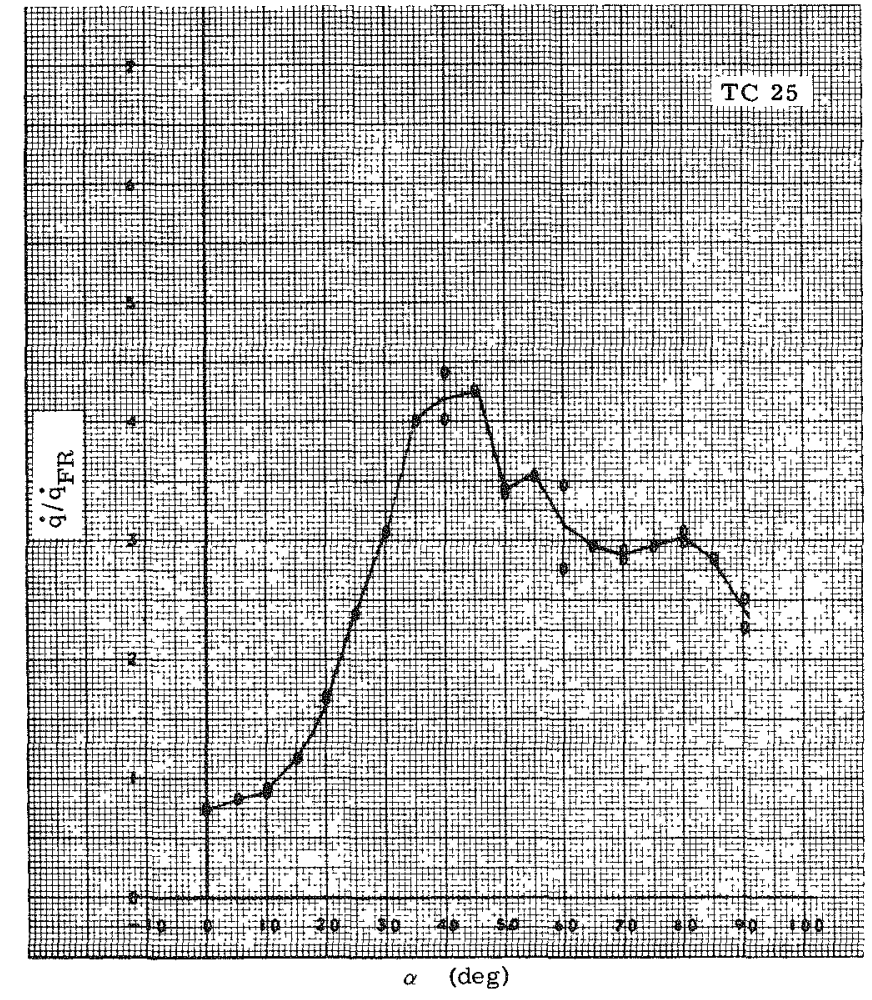

Fig. 86. Heat Transfer, TC 25, Configuration 100

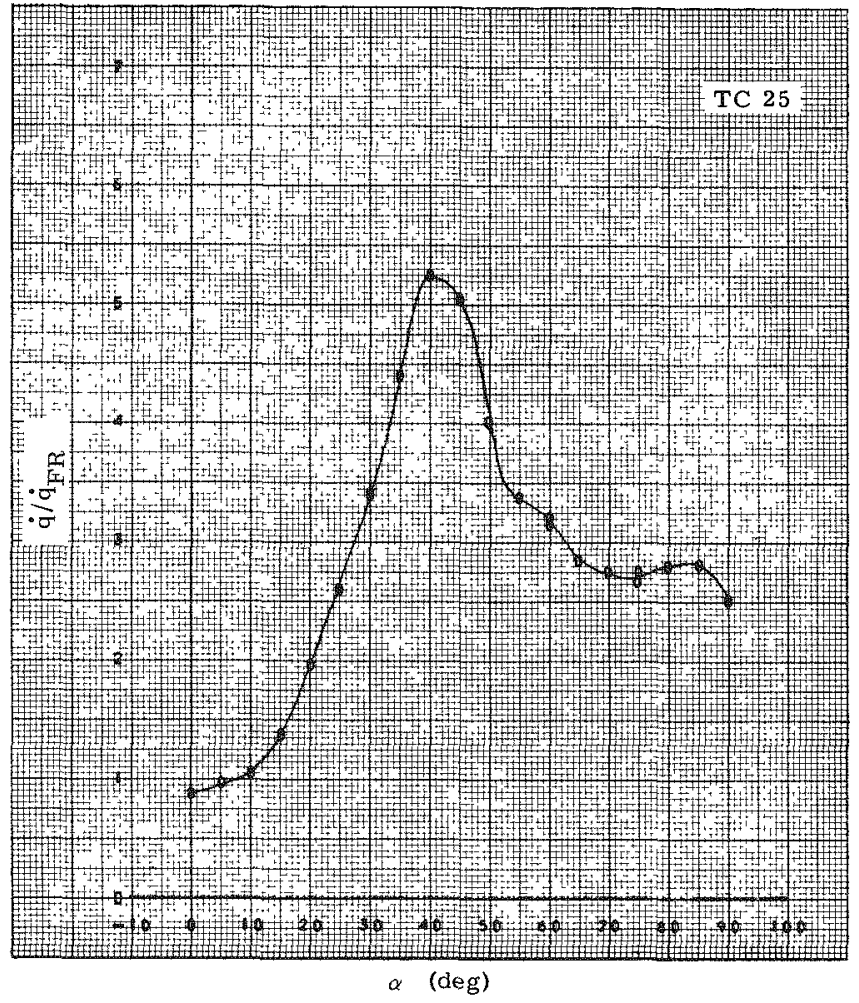

Fig. 87. Heat Transfer, TC 25, Configuration 200

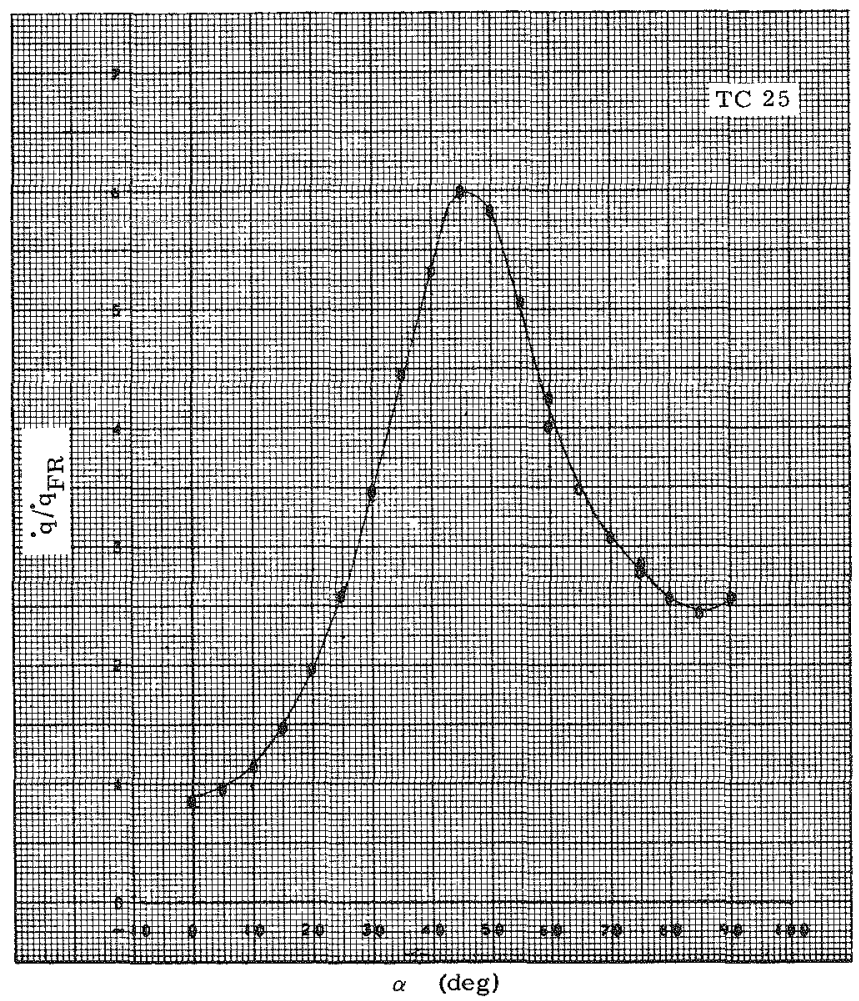

Fig. 88. Heat Transfer, TC 25, Configuration 300

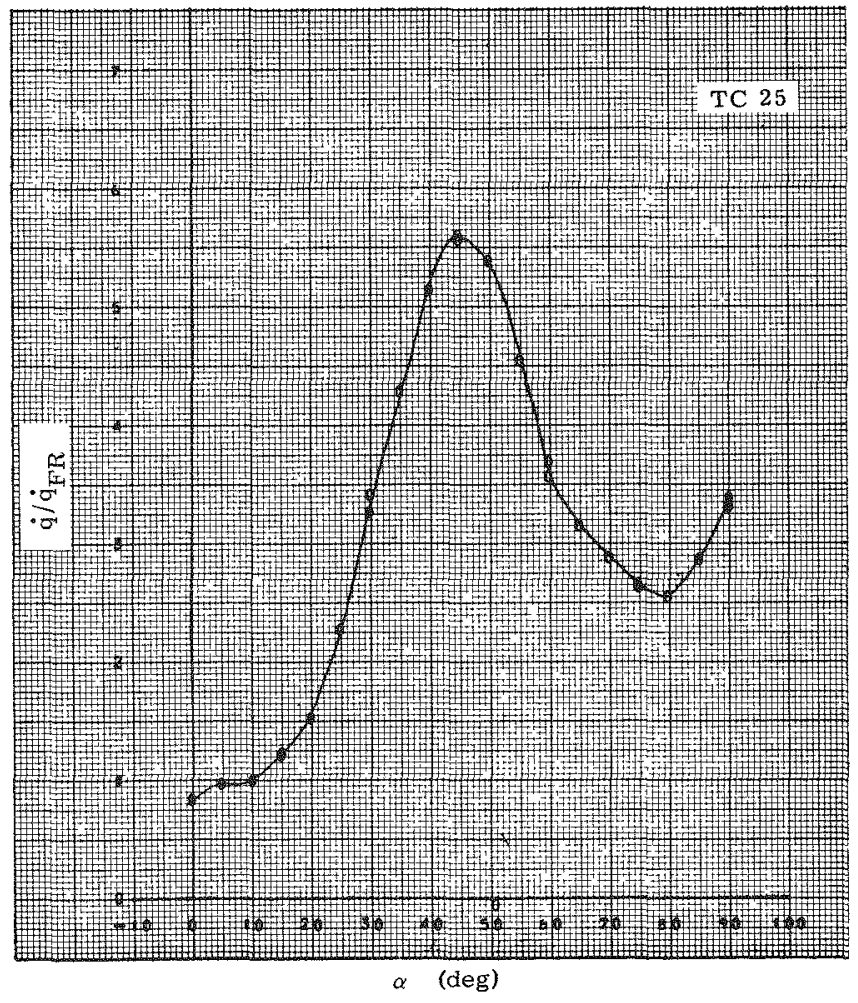

Fig. 89. Heat Transfer, TC 25, Configuration 400 


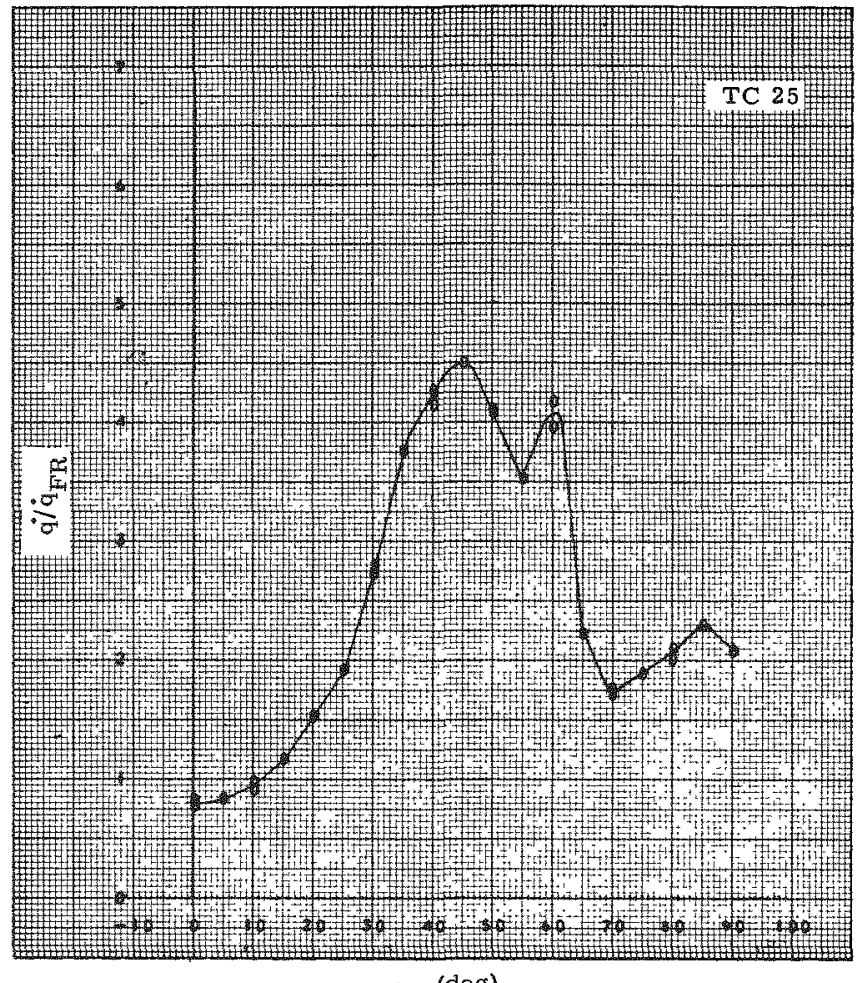

$\alpha$ (deg)

Fig. 90. Heat Transfer, TC 25, Configuration 130

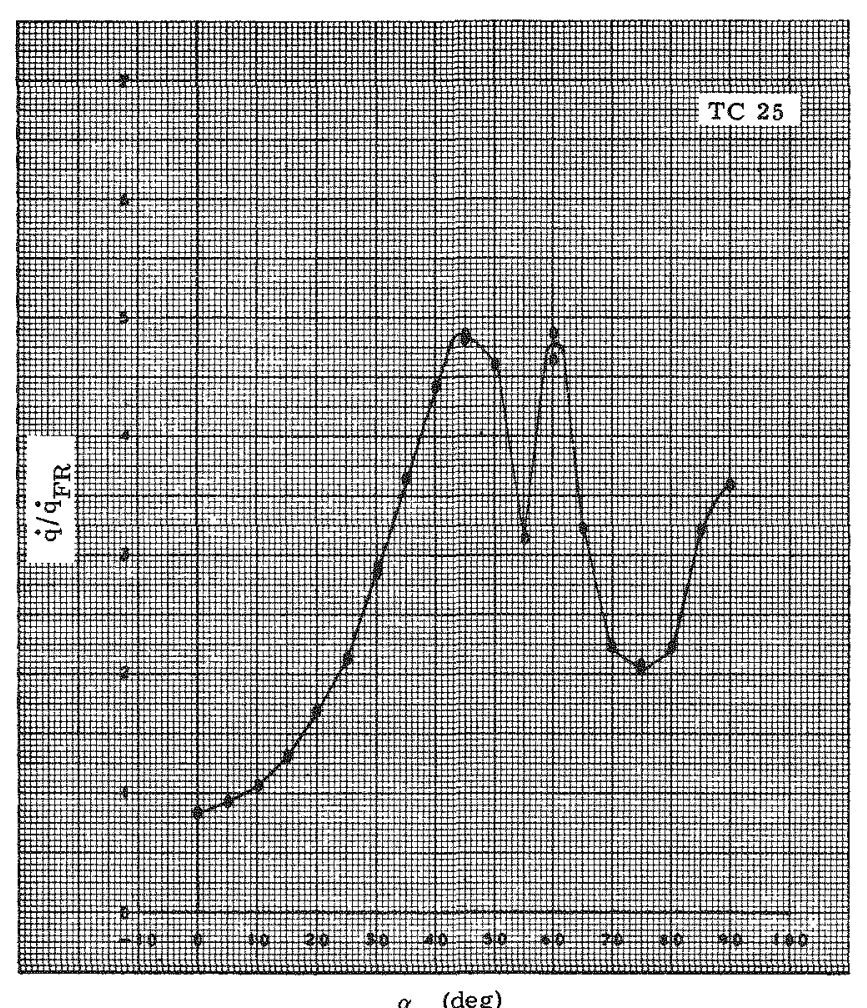

Fig. 91. Heat Transfer, TC 25, Configuration 230

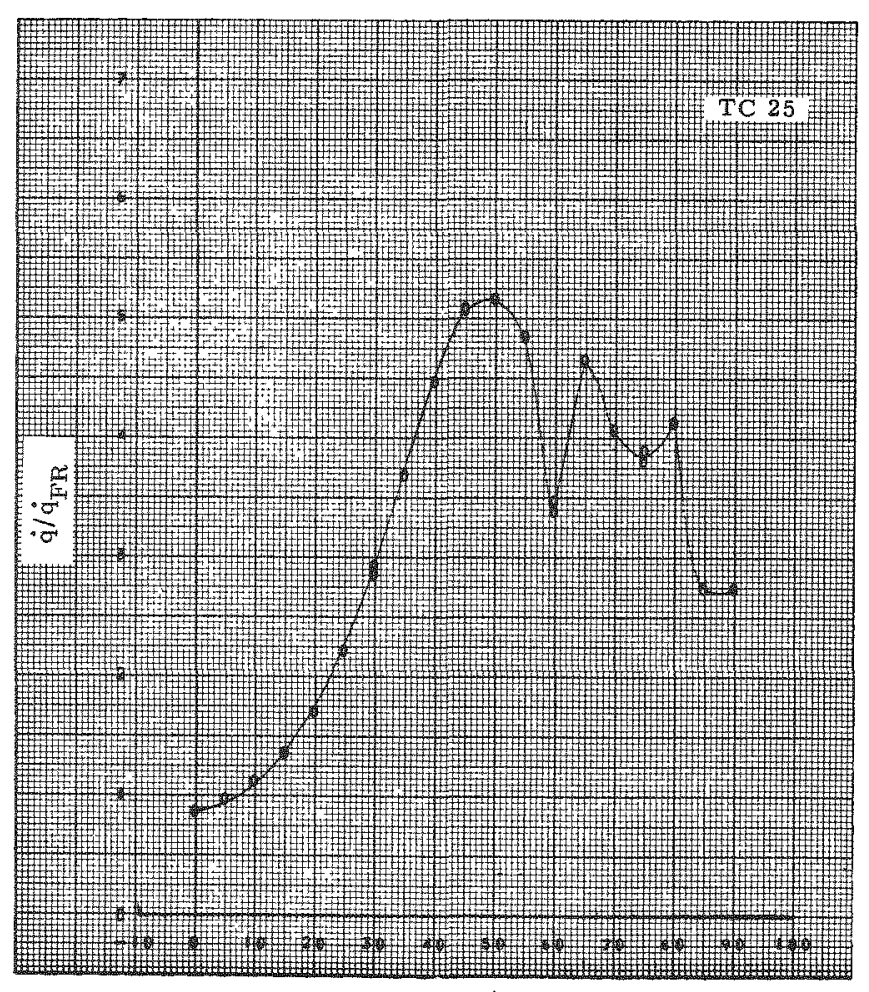

$\alpha \quad(\operatorname{deg})$

Fig. 92. Heat Transfer, TC 25, Configuration 330

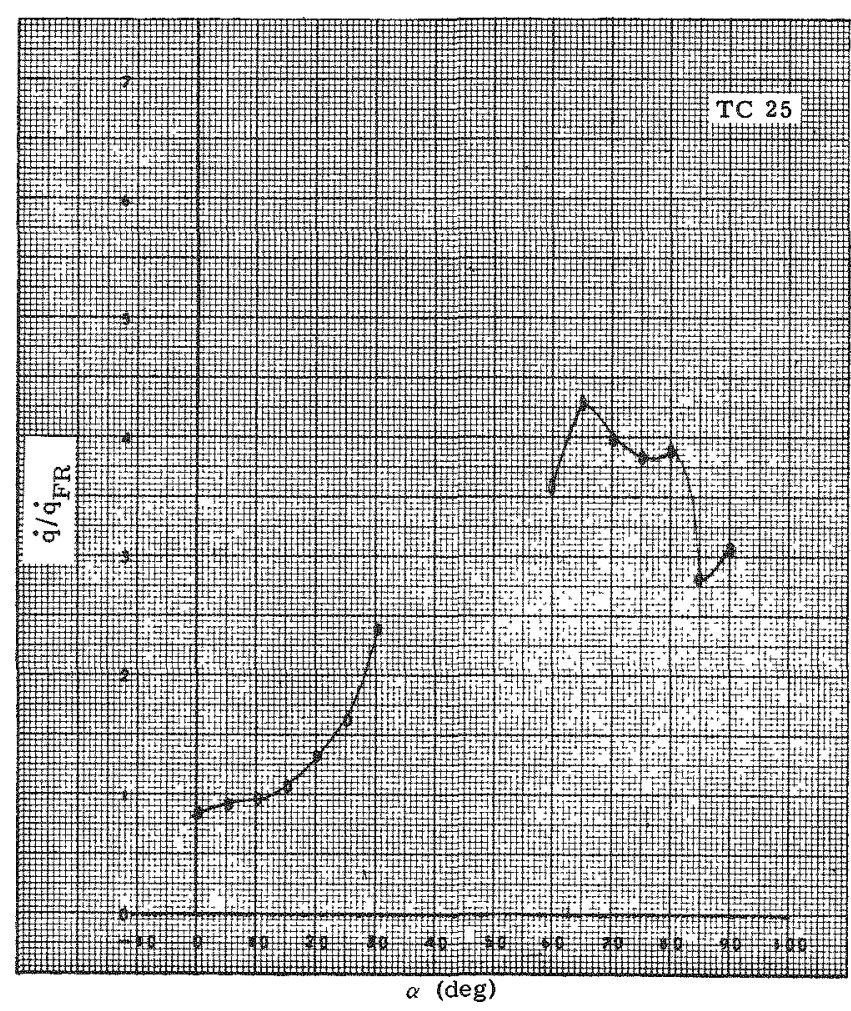

Fig. 93. Heat Transfer, TC 25, Configuration 430 


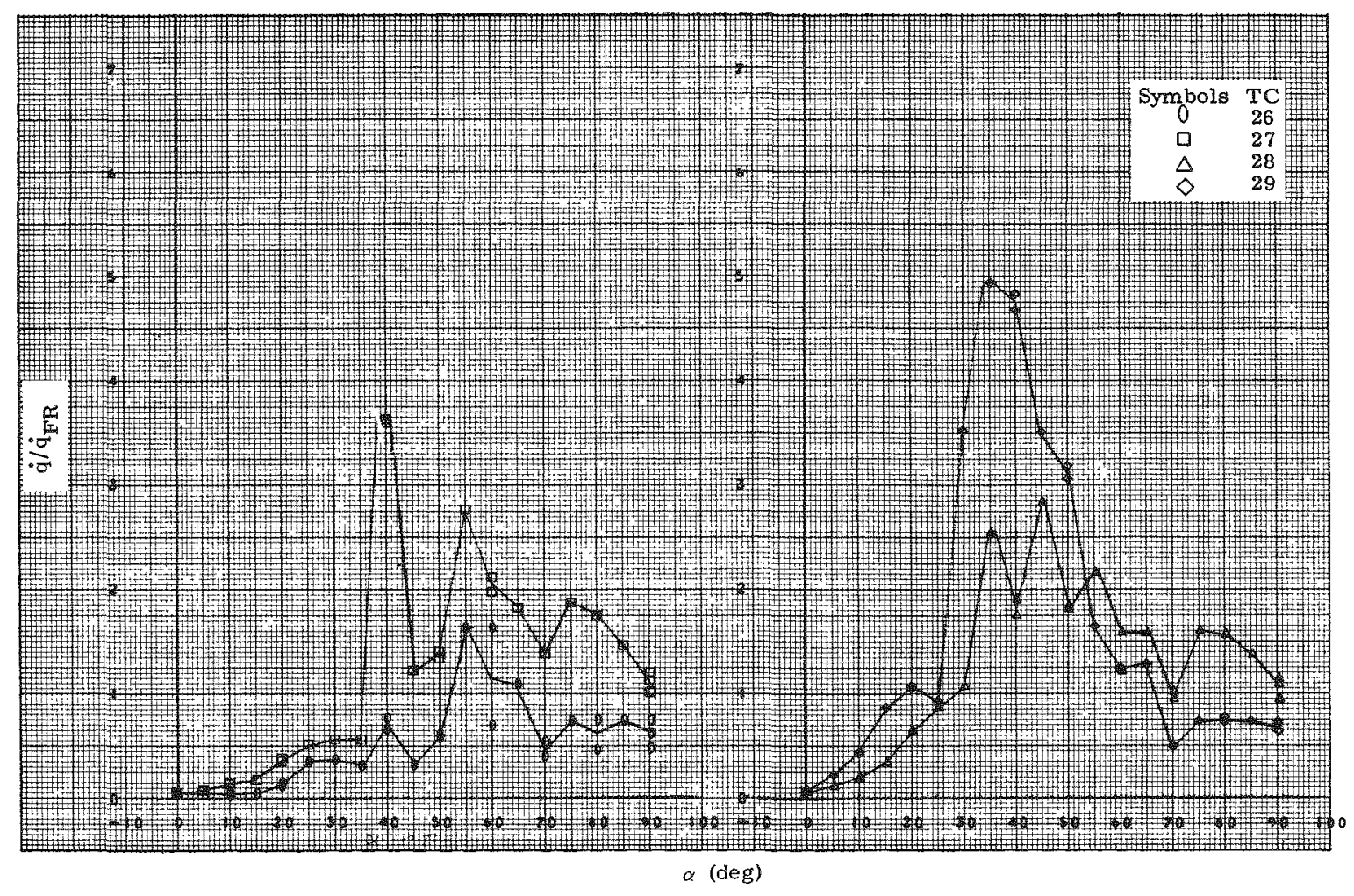

Fig. 94. Heat Transfer, TC $26-29$, Configuration 100

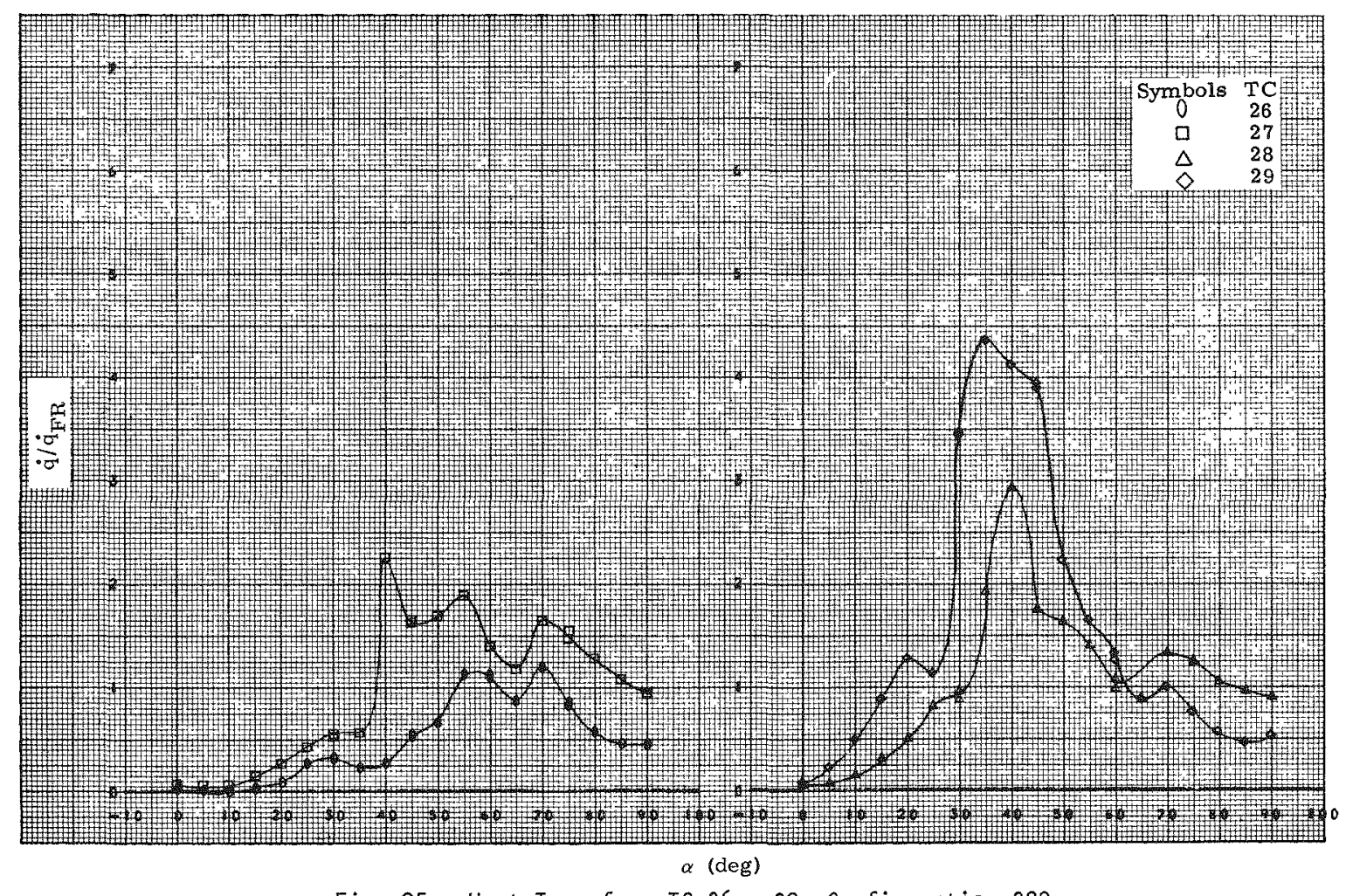

Fig. 95. Heat Transfer, TC $26-29$, Configuration 200 


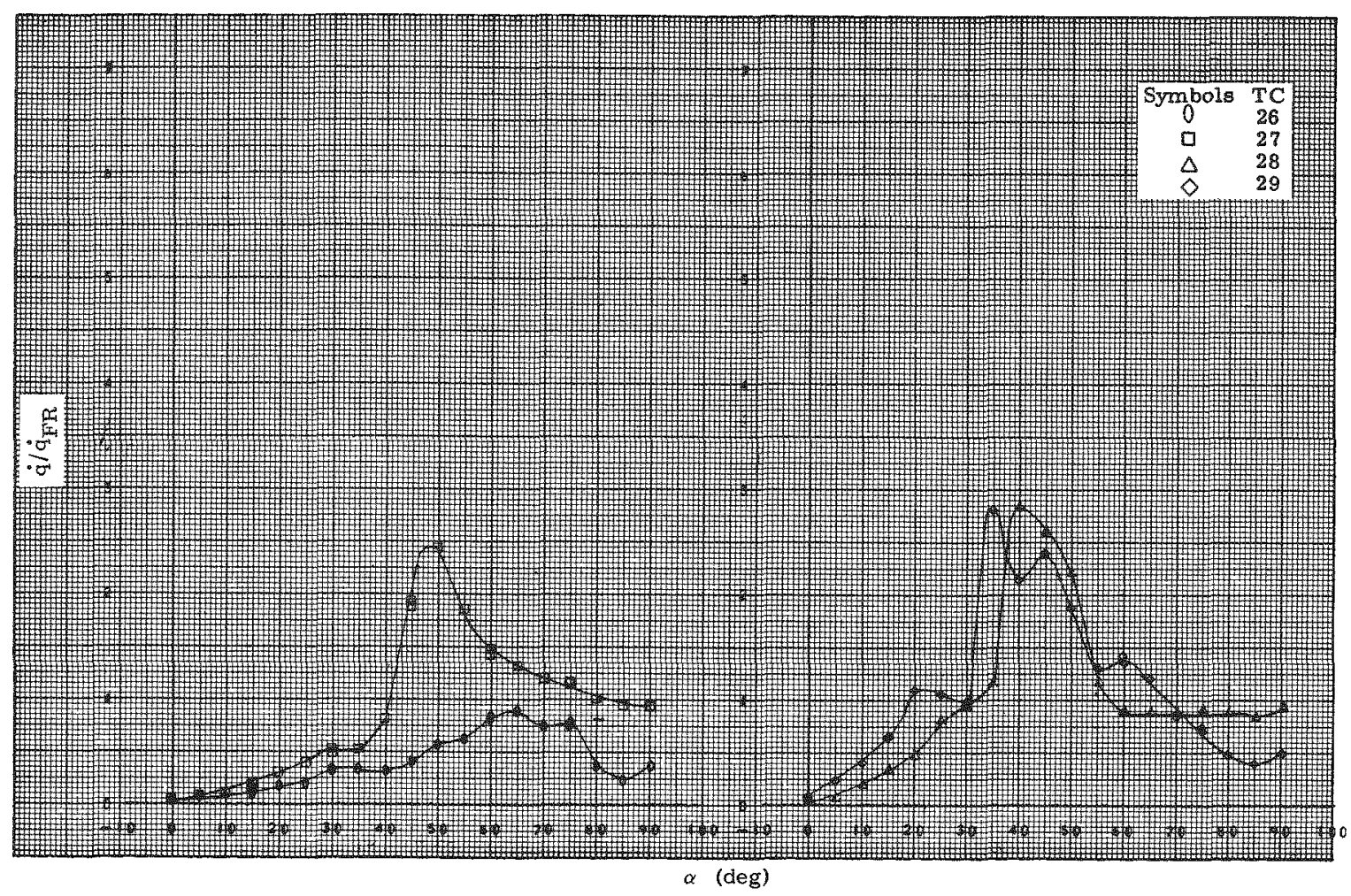

Fig. 96. Heat Transfer, TC $26-29$, Configuration 300

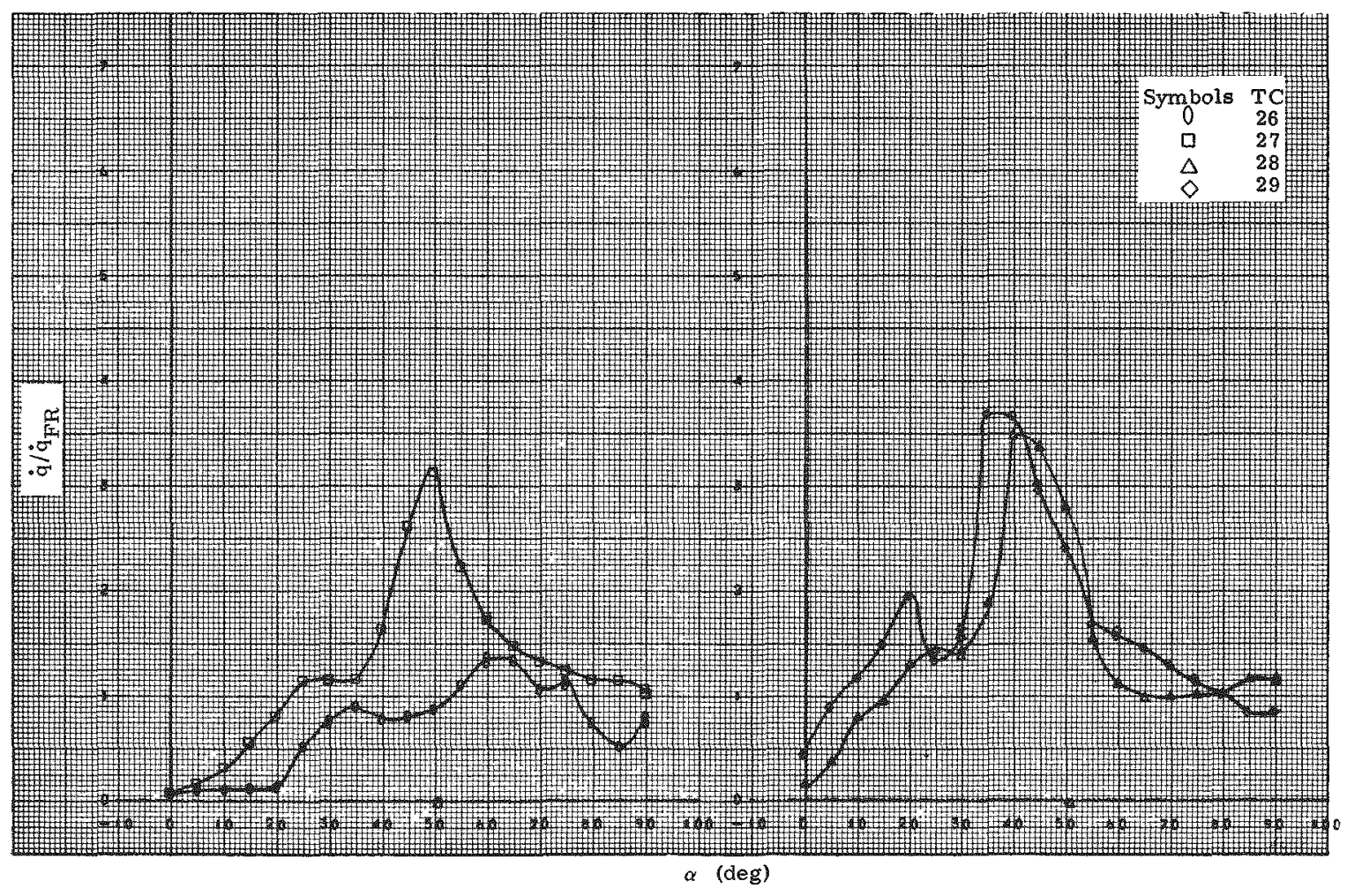

Fig. 97. Heat Transfer, TC $26-29$, Configuration 400 

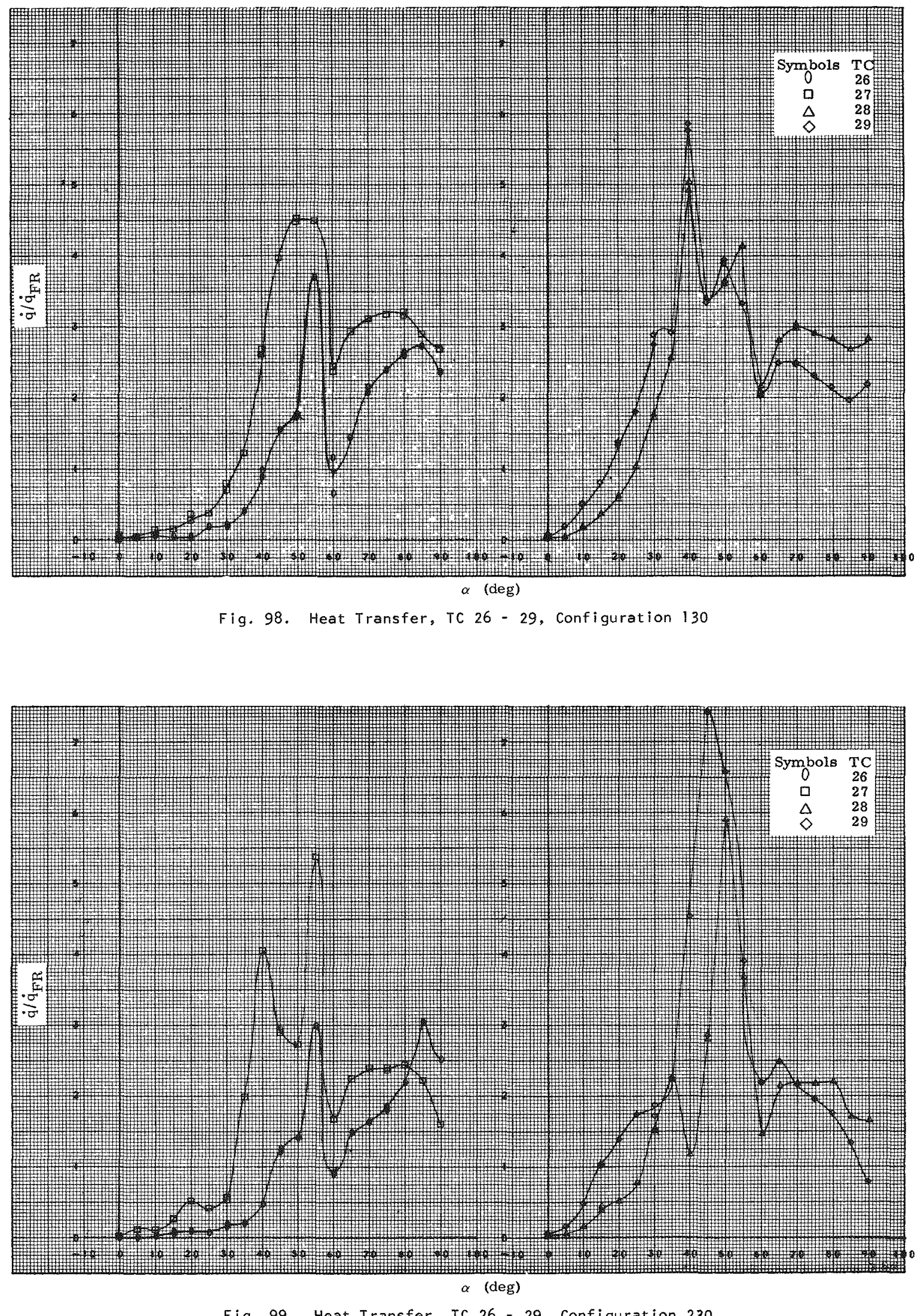

Fig. 99. Heat Transfer, TC $26-29$, Configuration 230 


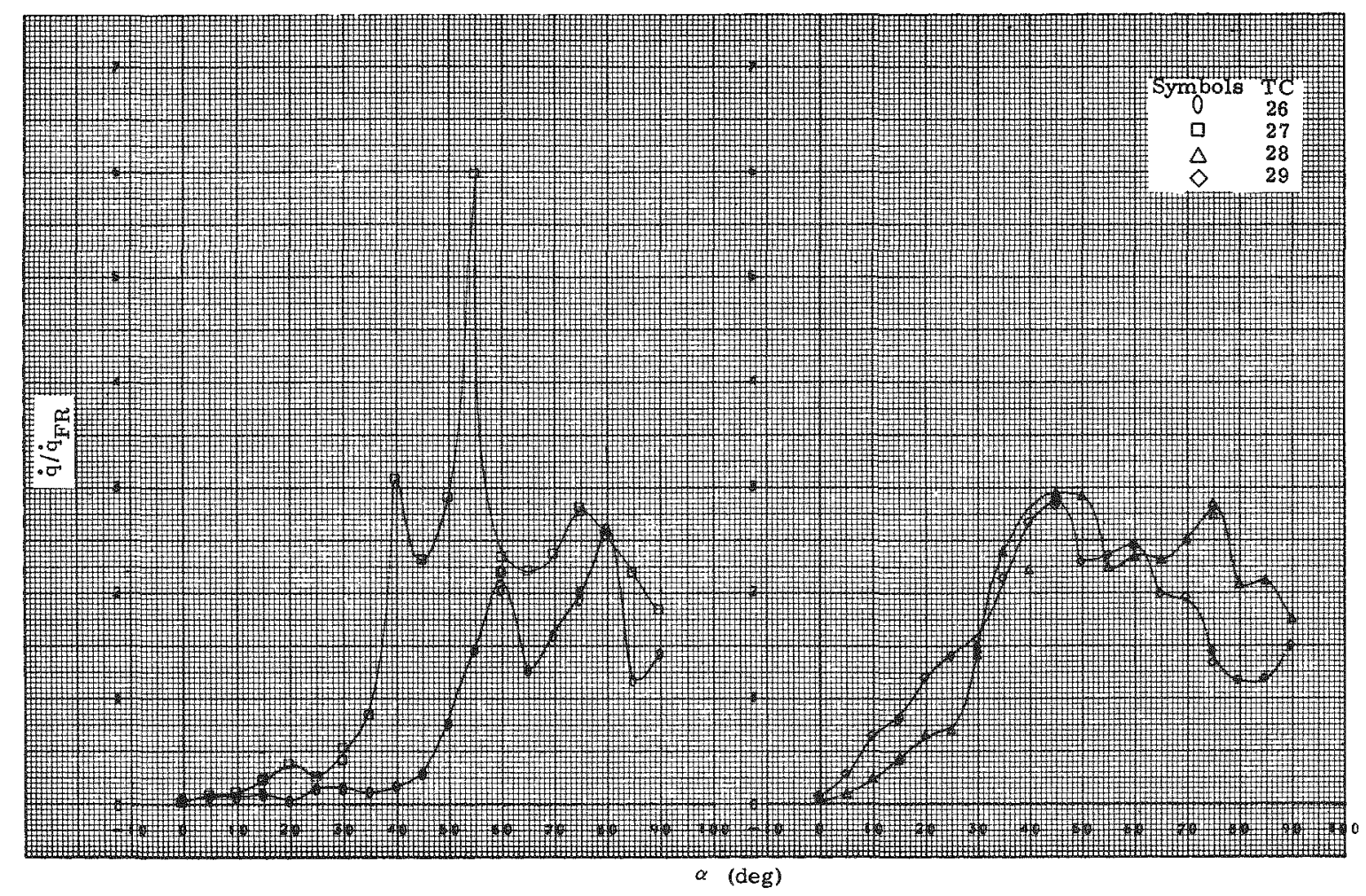

Fig. 100. Heat Transfer, TC 26 -29, Configuration 330

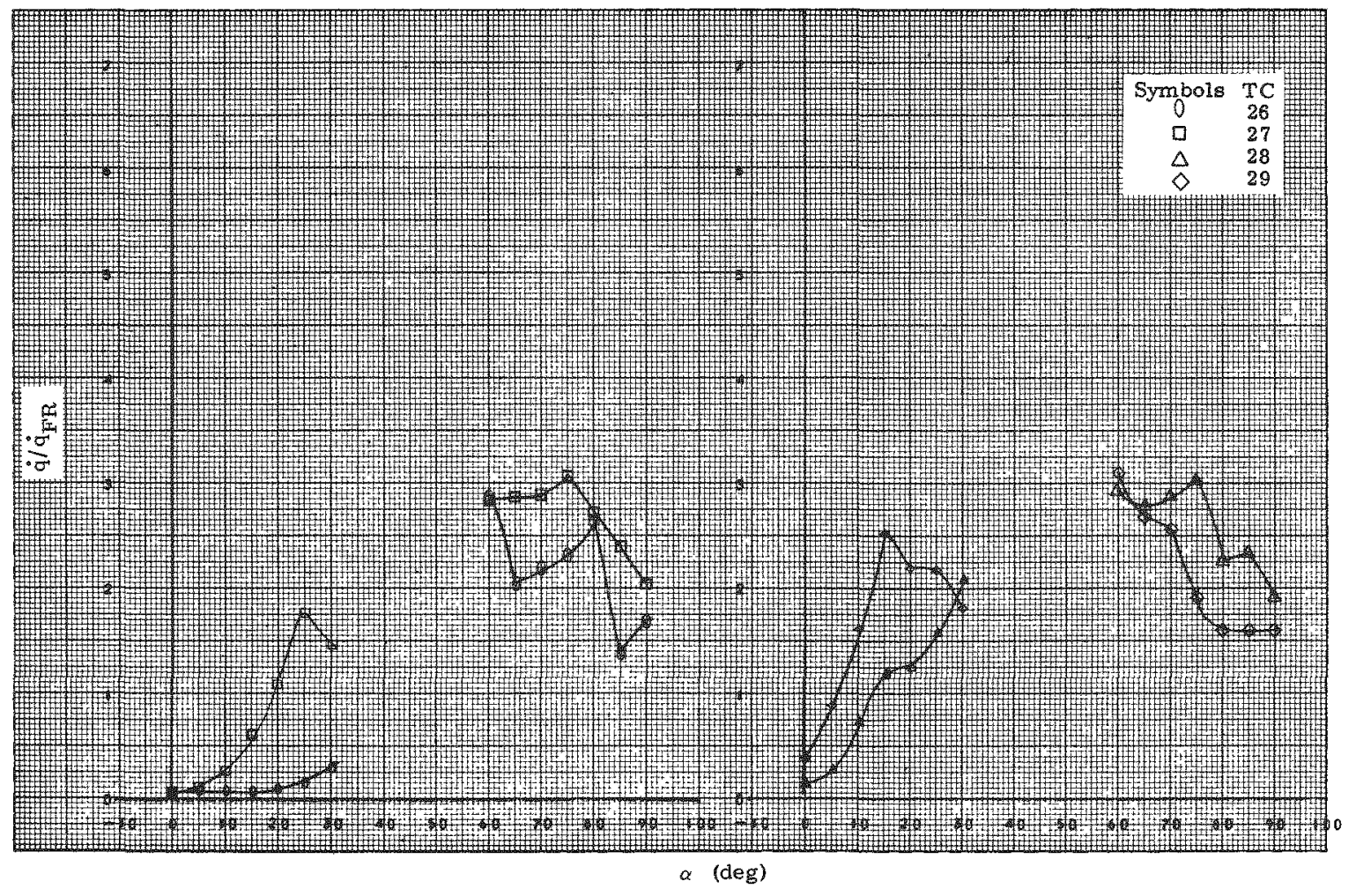

Fig. 101. Heat Transfer, TC $26-29$, Configuration 430 


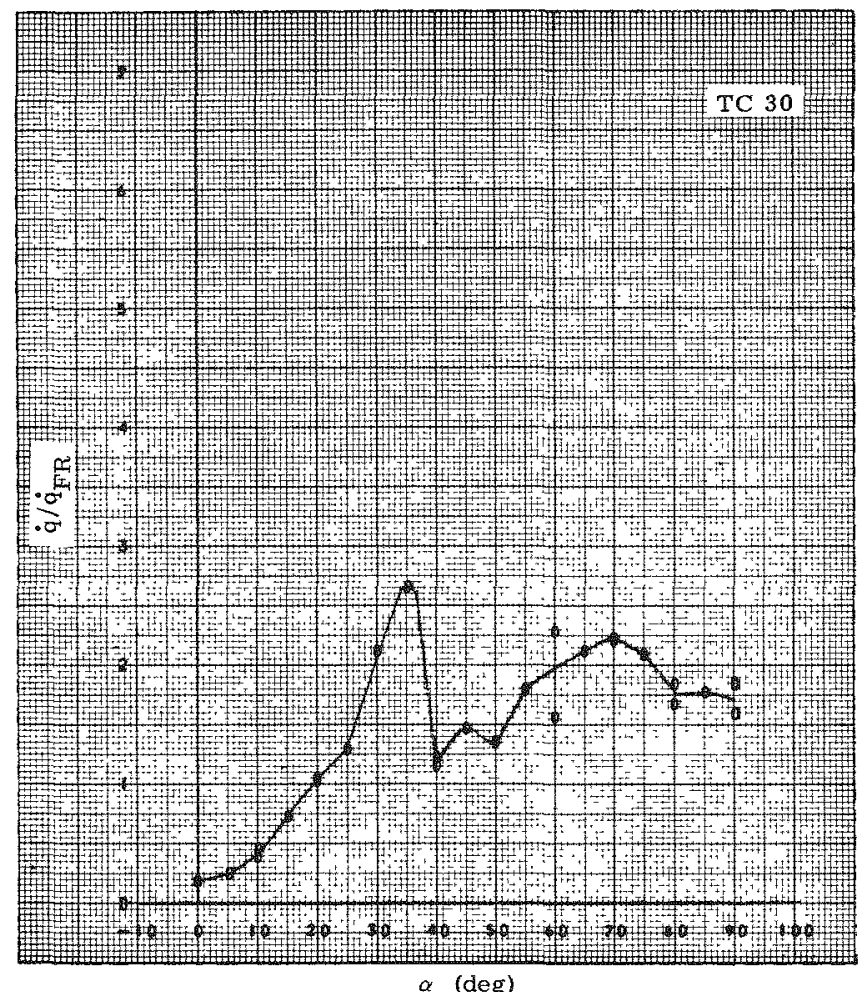

Fig. 102. Heat Transfer, TC 30 , Configuration 100

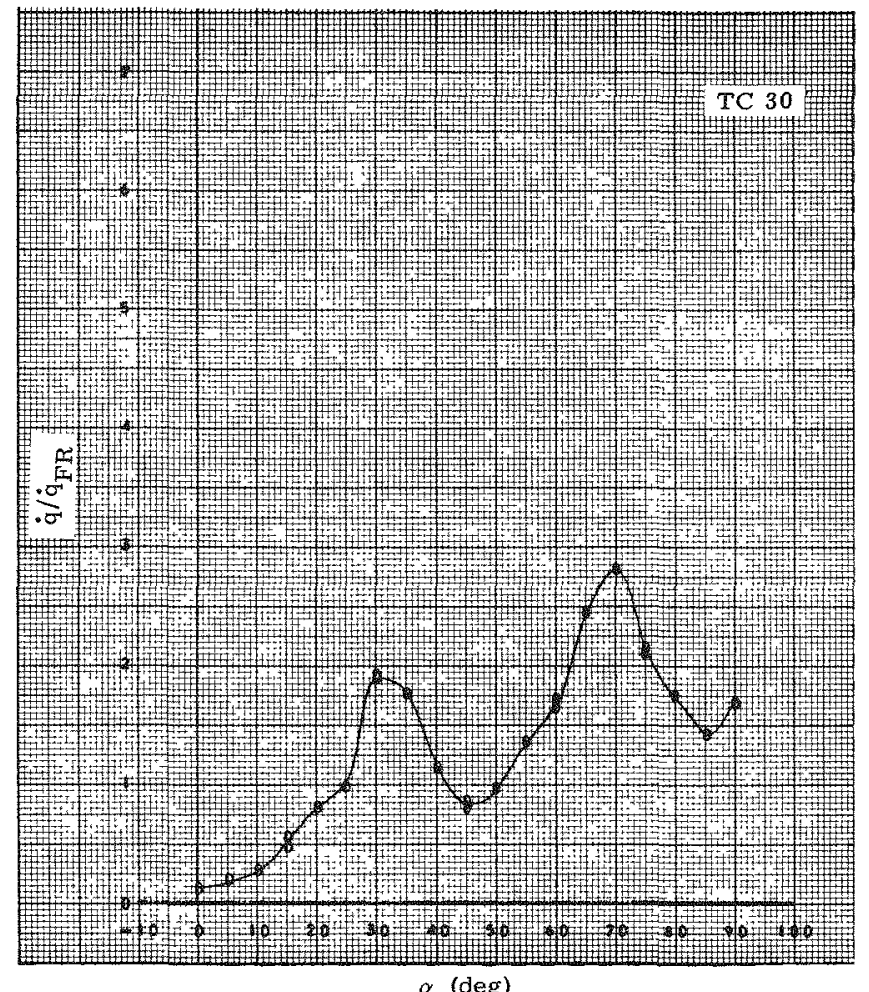

Fig. 103. Heat Transfer, TC 30, Configuration 200

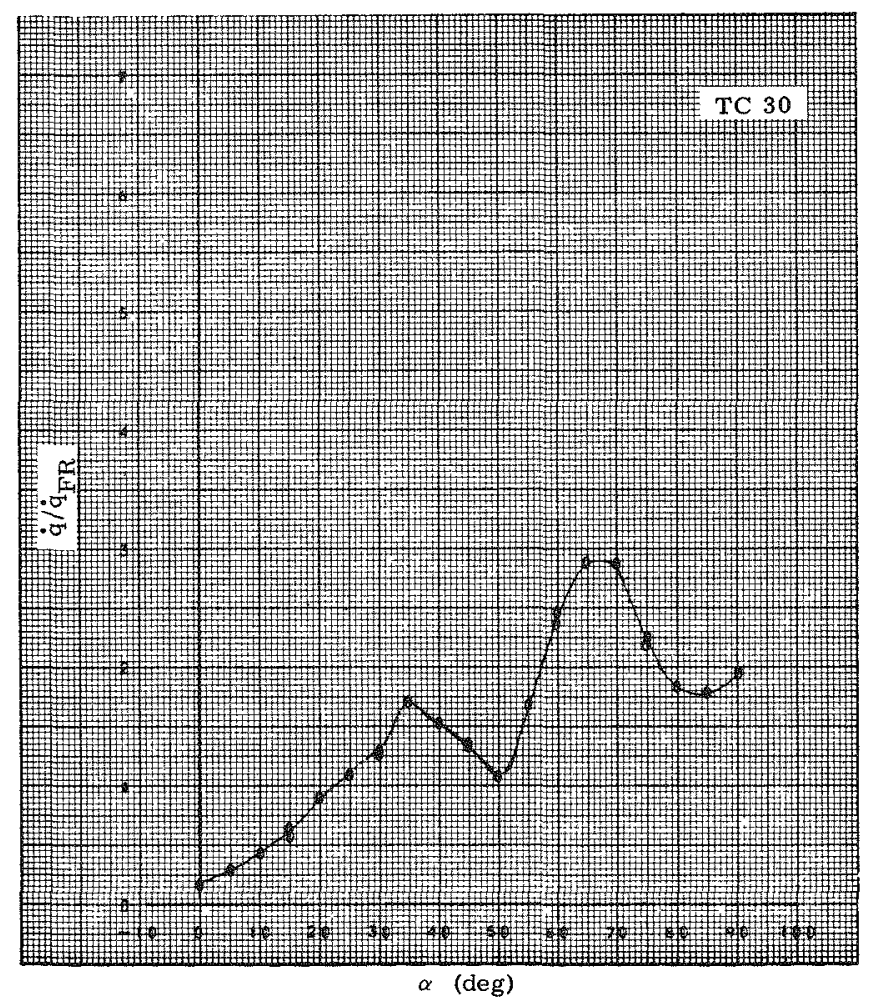

Fig. 104. Heat Transfer, TC 30 , Configuration 300

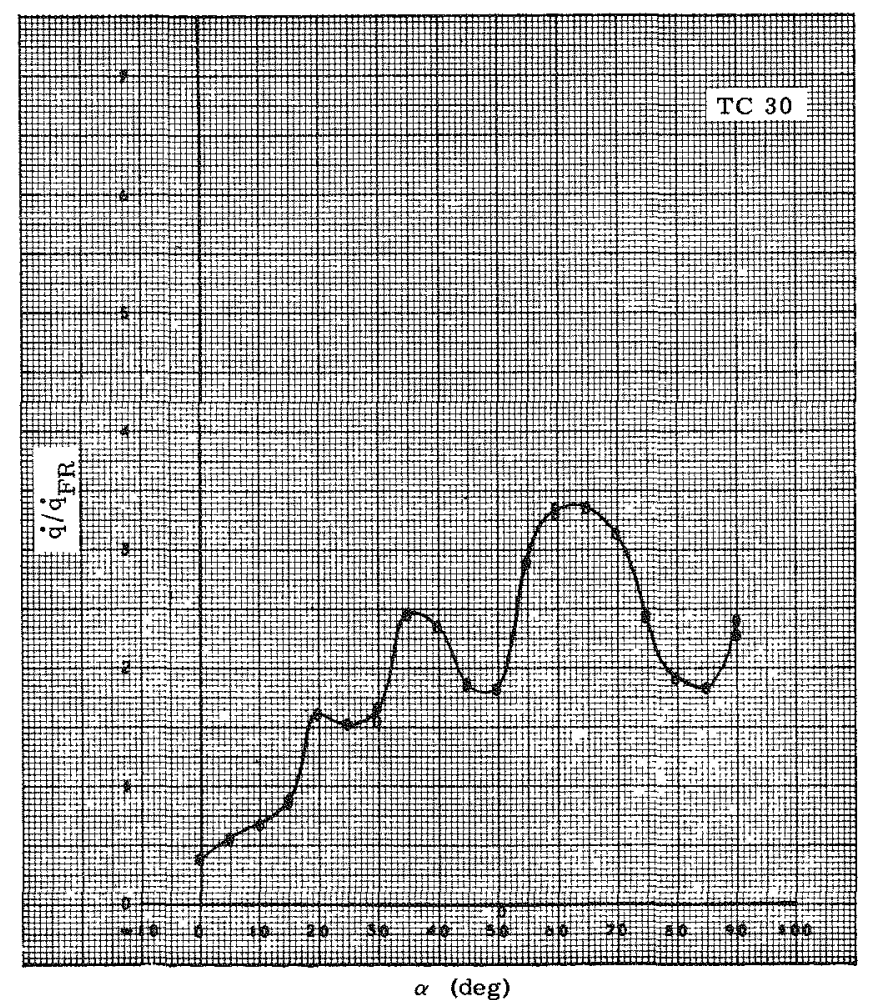

Fig. 105. Heat Transfer, TC 30, Configuration 400 


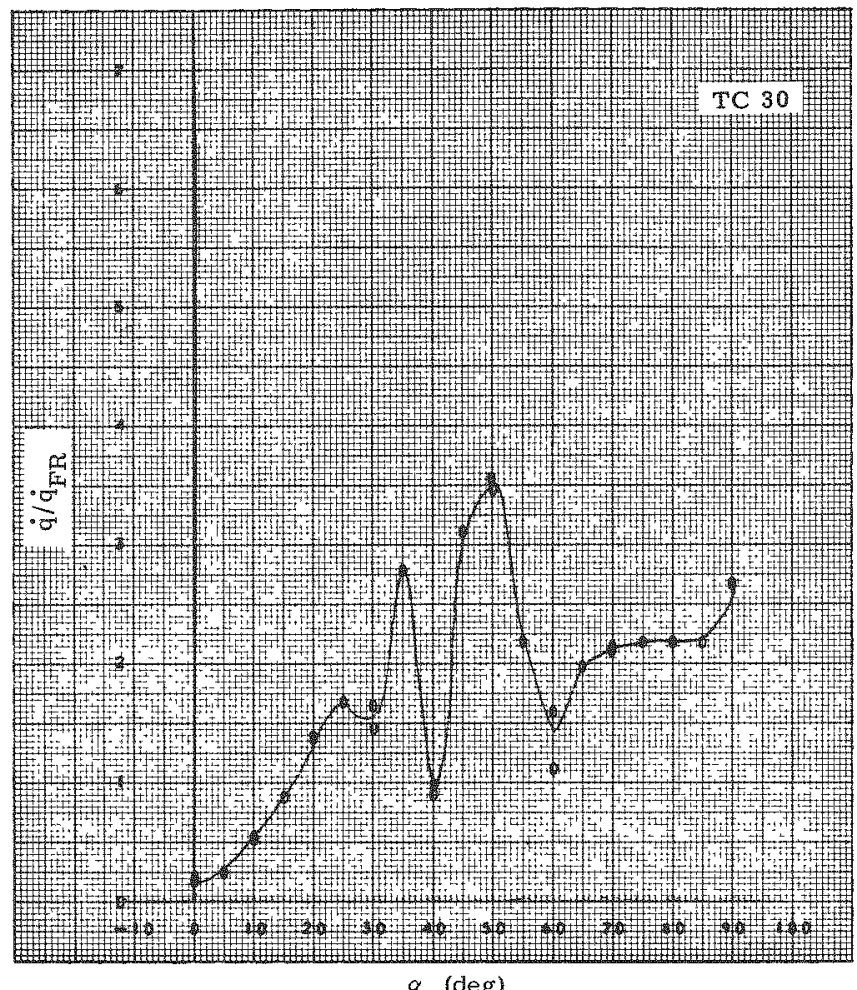

Fig. 106. Heat Transfer, TC 30 , Configuration 130

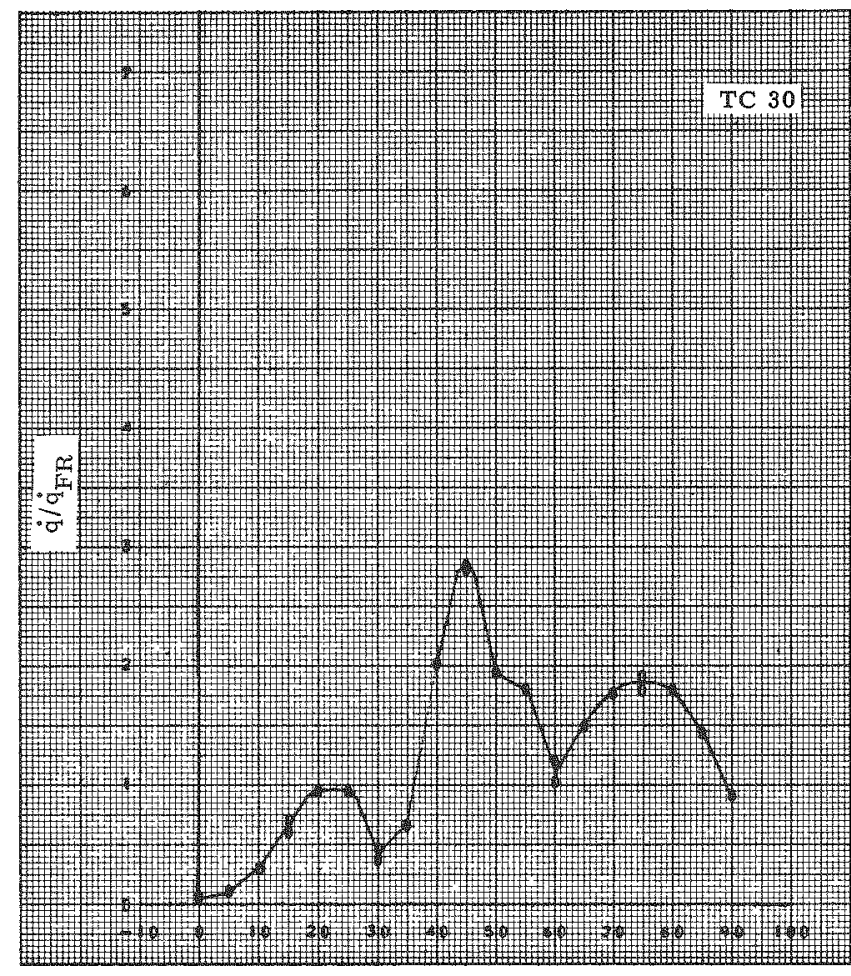

$\alpha$ (deg)

Fig. 107. Heat Transfer, TC 30 , Configuration 230

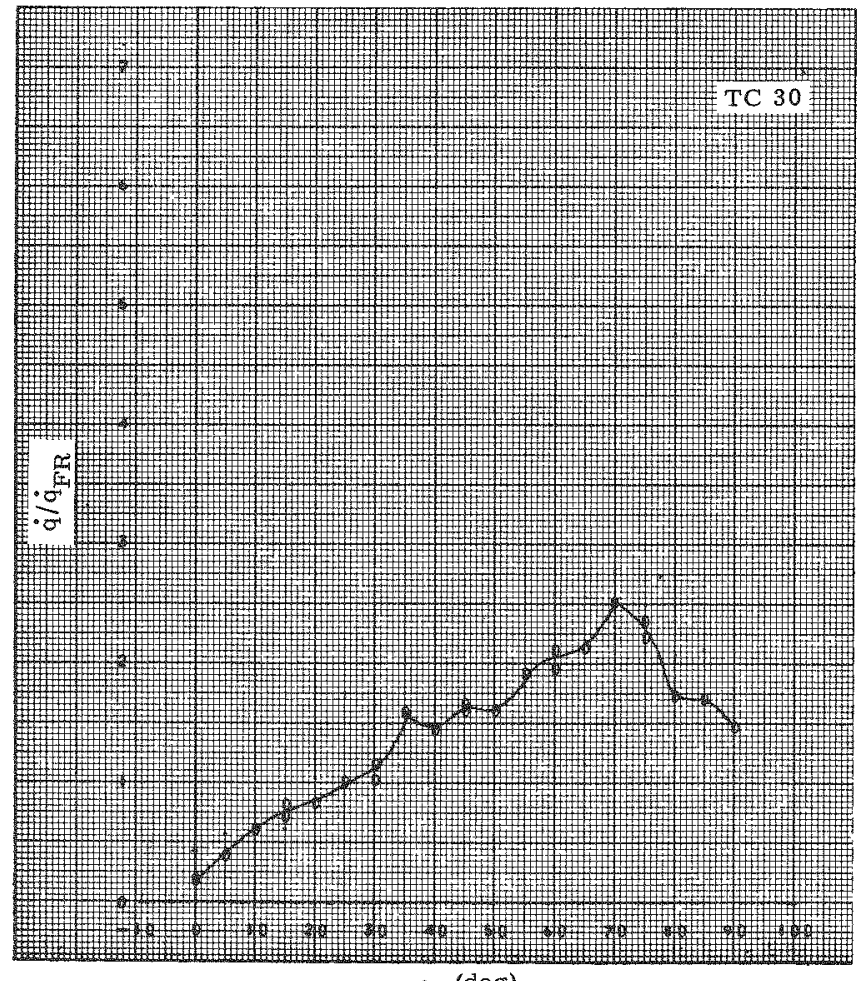

$\alpha$ (deg)

Fig. 108. Heat Transfer, TC 30 , Configuration 330

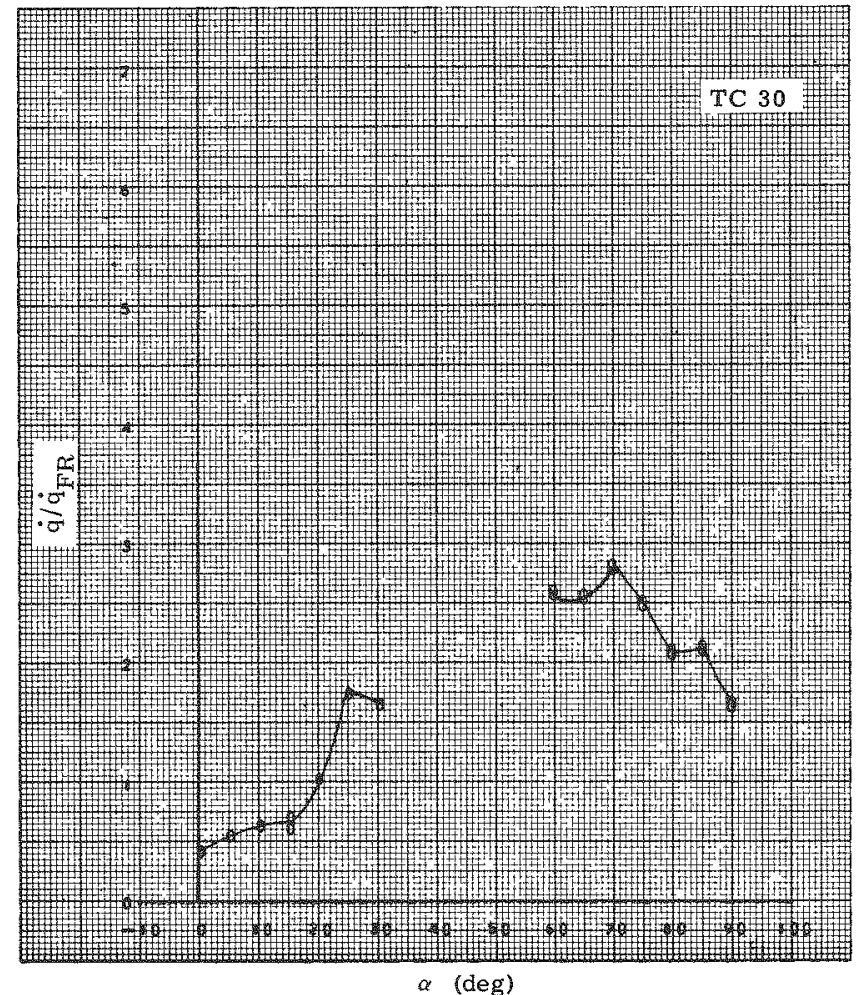

Fig. 109. Heat Transfer, TC 30 , Configuration 430 


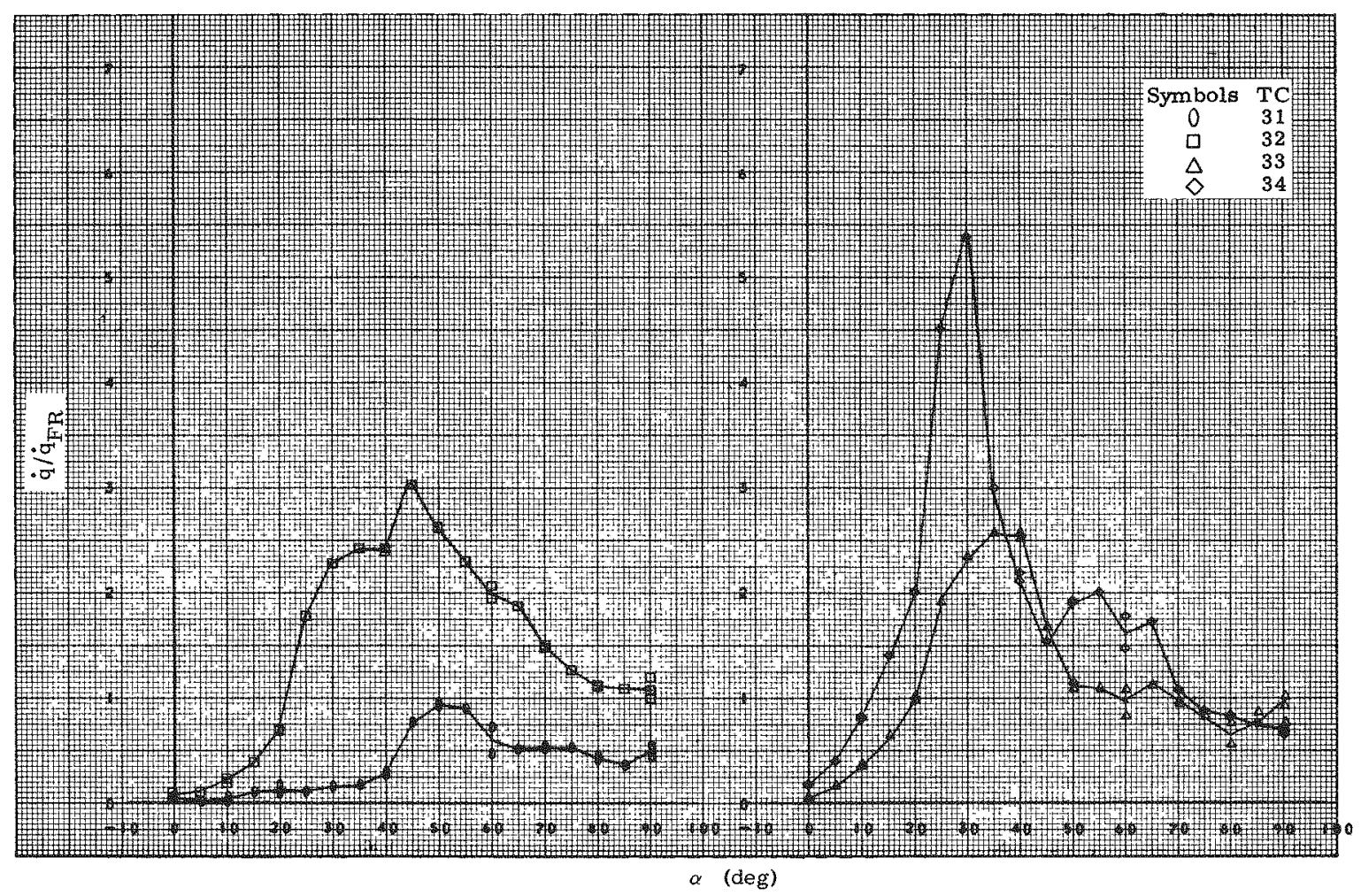

Fig. 110. Heat Transfer, TC $31-34$, Configuration 100

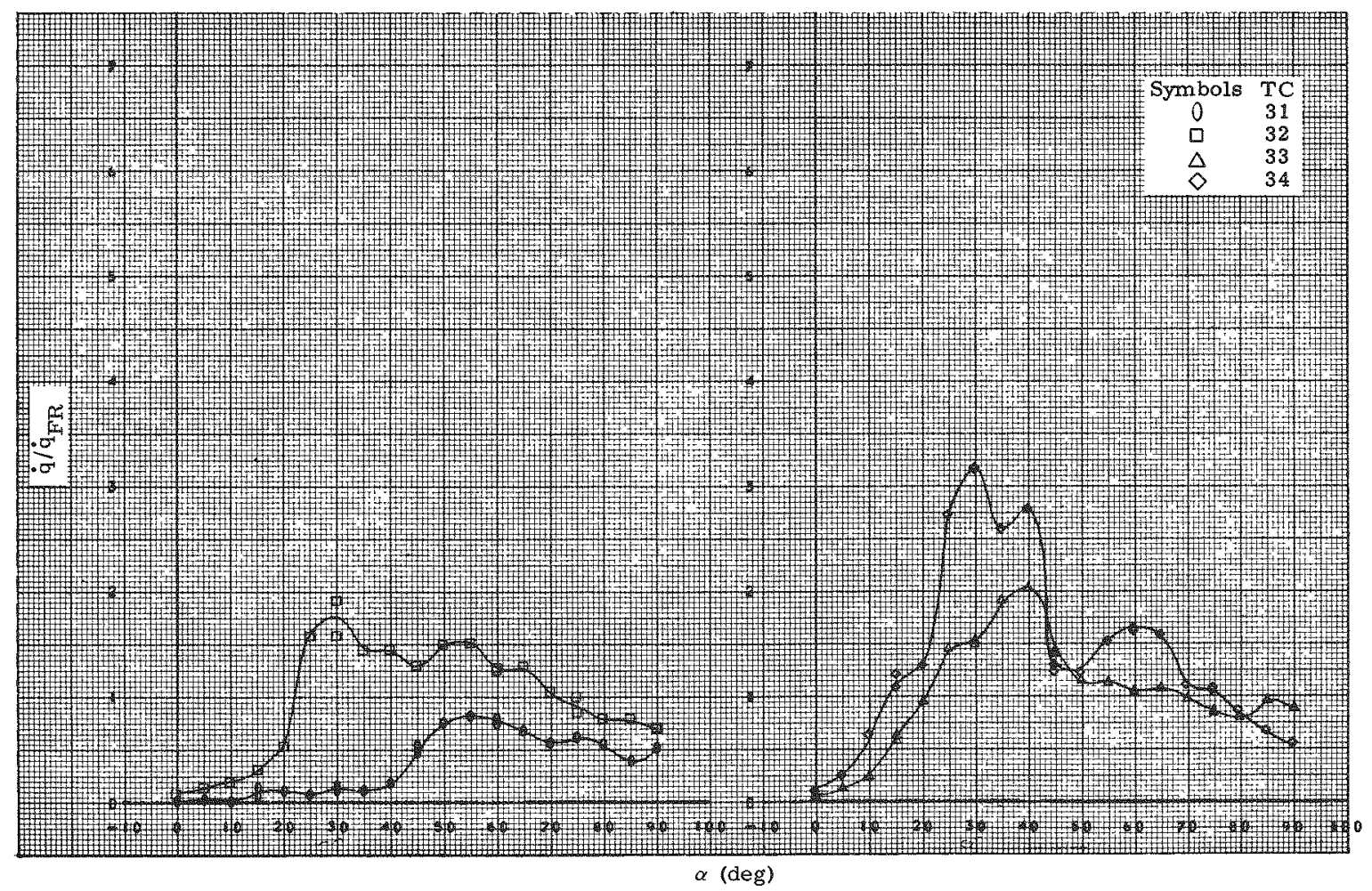

Fig. 111. Heat Transfer, TC $31-34$, Configuration 200 


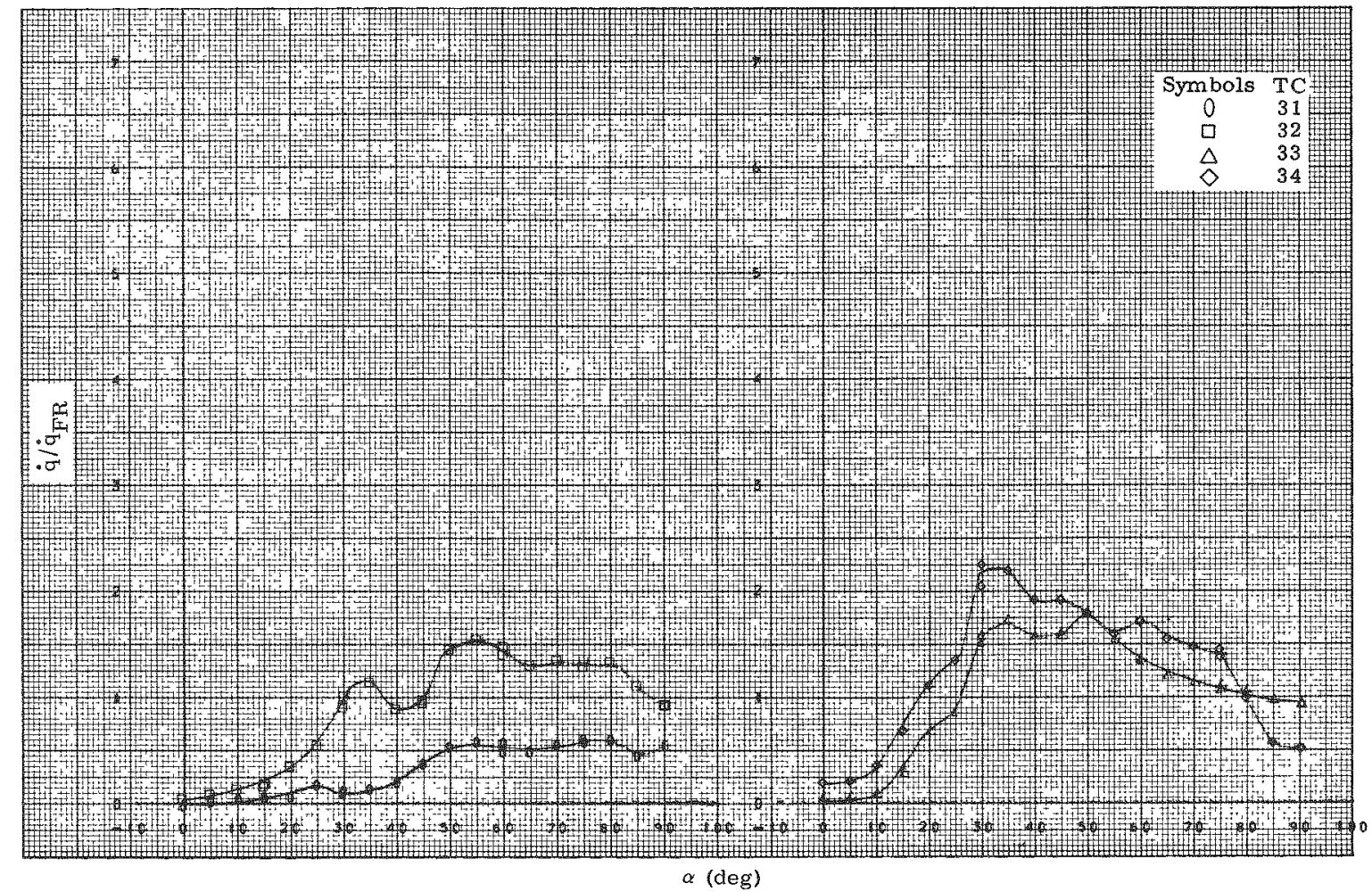

Fig. 112. Heat Transfer, TC $31-34$, Configuration 300

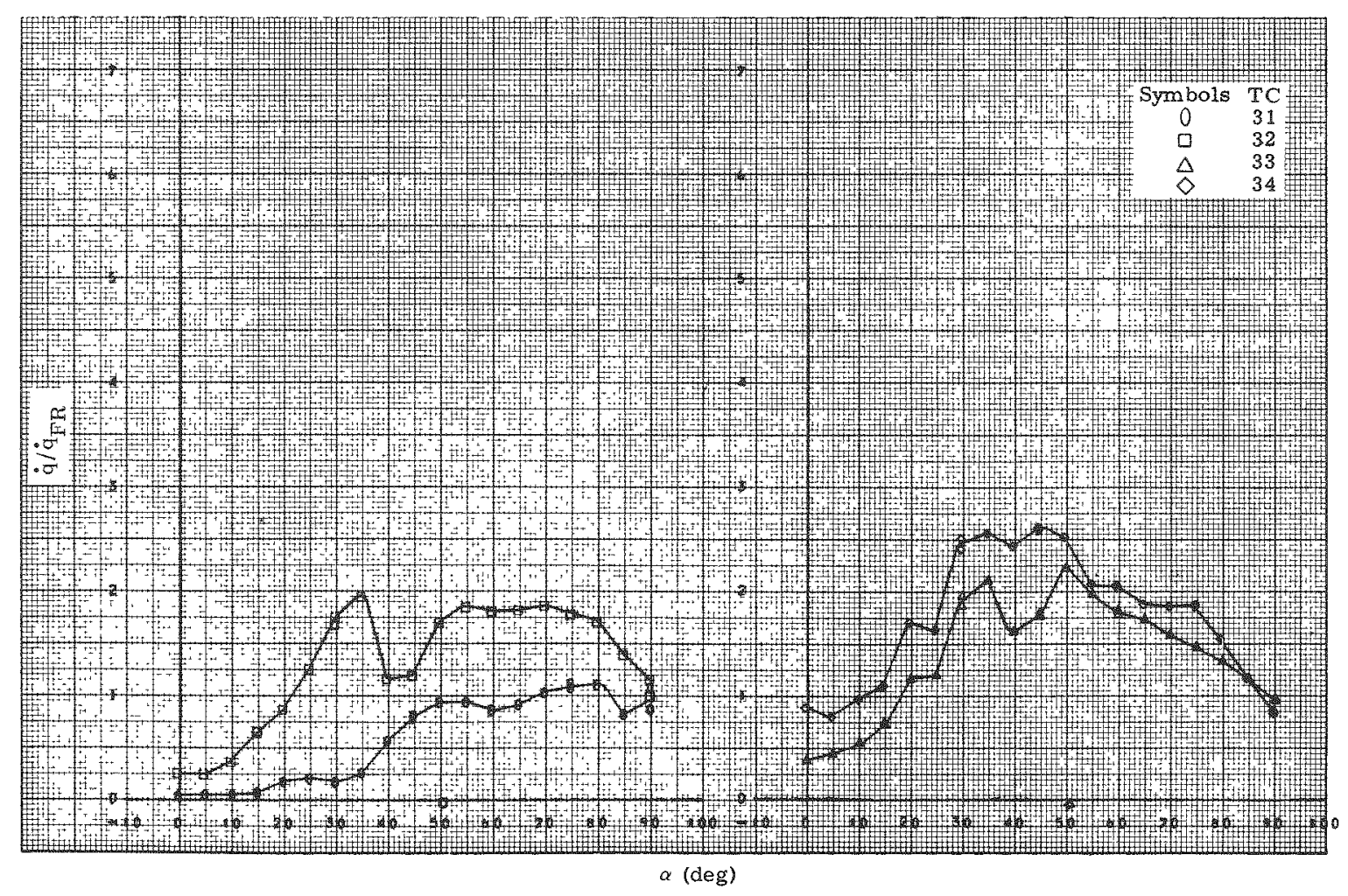

Fig. 113. Heat Transfer, TC $31-34$, Configuration 400 

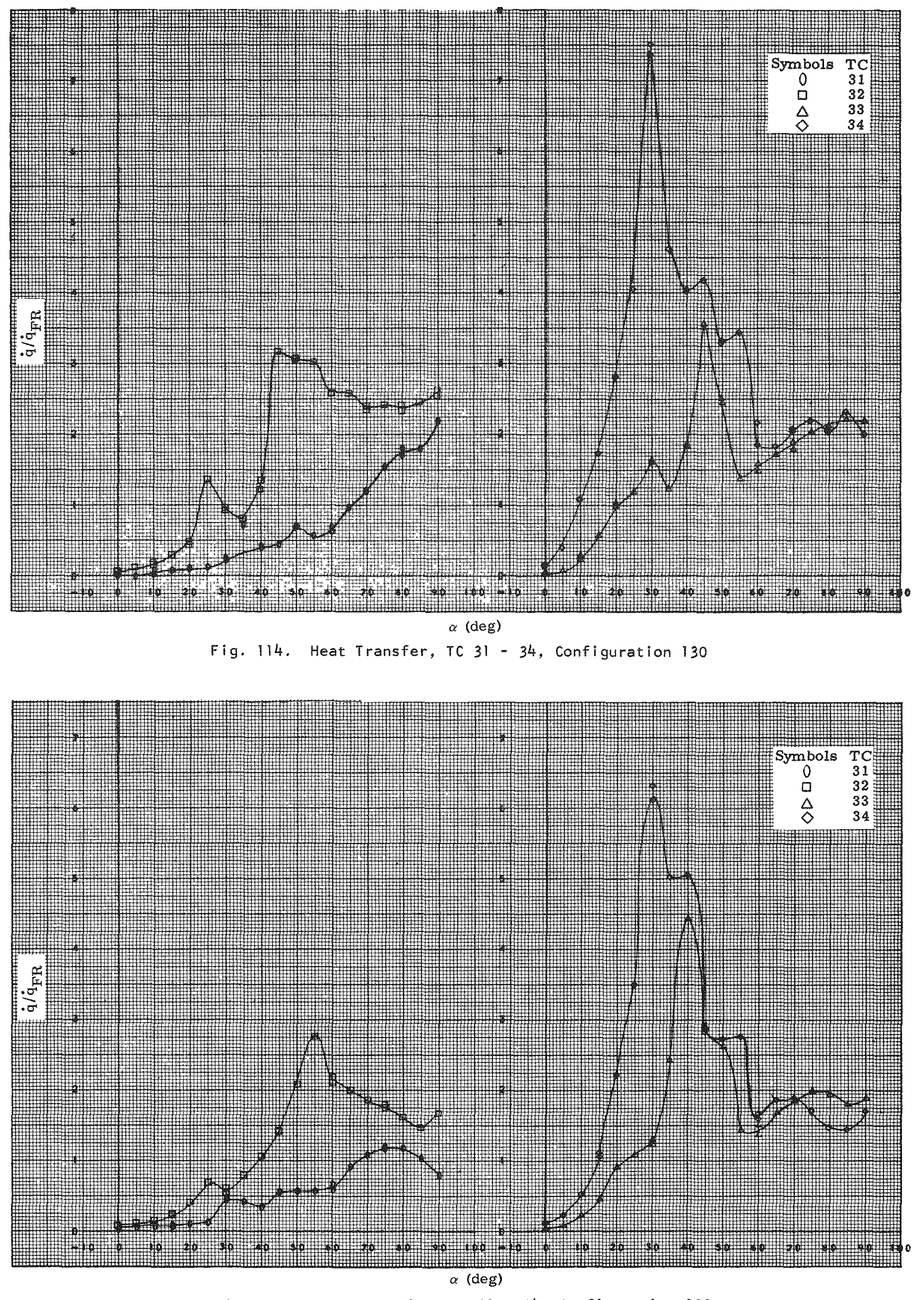

Fig. 115. Heat Transfer, TC $31-34$, Configuration 230 


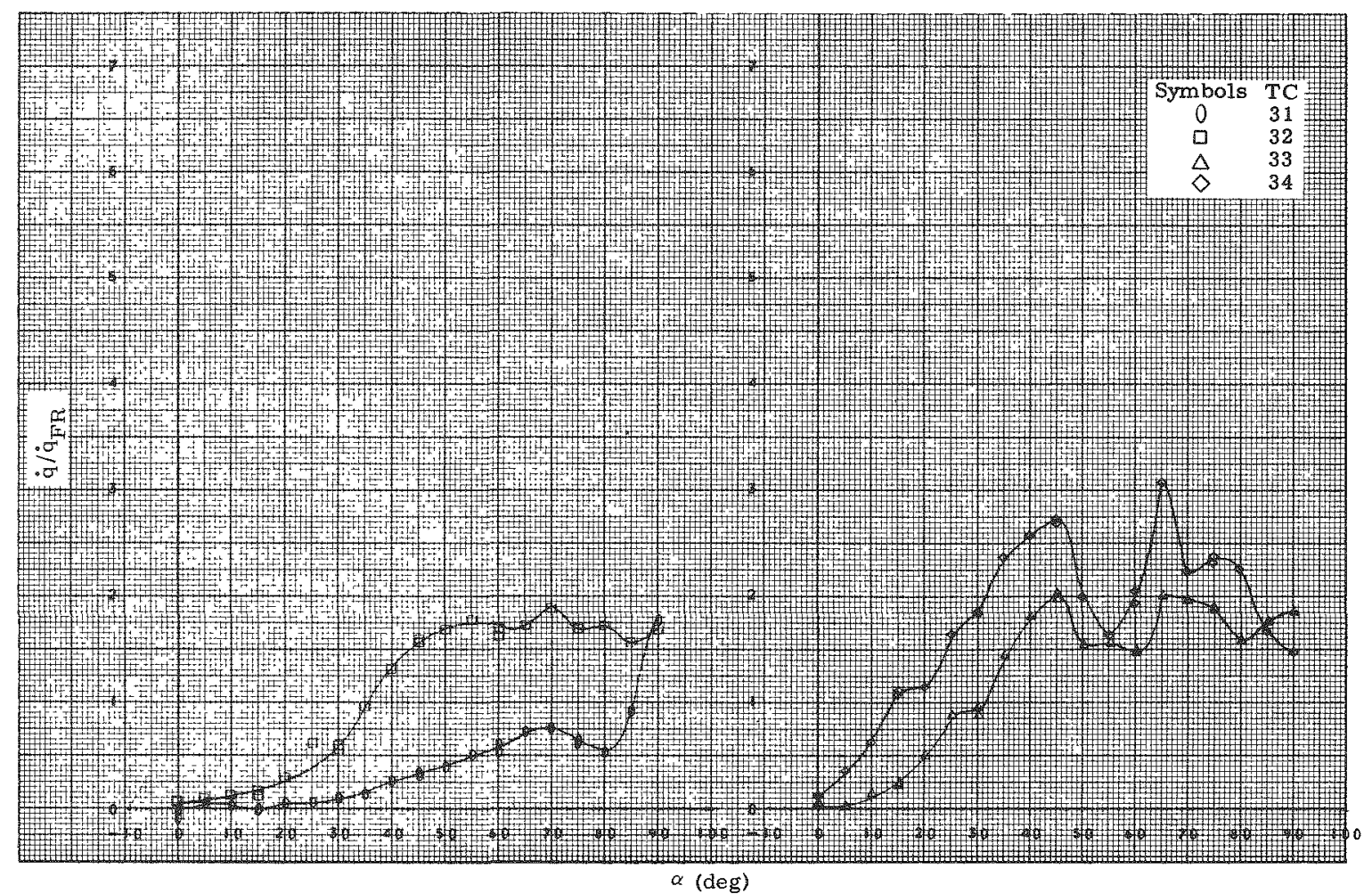

Fig. 116. Heat Transfer, TC 31-34, Configuration 330

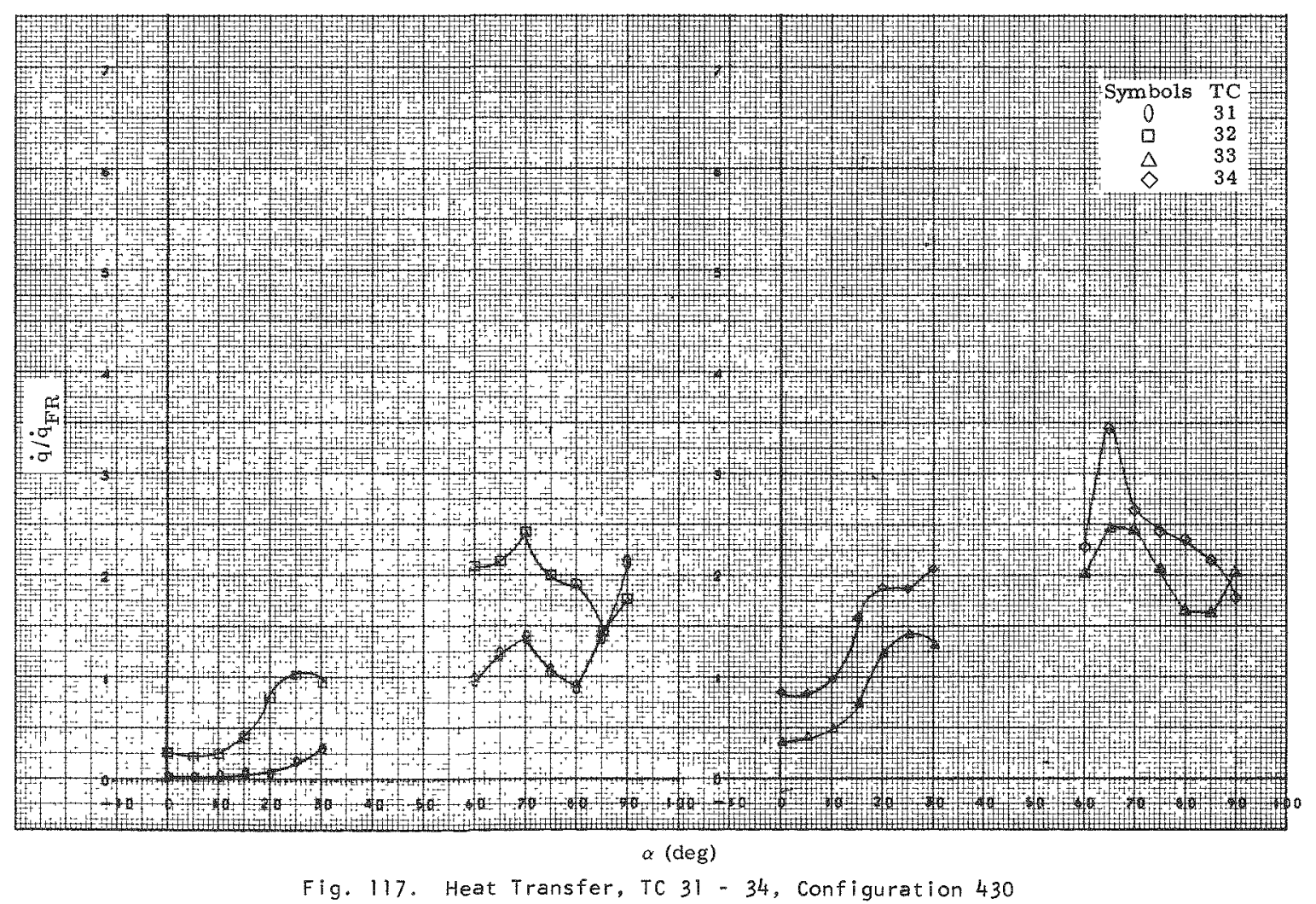

MND-3607-92 


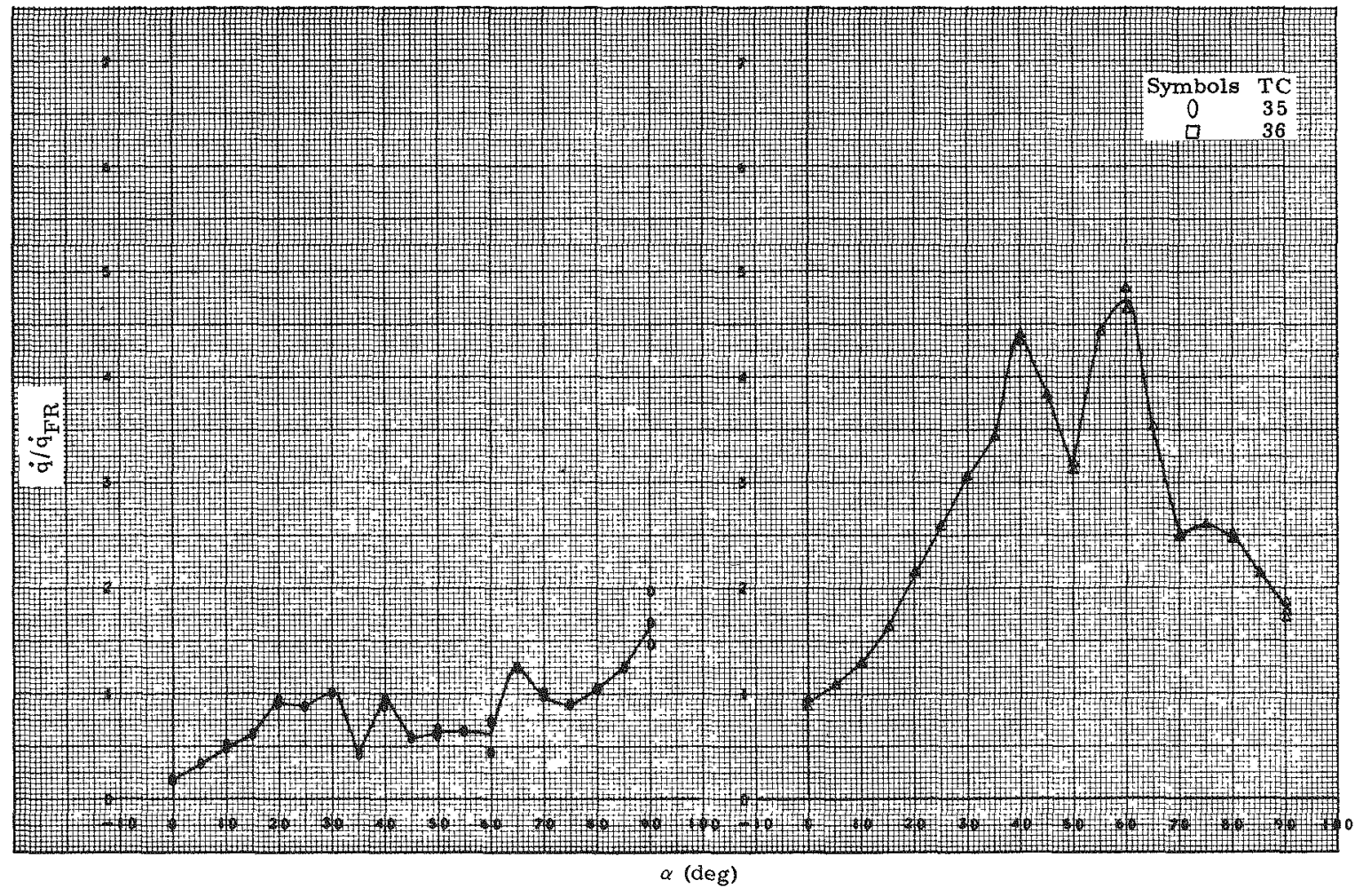

Fig. 118. Heat Transfer, TC 35 and 36, Configuration 100

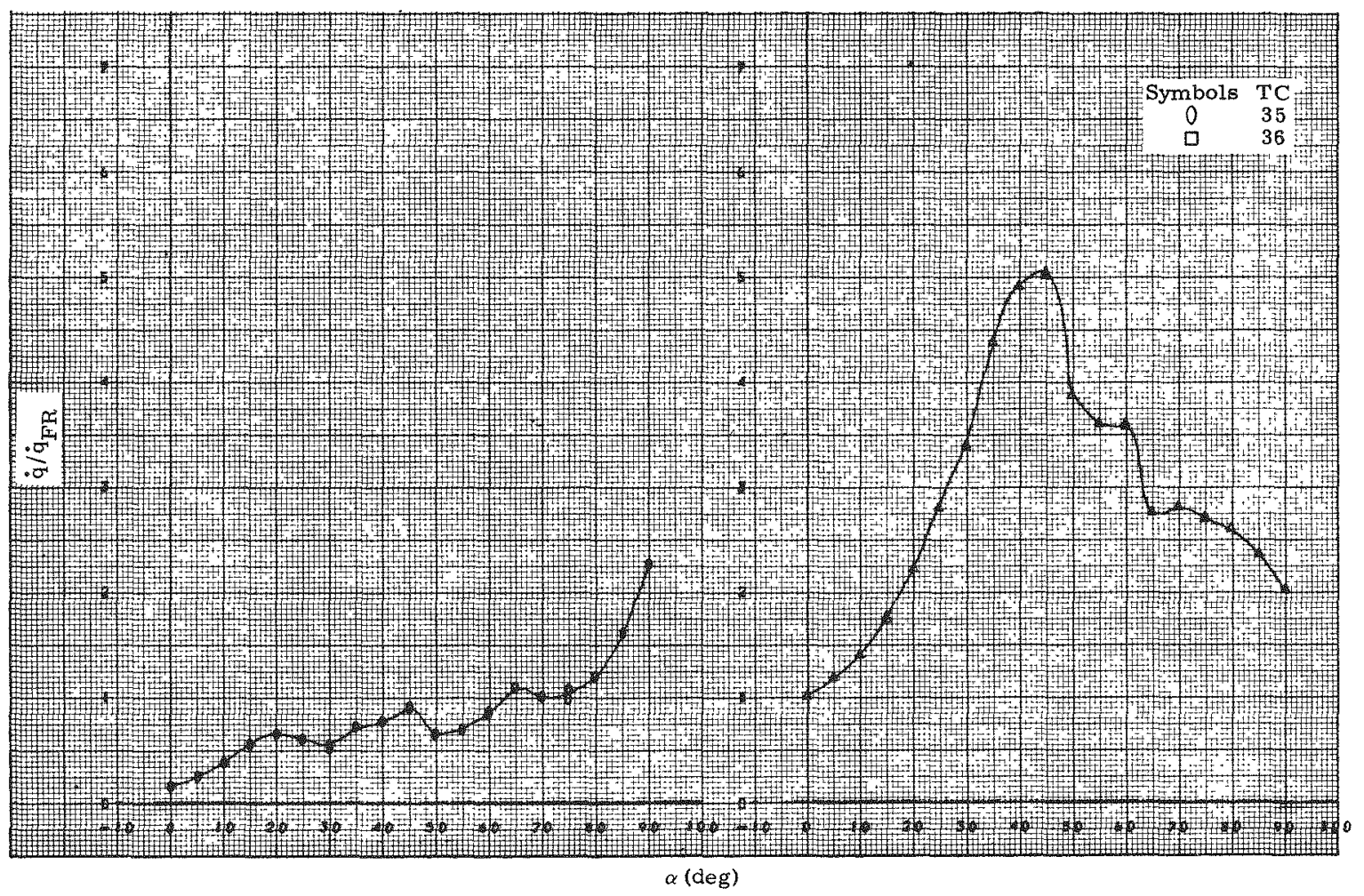

Fig. 119. Heat Transfer, TC 35 and 36, Configuration 200 


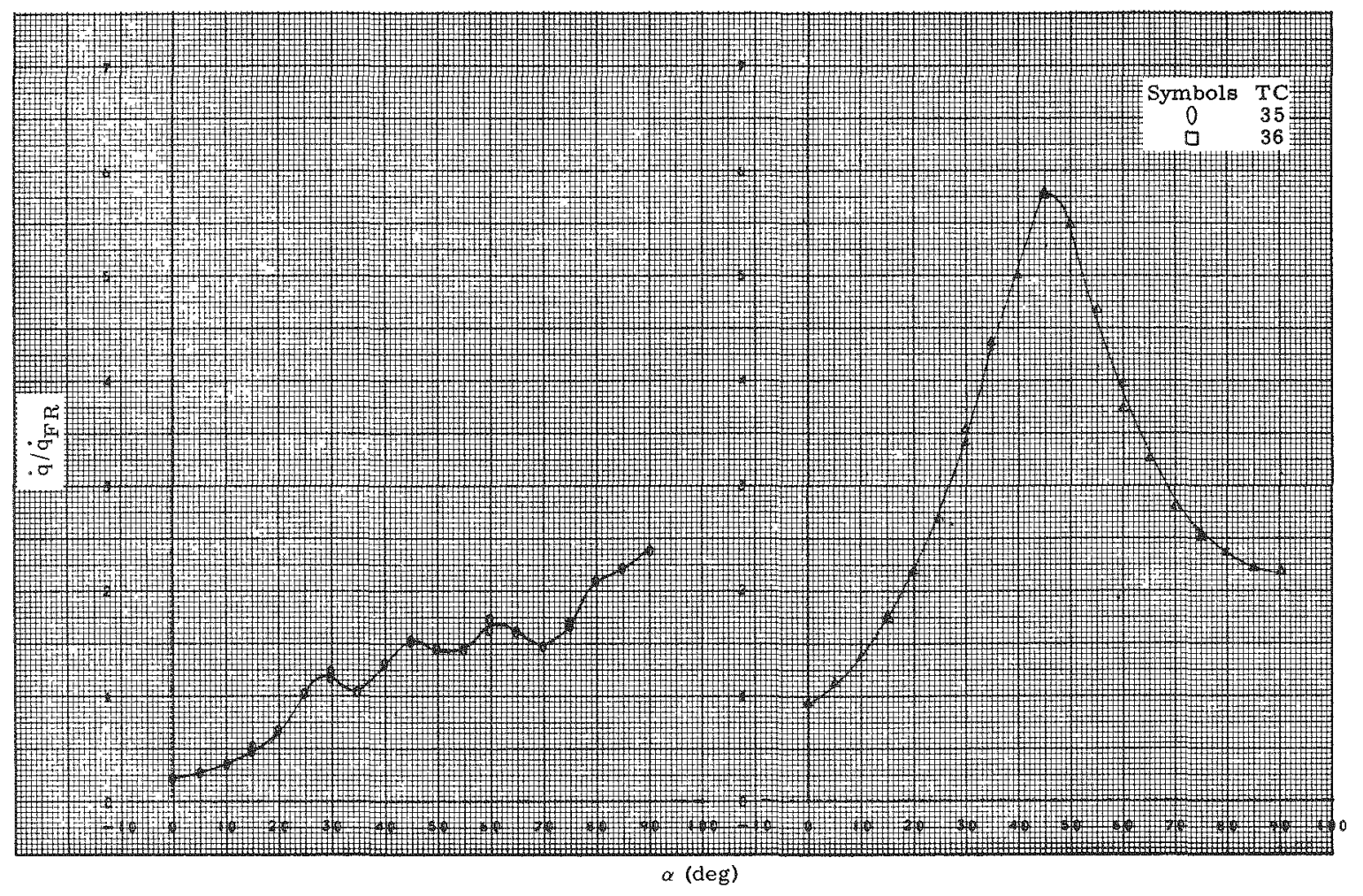

Fig. 120. Heat Transfer, TC 35 and 36 , Configuration 300

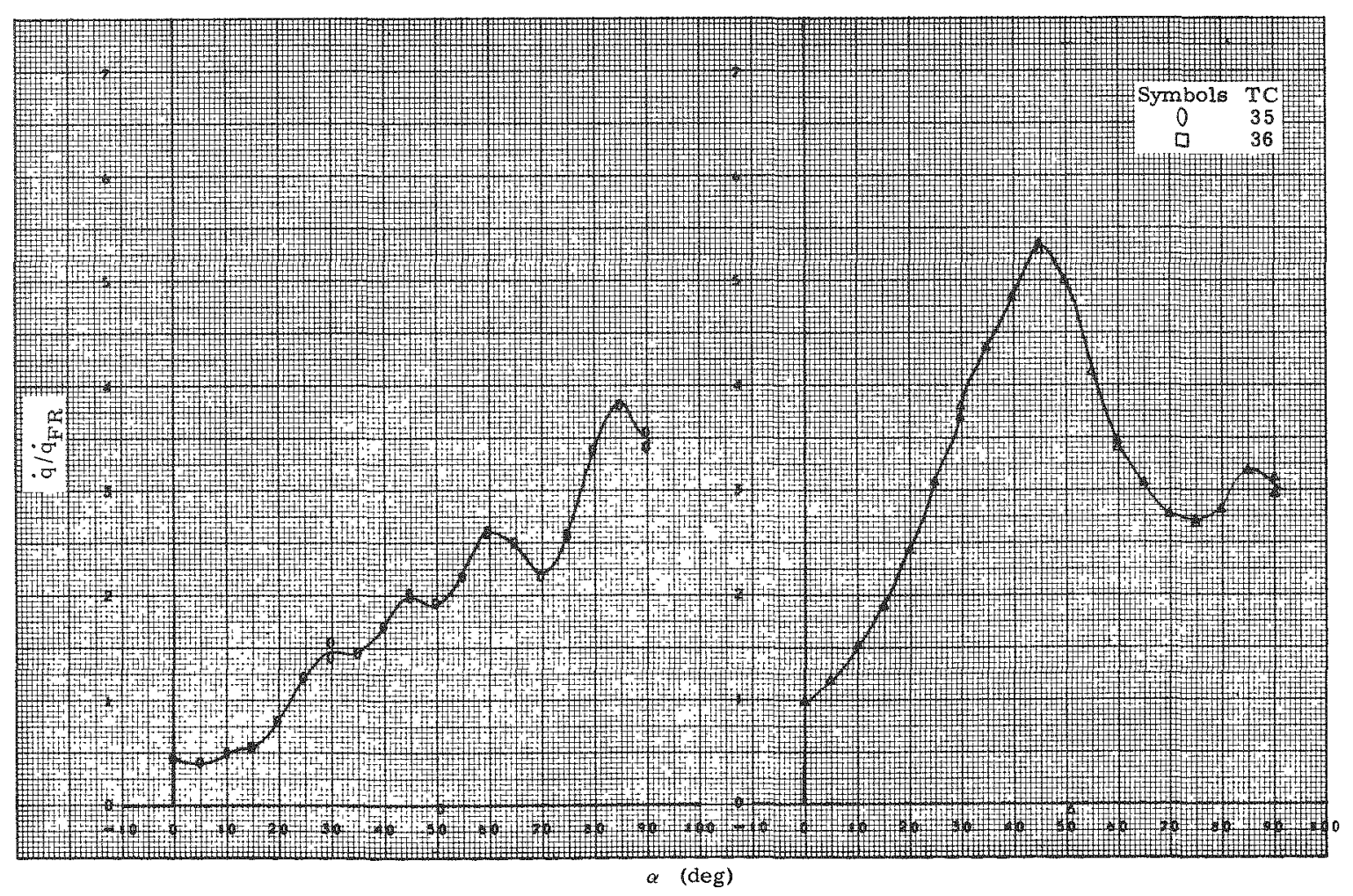

Fig. 121. Heat Transfer, TC 35 and 36, Configuration 400 


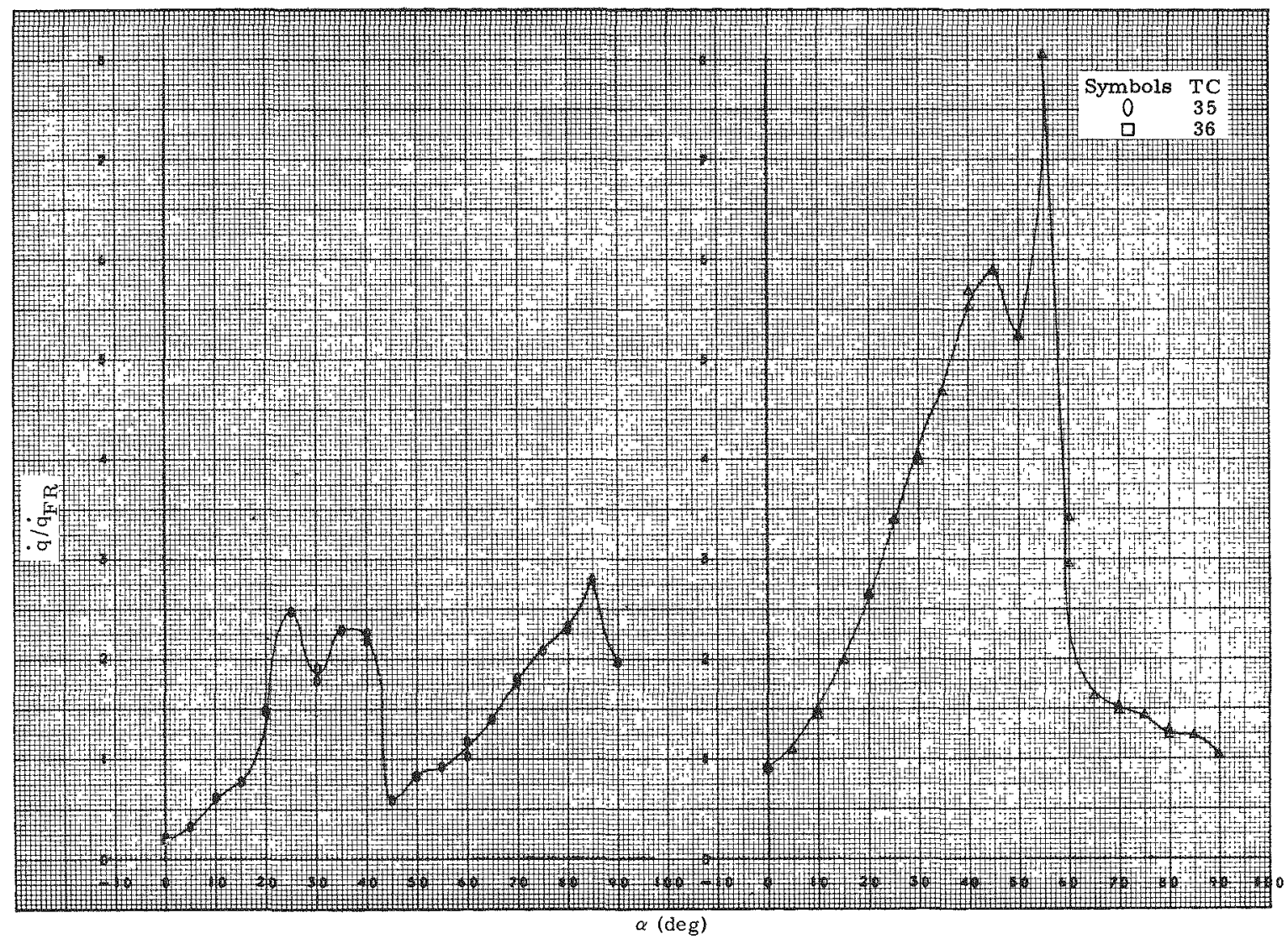

Fig. 122. Heat Transfer, TC 35 and 36 , Configuration 130

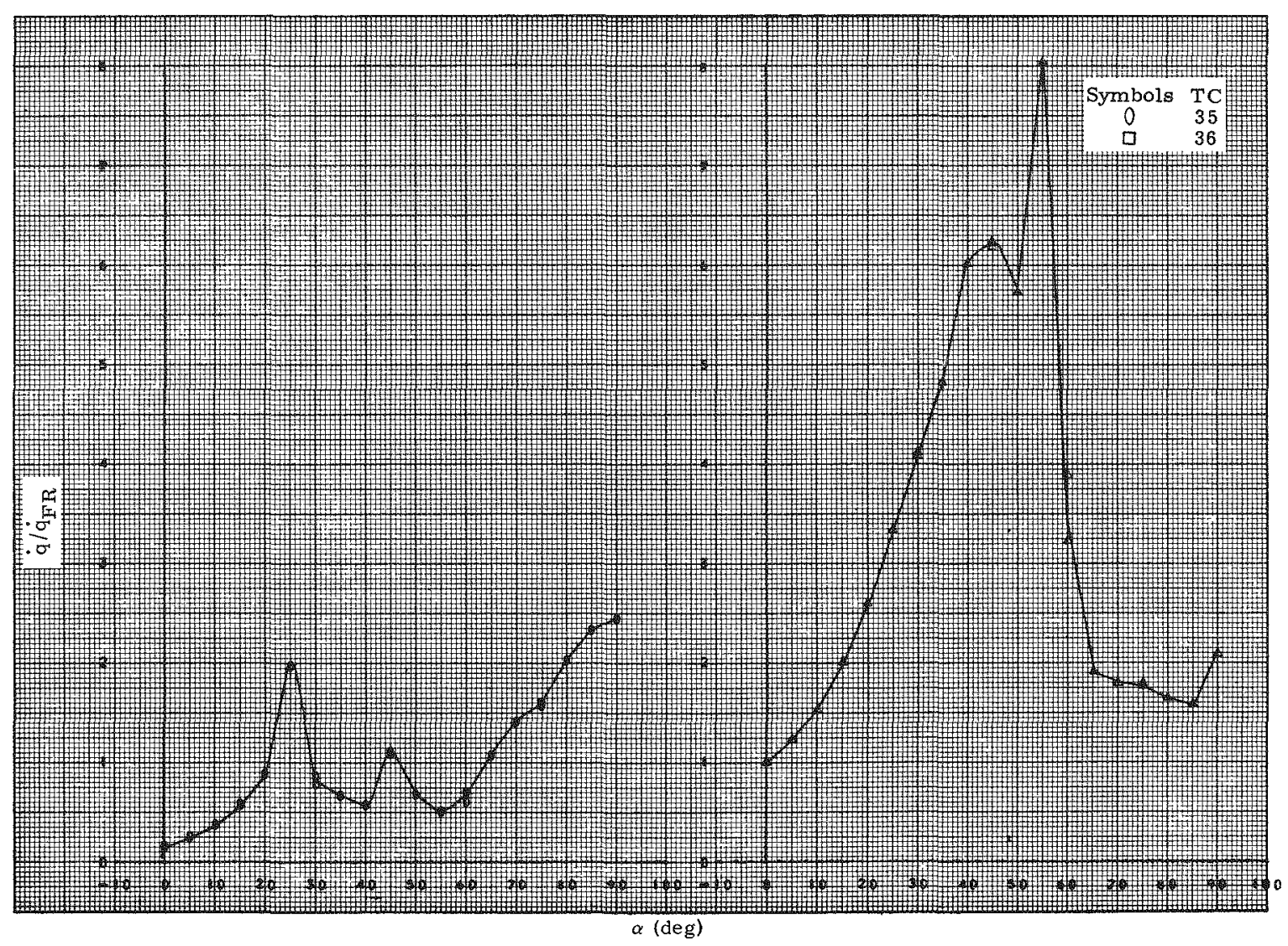

Fig. 123. Heat Transfer, TC 35 and 36 , Configuration 230 


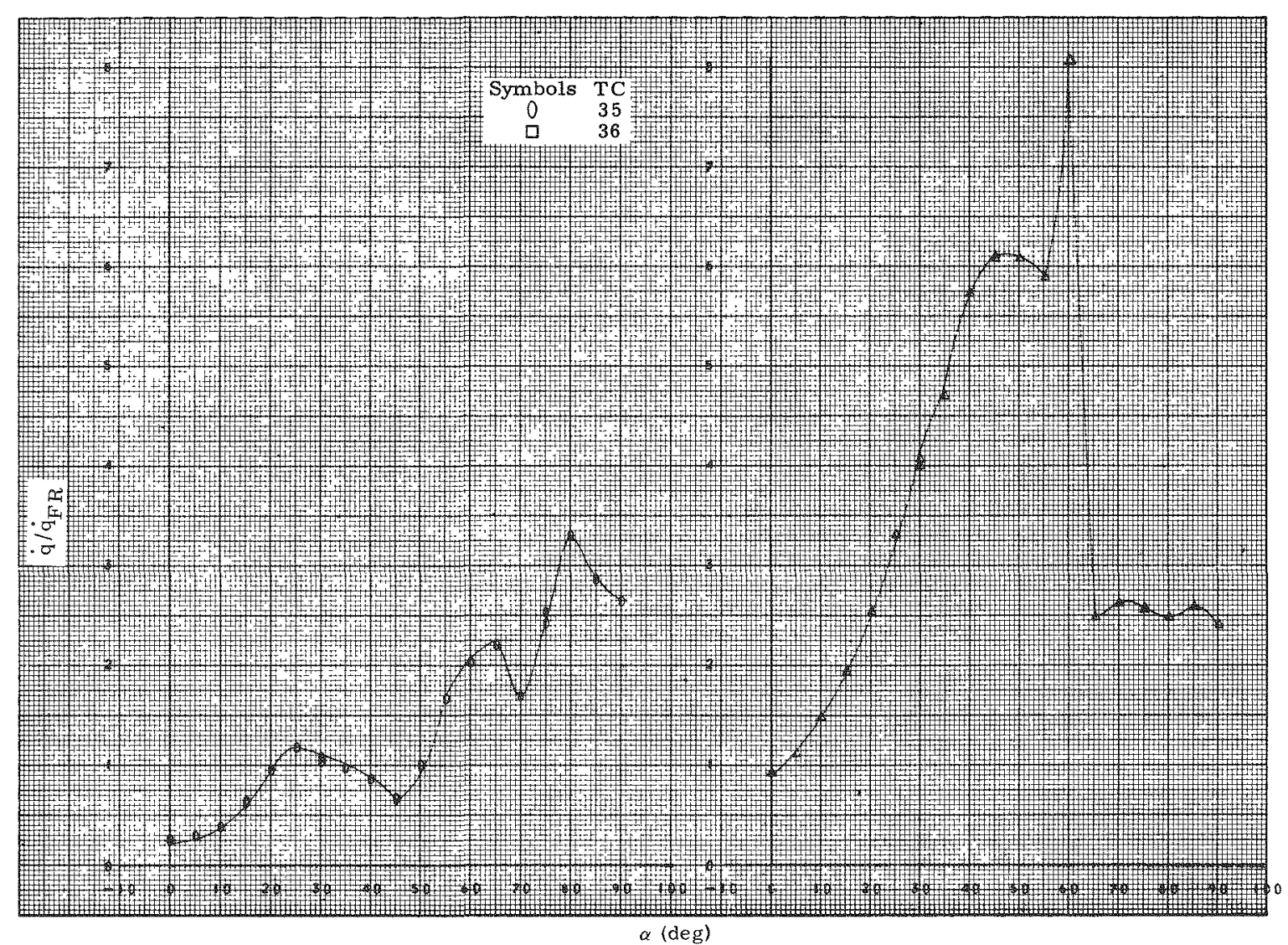

Fig. 124. Heat Transfer, TC 35 and 36 , Configuration 330

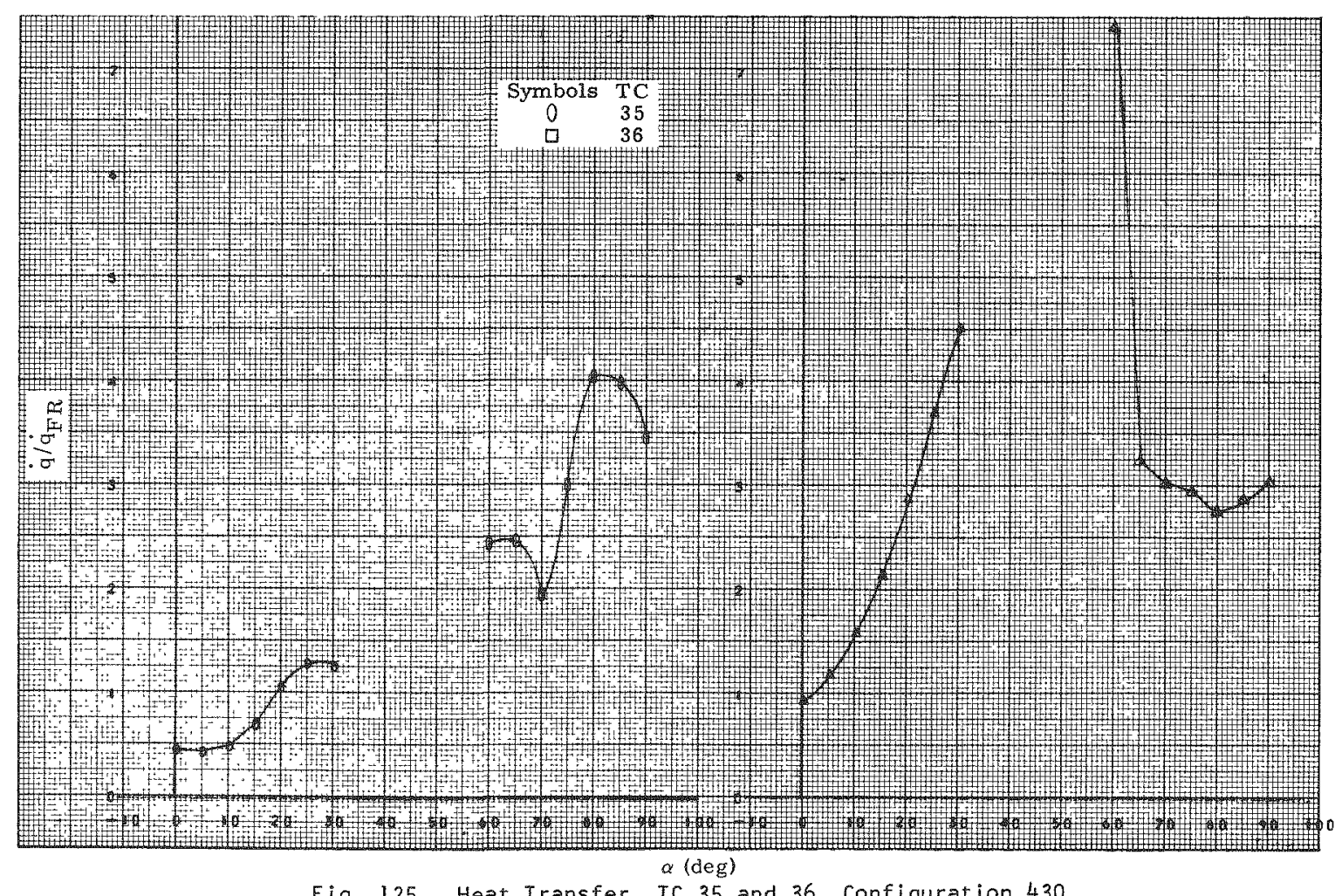

Fig. 125. Heat Transfer, TC 35 and 36, Configuration 430 


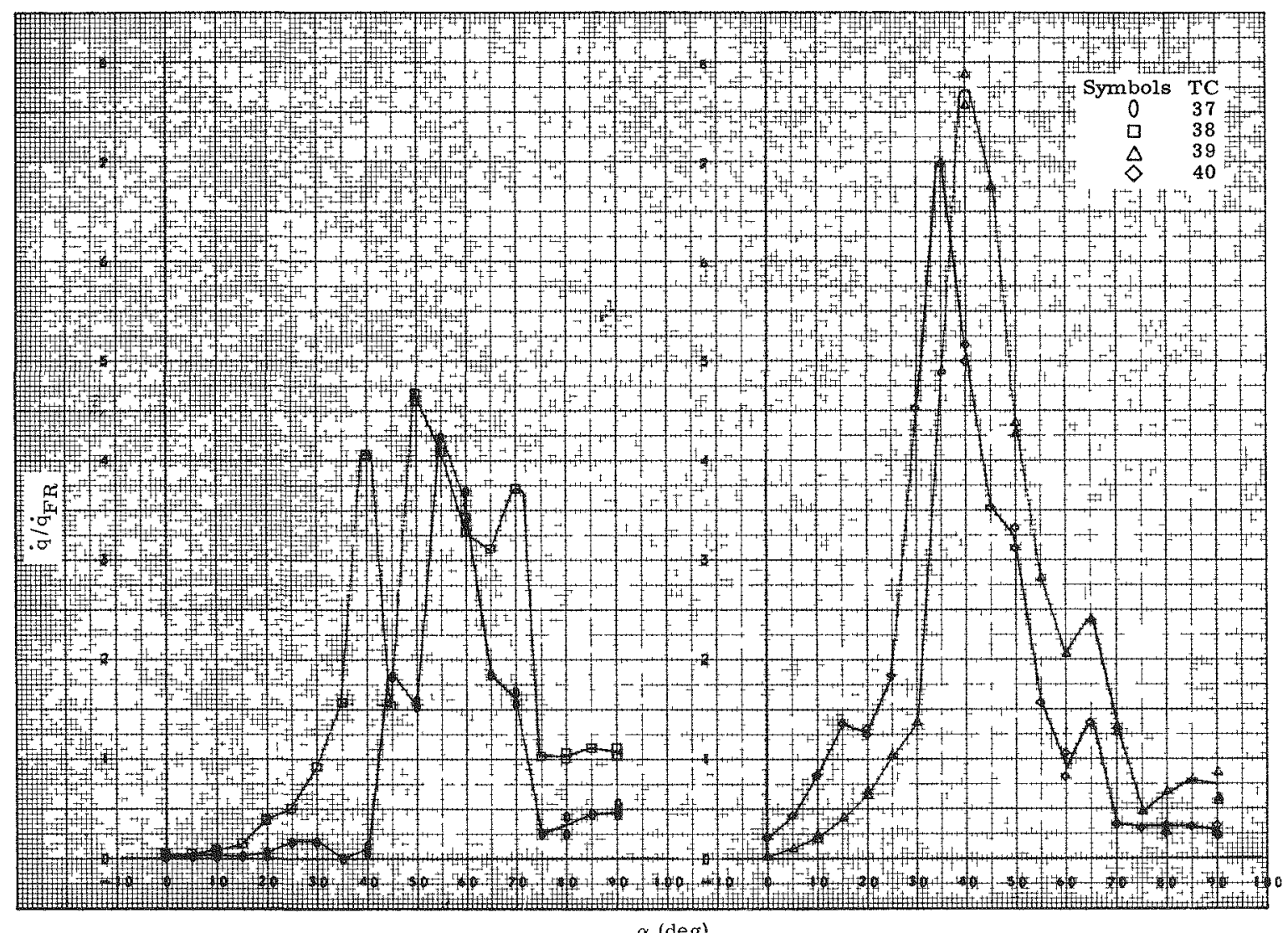

Fig. 126. Heat Transfer, TC $37-40$, Configuration 100

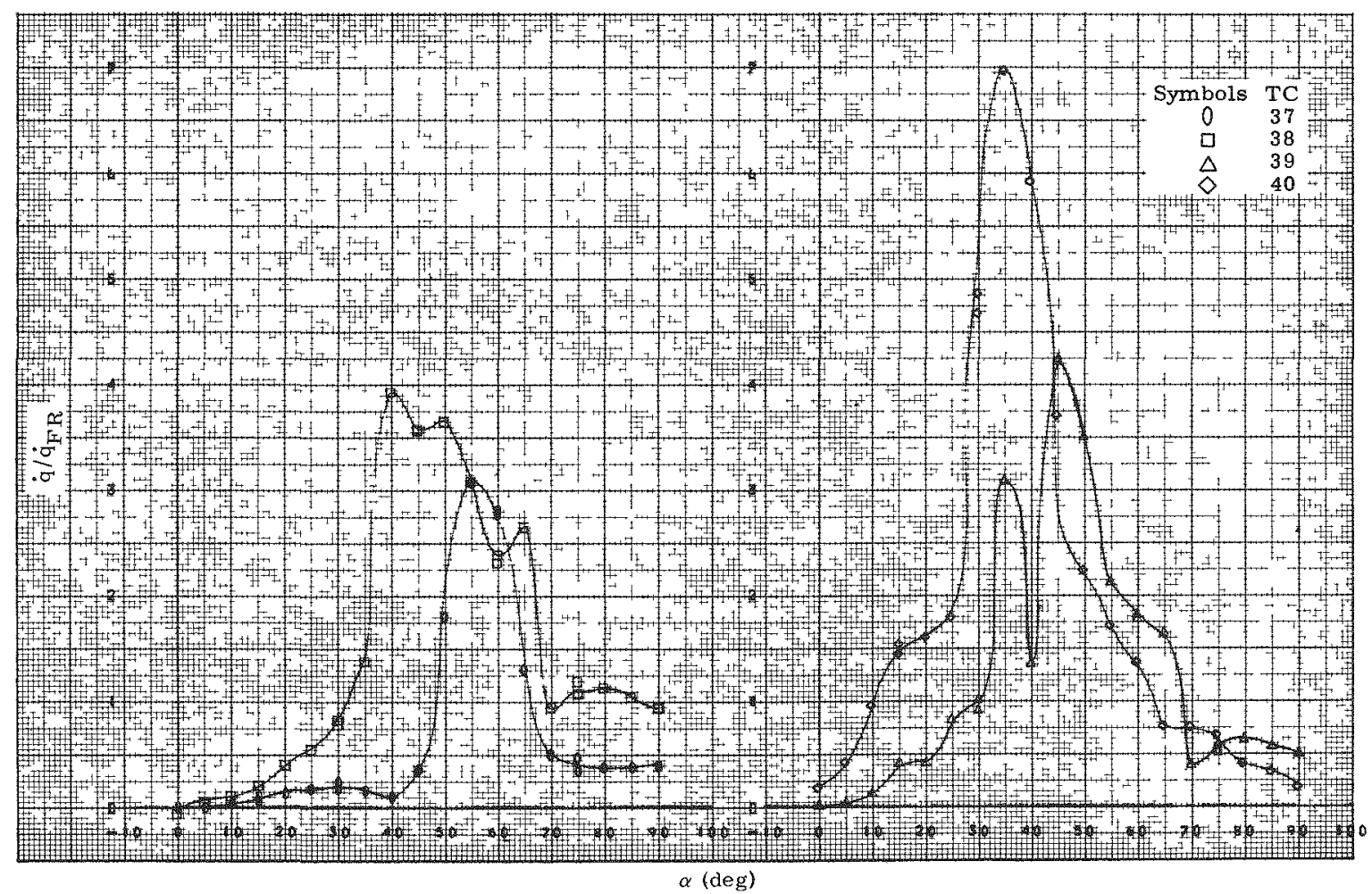

Fig. 127. Heat Transfer, TC $37-40$, Configuration 200 


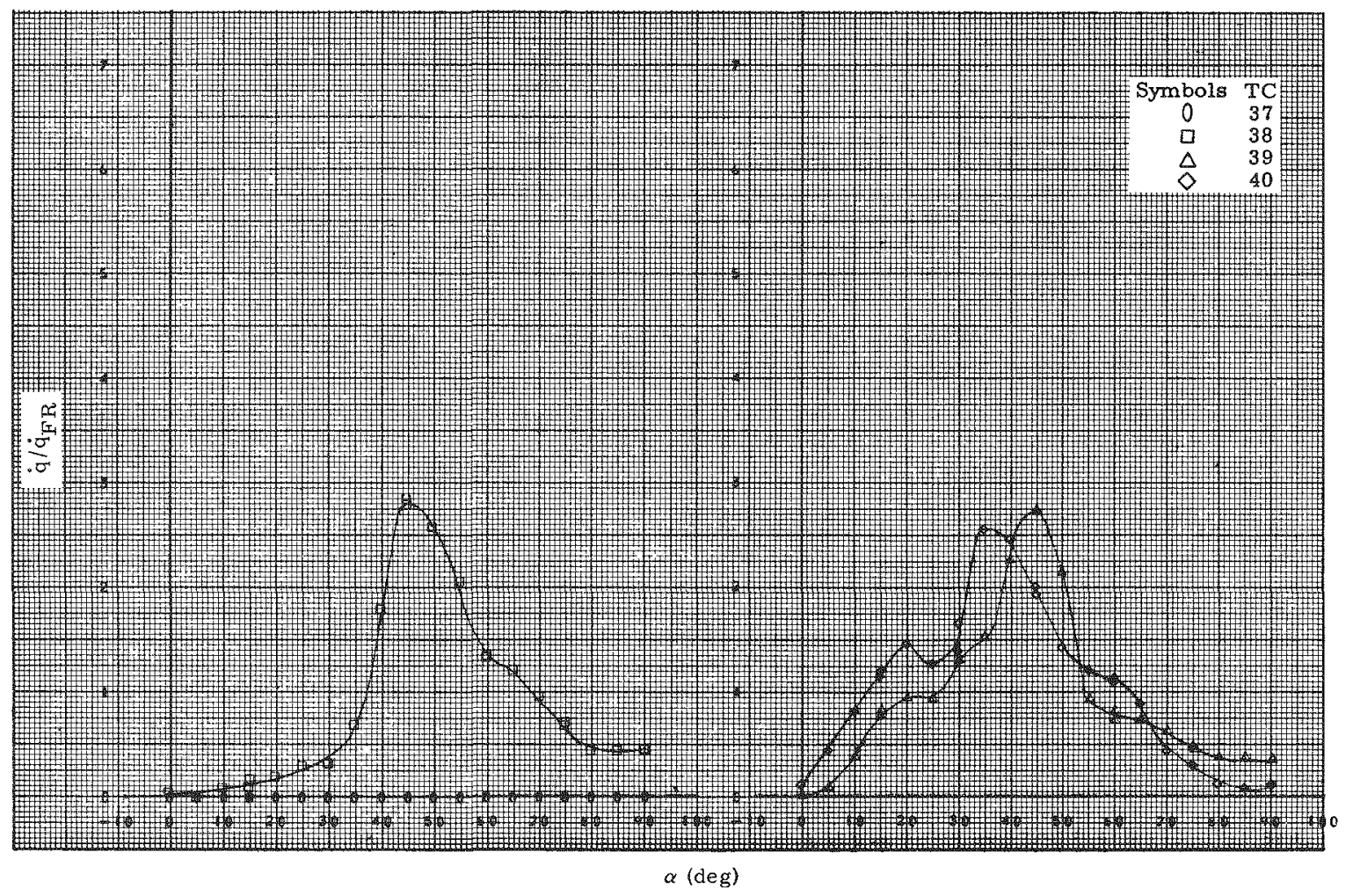

Fig. 128. Heat Transfer, TC $37-40$, Configuration 300

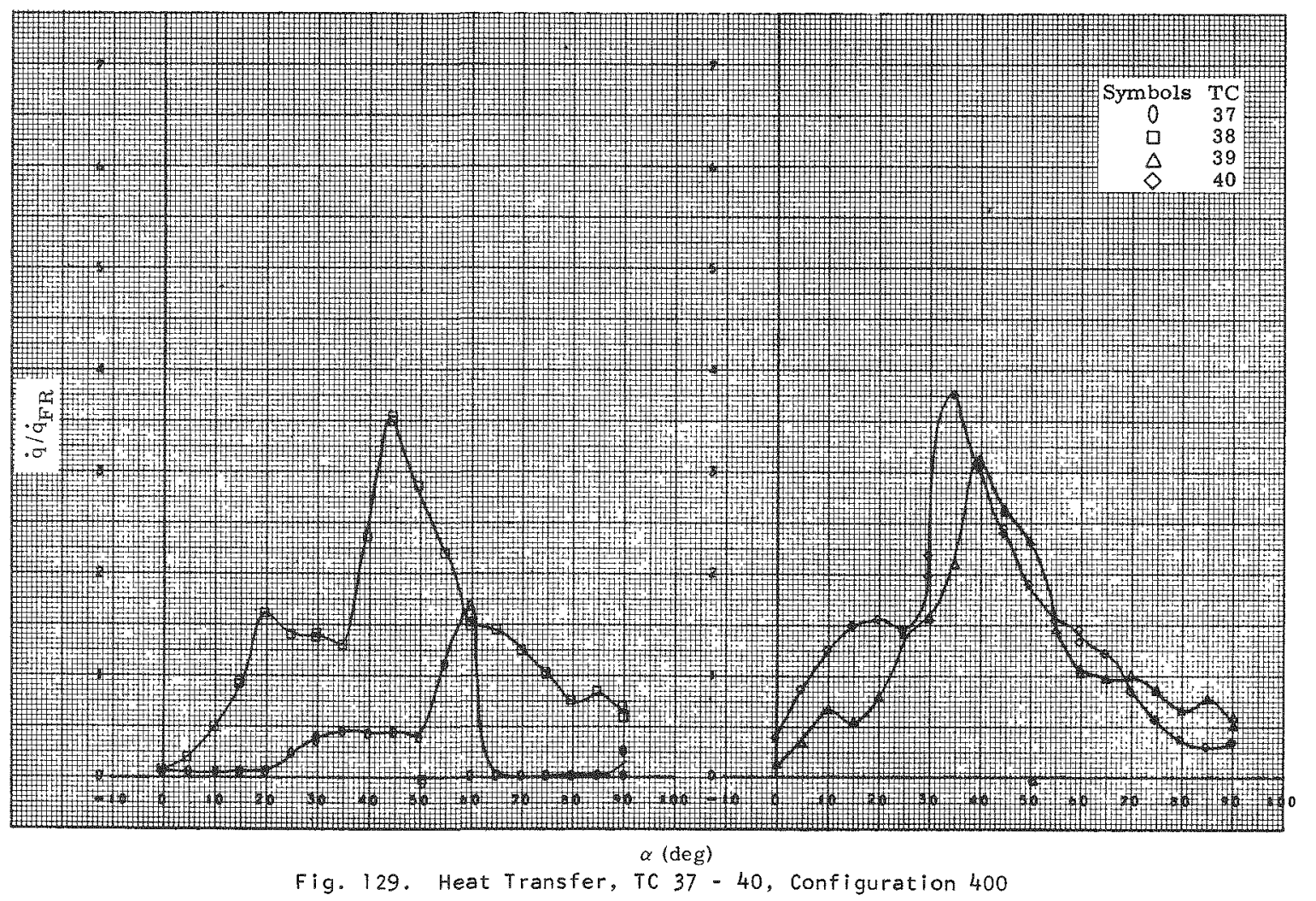




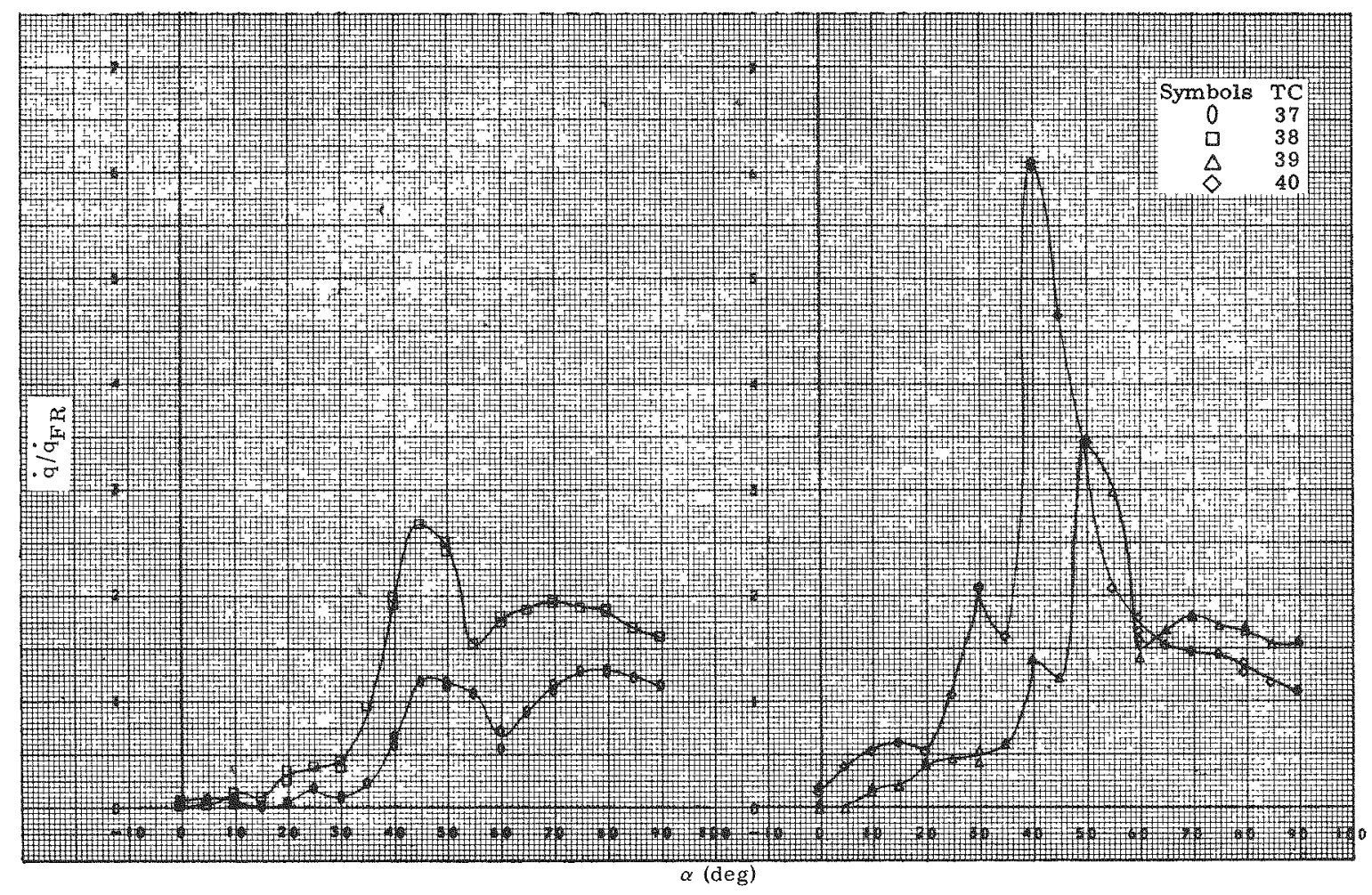

Fig. 130. Heat Transfer, TC $37-40$, Configuration 130

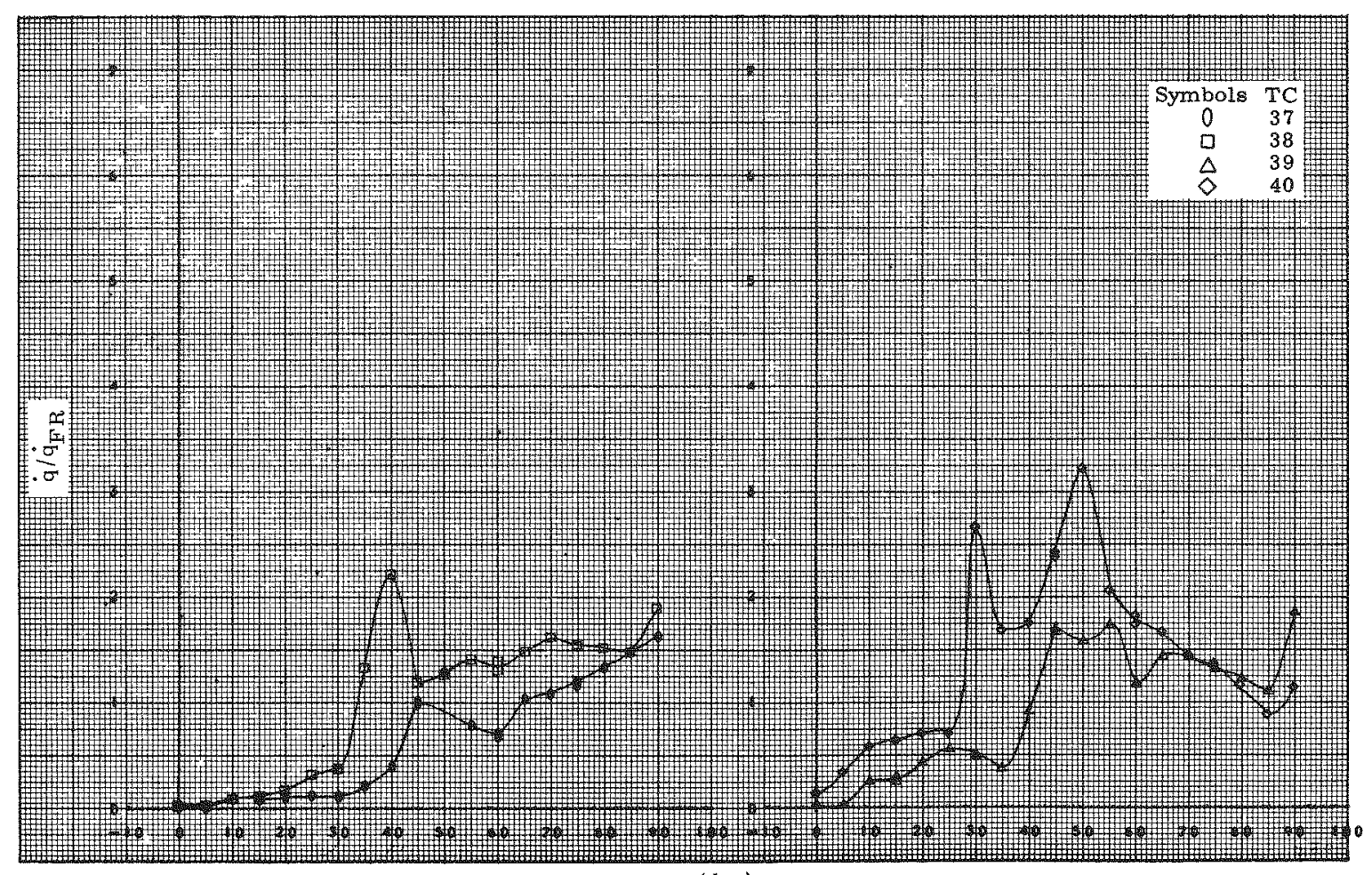

$\alpha$ (deg)

Fig. 131. Heat Transfer, TC $37-40$, Configuration 230 


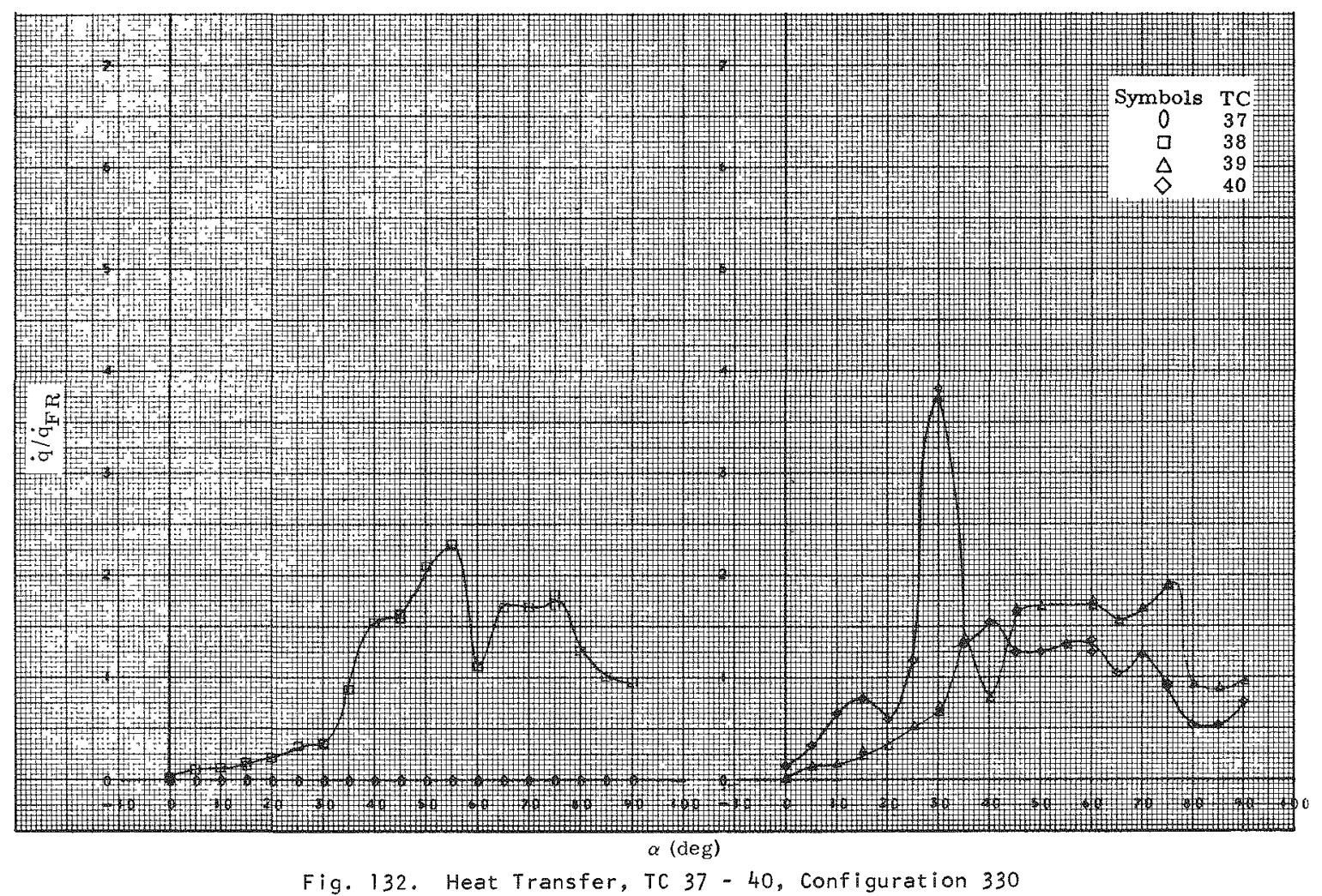

Fig. 132. Heat Transfer, TC $37-40$, Configuration 330

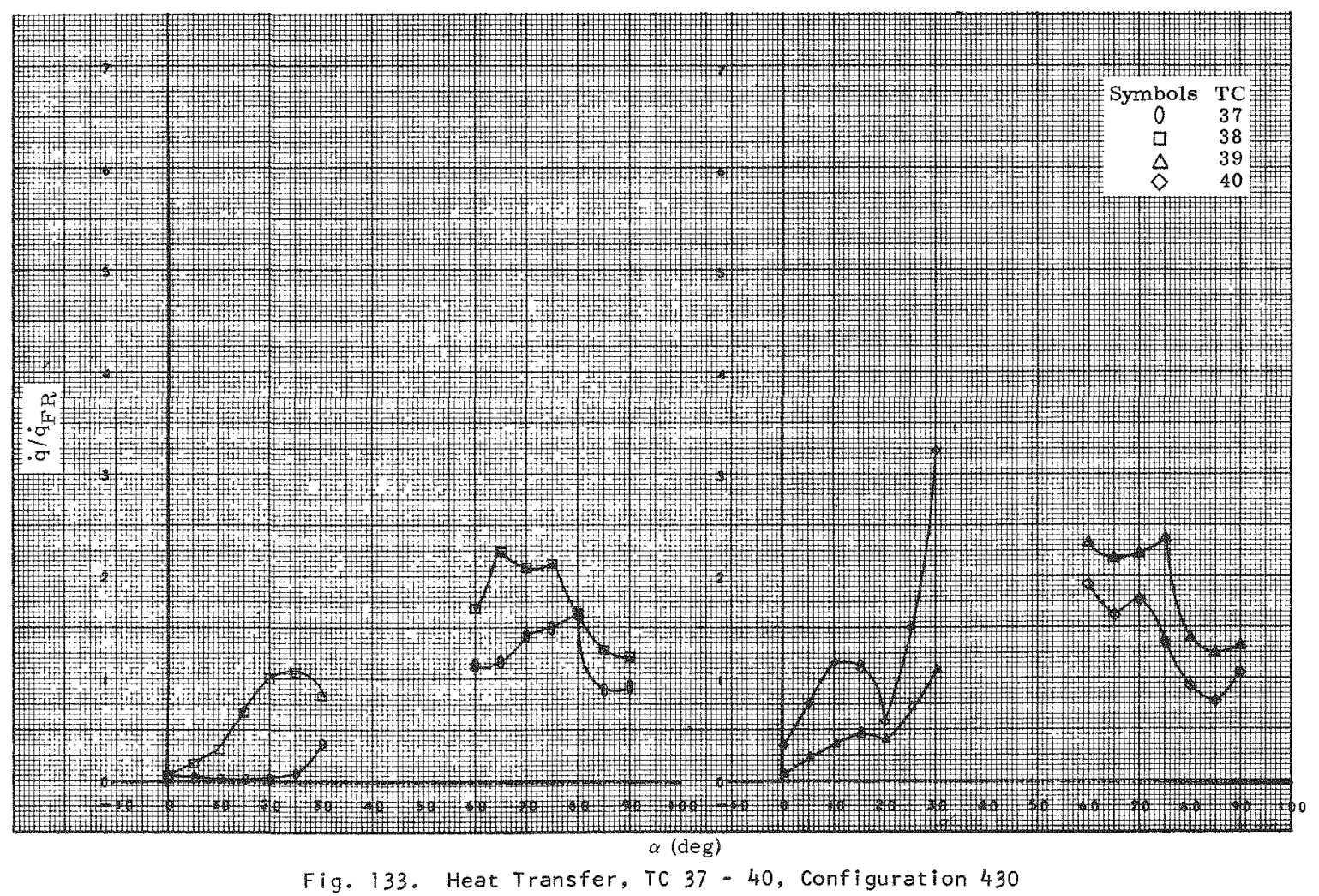

MND-3607-92 


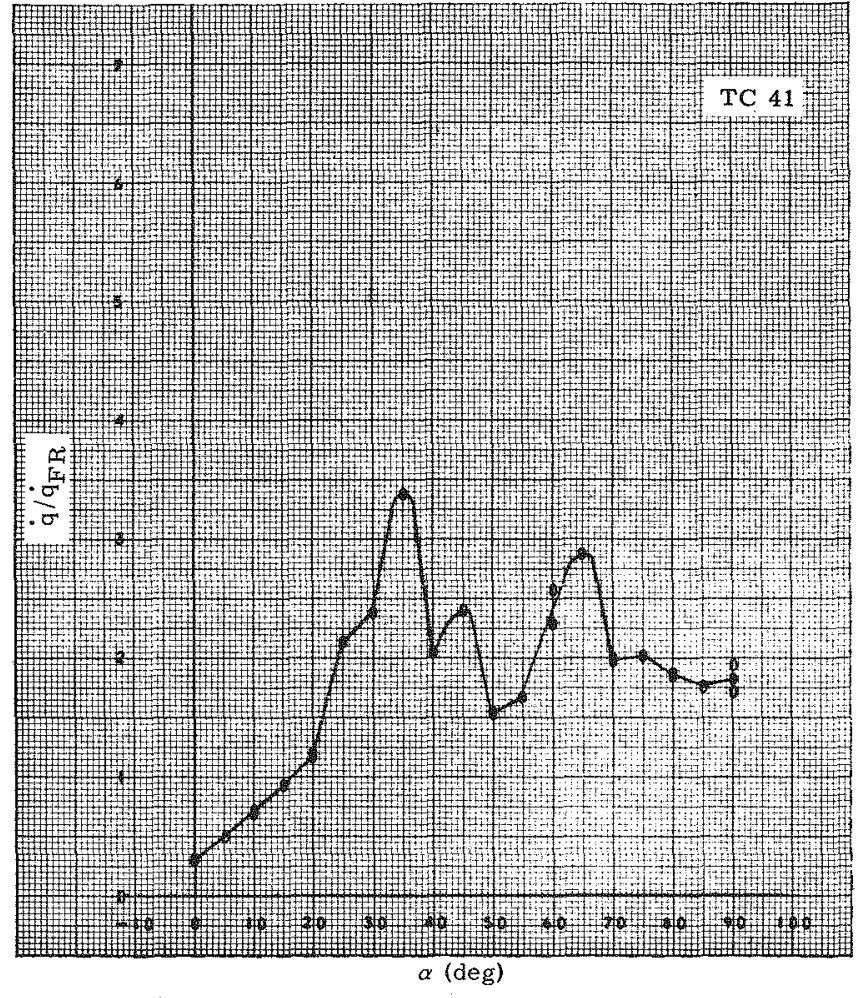

Fig. 134. Heat Transfer, TC 41, Configuration 100

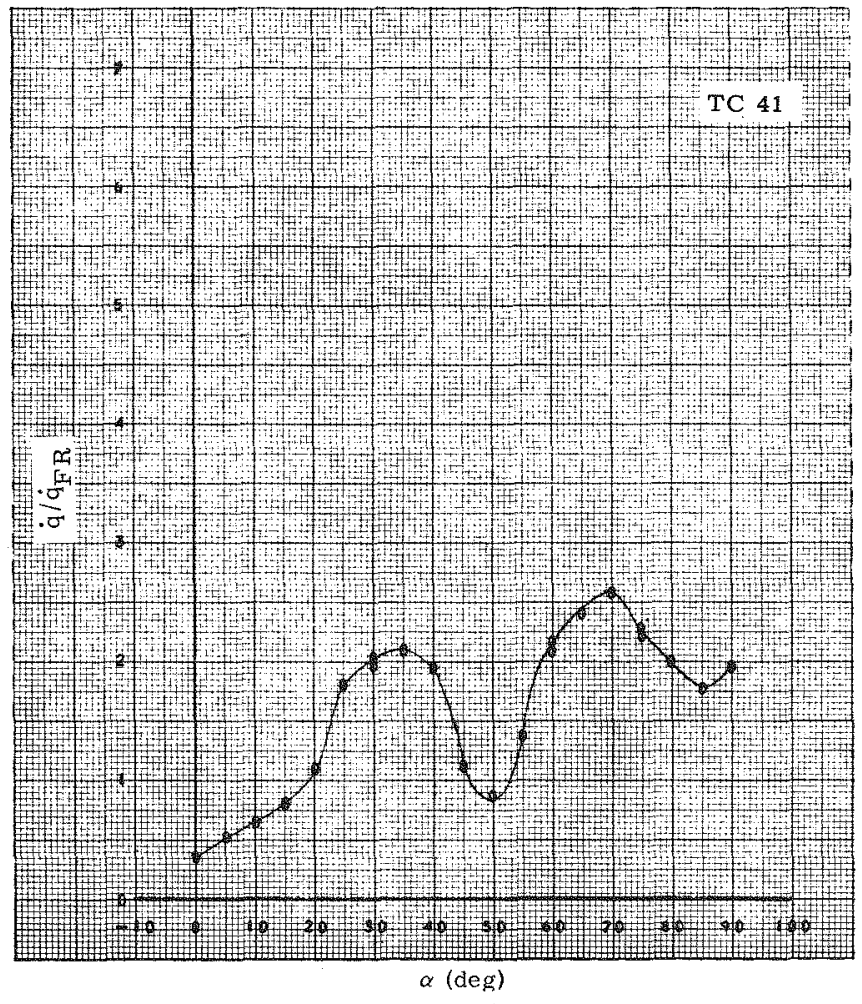

Fig. 135. Heat Transfer, TC 41, Configuration 200

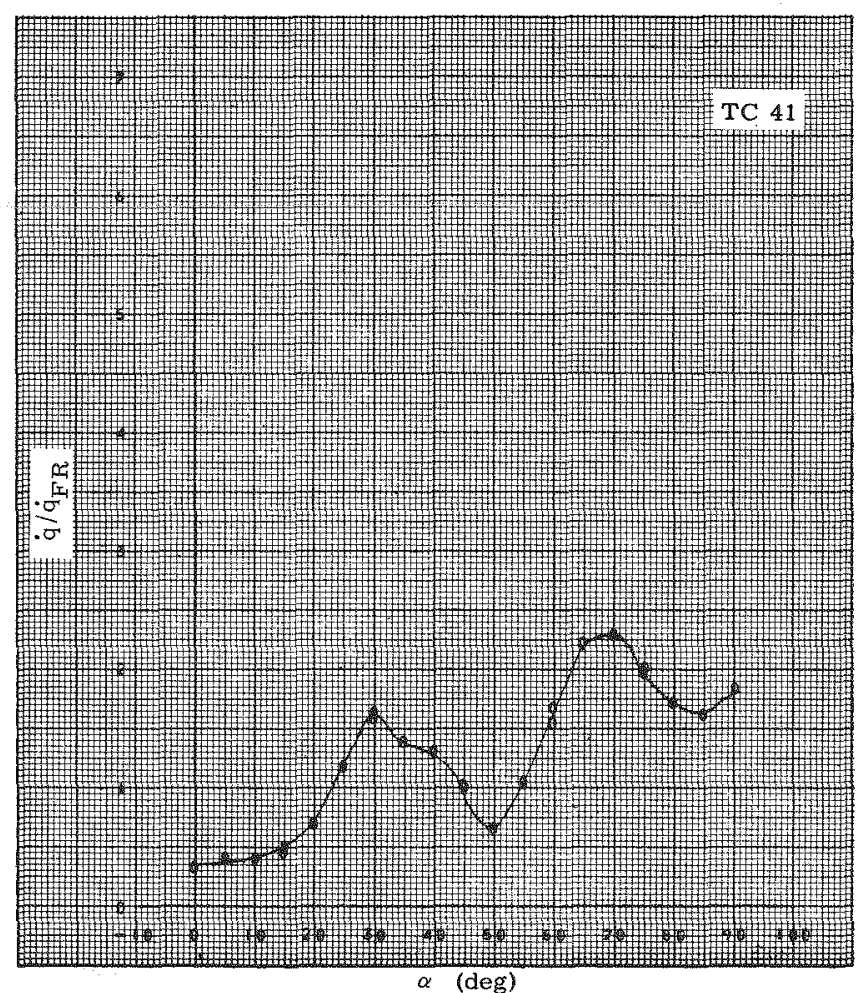

Fig. 136. Heat Transfer, TC 41, Configuration 300

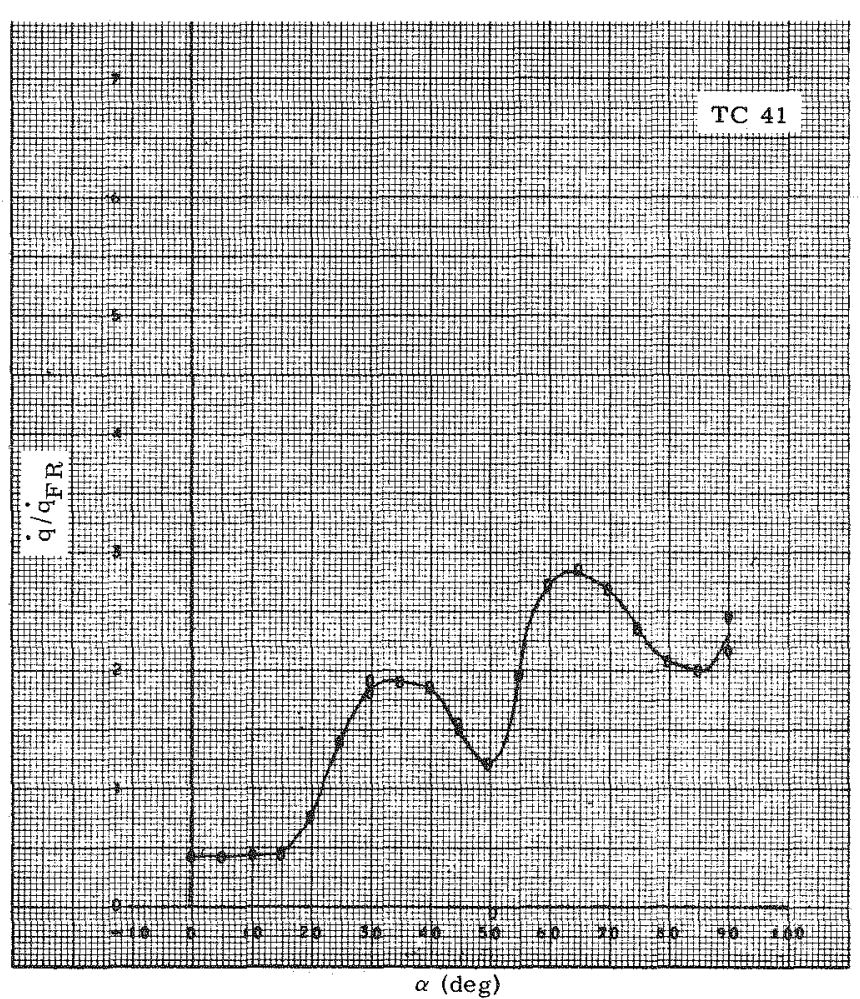

Fig. 137. Heat Transfer, TC 41, Configuration 400 


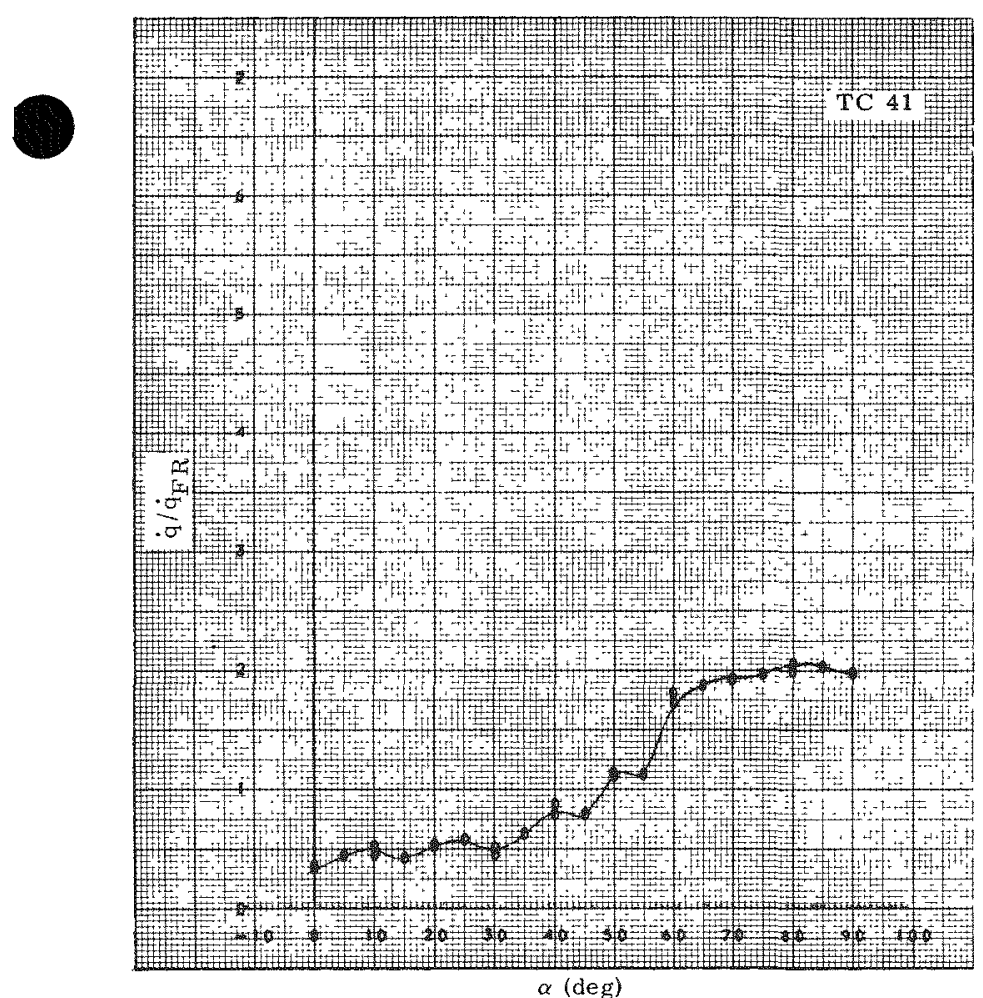

Fig. 138. Heat Transfer, TC 41 , Configuration 130

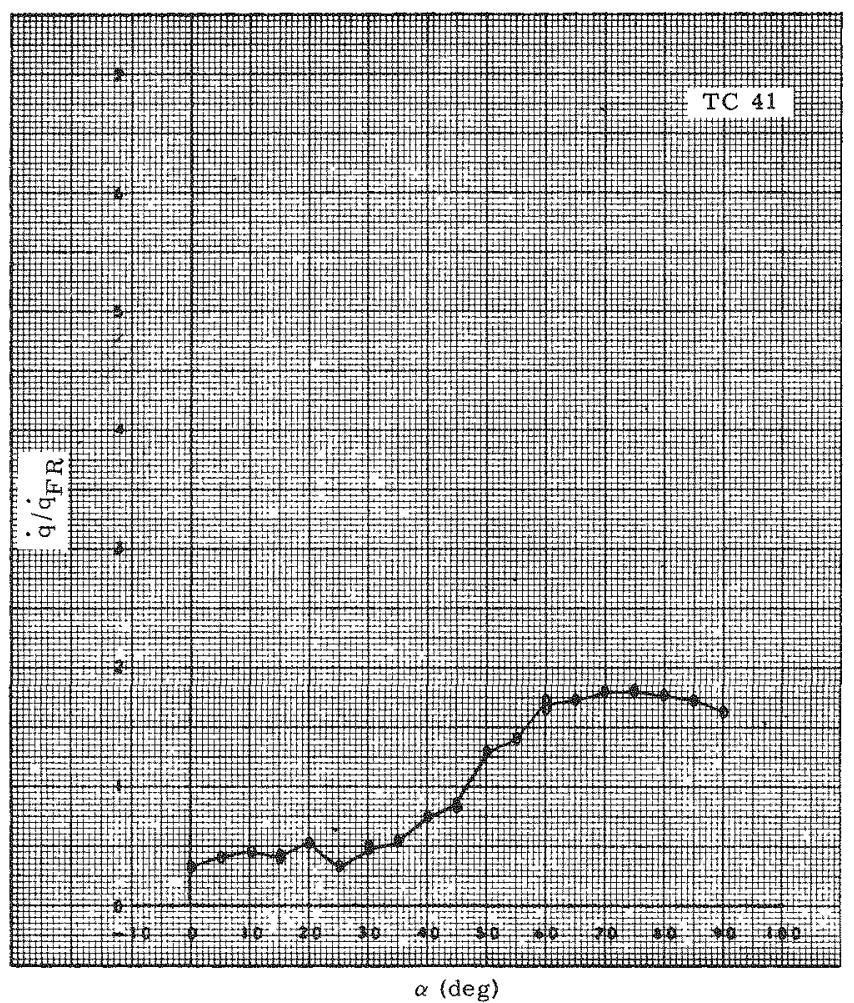

Fig, 139. Heat Transfer, TC 41, Configuration 230

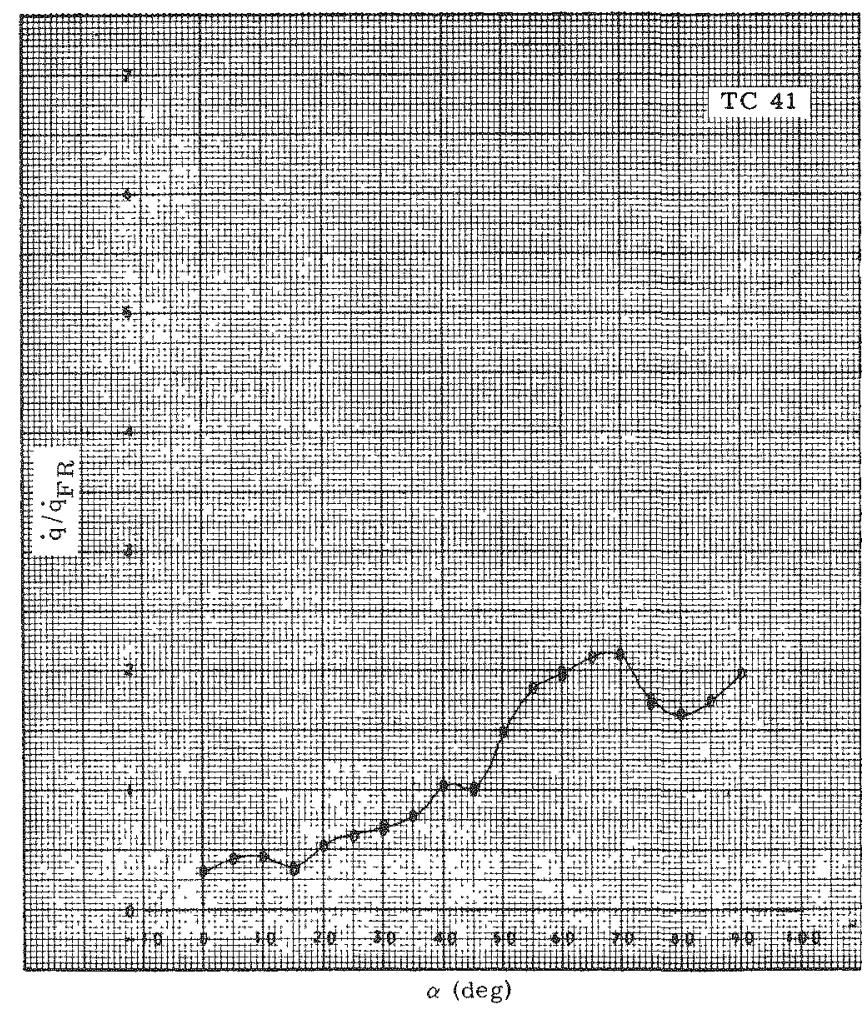

Fig. 140. Heat Transfer, TC 41, Configuration 330

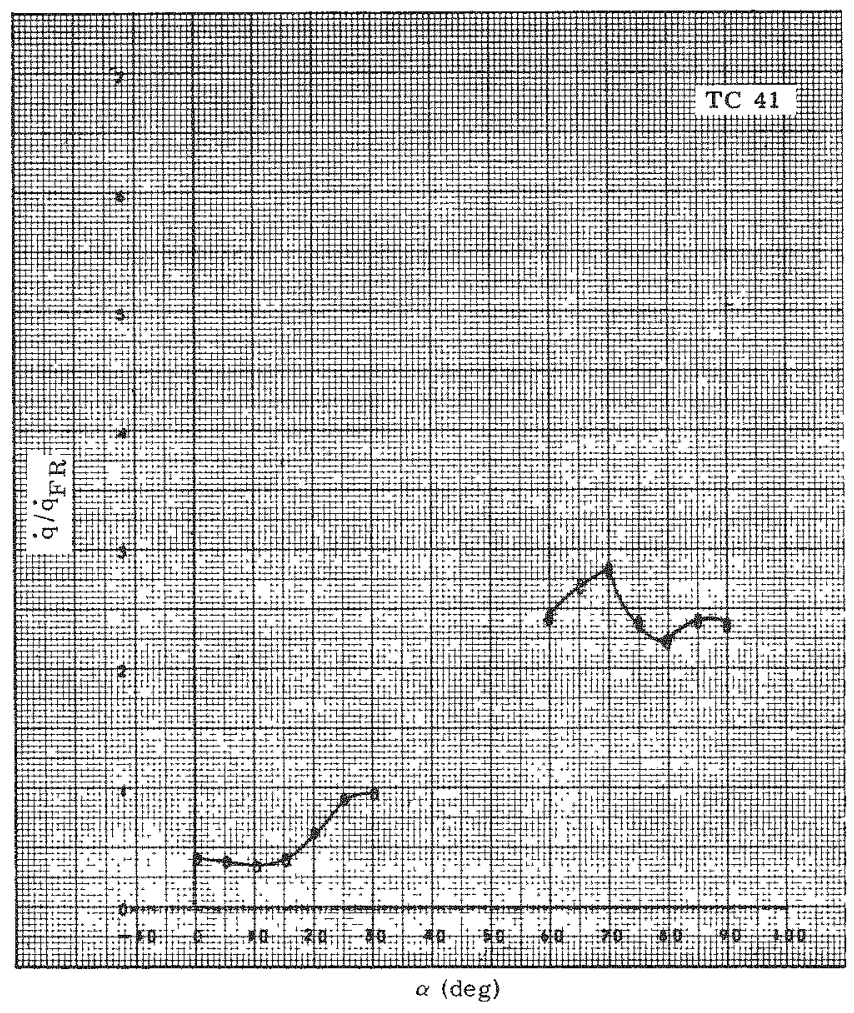

Fig. 141. Heat Transfer, TC 41, Configuration 430 


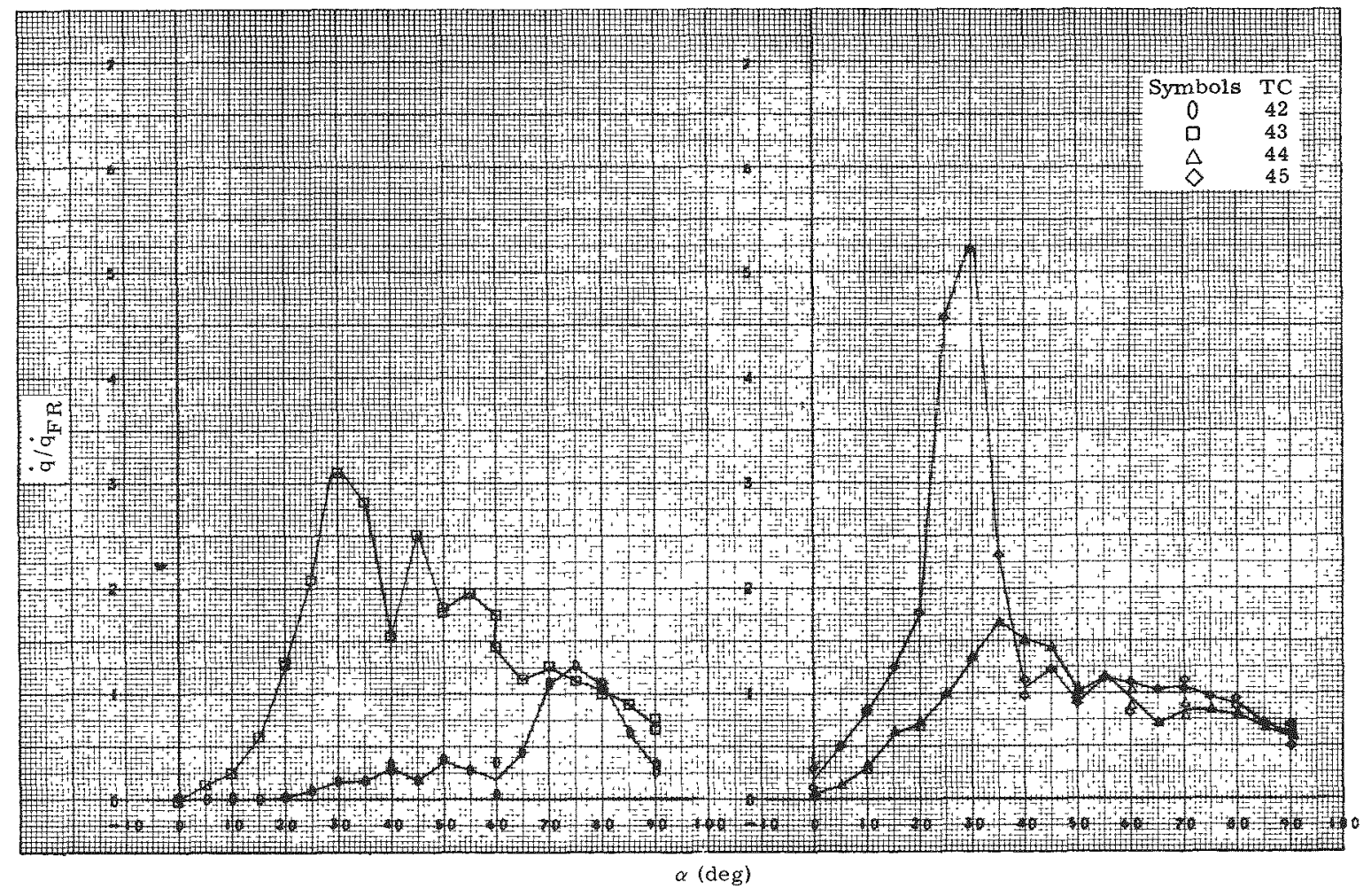

Fig. 142. Heat Transfer, TC 42- 45, Configuration 100

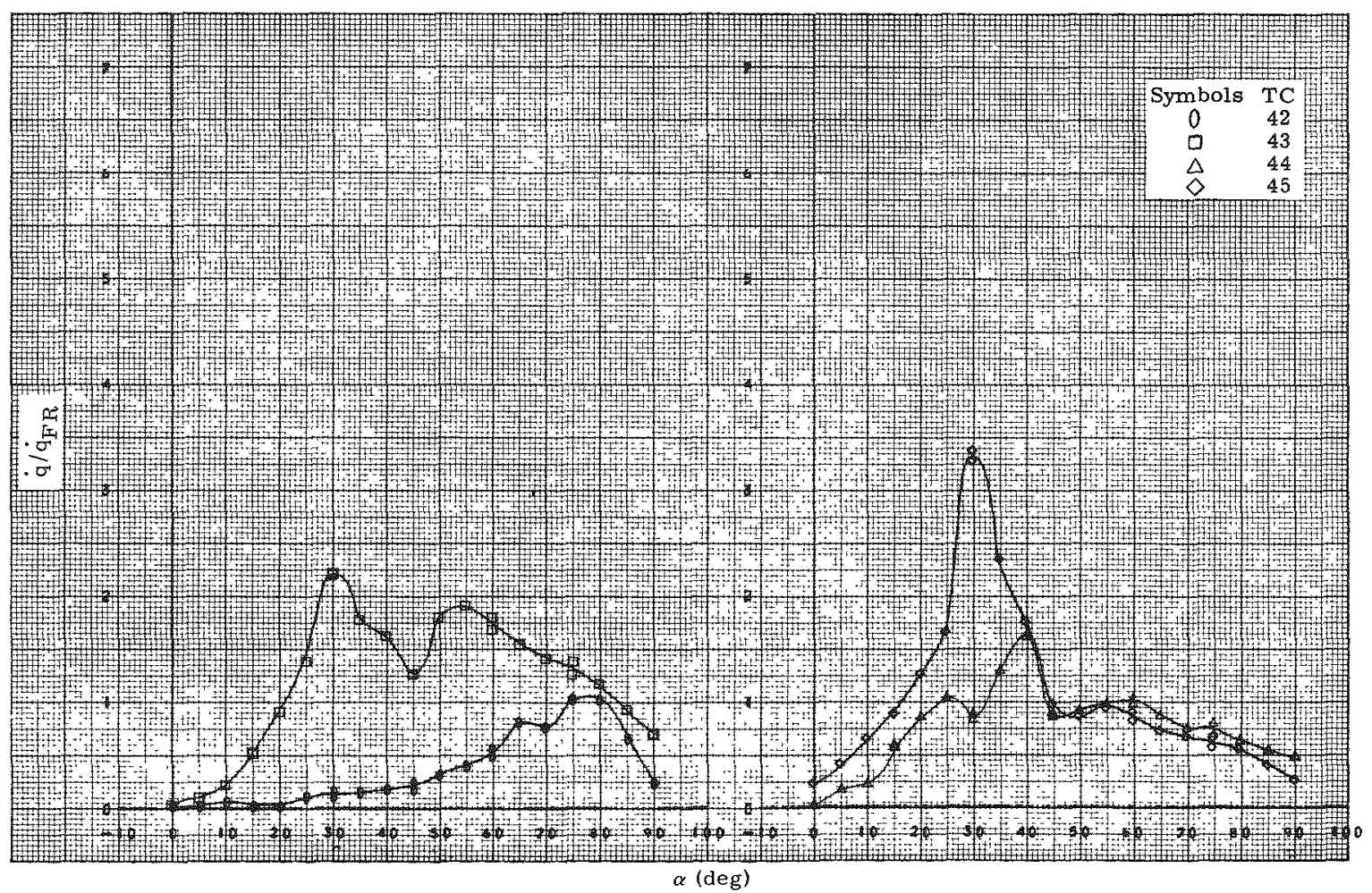

Fig. 143. Heat Transfer, TC $42-45$, Configuration 200 


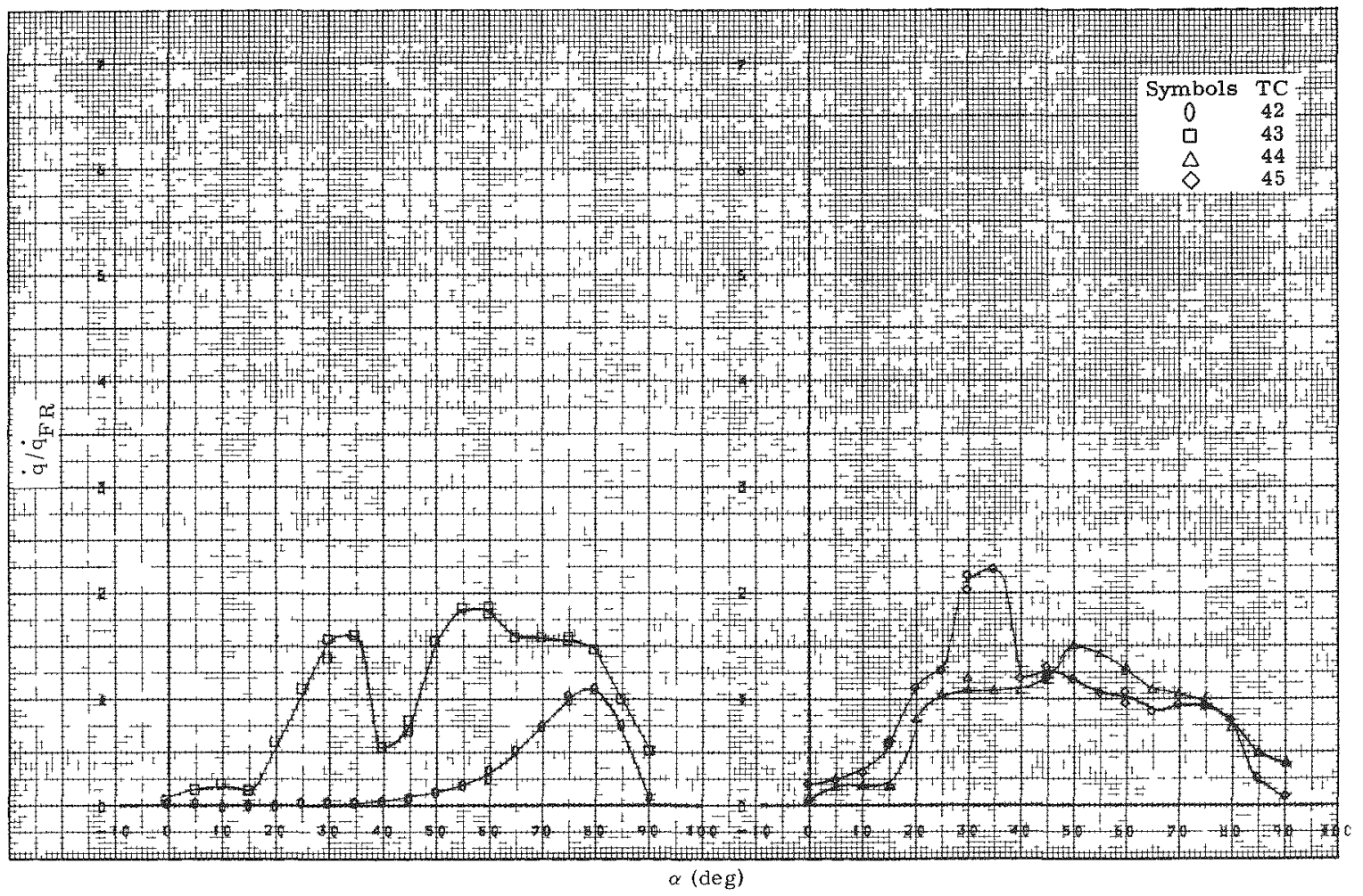

Fig. 144. Heat Transfer, TC $42-45$, Configuration 300

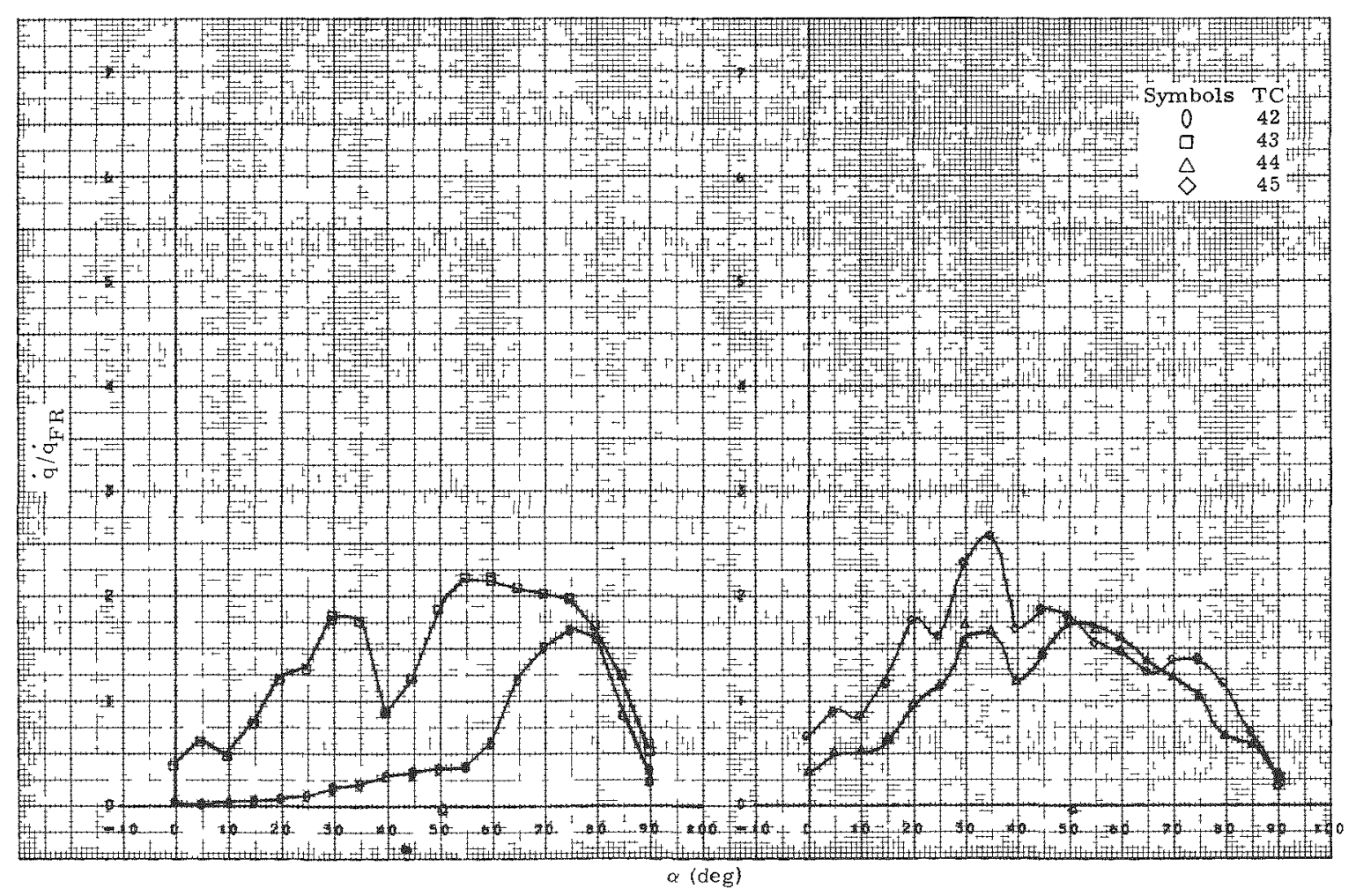

Fig. 145. Heat Transfer, TC $42-45$, Configuration 400 


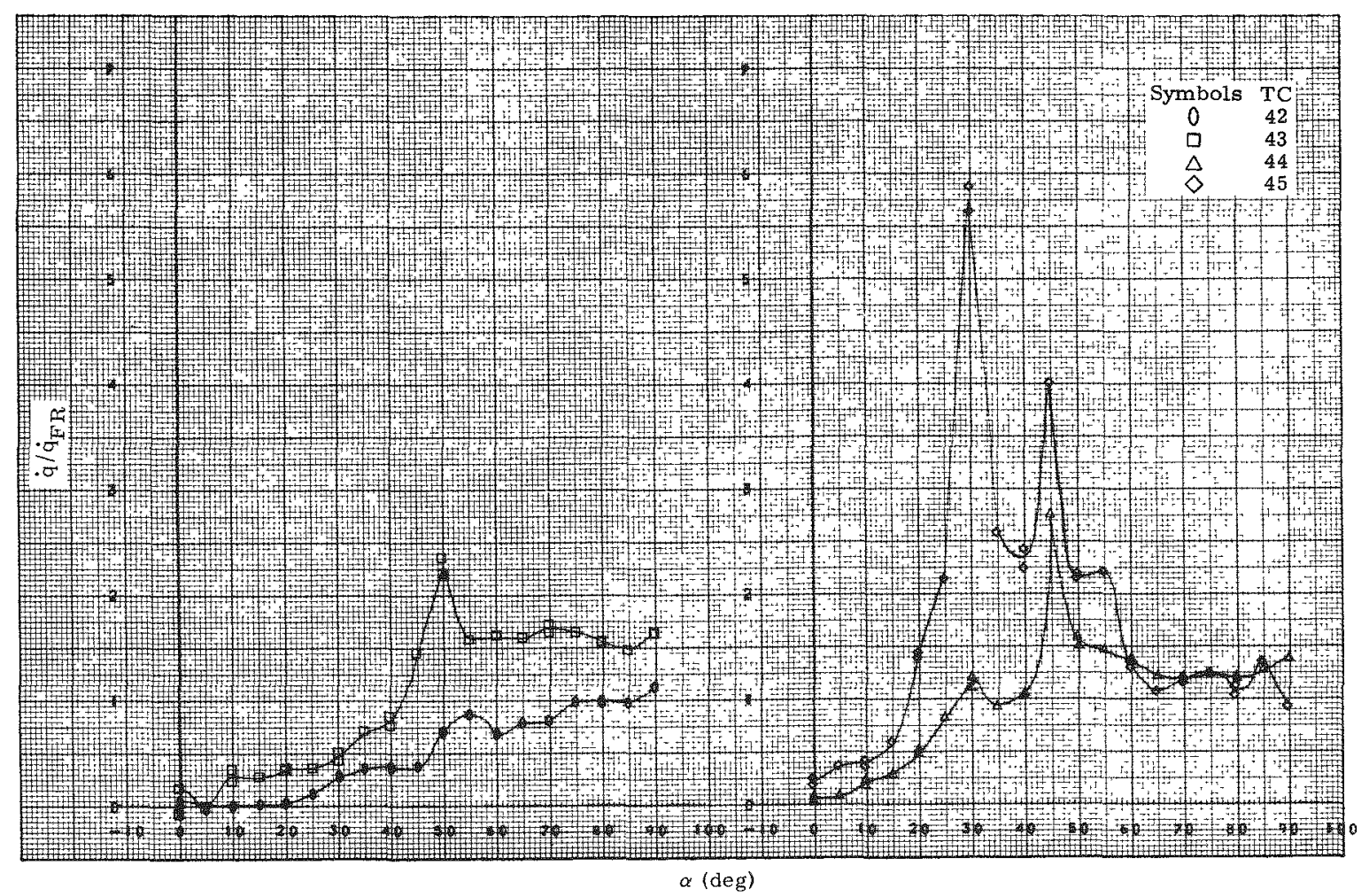

Fig. 146. Heat Transfer, TC $42-45$, Configuration 130

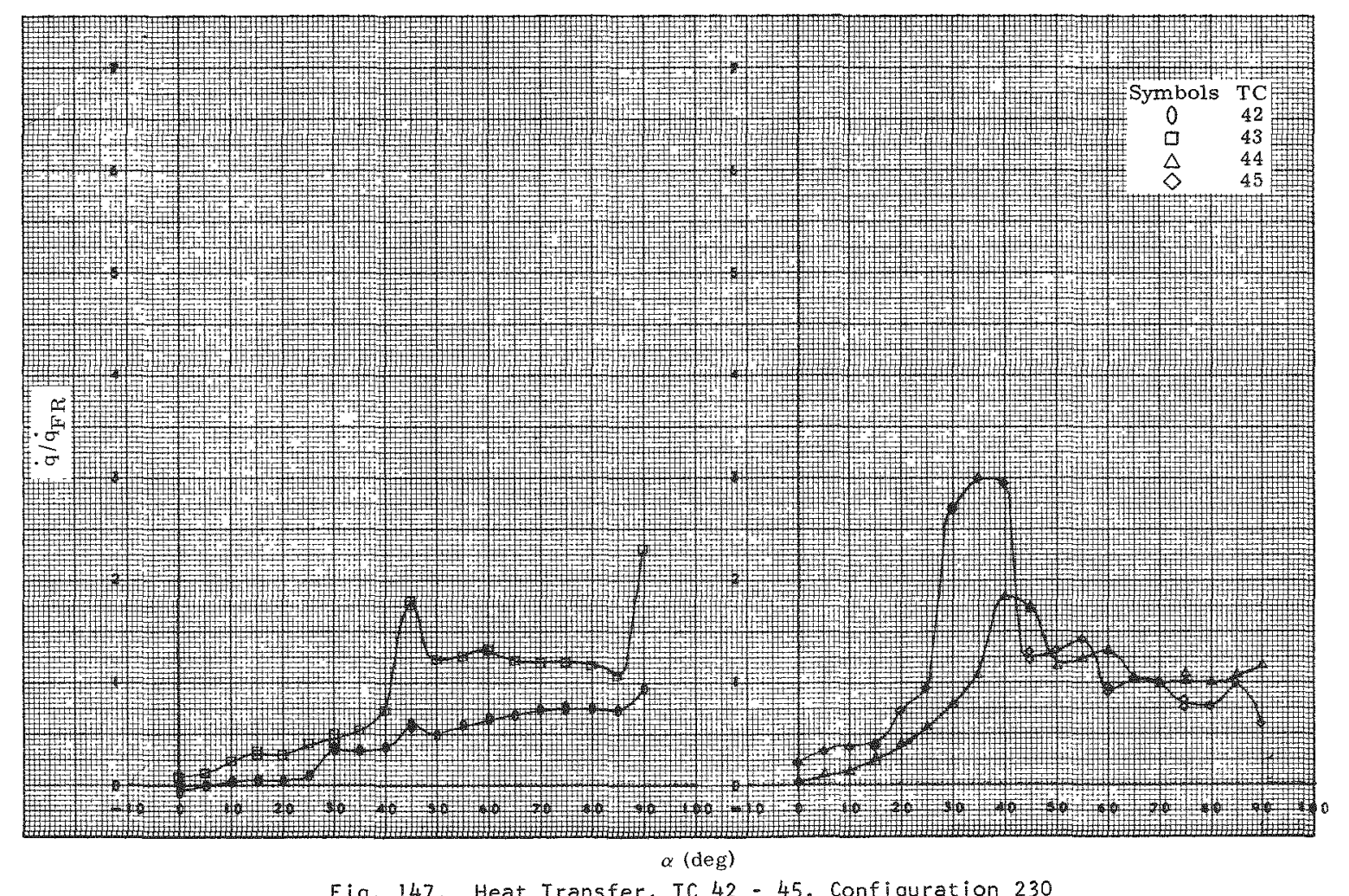

Fig. 147. Heat Transfer, TC $42-45$, Configuration 230 


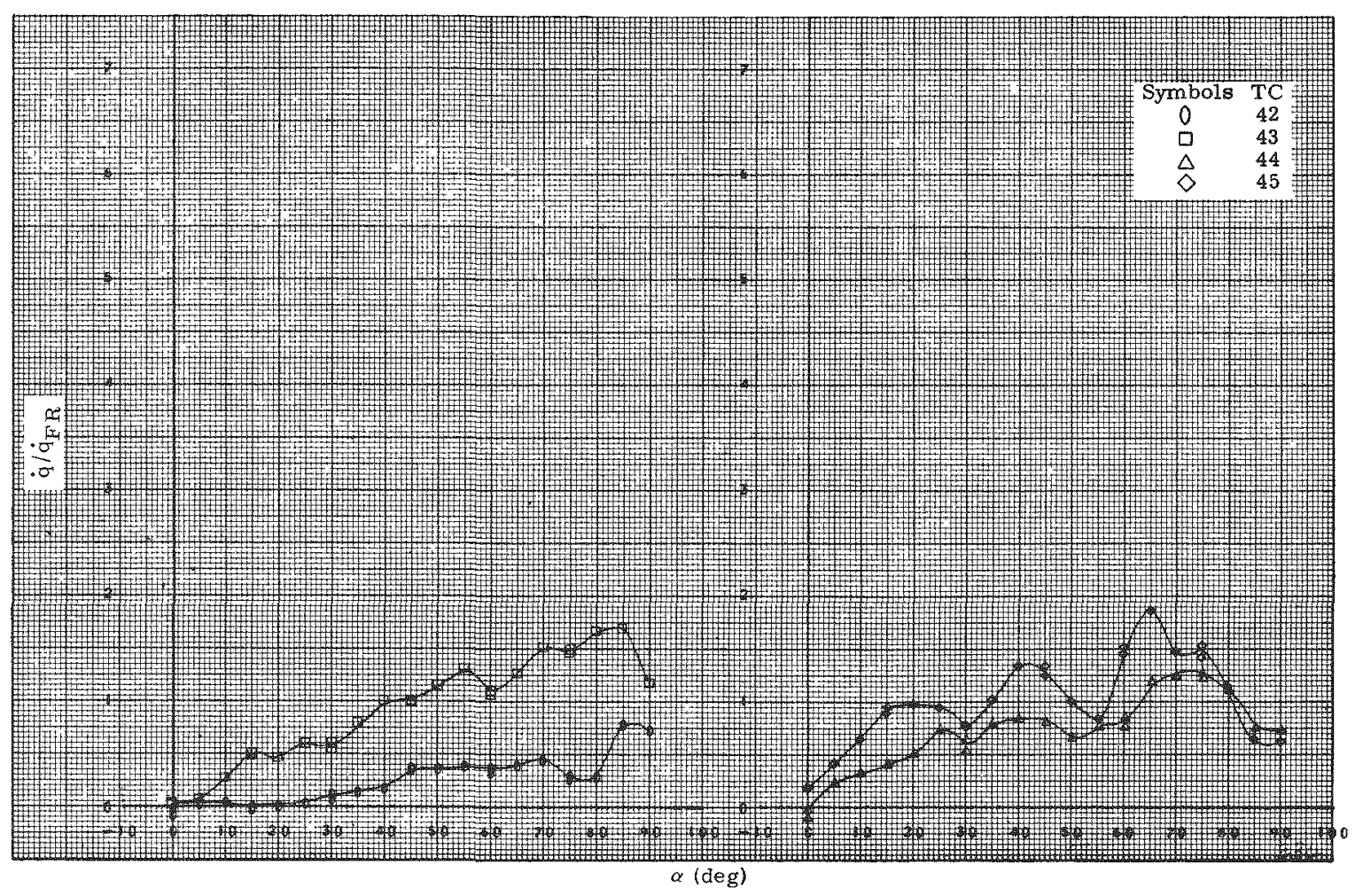

Fig. 148. Heat Transfer, TC 42-45, Configuration 330

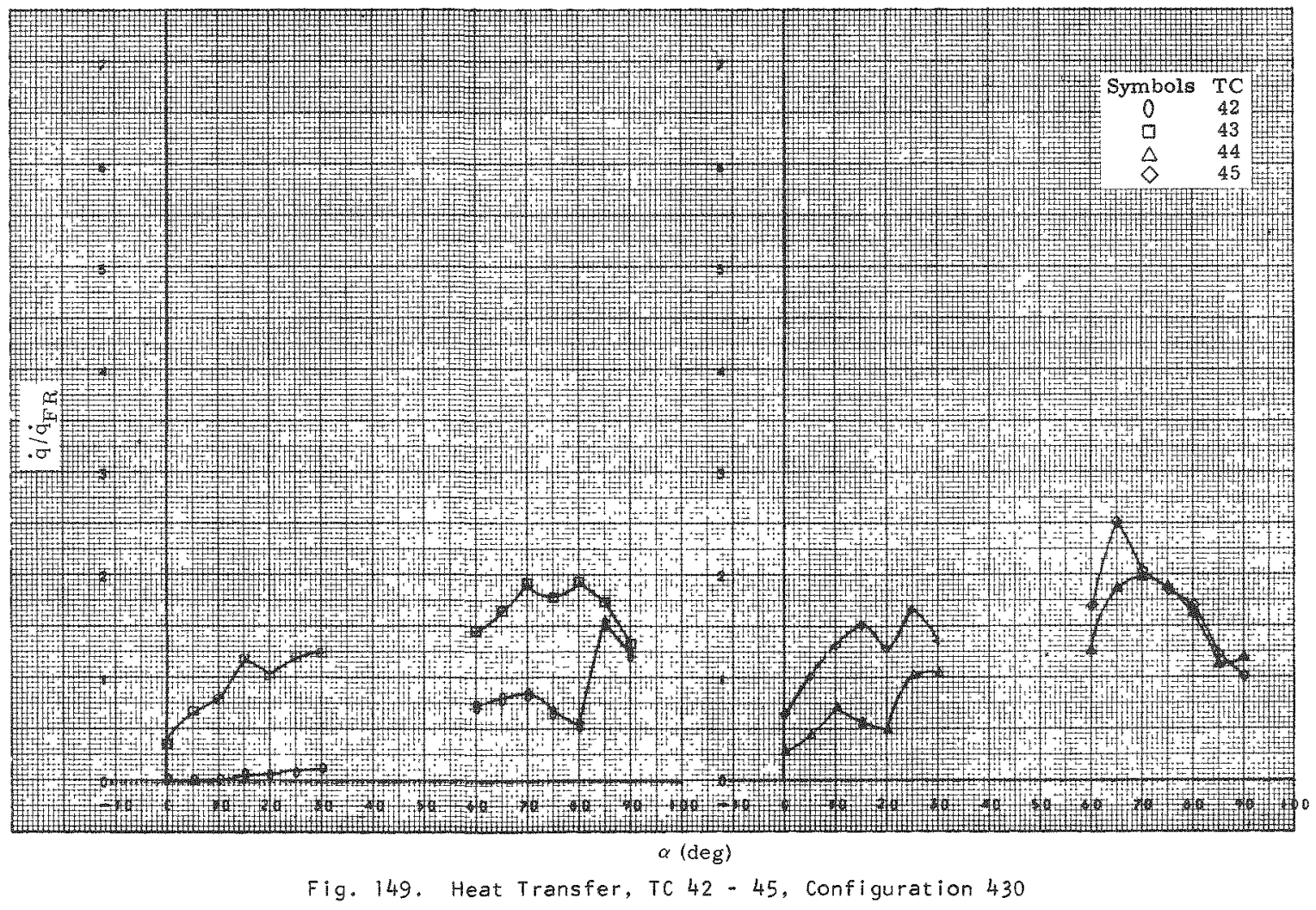

MND-3607-92 


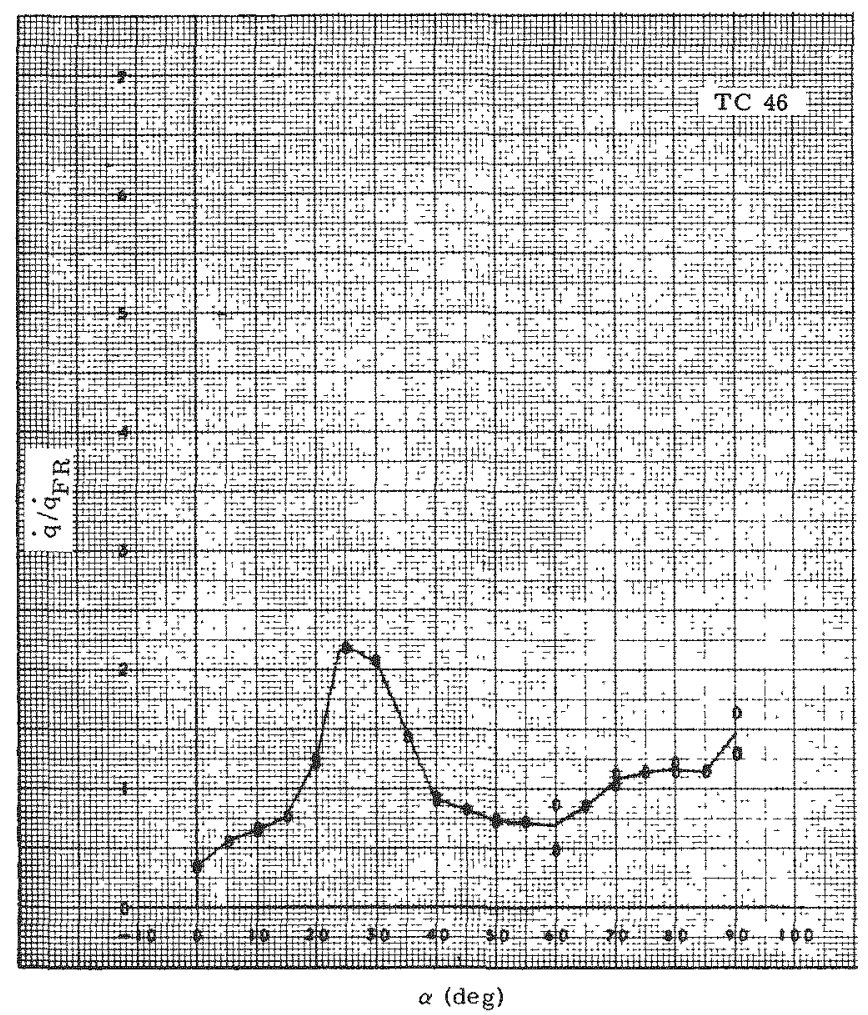

Fig. 150. Heat Transfer, TC 46, Configuration 100

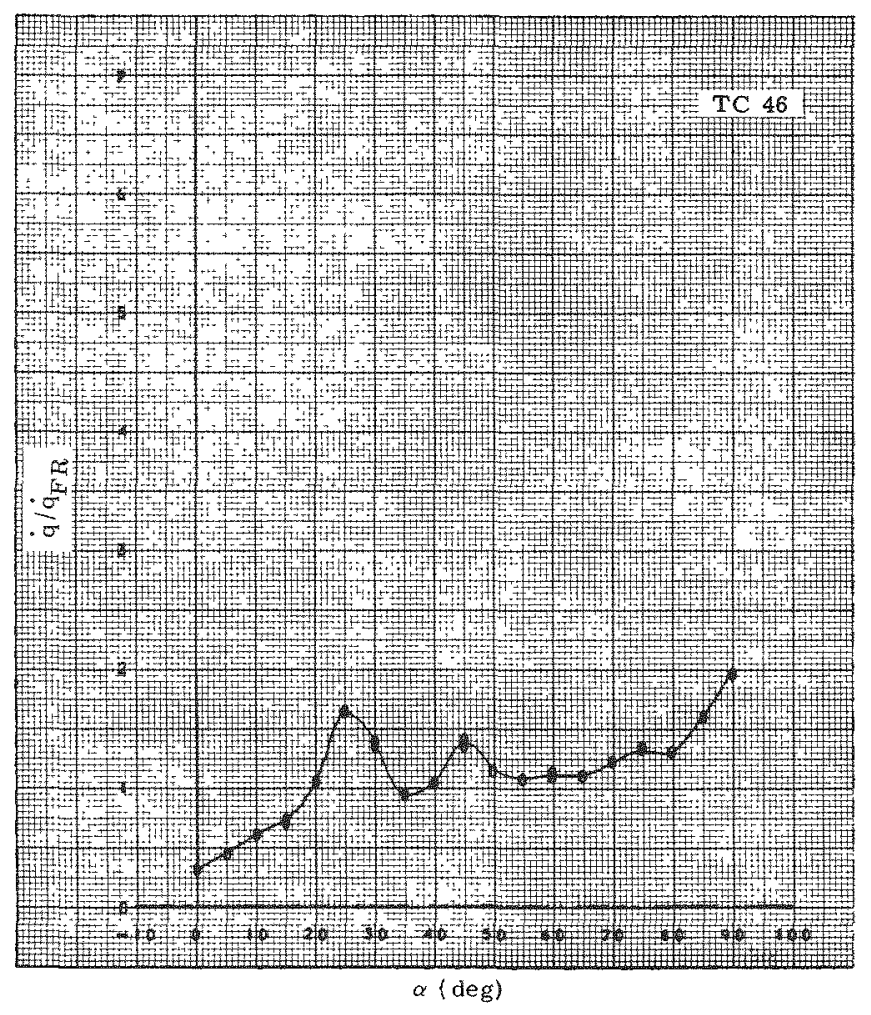

Fig. 151. Heat Transfer, TC 46, Configuration 200

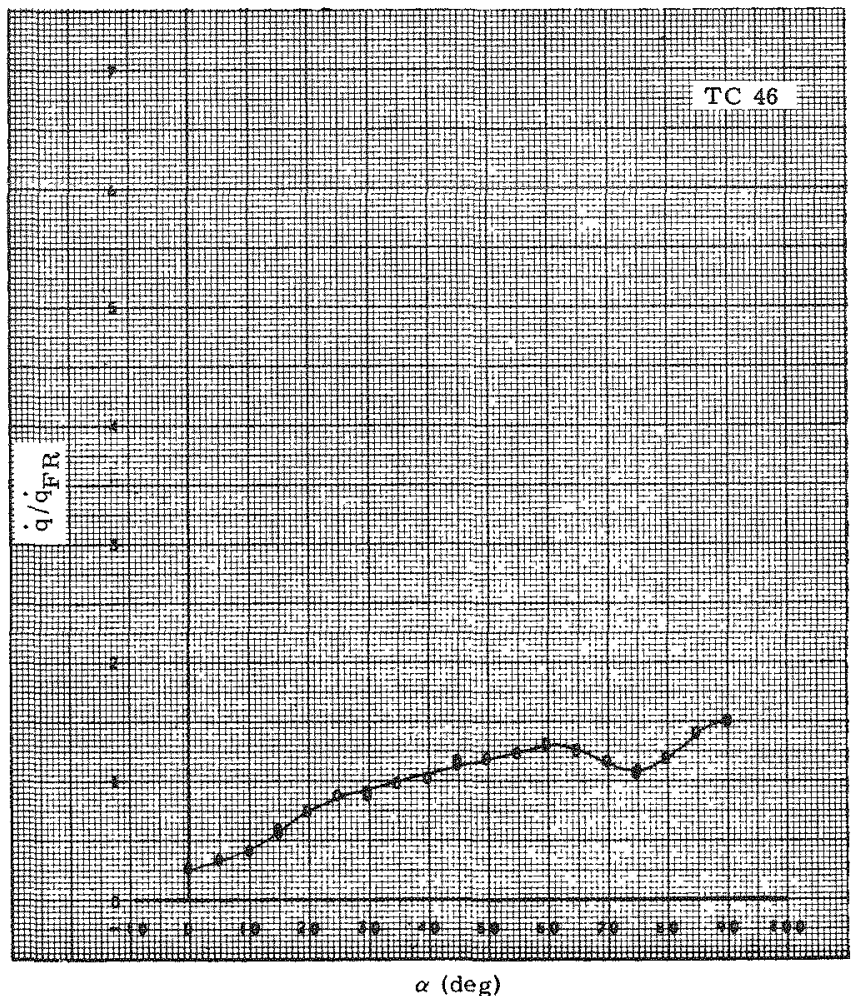

Fig. 152. Heat Transfer, TC 46, Configuration 300

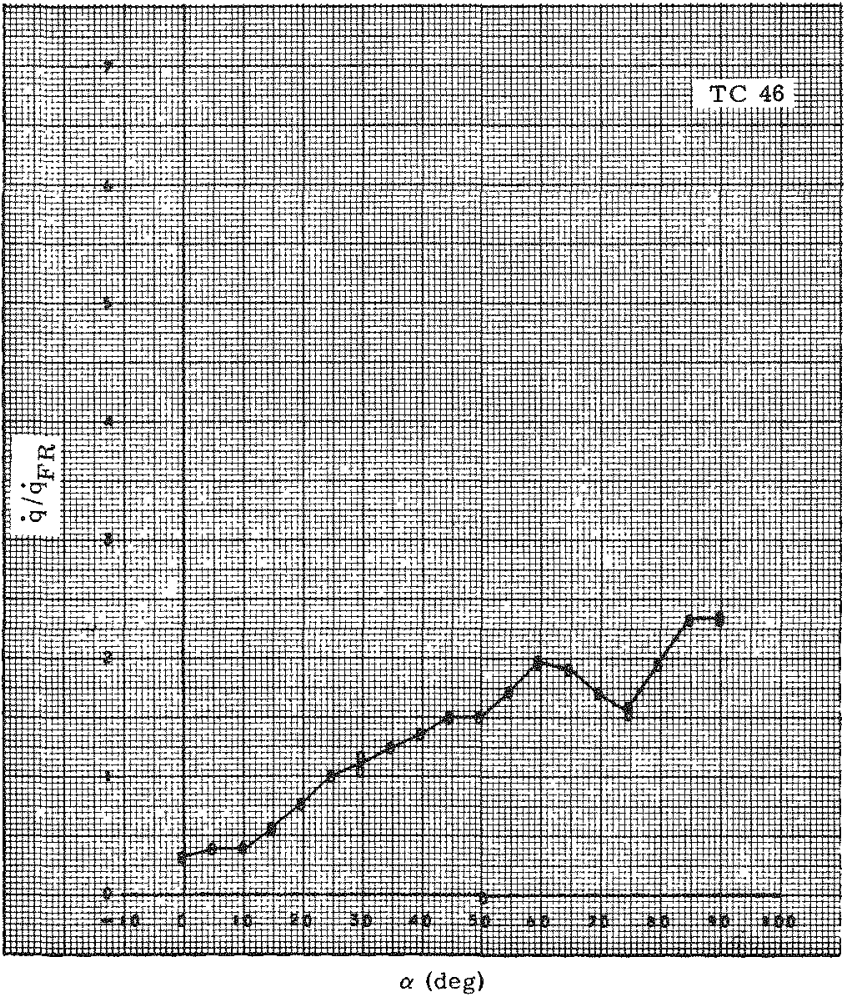

Fig. 153. Heat Transfer, TC 46, Configuration 400 


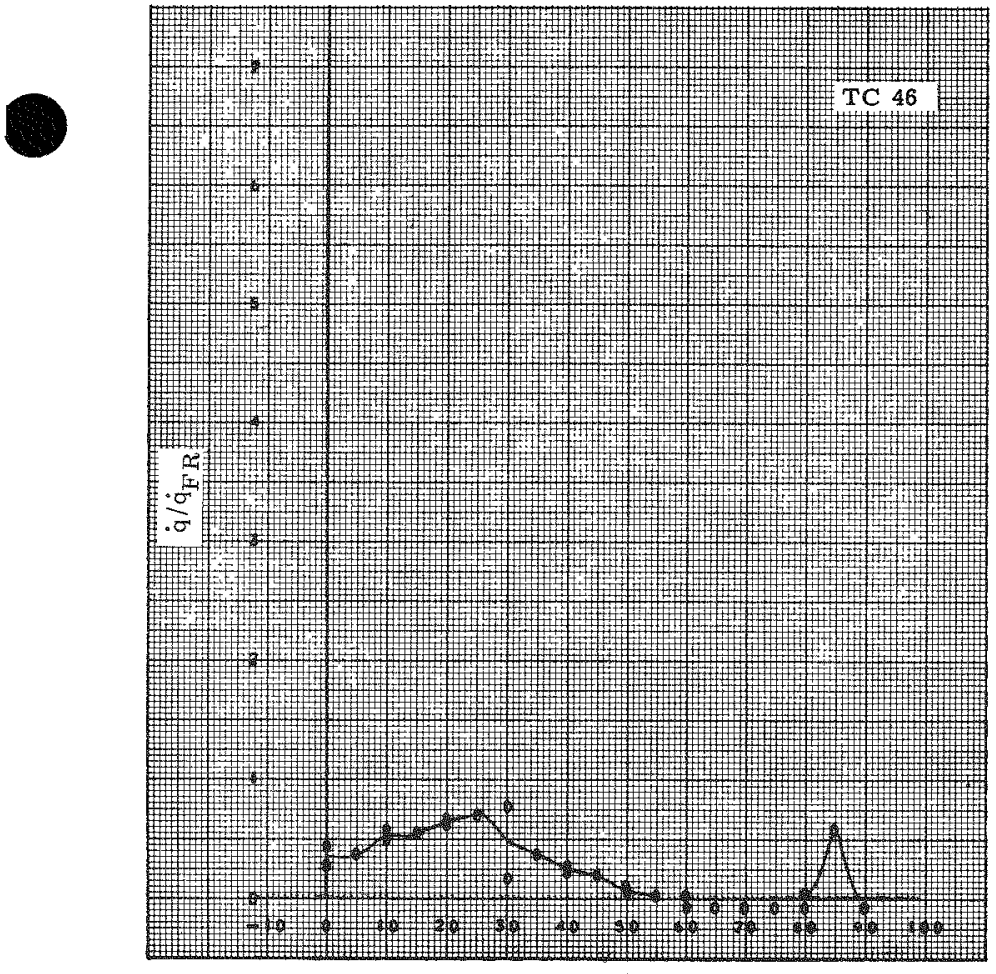

Fig. 154. Heat Transfer, TC 46, Configuration 130

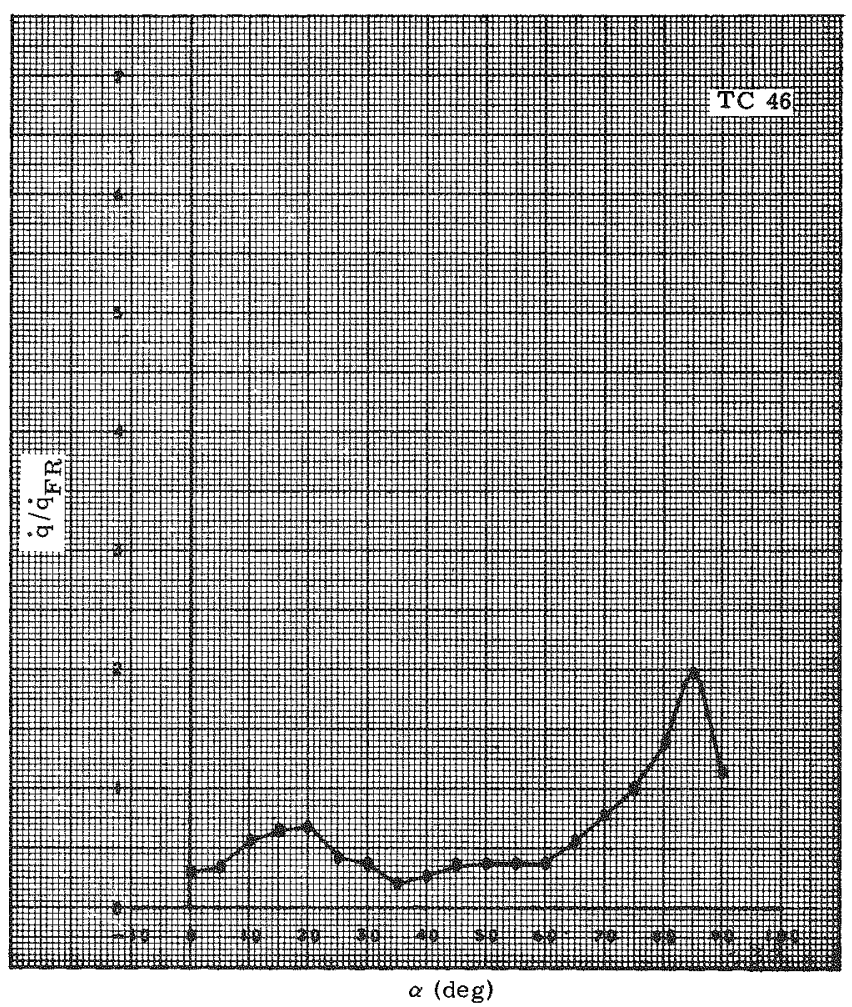

Fig. 155. Heat Transfer, TC 46, Configuration 230

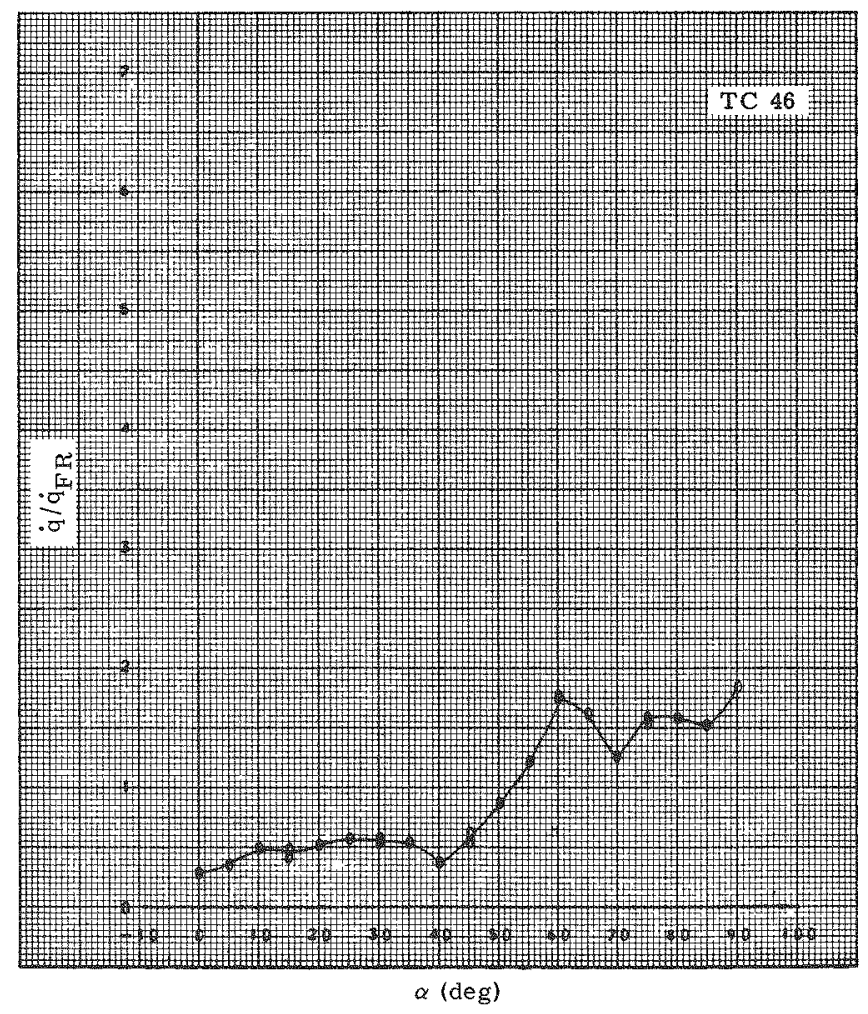

Fig. 156. Heat Transfer, TC 46, Configuration 330

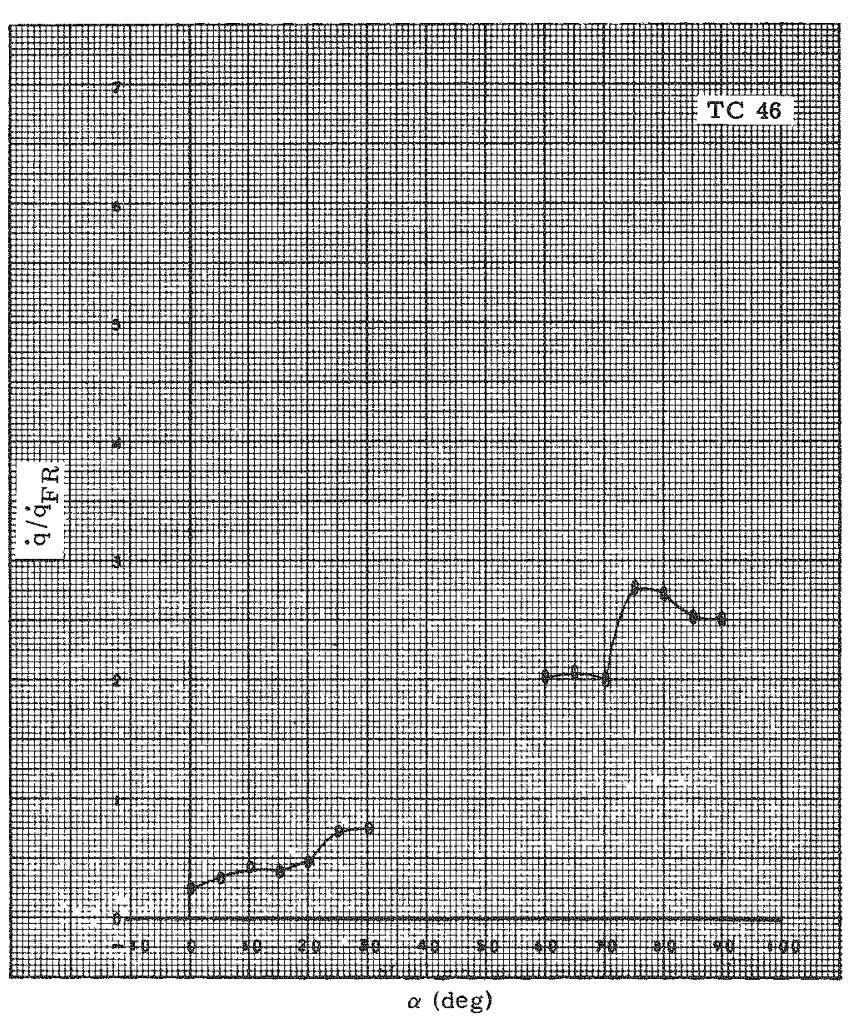

Fig. 157. Heat Transfer, TC 46, Configuration 430 


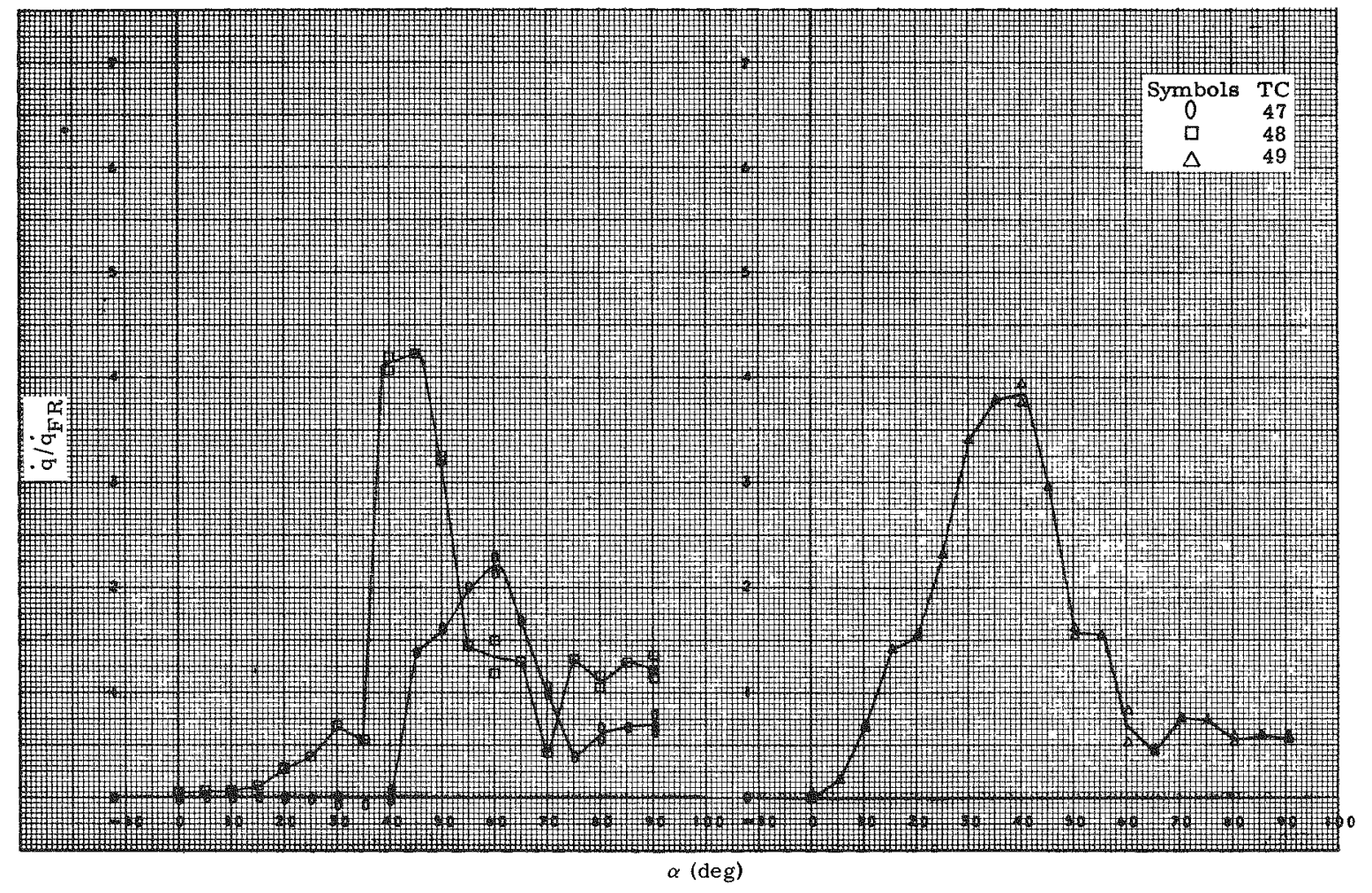

Fig. 158. Heat Transfer, TC $47-49$, Configuration 100

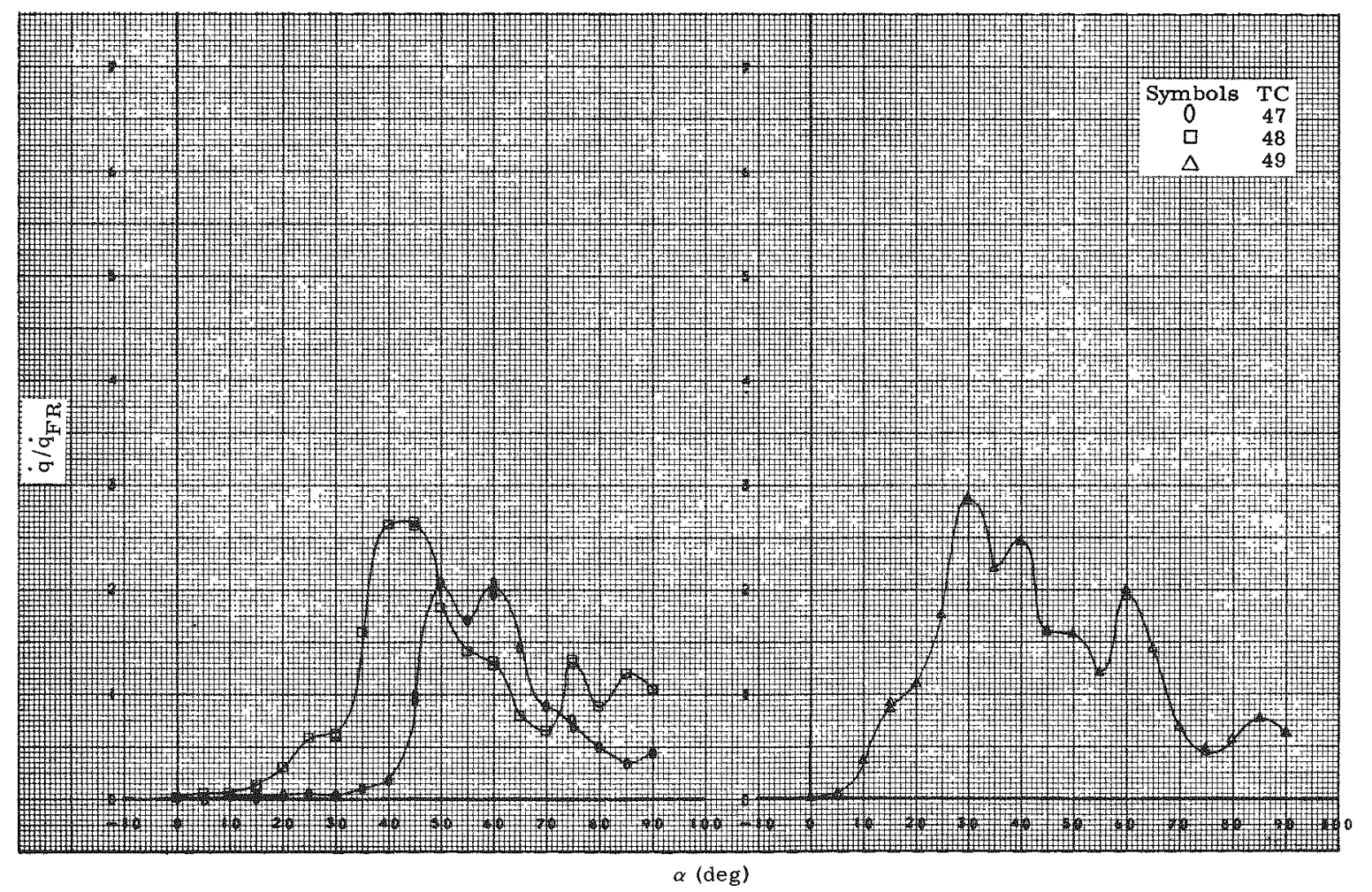

Fig. 159. Heat Transfer, TC $47-49$, Configuration 200 


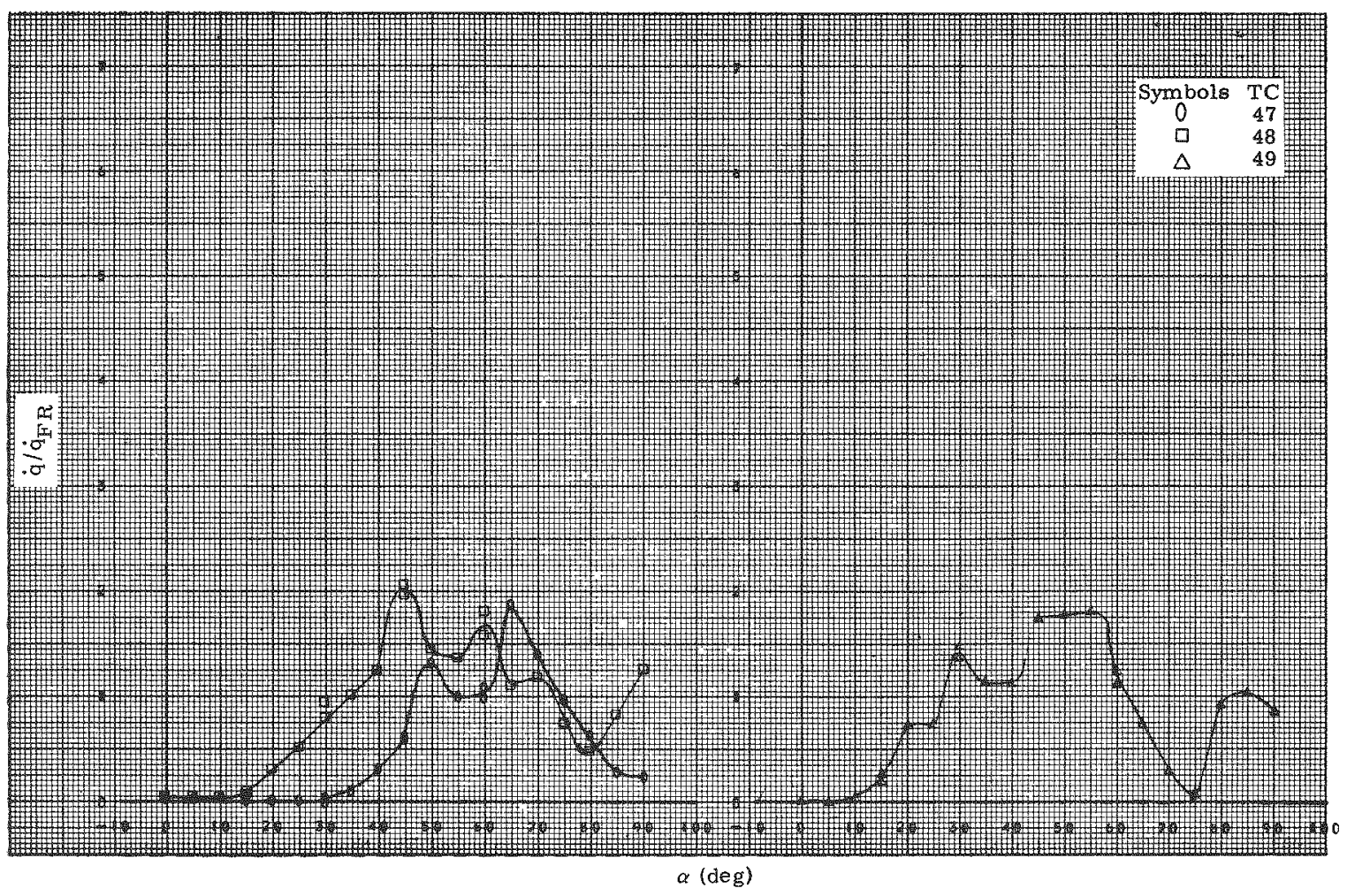

Fig. 160. Heat Transfer, TC $47-49$, Configuration 300

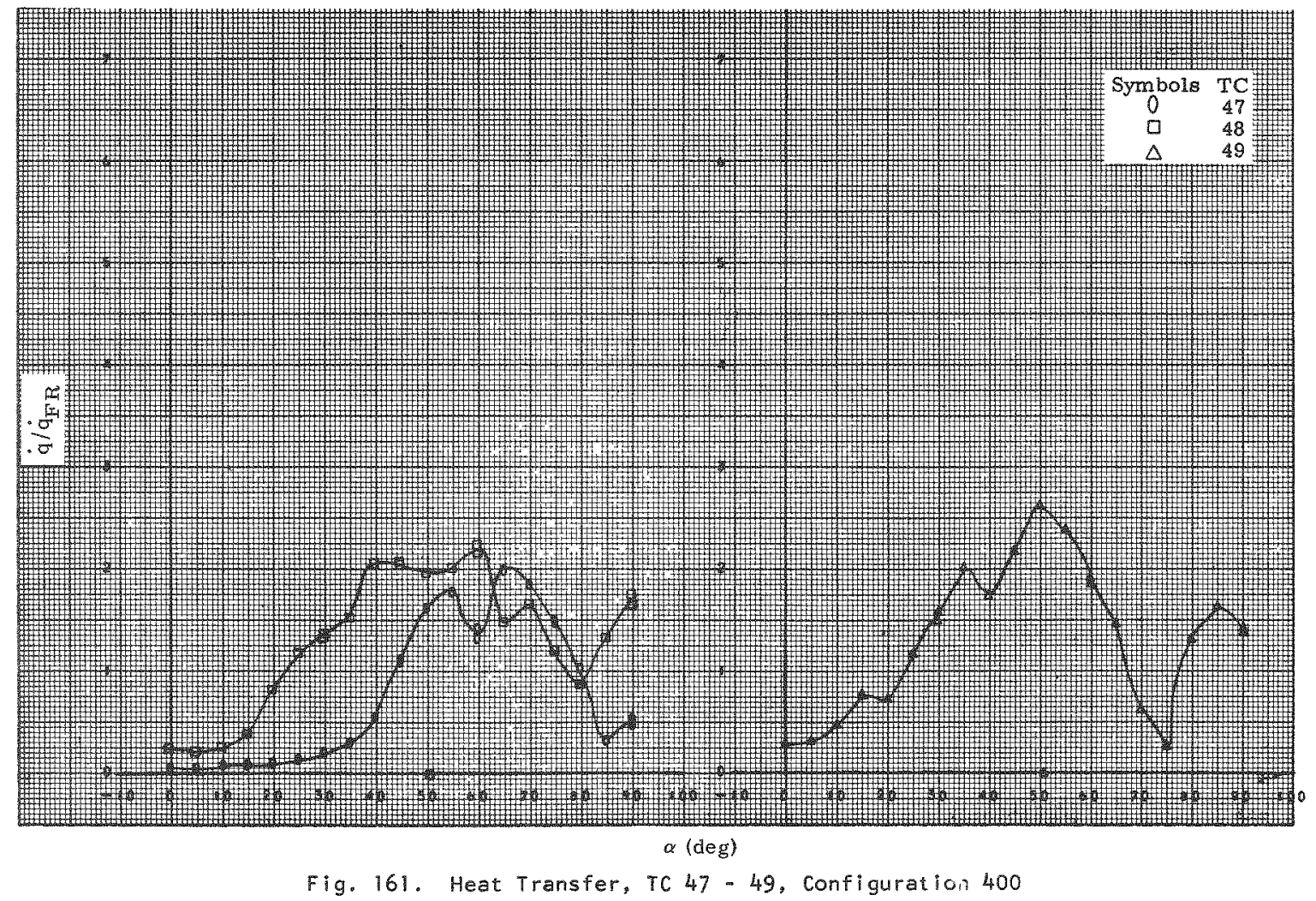

MND-3607-92

111 

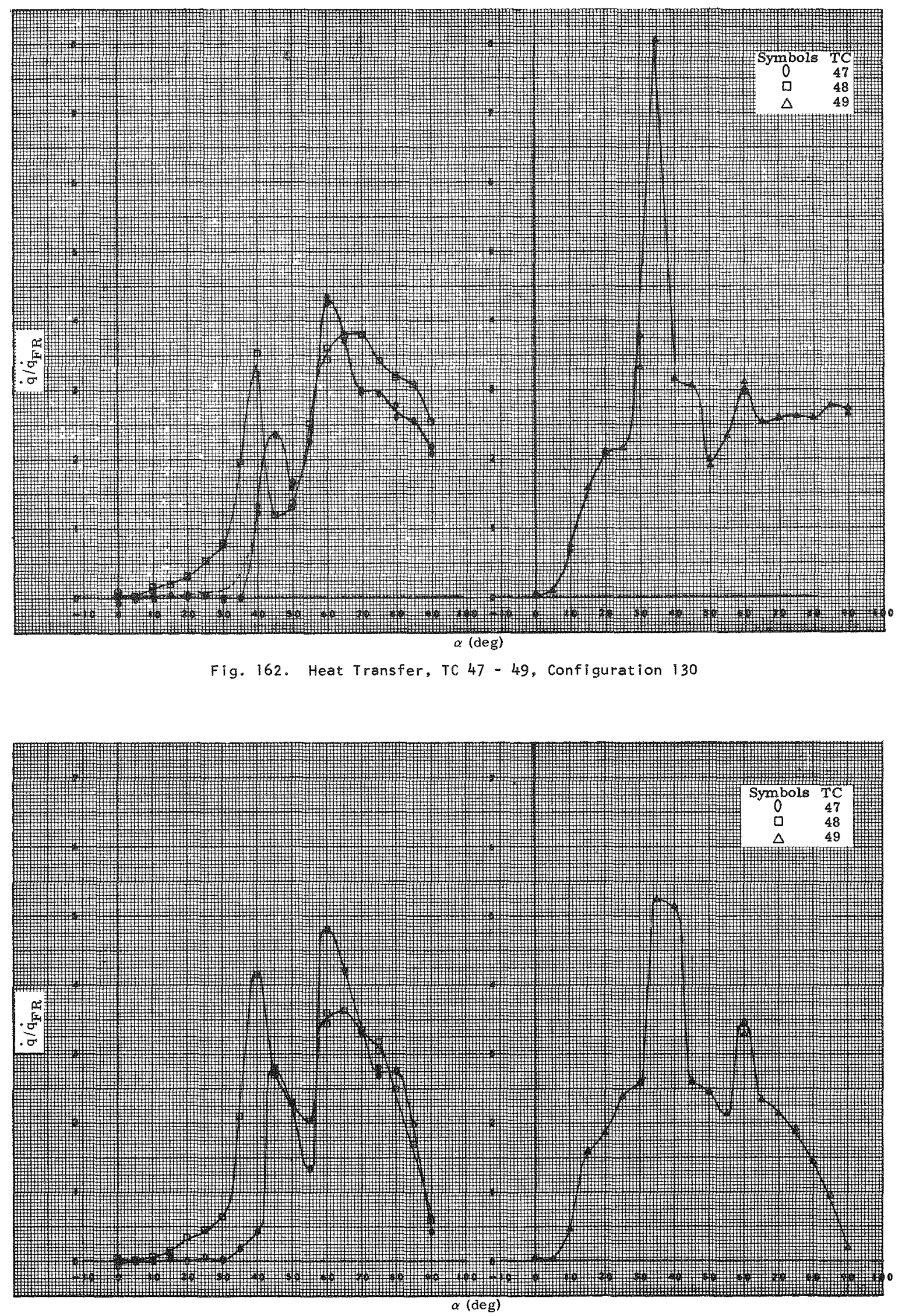

Fig. 163. Heat Transfer, TC $47-49$, Configuration 230 

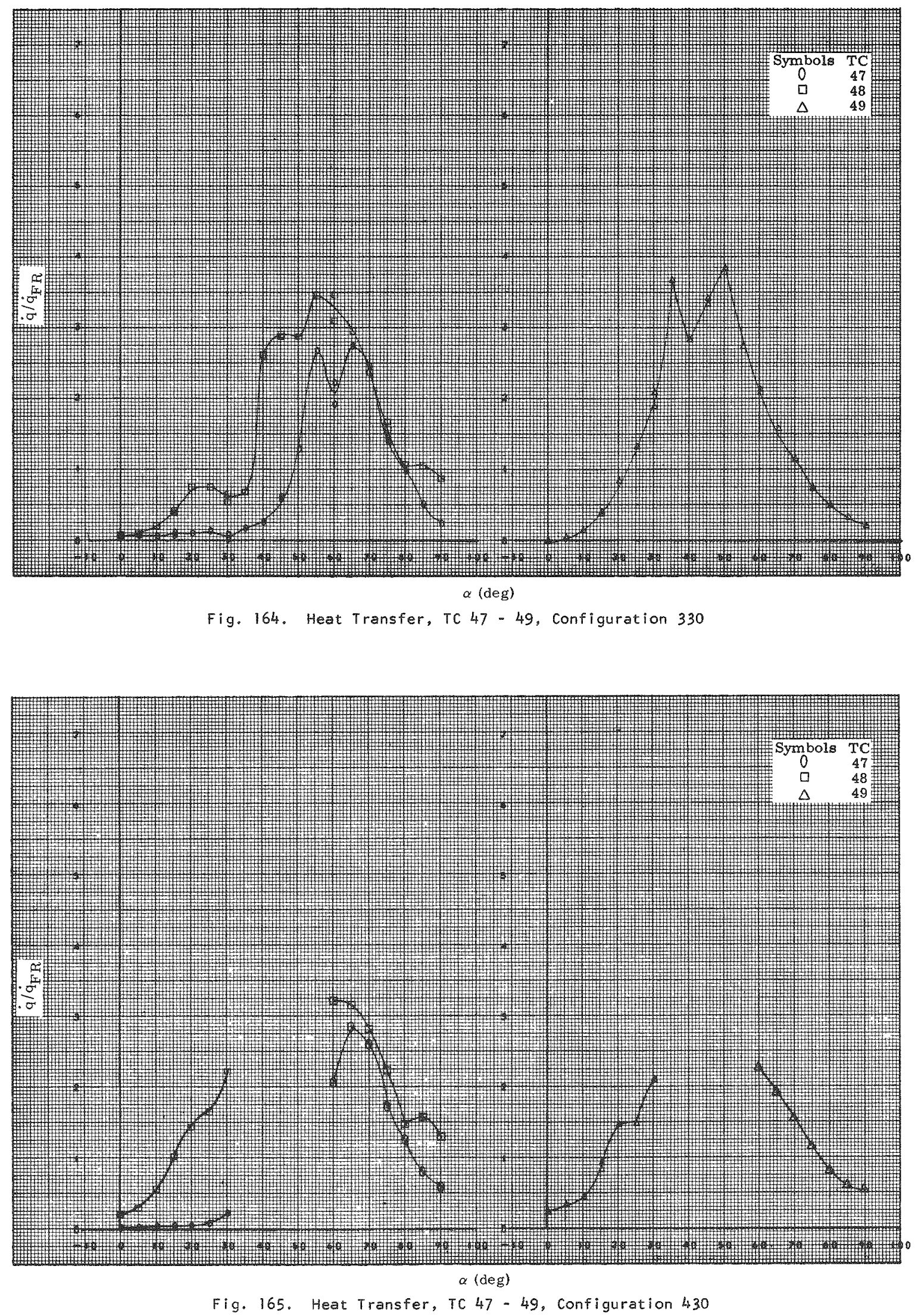

MND-3607-92

113 


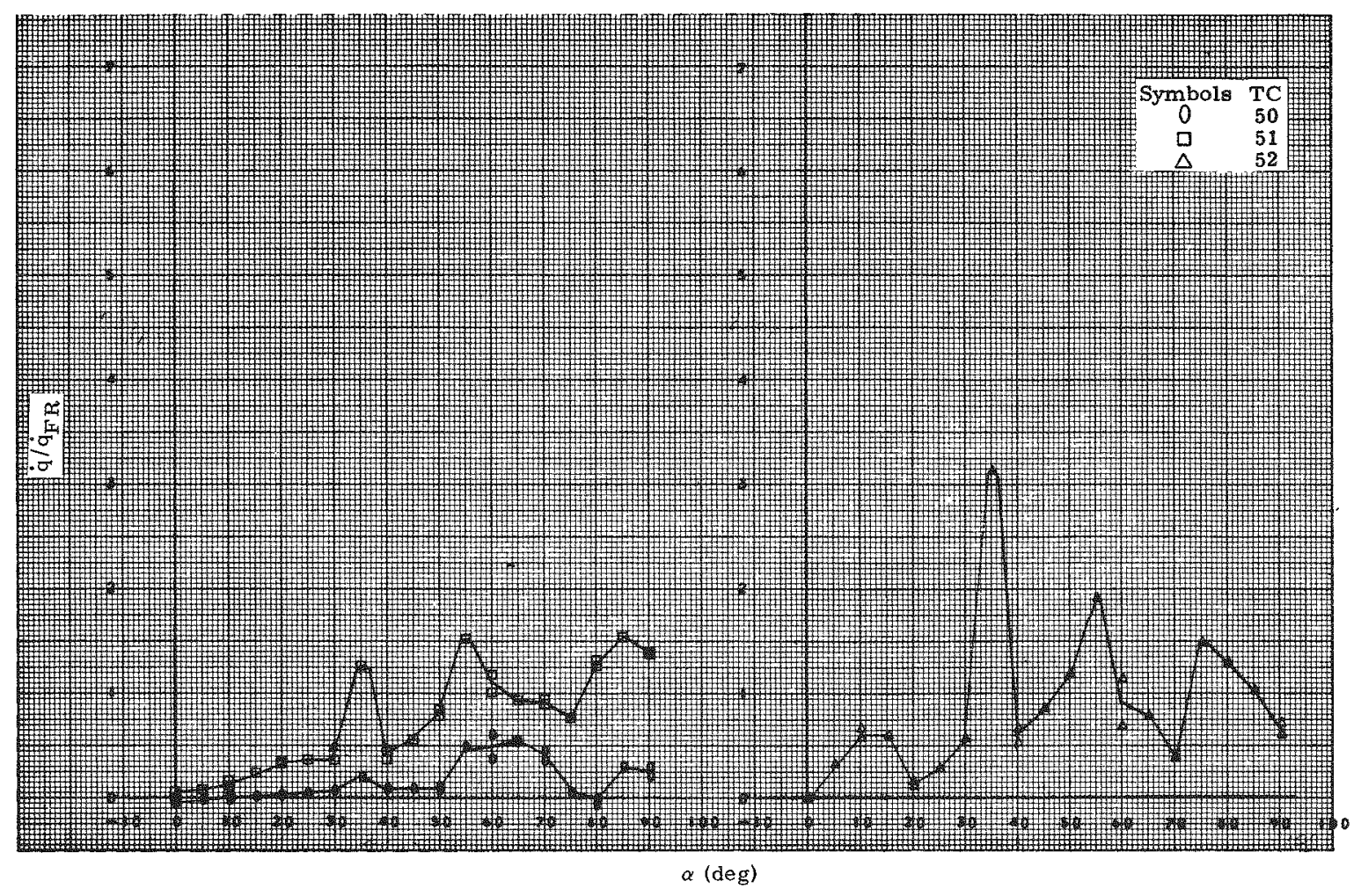

Fig. 166. Heat Transfer, TC $50-52$, Configuration 100

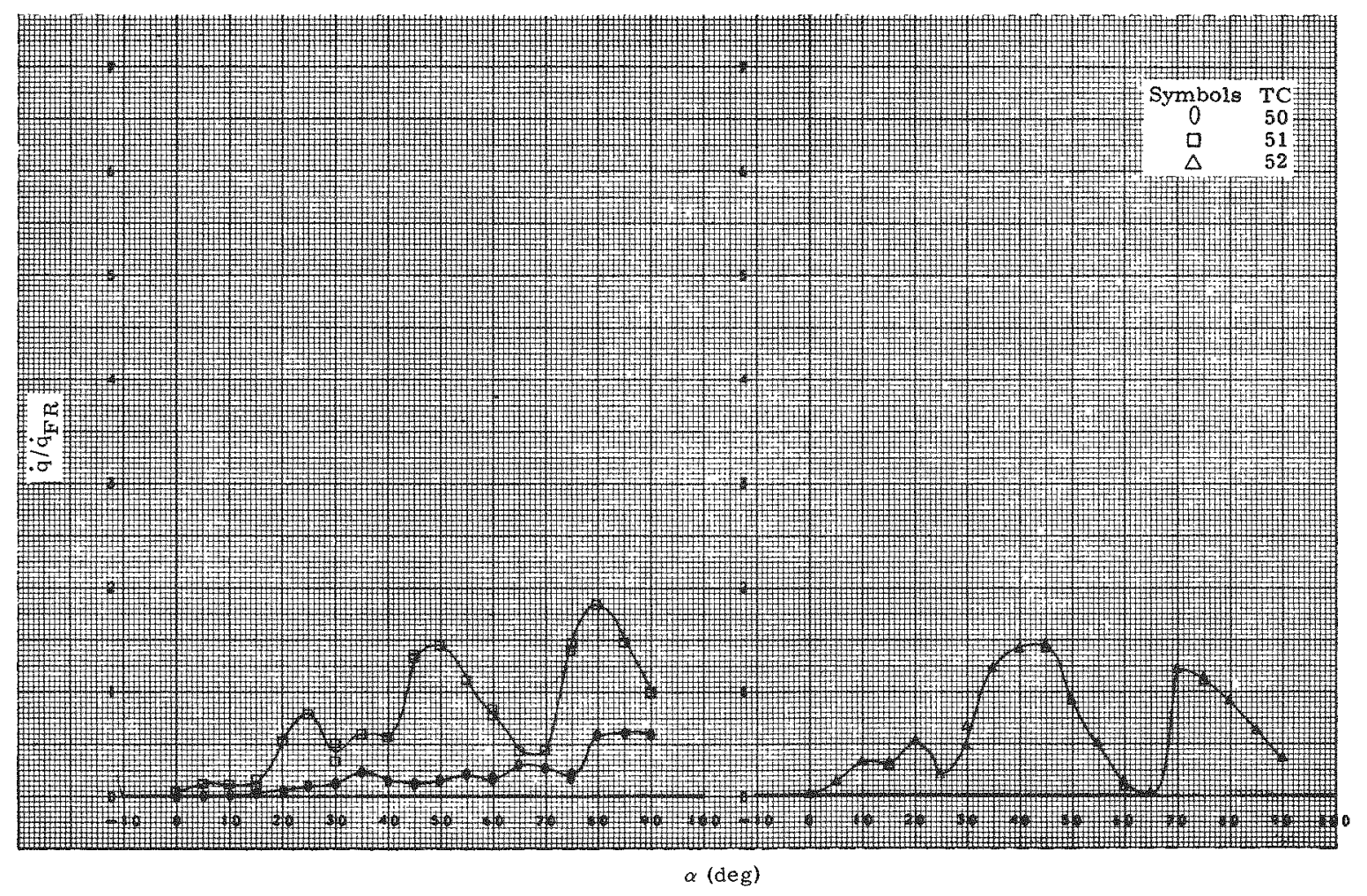

Fig. 167. Heat Transfer, TC $50-52$, Configuration 200 


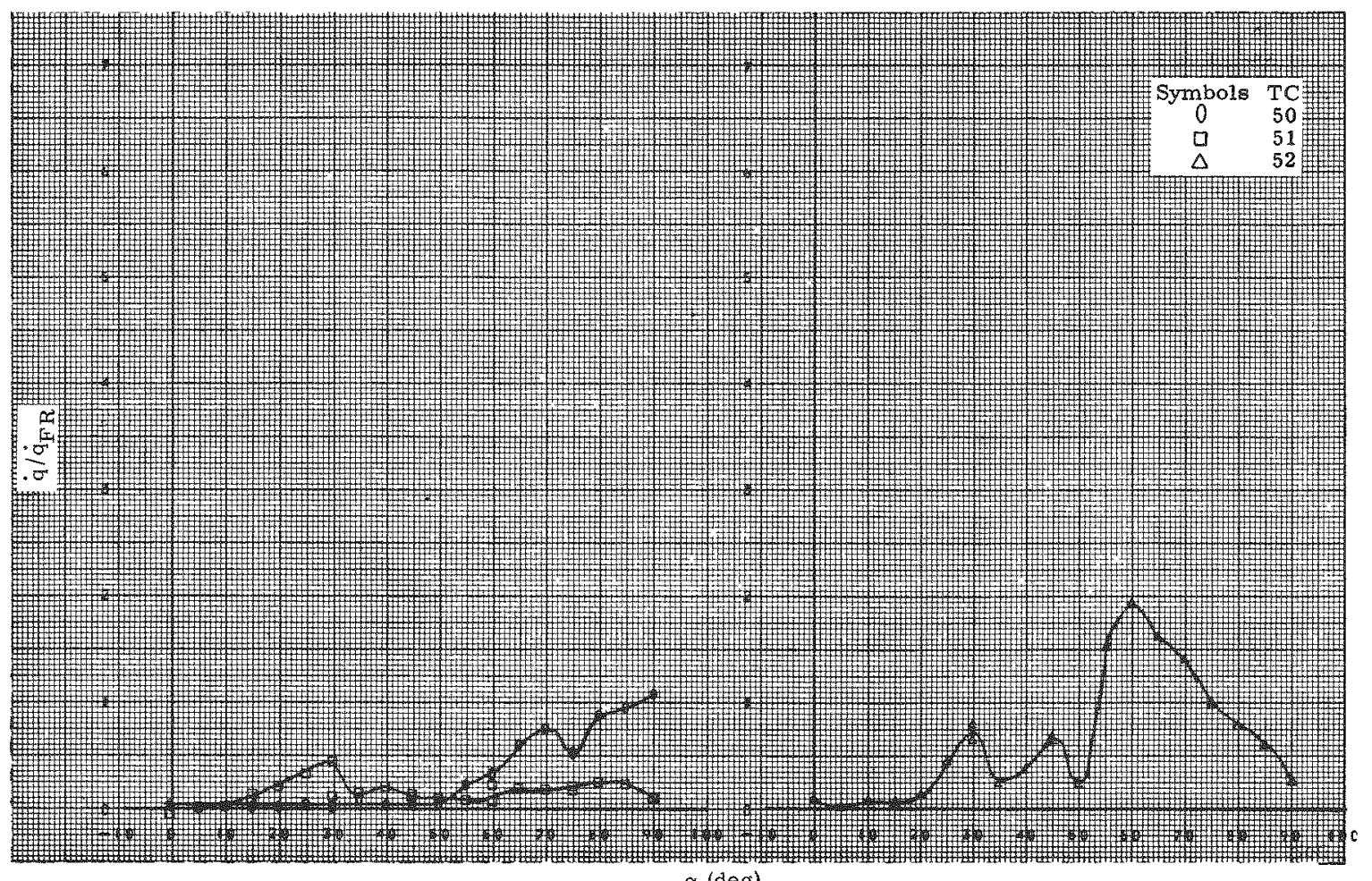
$\alpha(\operatorname{deg})$

Fig. 168. Heat Transfer, TC $50-52$, Configuration 300

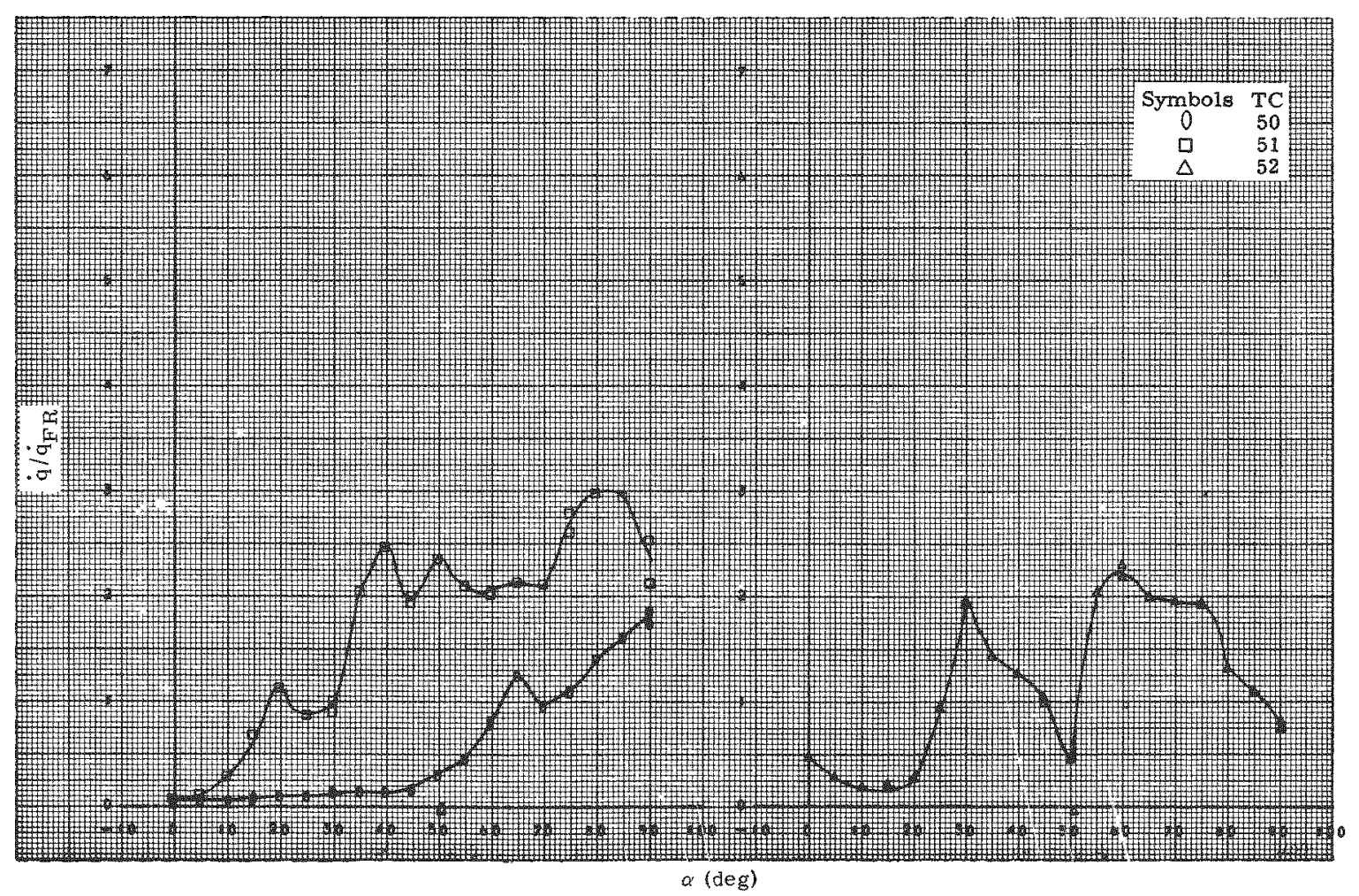

Fig. 169. Heat Transfer, TC $50-52$, Configuration 400 

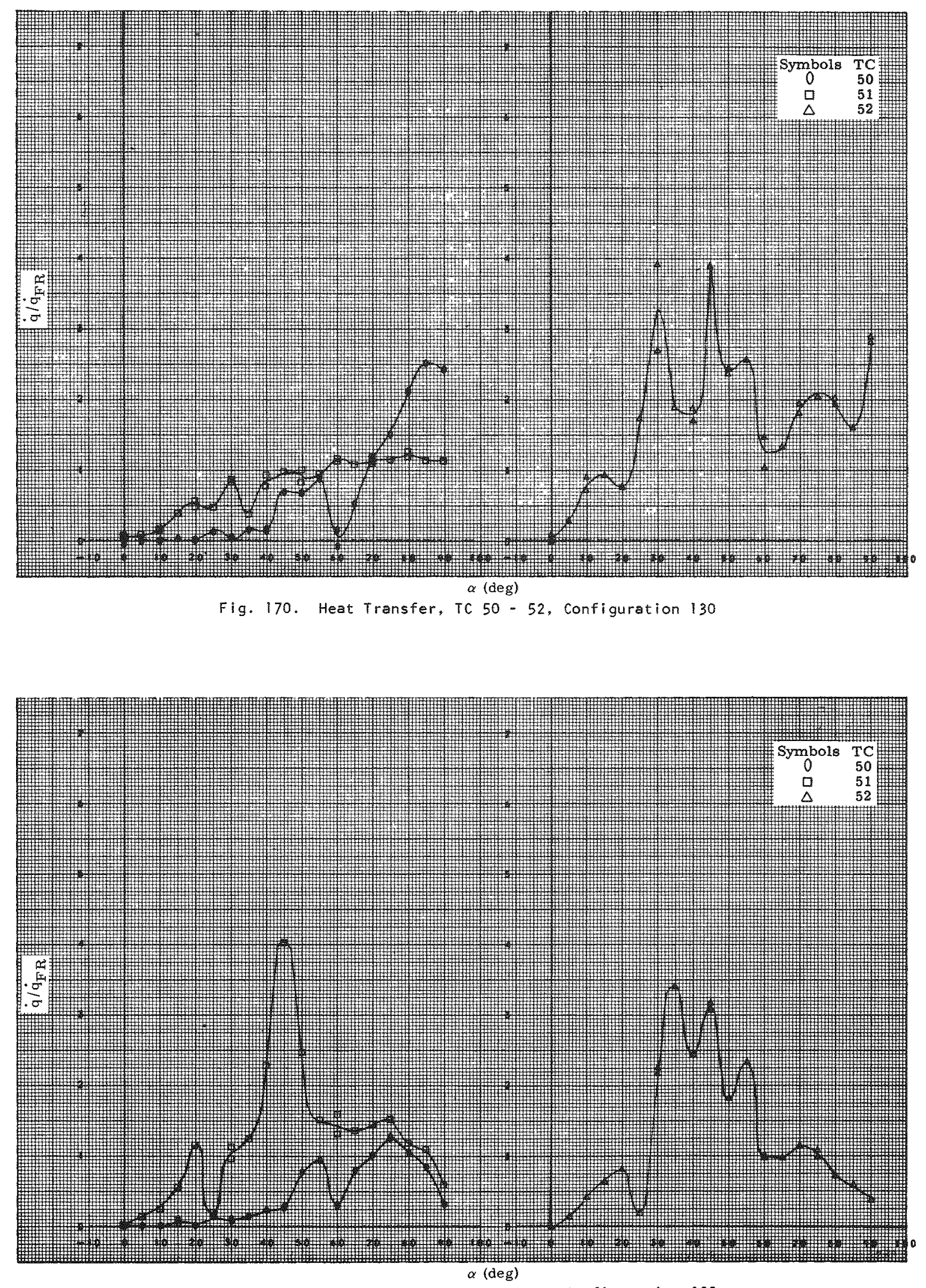

Fig. 171. Heat Transfer, TC $50-52$, Configuration 230 


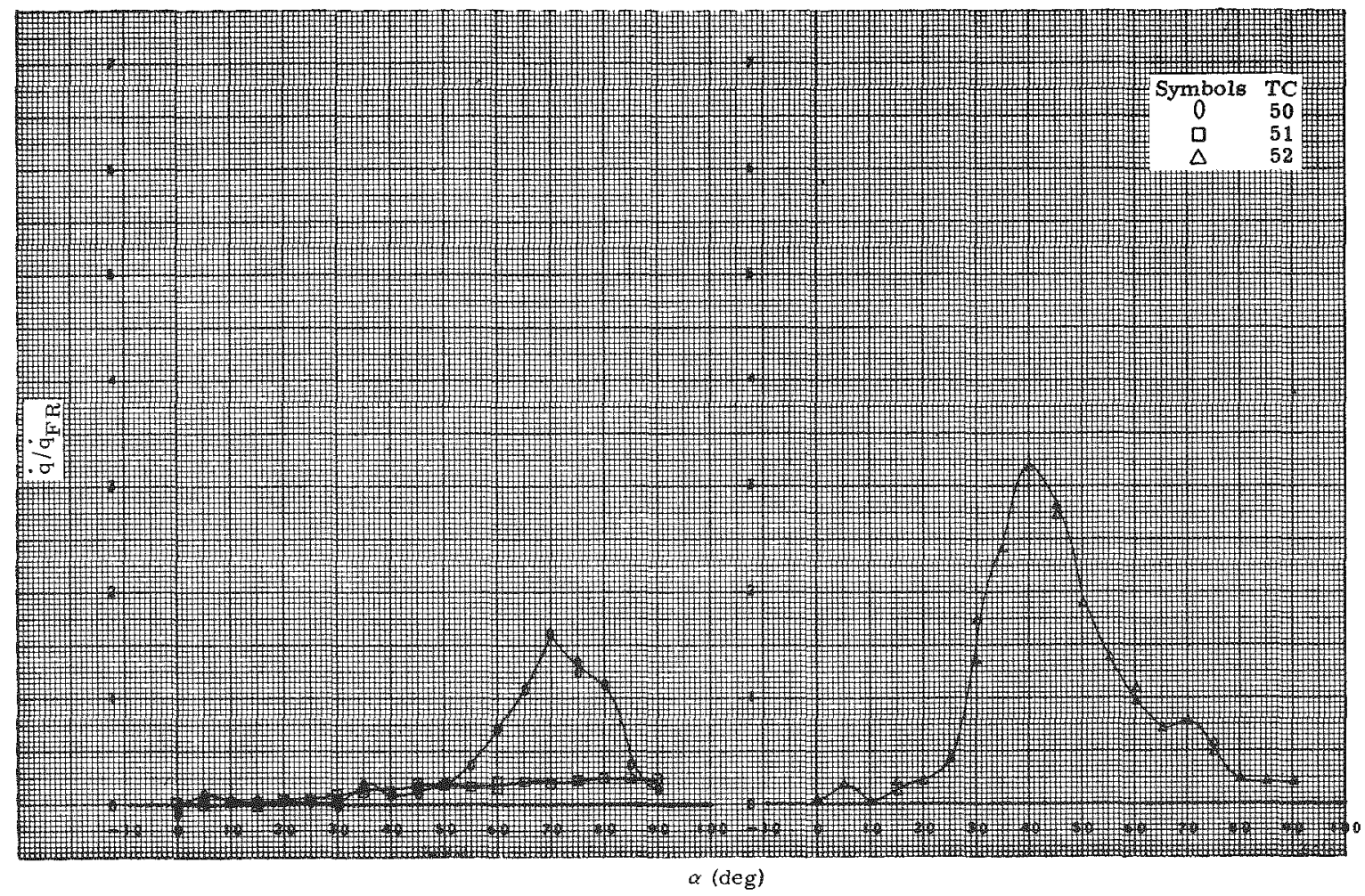

Fig. 172. Heat Transfer, TC $50-52$, Configuration 330

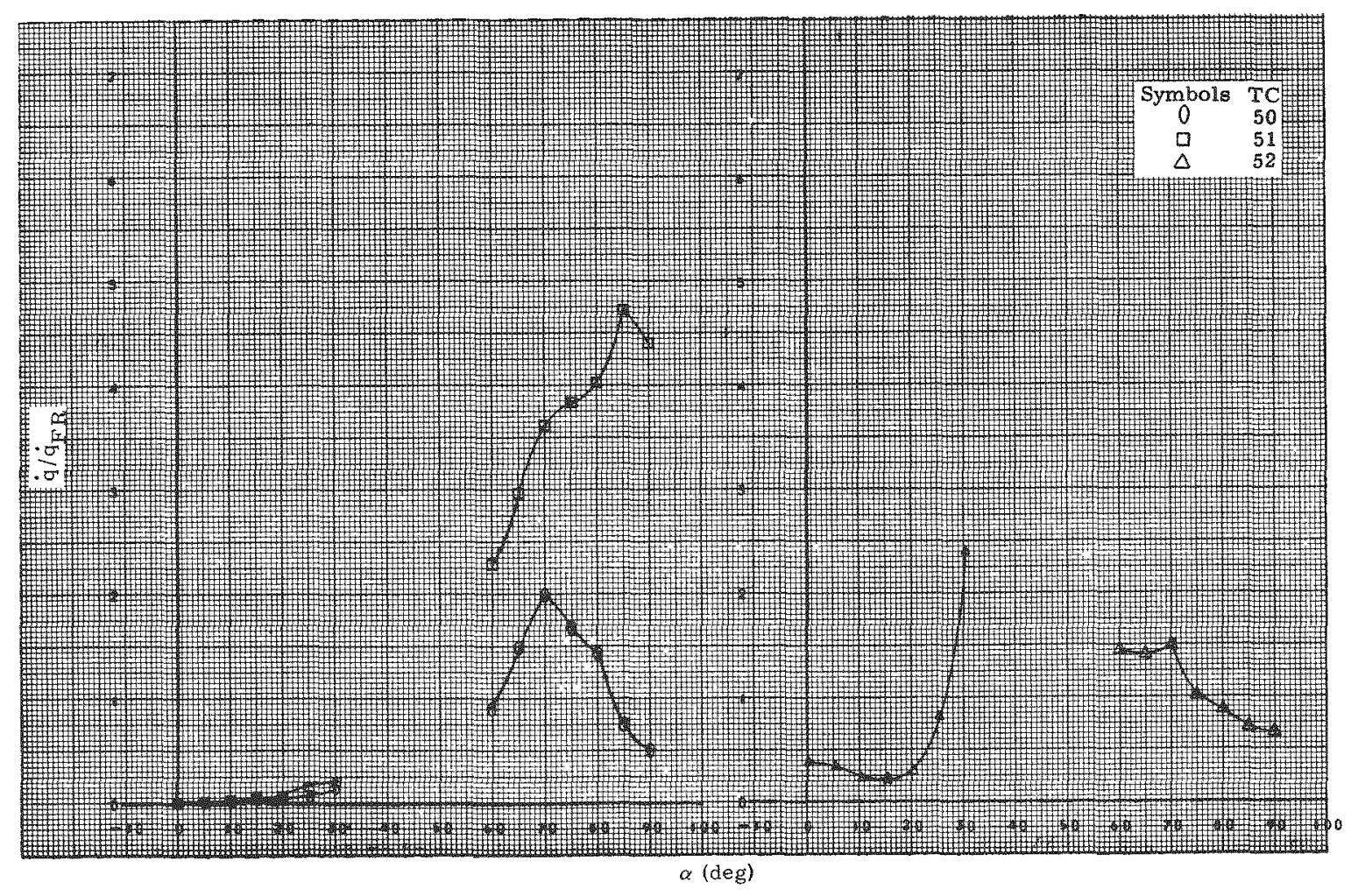

Fig. 173. Heat Transfer, TC $50-52$, Configuration 430 


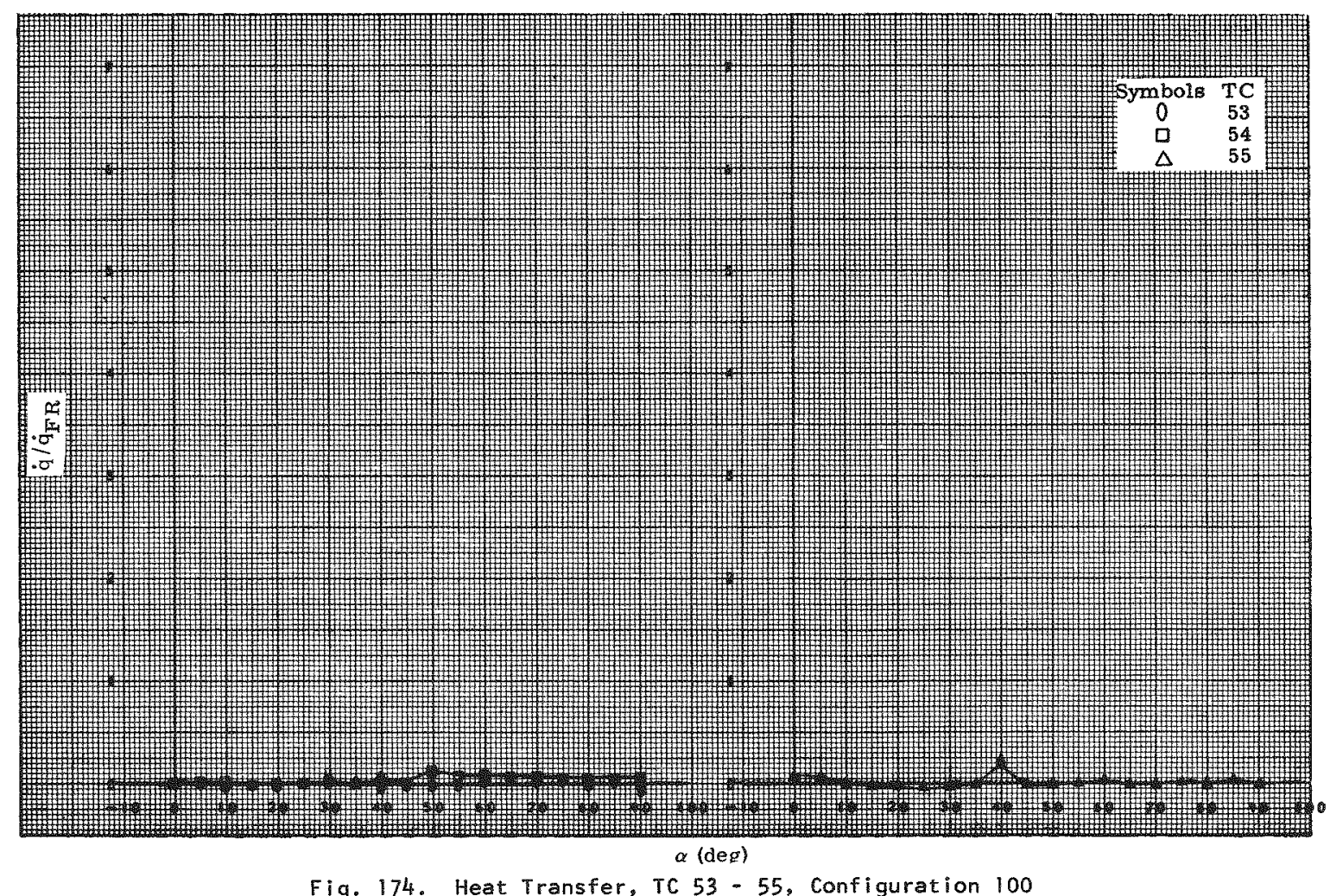

Fig. 174. Heat Transfer, TC $53-55$, Configuration 100

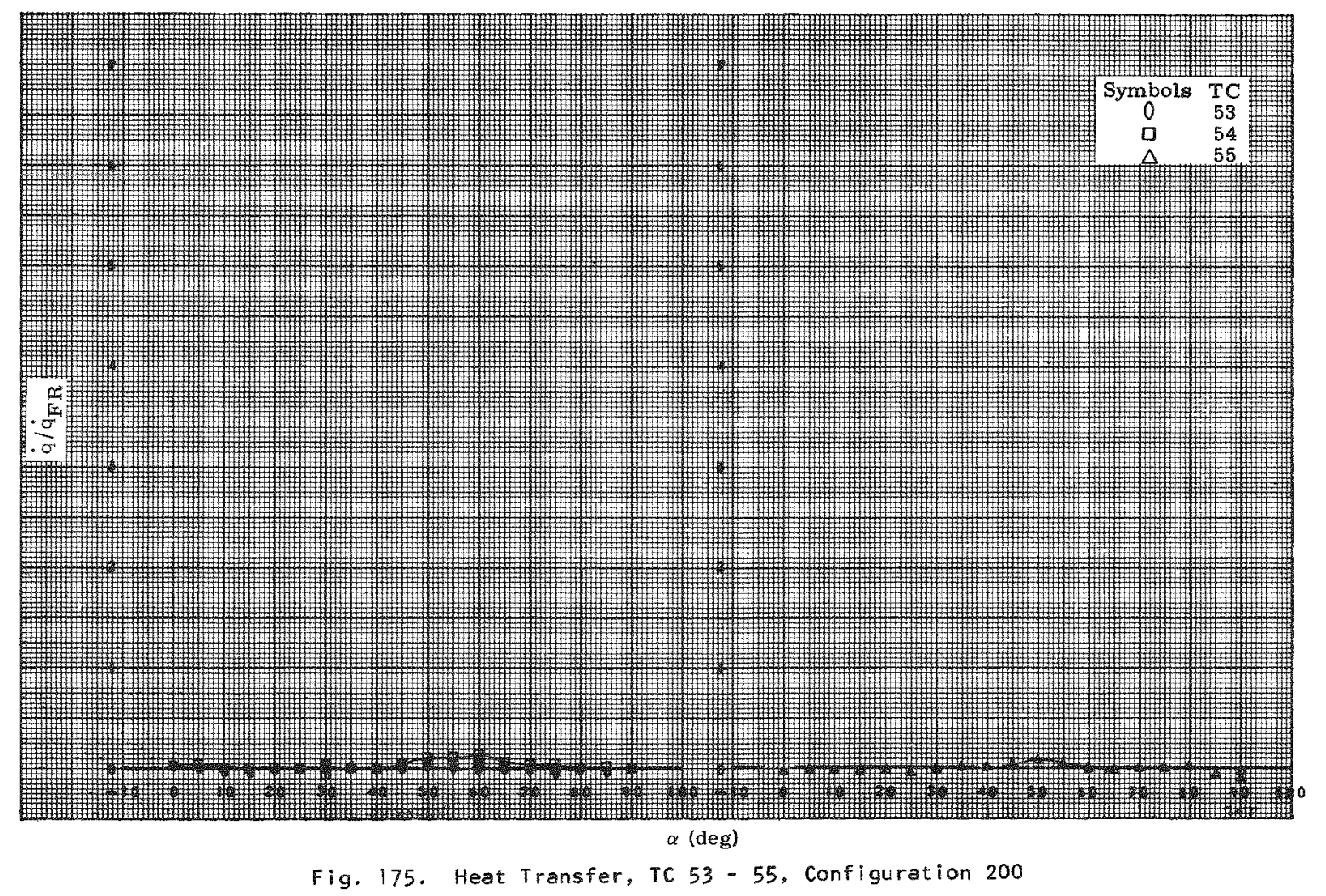

MND-3607-92

118 


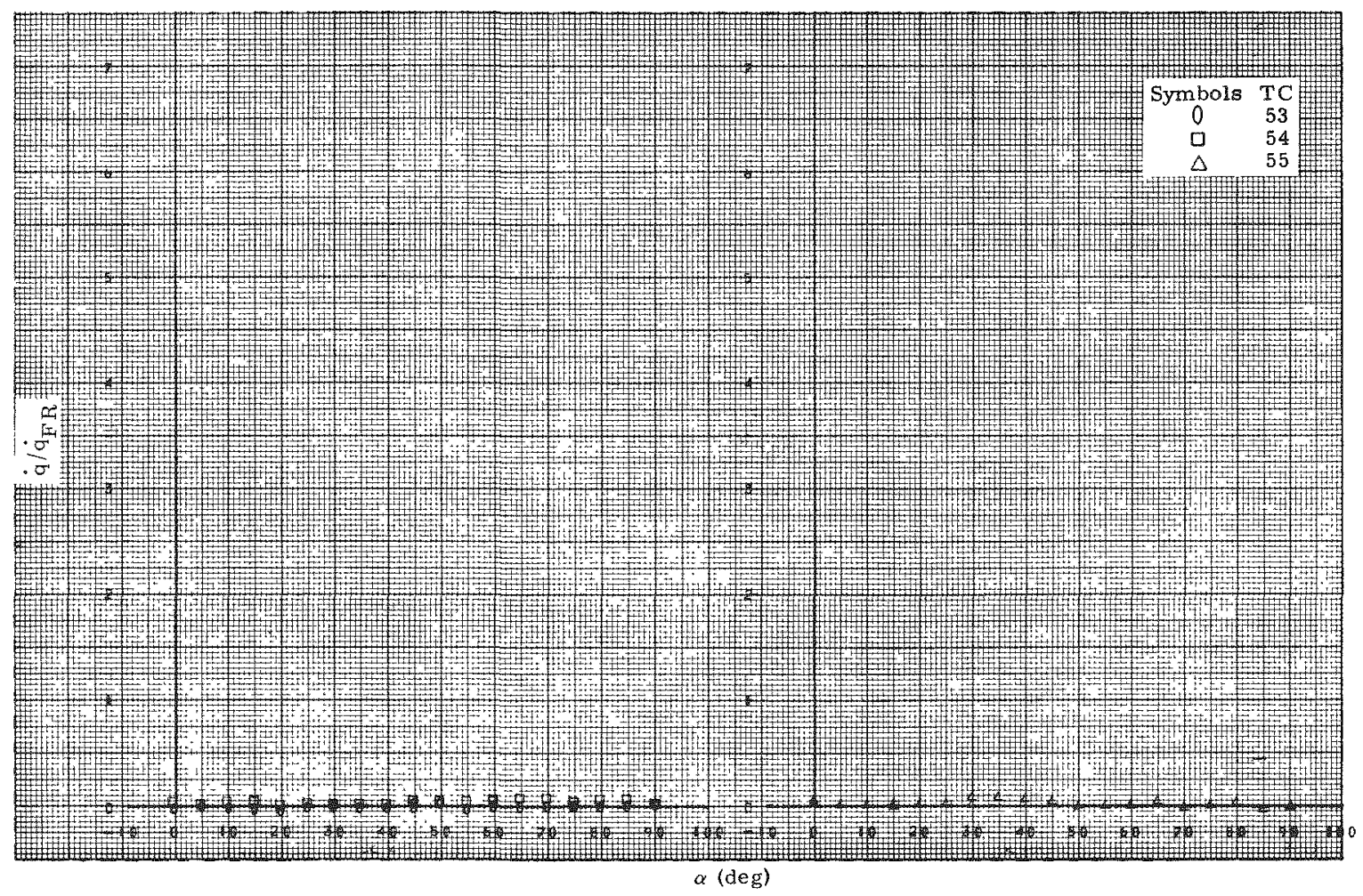

Fig. 176. Heat Transfer, TC 53-55, Configuration 300

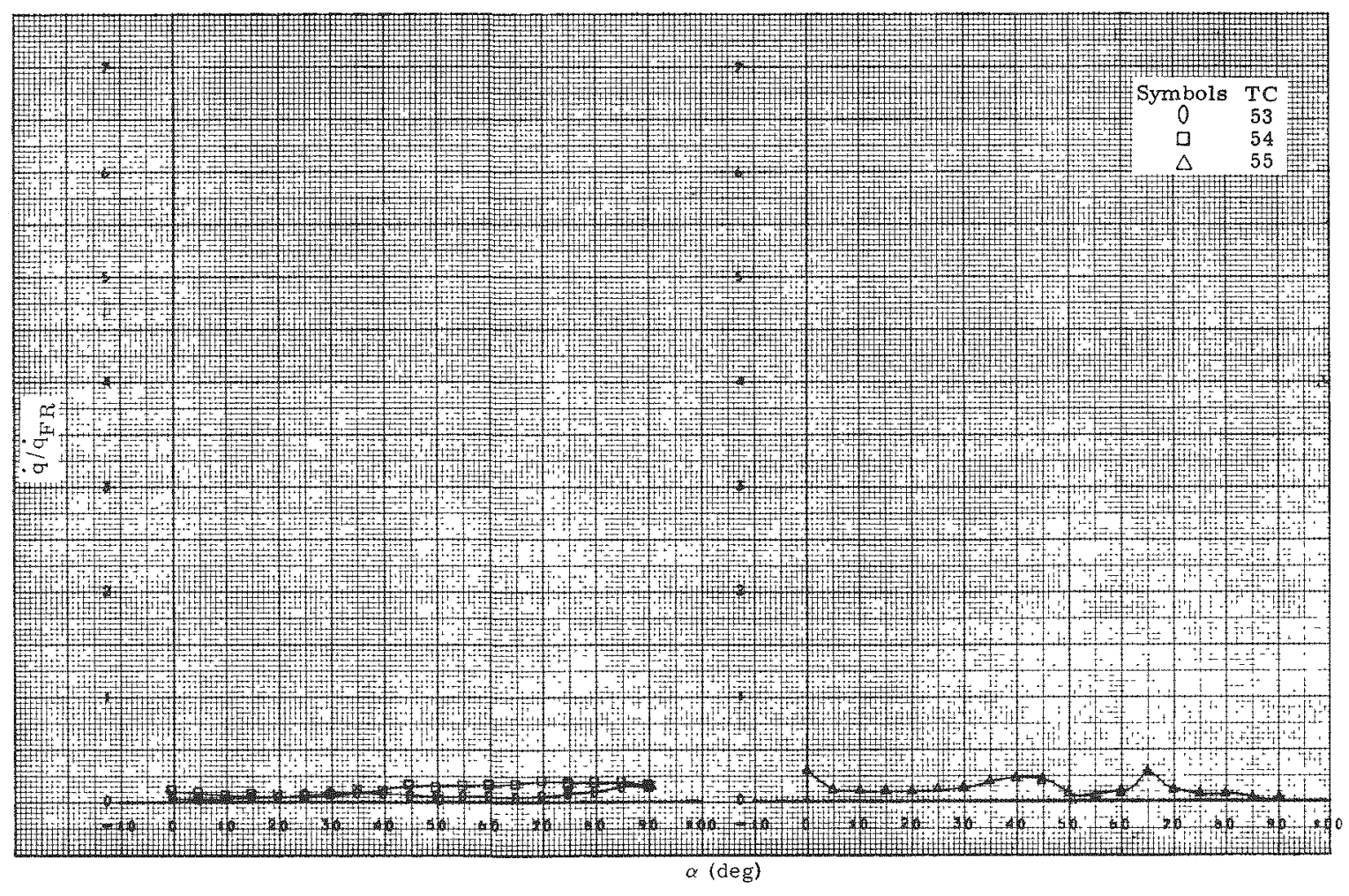

Fig. 177. Heat Transfer, TC $53-55$, Configuration 400 


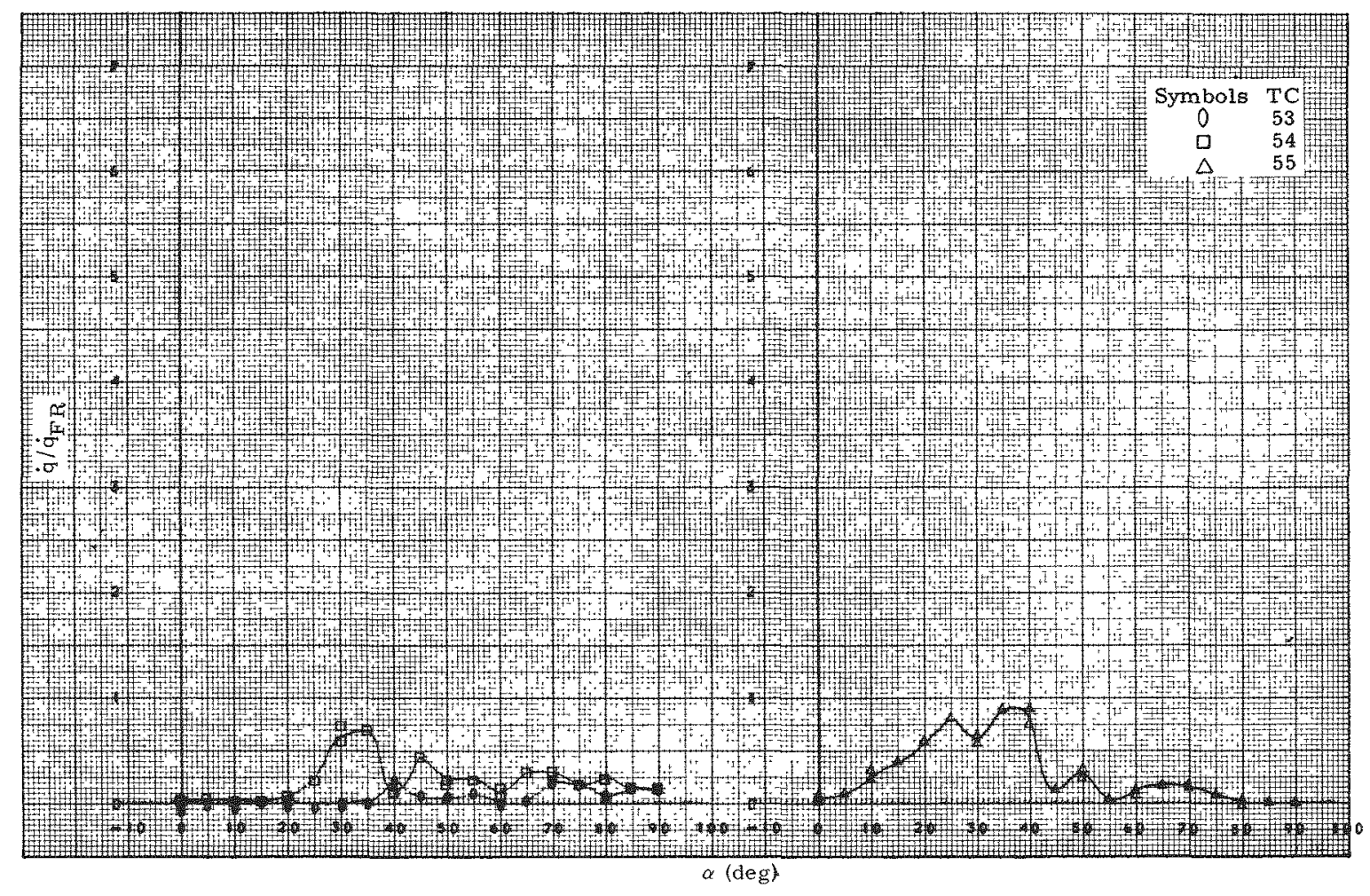

Fig. 178. Heat Transfer, TC $53-55$, Configuration 130

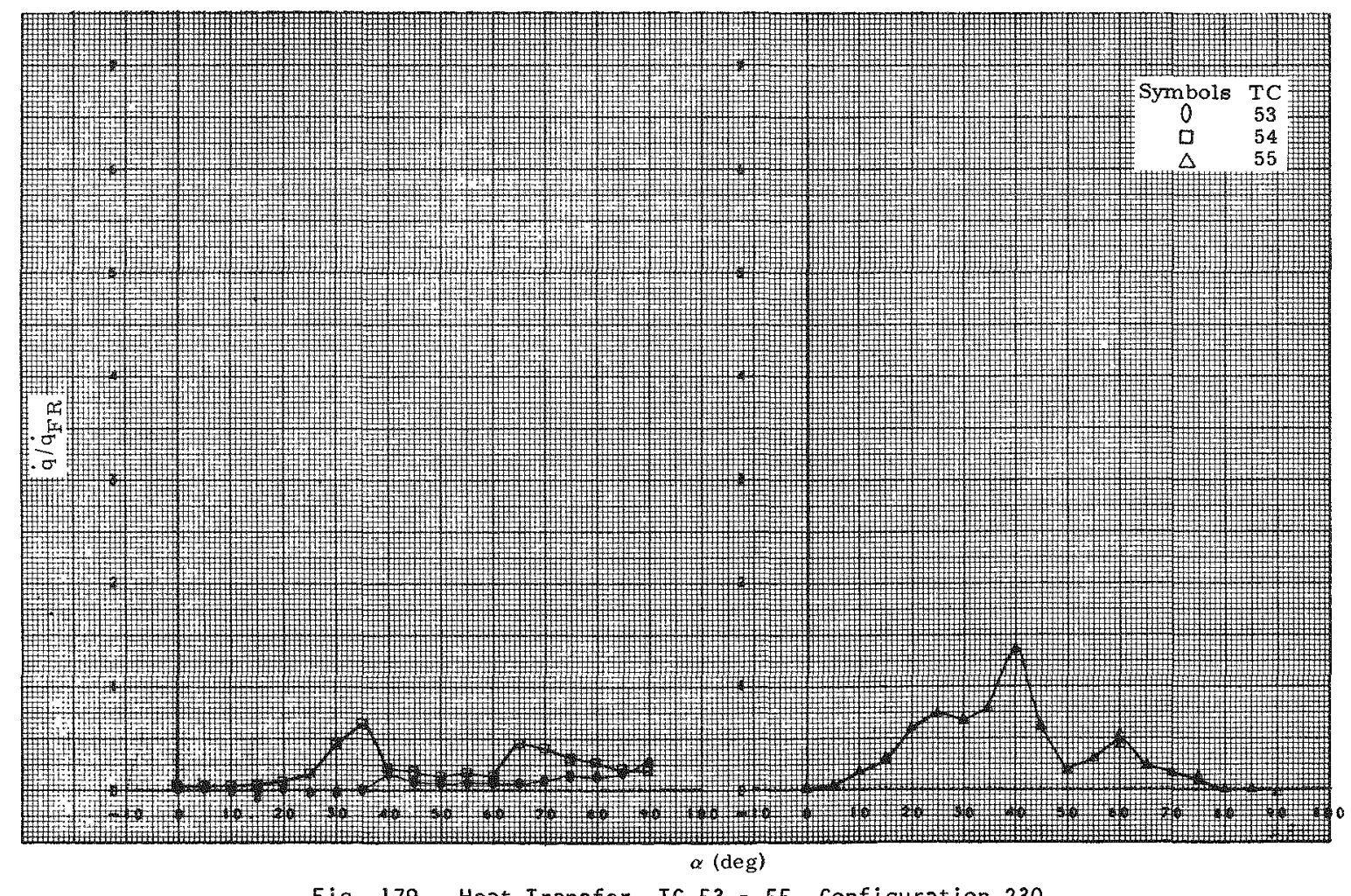

Fig. 179. Heat Transfer, TC $53-55$, Configuration 230 


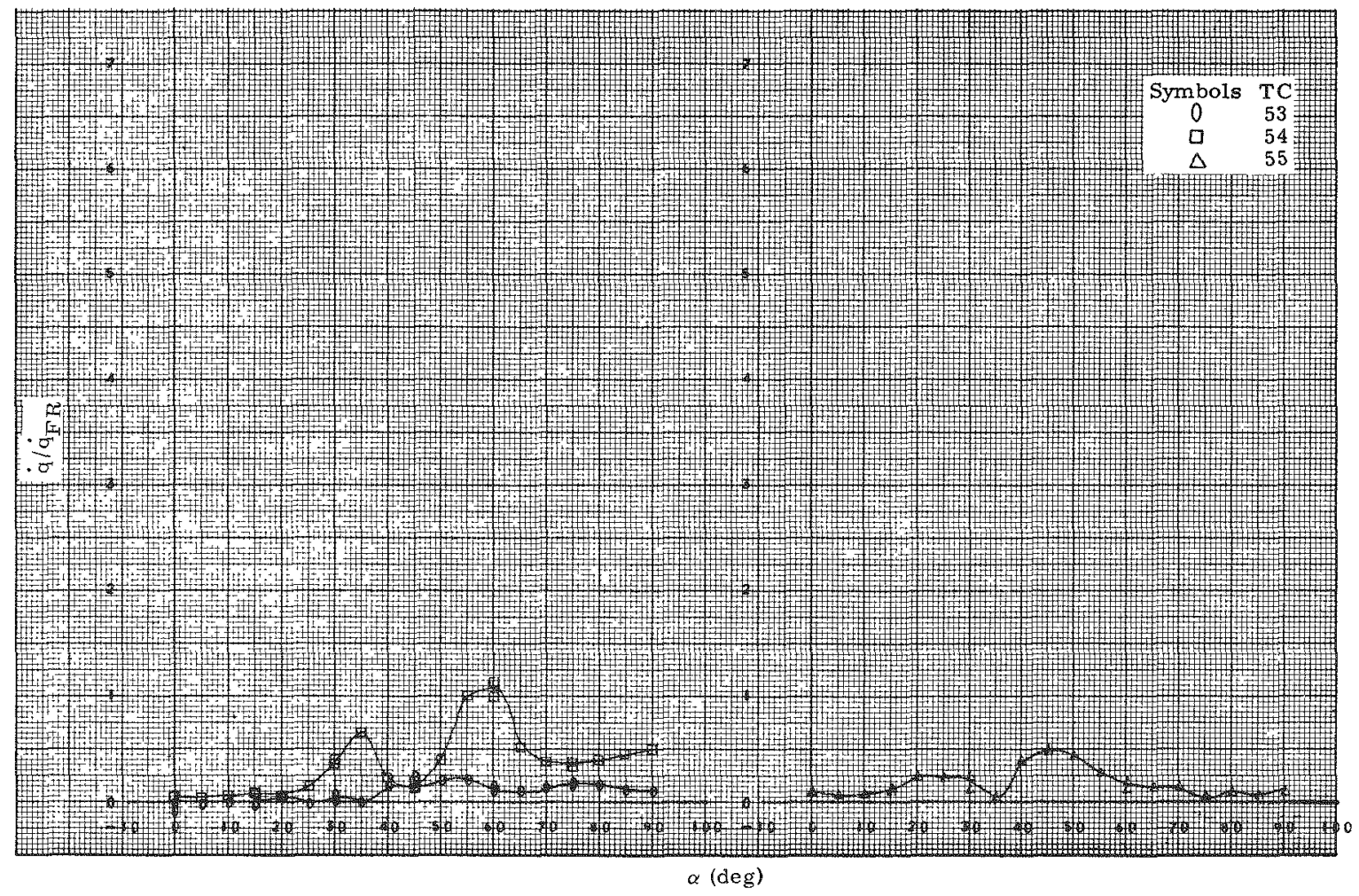

Fig. 180. Heat Transfer, TC $53-55$, Configuration 330

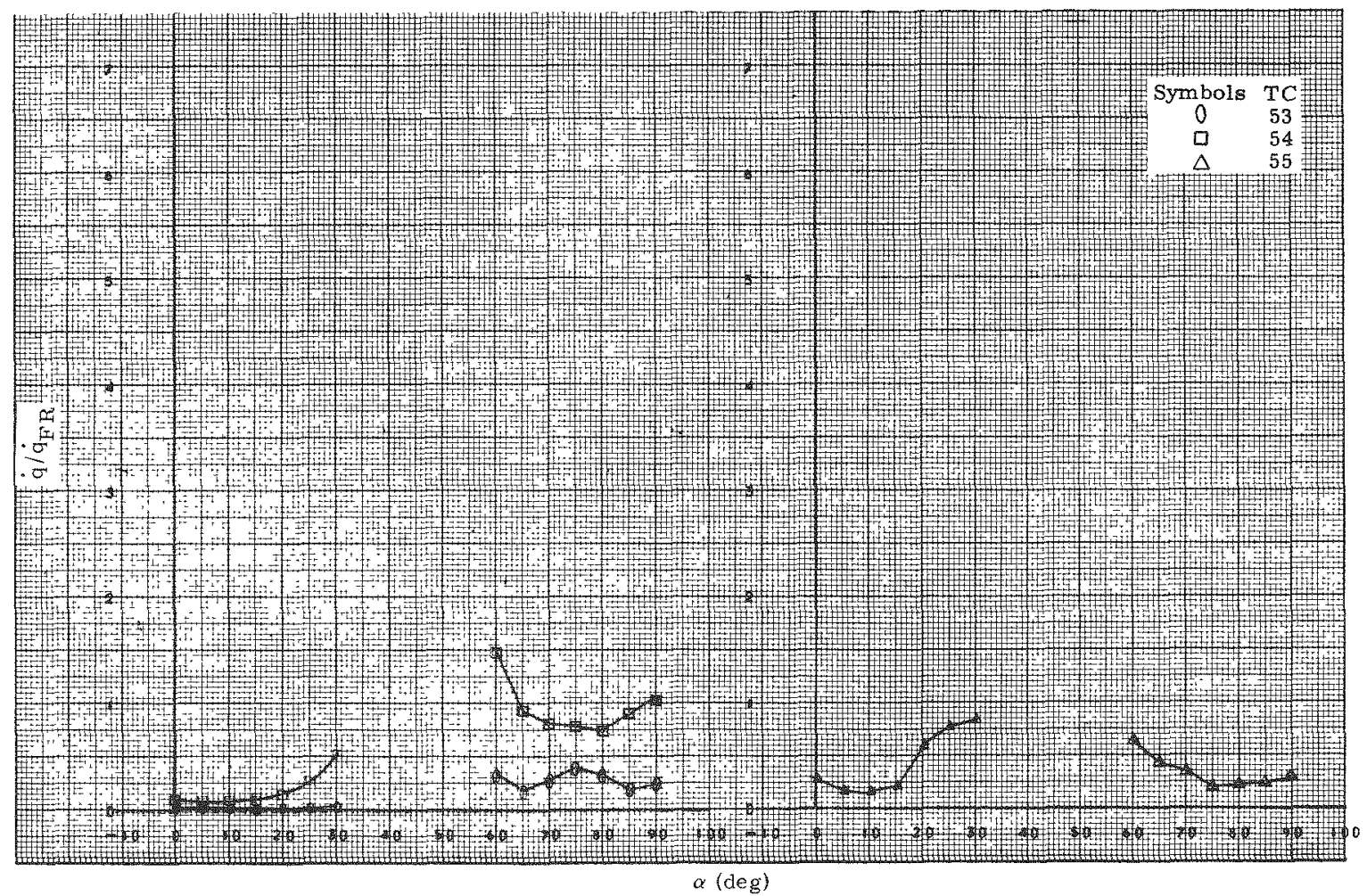

Fig. 181. Heat Transfer, TC $53-55$, Configuration 430 


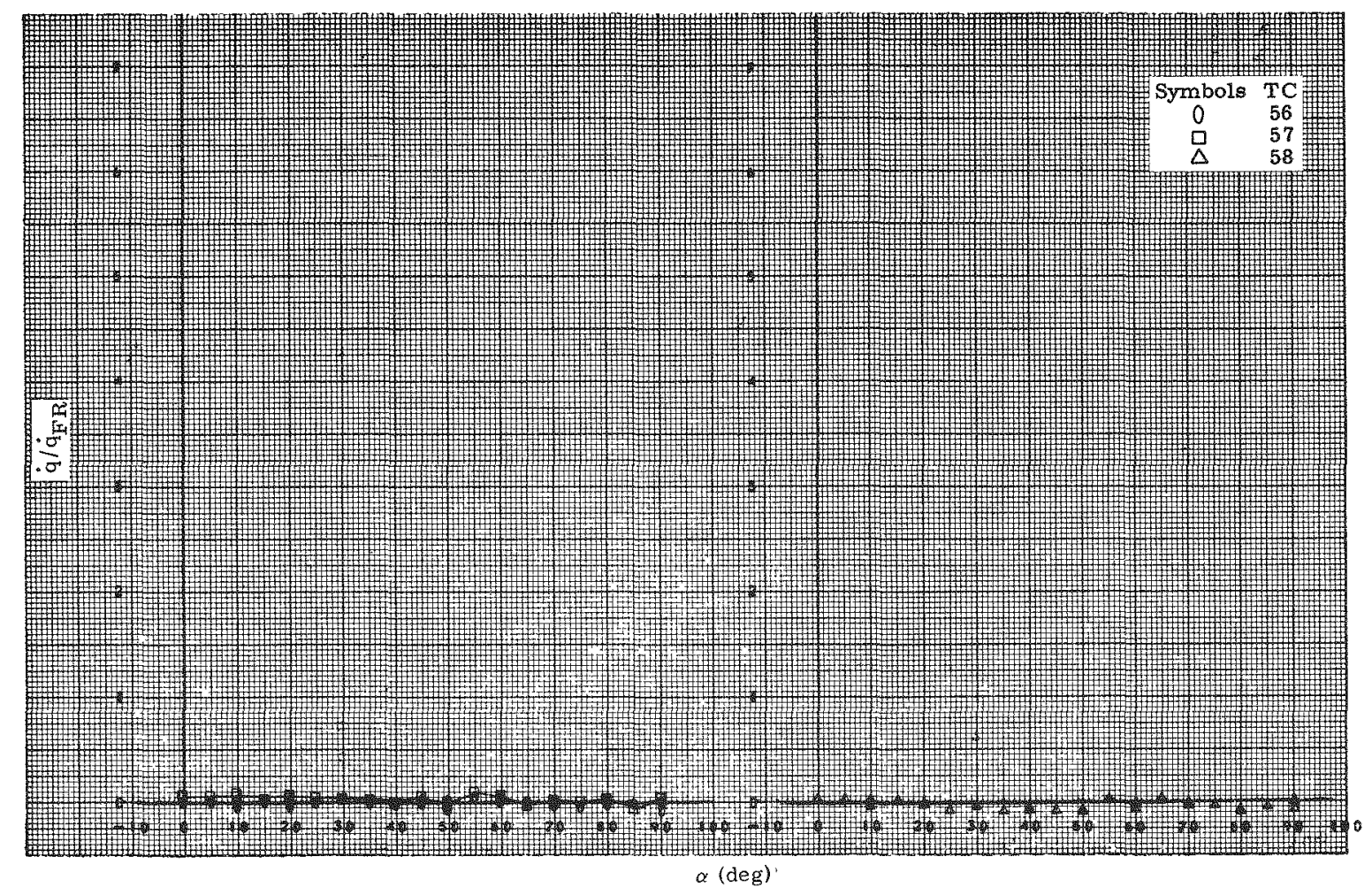

Fig. 182. Heat Transfer, TC $56-58$, Configuration 100

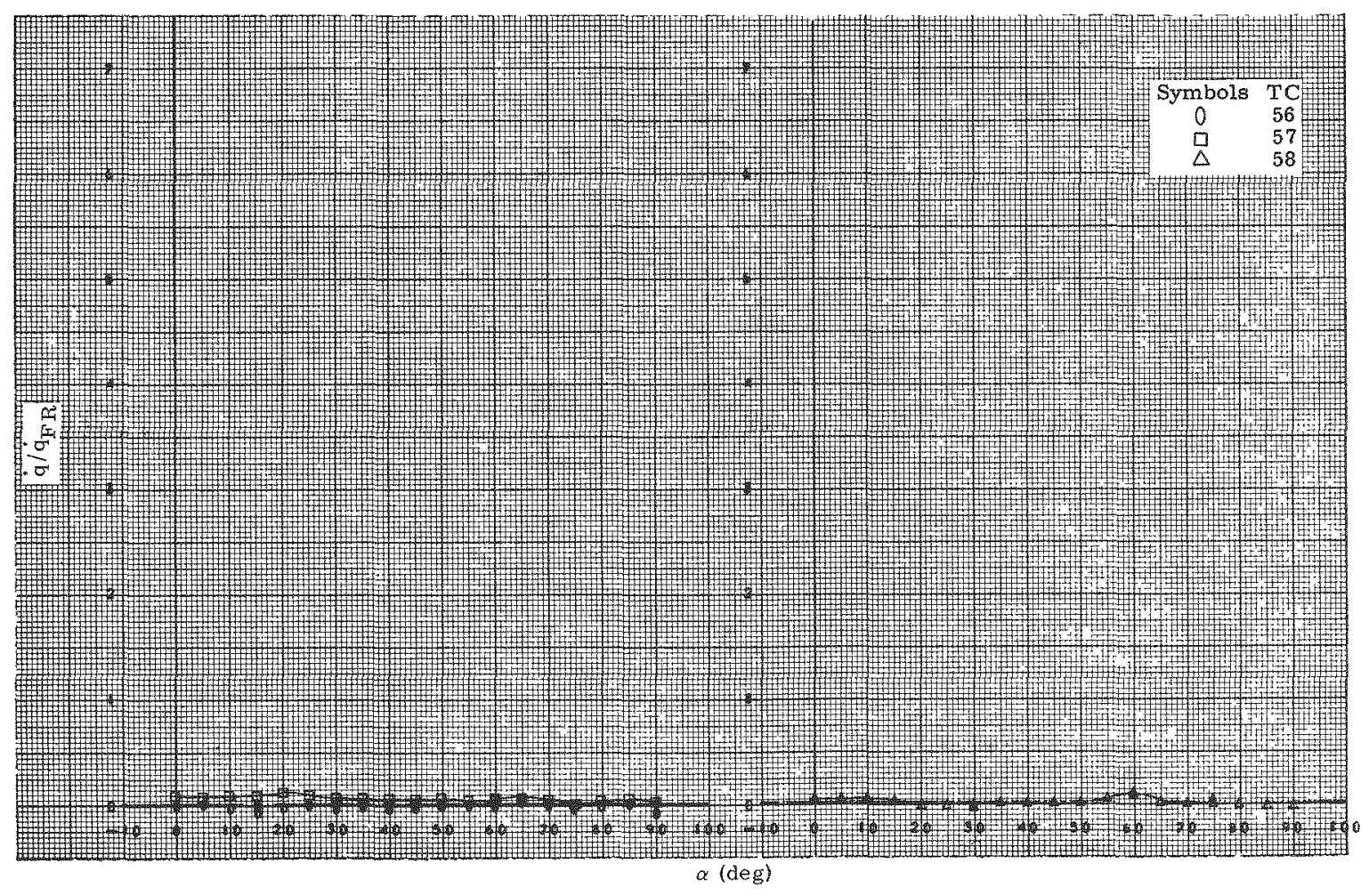

Fig. 183. Heat Transfer, TC $56-58$, Configuration 200 


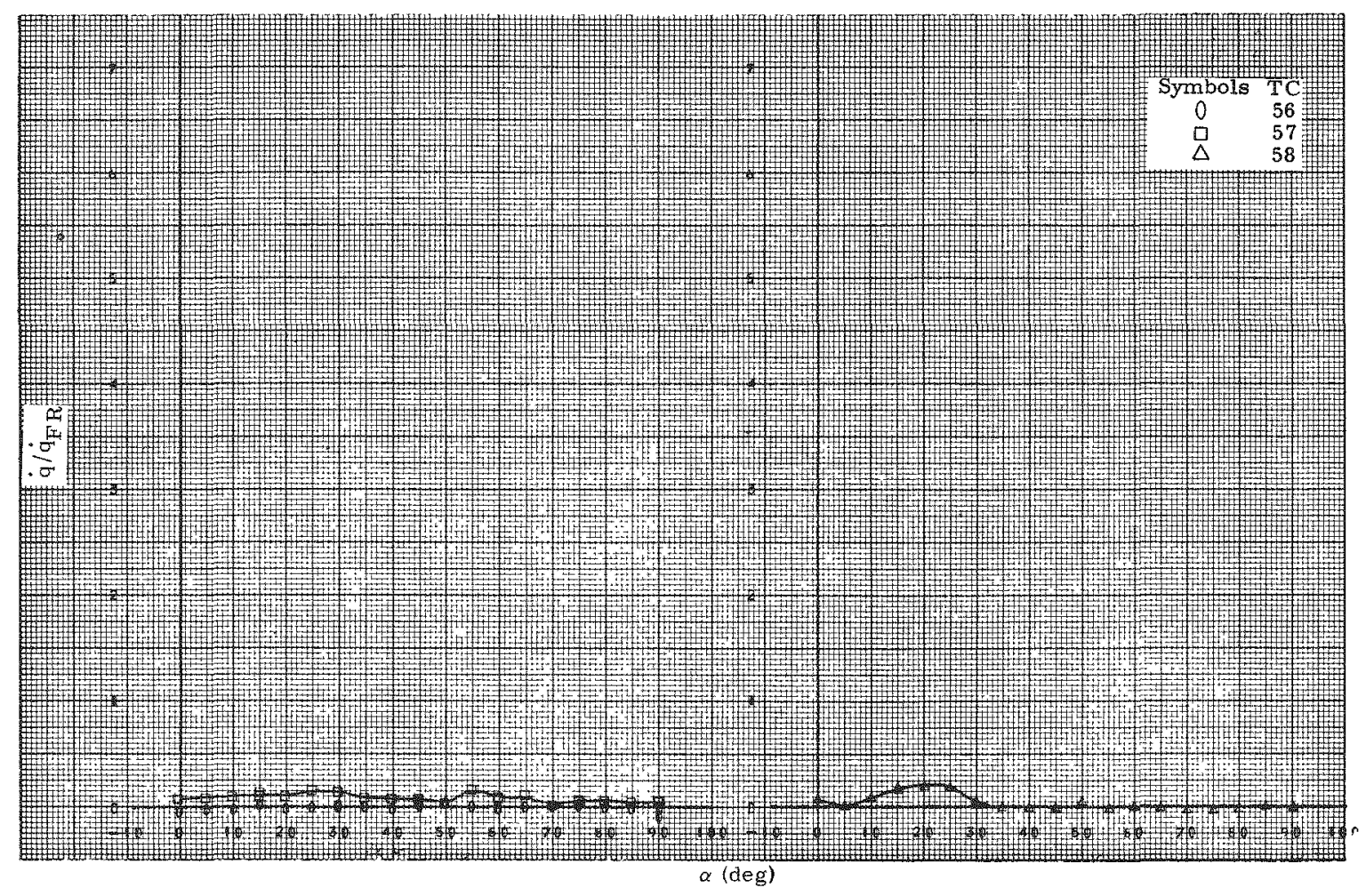

Fig. 184. Heat Transfer, TC $56-58$, Configuration 300

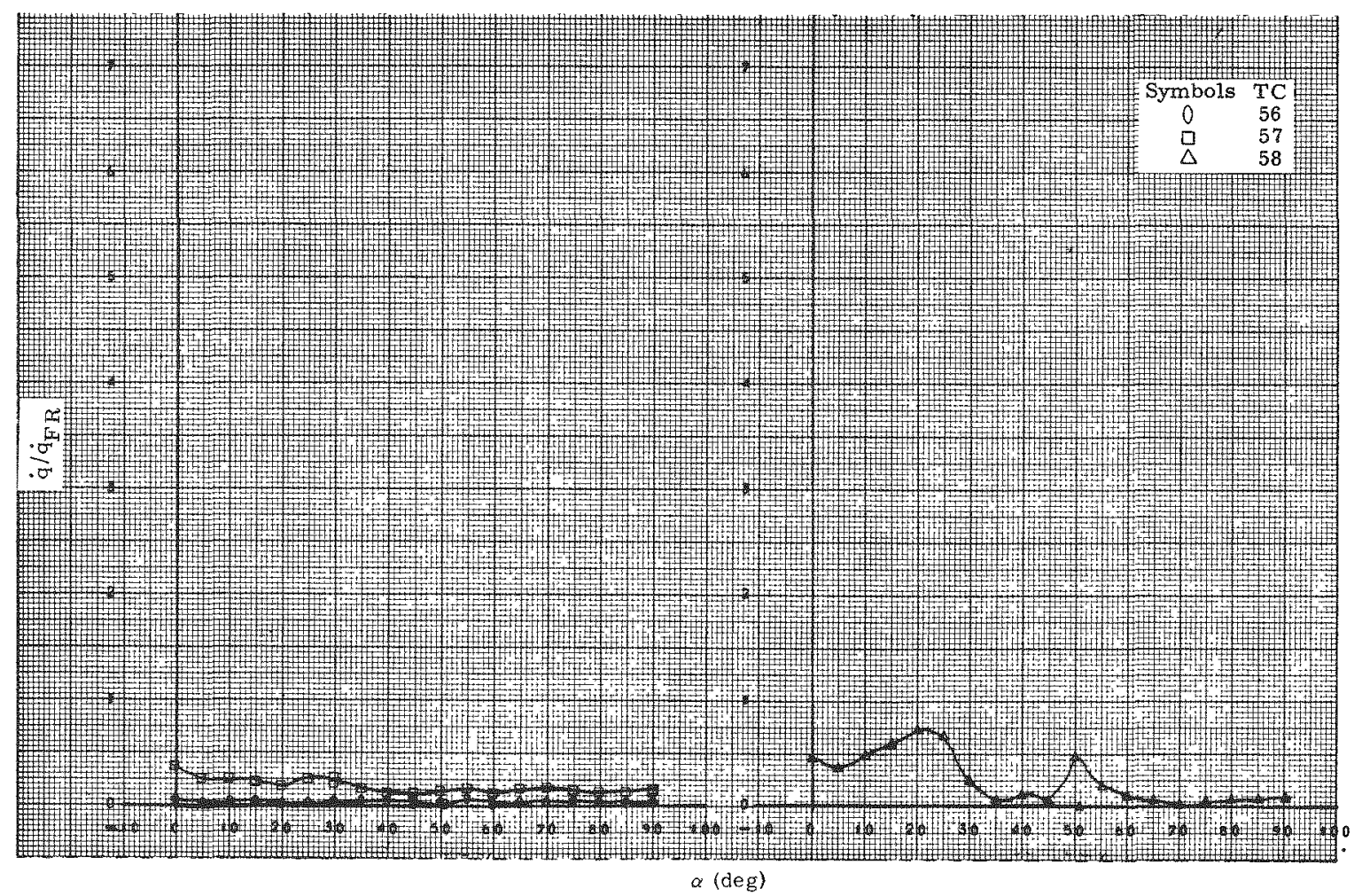

Fig. 185. Heat Transfer, TC $56-58$, Configuration 400 


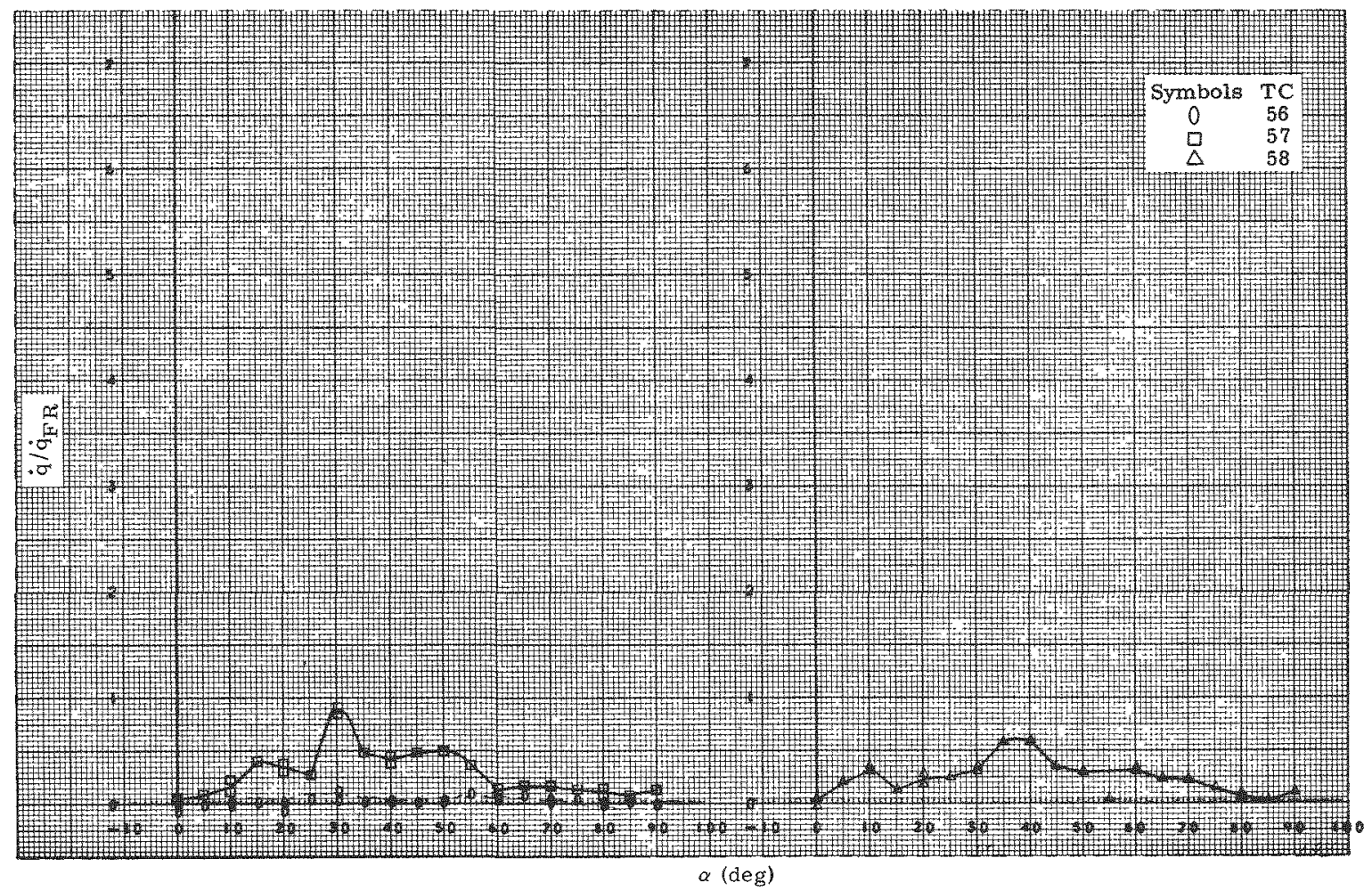

Fig. 186. Heat Transfer, TC 56 - 58, Configuration 130

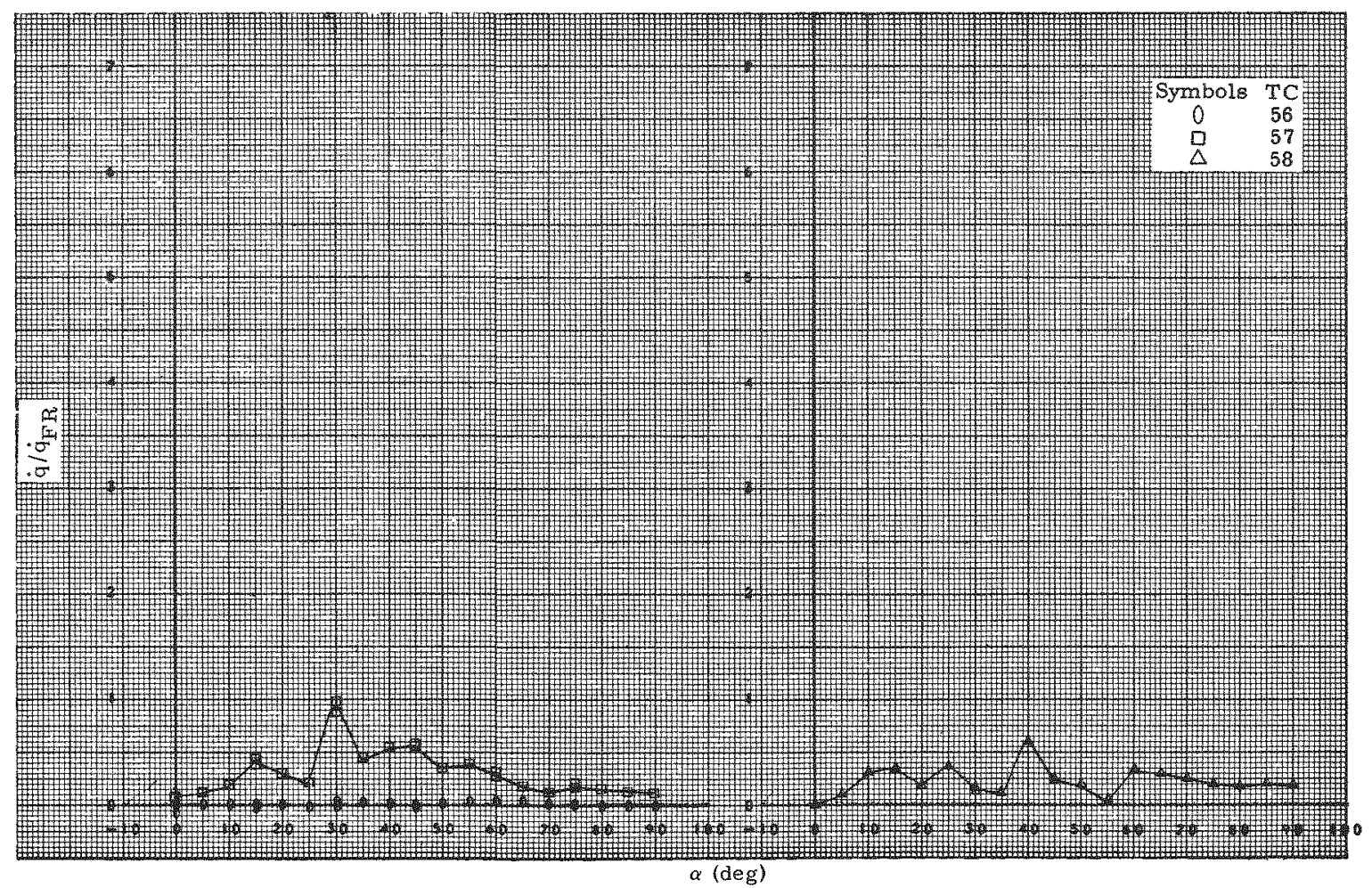

Fig. 187. Heat Transfer, TC $56-58$, Configuration 230 

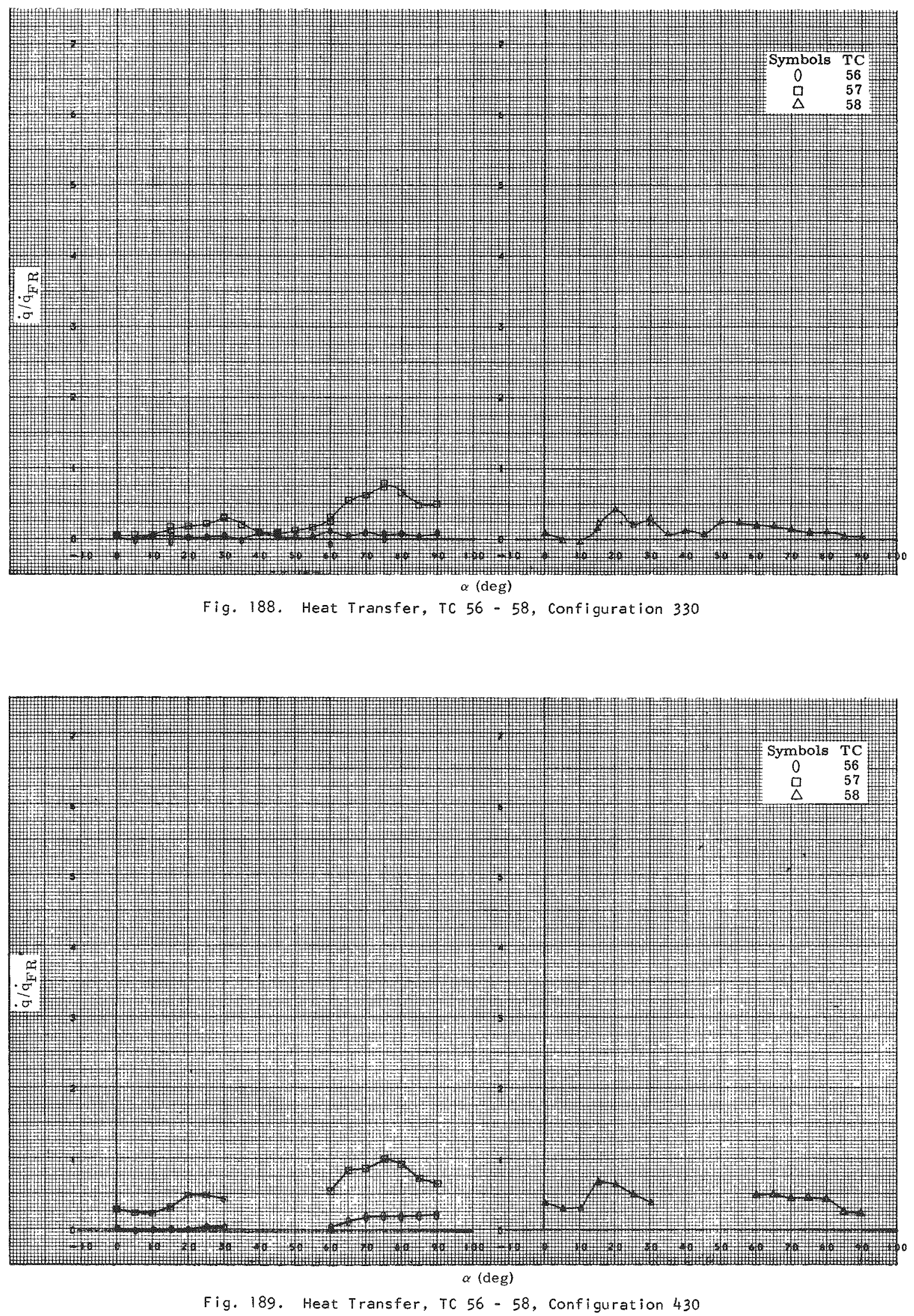


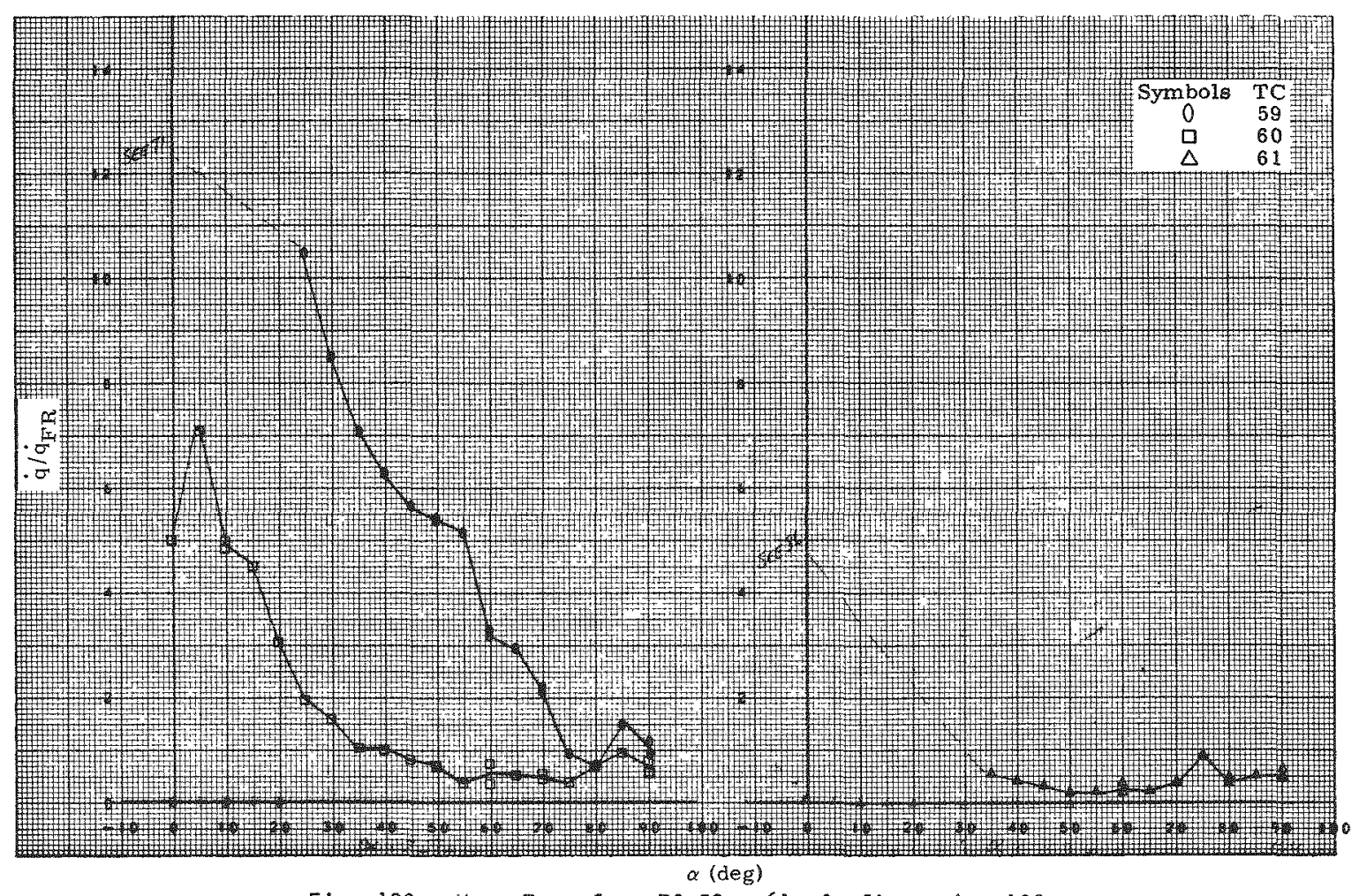

Fig. 190. Heat Transfer, TC 59-61, Configuration 100

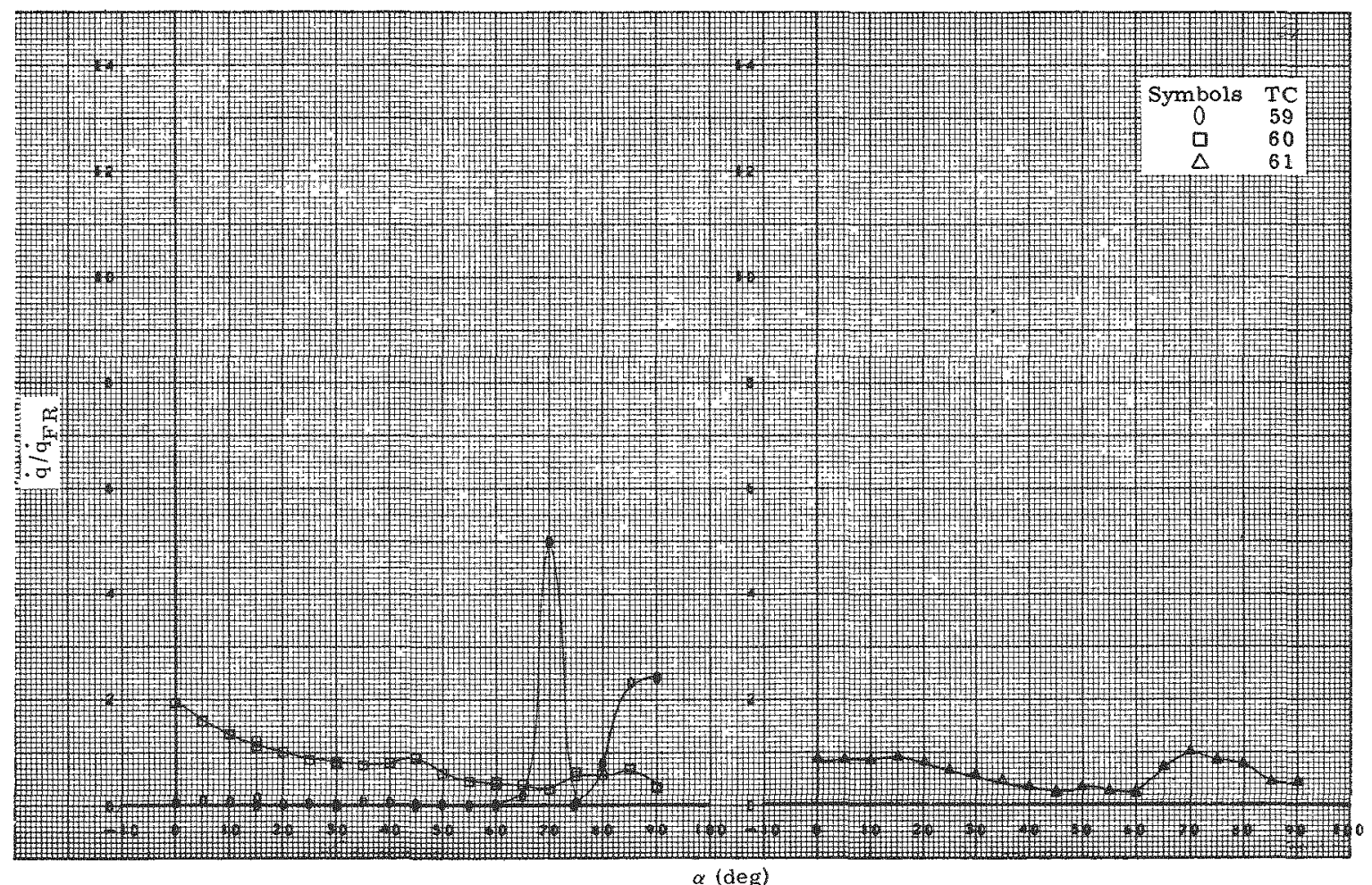

Fig. 191. Heat Transfer, TC $59-61$, Configuration 200 


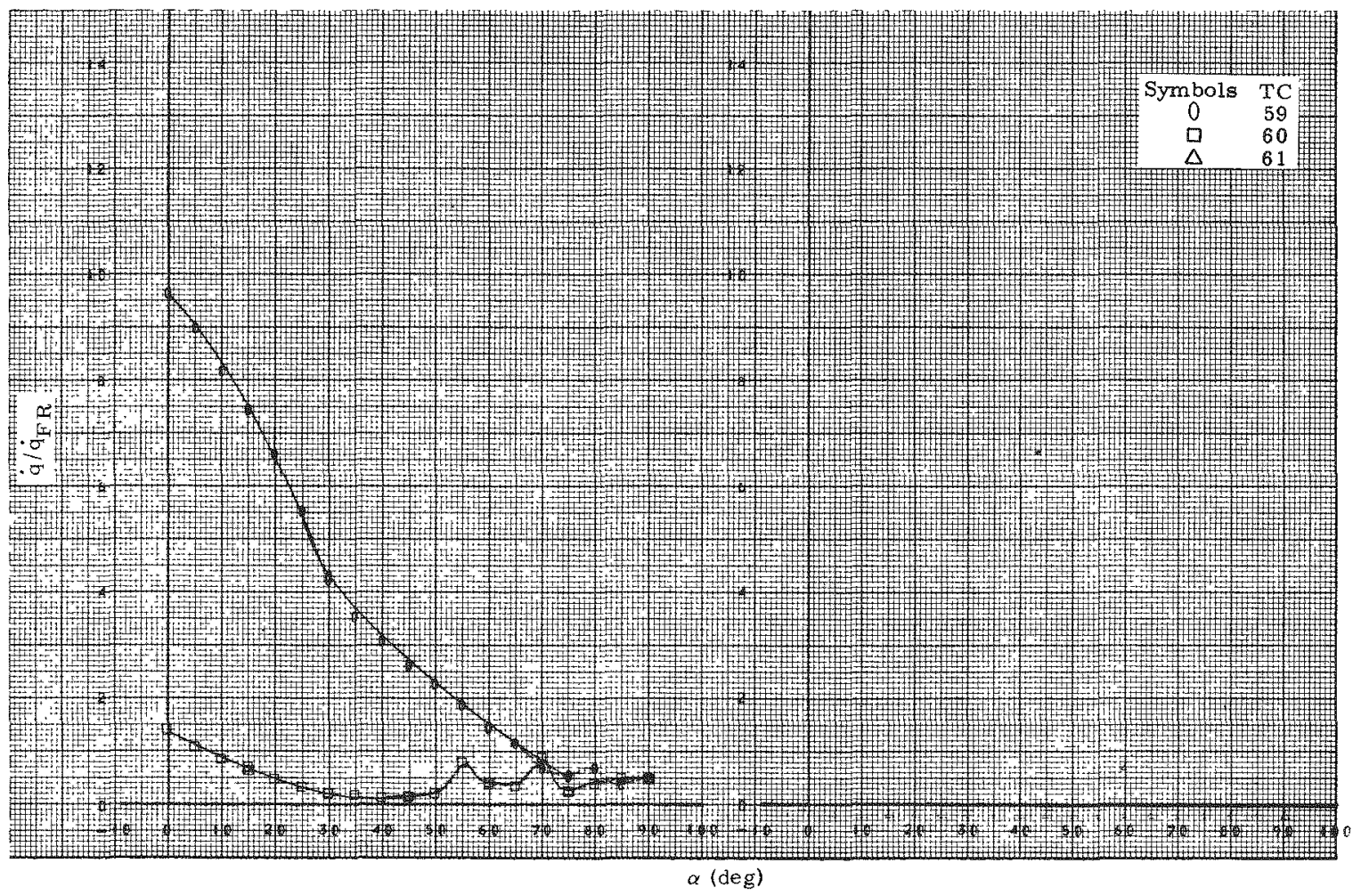

Fig. 192. Heat Transfer, TC $59-61$, Configuration 300

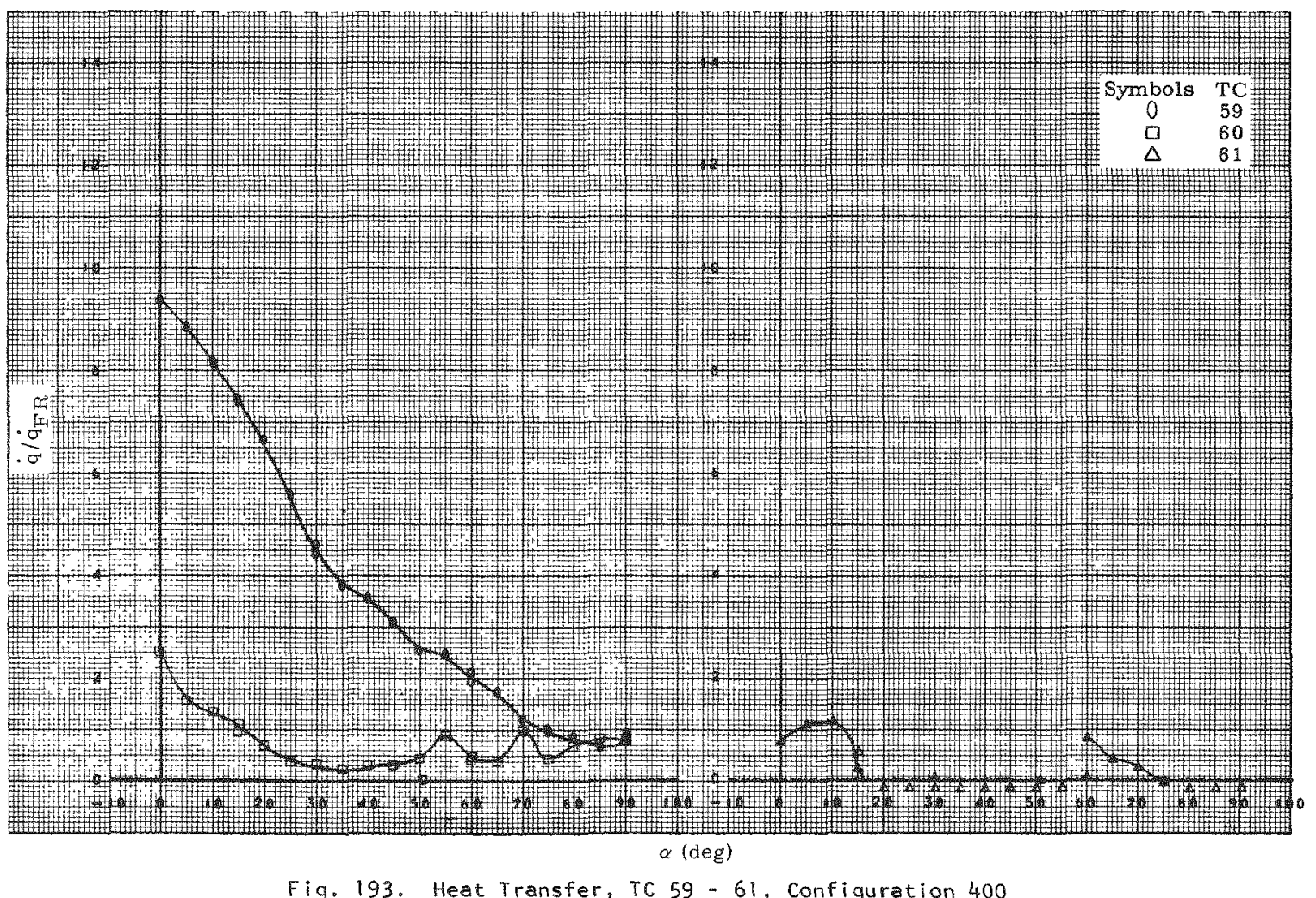

MND-3607-92 


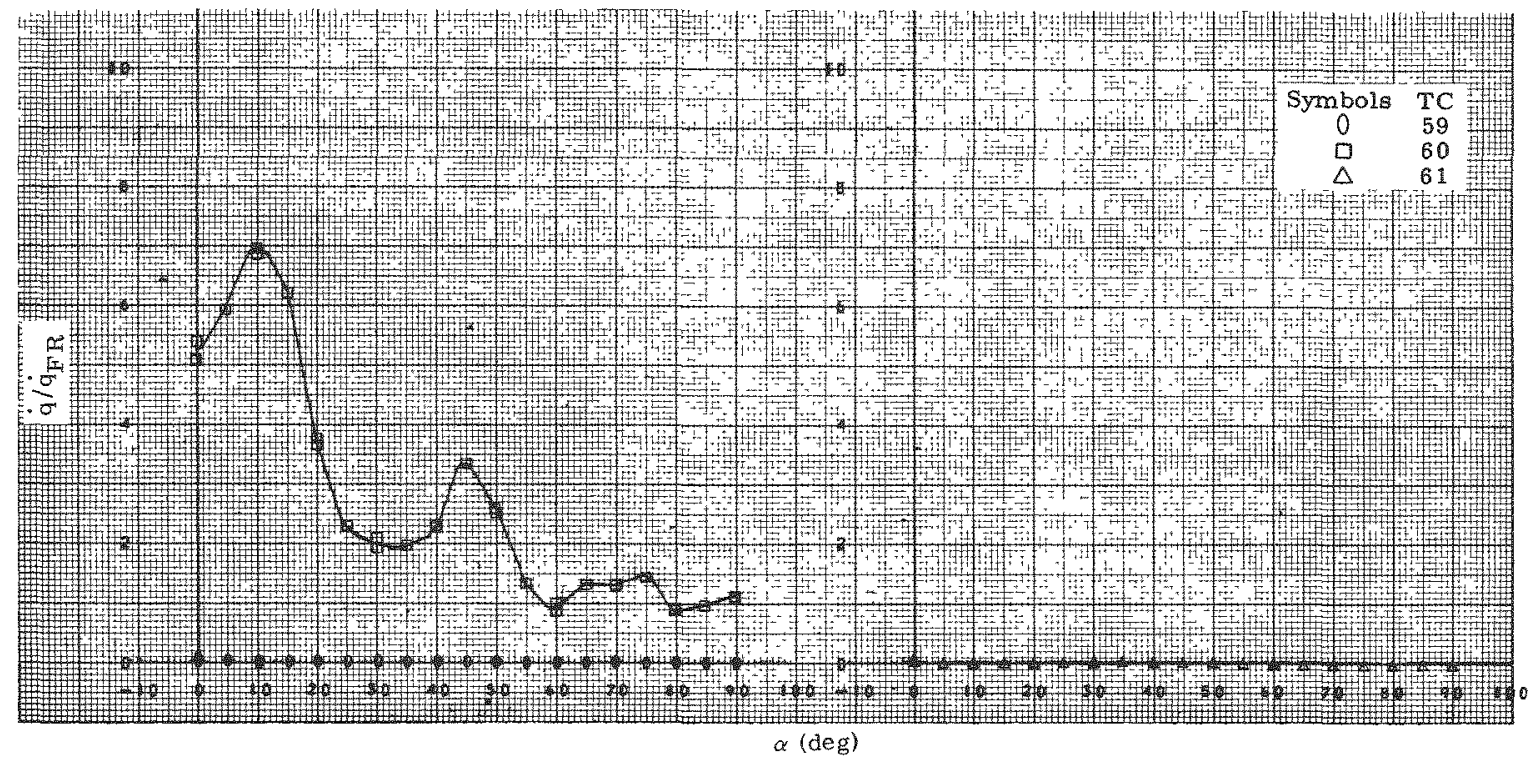

Fig. 194. Heat Transfer, TC 59-61, Configuration 130

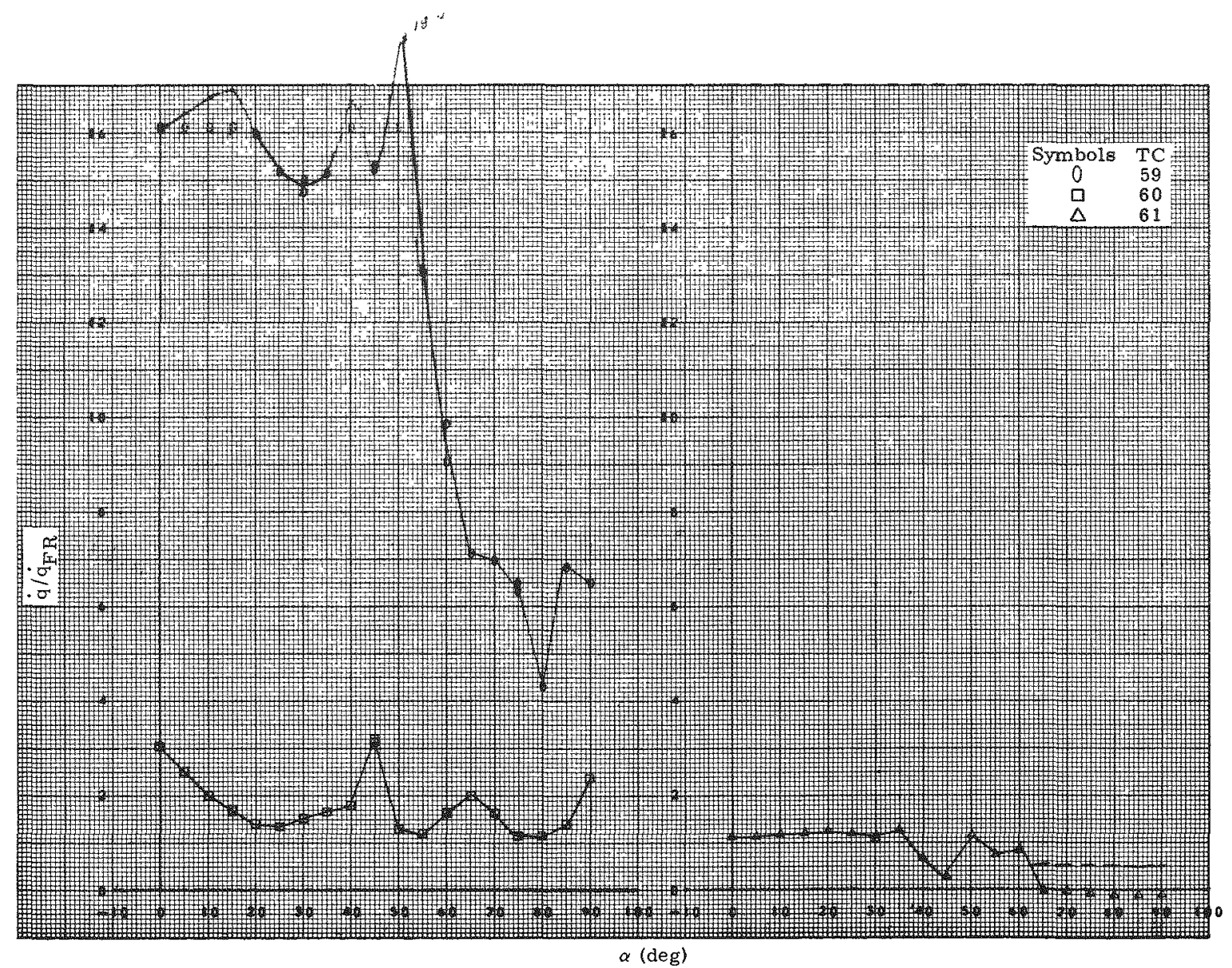

Fig. 195. Heat Transfer, TC 59-61, Configuration 230 


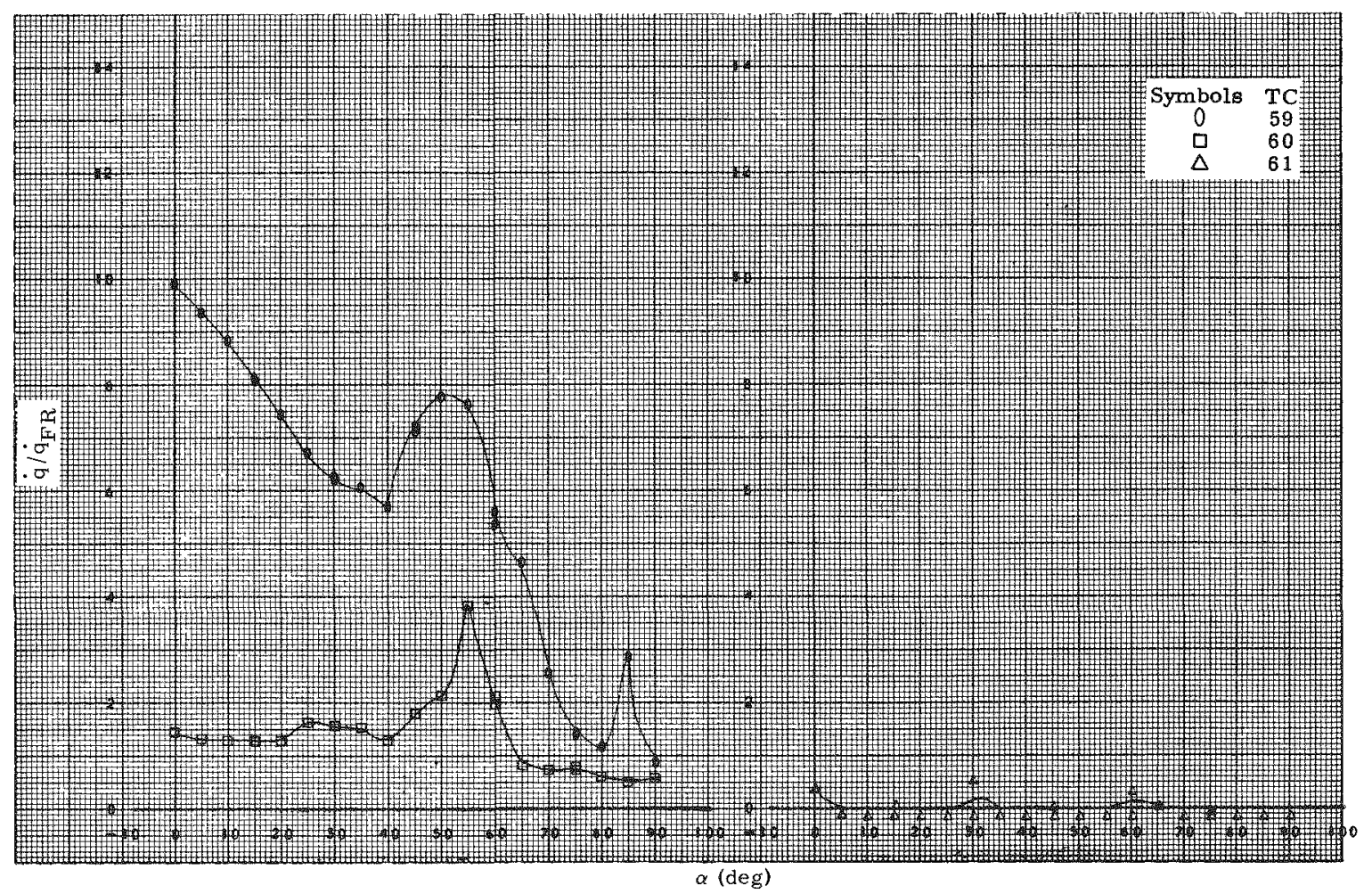

Fig. 196. Heat Transfer, TC $59-61$, Configuration 330

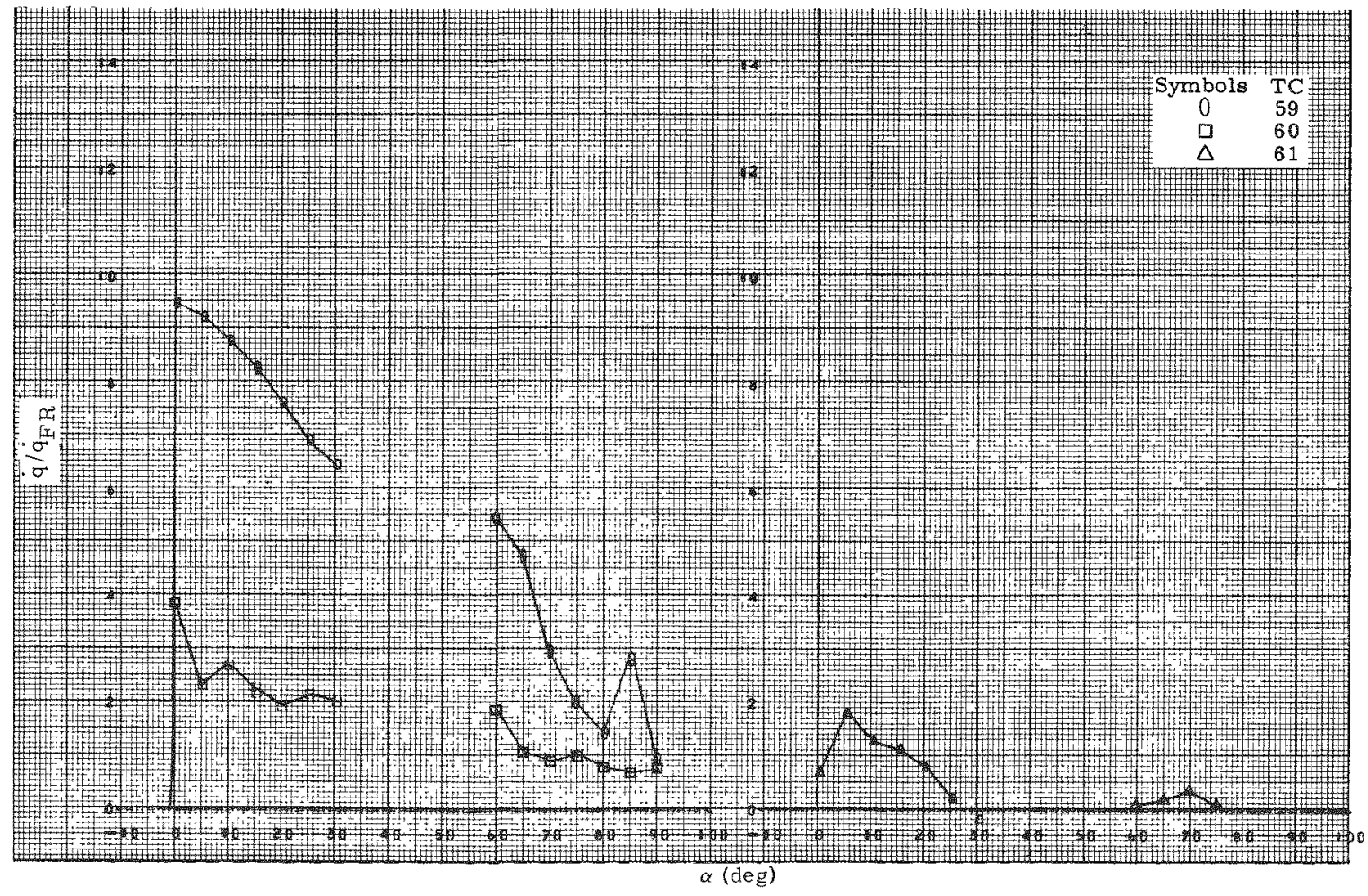

Fig. 197. Heat Transfer, TC 59-61, Configuration 430 


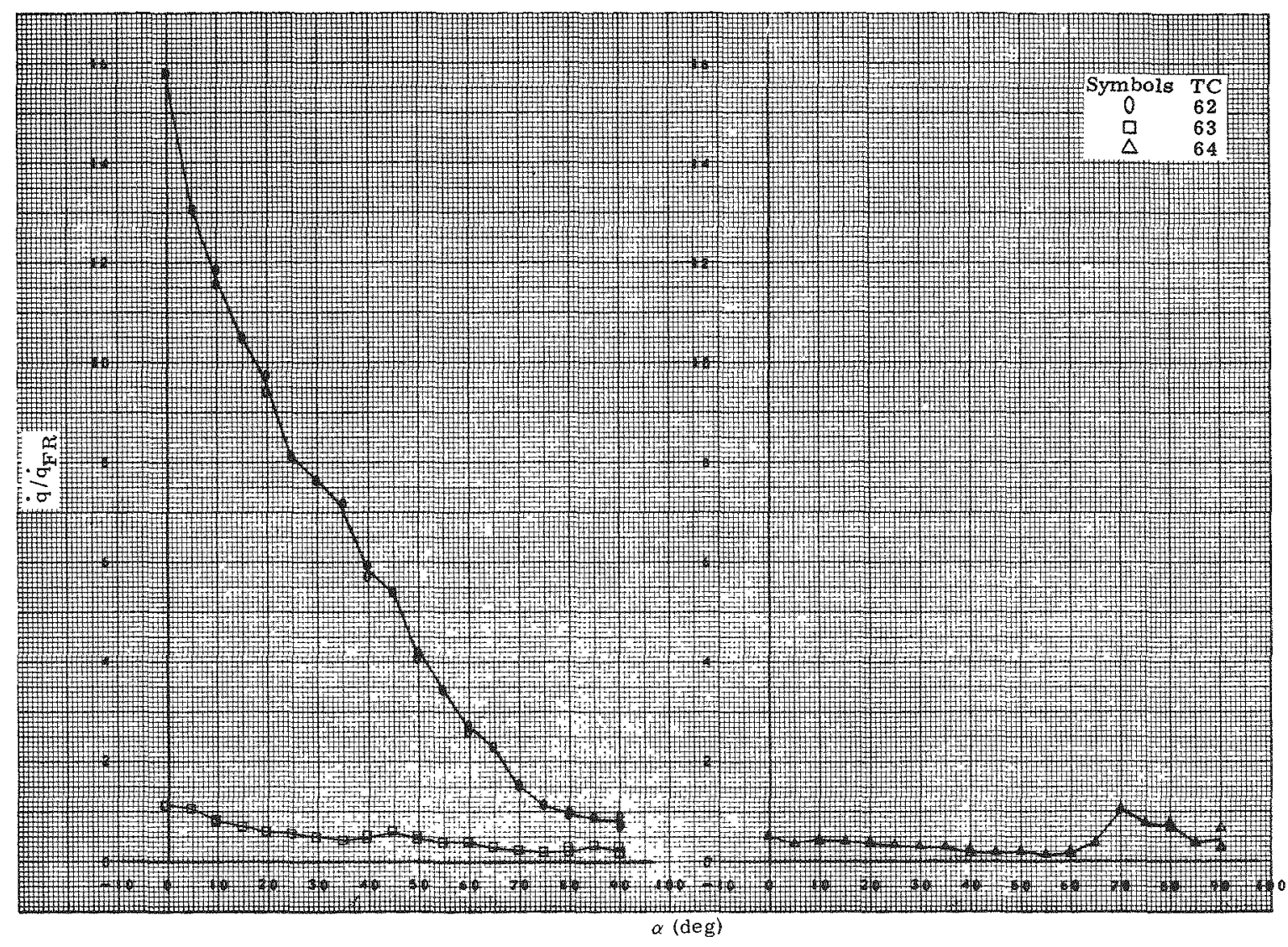

Fig. 198. Heat Transfer, TC $62-64$, Configuration 100

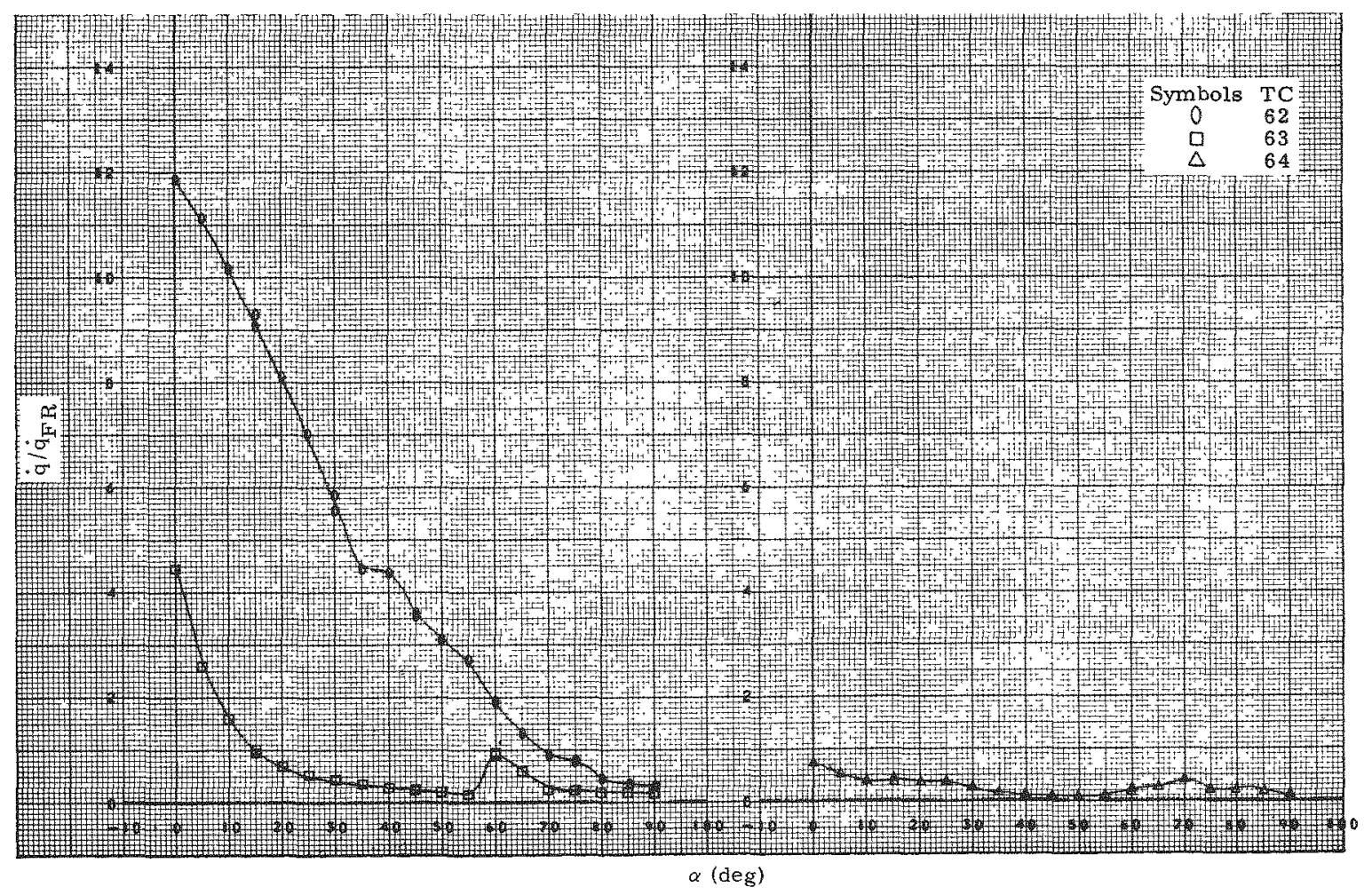

Fig. 199. Heat Transfer, TC $62-64$, Configuration 200 


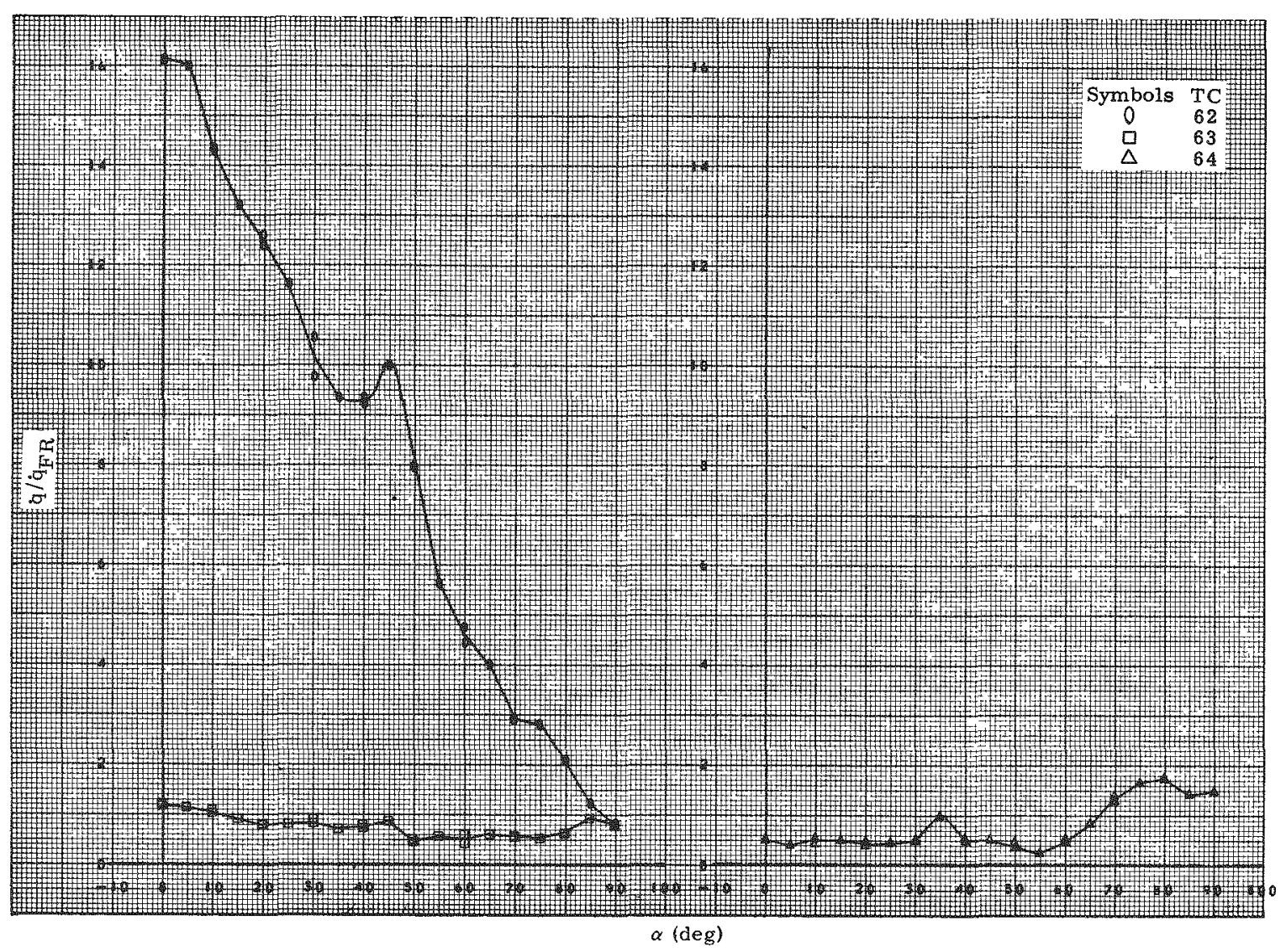

Fig. 200. Heat Transfer, TC $62-64$, Configuration 130

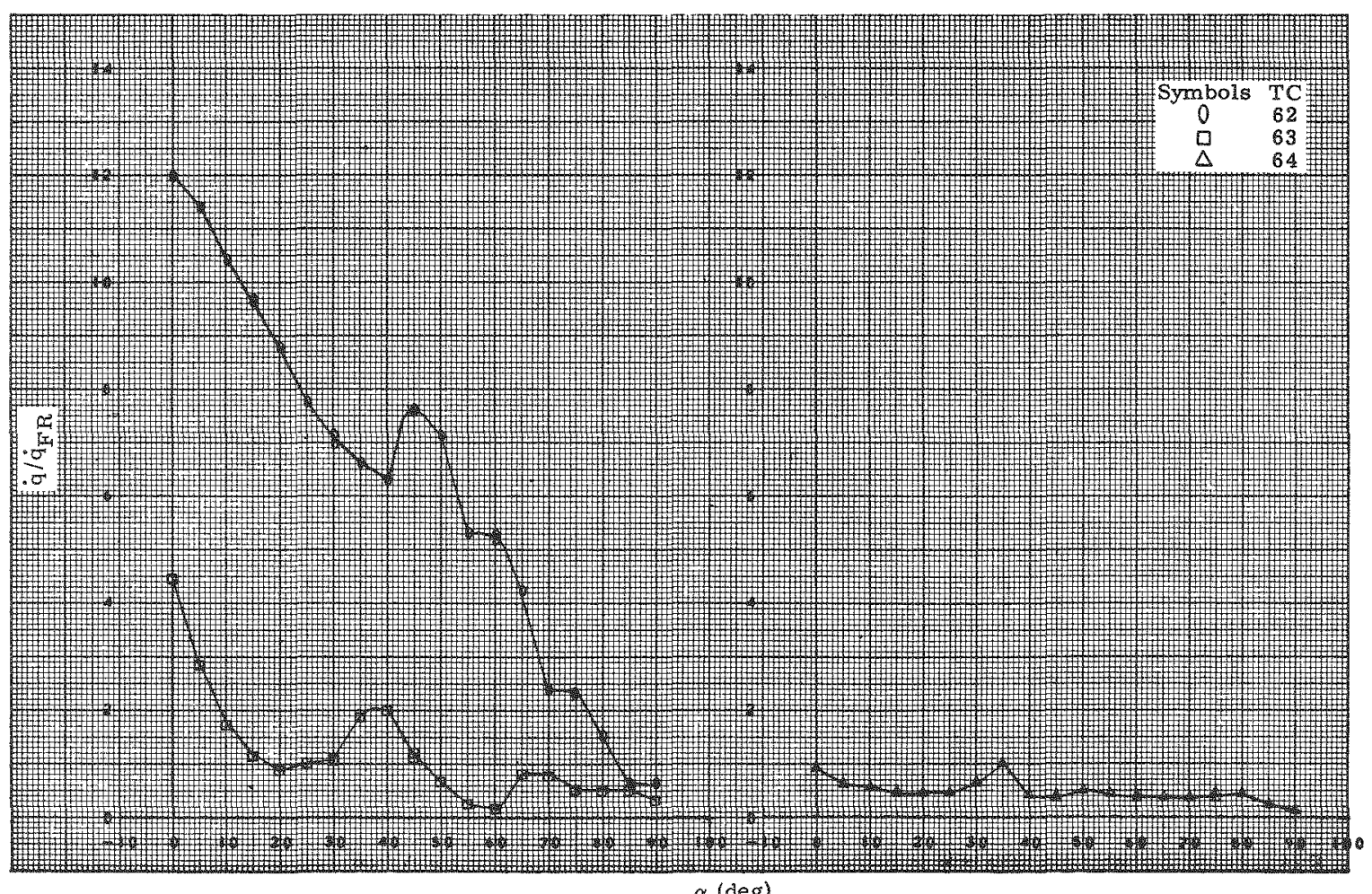

Fig. 201. Heat Transfer, TC $62-64$, Configuration 230 


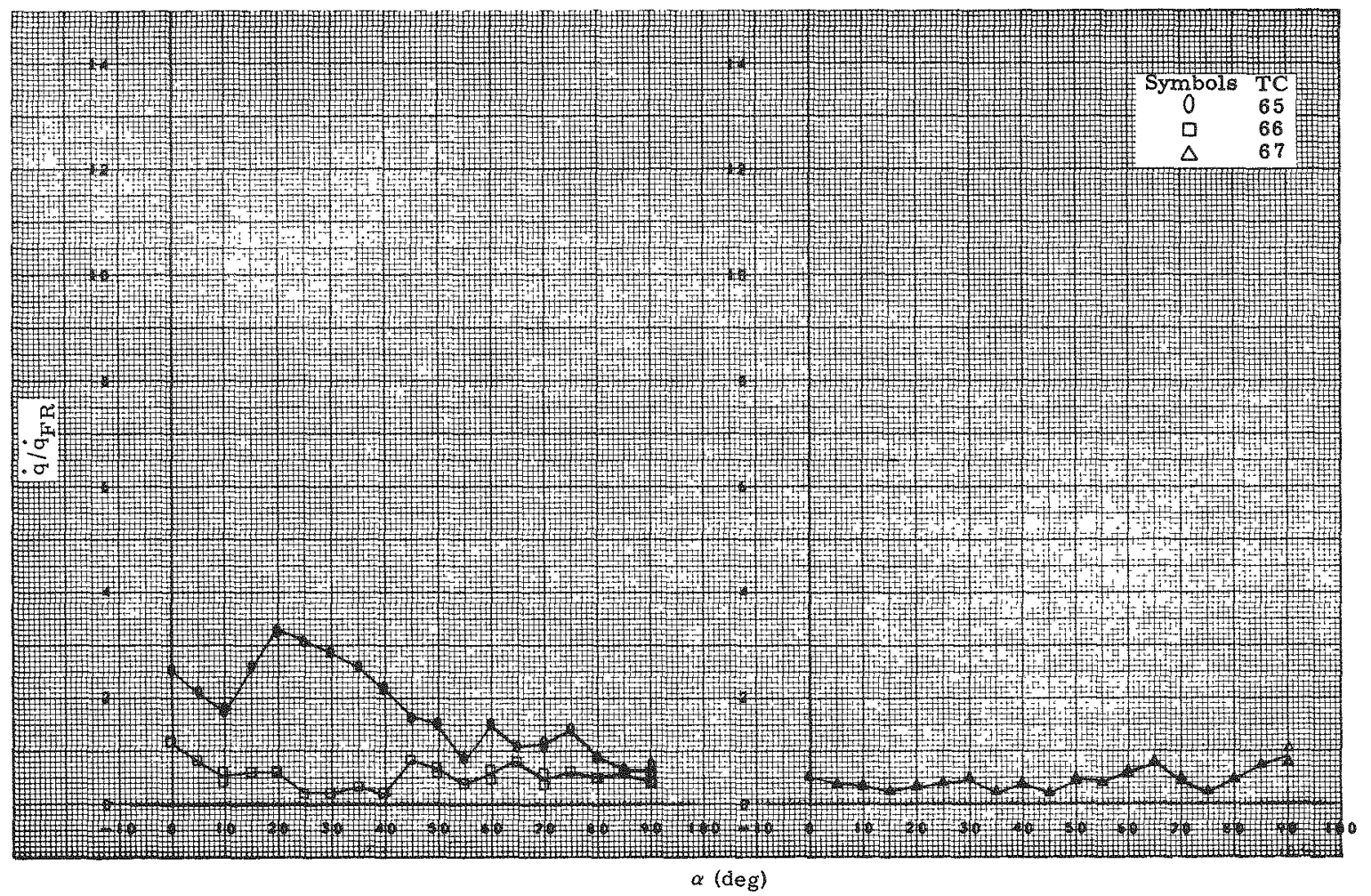

Fig. 202. Heat Transfer, TC $65-67$, Configuration 100

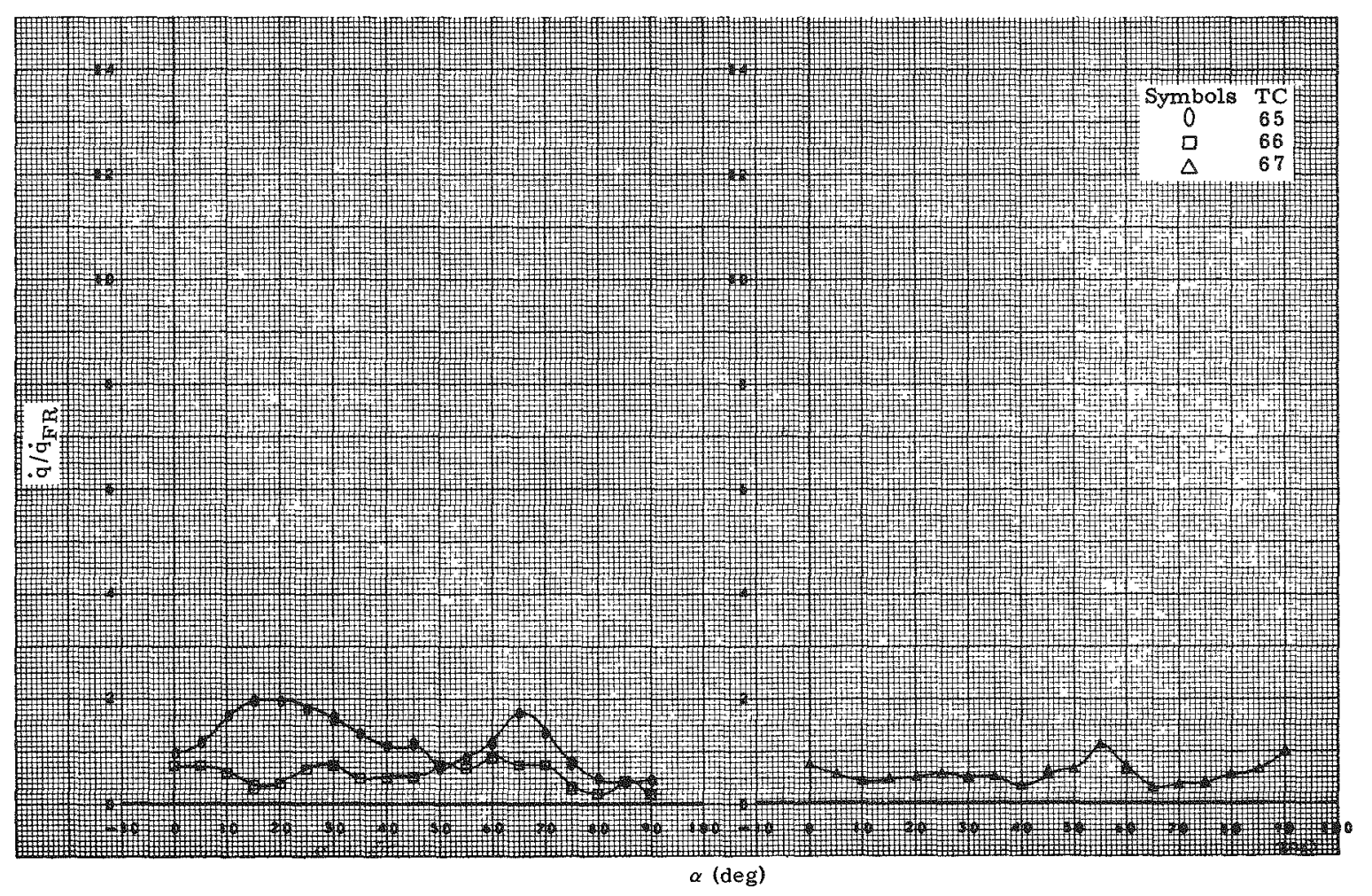

Fig. 203. Heat Transfer, TC $65-67$, Configuration 200 


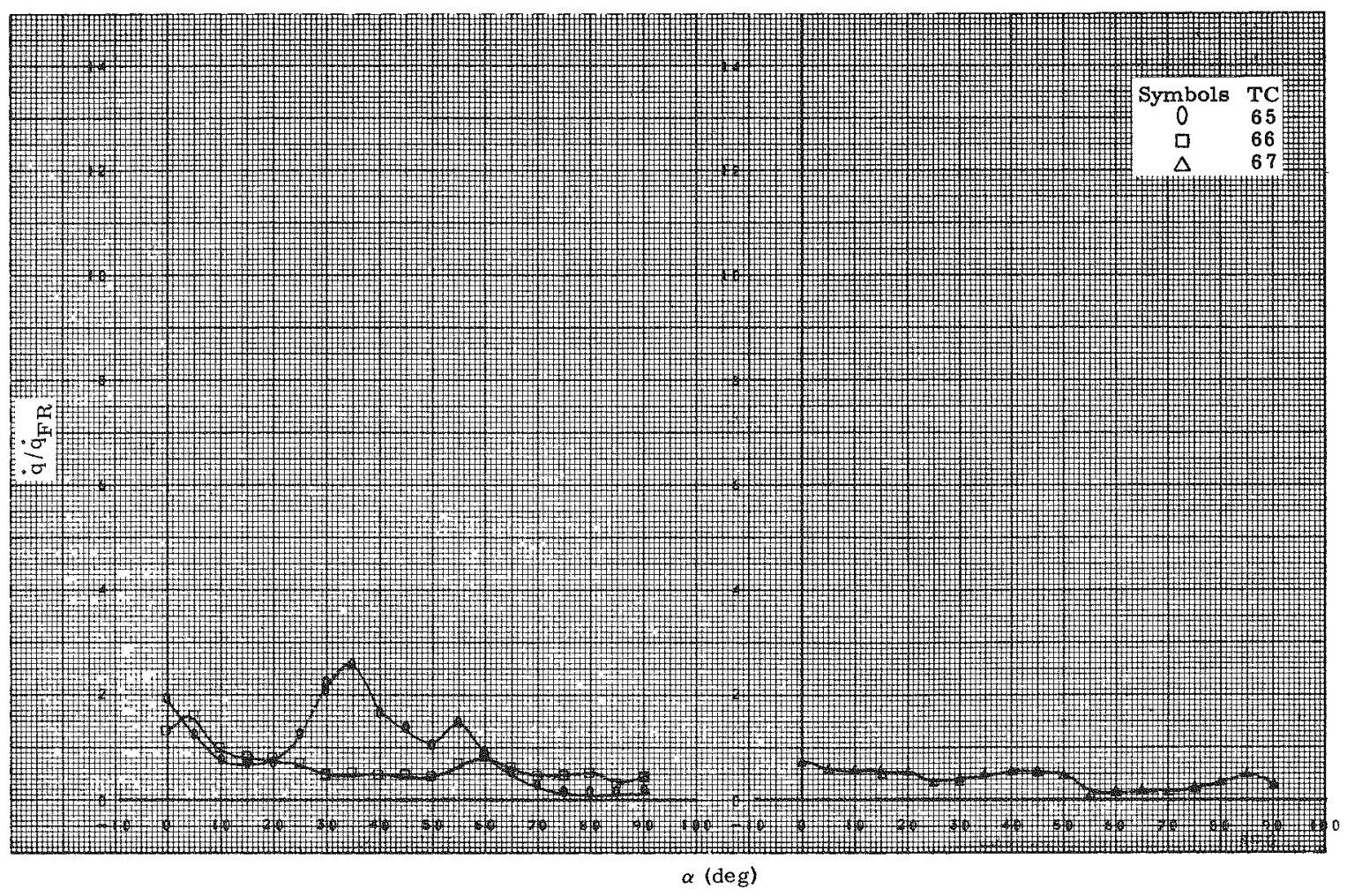

Fig. 204. Heat Transfer, TC $65-67$, Configuration 300

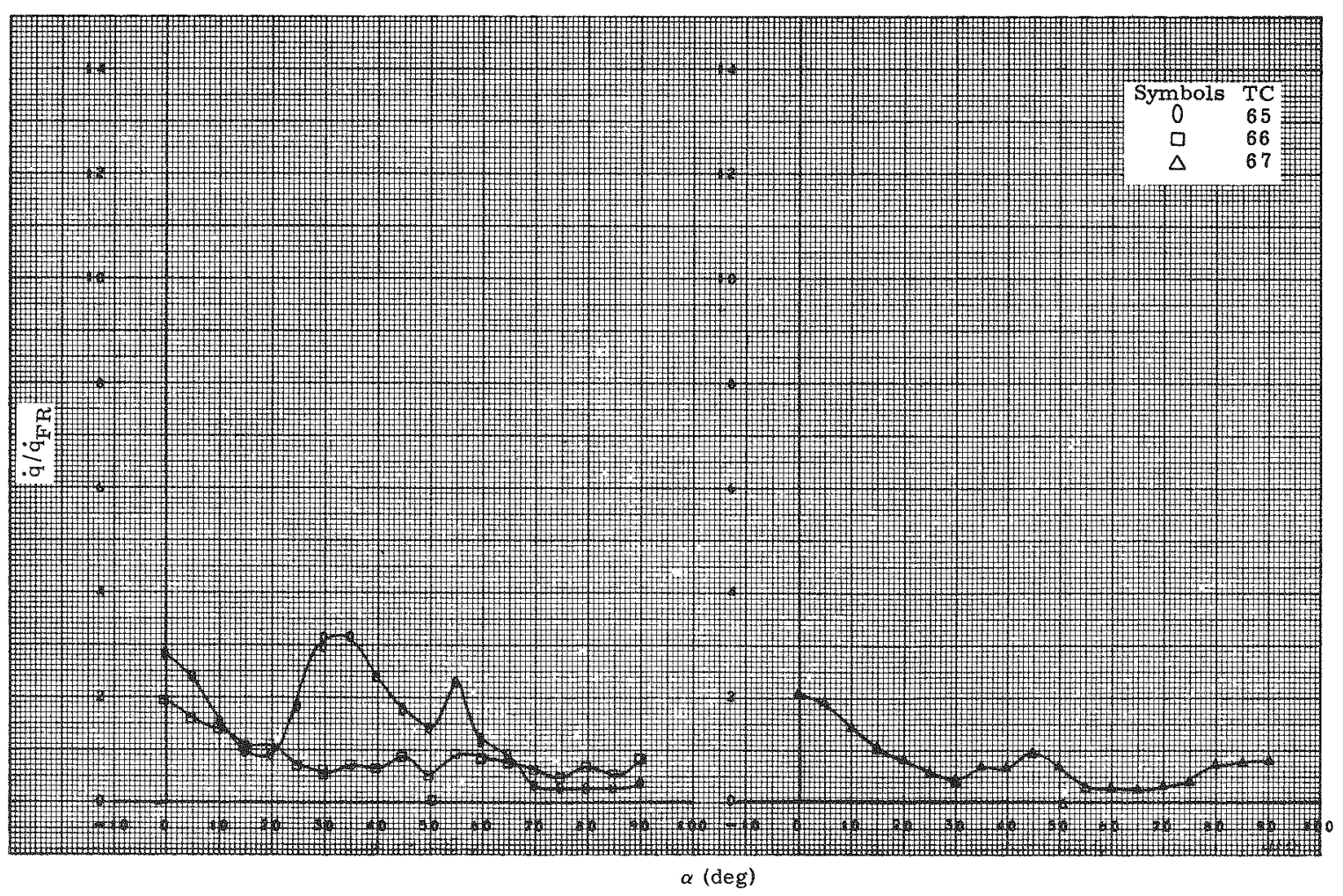

Fig. 205. Heat Transfer, TC $65-67$, Configuration 400 


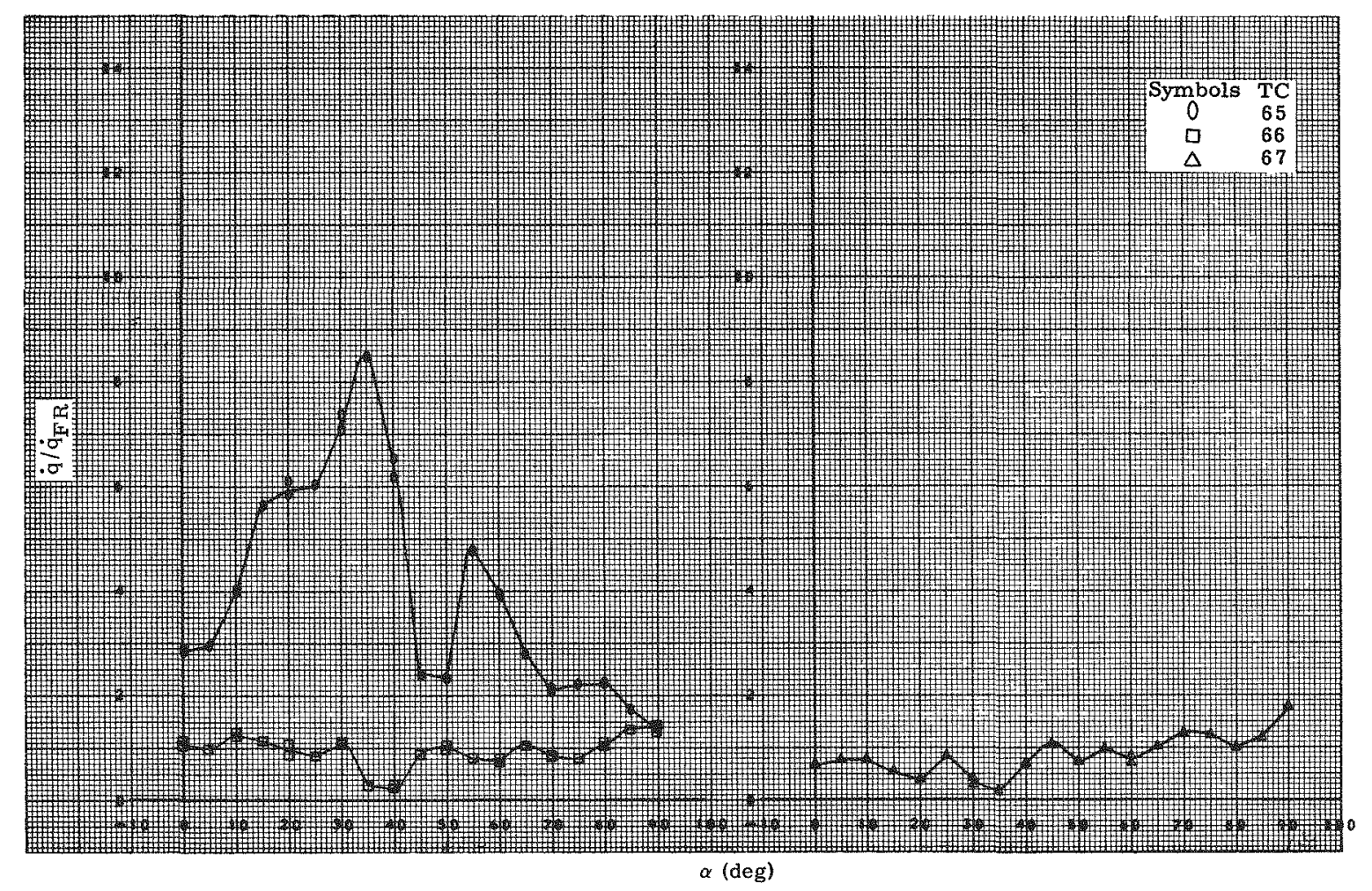

Fig. 206. Heat Transfer, TC $65-67$, Configuration 130

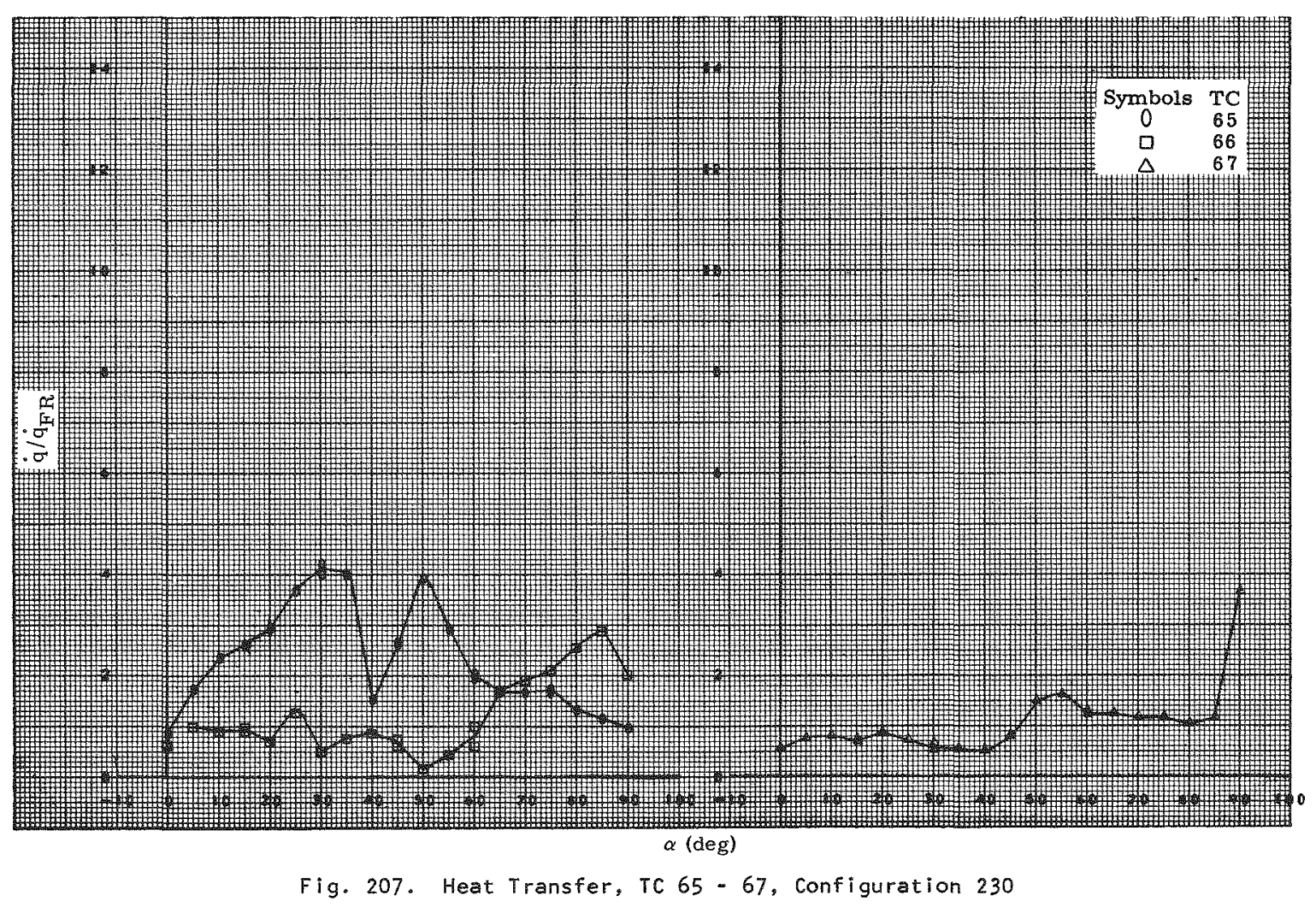

MND-3607-92

134 


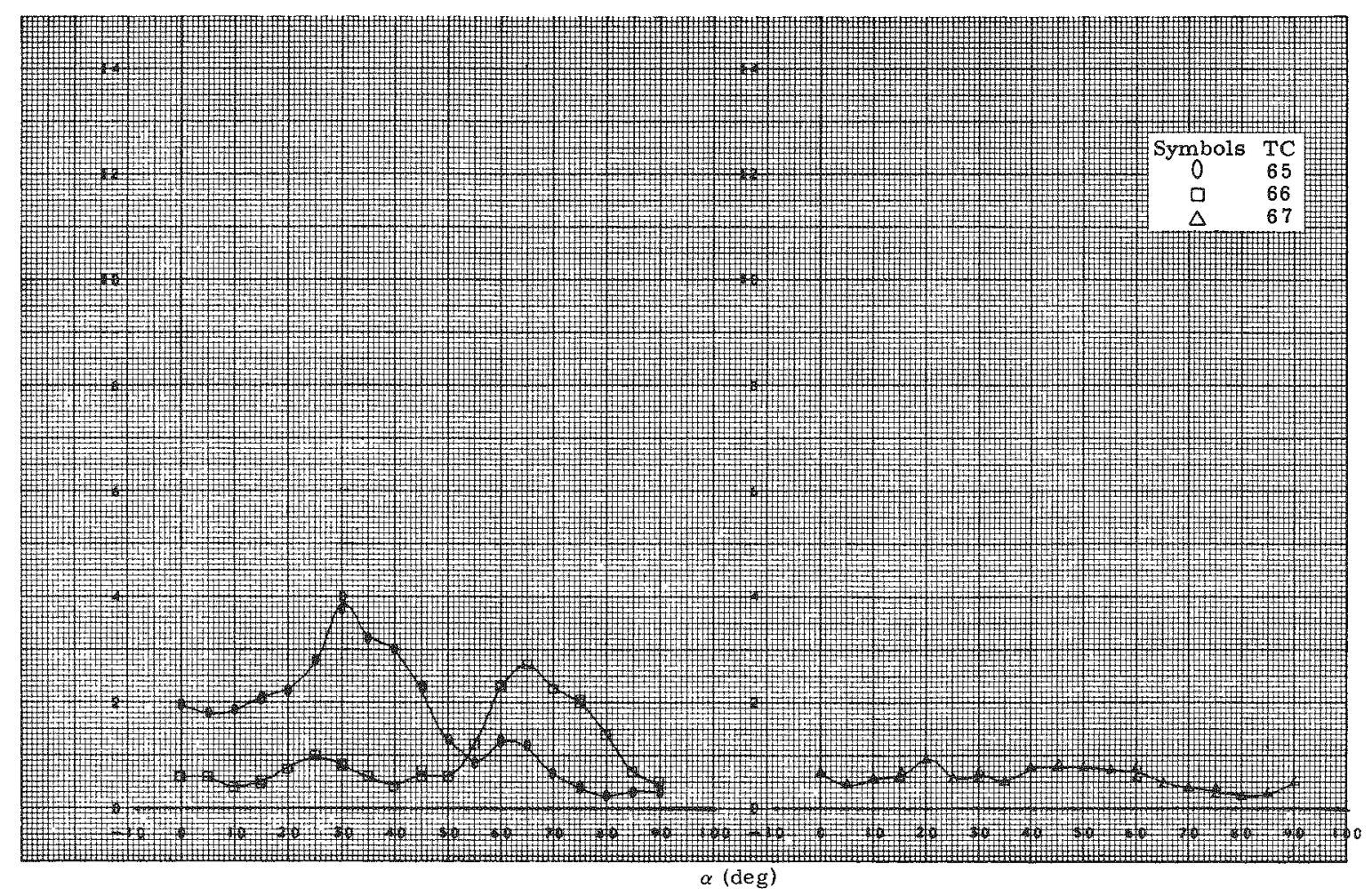

Fig. 208. Heat Transfer, TC $65-67$, Configuration 330

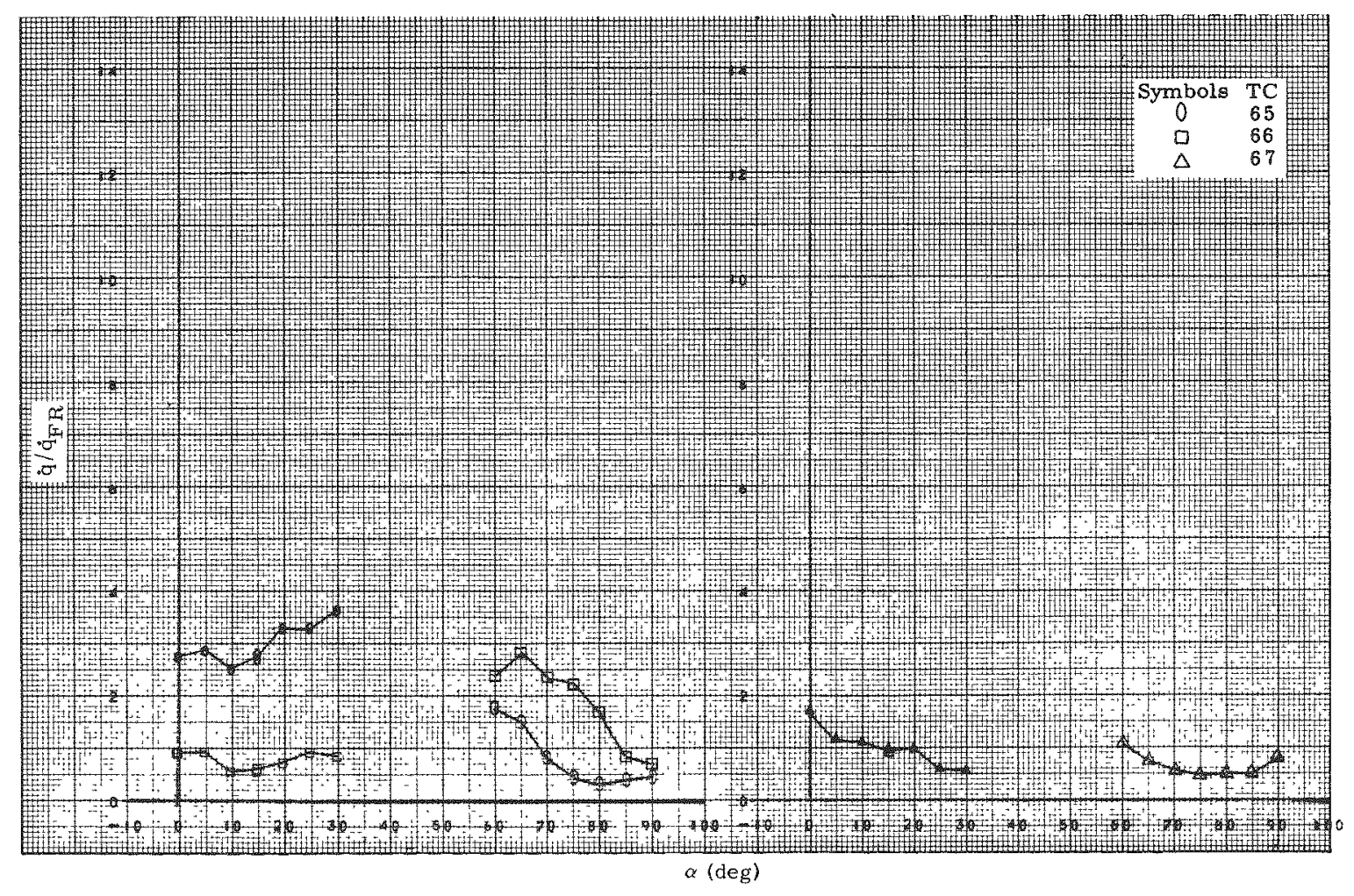

Fig. 209. Heat Transfer, TC $65-67$, Configuration 430 


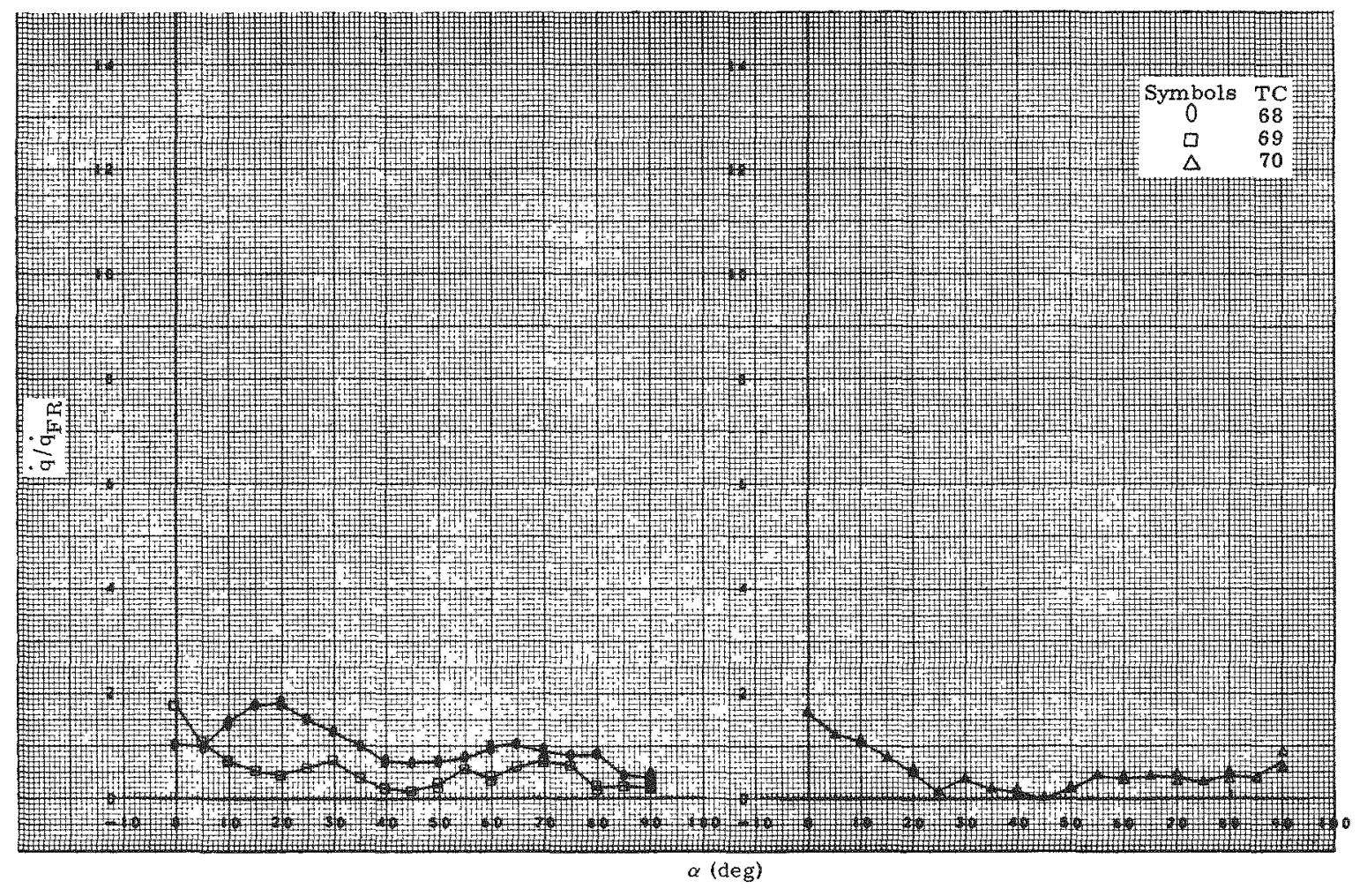

Fig. 210. Heat Transfer, TC $68-70$, Configuration 100

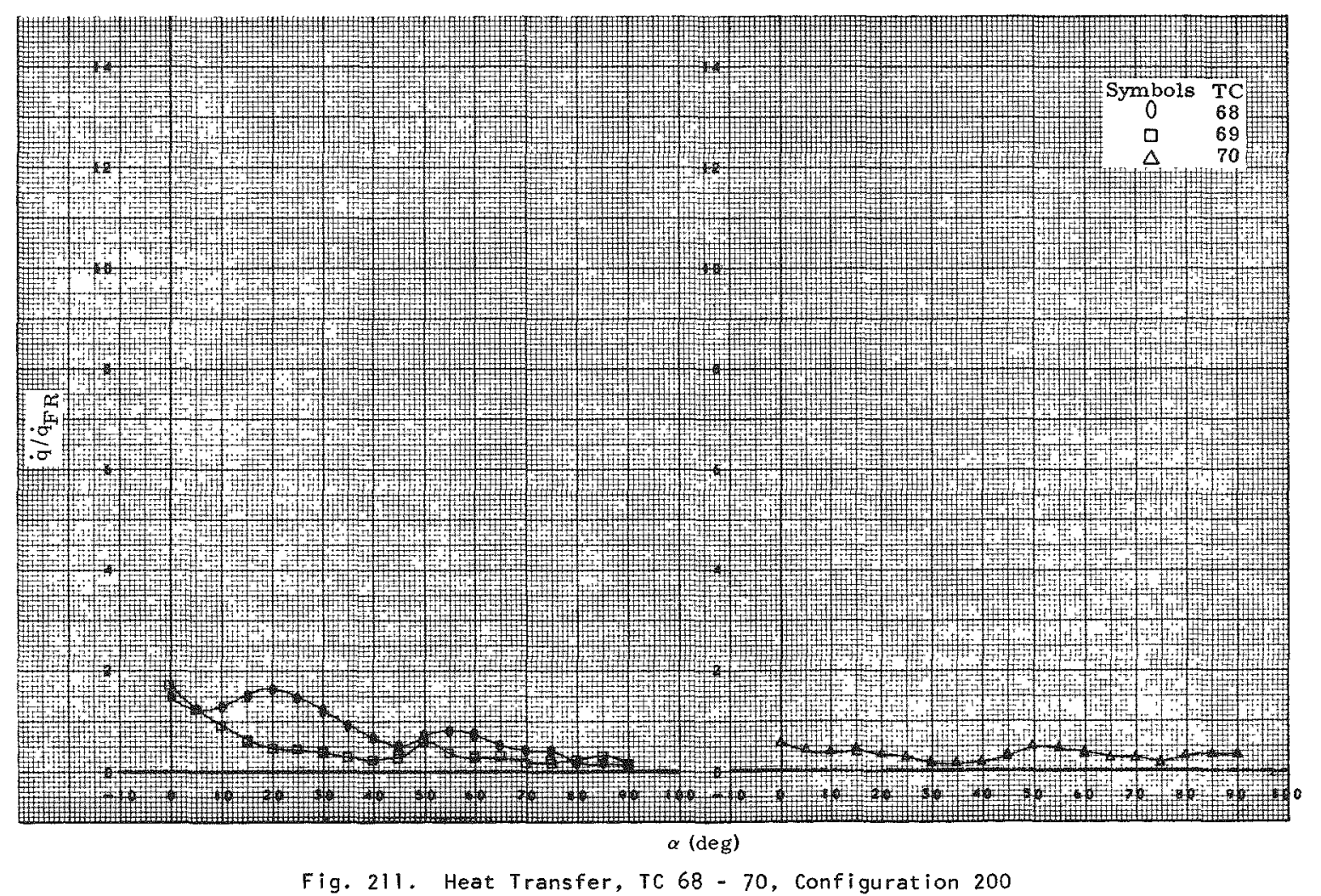

Fig. 211. Heat Transfer, TC $68-70$, Configuration 200 


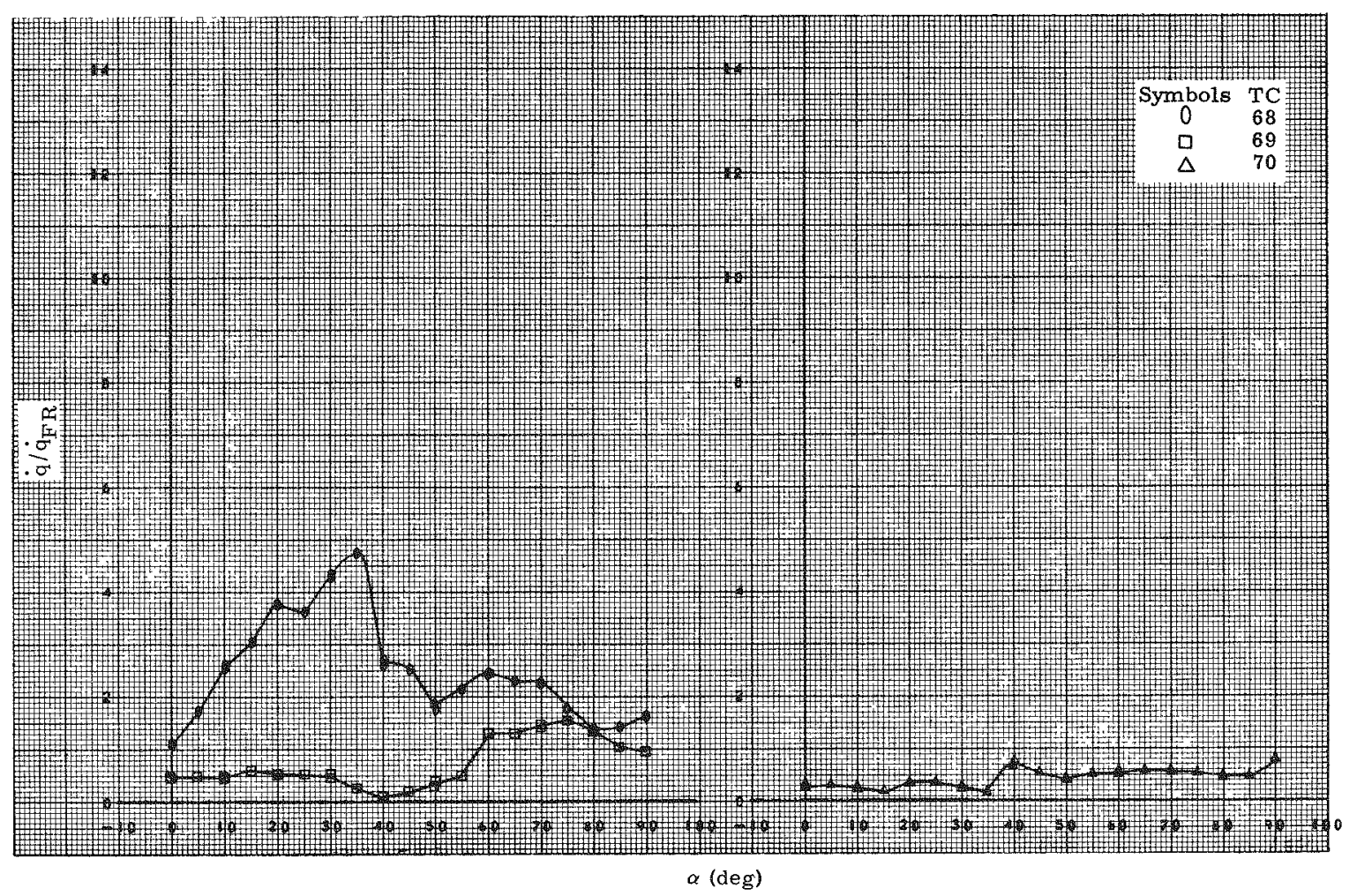

Fig. 212. Heat Transfer, TC $68-70$, Configuration 130

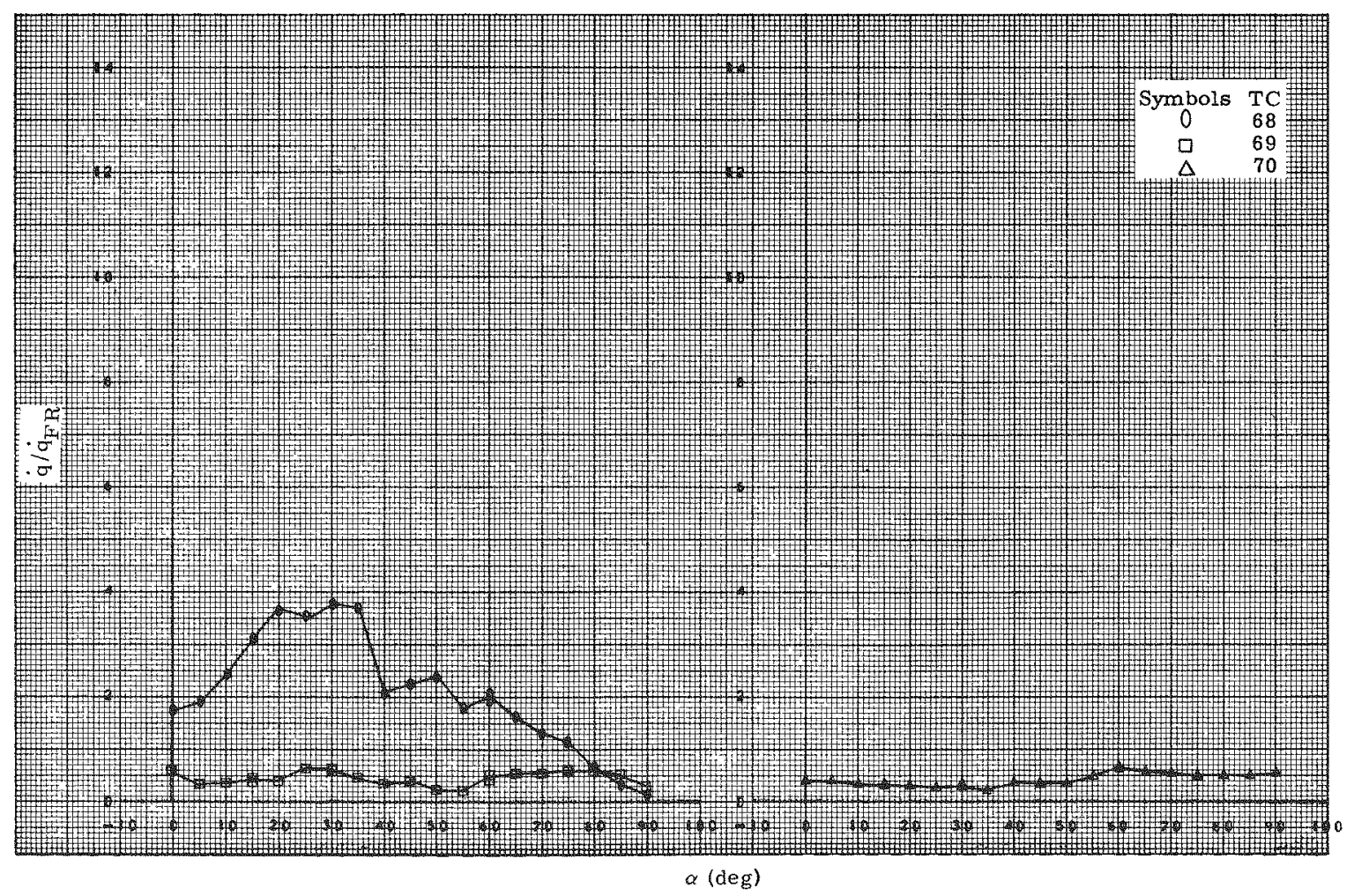

Fig. 213. Heat Transfer, TC $68-70$, Configuration 230 


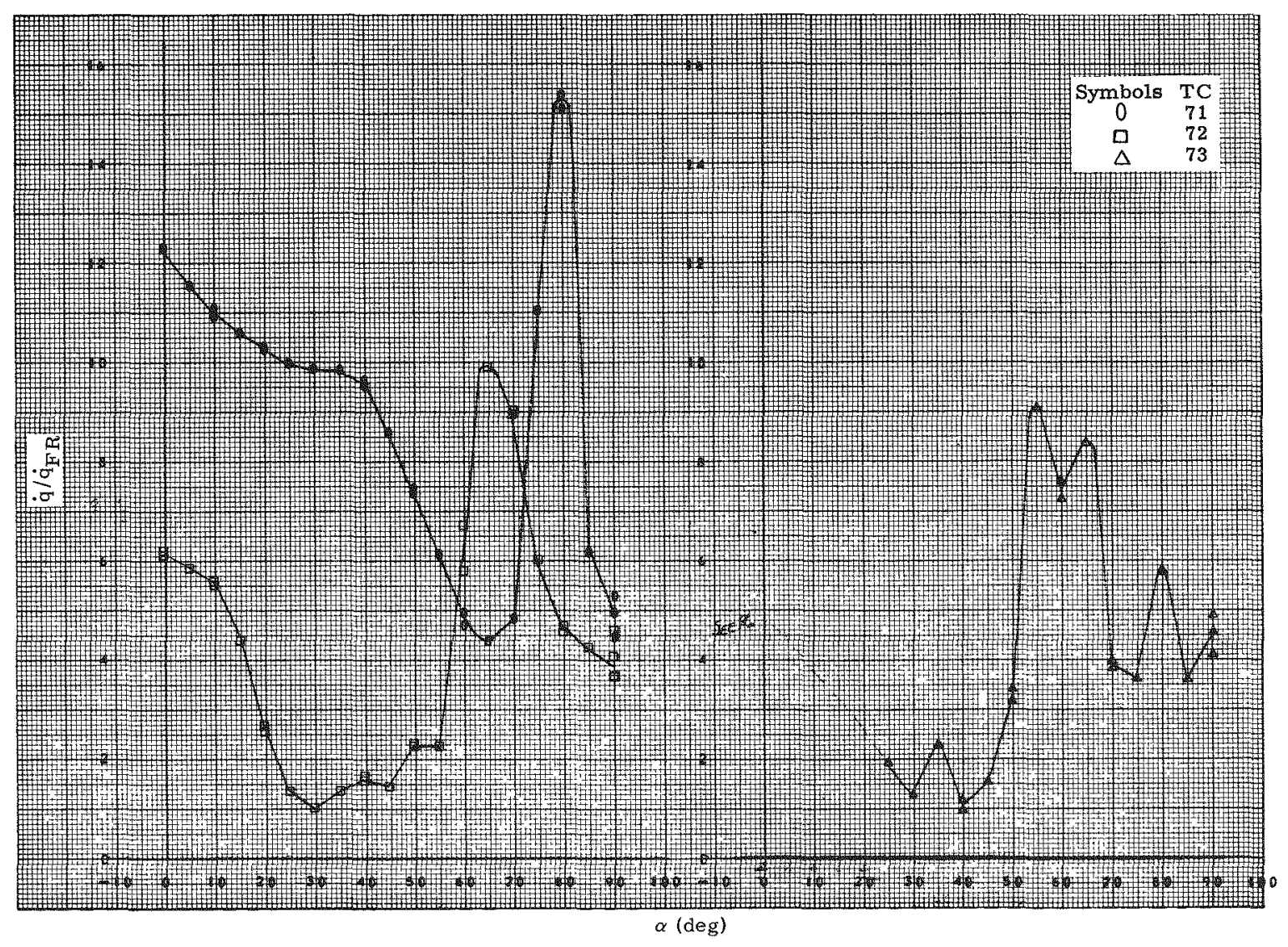

Fig. 214. Heat Transfer, TC $71-73$, Configuration 100

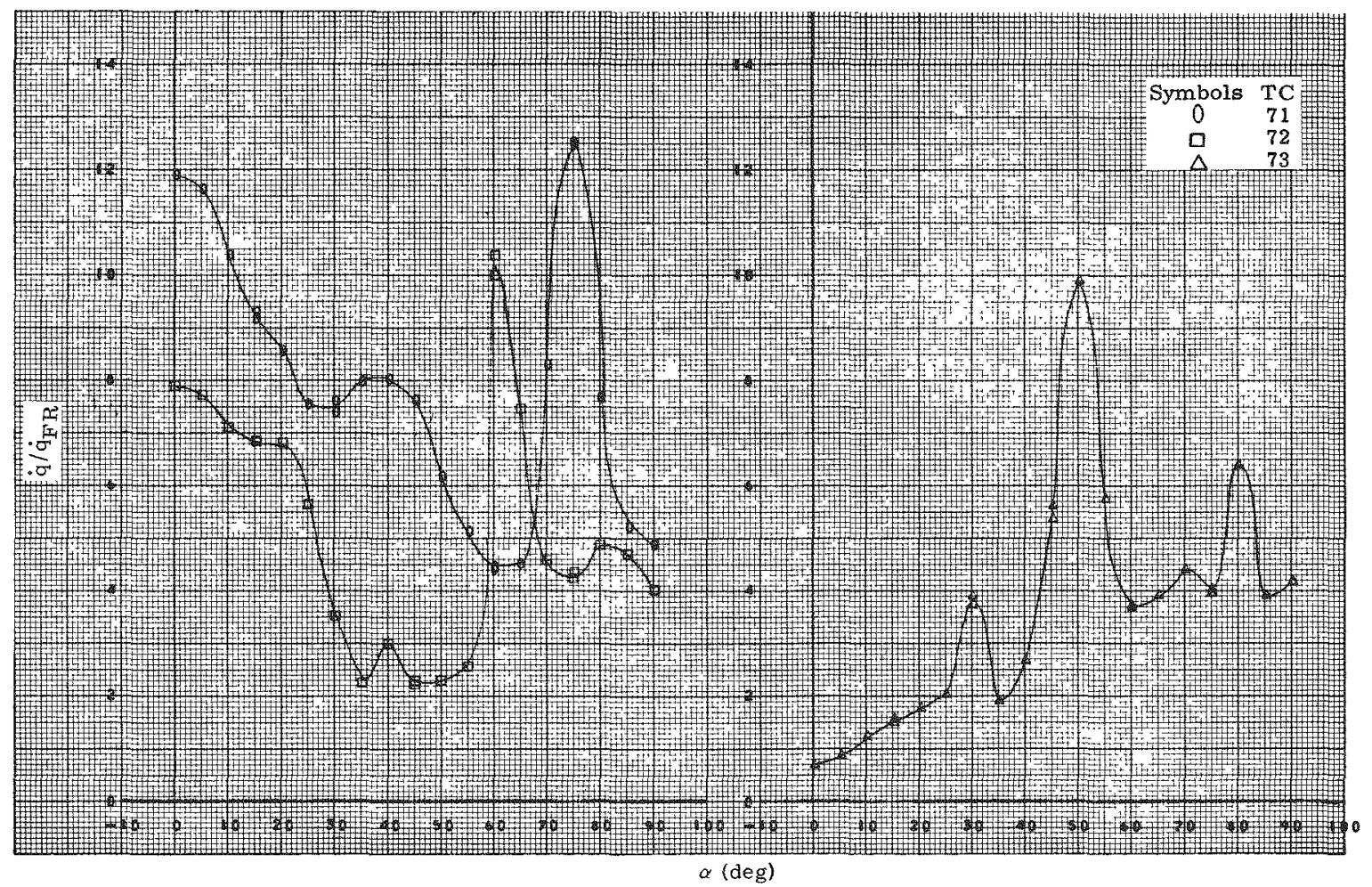

Fig. 215. Heat Transfer, TC $71-73$, Configuration 200 


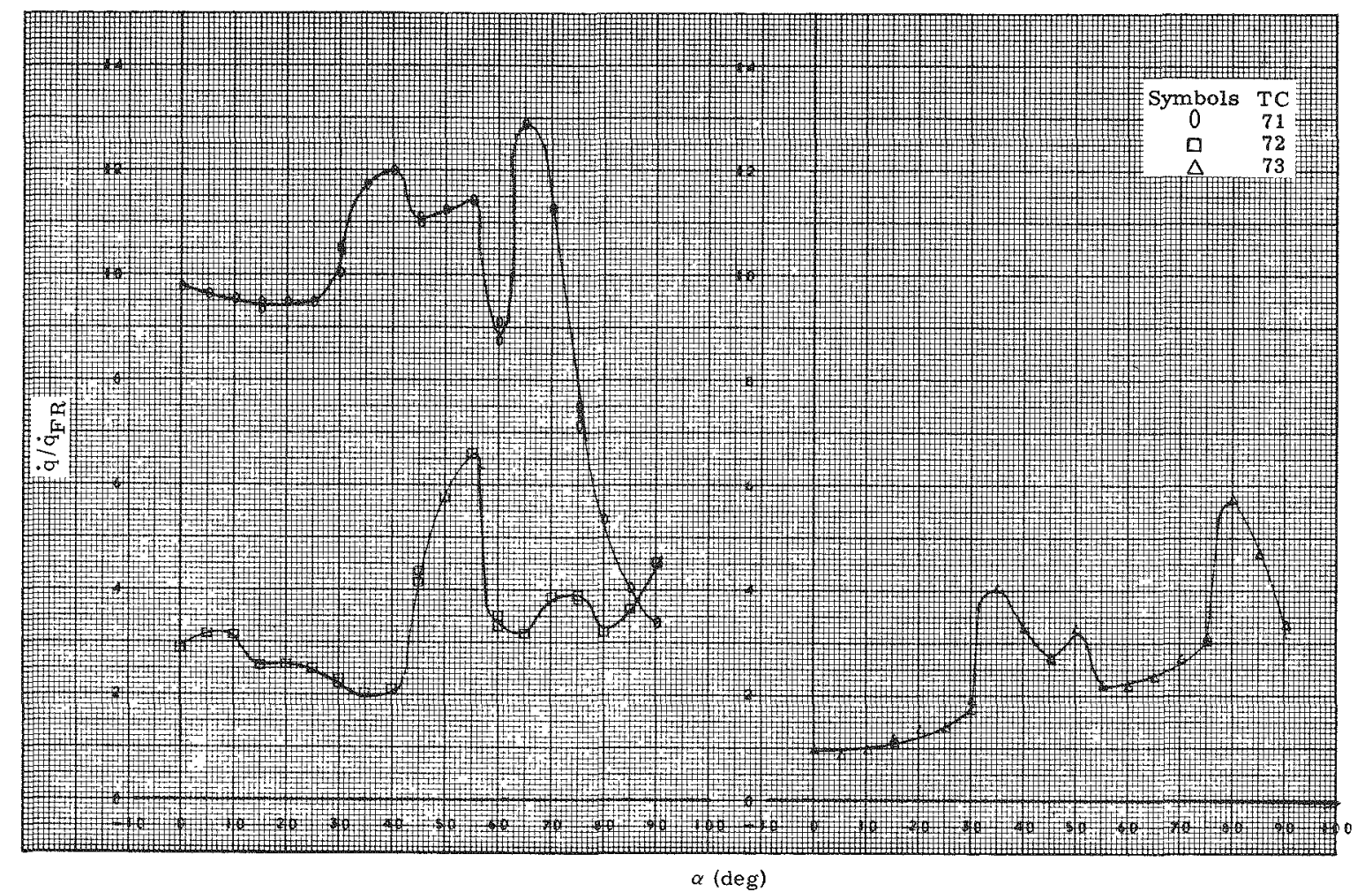

Fig. 216. Heat Transfer, TC $71-73$, Configuration 300

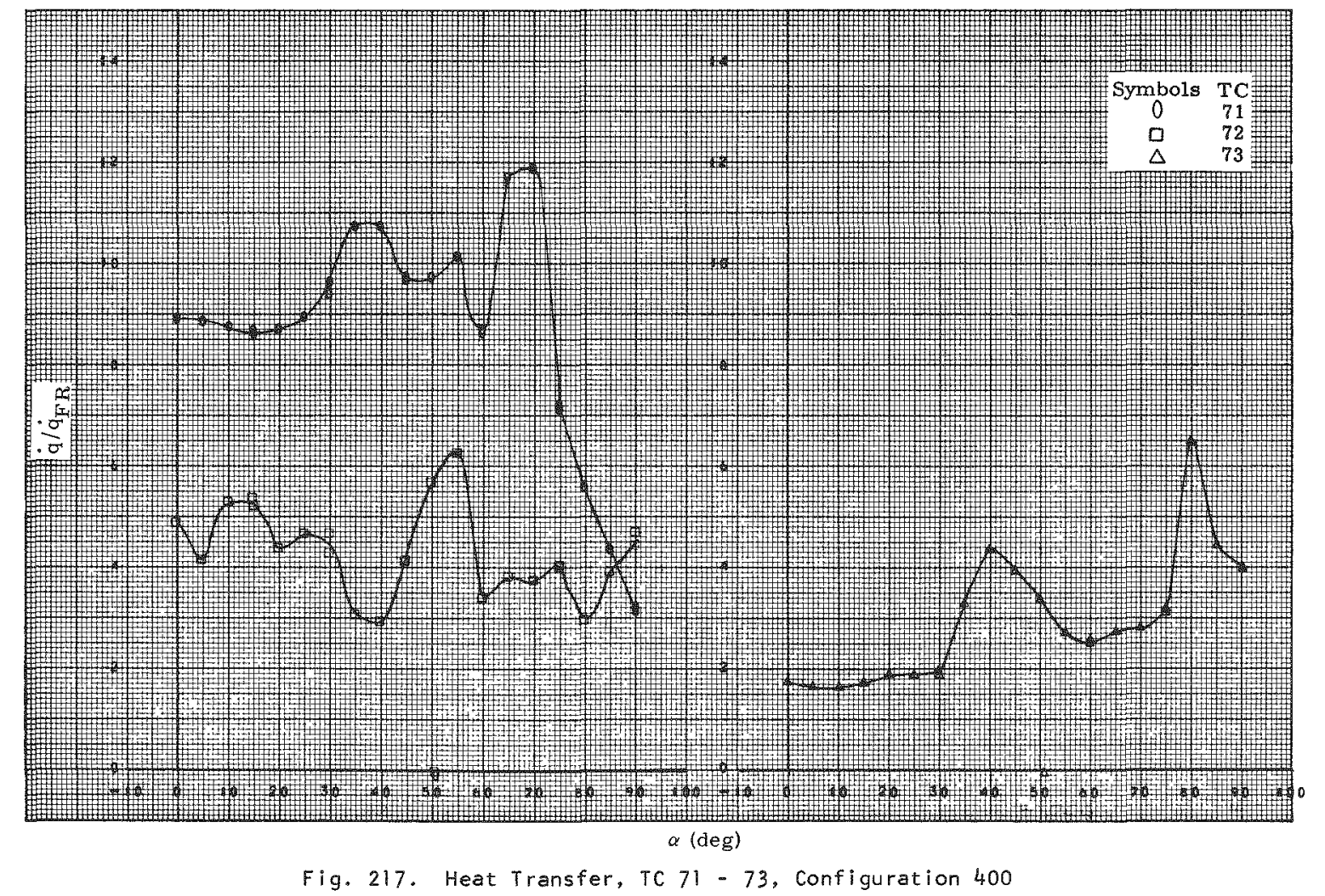

MND-3607-92 


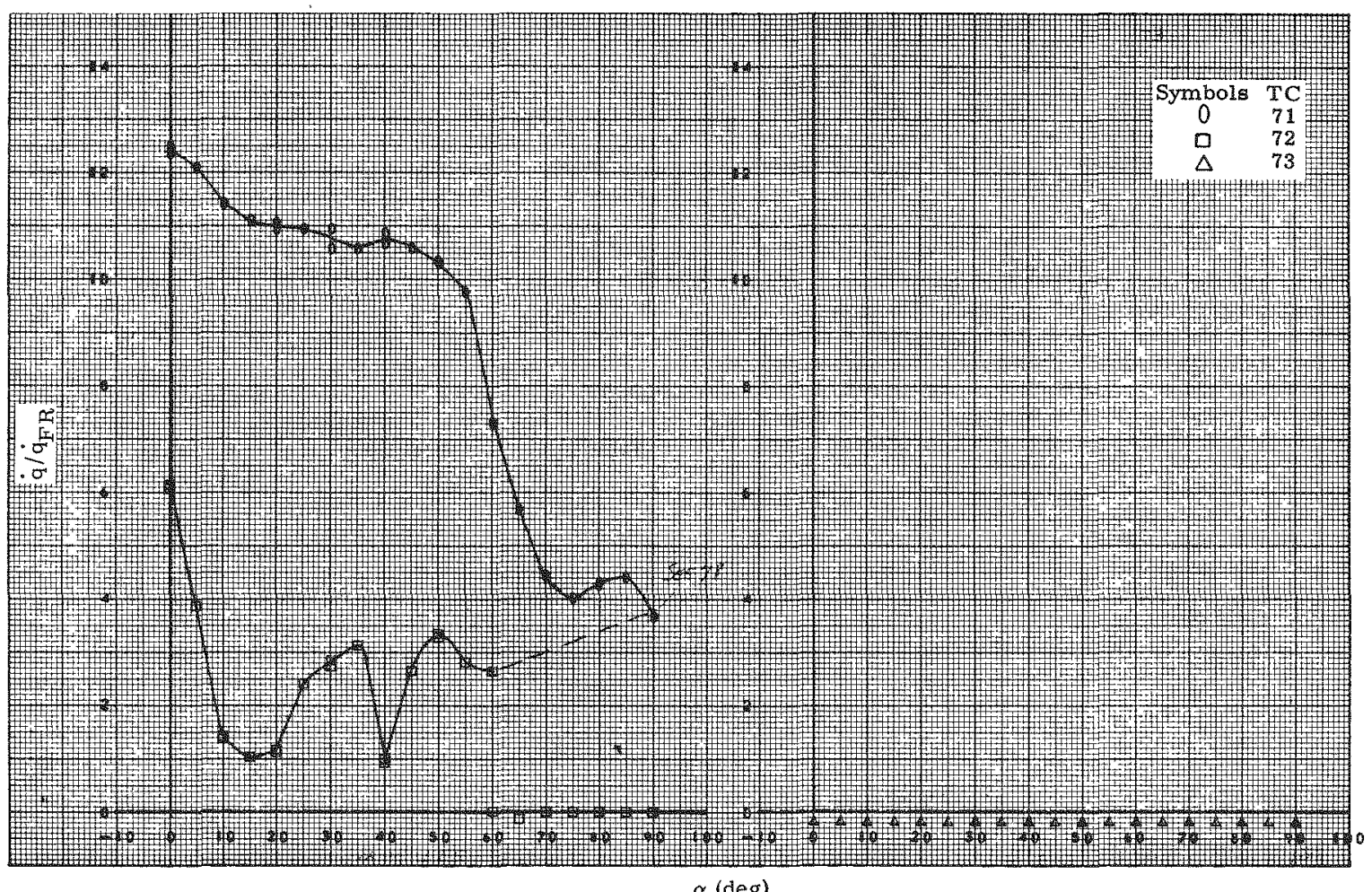

Fig. 218. Heat Transfer, TC $71-73$, Configuration 130

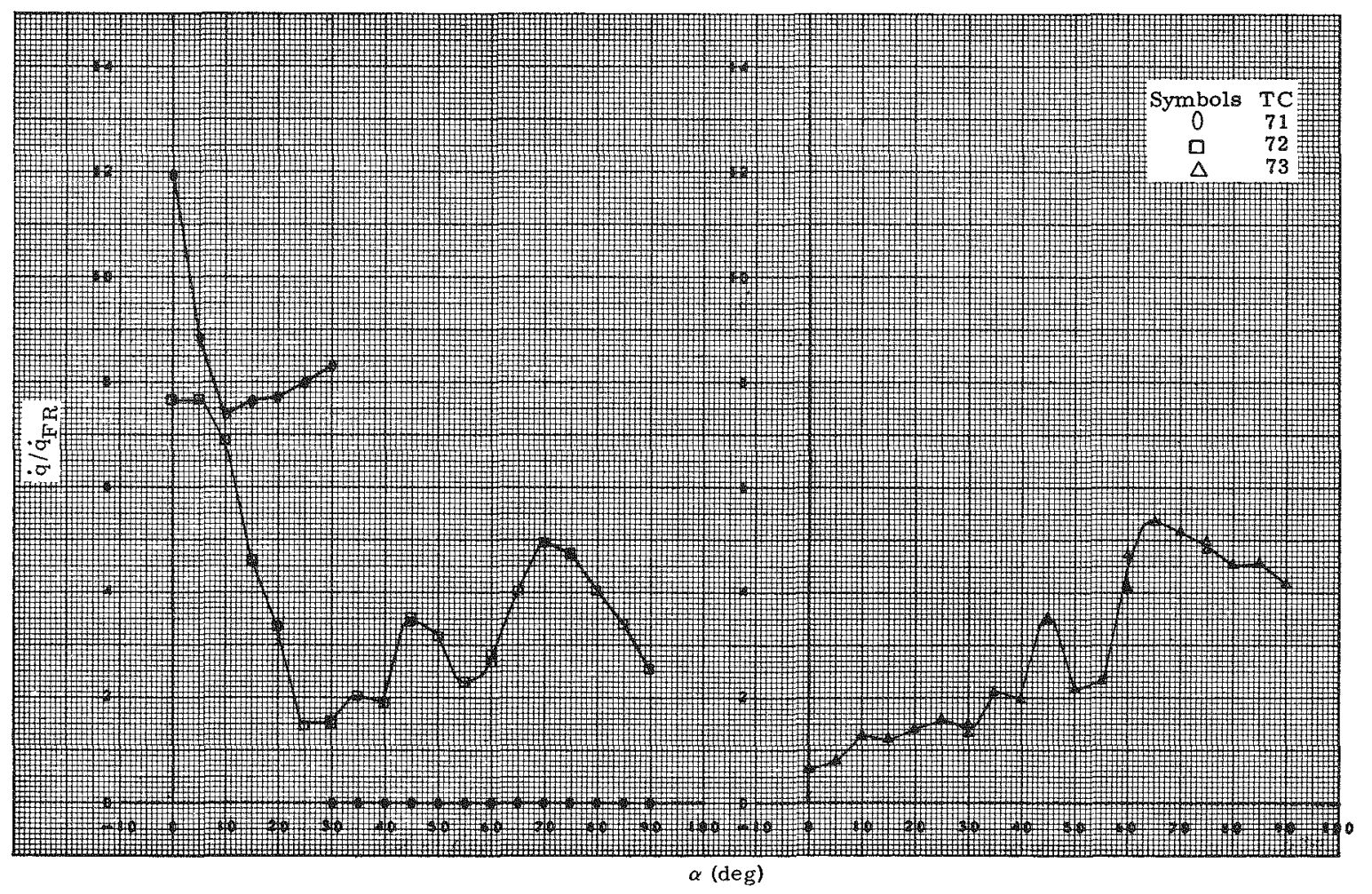

Fig. 219. Heat Transfer, TC $71-73$, Configuration 230 


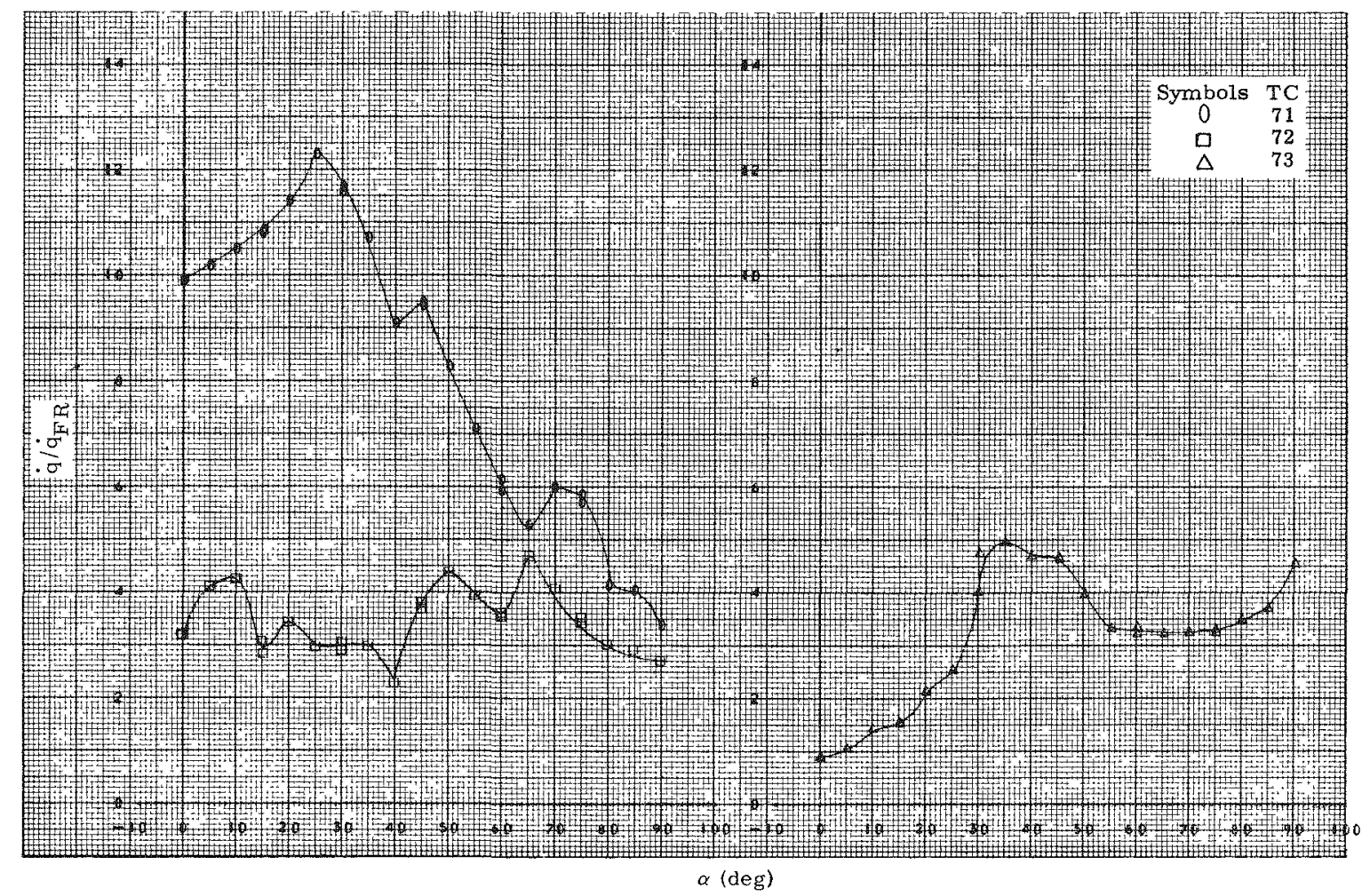

Fig. 220. Heat Transfer, TC $71-73$, Configuration 330

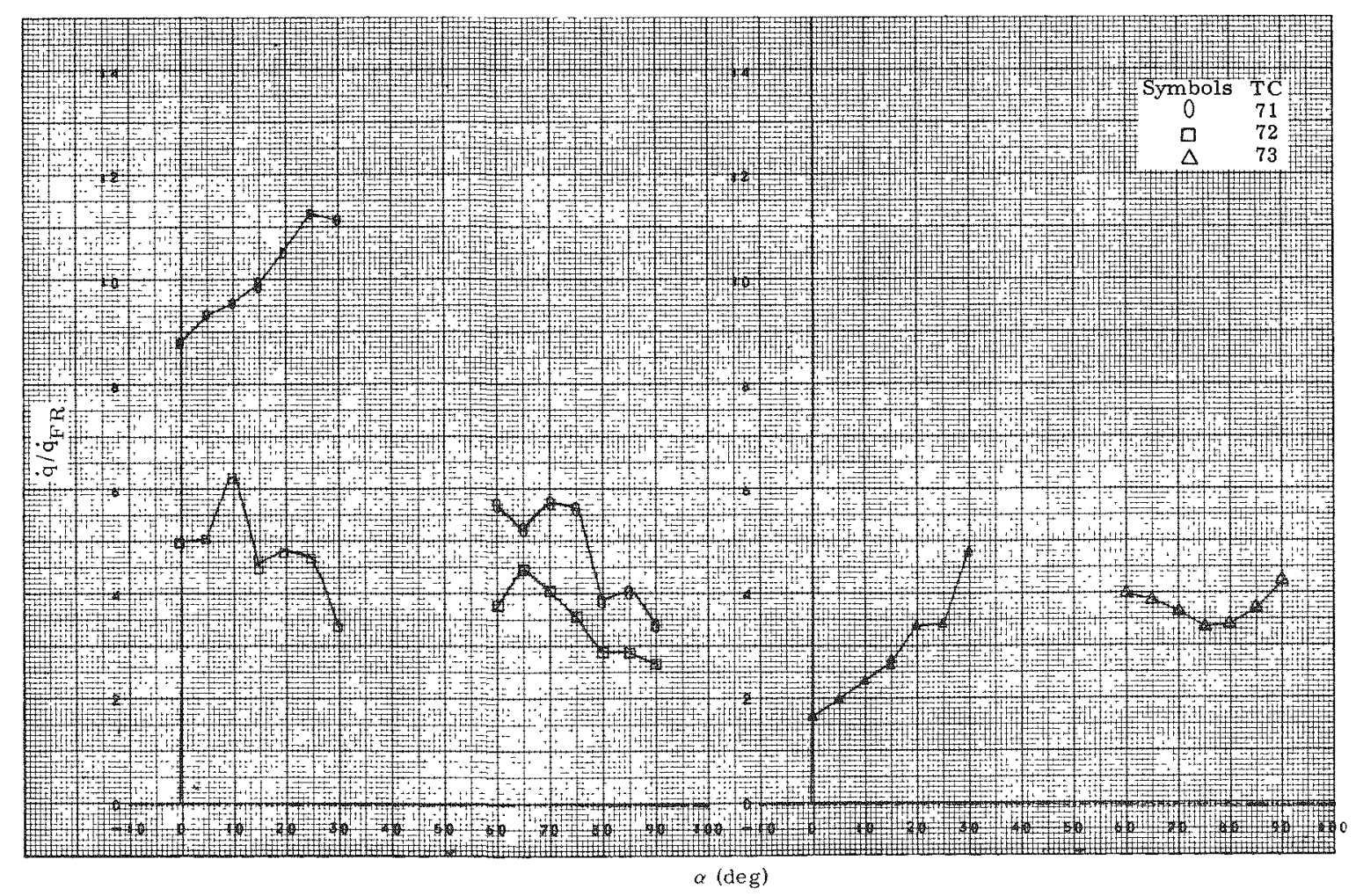

Fig. 221, Heat Transfer, TC 71- 73, Configuration 430 


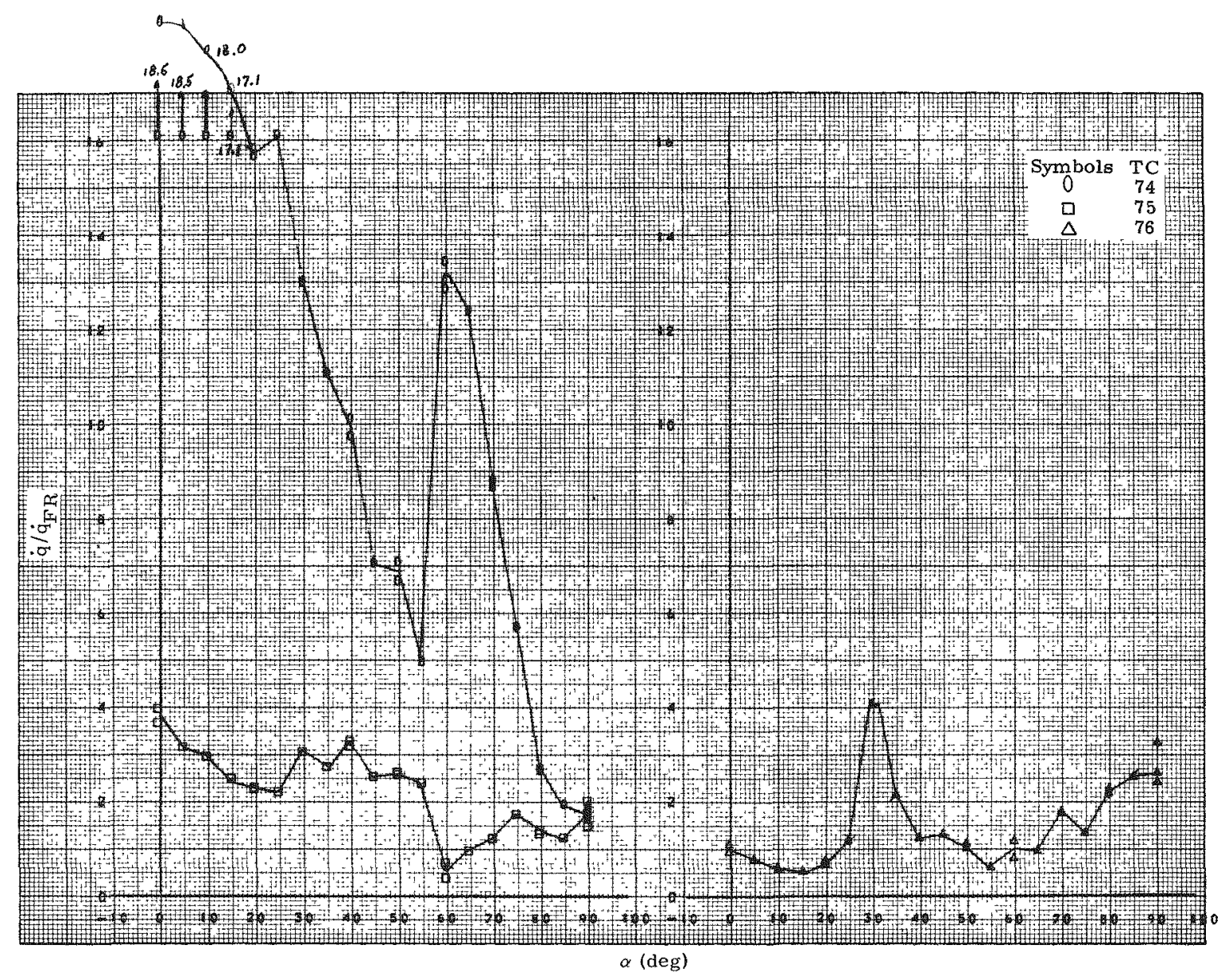

Fig. 222. Heat Transfer, TC $74-76$, Configuration 100

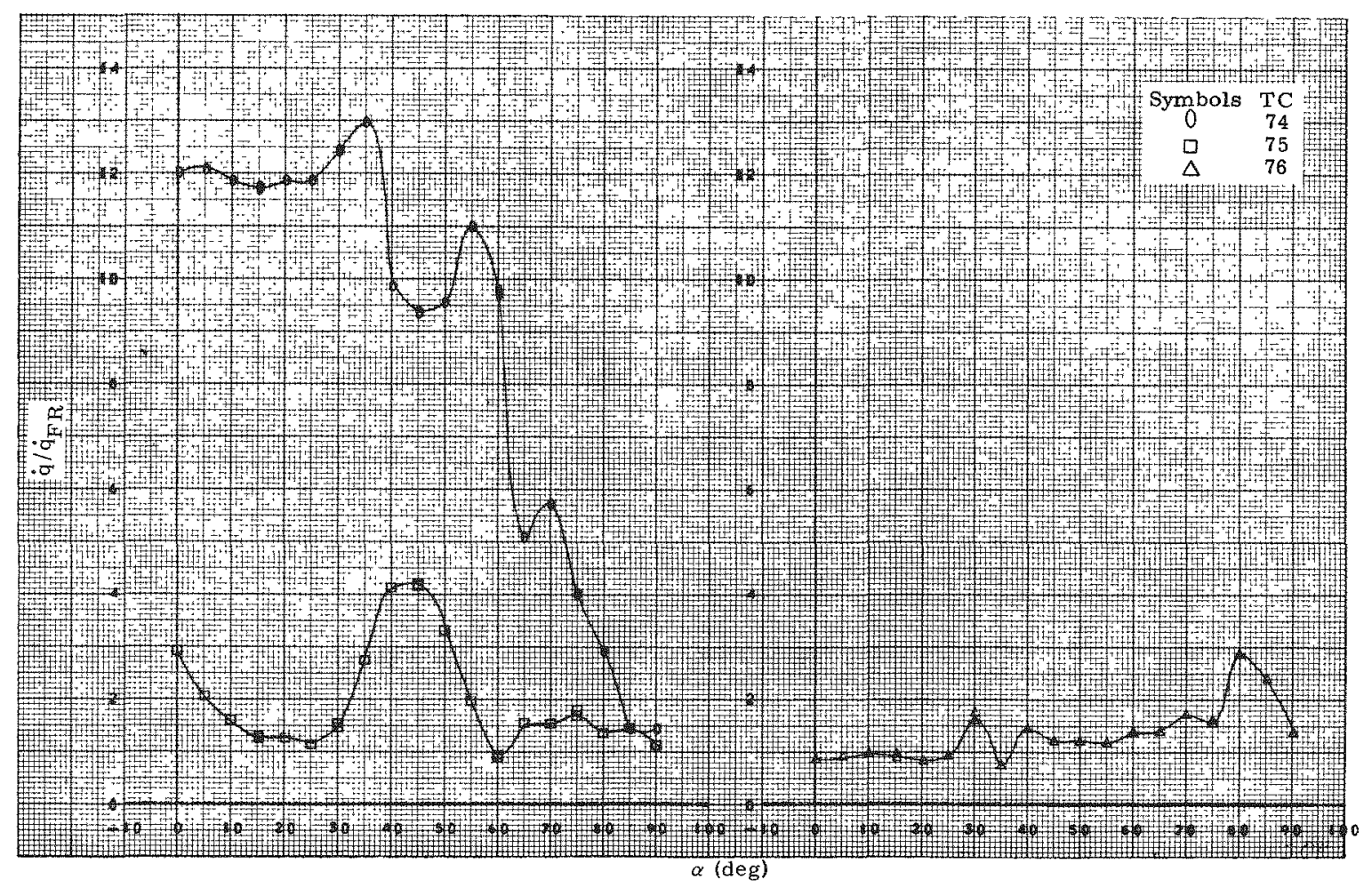

Fig. 223. Heat Transfer, TC $74-76$, Configuration 200 


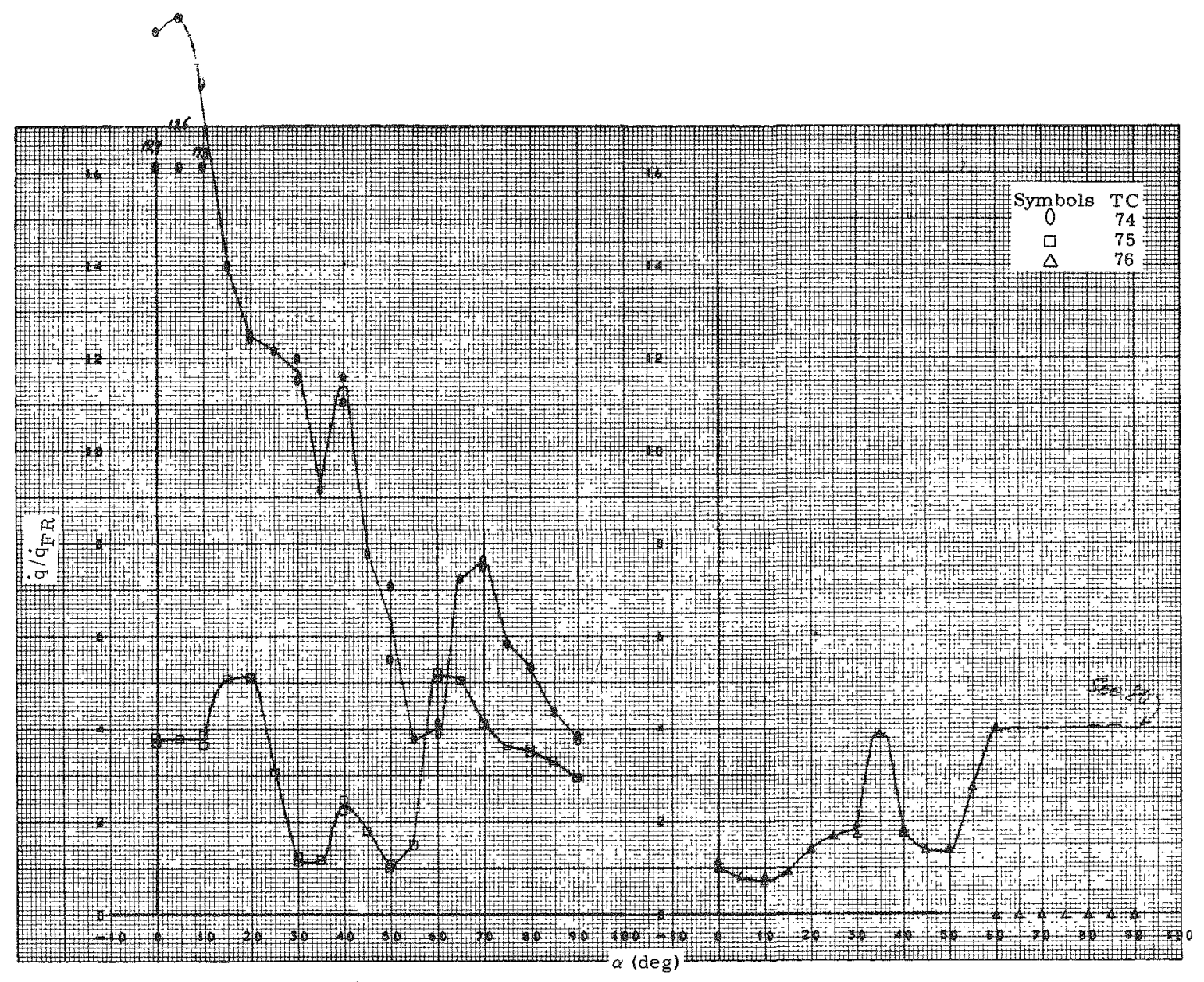

Fig. 224. Heat Transfer, TC $74-76$, Configuration 130

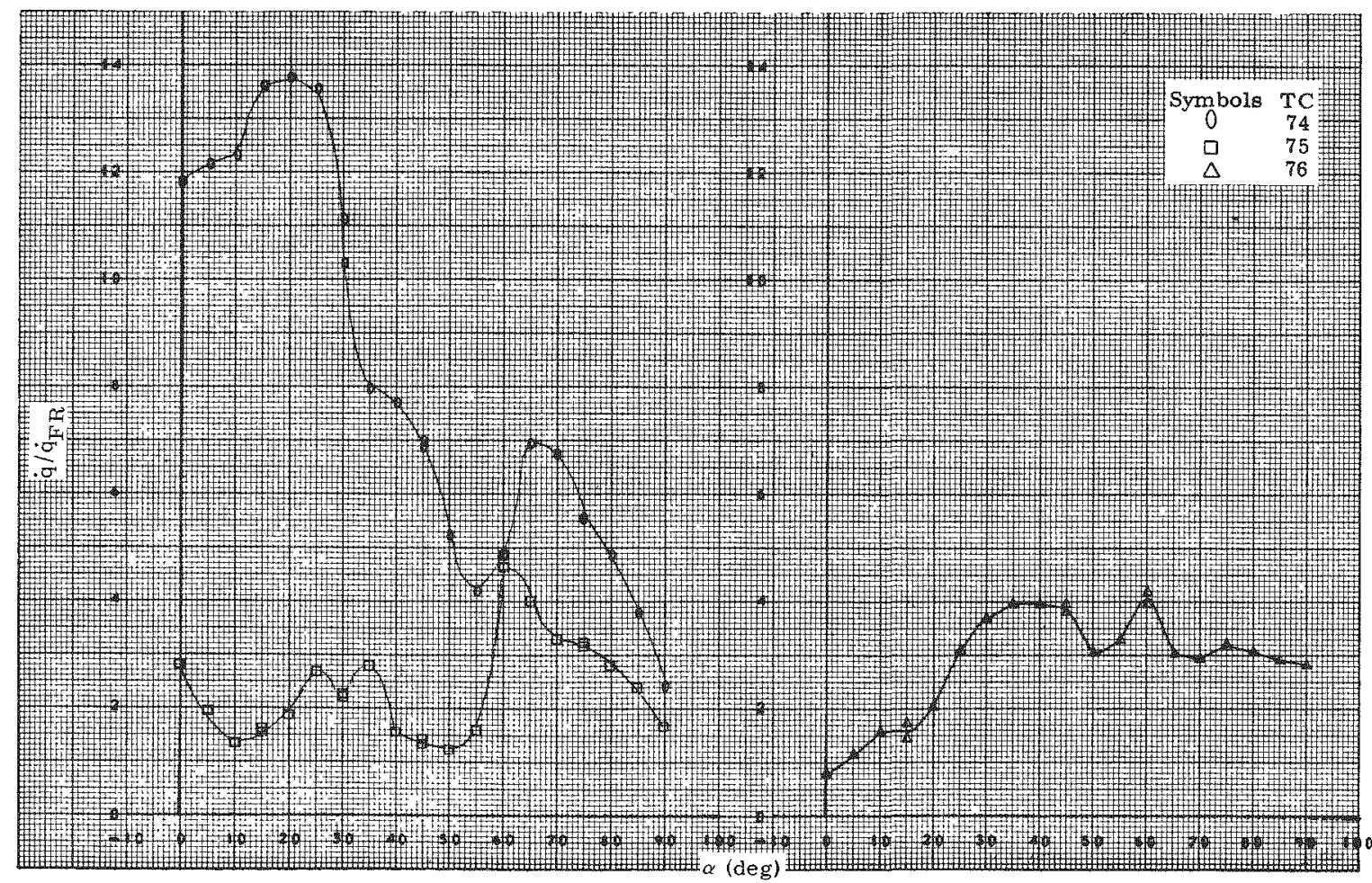

Fig. 225. Heat Transfer, TC $74-76$, Configuration 230 


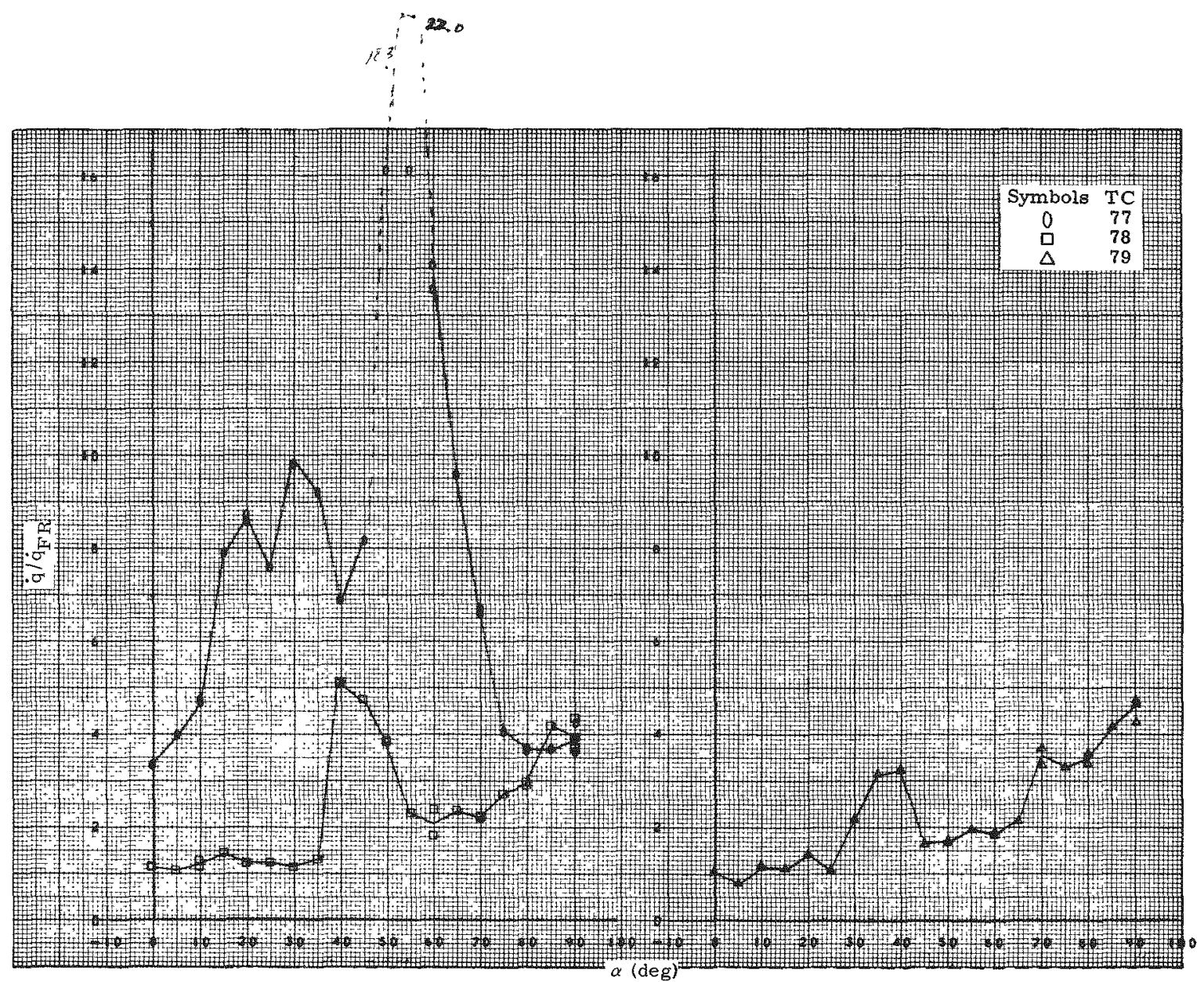

Fig. 226. Heat Transfer, TC $77-79$, Configuration 100

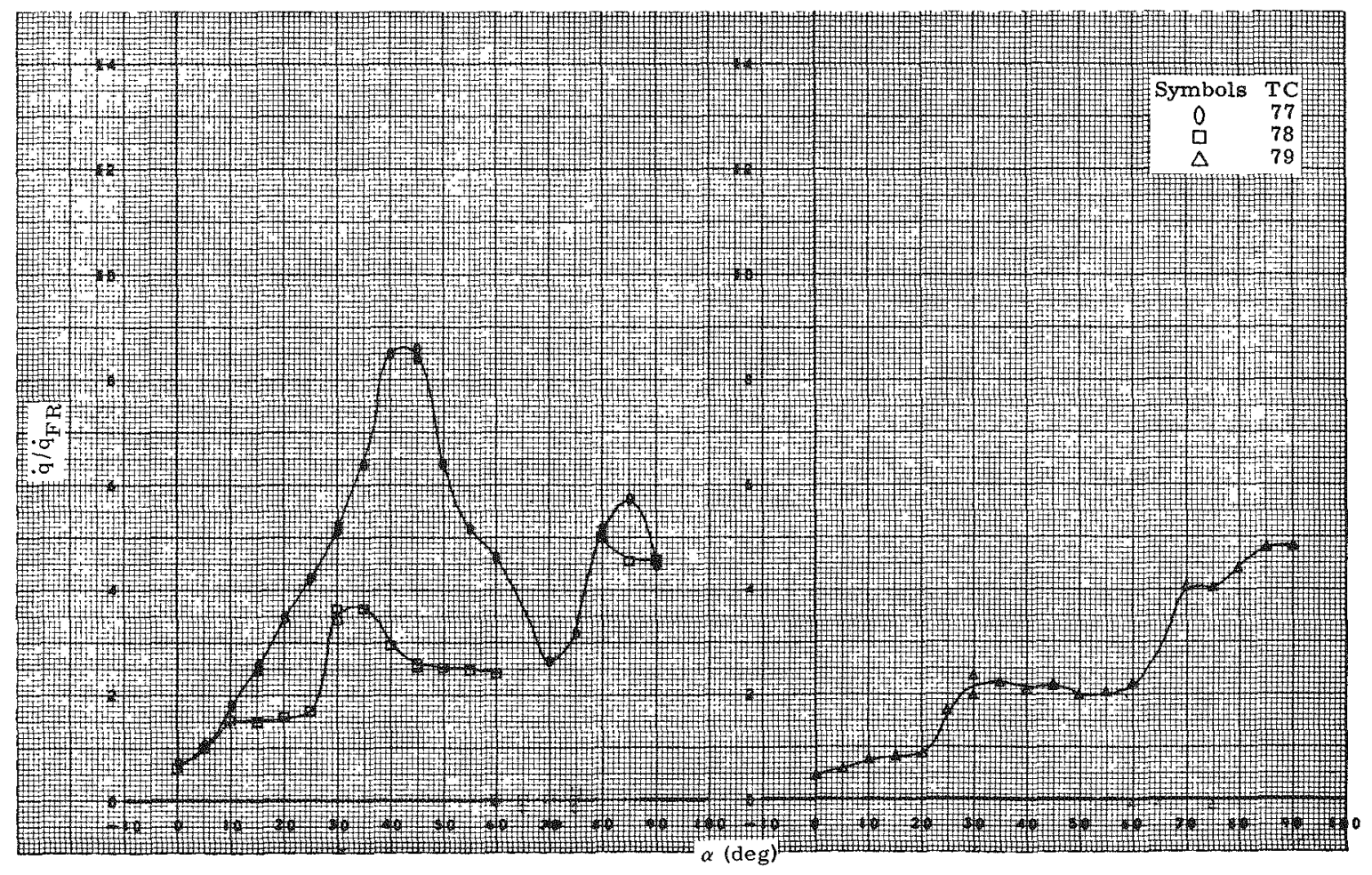

Fig. 227. Heat Transfer, TC $77-79$, Configuration 200 


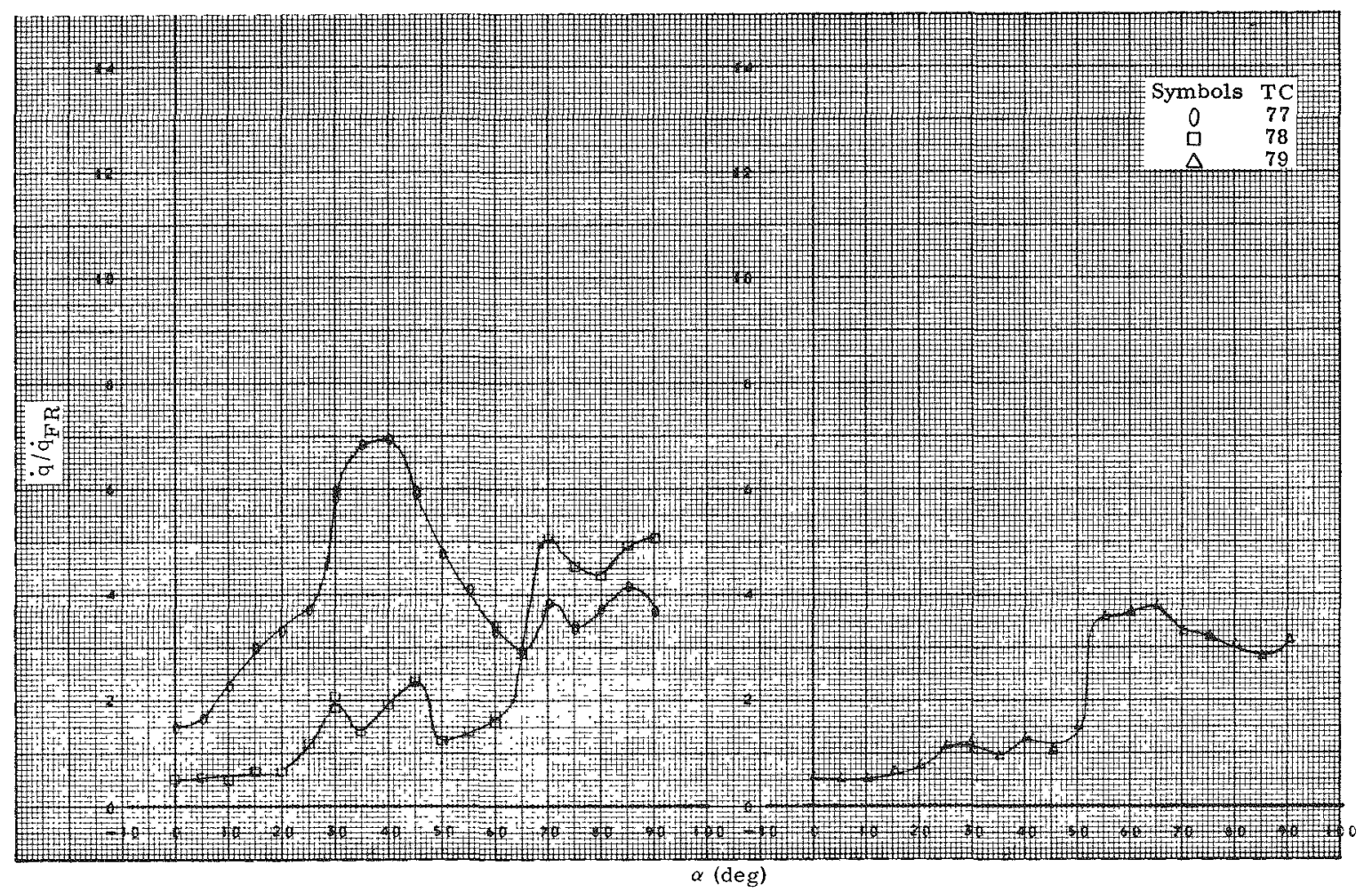

Fig. 228. Heat Transfer, TC $77-79$, Configuration 300

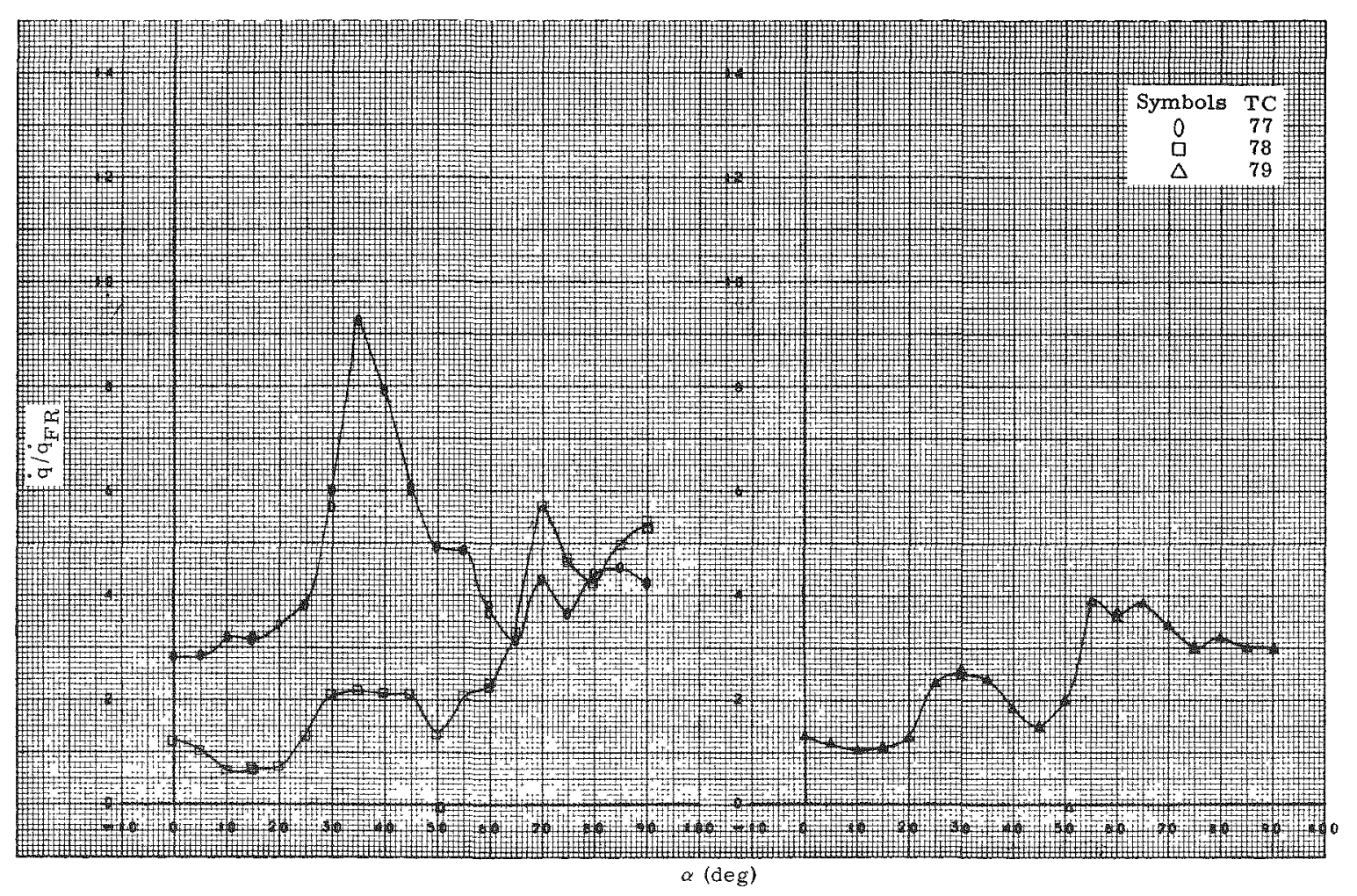

Fig. 229. Heat Transfer, TC $77-79$, Configuration 400 


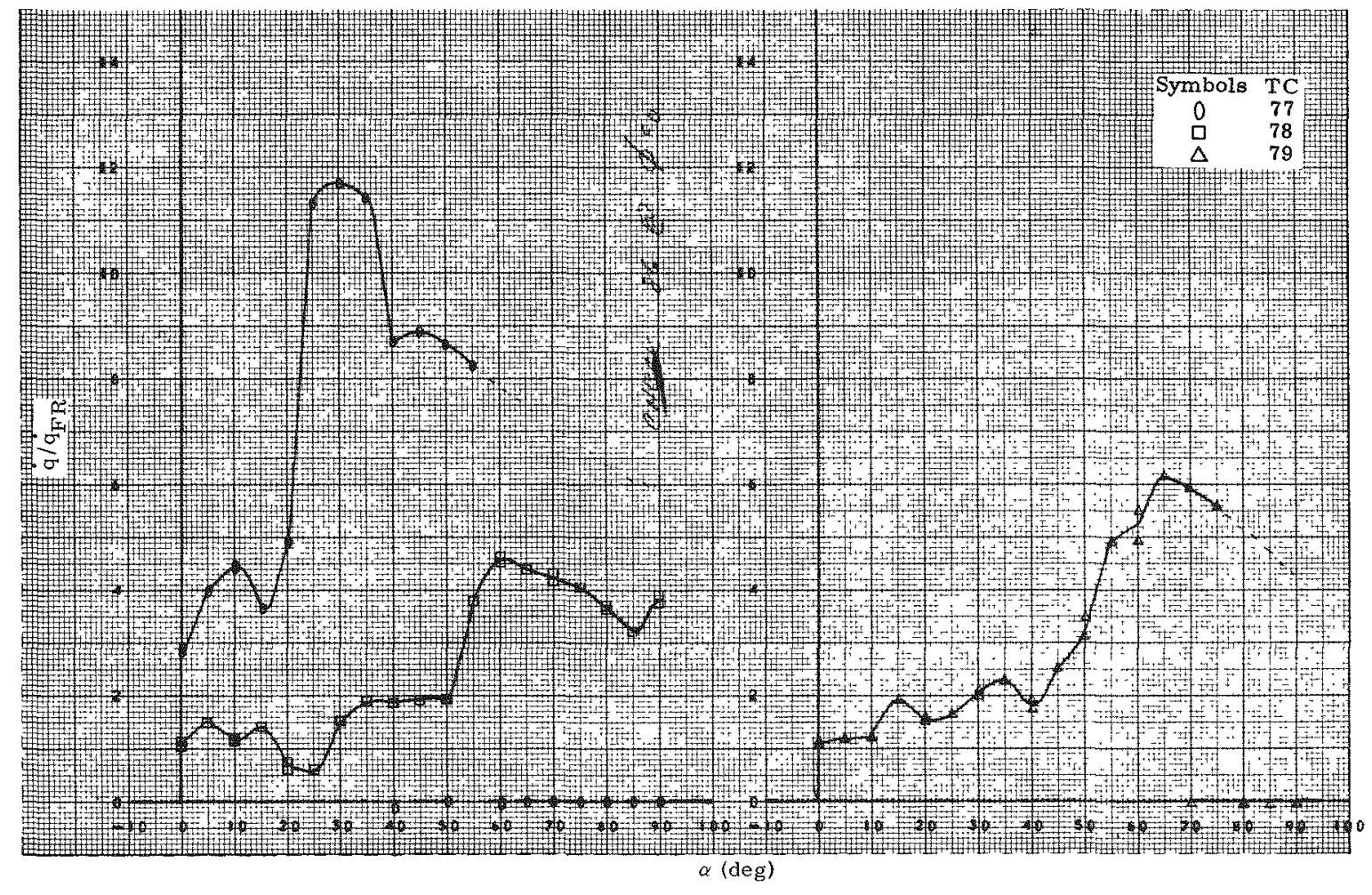

Fig. 230. Heat Transfer, TC $77-79$, Configuration 130

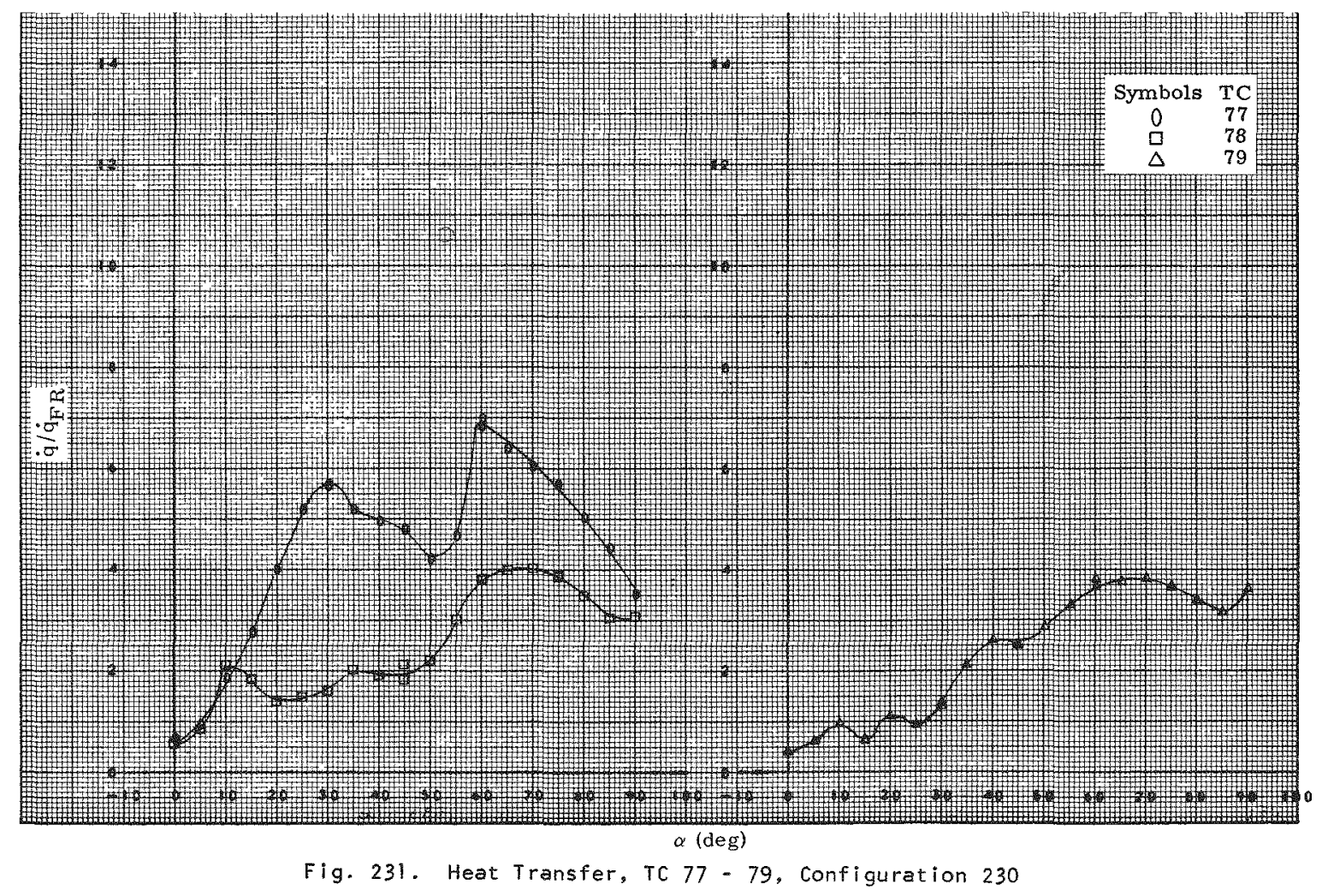

MND-3607-92 

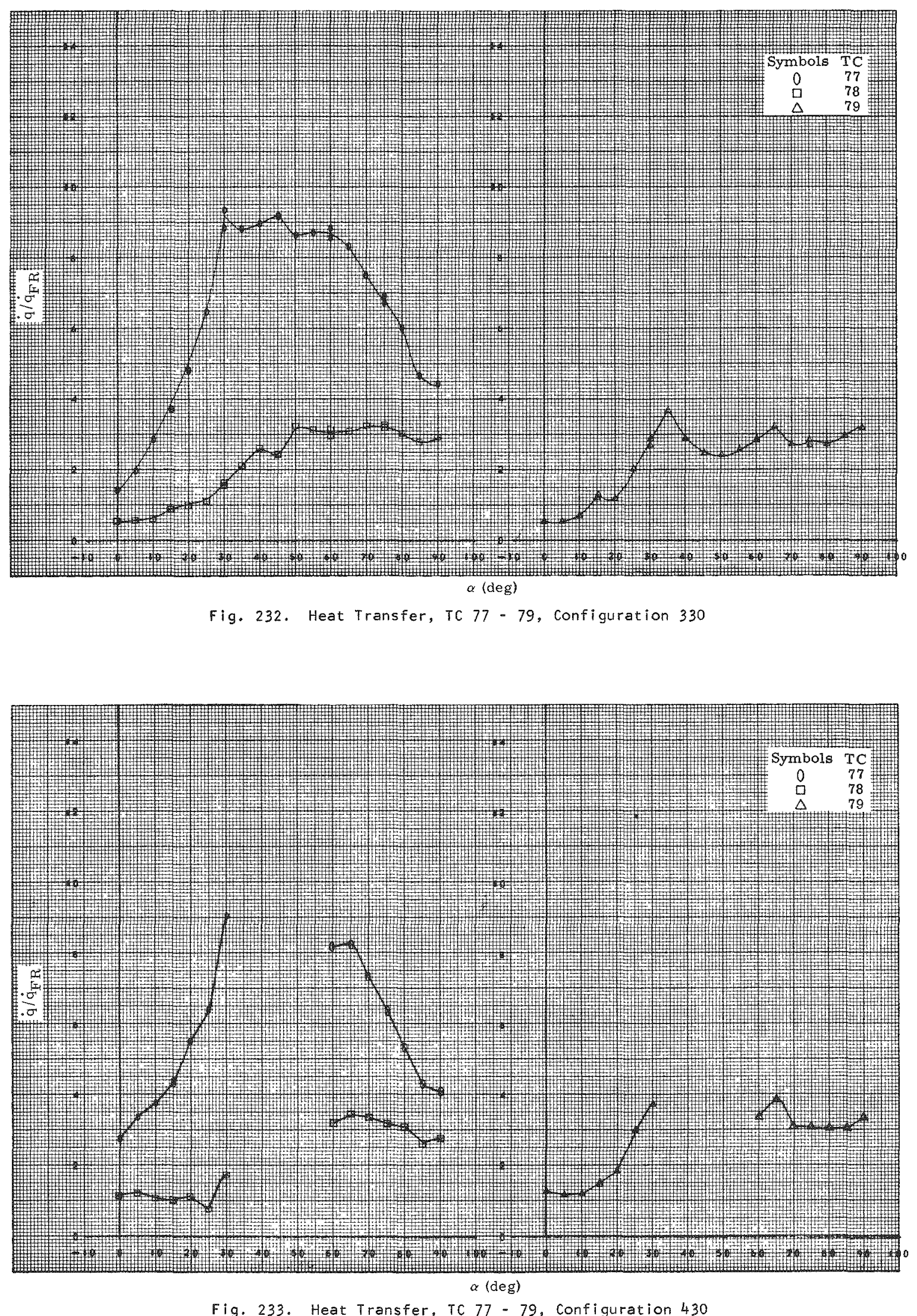

MND-3607-92 


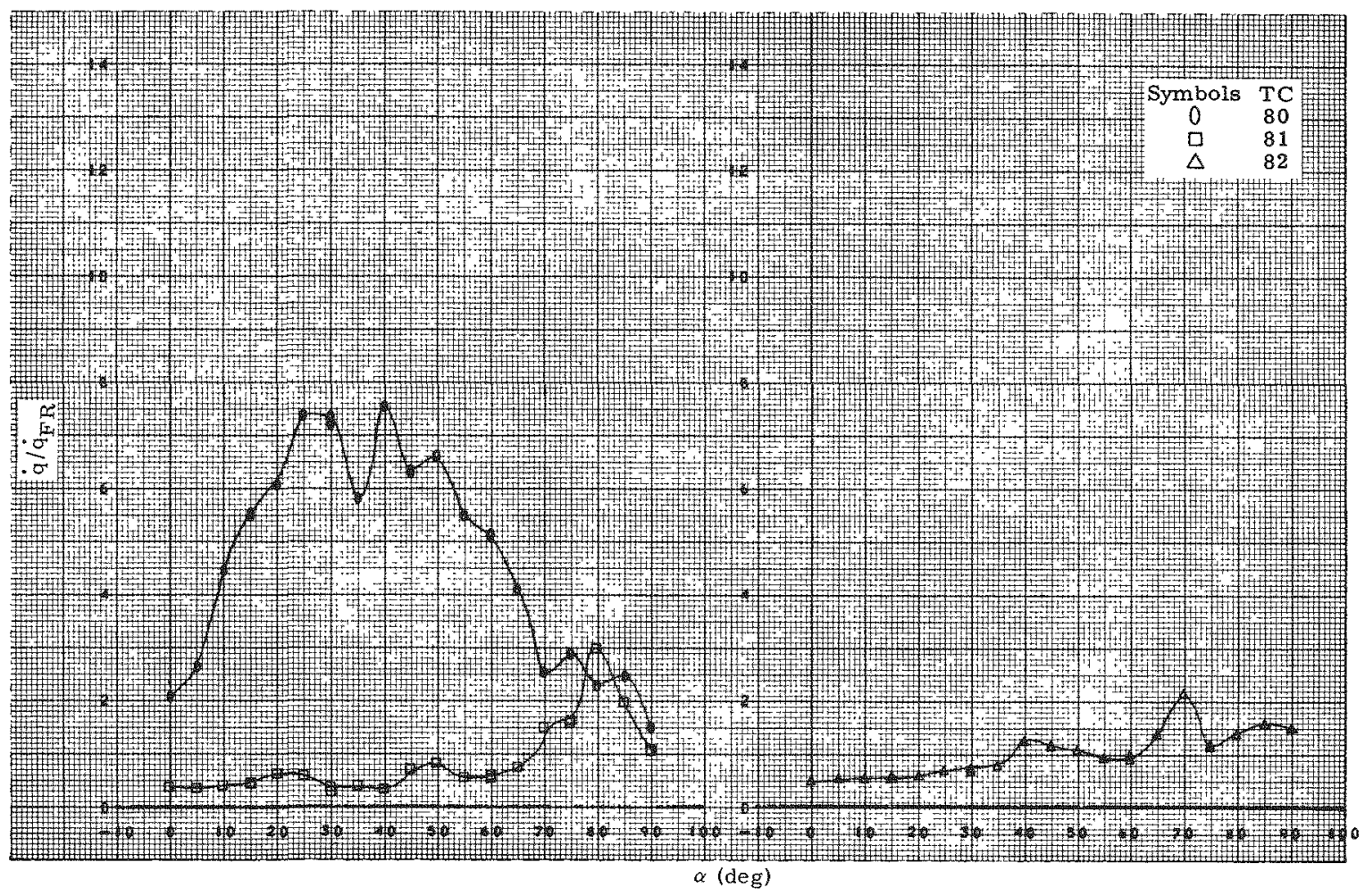

Fig. 234. Heat Transfer, TC $80-82$, Configuration 100

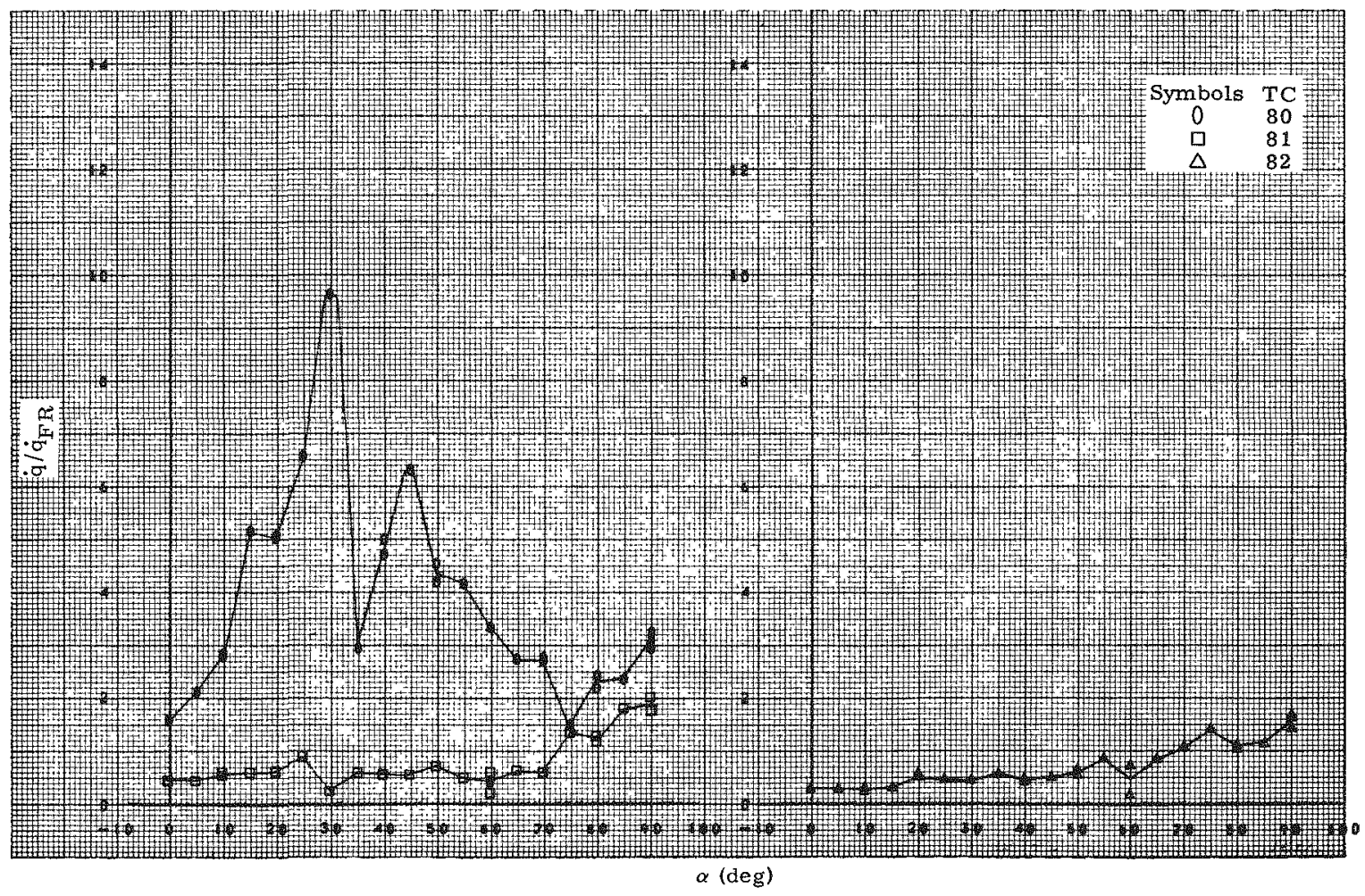

Fig. 235. Heat Transfer, TC $80-82$, Configuration 200 


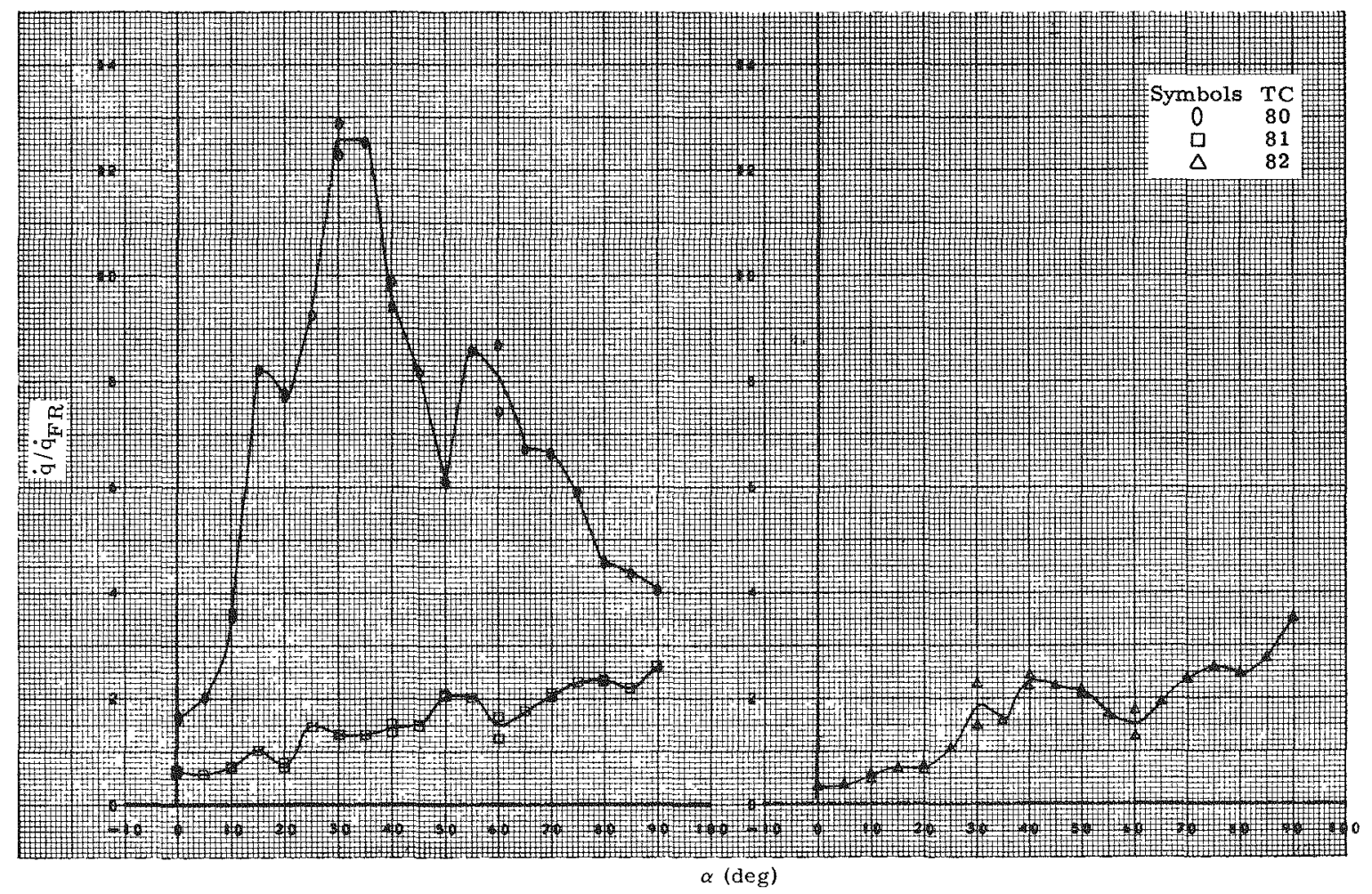

Fig. 236. Heat Transfer, TC $80-82$, Configuration 130

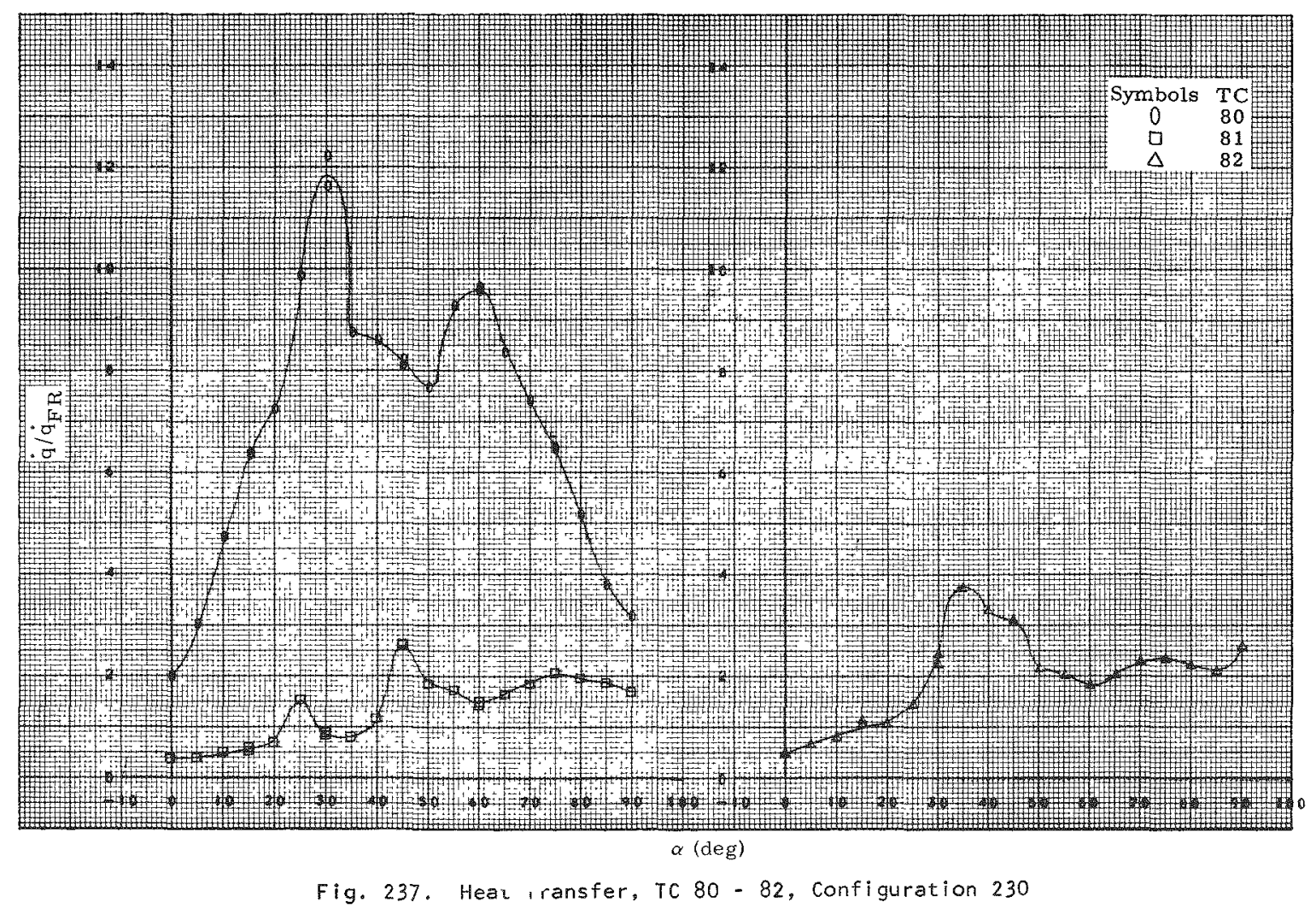

MND-3607-92

149 


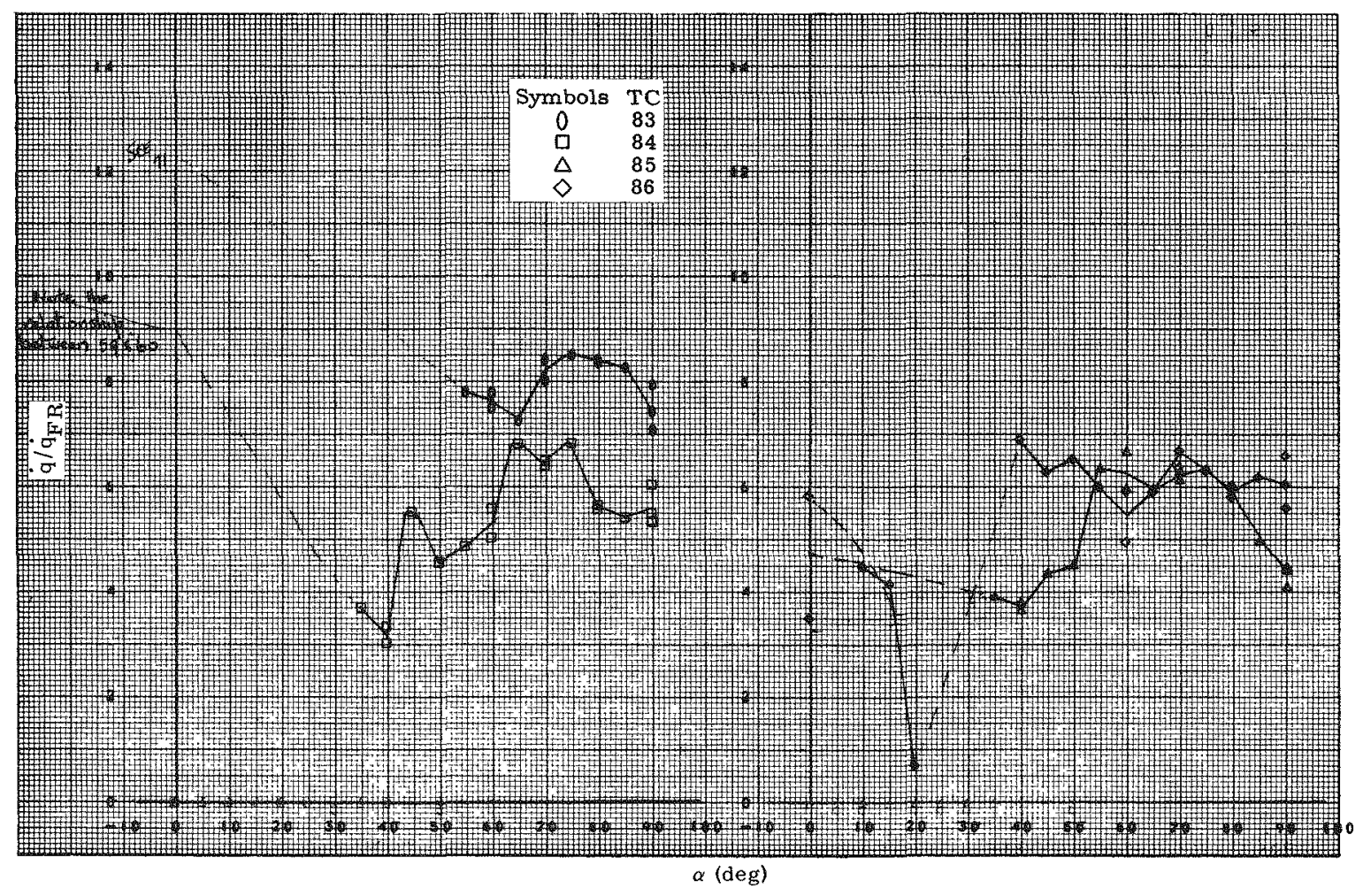

Fig. 238. Heat Transfer, TC $83-86$, Configuration 100

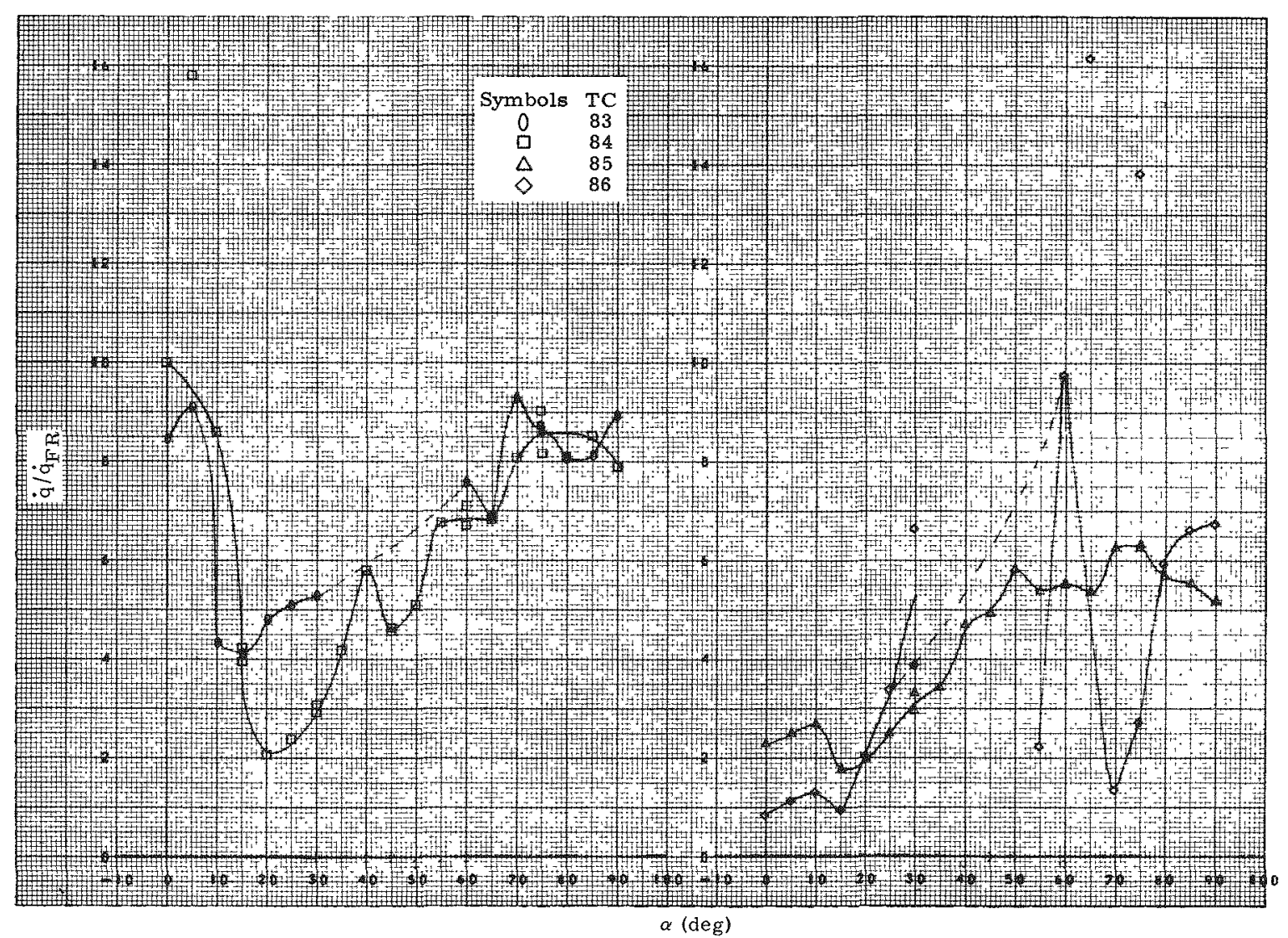

Fig. 239. Heat Transfer, TC $83-86$, Configuration 200 


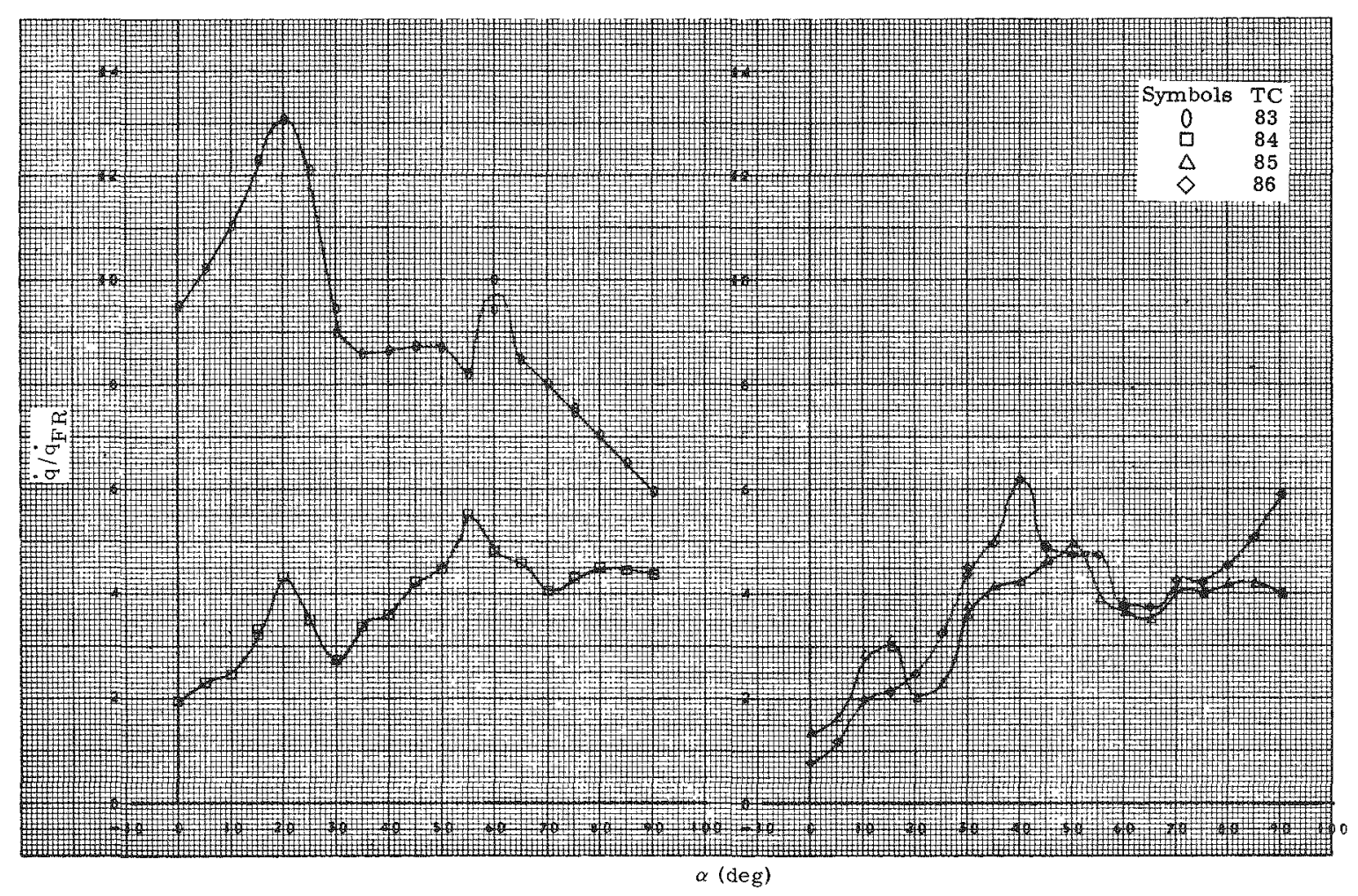

Fig. 240. Heat Transfer, TC $83-86$, Configuration 300

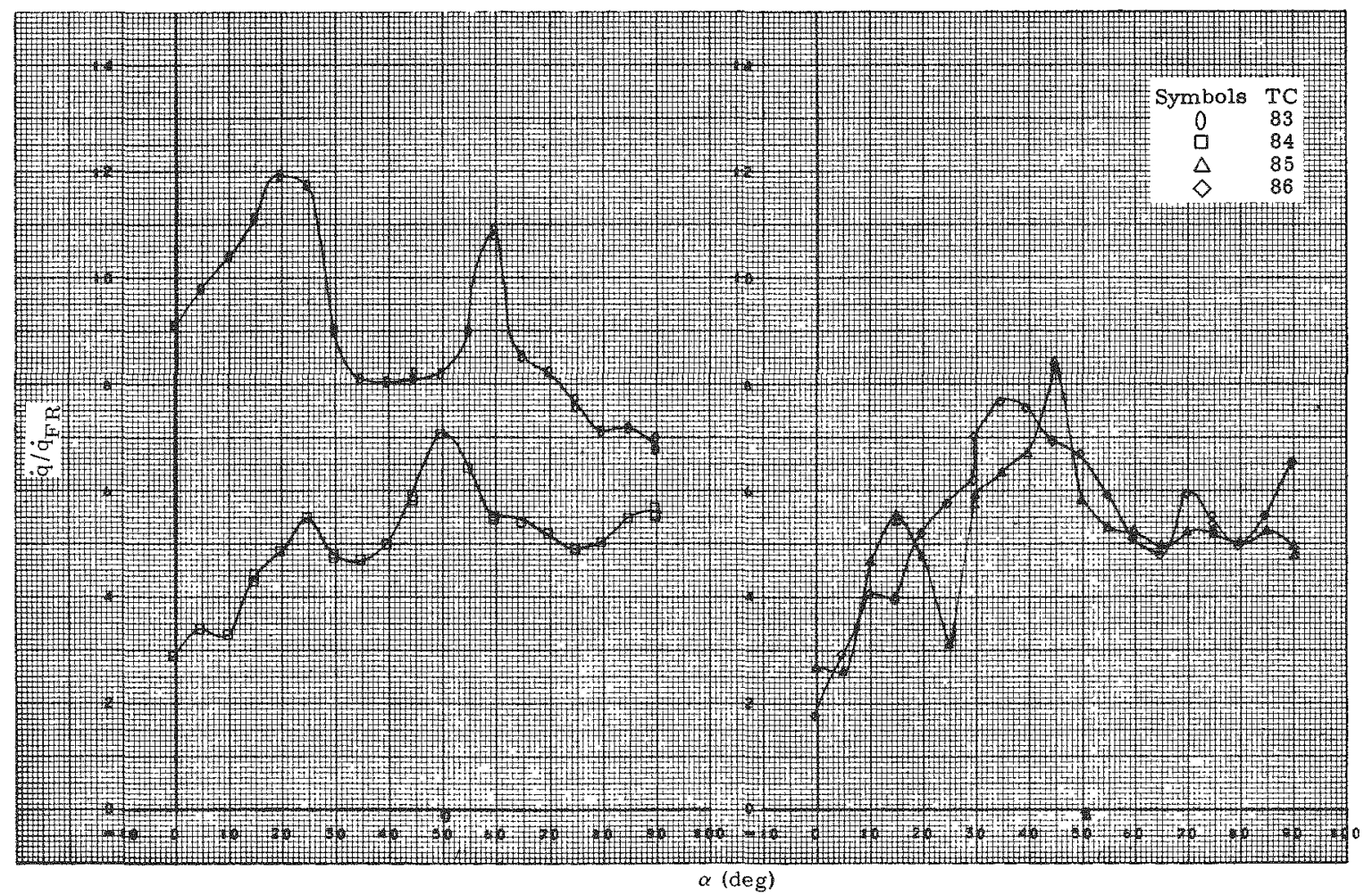

Fig. 241. Heat Transfer, TC $83-86$, Configuration 400 


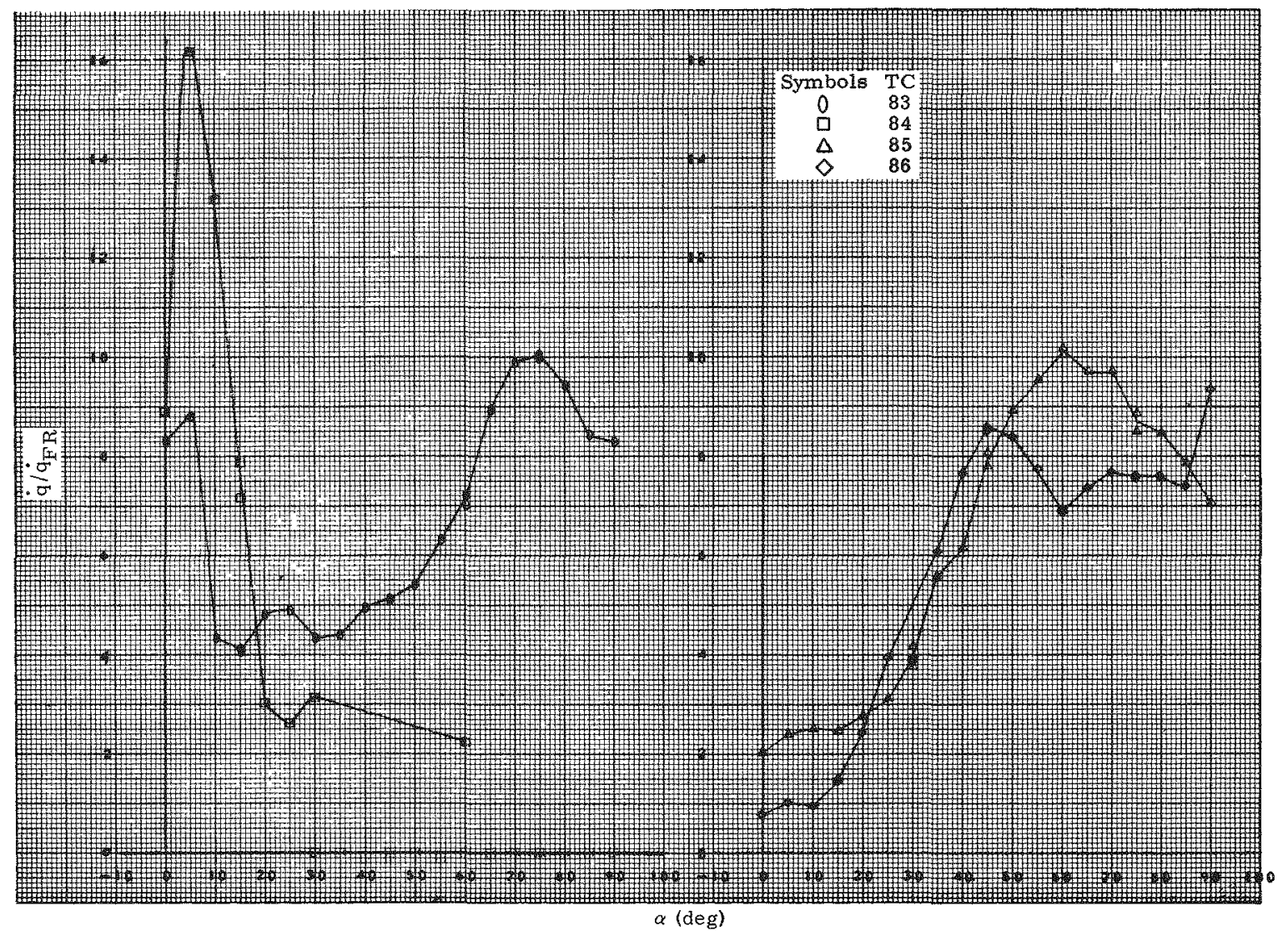

Fig. 242. Heat Transfer, TC $83-86$, Configuration 230

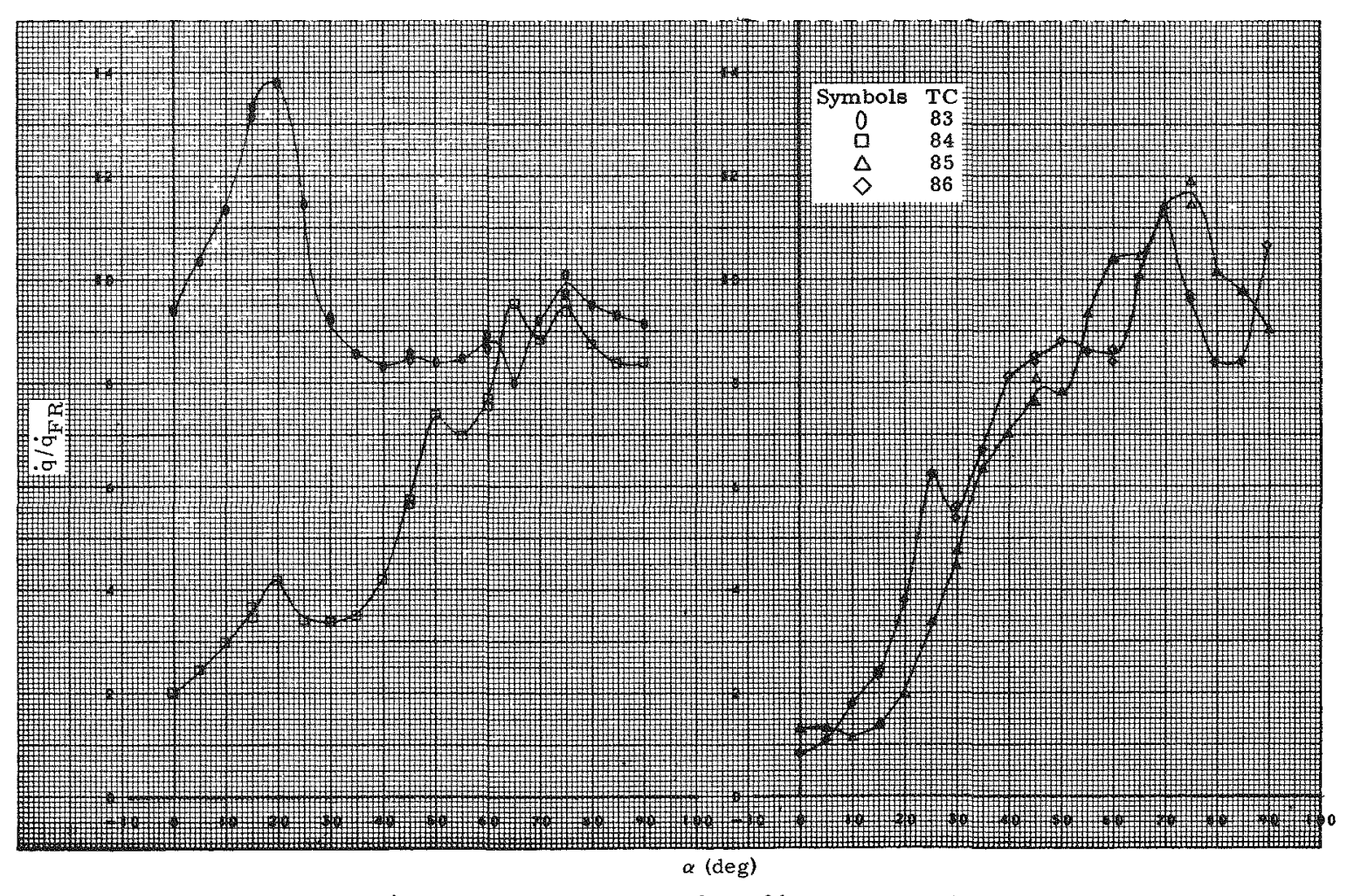

Fig. 243. Heat Transfer, TC $83-86$, Configuration 330 


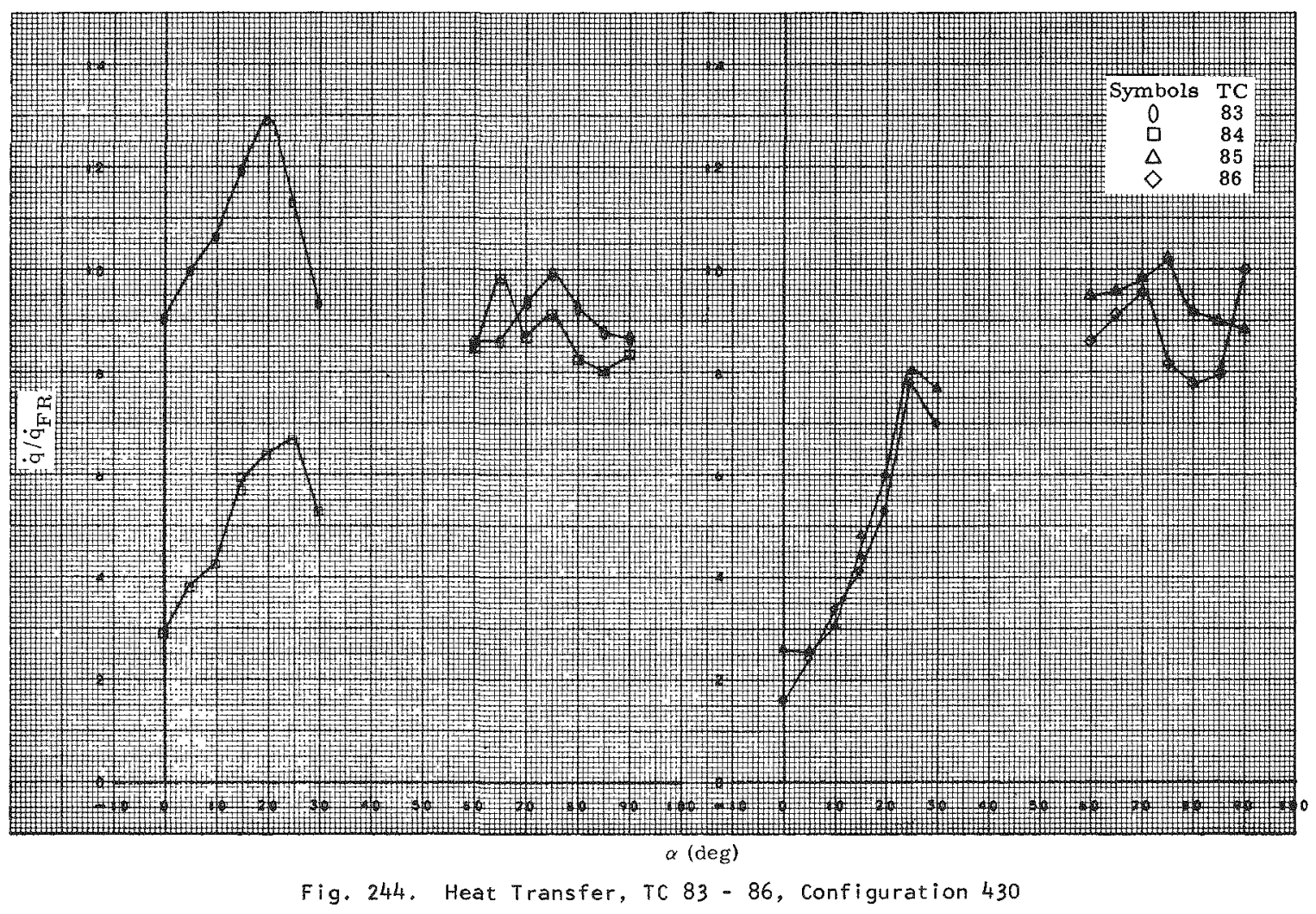

MND-3607-92

153 


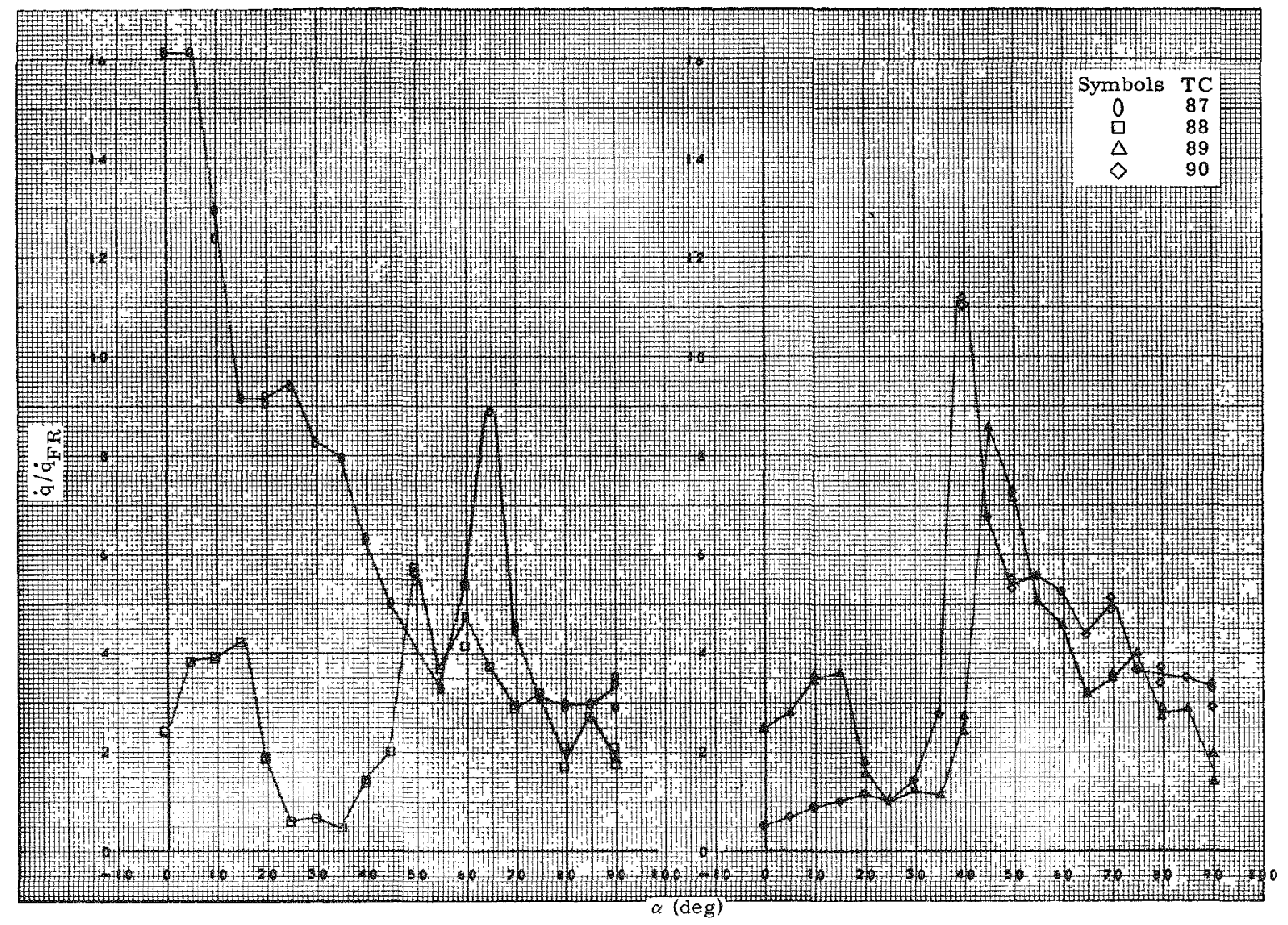

Fig. 245. Heat Transfer, TC $87-90$, Configuration 100

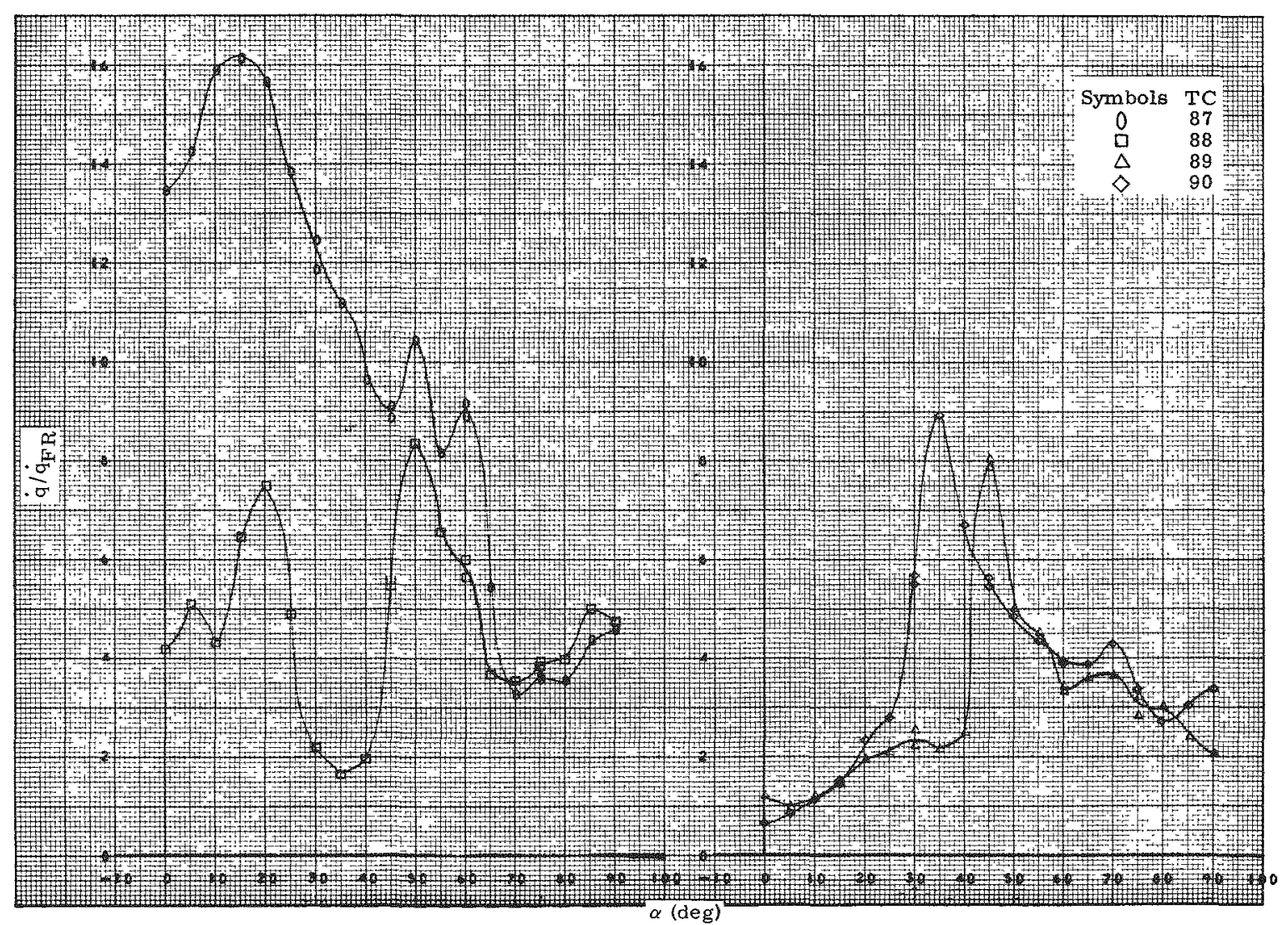

Fig. 246. Heat Transfer, TC $87-90$, Configuration 200 


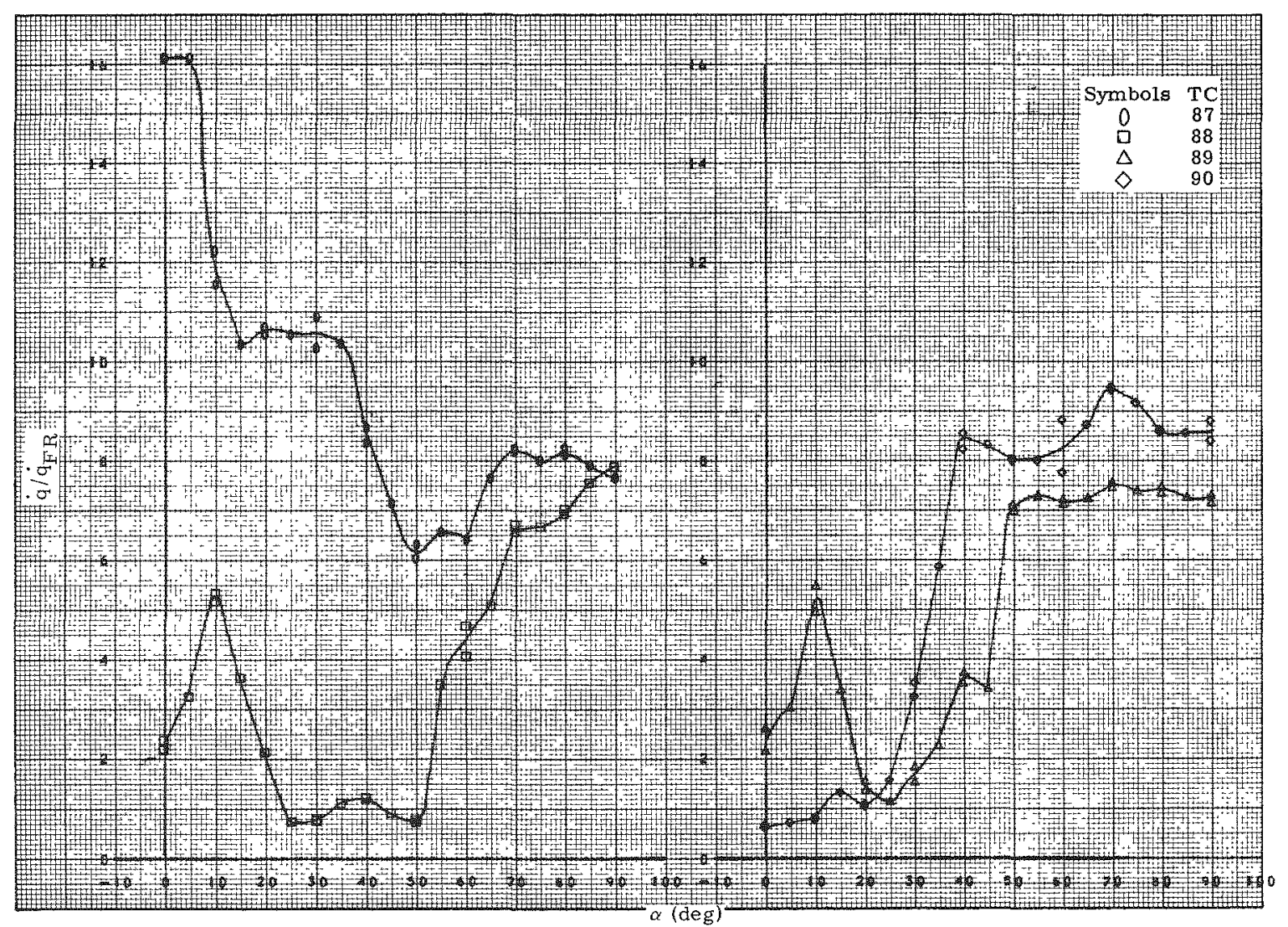

Fig. 247. Heat Transfer, TC $87-90$, Configuration 130

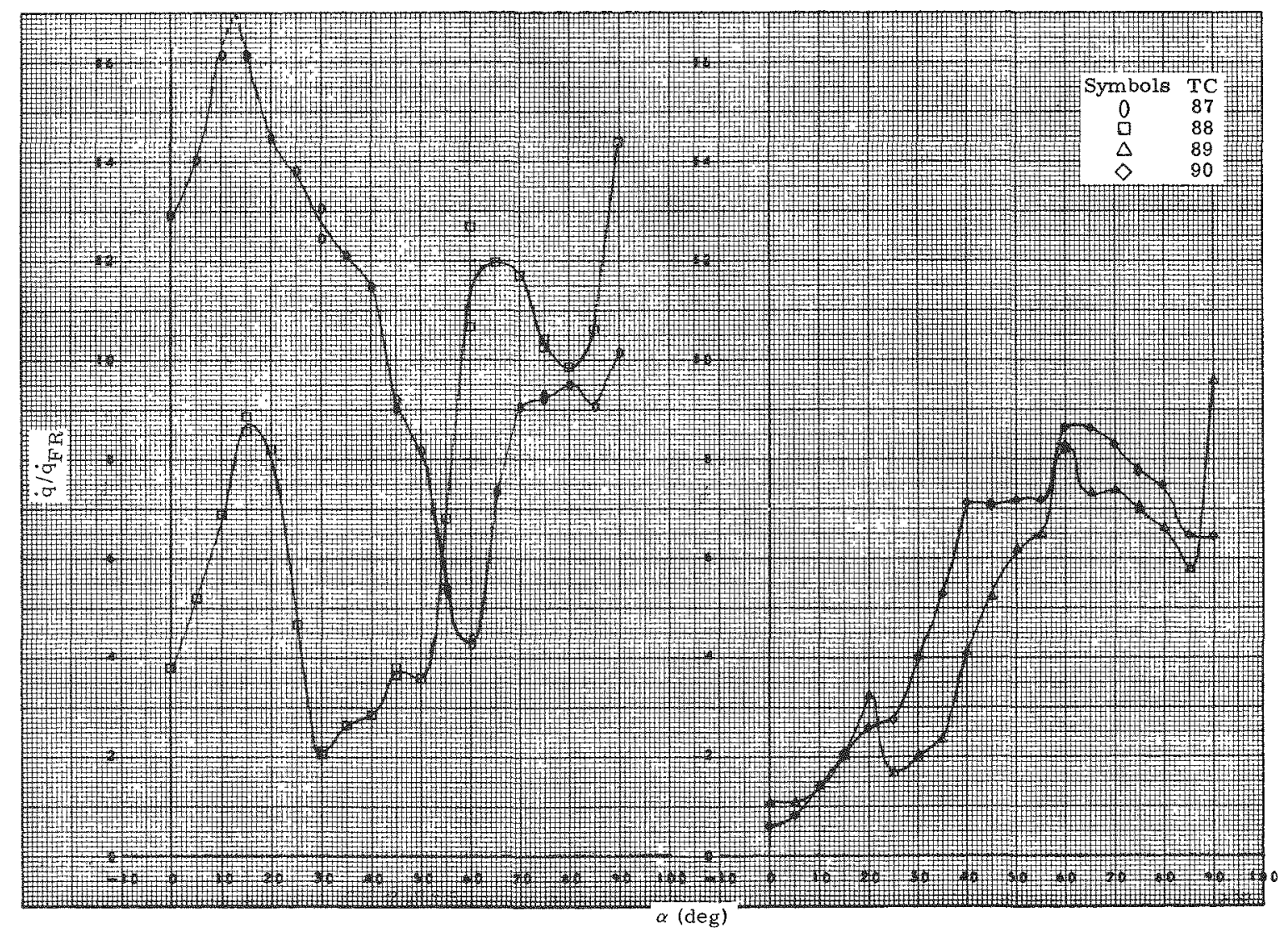

Fig. 248. Heat Transfer, TC $87-90$, Configuration 230 


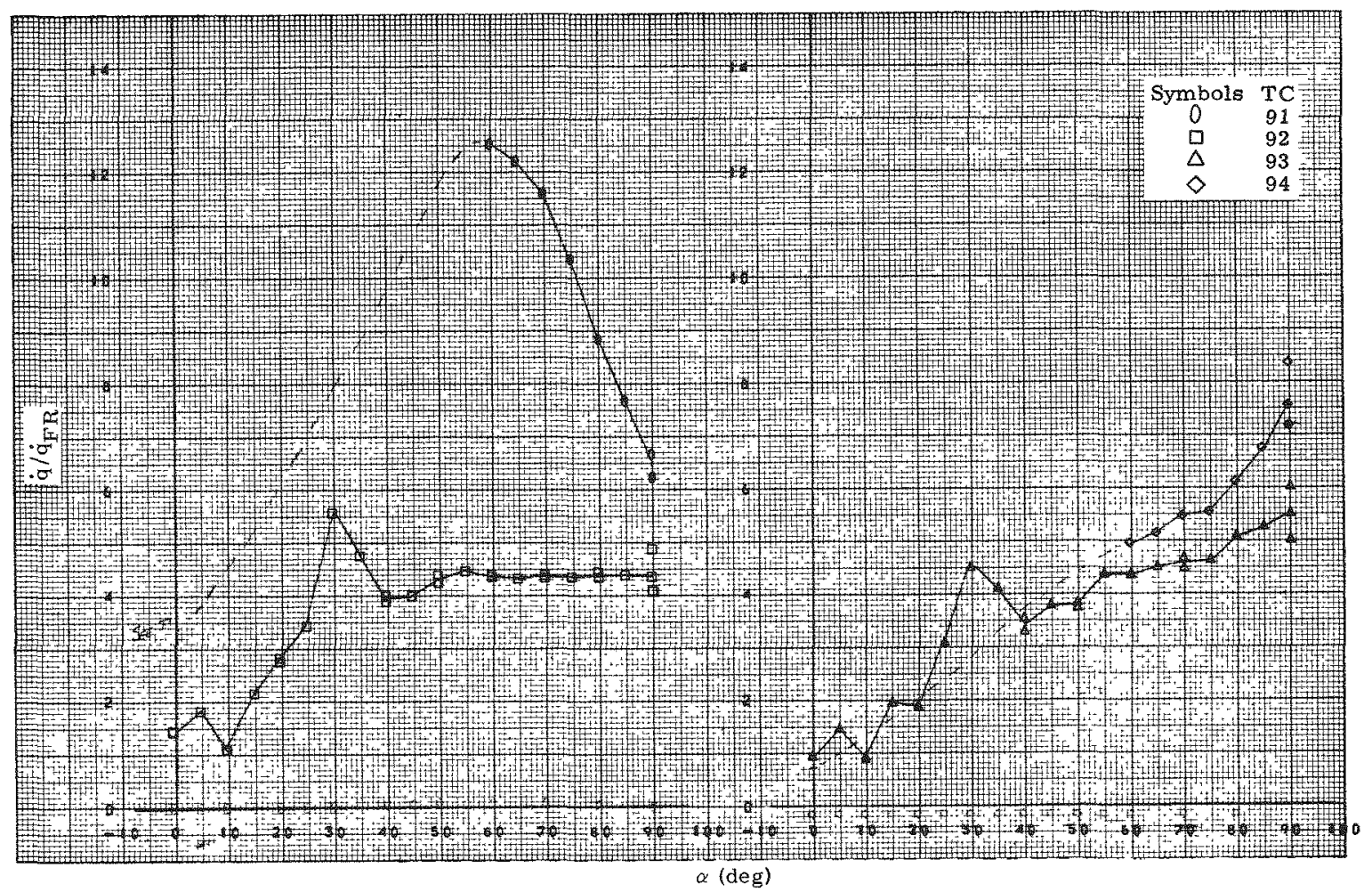

Fig. 249. Heat Transfer, TC $91-94$, Configuration 100

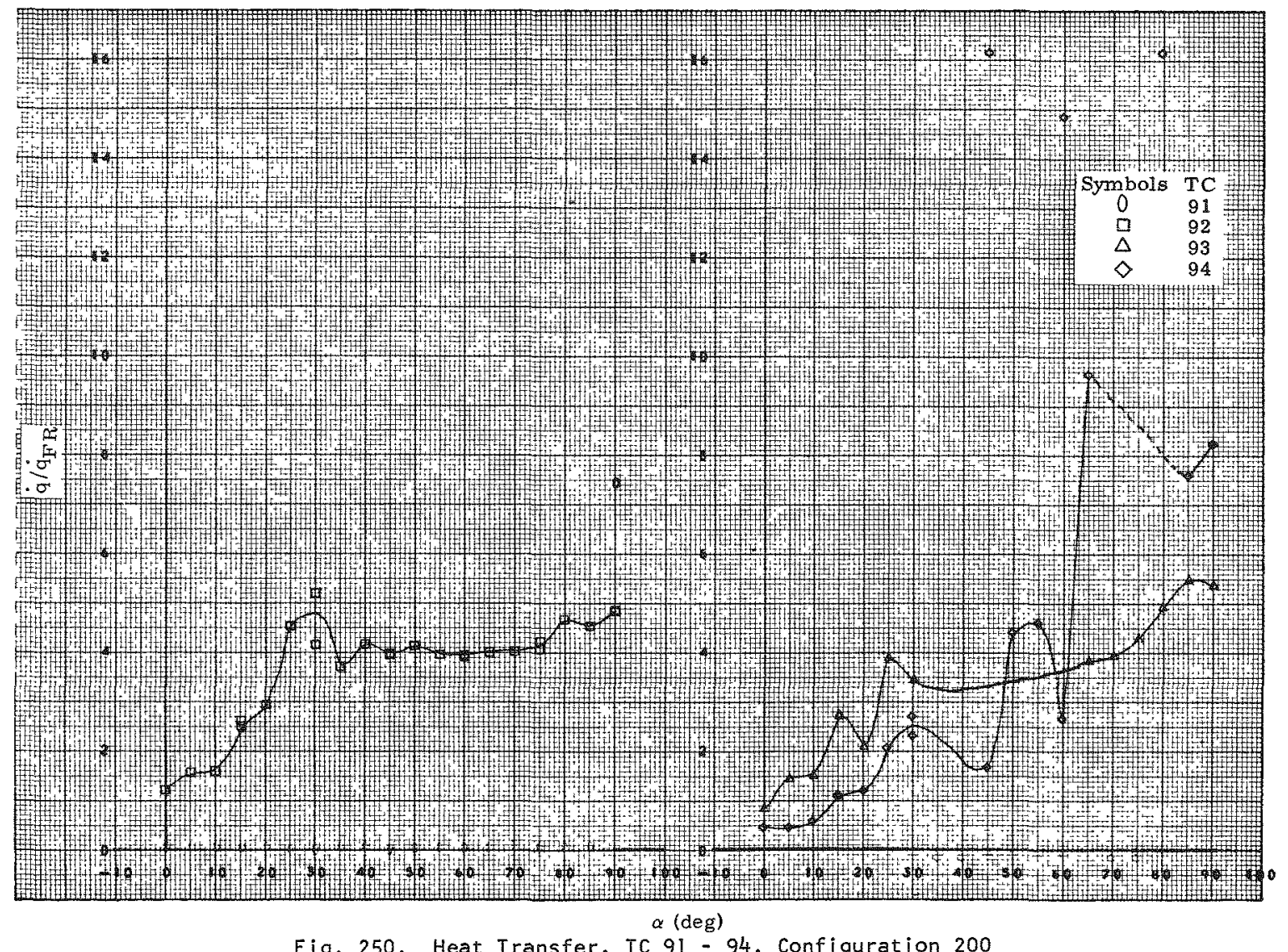

Fig. 250. Heat Transfer, TC $91-94$, Configuration 200 


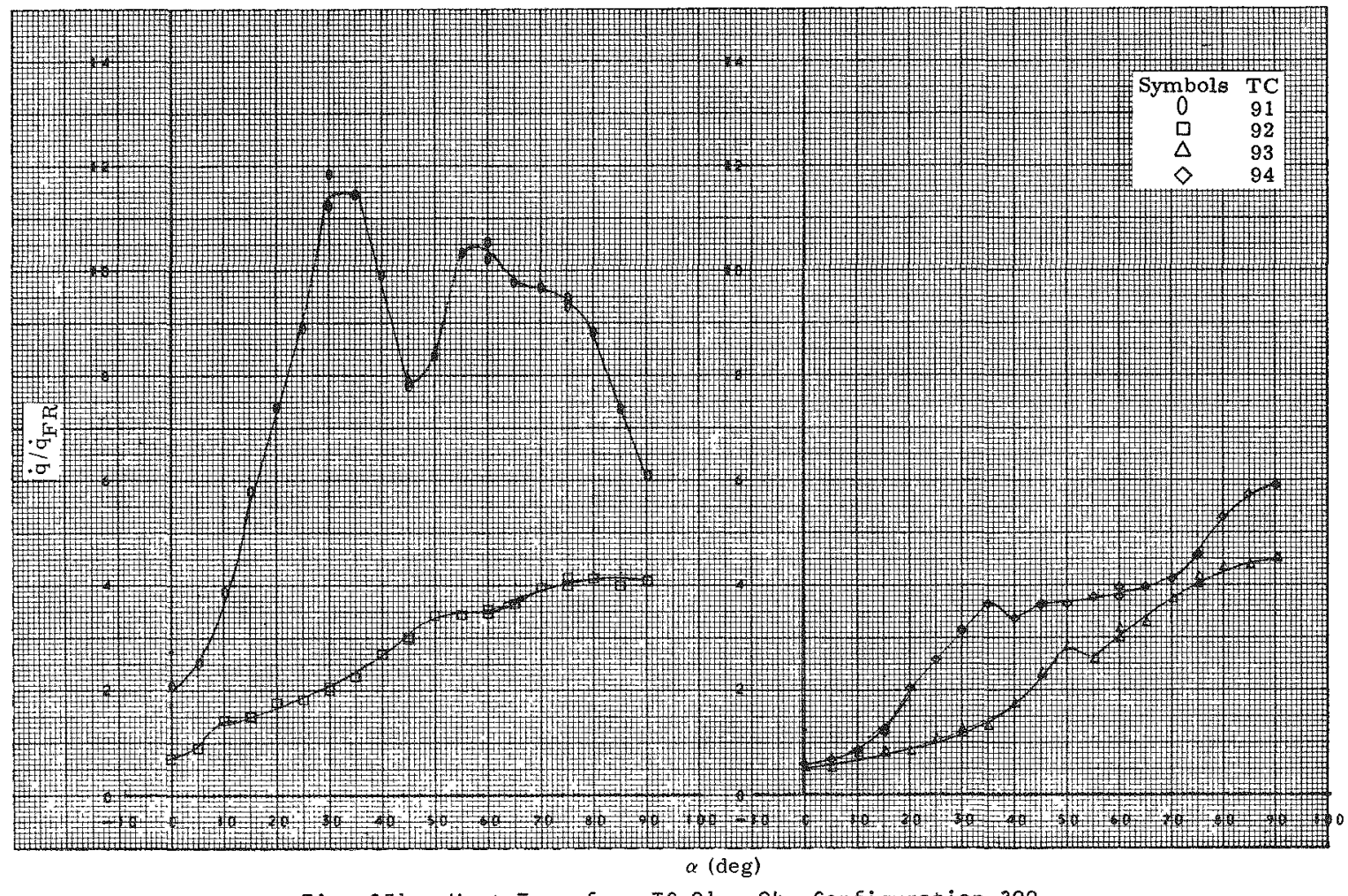

Fig. 251. Heat Transfer, TC $91-94$, Configuration 300

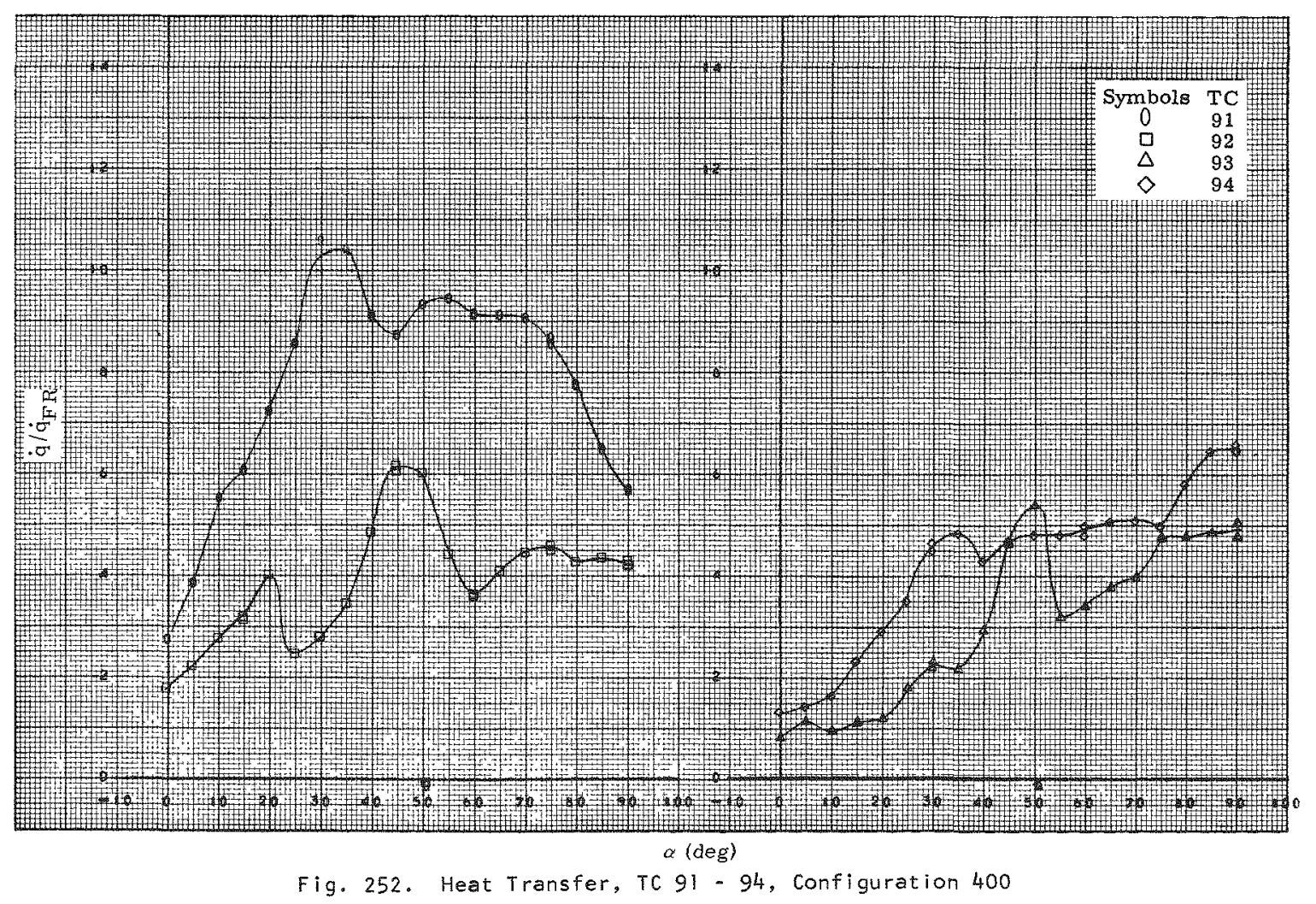




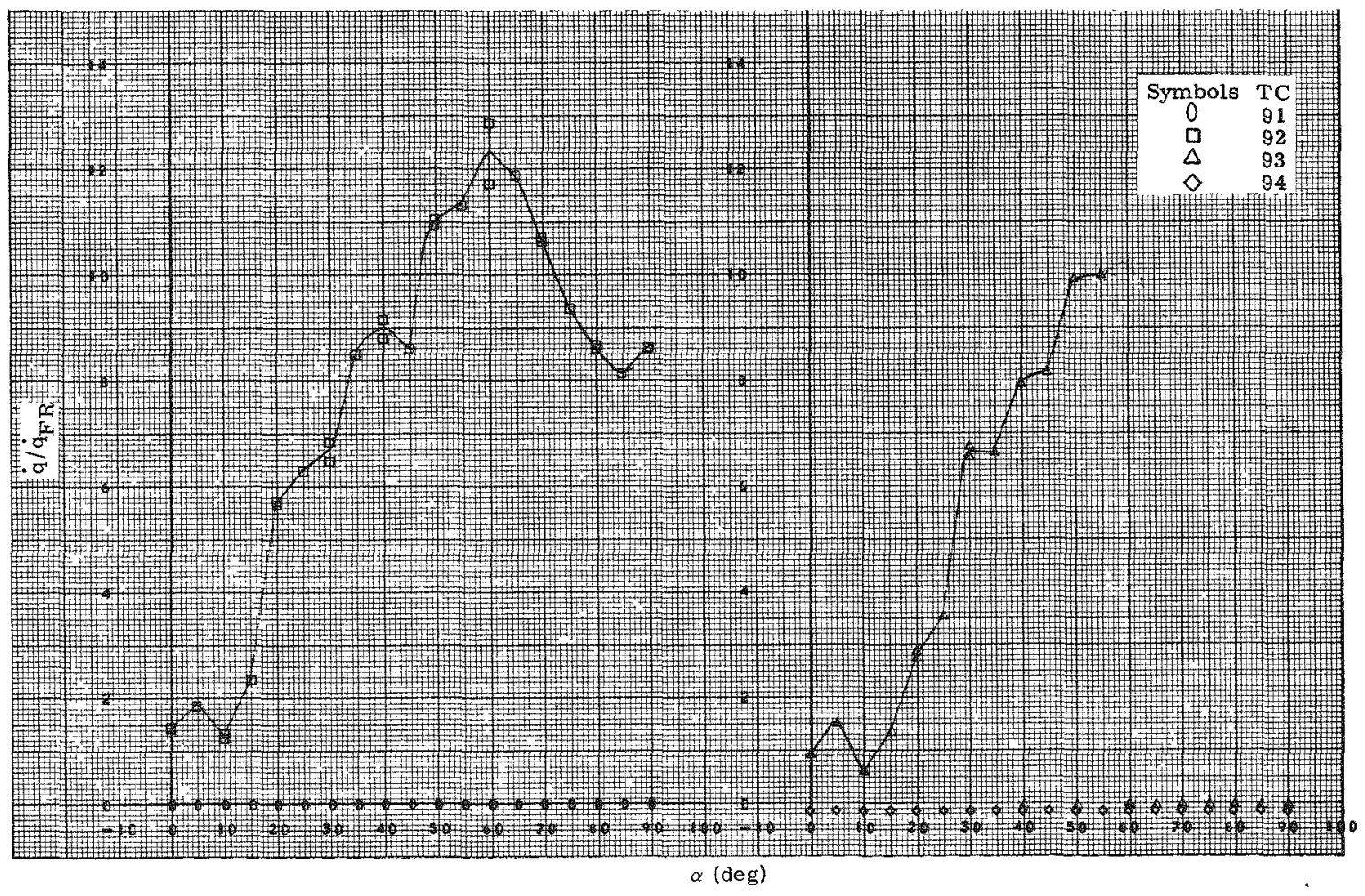

Fig. 253. Heat Transfer, TC $91-94$, Configuration 130

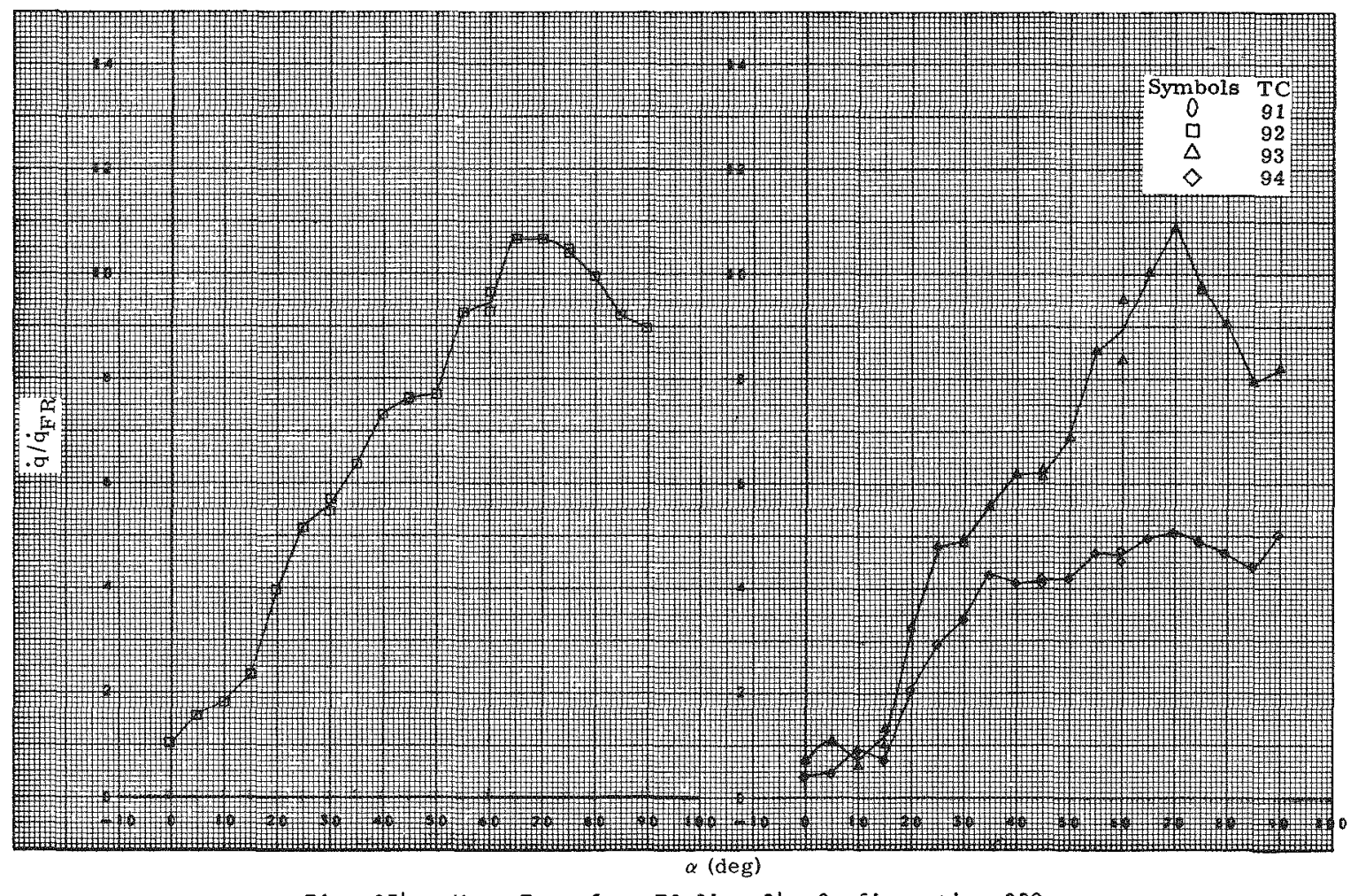

Fig. 254. Heat Transfer, TC 91 - 94 , Configuration 230 


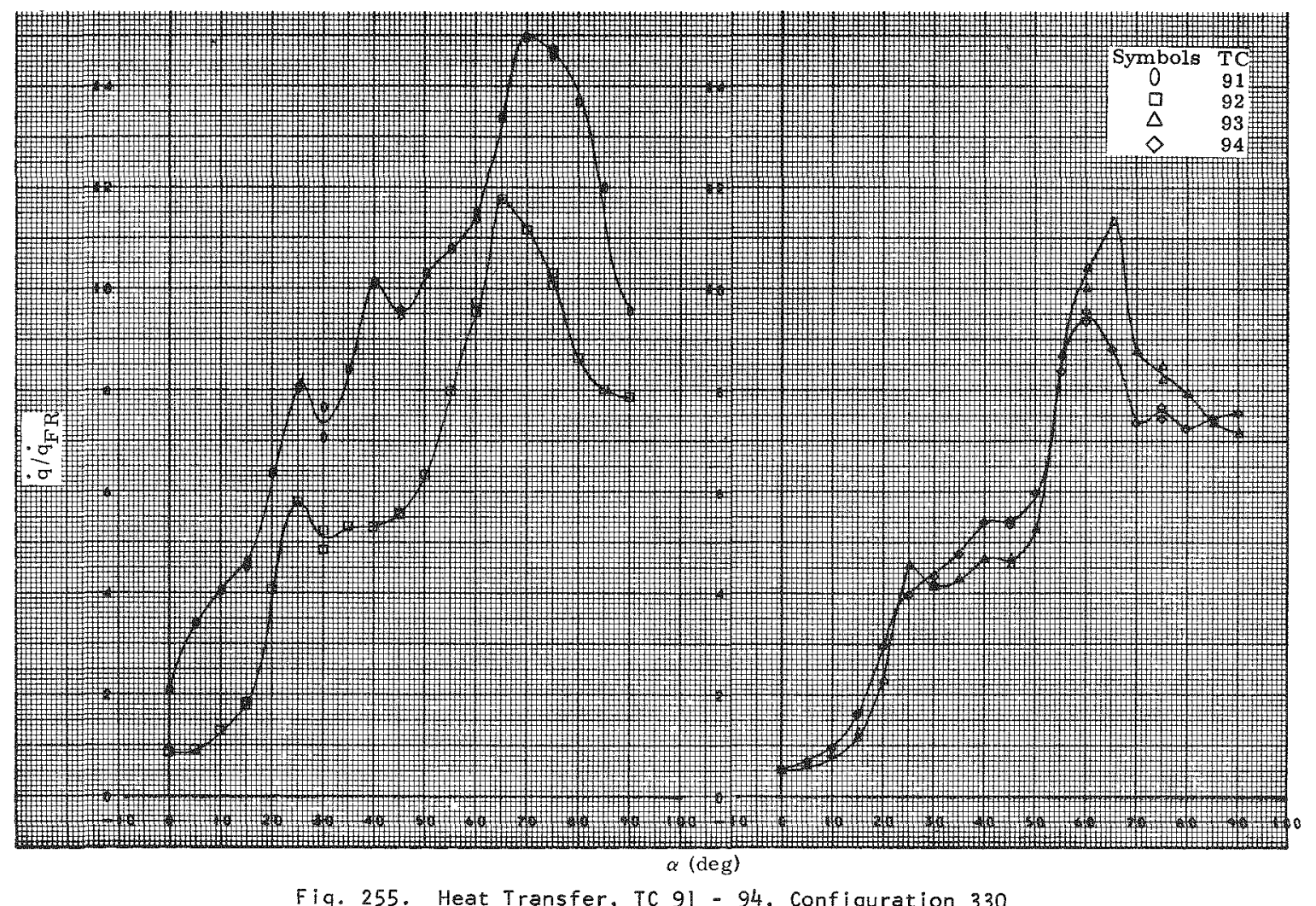

Fig. 255. Heat Transfer, TC $91-94$, Configuration 330

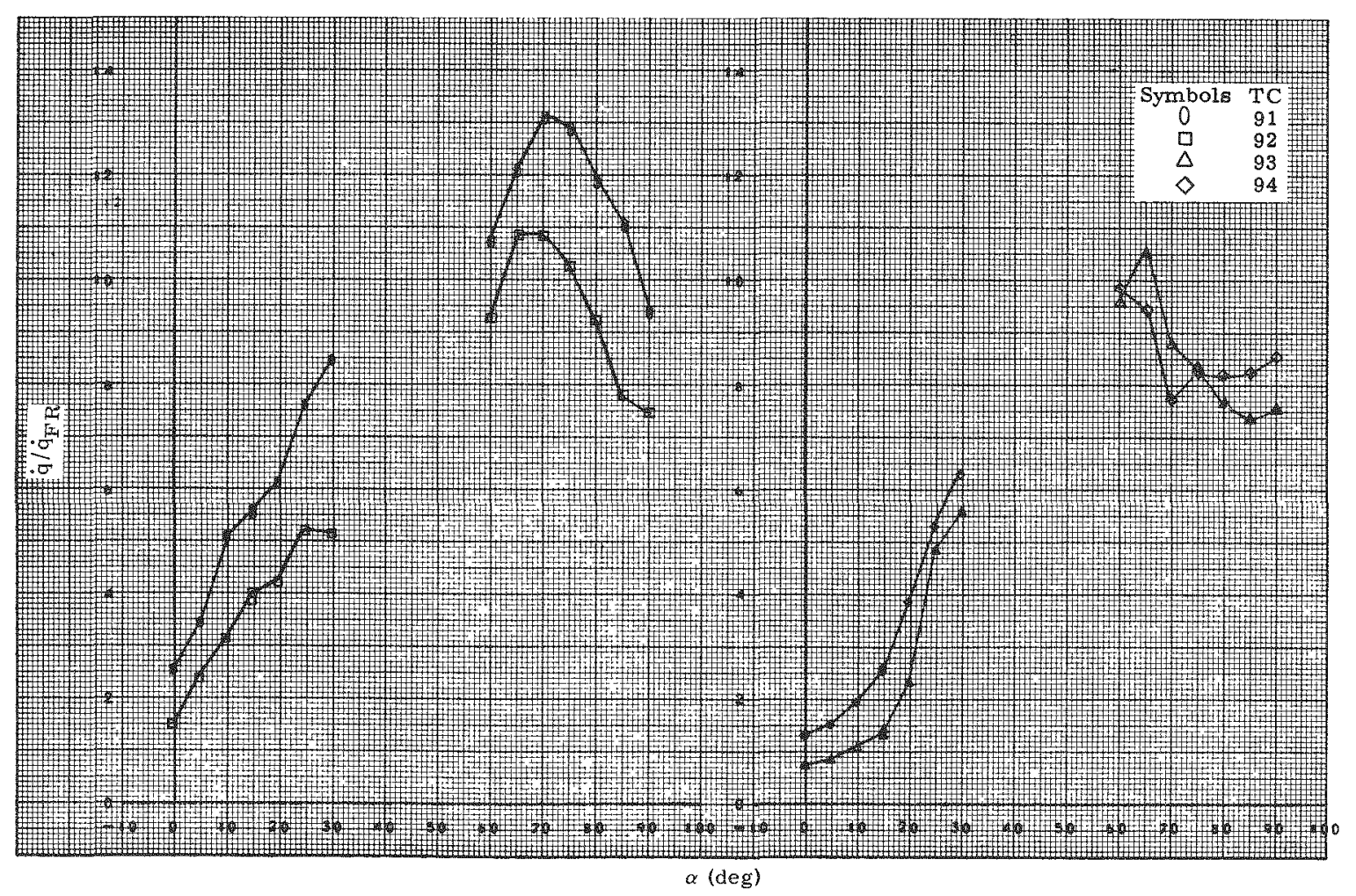

Fig. 256. Heat Transfer, TC $91-94$, Configuration 430 


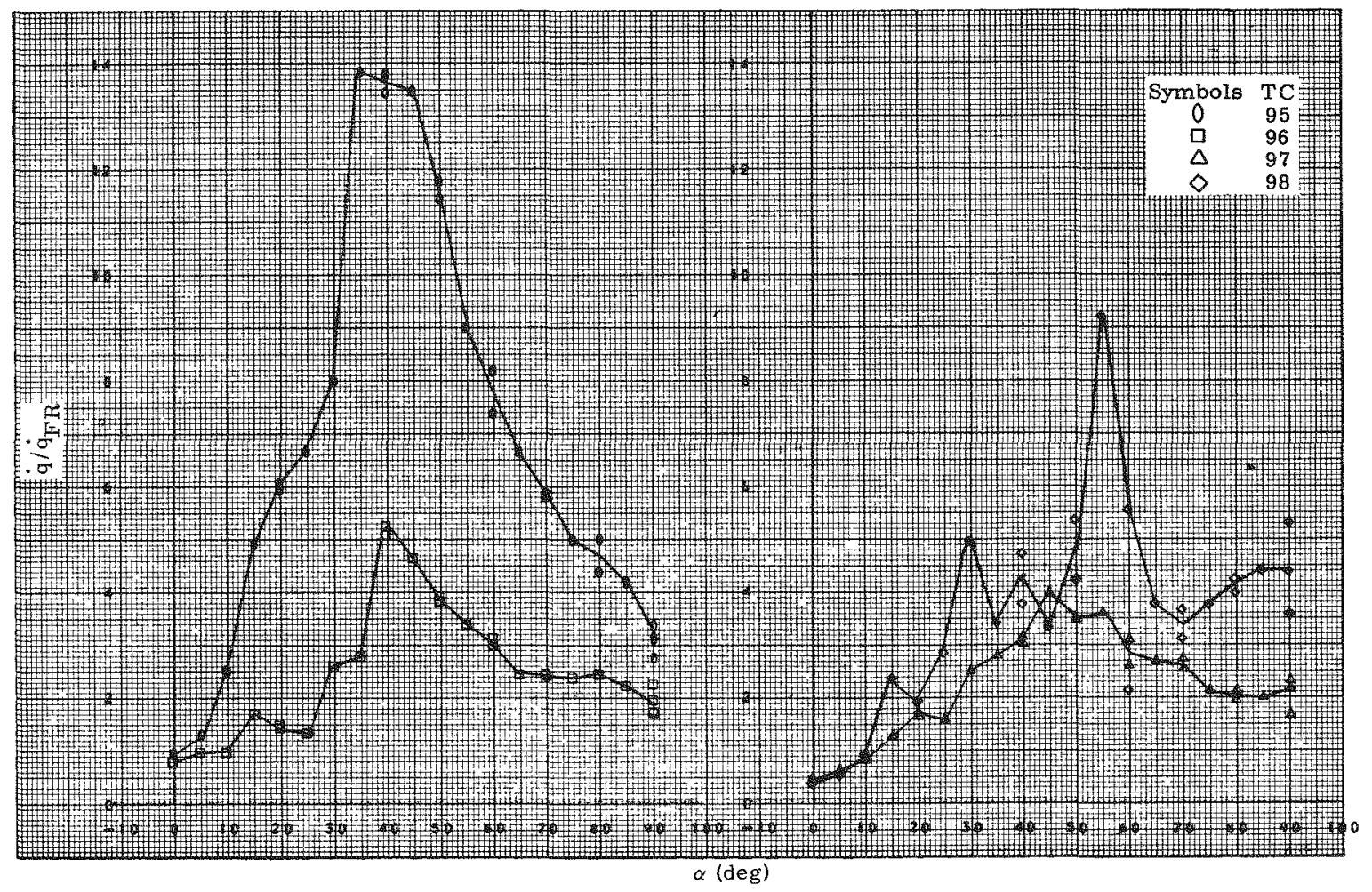

Fig. 257. Heat Transfer, TC 95-98, Configuration 100

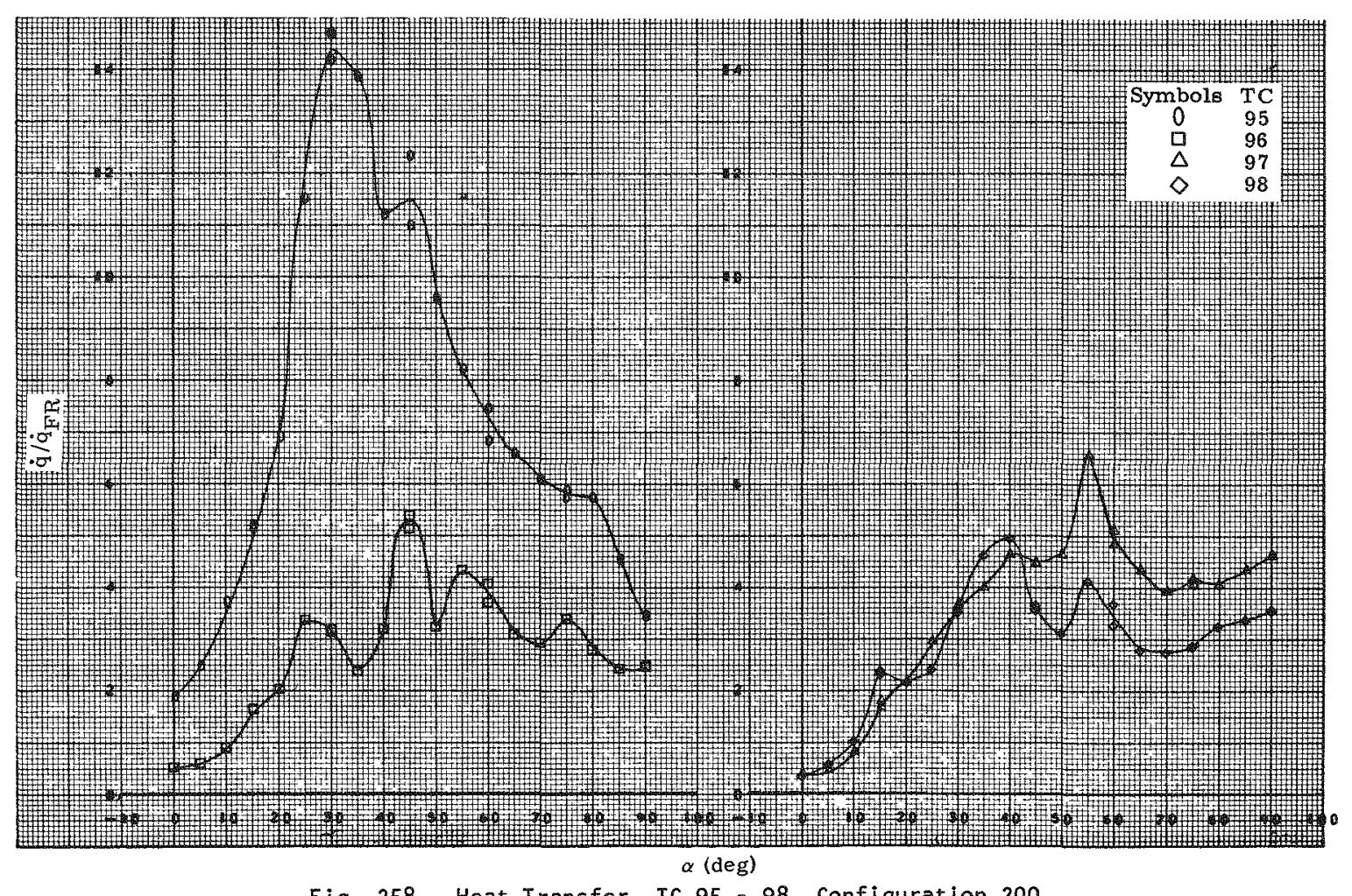

Fig. 258. Heat Transfer, TC $95-98$, Configuration 200 


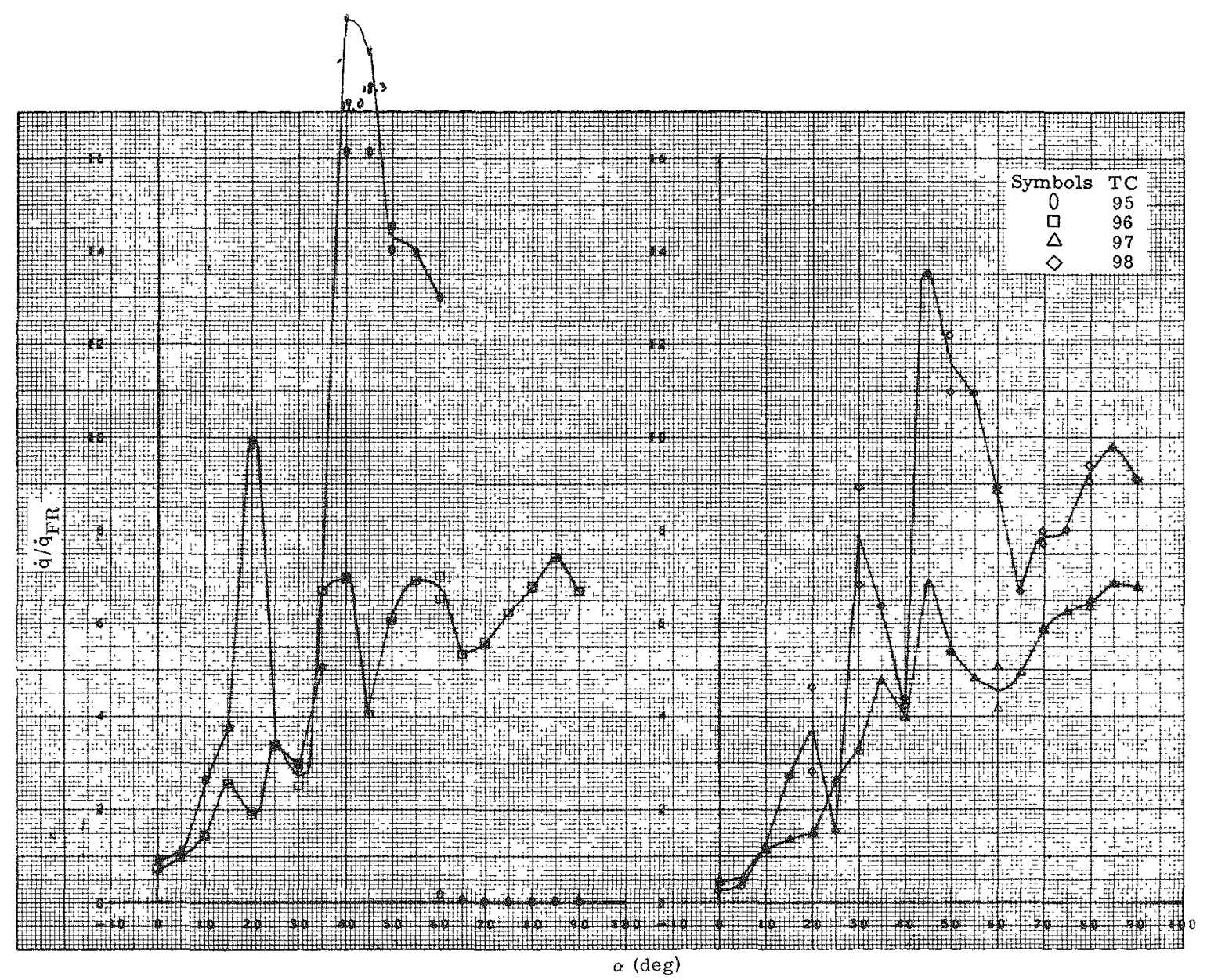

Fig. 259. Heat Transfer, TC $95-98$, Configuration 130

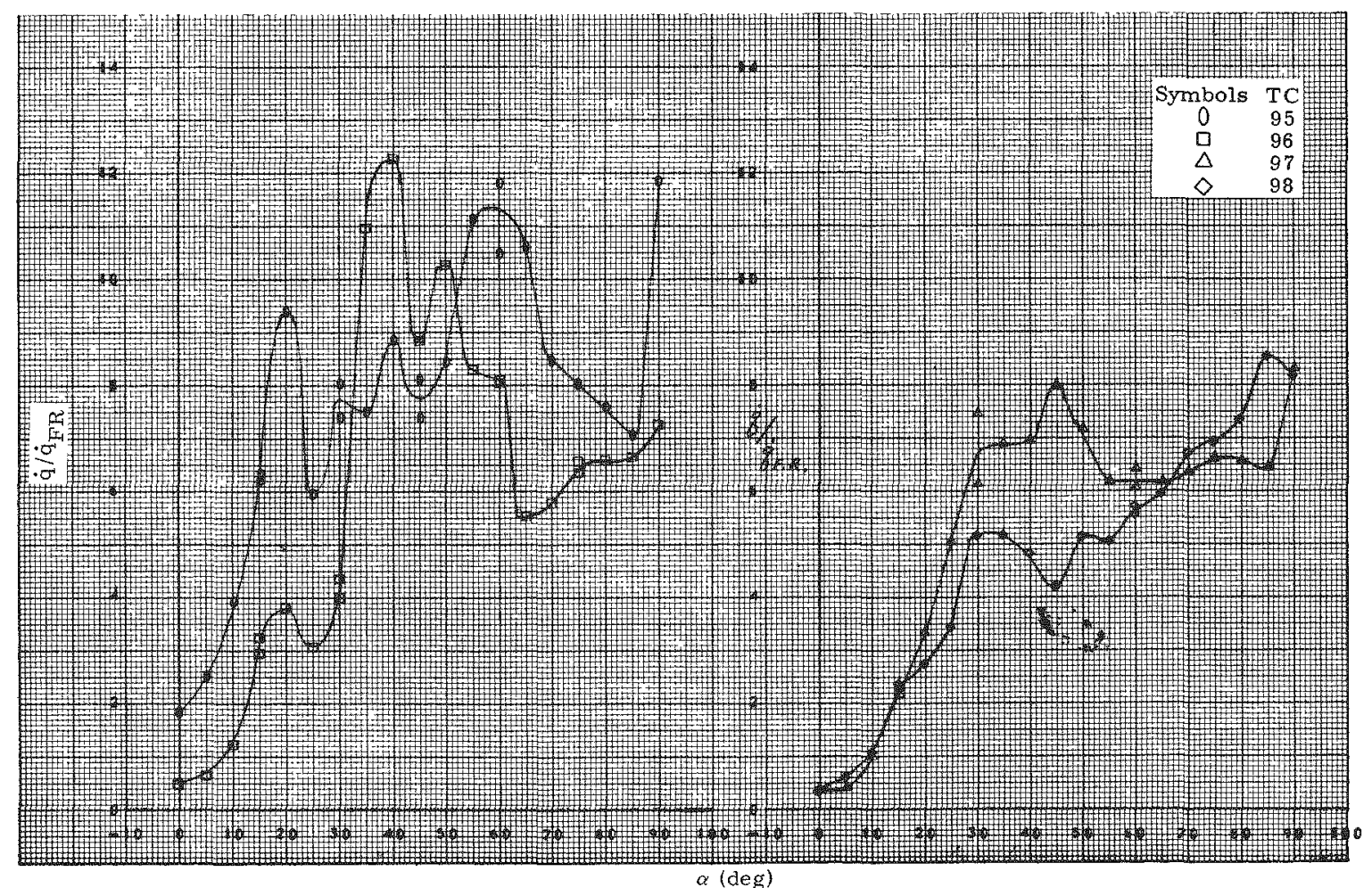

Fig. 260. Heat Transfer, TC $95-98$, Configuration 230 


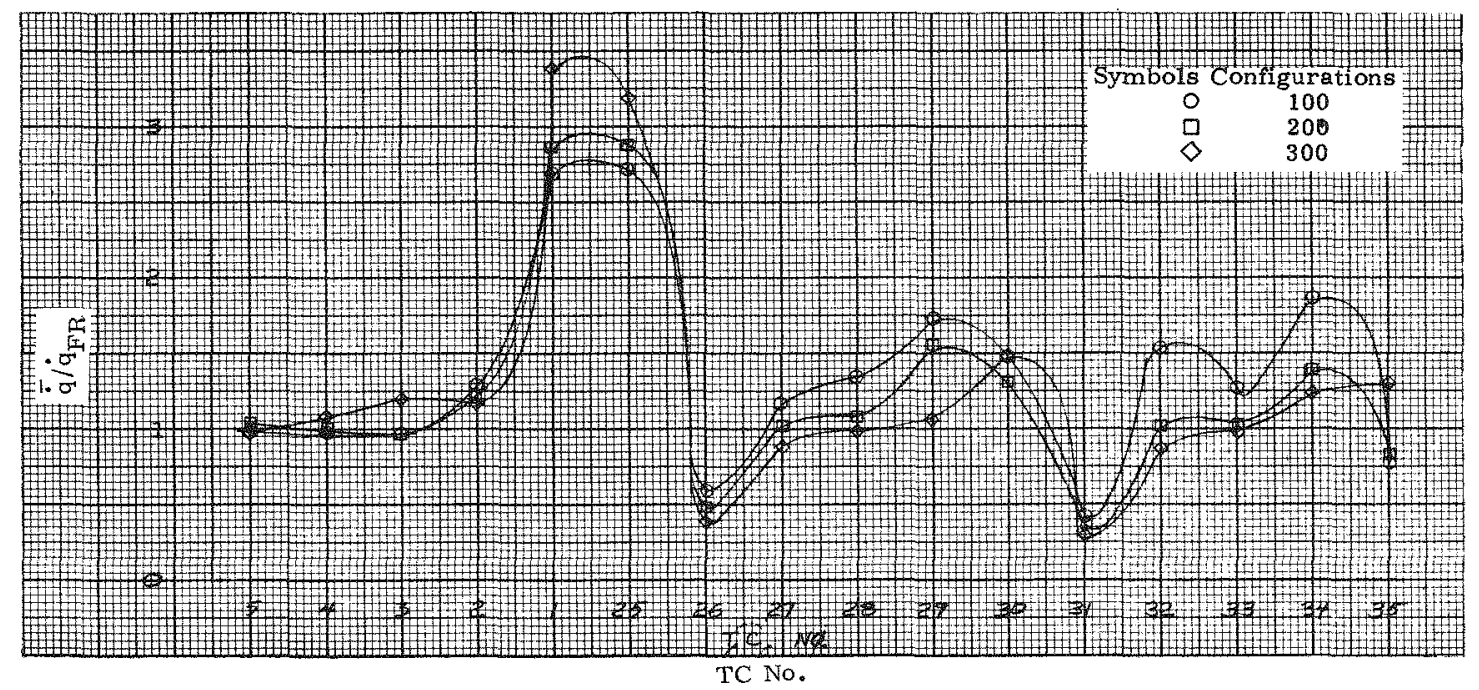

Fig. 261. Averaged Heating Values, TC $1-35$, Configurations 100, 200, 300

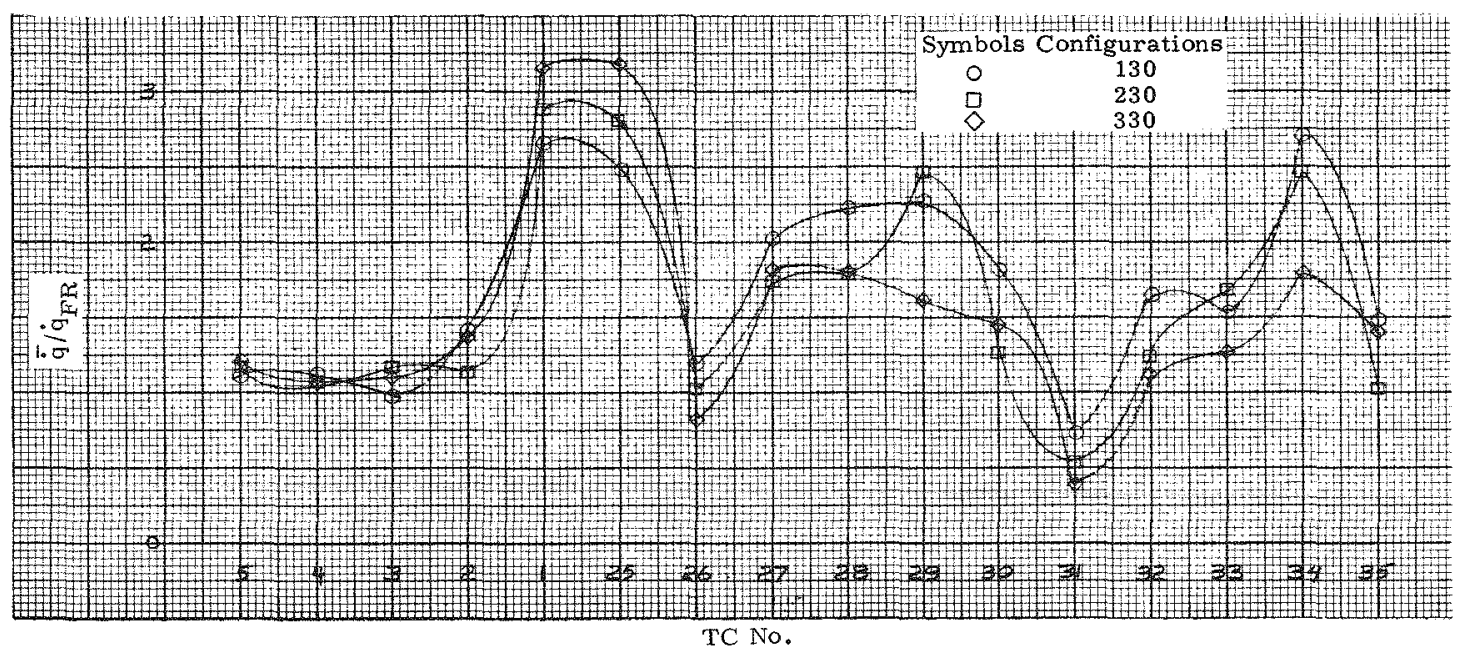

Fig. 262. Averaged Heating Values, TC $1-35$, Configurations 130, 230, 330

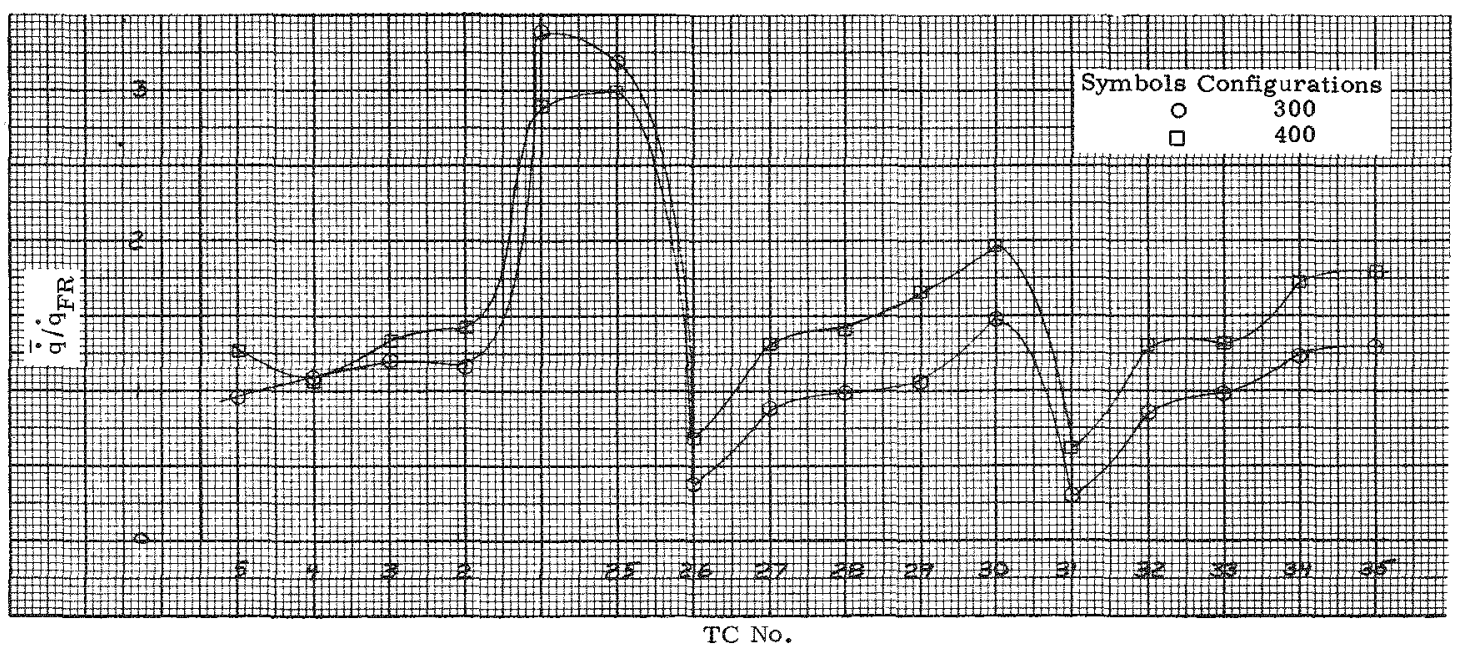

Fig. 263. Averaged Heating Values, TC 1-35, Configurations 300,400 


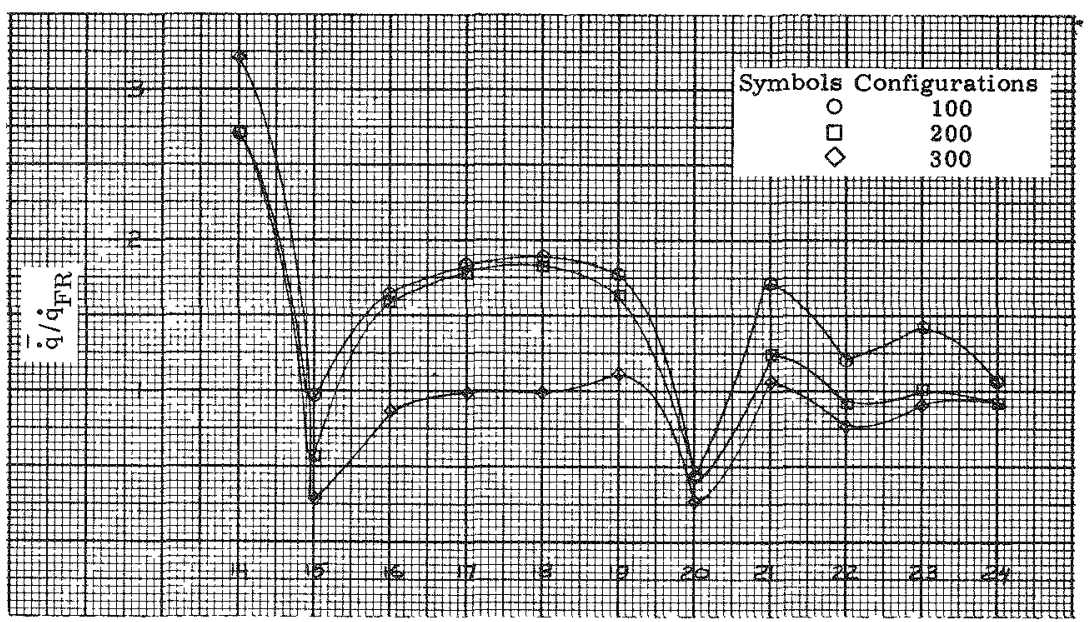

TC No.

Fig. 264. Averaged Heating Values, TC $14-24$, Configurations $100,200,300$

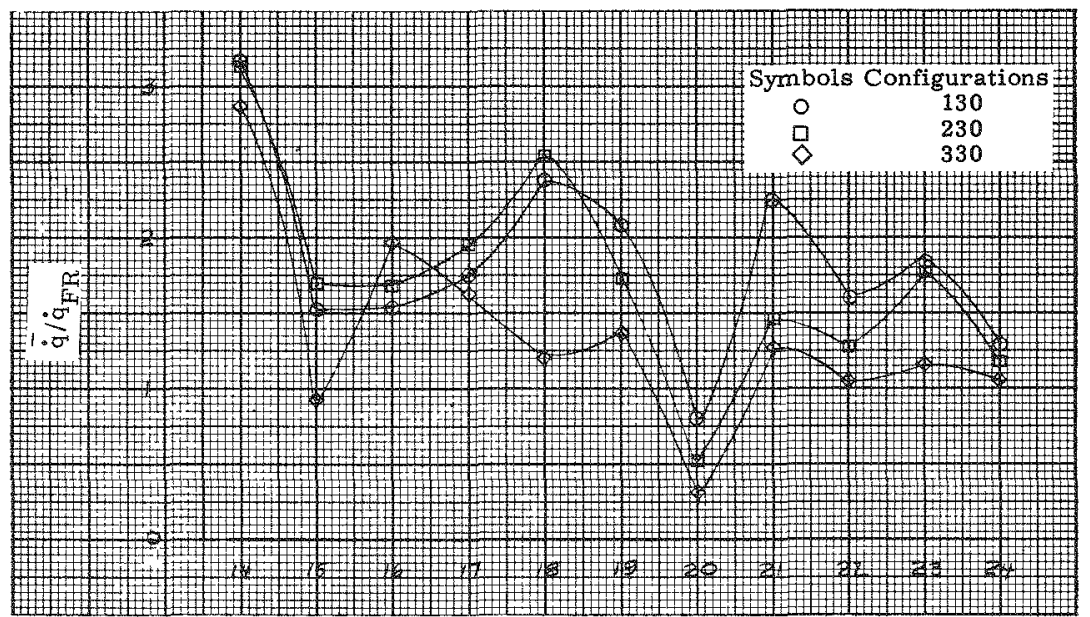

TC No.

Fig. 265. Averaged Heating Values, TC $14-24$, Configurations $130,230,330$

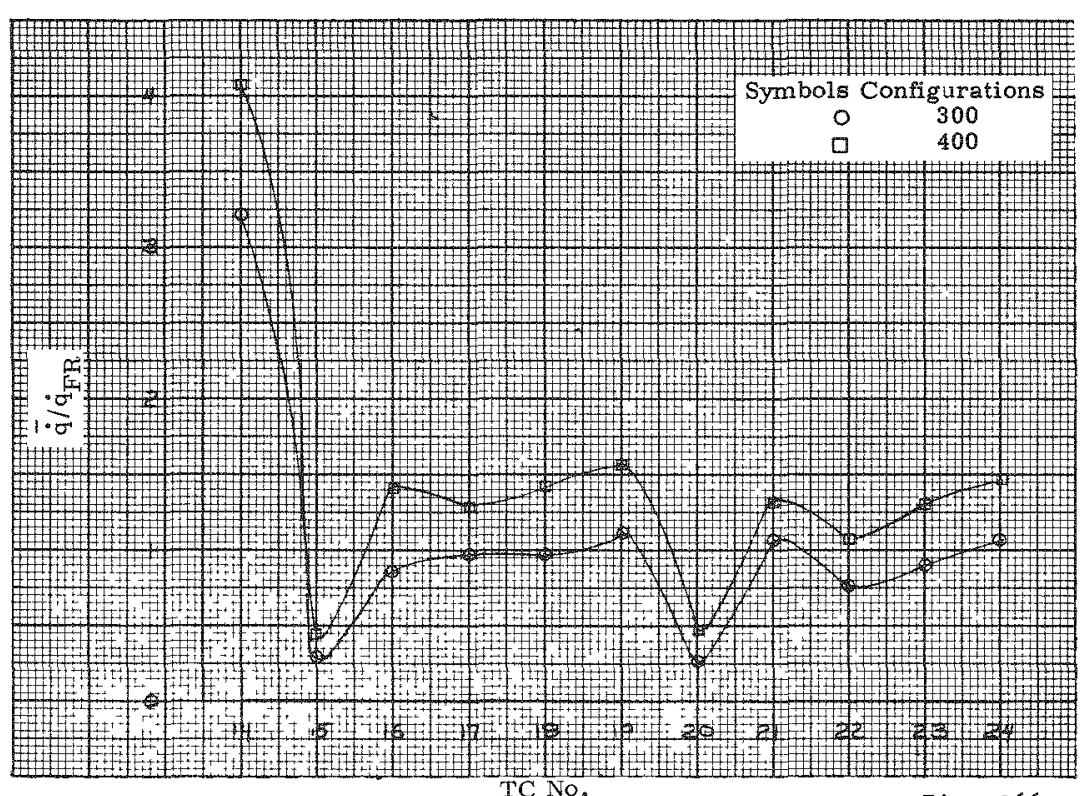
TC No.

Fig. 266. Averaged Heating Values, TC $14-24$, Configurations 300,400 


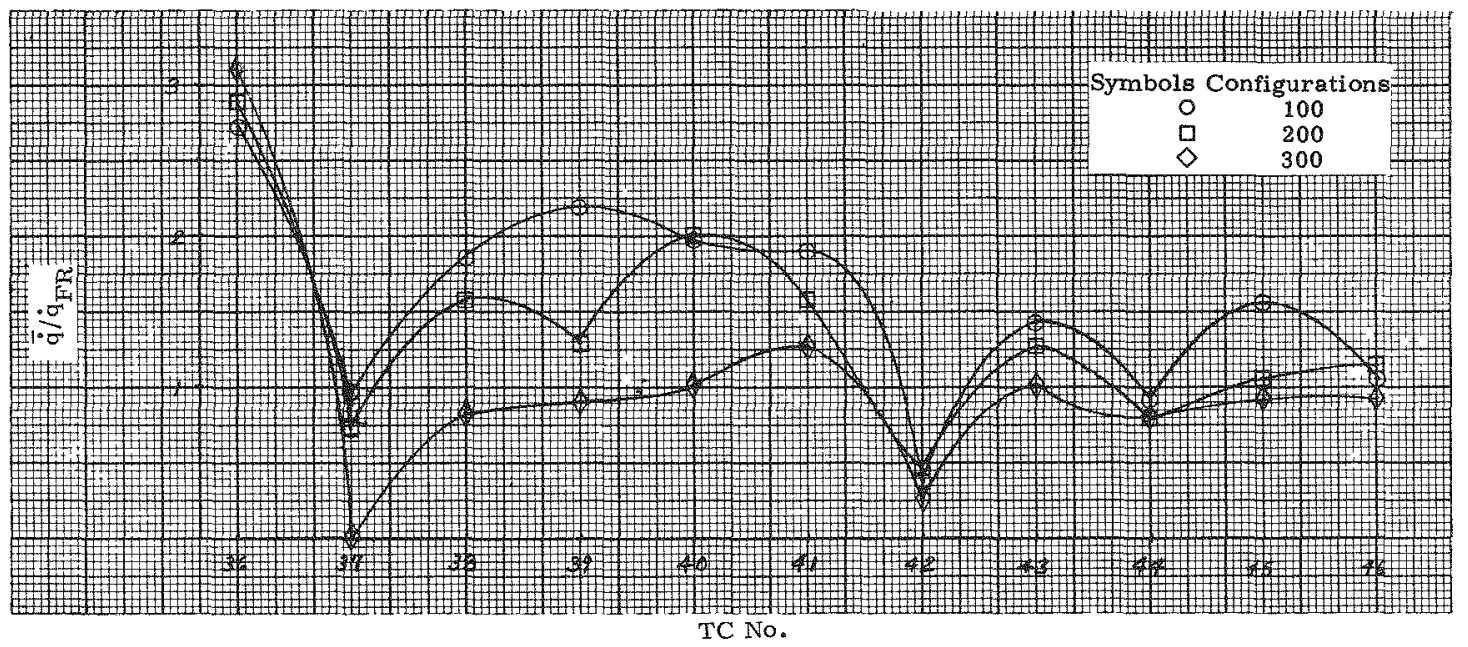

Fig. 267. Averaged Heating Values, TC $36-46$, Configurations 100, 200, 300

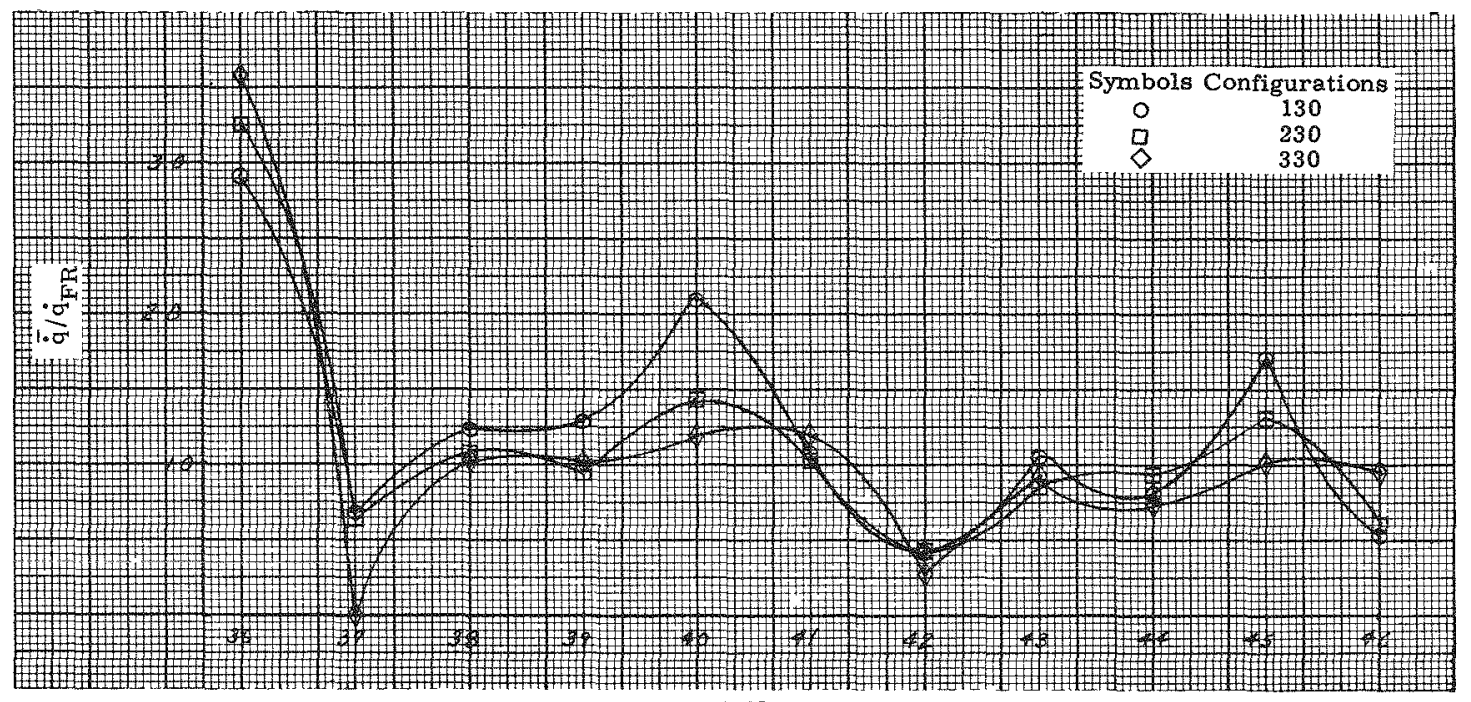
TC No.

Fig. 268. Averaged Heating Values, TC $36-46$, Configurations 130, 230, 330

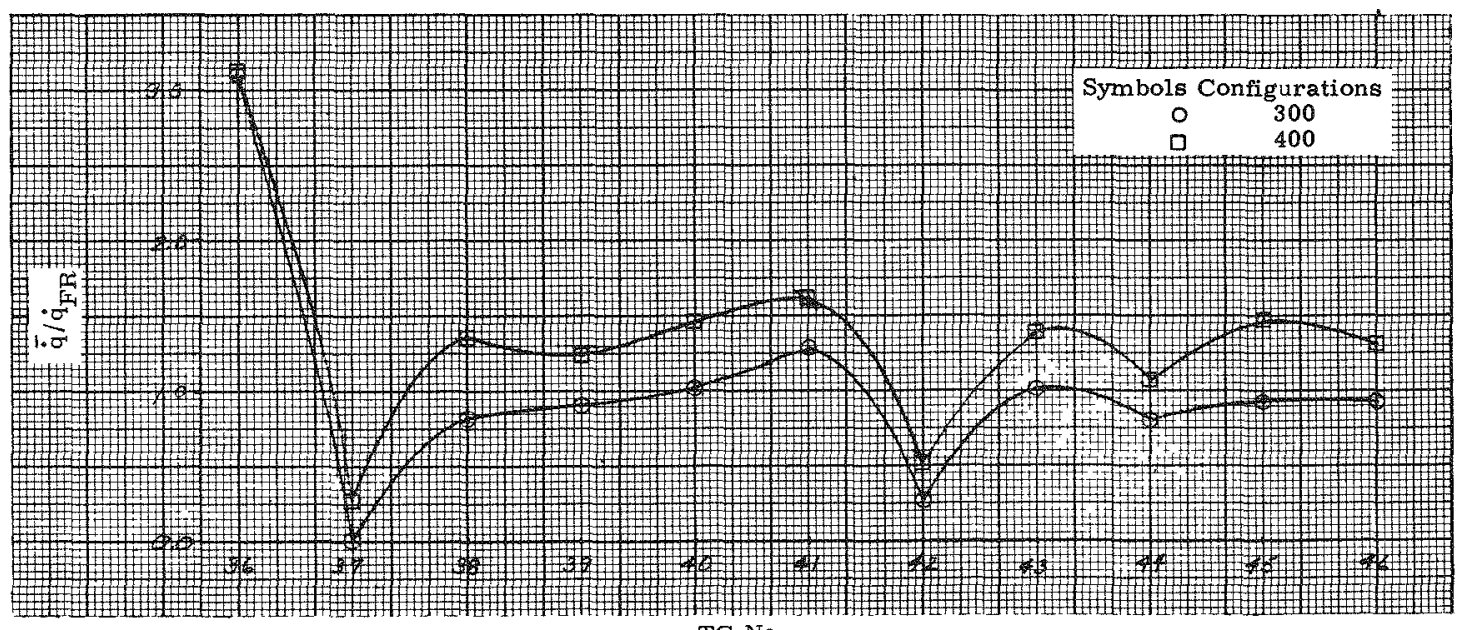

TC No.

Fig. 269. Averaged Heating Values, TC $36-46$, Configurations 300,400 


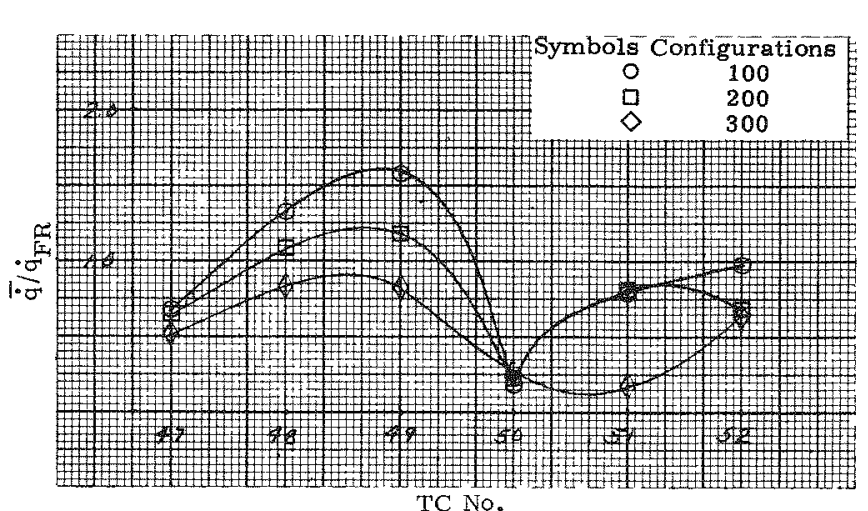

Fig. 270. Averaged Heating Values, TC $47-52$, Configurations $100,200,300$

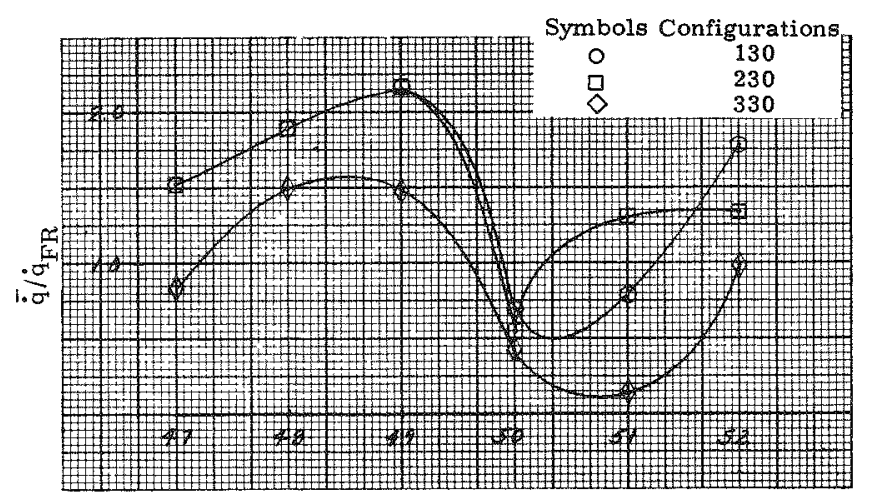

TC No.

Fig. 271. Averaged Heating Values, TC $47-52$, Configurations $130,230,330$

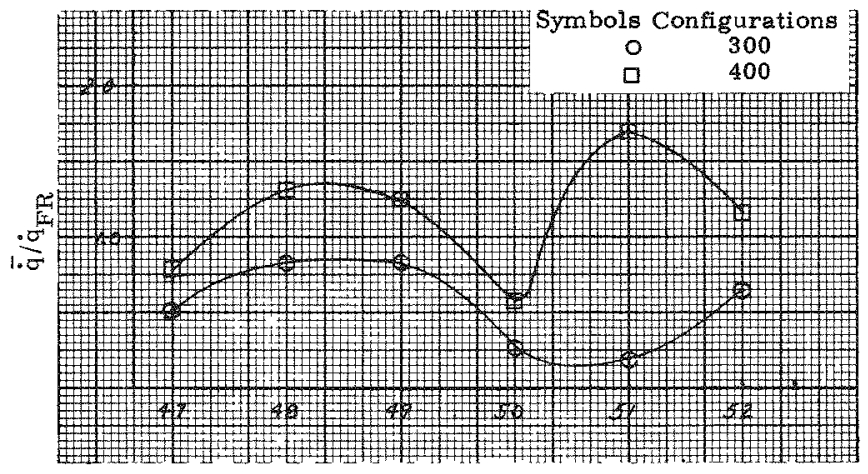

TC No.

Fig. 272. Averaged Heating Values, TC $47-52$, Configurations 300,400

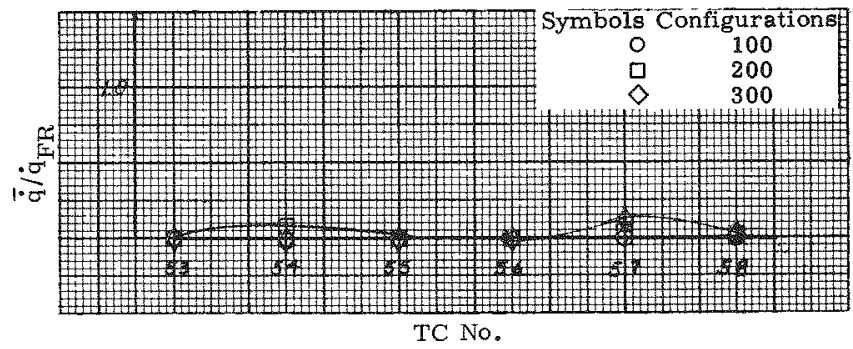

Fig. 273. Averaged Heating Values, TC $53-58$, Configurations $100,200,300$

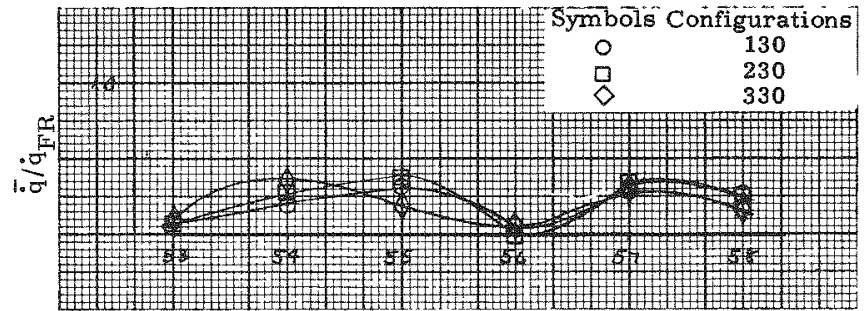

TC No.

Fig. 274. Averaged Heating Values, TC $53-58$ Configurations $130,230,330$

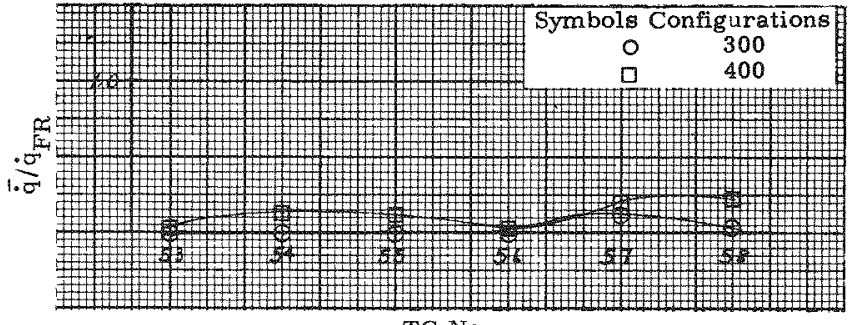

TC No.

Fig. 275. Averaged Heating Values, TC $53-58$, Configurations 300,400 


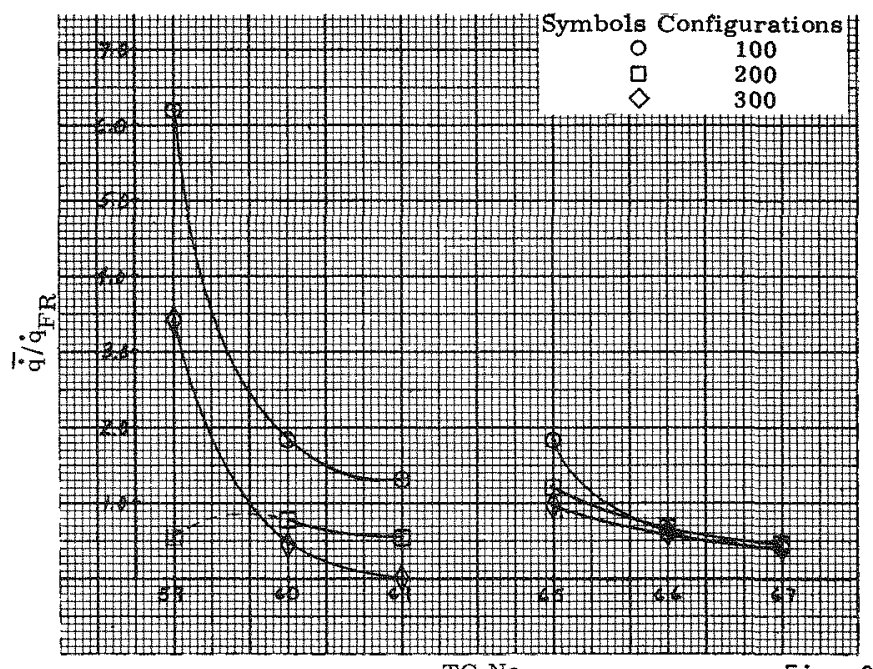

TC No.

Fig. 276. Averaged Heating Values, TC $59-67$,

(2) Configurations $100,200,300$

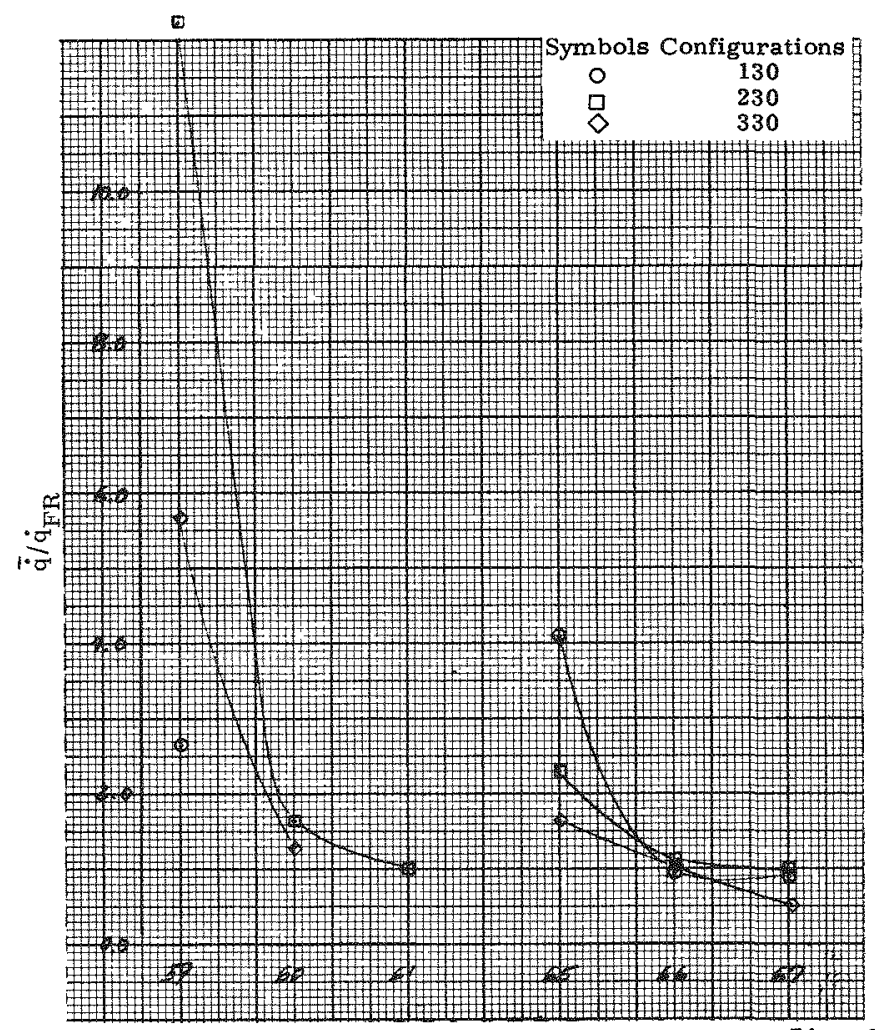

TC No.

Fig. 277. Averaged Heating Values, TC $59-67$, Configurations $130,230,330$

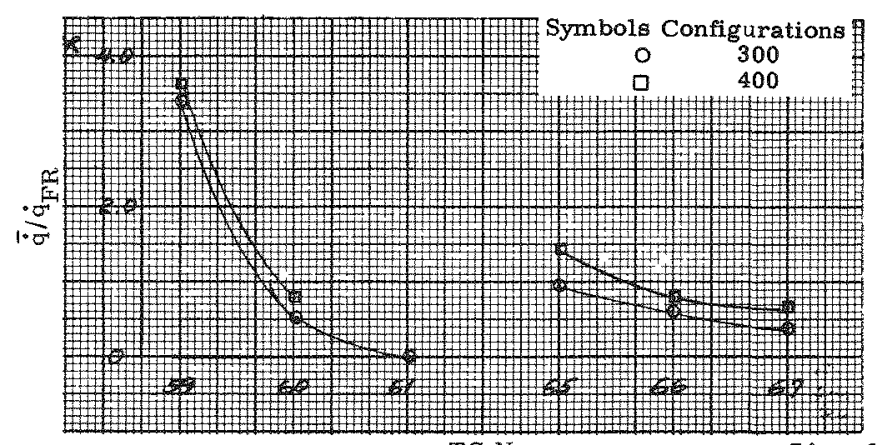

TC No.

Fig. 278. Averaged Heating Values, TC 59-67, Configurations 300,400 


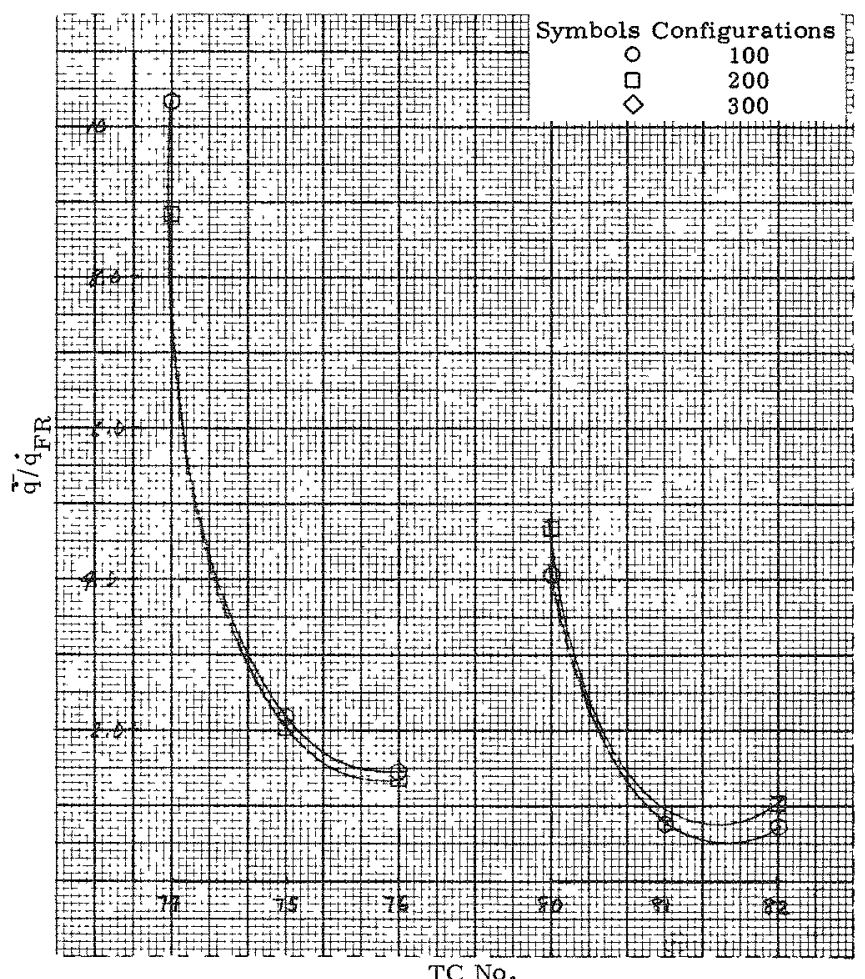

Fig. 279. Averaged Heating Values, TC $74^{\circ}-82$, Configurations $100,200,300$

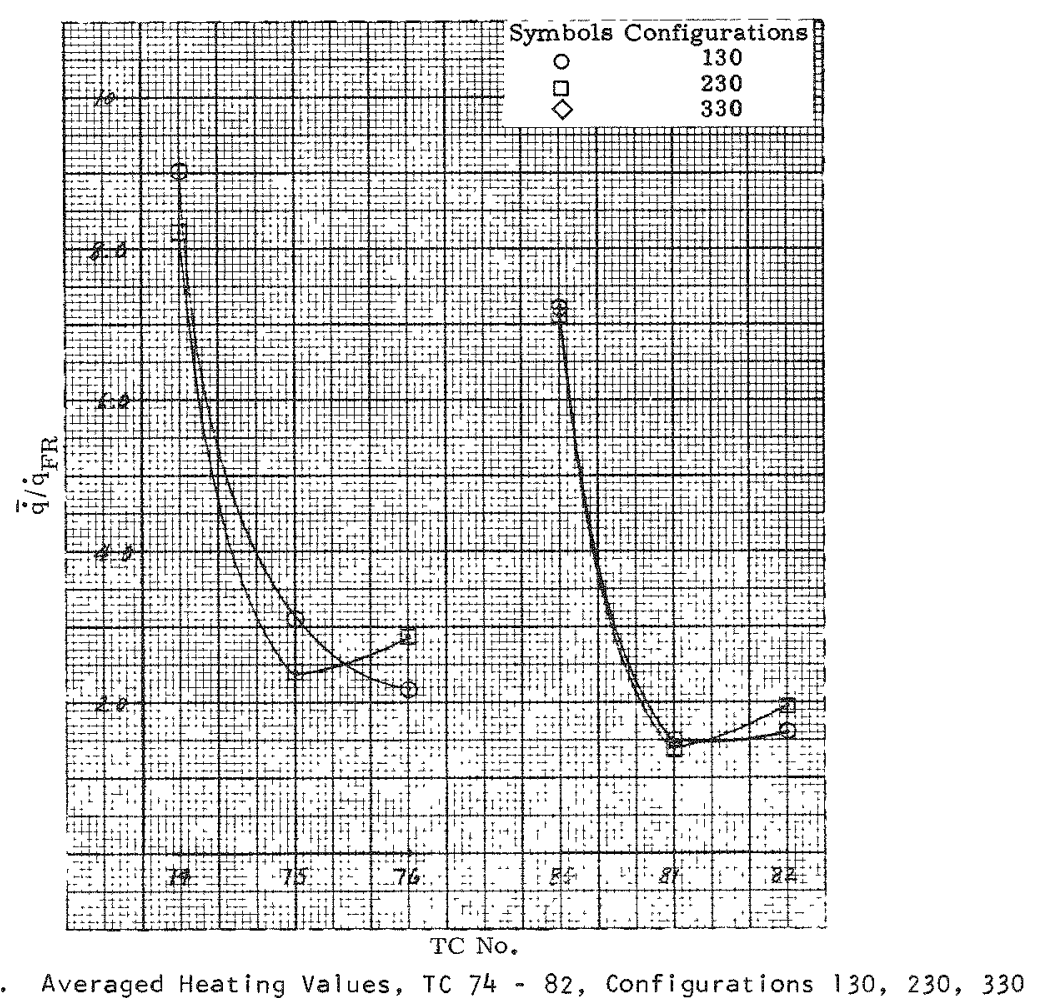



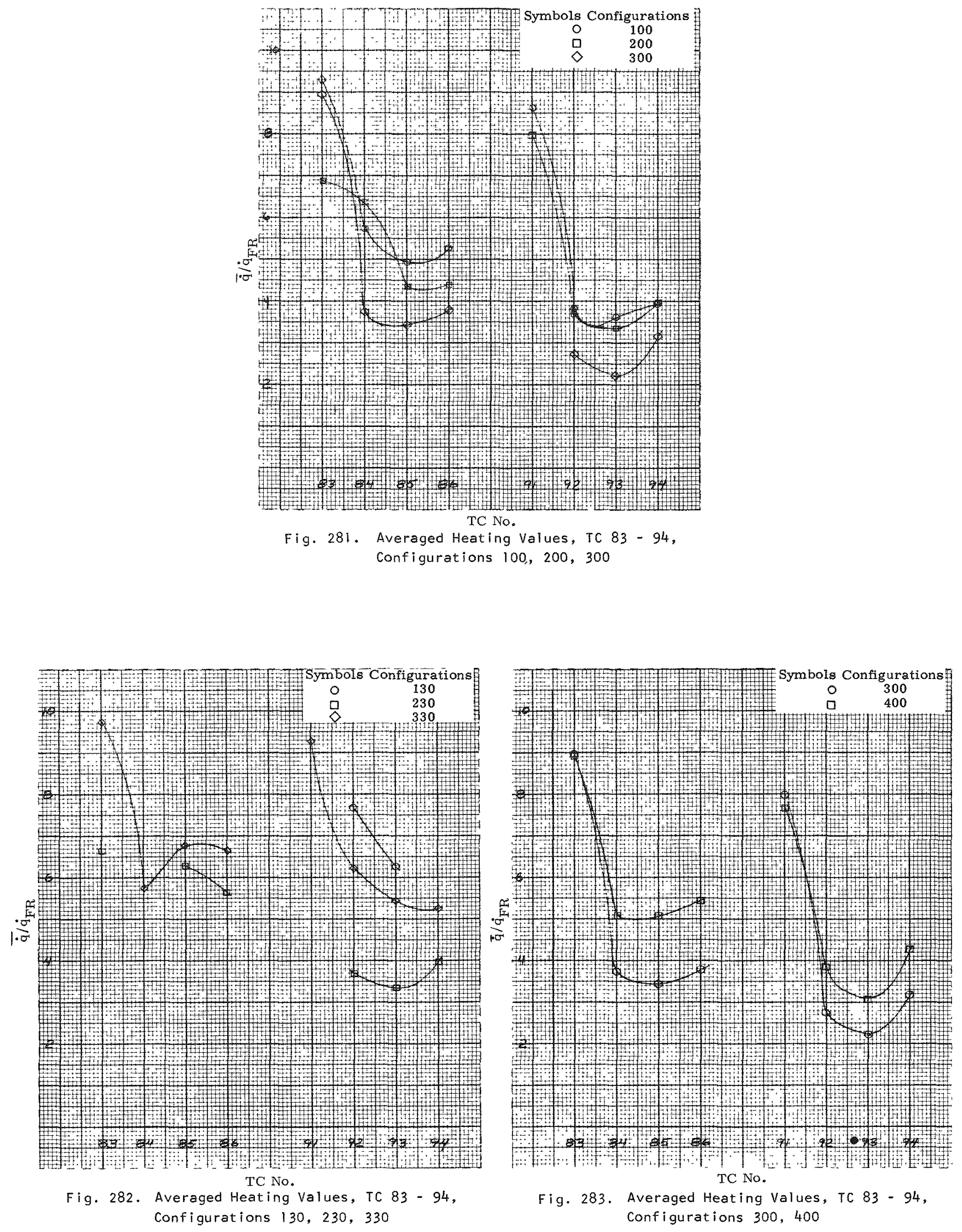

MND-3607-92 


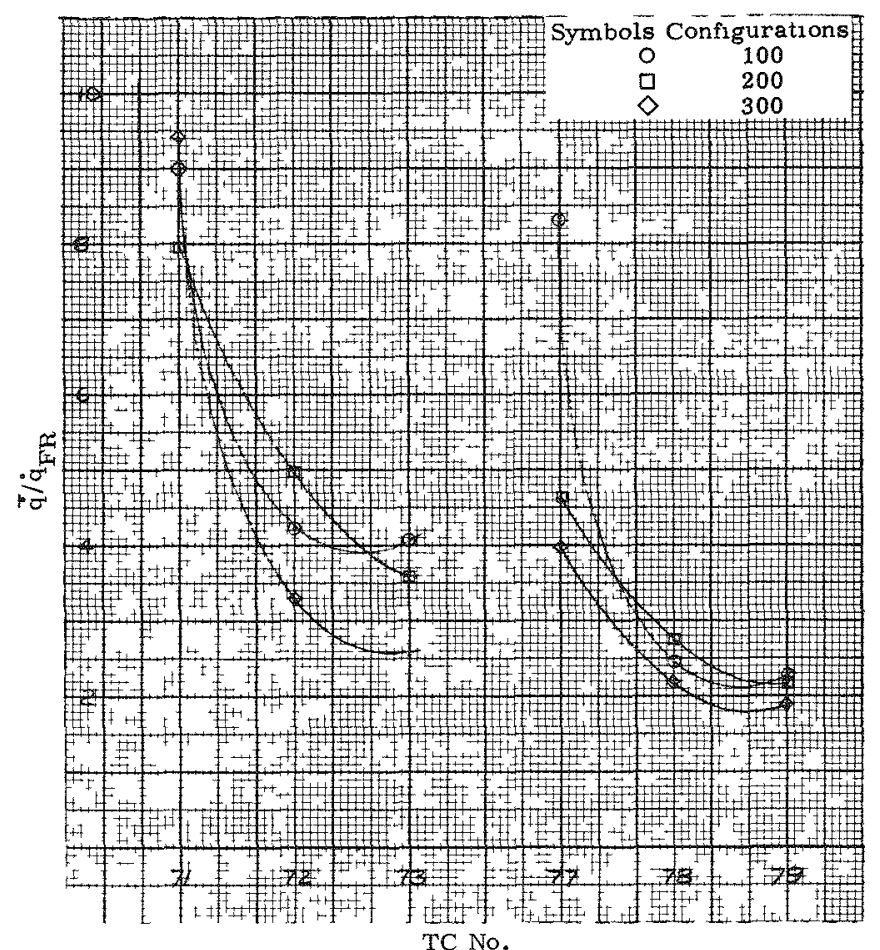

Fig. 284 Averaged Heating Values, TC $71-79$, Configurations 100, 200, 300

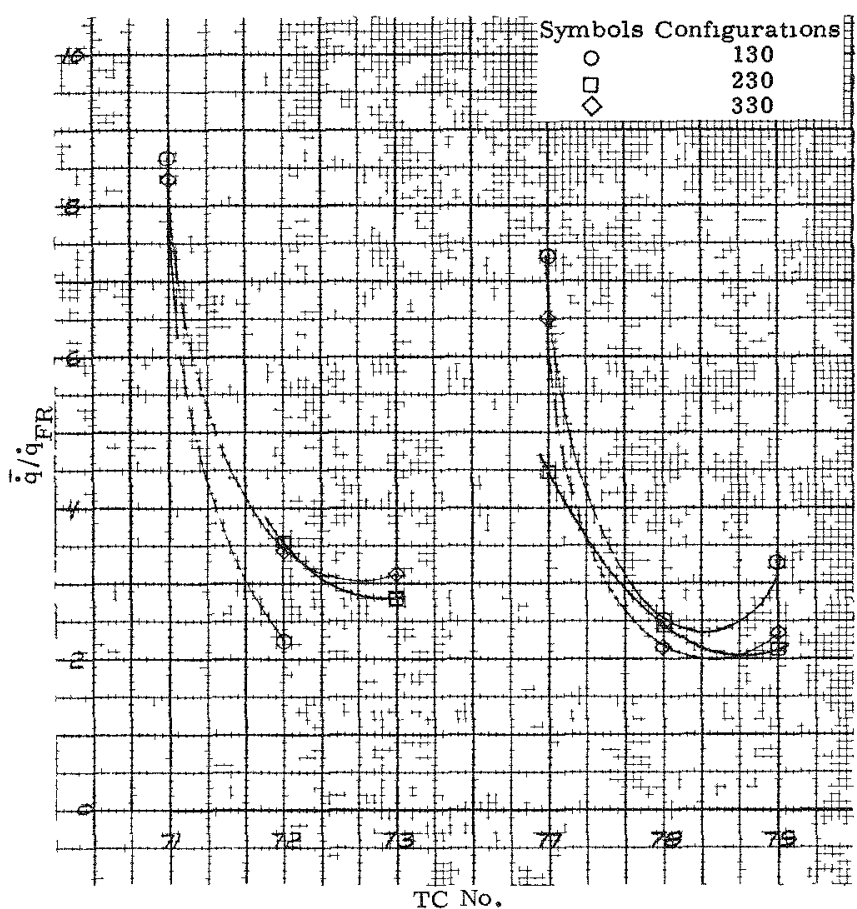

Fig 285 Averaged Heating Values, TC $71-79$, Configurations $130,230,330$

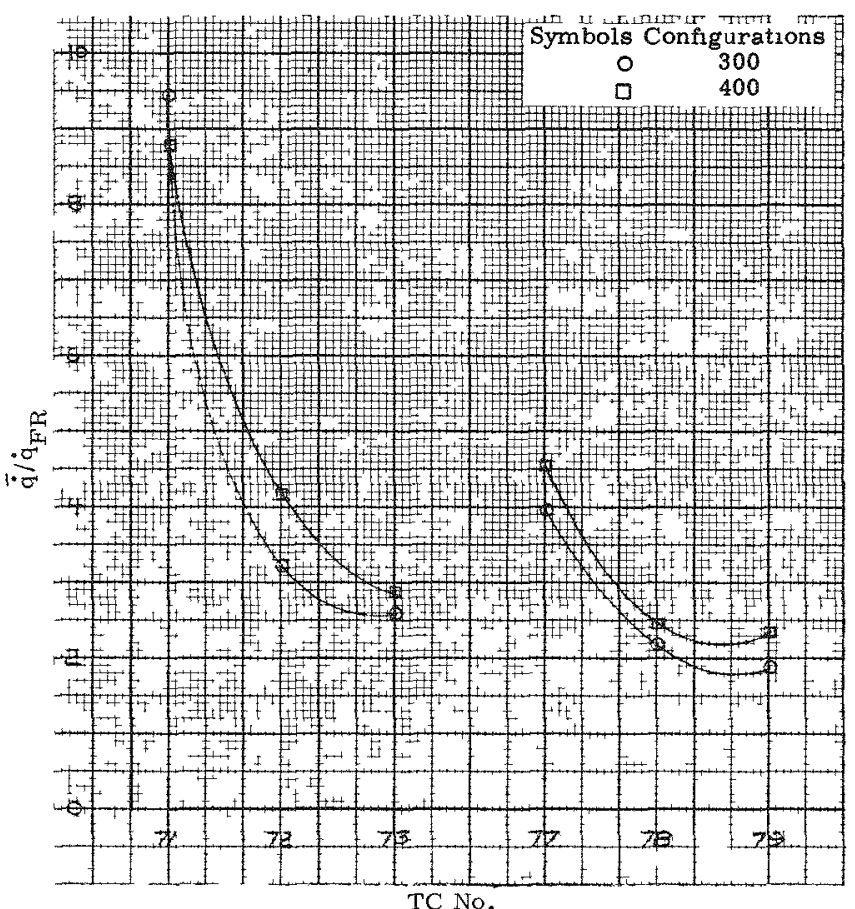

Fig 286 Averaged Heating Values, TC 71 - 79, Configurations 300,400 


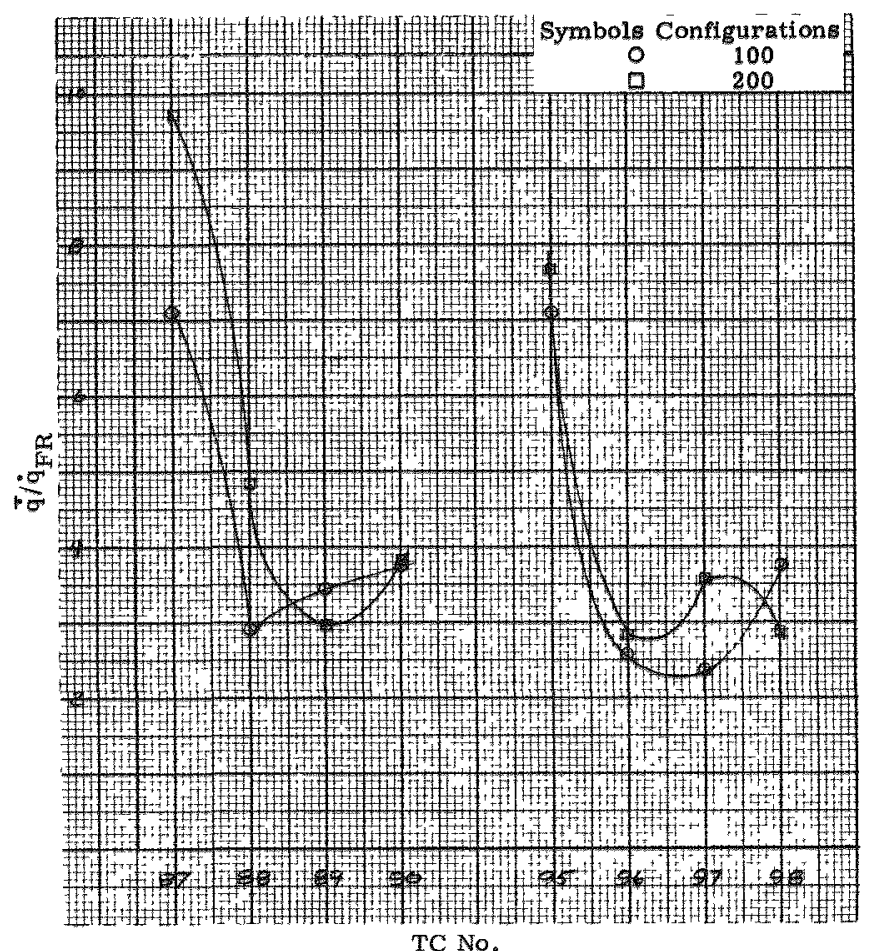

Fig. 287. Averaged Heating Values, TC $87-98$, Configurations 100, 200

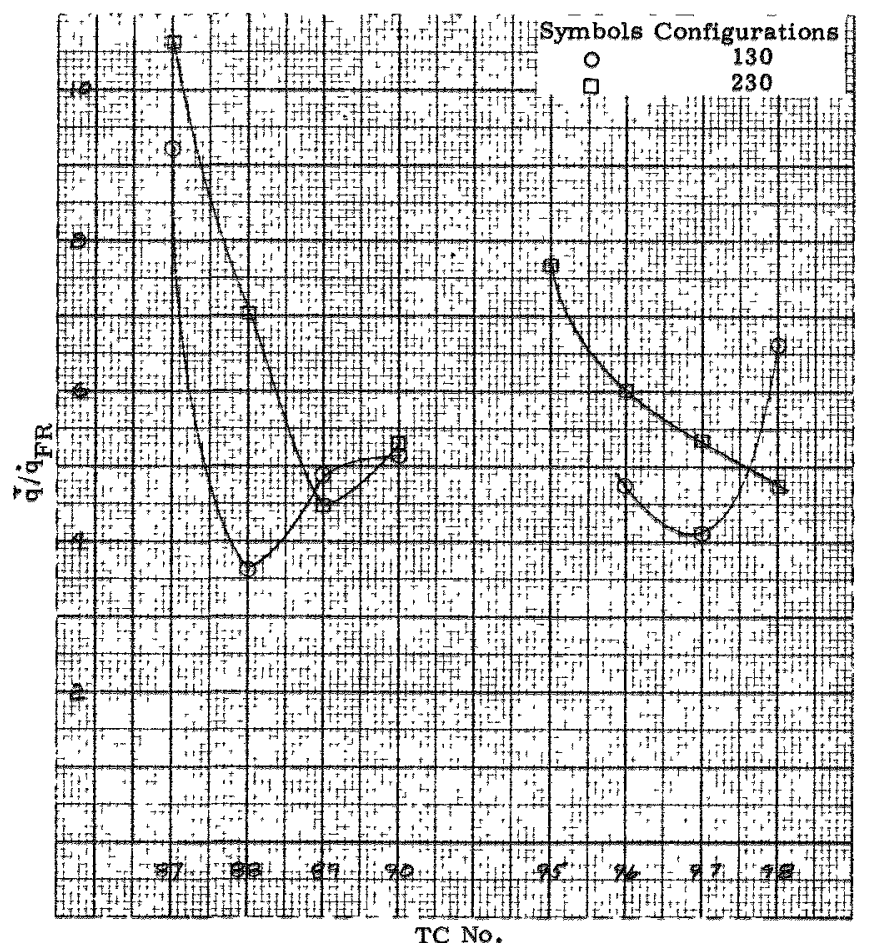

Fig. 288. Averaged Heating Vaiues, TC $87-98$, Configurations 130, 230 